Pacific Northwest

National Laboratory

Operated by Battelle for the

U.S. Department of Energy

\section{Waste Form Release Data Package for the 2005 Integrated Disposal Facility Performance}
E. M. Pierce
K. M. Krupk
B. P. McGrail
E. A. Rodriguez
P. F. Martin
S. R. Baum
H. T. Schaef
K. N. Geiszler
K. P. Saripalli
L. R. Reed
R. J. Serne
W. J. Shaw

September 2004

Prepared for the U.S. Department of Energy under Contract DE-AC06-76RL01830 


\section{DISCLAIMER}

This report was prepared as an account of work sponsored by an agency of the United States Government. Neither the United States Government nor any agency thereof, nor Battelle Memorial Institute, nor any of their employees, makes any warranty, expressed or implied, or assumes any legal liability or responsibility for the accuracy, completeness, or usefulness of any information, apparatus, product, or process disclosed, or represents that its use would not infringe privately owned rights. Reference herein to any specific commercial product, process, or service by trade name, trademark, manufacturer, or otherwise does not necessarily constitute or imply its endorsement, recommendation, or favoring by the United States Government or any agency thereof, or Battelle Memorial Institute. The views and opinions of authors expressed herein do not necessarily state or reflect those of the United States Government or any agency thereof.

\section{PACIFIC NORTHWEST NATIONAL LABORATORY operated by \\ BATTELLE MEMORIAL INSTITUTE \\ for the \\ UNITED STATES DEPARTMENT OF ENERGY \\ under Contract DE-AC06-76RLO 1830}

Printed in the United States of America

$$
\begin{gathered}
\text { Available to DOE and DOE contractors from the } \\
\text { Office of Scientific and Technical Information, } \\
\text { P.O. Box 62, Oak Ridge, TN 37831-0062; } \\
\text { ph: (865) 576-8401 } \\
\text { fax: (865) 576-5728 } \\
\text { email: reports@adonis.osti.gov }
\end{gathered}
$$

Available to the public from the National Technical Information Service,

U.S. Department of Commerce, 5285 Port Royal Rd., Springfield, VA 22161

$$
\begin{aligned}
& \text { ph: (800) 553-6847 } \\
& \text { fax: (703) 605-6900 }
\end{aligned}
$$

email: orders@ntis.fedworld.gov

online ordering: http://www.ntis.gov/ordering.htm 


\title{
Waste Form Release Data Package for the 2005 Integrated Disposal Facility Performance Assessment
}

\author{
E. M. Pierce \\ B. P. McGrail \\ E. A. Rodriguez \\ H. T. Schaef \\ K. P. Saripalli \\ R. J. Serne \\ K. M. Krupka \\ P. F. Martin \\ S. R. Baum \\ K. N. Geiszler \\ L. R. Reed \\ W. J. Shaw
}

September 2004

Prepared for the U.S. Department of Energy under Contract DE-AC06-76RLO 1830

Pacific Northwest National Laboratory

Richland, Washington 99352 


\section{SUMMARY}

The Hanford Site in southeastern Washington State has been used extensively to produce nuclear materials for the U.S. defense arsenal by the U.S. Department of Energy (DOE). A large inventory of radioactive and mixed waste has accumulated in 177 buried single- and double-shell tanks. Liquid waste recovered from the tanks will be pretreated to separate the low-activity fraction from the high-level and transuranic wastes. The low-activity waste (LAW) will be immobilized in glass, via vitrification, and placed into a near-surface disposal system on the Hanford Site. Before the immobilized low-activity waste (ILAW) can be placed into the disposal system, DOE must approve a performance assessment (PA), which is a document that describes the longterm impact of the disposal facility on public health and environmental resources.

A critical component of the PA will be to provide quantitative estimates of radionuclide release rates from the engineered portion of the disposal facilities (source term). Researchers from Pacific Northwest National Laboratory (PNNL) were selected by CH2M Hill Hanford Group to determine the experimentally derived input data on the three prototypic LAW glasses: LAWA44, LAWB45, and LAWC22. These data will be used for Subsurface Transport Over Reactive Multi-phases (STORM) simulations of the Integrated Disposal Facility (IDF) for immobilized low-activity waste (ILAW). The STORM code will be used to provide the near-field radionuclide release source term for a performance assessment to be issued in July 2005. Documented in this data package are data related to 1) kinetic rate law parameters for glass dissolution, 2) alkali $\left(\mathrm{Na}^{+}\right)$-hydrogen $\left(\mathrm{H}^{+}\right)$ion exchange rate, 3) chemical reaction network of secondary phases that form in accelerated weathering tests, and 4) thermodynamic equilibrium constants assigned to these secondary phases. The kinetic rate law and $\mathrm{Na}^{+}-\mathrm{H}^{+}$ion exchange rate were determined from single-pass flow-through experiments. Pressurized unsaturated flow (PUF) and product consistency (PCT) tests were used for accelerated weathering or aging of the glasses to determine a chemical reaction network of secondary phases that form. The majority of the thermodynamic data used in this data package were extracted from the thermodynamic database package shipped with the geochemical code EQ3/6, version 8.0.

In addition to the experimentally derived input data for each of the representative waste glasses, this data package contains recommended effective diffusion coefficients for grouted secondary waste containing several key contaminants $\left(\mathrm{Cr}, \mathrm{I}, \mathrm{NO}_{3}, \mathrm{Hg}\right.$, $\mathrm{Tc}$, and $\mathrm{U}$ ) obtained from a survey of the literature. These effective diffusion coefficients should be considered generic values; no secondary waste streams from vitrification operations have been produced at Hanford for testing. Therefore, the authors recommend that activities be initiated to generate IDF sitespecific data on the release of key contaminants of concern from secondary waste solidified in cementitious waste forms. 


\section{Contents}

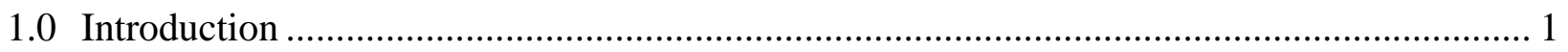

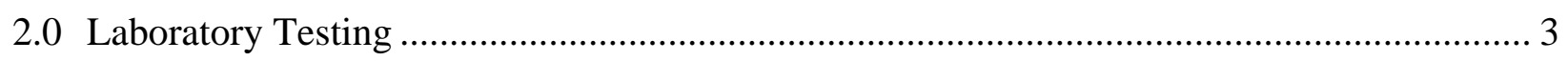

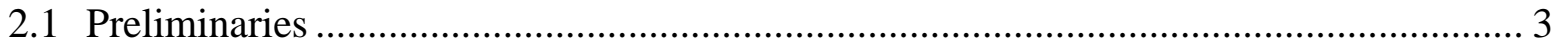

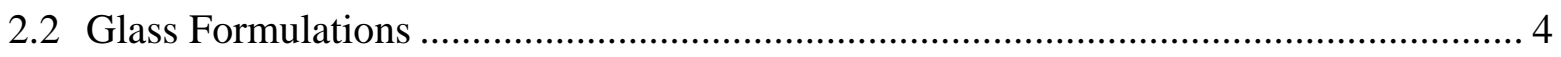

3.0 Kinetic Rate Law Parameters ......................................................................................... 5

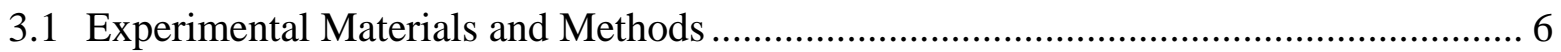

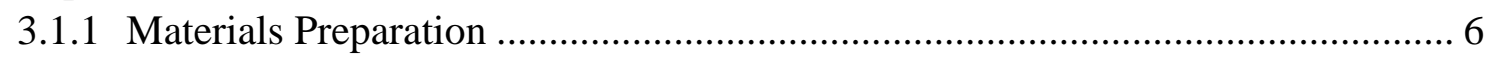

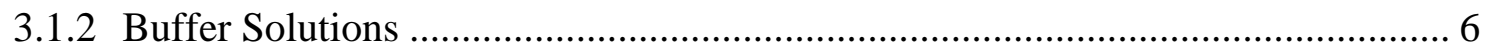

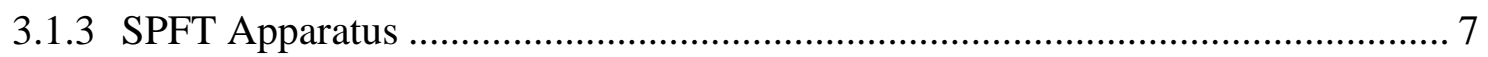

3.1.4 Dissolution Rate and Error Calculations ............................................................... 8

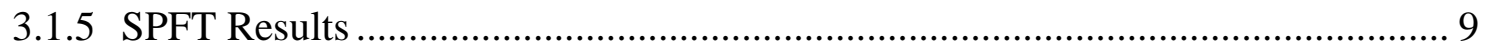

3.1.5.1 SPFT Results for LAWA44 Glass ....................................................... 10

3.1.5.1.1 Achievement of Steady-State and Consistency of Results.... 10

3.1.5.1.2 Effect of q/S Variations .......................................................... 10

3.1.5.1.3 Effect of $\mathrm{pH}$.......................................................................... 11

3.1.5.1.4 Effect of Alkali-Hydrogen Exchange...................................... 12

3.1.5.1.5 Effect of Solution Saturation State ......................................... 12

3.1.5.2 SPFT Results for LAWB45 Glass ……………....................................... 15

3.1.5.2.1 Effect of $\mathrm{pH}$........................................................................ 15

3.1.5.2.2 Effect of Solution Saturation State ........................................ 15

3.1.5.3 SPFT Results For LAWC22 Glass ............................................................ 17

3.1.5.3.1 Effect of $\mathrm{pH}$....................................................................... 17

3.1.5.3.2 Effect of Alkali-Hydrogen Exchange.................................... 17

3.1.5.3.3 Effect of Solution Saturation State.......................................... 18

3.2 Characterization of Glass Structure ………………….................................................. 20

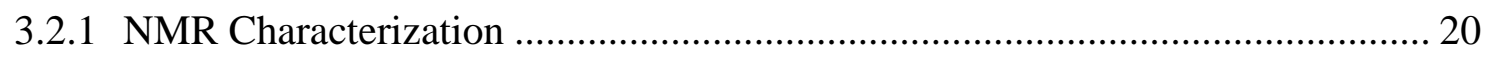

3.2.2 Raman Characterization ................................................................................ 20

3.3 Summary of SPFT Test Results ...................................................................................... 21

4.0 Chemical Reaction Network …….................................................................................. 22

4.1 Pressurized Unsaturated Flow (PUF) Apparatus Experiments ....................................... 22

4.1.1 Description of the PUF Apparatus ...................................................................... 23

4.1.2 Experimental Materials and Methods.............................................................. 23

4.1.2.1 Materials Preparation ............................................................................ 23

4.1.2.2 Experimental Setup ............................................................................. 24

4.1.2.3 Release Rate and Error Calculations....................................................... 24

4.1.3 PUF Test Results ............................................................................................. 25

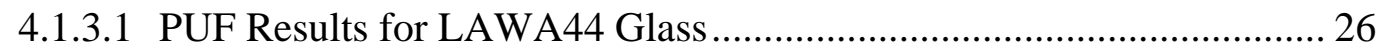

4.1.3.2 PUF Results for LAWB45 and LAWC22 Glasses .................................. 29

4.1.3.3 PUF Results for LAWAN102 and LAWAP101 Glasses......................... 32 


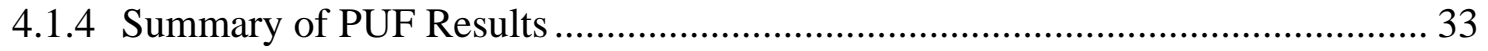

4.2 Product Consistency Test (PCT) Experiments …....................................................... 33

4.2.1 Experimental Materials and Methods.......................................................... 34

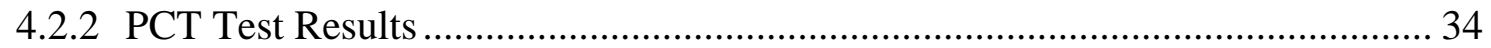

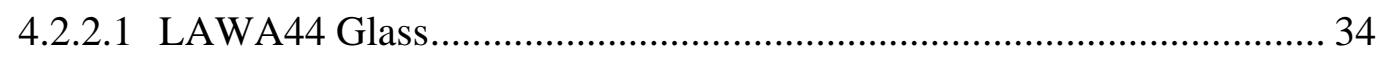

4.2.2.2 LAWB45 and LAWC22 Glasses ....................................................... 36

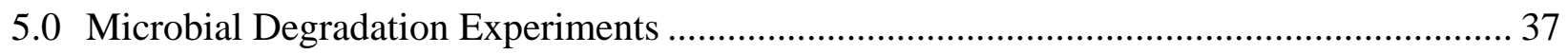

5.1 Experimental Methods ........................................................................................ 38

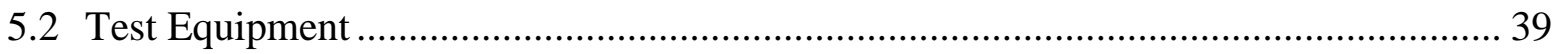

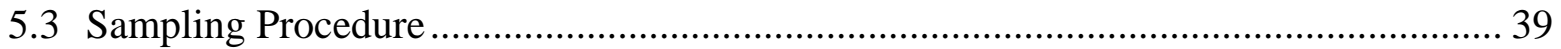

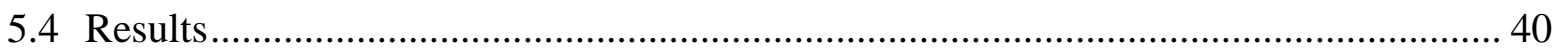

6.0 Release of Contaminants from Secondary Waste ........................................................ 42

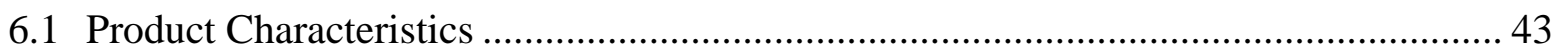

6.2 Release Modeling...................................................................................... 45

6.3 Effective Diffusion Coefficients for Key Contaminants to be Disposed in IDF .......... 46

6.4 Iodine Release From Secondary Waste ............................................................... 49

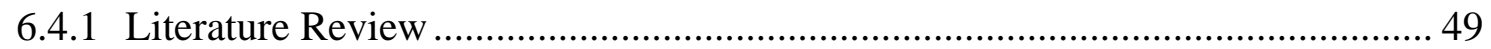

6.4.2 Iodine Parameter Recommendations ................................................................. 55

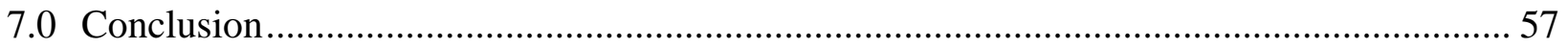

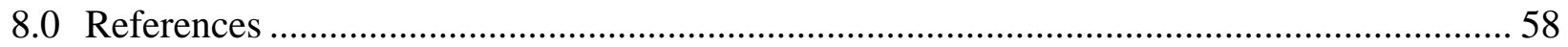




\section{Figures}

1. Schematic of the Single Pass Flow-Through (SPFT) Apparatus 7

2. Normalized B Concentration as a Function of Time and Temperature for LAWA44 Glass with increased resolution for the $23^{\circ} \mathrm{C}$ results between day 30 and 38 .

3. Effect of Variation in the Ratio of Flow Rate, $q$, to Sample Surface Area, $S$, on LAWA44 Glass Dissolution Rate 10

4. Normalized B Release Rate as a Function of $\mathrm{pH}$ and Temperature for LAWA44 Glass ..... 11

5. Na Ion Exchange Rate as a Function of Temperature with Changing a[SiO LAWA44 Glass

6. Normalized Release Rate with Respect to B and Na Versus $\mathrm{SiO}_{2}(\mathrm{aq})$ Activity at 23, 40, 70, and $90^{\circ} \mathrm{C}$ for LAWA44 Glass. 13

7. $\quad$ ln $\mathrm{K}_{\mathrm{g}}$ vs. Inverse Temperature for LAWA44 Glass ............................................................. 14

8. Normalized B Release Rate as a Function of pH and Temperature for LAWB45 Glass...... 15

9. Normalized Release Rate with Respect to $\mathrm{B}$ and $\mathrm{Na}$ Versus $\mathrm{SiO}_{2}$ (aq) Activity at 23, 40,70 , and $90^{\circ} \mathrm{C}$ for LAWB45 Glass 16

10. $\ln \mathrm{K}_{\mathrm{g}}$ vs. Inverse Temperature for LAWB45 Glass......................................................... 16

11. Normalized B Release Rate as a Function of pH and Temperature for LAWC22 Glass...... 17

12. Na-IEX Rate as a Function of Solution $\mathrm{pH}$ and Temperature................................................. 18

13. Na Ion Exchange Rate as a Function of Temperature with changing $a\left[\mathrm{SiO}_{2}(\mathrm{aq})\right]$ for LAWC22 Glass

14. Normalized Release Rate with Respect to B and Na Versus $\mathrm{SiO}_{2}(\mathrm{aq})$ Activity at 23, 40, 70, and $90^{\circ} \mathrm{C}$ for LAWC22 Glass.

15. $\ln \mathrm{K}_{\mathrm{g}}$ vs. Inverse Temperature for LAWC22 Glass.

16. ${ }^{29}$ Si Nuclear Magnetic Resonance (NMR) Spectra in ppm for LAWA44, LAWB45, and LAWC22 Glasses 20

17. Raman spectra of LAWA44, LAWB45, LAWC22 and Reference Spectra for Quartz ........ 20

18. Computer Monitored Test Metrics From PUF Tests with LAWA44 Glass............................ 26

19. Normalized Release Rate for Selected Elements in PUF Tests with LAWA44 Glass .......... 26

20. Moisture Fraction as a Function of Distance from the PUF Column Inlet for LAWA44 Glass

21. SEM Photographs of Reacted Grains of LAWA44 Glass After 858 Days in PUF Test at 2 $\mathrm{mL} / \mathrm{d}$ and $99^{\circ} \mathrm{C}$

22. XRD Analyses of Reacted LAWA44 Glass Samples Taken from PUF Column After 859 days at $2 \mathrm{~mL} \mathrm{~d}^{-1}$ and $99^{\circ} \mathrm{C}$. 
23. Computer Monitored Test Metrics from PUF Tests with LAWB45 (top) and LAWC22 (bottom) Glass Formulations.

24. Normalized Release Rate for Selected Elements in PUF Test with LAWB45 (top) and LAWC22 (bottom) Glasses 30

25. Volumetric Water Content as a Function of Distance from the PUF Column Inlet for LAWB45 and LAWC22.

26. XRD Analyses of Reacted LAWB45 Glass Samples Taken from PUF Column After 530 days at $2 \mathrm{~mL} \mathrm{~d}^{-1}$ and $99^{\circ} \mathrm{C}$ 31

27. Computer Monitored Test Metrics from PUF Tests with LAWAN102 (top) and LAWAP101 (bottom) Glass Formulations.

28. Normalized Release Rate for Selected Elements in PUF Test with LAWAN102 (left) and LAWAP101 (right) Glasses. 32

29. Comparison of PCT Solution Concentration Data (symbols) with the Solution Composition Calculated with the EQ3/6 Code (lines) for LAWA44 Glass. 34

30. Predicted Paragenetic Sequence of Alteration Phases Formed During the Reaction of LAWA44 Glass in Deionized Water 34

31. XRD Results of the PCT test reacted LAWA44 35

32. SEM Results of the Reacted LAWA44 Glass After $350 \mathrm{~d}$ PCT Test 35

33. PCT-B Results for LAWB45 (top) and LAWC22 (bottom) Glasses ................................. 36

34. Visual Observation of Bacterial Growth After 14 Weeks. 40

35. Comparison of Element Release Rates From LAWA44 Glass in Static Tests Conducted with DIW Only (black data points) versus Hanford Soil Extract (red data points) 40

36. SEM Picture of Reacted Solids Removed From Static Corrosion Test with HSE Solution After $700 \mathrm{~d}$ at $40^{\circ} \mathrm{C}$ 41

37. Comparison of XRD Patterns for Reacted Solids Removed After 700 days from Test MBD44-16 and Hanford Soil 41

38. Change of Pore Water pH Resulting from Reactions of Cement Components. 44 


\section{Tables}

1. Overview of Test Methods Discussed in this Data Package ................................................... 2

2. Composition (Mass\%) of Selected ILAW Glasses ................................................................. 4

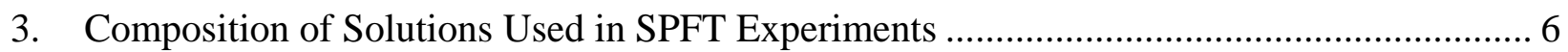

4. Estimate of the Pseudo-Equilibrium Constants for LAWA44 Glass as a Function of

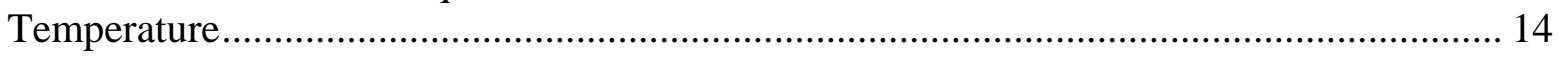

5. Estimate of the Pseudo-Equilibrium Constants for LAWB45 Glass as a Function of Temperature............................................................................................................. 16

6. Estimate of the Pseudo-Equilibrium Constants for LAWC22 Glass as a Function of

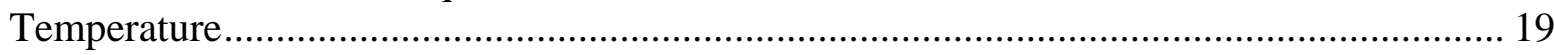

7. Summary of Best Estimate Rate Law Parameters for LAWA44, LAWB45, and LAWC22 Glasses at $15^{\circ} \mathrm{C}$. ............................................................................................. 21

8. Summary of the Long-Term B Release Rates for PUF Tests on LAWA44, LAWB45,

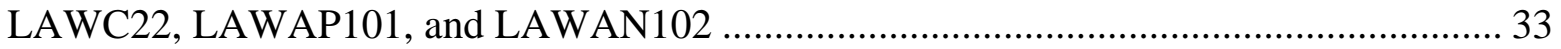

9. Secondary Phase Reaction Network for LAWA44 Glass ....................................................... 35

10. Matrix of Experimental Variable in the Glass Biodegradation Experiments......................... 38

11. Concentrations (ppb) of Constituents in Initial Solutions Without Glass Contact................. 39

12. Secondary Waste Simulant Recipe................................................................................... 42

13. Most Probable and Conservative Estimates for "Proxy" Effective Diffusion Coefficients $\left(\mathrm{cm}^{2} \mathrm{~s}^{-1}\right)$ for Key Contaminants in Secondary Waste Solidified in Cementitious Waste

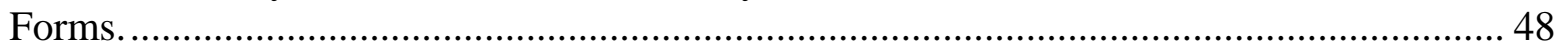

14. Average Leach Rate of Four Iodine Bearing Salts From Portland Cement .......................... 51

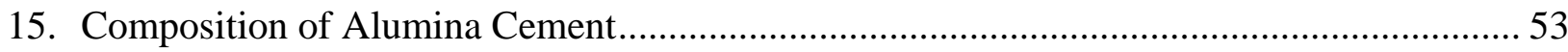

16. Recommended Values to Use in Simple Diffusion Controlled Release Conceptual Models for Iodine Solidified in Cement and Solubility-limited Release Model.................... 56

17. Summary of Best Estimate Rate Law Parameters for LAWA44, LAWB45, and LAWC22 Glasses at $15^{\circ} \mathrm{C}$. 


\section{$\underline{\text { ACRONYMS }}$}

ANL Argonne National Laboratory

ASTM American Society for Testing and Materials

BFS blast furnace slag

BKV bulk vitrification

$\mathrm{CSH} \quad$ calcium silicate hydrate

DIW deionized water

DOE Department of Energy

EDXS energy dispersive X-ray spectroscopy

ESP Environmental Simulation Program

EXAFS extend X-ray absorption fine-structure

HLW high-level waste

HSE Hanford soil microorganism extract

IAEA International Atomic Energy Agency

ICP-OES inductively coupled plasma-optical emission spectrometry

ICP-MS inductively coupled plasma-mass spectrometry

IDF integrated disposal facility

IEX alkali-hydrogen exchange

ILAW immobilized low activity waste

LAW low-activity waste

LLW low-level waste

MLLW mixed-low level waste

M\&TE materials and test equipment

PA performance assessment

PBS phosphate-buffered saline

PCT product consistency test

PEEK polyetheretherketone

PNNL Pacific Northwest National Laboratory

PUF pressurized unsaturated flow

QA quality assurance

QAPD quality assurance program documents

SAED selected area electron diffraction

SEM scanning electron microscope

SPFT single-pass flow-through (glass test)

SPS sodium pyrophosphate solution

STORM Subsurface Transport Over Reactive Multiphases (computer code)

S/V Surface area-to-solution volume ratio

THAM tris (hydroxymethyl) aminomethane 
TMS Tetrakis (trimethylsilyl) silane

TPM Thiobacillus perometabolis

TST transition state theory

WTP Waste Treatment Plant

XRD X-ray diffraction 


\subsection{Introduction}

The Hanford Site in southeastern Washington State has been used extensively to produce nuclear materials for the U. S. defense arsenal by the U.S. Department of Energy (DOE). A large inventory of radioactive and mixed waste has accumulated in 177 buried single- and double-shell tanks. Liquid waste recovered from the tanks will be pretreated to separate the low-activity fraction from the high-level and transuranic wastes. The low-activity waste (LAW) will be immobilized in glass, via vitrification, and placed into a near-surface disposal system on the Hanford Site. The LAW streams are divided into three classifications or compositional envelopes (Envelopes A, B, and C). In general, the chemical composition of each envelope is characteristic of one of the three major chemical separation processes used to extract plutonium; (REDOX [Envelope A]), and later, plutonium and uranium (bismuth phosphate [Envelope B] and PUREX [Envelope $\mathrm{C}]$ ) from irradiated fuels at Hanford. For a detail discussion of the chemical composition and the variability associated with each envelope an interest reader should consult Muller et al. (2001).

The immobilized low-activity waste (ILAW) at Hanford is among the largest volumes of waste within the DOE complex and is one of the largest inventories of long-lived radionuclides planned for disposal in a low-level waste facility (approximately 2.4 million curies total activity). Before the ILAW can be disposed, DOE must approve a performance assessment (PA), which is a document that describes the long-term impacts of the disposal facility on public health and environmental resources. A sound scientific basis for determining the long-term release rates of radionuclides from LAW glasses must be developed if the PA is to be accepted by regulatory agencies, stakeholders, the public, and accord with the Tri-Party agreement. Currently, the Hanford Integrated Disposal Facility (IDF) Program is planning to issue a performance assessment (PA) in July of 2005. The major goals of the performance assessment activity are to:

- $\quad$ support the design of disposal facilities

- provide the technical basis for the DOE to authorize construction of disposal facilities

- obtain approval to dispose of immobilized low-activity Hanford tank waste and other wastes in those facilities

- provide a technical basis for final closure of the disposal facilities.

A critical component of the PA will be to provide quantitative estimates of radionuclide release rates from the engineered portion of the disposal facilities (source term). Computer models are essential for this purpose because the impact on groundwater resources must be projected out to time periods of 10,000 years and longer. Details on the recommended technical strategy for developing this source term have been published (MCGRAIL et al., 2000b) and have undergone review by an international panel of experts. This data package was developed from a direct implementation of that technical strategy.

The computer model selected for modeling the radionuclide source-term is the Subsurface Transport Over Reactive Multiphases (STORM) code (MCGRAIL and BACON, 1998). The required inputs to this code will be derived from literature sources and from laboratory experiments with ILAW glasses. This report, therefore, functions to document the input data that will be used for STORM simulations. The STORM code requires input of two main general classifications of data: 1) multiphase flow, and 2) reactive transport. Multiphase flow input is defined in 
the near-field hydraulic properties data package (MEYER et al., 2004) or the far-field hydraulic properties data package (FAYER and SZECSODY, 2004). Experimentally derived input related to conducting reactive transport calculations is defined within this data package.

Laboratory testing provides a majority of the key input data required to assess the long-term performance of ILAW glasses with the STORM code. Test data from four principal methods, as described by McGrail et al. (MCGRAIL et al., 2000b), are discussed in this data package including the single-pass flow-through test (SPFT), pressurized unsaturated flow (PUF) test, and product consistency test (PCT). Each of these test methods focuses on different aspects of the glass corrosion process. Linkages between the test methods, their principal function, and the data they provide for STORM modeling is described in Table 1. The interested reader should consult McGrail et al. (MCGRAIL et al., 2000b) for additional details regarding these test methods and their use in evaluating long-term glass performance.

In addition to the SPFT, PUF, and PCT test results, this data package also contains empirical effective diffusion coefficients for several key contaminants $\left(\mathrm{Cr}, \mathrm{I}, \mathrm{NO}_{3}, \mathrm{Hg}\right.$, Tc, and $\left.\mathrm{U}\right)$ in grouted secondary waste. Secondary waste streams generated during vitrification operations are currently planned to be encapsulated in a cementitious waste form and disposed of in the IDF along with ILAW glass and spent melters. These diffusion coefficients will be used in sourceterm calculations with the STORM computer code to describe how these cementitious waste forms will impact overall contaminant release from the IDF.

Table 1. Overview of Test Methods Discussed in this Data Package

\begin{tabular}{|l|l|l|l|l|}
\hline $\begin{array}{c}\text { Test } \\
\text { Method }\end{array}$ & $\begin{array}{c}\text { Temperature } \\
\text { Range }\end{array}$ & Duration & \multicolumn{1}{|c|}{ Data Provided } & \multicolumn{1}{c|}{ Purpose } \\
\hline SPFT & $23-90^{\circ} \mathrm{C}$ & $\begin{array}{l}14-28 \\
\text { days }\end{array}$ & $\begin{array}{l}\text { Dissolution rate as a function } \\
\text { of temperature, } \mathrm{pH} \text {, and solu- } \\
\text { tion composition }\end{array}$ & $\begin{array}{l}\text { Parameterization of kinetic } \\
\text { rate law for glass dissolution }\end{array}$ \\
\hline PUF & $40-100^{\circ} \mathrm{C}$ & $\begin{array}{l}\text { Months to } \\
\text { years }\end{array}$ & $\begin{array}{l}\text { Effluent chemical composition } \\
\text { and dissolution rate as a func- } \\
\text { tion of temperature and flow } \\
\text { rate, secondary phases, hy- } \\
\text { draulic property changes }\end{array}$ & $\begin{array}{l}\text { Highly accelerated test for } \\
\text { glass screening, secondary } \\
\text { phases for STORM reaction } \\
\text { network, validation of } \\
\text { STORM Code }\end{array}$ \\
\hline PCT & 20 to $100^{\circ} \mathrm{C}$ & Weeks to & $\begin{array}{l}\text { Solution composition and dis- } \\
\text { solution rate as a function of } \\
\text { S/V ratio and temperature, } \\
\text { secondary phases }\end{array}$ & $\begin{array}{l}\text { Glass screening, secondary } \\
\text { phases for STORM reaction } \\
\text { network, calibration of reac- } \\
\text { tion network with EQ3/6 } \\
\text { code }\end{array}$ \\
\hline
\end{tabular}

$\mathrm{PCT}=$ product consistency test

PUF $=$ pressurized unsaturated flow test

SPFT $=$ single pass flow-through (glass test)

$\mathrm{S} / \mathrm{V}=$ surface area-to-solution volume ratio

STORM - Subsurface Transport Over Reactive Multiphases 


\subsection{Laboratory Testing}

Laboratory testing of a large number of prototypic ILAW glasses has been performed. The set of ILAW glasses investigated for this data package release are reference glass formulations provided to PNNL by the Waste Treatment Plant (WTP) and represent glass formulation from each Envelope; LAWA44 (Envelope A), LAWB45 (Envelope B), and LAWC22 (Envelope C). These glasses are expected to represent reasonable bounds on the range of performance of ILAW glass products to be eventually produced at Hanford based on the current understanding of the tank waste processing flow sheet, vitrification plant design, and current waste acceptance specifications. All of these are subject to change, which could and likely would impact long-term performance projections.

The LAWA44, LAWB45, and LAWC22 glasses are all simulated LAW glasses and contain no radioactive elements. An important addition to this data package is the inclusion of test data on two LAW glasses, LAWAN102 and LAWAP101 that were produced with actual tank waste. These glasses were made at the Savannah River National Laboratory and shipped to PNNL for testing. Their composition is provided in Table 2. Due to the limited quantity of these glasses, only accelerated corrosion testing was performed using the PUF test method.

\subsection{Preliminaries}

The interested reader should consult McGrail et al. (MCGRAIL et al., 2000b) for a thorough discussion of how each of the tests described in this data package fit into an overall strategy to evaluate the long-term performance of ILAW glasses. All testing work reported in this data package was conducted in accordance with PNNL's Quality Management System Description and associated quality assurance program documents (QAPD), which are maintained electronically as part of the Standards Based Management System. All instrument calibrations and materials are traceable, test procedures and associated training activities are documented in detail, and test methods comply with established plans and procedures. Computer Software and Database Control procedures are being followed for data analysis software being used to store, sort, and reduce data.

All staff members contributing to this data package received proper technical and quality assurance training in accordance with QAPD Training and Qualification for Staff. Equipment is either calibrated periodically or at the time of use and the calibration status of each piece of equipment is documented through a material and test equipment (M\&TE) sheet, which is maintained as a part of the QA file. The M\&TE sheets specify the required calibration methods, usually include a calibration procedure, and document the status of the equipment. All equipment requiring calibration prior to its use will be so labeled.

Documented procedures were used for sample preparation, test performance, and sample analysis. Operations not specifically covered in a documented procedure were documented in a Laboratory Record Book. Comments regarding the test performance and test activities are contained in a Laboratory Record Book associated with each test. 


\subsection{Glass Formulations}

The test results presented in the following sections will reference five different ILAW glass compositions. These are provided in Table 2 for reference. LAWA44, LAWB45, LAWC22, LAWAP101, and LAWAN102 are prototypic ILAW glasses. These glasses vary in the concentrations of $\mathrm{SiO}_{2}, \mathrm{Al}_{2} \mathrm{O}_{3}, \mathrm{~B}_{2} \mathrm{O}_{3}, \mathrm{Fe}_{2} \mathrm{O}_{3}, \mathrm{TiO}_{2}, \mathrm{ZnO}, \mathrm{ZrO}_{2}, \mathrm{MgO}$, and $\mathrm{Na}_{2} \mathrm{O}$ across a wide composition range that covers, with high probability, the expected processing composition range for candidate ILAW glasses.

The glasses were prepared by mixing measured amounts of dried reagent-grade chemicals (oxides, fluorides, iodides, and sulphides) in an agate mill. The mixtures were melted in a Pt $(10 \%) \mathrm{Rh}$ crucible, and the molten glass was poured onto a cool stainless steel plate. Each glass was then subjected to heat treatment by placing the glass in a preheated oven at $930^{\circ} \mathrm{C}$ and then cooling at $21^{\circ} \mathrm{C} / \mathrm{hr}$. This cooling rate is consistent with a computed thermal profile for a $1.2 \mathrm{~m} \mathrm{x}$ $1.2 \mathrm{~m} \times 1 \mathrm{~m}$ container that was the design being considered for LAW. The container design has since been modified to a cylinder of $1.2 \mathrm{~m}$ diameter $\mathrm{x} 2.3 \mathrm{~m}$ tall.

Table 2. Composition (Mass\%) of Selected ILAW Glasses

\begin{tabular}{|c|c|c|c|c|c|}
\hline Oxide & LAWA44 & LAWB45 & LAWC22 & *LAWAN102 & *LAWAP101 \\
\hline $\mathrm{Al}_{2} \mathrm{O}_{3}$ & $6.20 \%$ & $6.13 \%$ & $6.08 \%$ & $6.19 \%$ & $5.66 \%$ \\
\hline $\mathrm{B}_{2} \mathrm{O}_{3}$ & $8.90 \%$ & $12.34 \%$ & $10.06 \%$ & $10.05 \%$ & $9.85 \%$ \\
\hline $\mathrm{CaO}$ & $1.99 \%$ & $6.63 \%$ & $5.12 \%$ & $6.24 \%$ & $2.00 \%$ \\
\hline $\mathrm{Cl}$ & $0.65 \%$ & $0.01 \%$ & $0.09 \%$ & $0.03 \%$ & $0.17 \%$ \\
\hline $\mathrm{Cr}_{2} \mathrm{O}_{3}$ & $0.02 \%$ & $0.07 \%$ & $0.02 \%$ & $0.08 \%$ & $0.03 \%$ \\
\hline $\mathrm{F}$ & $0.01 \%$ & $0.08 \%$ & $0.16 \%$ & & $0.27 \%$ \\
\hline $\mathrm{Fe}_{2} \mathrm{O}_{3}$ & $6.98 \%$ & $5.26 \%$ & $5.43 \%$ & $6.94 \%$ & $5.56 \%$ \\
\hline $\mathrm{HfO}_{2}$ & & & & $0.05 \%$ & \\
\hline $\mathrm{K}_{2} \mathrm{O}$ & $0.50 \%$ & $0.26 \%$ & $0.10 \%$ & $0.19 \%$ & $3.82 \%$ \\
\hline $\mathrm{Li}_{2} \mathrm{O}$ & & $4.62 \%$ & $2.51 \%$ & $2.76 \%$ & \\
\hline $\mathrm{MgO}$ & $1.99 \%$ & $2.97 \%$ & $1.51 \%$ & $1.41 \%$ & $1.49 \%$ \\
\hline $\mathrm{MnO}$ & & & $0.04 \%$ & $0.03 \%$ & $0.01 \%$ \\
\hline $\mathrm{MoO}_{3}$ & $0.01 \%$ & & & $0.003 \%$ & \\
\hline $\mathrm{Na}_{2} \mathrm{O}$ & $20.00 \%$ & $6.50 \%$ & $14.40 \%$ & $11.23 \%$ & $18.46 \%$ \\
\hline $\mathrm{NiO}$ & & & $0.03 \%$ & $0.08 \%$ & $0.01 \%$ \\
\hline $\mathrm{P}_{2} \mathrm{O}_{5}$ & $0.03 \%$ & $0.03 \%$ & $0.17 \%$ & $0.17 \%$ & $0.09 \%$ \\
\hline $\mathrm{PbO}_{2}$ & & & $0.02 \%$ & $0.02 \%$ & \\
\hline $\mathrm{Rh}_{2} \mathrm{O}_{3}$ & & & & $0.001 \%$ & \\
\hline $\mathrm{Re}_{2} \mathrm{O}_{7}$ & $0.10 \%$ & $0.01 \%$ & $0.01 \%$ & & \\
\hline $\mathrm{SO}_{3}$ & $0.10 \%$ & $0.84 \%$ & $0.34 \%$ & $0.31 \%$ & $0.31 \%$ \\
\hline $\mathrm{SiO}_{2}$ & $44.55 \%$ & $47.86 \%$ & $46.67 \%$ & $47.41 \%$ & $44.27 \%$ \\
\hline $\begin{array}{c}\mathrm{SnO}_{2} \\
\mathrm{SrO}\end{array}$ & & & & $\begin{array}{c}0.002 \% \\
0.02 \%\end{array}$ & $0.010 \%$ \\
\hline $\mathrm{TcO}_{2}$ & & & & $0.0001 \%$ & $0.001 \%$ \\
\hline $\mathrm{TiO}_{2}$ & $1.99 \%$ & & $1.14 \%$ & $1.24 \%$ & $2.01 \%$ \\
\hline $\mathrm{UO}_{2}$ & & & & $0.001 \%$ & $0.001 \%$ \\
\hline $\mathrm{V}_{2} \mathrm{O}_{5}$ & & & & $0.02 \%$ & $0.01 \%$ \\
\hline $\mathrm{ZnO}$ & $2.96 \%$ & $3.15 \%$ & $3.07 \%$ & $2.99 \%$ & $2.97 \%$ \\
\hline $\mathrm{ZrO}_{2}$ & $2.99 \%$ & $3.15 \%$ & $3.03 \%$ & $2.54 \%$ & $3.01 \%$ \\
\hline
\end{tabular}




\subsection{Kinetic Rate Law Parameters}

To predict the long-term fate of glass in the subsurface over the period of regulatory concern, a mathematical model that describes glass reactivity is needed. Over the last few decades, a general rate equation has been fashioned to describe the dissolution of glass (and more ordered materials) into aqueous solution. As described below, the equation is based upon the Transition State Theory (TST) of chemical kinetics, in which the overall reaction rate is governed by the slowest elementary reaction. Elementary reactions have simple stoichiometry and can be combined as an overall reaction. In many cases, the elementary reactions can only be inferred. As an example of the elementary reaction, consider the dissolution of $\mathrm{SiO}_{2}$ polymorphs to form silicic acid:

$$
\mathrm{SiO}_{2}(s)+2 \mathrm{H}_{2} \mathrm{O} \leftrightarrow \mathrm{SiO}_{2} \cdot 2 \mathrm{H}_{2} \mathrm{O}^{\ddagger} \rightarrow \mathrm{H}_{4} \mathrm{SiO}_{4}(a q)
$$

in which $\mathrm{SiO}_{2} \cdot 2 \mathrm{H}_{2} \mathrm{O}^{\ddagger}$ represents an activated complex. Note that the reactants and the activated complex in Equation (1) are linked by a double-headed arrow symbolizing a reversible reaction. Equation (1) also illustrates that the TST formulation assumes the decay of the activated complex is an irreversible reaction.

With these assumptions, a general equation describing the rate of reaction as a function of $\mathrm{pH}$, temperature, saturation state of the system, and the activities of rate enhancing or inhibiting species (AAGAARD and HELGESON, 1982) has been proposed

$$
r=\vec{k} v_{i} a_{\mathrm{H}^{+}}^{-\eta} \exp \left(\frac{-E_{a}}{\mathrm{R} T}\right)\left[1-\left(\frac{Q}{K_{g}}\right)^{\sigma}\right] \prod_{j} a_{j}^{\eta_{i}}, \quad i=1,2, \ldots \mathrm{N}
$$

where $r$ is the dissolution rate in $\mathrm{g} \mathrm{m}^{-2} \mathrm{~d}^{-1}, \vec{k}$ is the intrinsic rate constant in $\mathrm{g} \mathrm{m}^{-2} \mathrm{~d}^{-1}, v_{i}$ is the mass fraction of element $i, a_{\mathrm{H}^{+}}$is the hydrogen ion activity, $a_{j}$ is the activity of the $j$ th aqueous species that acts as an inhibitor or catalyst, $E_{a}$ is the activation energy in $\mathrm{kJ} \mathrm{mol}^{-1}, \mathrm{R}$ is the gas constant in $\mathrm{kJ} \mathrm{mol}^{-1} \mathrm{~K}^{-1}, T$ is the temperature in $\mathrm{K}, Q$ is the ion activity product, $K_{g}$ is the pseudoequilibrium constant for glass, $\eta$ is the power law coefficient, and $\sigma$ is the Temkin coefficient. Although there are a number of issues regarding the applicability of Equation (2) for modeling glass dissolution, McGrail et al. (McGraIL et al., 2000b) concluded that this rate law currently "...best describes the majority of the experimental data that has been gathered after over 35 years of studying the glass/water reaction processes." Consequently, parameterization of this equation is required to conduct source-term calculations with STORM code. Because the disposal system temperature is a known constant, the determination of five parameters; $k, E_{a}, \eta, \sigma, K_{g}$, is required for each glass formulation (neglecting the $\prod_{j} a_{j}^{\eta_{i}}$ term). The ion activity product $(Q)$ is a vari-

able and must be computed with STORM as a function of time and space for the disposal system. Lasaga (1995) convincingly argues that $\sigma=1$ in the above equation because any value where $\sigma \neq$ 1 is inconsistent with transition state theory. Consequently, $\sigma=1$ is assumed for this work, thus eliminating $\sigma$ as an unknown parameter in the rate law. 


\subsection{Experimental Materials and Methods}

The experimental materials and methods section will discuss the techniques and procedures used to prepare each glass sample, buffer solutions, SPFT test, and calculate the dissolution rate and associated uncertainty.

\subsubsection{Materials Preparation}

The samples used in this study were prepared by crushing a sub-sample of glass in a ceramic ball mill. The crushed glass was then sieved into $-100+200$ mesh (149 to $75 \mu \mathrm{m}$ diameter) size fractions, washed in deionized water (DIW), sonicated in DIW, rinsed in ethanol, and dried in a $90^{\circ} \mathrm{C}$ oven. The specific surface area of each sample was calculated using a geometric formula (MCGRAIL et al., 1997). This formula assumes that the particles are spherical, size distributions of the grains are normally distributed, and that surface pits, cracks, and other forms of surface roughness do not affect the surface area (or at least are not important after a short time). Although all three of these assumptions may not be valid, results from LAW glass experiments using glass coupons, with a calculated and measured surface area, have shown that the geometric surface area best represents the overall glass surface area (MCGRAIL et al., 2000a).

\subsubsection{Buffer Solutions}

The solutions used to control the $\mathrm{pH}$ during the SPFT experiments are summarized in Table 3. Table 3 also contains a summary of the in-situ $\mathrm{pH}$ values computed at each test temperature using the thermodynamic software package EQ3NR (WOLERY, 1992). It is important to take into account the change in $\mathrm{pH}$ that occurs at different temperatures when computing dissolution rates from SPFT data as the in-situ $\mathrm{pH}$ can vary by as much as $1.5 \mathrm{pH}$ units over the temperature range from $23^{\circ}$ to $90^{\circ} \mathrm{C}$. These solutions were prepared by adding small amounts of the organic tris (hydroxmethl) aminomethane (THAM) buffer to DIW and adjusting the solution to the desired $\mathrm{pH}$ value using $15.8 \mathrm{M} \mathrm{HNO}_{3}$ or $1 \mathrm{M} \mathrm{LiOH}$. The THAM buffer range is between $\mathrm{pH} 7$ to

Table 3. Composition of Solutions Used in SPFT Experiments. Solution $\mathrm{pH}$ values above $23^{\circ} \mathrm{C}$ were calculated with EQ3NR Code V7.2b database.

\begin{tabular}{|c|c|c|c|c|c|}
\hline \multirow[t]{2}{*}{ Solution } & \multirow[t]{2}{*}{ Composition } & \multicolumn{4}{|c|}{ pH@ } \\
\hline & & $23^{\circ} \mathrm{C}$ & $40^{\circ} \mathrm{C}$ & $70^{\circ} \mathrm{C}$ & $90^{\circ} \mathrm{C}$ \\
\hline 1 & $0.05 \mathrm{M}$ THAM $+0.047 \mathrm{M} \mathrm{HNO}_{3}$ & 7.01 & 6.57 & 5.91 & 5.55 \\
\hline 2 & $0.05 \mathrm{M}$ THAM $+0.02 \mathrm{M} \mathrm{HNO}_{3}$ & 8.32 & 7.90 & 7.25 & 6.89 \\
\hline 3 & $0.05 \mathrm{M}$ THAM $+0.0041 \mathrm{M} \mathrm{HNO}_{3}$ & 8.99 & 8.67 & 8.08 & 7.72 \\
\hline 4 & $0.05 \mathrm{M}$ THAM $+0.003 \mathrm{M} \mathrm{LiOH}$ & 9.99 & 9.55 & 8.88 & 8.52 \\
\hline 5 & $0.0107 \mathrm{M} \mathrm{LiOH}+0.010 \mathrm{M} \mathrm{LiCl}$ & 11.00 & 10.89 & 10.43 & 10.06 \\
\hline 6 & $0.0207 \mathrm{M} \mathrm{LiOH}+0.010 \mathrm{M} \mathrm{LiCl}$ & 12.02 & 11.74 & 11.08 & 10.70 \\
\hline 7 & $0.05 \mathrm{M}$ THAM $+\mathrm{Si}^{*}$ & 9.00 & 8.83 & 8.51 & 8.27 \\
\hline
\end{tabular}


10; therefore, the alkaline solutions, $\mathrm{pH}$ range 11 and 12, were prepared by adding $\mathrm{LiOH}$ and $\mathrm{LiCl}$ to DIW and adjusting the solution to the desired $\mathrm{pH}$ value using $15.8 \mathrm{M} \mathrm{HNO}_{3}$ or $1 \mathrm{M}$ LiOH.

Influent silicon concentration was varied from dilute to saturated with respect to amorphous silica $\left[\mathrm{SiO}_{2}(\mathrm{am})\right]$, based on the results from calculations using EQ3NR (WOLERY, 1992) for select experiments. It is important to note that the solubility behavior of $\mathrm{SiO}_{2}(\mathrm{am})$ changes with temperature; therefore, the target amount of Si added to each solution was adjusted to correspond to the experimental temperature being interrogated, resulting in Si solution concentrations that ranged from 15 to $140 \mathrm{ppm}$. These solutions were prepared by dissolving analytical grade silicic acid powder $\left(\mathrm{SiO}_{2} \cdot \mathrm{H}_{2} \mathrm{O}\right)$ in a solution of $0.05 \mathrm{M}$ THAM buffer and heating the mixture in a $90^{\circ} \mathrm{C}$ oven for no less than three days to facilitate complete dissolution. Upon complete dissolution, each solution was removed from the oven, allowed to cool, and $\mathrm{pH}$ adjusted (target $\mathrm{pH}=9$ ) using aliquots of $15.8 \mathrm{M} \mathrm{HNO}_{3}$ or $1 \mathrm{M} \mathrm{LiOH}$.

\subsubsection{SPFT Apparatus}

Dissolution experiments were conducted using the SPFT apparatus (Figure 1). The SPFT experimental system provides a continuous flow of fresh influent solution, prevents the build-up of reaction products, maintains the bulk solution composition throughout an experiment, provides a direct measure of the dissolution rate, and allows an investigator to study the reactivity of a material over a wide range of experimental conditions. This system has been extensively described by others (MCGRAIL et al., 2000a); and an interested reader should consult these references, as well as the references contained therein for more detail.

In general, solution is transferred using a Kloehn syringe pump (Model 50300) from a reservoir bottle to a Teflon reactor and finally to a sample collection vial using 1.59-mm Teflon tub-

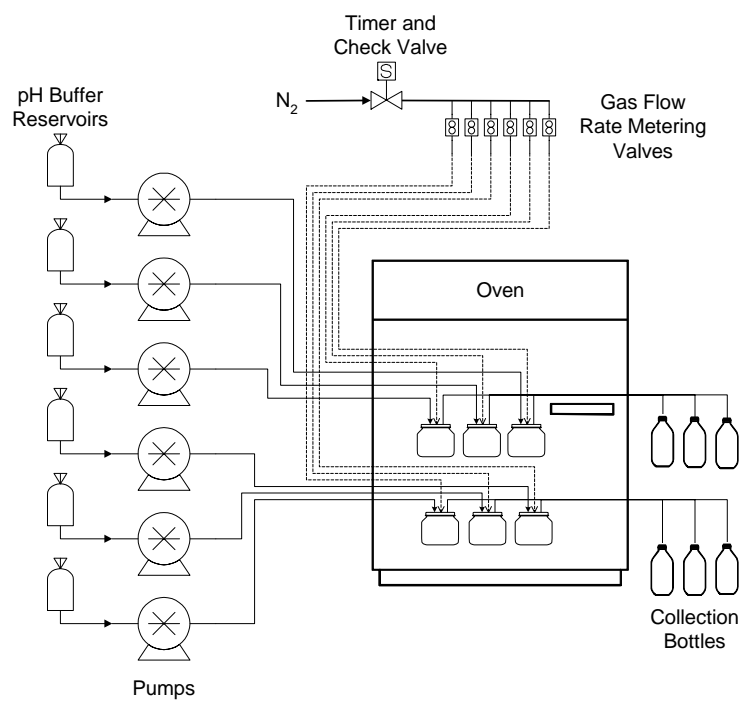

Figure 1. Schematic of the Single Pass FlowThrough (SPFT) Apparatus ing. The Teflon reactor vessels consisted of two main pieces, (e.g., a top and bottom) that threaded together to form a cylinder with a 47.5-mm outer diameter and 63-mm height, with a total inner volume of approximately $80 \mathrm{~mL}$. The relatively large diameter of the sample holder (40.6-mm inner diameter) allows the glass particles to form a thin layer at the reactor bottom and interact with the contacting solution. The effluent solutions were monitored for four major glass components, aluminum (Al), boron (B), sodium (Na), and silicon ( $\mathrm{Si}$ ) using inductively coupled plasma-optical emission spectroscopy (ICP-OES). 


\subsubsection{Dissolution Rate and Error Calculations}

Dissolution rates, based on steady-state concentrations of elements in the effluent, are normalized to the amount of the element present in the sample by the following formula:

$$
\text { Normalized dissolution rate }\left(\mathrm{g} \mathrm{m}^{-2} \mathrm{~d}^{-1}\right)=\frac{\left(C_{i}-\bar{C}_{i, b}\right) q}{f_{i} S}
$$

where $C_{i}$ is the concentration of the element, $i$, in the effluent $\left(\mathrm{g} \mathrm{L}^{-1}\right), \bar{C}_{i, b}$ is the average background concentration of the element of interest $\left(\mathrm{g} \mathrm{L}^{-1}\right), q$ is the flow-through rate $\left(\mathrm{L} \mathrm{d}^{-1}\right), f_{i}$ is the mass fraction of the element in glass (dimensionless), and $S$ is the surface area of the sample $\left(\mathrm{m}^{2}\right)$. The value of $f_{i}$ can be calculated from the chemical composition of the sample. Flowthrough rates are determined by gravimetric analysis of the fluid collected in each effluent collection vessel upon sampling. The background concentration of the element of interest is determined, as previously discussed, by analyses of the starting input solution and the three blank solutions. Typically, background concentrations of elements are below their respective detection threshold. The detection threshold of any element is defined here as the lowest calibration standard that can be determined reproducibly during an analytical run within $10 \%$. In cases where the analyte is below the detection threshold, the background concentration of the element is set at the value of the detection threshold.

Determining the experimental uncertainty of the dissolution rate takes into account uncertainties of each parameter in Equation (3). For uncorrelated random errors, the standard deviation of a function $f\left(x_{1}, x_{2}, \ldots x_{n}\right)$ is given by:

$$
\sigma_{f}=\sqrt{\sum_{i=1}^{n}\left(\frac{\partial f}{\partial x_{i}}\right)^{2} \sigma_{i}^{2}}
$$

where $\sigma_{f}$ is the standard deviation of the function $f_{.,} x_{i}$ is the parameter $i$, and $\sigma_{i}$ is the standard deviation of parameter $i$. Substituting (3) into (4) results in:

$$
\sigma_{r_{i}}=\sqrt{\left(\frac{q}{f_{i} S}\right)^{2}\left(\sigma_{C_{i}}^{2}+\sigma_{\bar{C}_{i, b}}^{2}\right)+\left(\frac{C_{i}-\bar{C}_{i, b}}{f_{i} S}\right)^{2} \sigma_{q}^{2}+\left(\frac{\left(C_{i}-\bar{C}_{i, b}\right) q}{f_{i}^{2} S}\right)^{2} \sigma_{f_{i}}^{2}+\left(\frac{\left(C_{i}-\bar{C}_{i, b}\right) q}{f_{i} S^{2}}\right)^{2} \sigma_{S}^{2}}
$$

Equation (5) can also be expressed in terms of the relative error, $\hat{\sigma}_{r_{i}}=\sigma_{r_{i}} / r_{i}$, and is given by

$$
\hat{\sigma}_{r_{i}}=\sqrt{\frac{\left(\hat{\sigma}_{C_{i}} C_{i}\right)^{2}+\left(\hat{\sigma}_{\bar{C}_{i, b}} \bar{C}_{i, b}\right)^{2}}{\left(C_{i}-\bar{C}_{i, b}\right)^{2}}+\hat{\sigma}_{q}^{2}+\hat{\sigma}_{f_{i}}^{2}+\hat{\sigma}_{s}^{2}}
$$

Relative errors of $10 \%, 10 \%, 5 \%, 3 \%$, and $15 \%$ for $C_{i}, \bar{C}_{i, b}, q, f_{i}$, and $S$, respectively, are typical for measurements conducted at PNNL. Although the absolute error in $f_{i}$ is likely higher than $3 \%$, this error is non-systematic and so does not contribute significantly to sample-to- 
sample uncertainty, which is the principal error of interest here. The conservative appraisal of errors assigned to the parameters in Equation (6), in addition to the practice of imputing detection threshold values to background concentrations, results in typical uncertainties of approximately $\pm 35 \%$ on the dissolution rate.

\subsubsection{SPFT Results}

Dissolution rates and experimental conditions, including temperature, solution $\mathrm{pH}$, flowthrough rates, sample mass, and surface area, are listed in Appendix A. The majority of the rates reported are computed based on concentration of $\mathrm{B}$. Boron is typically the most reliable index for matrix dissolution since it, along with $\mathrm{Si}$ and $\mathrm{Al}$, forms the glass polymer network. In addition, when B is released during dissolution, it is not retained either in secondary minerals or "leach layers" that build up on the surface of glass. Other network forming elements, such as $\mathrm{Al}$ and $\mathrm{Si}$, may be retained after initial release in experiments with slow flow-through rates and, clearly, neither Al nor Si can be used as an index of dissolution in cases where these elements are added to input solutions. Rates based on alkali elements, in this case, $\mathrm{Na}$, are also subject to uncertainty under conditions of slow matrix dissolution rates.

As discussed in more detail below in Section 3.1.5.1.4 and 3.1.5.3.2, release of Na to solution is through two separate mechanisms; matrix dissolution and alkali-hydrogen exchange. For example, when flow-through rates are slow, the concentration of $\mathrm{Si}$ in solution in contact with glass builds up, causing the dissolution rate to decrease. Relatively large amounts of $\mathrm{Na}$ are released into solution, however, because the $\mathrm{Na}^{+}-\mathrm{H}^{+}$exchange mechanism continues to operate. Thus, in this example, the calculated dissolution rate would be too fast. However, in many experiments the $\log _{10}$ dissolution rate based upon $\mathrm{Al}, \mathrm{B}, \mathrm{Na}$, and $\mathrm{Si}$ agrees to within $0.2 \log$ units and is reported as an average. In some extreme cases, the concentration of B in solution is below the detection threshold and we are forced to rely on concentrations of Al, Na, and Si to compute dissolution rates. This may occur, for example, when flow-through rates are very fast and concentrations of elements in the effluent are dilute. However, if these rates are in disagreement with each other, then the dissolution rates for that experiment are not reported.

To simplify presentation of the results, each data set has been divided into four sections. Each section will present the results of tests conducted to determine rate law parameters for each glass composition; LAWA44, LAWB45, and LAWC22. This section will be followed by a section that will compare the experimental results and relate these differences to glass structure and changes in glass composition. 


\subsubsection{SPFT Results for LAWA44 Glass}

\subsection{Achievement of Steady-State and Consistency of Results}

Obtainment of valid dissolution rates depends on the glass-solution system reaching steady-state conditions. Figure 2 shows that these conditions are met for typical experiments at the four temperatures $\left(23^{\circ}, 40^{\circ}, 70^{\circ}\right.$, and $\left.90^{\circ} \mathrm{C}\right)$ investigated. Concentrations of $\mathrm{B}$ are invariant with respect to time after approximately seven reactor volumes in these experiments. Although the $23^{\circ} \mathrm{C}$ results suggest that this test has not attained steady-state, an increase in the plots resolution illustrates that steady-state was achieved (Figure 2 inset plot). The results shown in this diagram are typically observed in all experiments.

\subsection{Effect of $q / S$ Variations}

Figure 3 illustrates the effect of varying the ratio of flow-through rate, $q$, to sample surface area, $S$. Rates based on concentrations of $\mathrm{Al}, \mathrm{B}, \mathrm{Na}$, and $\mathrm{Si}$ are plotted for the conditions of $40^{\circ} \mathrm{C}, \mathrm{pH}$ $\left(23^{\circ} \mathrm{C}\right)=9$. This figure illustrates that as the $\mathrm{q} / \mathrm{S}$ ratio increases, dissolution rates increase and then reach a constant value, which is commonly referred to as the forward or maximum dissolution rate. Figure 3 also illustrates that over the range of $q / S$ interrogated $\mathrm{Al}, \mathrm{B}, \mathrm{Na}$, and $\mathrm{Si}$ are being released congruently from the glass, especially at higher $q / S$ ratio. The evidence for congruent release is illustrated by the normalized release rates for $\mathrm{Al}, \mathrm{B}, \mathrm{Na}$, and Si being within the experimental error of one another each $q / S$ ratio.

Dissolution rates decrease as the ratio of $\mathrm{q} / \mathrm{S}$ decreases because when flowthrough rates are low or sample surface

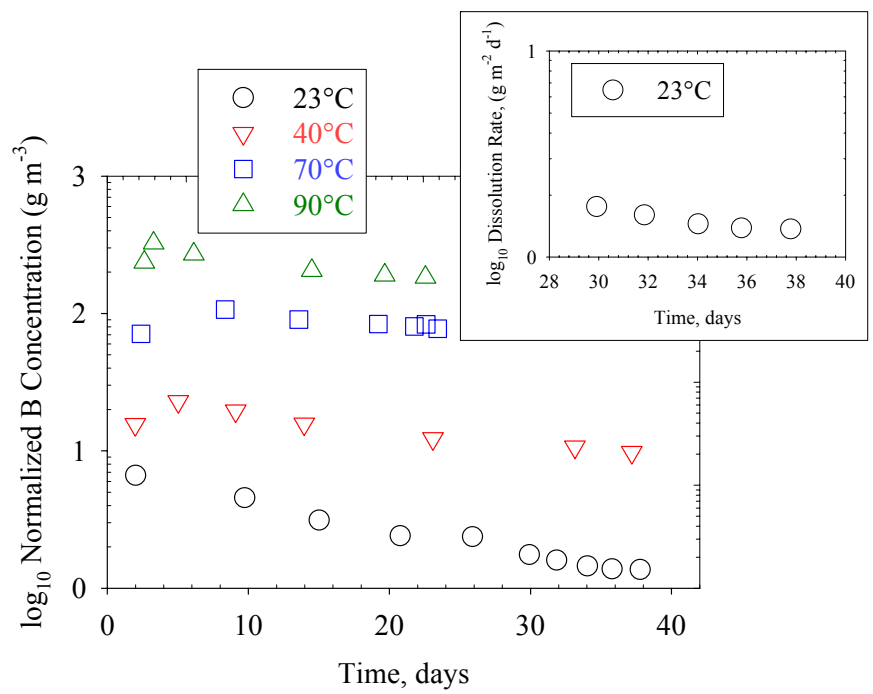

Figure 2. Normalized B Concentration as a Function of Time and Temperature for LAWA44 Glass with Increased Resolution for the $23^{\circ} \mathrm{C}$ Results Between Day 30 and 38 .

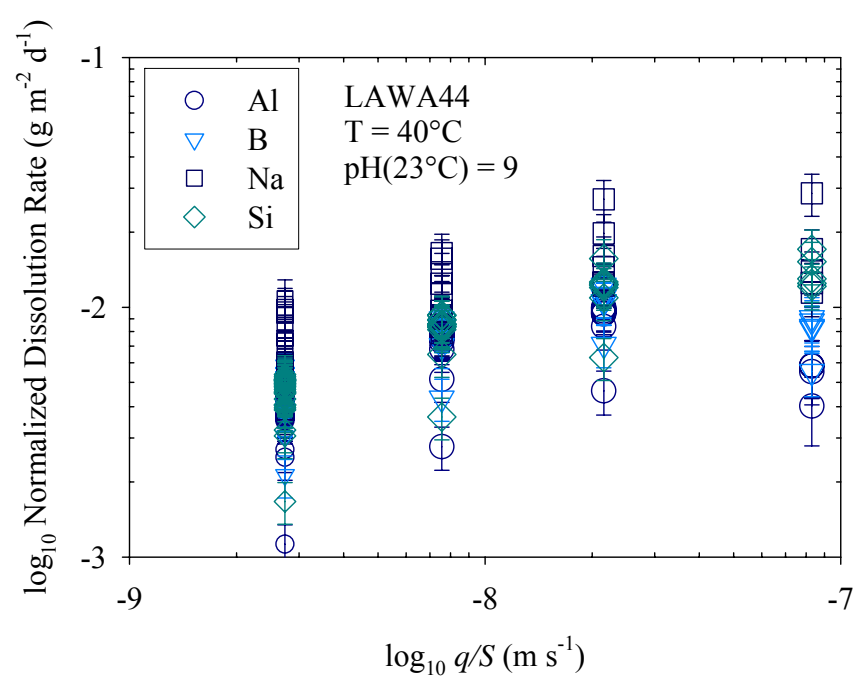

Figure 3. Effect of Variation in the Ratio of Flow Rate, $q$, to Sample Surface Area, S, on LAWA44 Glass Dissolution Rate area is high, the concentration of elements dissolved into solution are high. As the concentration of elements rise in solution increase, the solution approaches saturation with respect to some solid phase(s). Therefore, the dissolution rate decreases as the difference in chemical potential between glass and solution decreases. 


\subsection{Effect of $p H$}

To determine the effect of $\mathrm{pH}$ on the dissolution rate, solution $\mathrm{pH}$ values were varied between 7 and 12 at temperatures of $23,40,70$, and $90^{\circ} \mathrm{C}$. The in situ solution $\mathrm{pH}$ has been corrected for the effect of temperature using EQ3NR (Table 3).

Figure 4 illustrates that as the $\mathrm{pH}$ increases from 7 to 12 , the overall glass dissolution rate also increases. This direct relationship between the dissolution rate and $\mathrm{pH}$, going from the neutral to alkaline $\mathrm{pH}$ range, is typical of other LAW glass formulations (MCGRAIL et al., 2001a). Conducting a linear regression on the data at each temperature gave a slope $\eta=0.49$ \pm 0.08 indicating that $\eta$ does not depend on temperature within experimental error. Using this value for $\eta$, a non-linear regression was performed on the entire data set shown in Figure 4 using the kinetic rate law (MCGRAIL et al., 2003)

$$
J=k_{o} 10^{\eta[\mathrm{pH}]} \exp \left(\frac{-E_{a}}{\mathrm{RT}}\right)
$$

where $J$ is the normalized release rate, $k_{\mathrm{o}}$ is the intrinsic rate constant, $\eta$ is the $\mathrm{pH}$ power law coefficient, $E_{a}$ is the activation energy, $\mathrm{R}$ is the ideal gas constant, and $T$ is the temperature. The resulting regression coefficients are $k_{\mathrm{o}}=1.3 \times 10^{4} \mathrm{~g} \mathrm{~m}^{-2} \mathrm{~d}^{-1}, E_{a}=60 \pm 7 \mathrm{~kJ} \mathrm{~mol}^{-1}$ with a correlation coefficient $\left(\mathrm{R}^{2}\right)$ of 0.78 . The value of $E_{a}$ and $\eta$ are within the experimental error of values reported for LAW glass formulation LAWBP1 (MCGRAIL et al., 2001a), $\left(k_{\mathrm{o}}=3.4 \times 10^{6} \mathrm{~g} \mathrm{~m}^{-2} \mathrm{~d}^{-1}\right.$, $E_{a}=68 \mathrm{~kJ} \mathrm{~mol}^{-1}$, and $\left.\eta=0.35\right)$.

Figure 4 also illustrates that temperature has a strong effect on the dissolution rates. The apparent activation energy determined $\left(E_{a}=60 \pm 7 \mathrm{~kJ} \mathrm{~mol}^{-1}\right)$ corresponds to a surface controlled reaction process, $\sim 41.8$ to $83.7 \mathrm{~kJ} \mathrm{~mol}^{-1}$ (LASAGA, 1981). This value is in good agreement with the values reported for another LAW glass formulations and several $\mathrm{SiO}_{2}$ polymorphs [LAWABP1 $=68 \mathrm{~kJ} \mathrm{~mol}^{-1}$ (MCGRAIL et al., 2001a), quartz $=66-83 \mathrm{~kJ} \mathrm{~mol}^{-1}$ (Dove, 1994), $\mathrm{SiO}_{2}(\mathrm{am})=74.5 \mathrm{~kJ} \mathrm{~mol}^{-1}\left(\right.$ ICENHOWER and DOVE, 2000), and cristobalite $=69 \mathrm{~kJ} \mathrm{~mol}^{-1}$ (RENDERS et al., 1995), suggesting that the rupture of the Si-O bond is the rate-limiting step in dissolution.

Another factor affecting glass dissolution that is observed when evaluating the dissolution rate as a function of $\mathrm{pH}$ and temperature is ion exchange. Ion exchange is a process by which $\mathrm{H}^{+}$, contained in the solution, exchanges for the ions contained in the glass matrix, as illustrated by

$$
\text { Glass } \cdots \mathrm{Na}+\mathrm{H}^{+} \stackrel{J_{x}}{\longrightarrow} \text { Glass } \cdots \mathrm{H}+\mathrm{Na}^{+}
$$


The addition of this mechanism may affect LAW glass performance because of the significant $\mathrm{Na}_{2} \mathrm{O}$ content, almost $20 \%$ for LAWA44. Methods to quantify the alkali ion-exchange rate for the LAWA44 are discussed below.

\subsection{Effect of Alkali-Hydrogen Exchange}

The mechanism of alkali-hydrogen exchange (IEX) is widely recognized as an important process in glass dissolution (McGRAIL et al., 2001b). This IEX rate typically decreases with an increase in the solution $\mathrm{pH}$ or temperature, in other words, matrix dissolution becomes the dominant mechanism of dissolution. Consequently, as the solution $\mathrm{SiO}_{2}(\mathrm{aq})$ activity increases the divergence between the rate of matrix dissolution and IEX increases. Under these conditions, the IEX rate becomes more pronounced because as the ion activity product $(\mathrm{Q})$ approaches saturation with respect to some secondary phase(s), the rate of matrix dissolution slows.

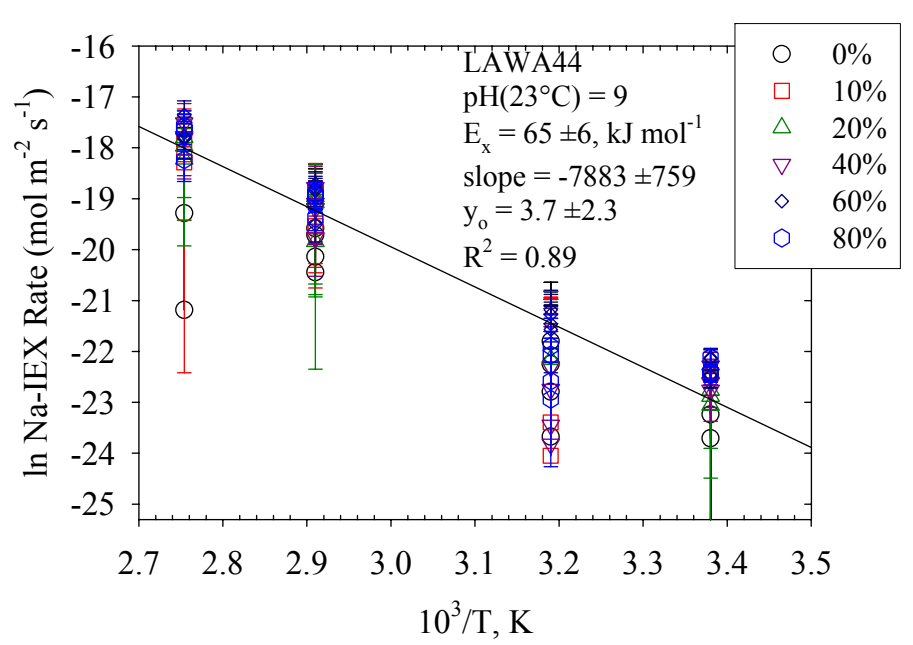

Figure 5. Na Ion Exchange Rate as a Function of Temperature with Changing a $\left.\mathrm{SiO}_{2}(\mathrm{aq})\right]$ for LAWA44 Glass

To compute the rate of ion exchange (IEX), the steady-state Na release rate was subtracted from the steady-state matrix dissolution rate, indexed by boron, and the resulting value was converted to moles of Na per square meter per second. Figure 5 illustrates the natural logarithm of the IEX rate versus $1 / \mathrm{T}$ for each $\mathrm{SiO}_{2}(\mathrm{aq})$ activity interrogated. Conducting a linear regression on the data and using these regressed coefficients Na-IEX rate at $15^{\circ} \mathrm{C}$ was computed, $r_{x}=5.3 \times$ $10^{-11} \mathrm{~mol} \mathrm{~m}^{-2} \mathrm{~s}^{-1}$. Using the slope an activation energy, $E_{X}=65 \pm 6 \mathrm{~kJ} \mathrm{~mol}^{-1}$, for Na-IEX was computed. This value is slightly higher than the values computed for the LAW glass formulations, LAWABP1 $\left(E_{x}=52 \mathrm{~kJ} \mathrm{~mol}^{-1}\right)$ (MCGRAIL et al., 2001a) and the bulk vitrification (BKV) baseline glass formulation, BKV1 $\left(E_{x}=53 \pm 2 \mathrm{~kJ} \mathrm{~mol}^{-1}\right)$.

\subsection{Effect of Solution Saturation State}

As previously discussed, experiments with input solutions doped with $\mathrm{Si}$ (ranging from 15 to $140 \mathrm{ppm}$ ) were conducted as a function of temperature at $\mathrm{pH}\left(23^{\circ} \mathrm{C}\right)=9$. Before discussing these results, it is important to determine the aqueous $\mathrm{Si}$ speciation at each temperature to correctly account for the change in Si speciation with temperature in the analysis. Therefore, the solution speciation of dissolved Si species was computed with the aid of the geochemical code EQ3NR (WOLERY, 1992). Results of this computation shows that $\mathrm{SiO}_{2}$ (aq) was the dominant solution species in the buffer solution from 23 to $90^{\circ} \mathrm{C}$, ranging from $90 \%$, at $23^{\circ} \mathrm{C}$, to $87 \%$, at $90^{\circ} \mathrm{C}$. The remaining 10 and $13 \%$, at 23 and $90^{\circ} \mathrm{C}$ respectively, corresponds to the solution species $\mathrm{HSiO}_{3}$. 
Normalized release rates for $\mathrm{B}$ and $\mathrm{Na}$ as a function of $a\left[\mathrm{SiO}_{2}(\mathrm{aq})\right]$ are shown in Figure 6. The trend, a decrease in the dissolution rate with increasing $\mathrm{SiO}_{2}(\mathrm{aq})$ activity, is similar to those obtained for several LAW glass formulations (MCGRAIL et al., 2001a). As the activity $\mathrm{SiO}_{2}$ (aq) increases, Figure 6 also shows an increasing discrepancy between the bulk glass dissolution rate, as indicated by the rate of $\mathrm{B}$ release, versus the normalized rate of $\mathrm{Na}$ release. The discrepancy has been assigned to a secondary reaction mechanism associated with $\mathrm{Na}$ ion exchange. However, unlike other LAW glass formulations, such as LAWABP1, the release rate of $\mathrm{Na}$ and $\mathrm{B}$ does not converge completely at $90^{\circ} \mathrm{C}$. This is almost certainly due to decrease in the $(\mathrm{Al}+\mathrm{B})$ :alkali (e.g., $\mathrm{Na}+\mathrm{Li}+\mathrm{K})$ ratio, 0.58:1 for LAWA44 and 0.67:1 for LAWABP1, which suggest that LAWA44 may contain more non-bridging oxygen sites (NBO) in comparison to LAWABP1. McGrail et al. (2001b) has illustrated with simple four component glasses, that the number of NBO sites within the glass structure is directly correlated with $\mathrm{Na}$ ion-exchange rates in simple glasses.
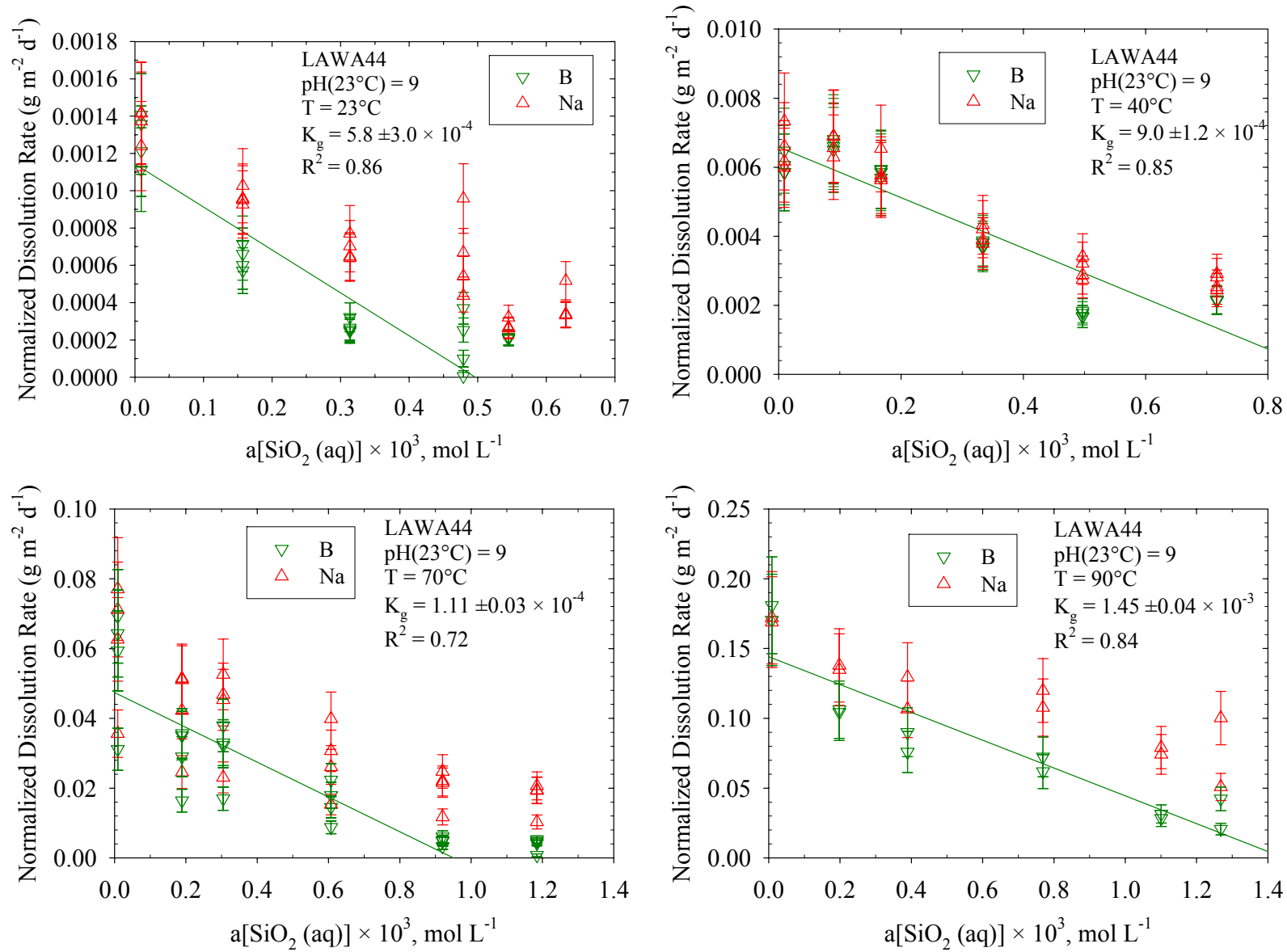

Figure 6. Normalized Release Rate with Respect to B and Na Versus $\mathrm{SiO}_{2}$ (aq) Activity at 23, 40, 70, and $90^{\circ} \mathrm{C}$ for LAWA44 Glass 
By applying a linear fit to the normalized B release rates as they approached zero for the data shown in Figure 6, the $\mathrm{x}$-intercept was determined at each temperature, which is equivalent to the pseudo-equilibrium constant $\left(K_{g}\right)$. The estimated $K_{g}$ values are given in Table 4 and also plotted versus inverse temperature in Figure 7, along with the temperature-dependent solubility products for quartz and $\mathrm{SiO}_{2}(\mathrm{am})$. The results show the $\mathrm{K}_{\mathrm{g}}$ for BKV1 glass is intermediate between quartz and amorphous silica. The slope of a line regressed through the data also provides a crude estimate of the enthalpy of reaction, $\Delta \mathrm{H}_{\mathrm{r}}=11 \pm 2 \mathrm{~kJ} \mathrm{~mol}^{-1}$. Using the regression line shown in Figure 7, the value for $\mathrm{K}_{\mathrm{g}}$ at the disposal system temperature of $15^{\circ} \mathrm{C}$ was calculated and is provided in Table 4.

In addition to the test conducted on LAWA44 glass, kinetic rate law parameters were measured for LAWB45 glass. The results of these experiments are discussed within the next section.

Table 4. Estimate of the Pseudo-Equilibrium Constants for LAWA44 Glass as a Function of Temperature

\begin{tabular}{|c|c|c|c|}
\hline $\left.\mathbf{T} \mathbf{~}^{\mathbf{}} \mathbf{C}\right)$ & $\mathbf{K}_{\mathbf{g}}$ & Error & $\mathbf{R}^{2}$ \\
\hline 15 & $5.45 \mathrm{E}-04$ & - & - \\
23 & $5.75 \mathrm{E}-04$ & $\pm 3.0 \mathrm{E}-04$ & 0.86 \\
40 & $9.00 \mathrm{E}-04$ & $\pm 1.2 \mathrm{E}-05$ & 0.85 \\
70 & $1.11 \mathrm{E}-03$ & $\pm 3.4 \mathrm{E}-05$ & 0.72 \\
90 & $1.45 \mathrm{E}-03$ & $\pm 4.3 \mathrm{E}-05$ & 0.84 \\
\hline
\end{tabular}

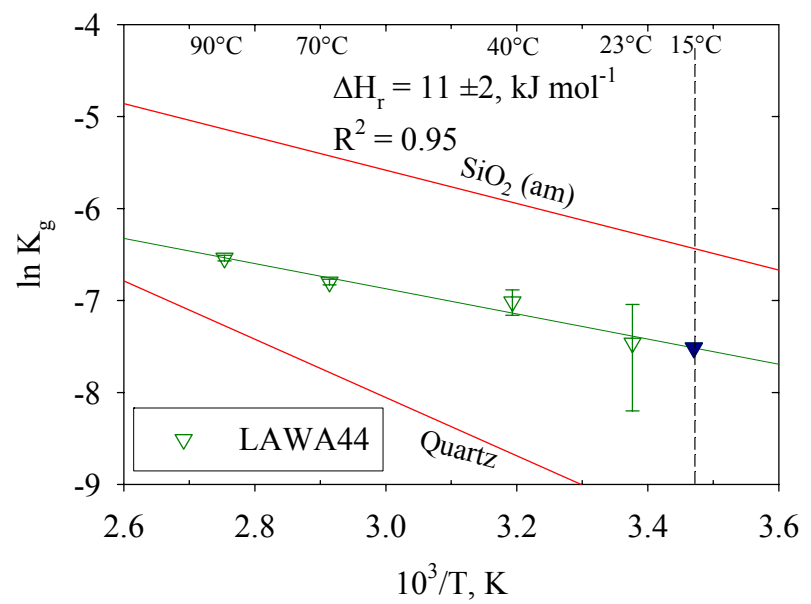

Figure 7. $\ln \mathrm{K}_{\mathrm{g}}$ vs. Inverse Temperature for LAWA44 Glass 


\subsubsection{SPFT Results for LAWB45 Glass}

\subsection{Effect of $\mathrm{pH}$}

Figure 8 illustrates the experimental results for LAWB45 as a function of $\mathrm{pH}$ and temperature. Unlike previous tests on LAW glass formulations, the dissolution rate for LAWB45 decreased from $\mathrm{pH} 7$ to 8 and began increasing from 8 to 12 . Therefore, the results at $\mathrm{pH} 7$ were excluded from the non-linear regression analysis. Results from LAWB45 illustrate a trend typical of most LAW glass formulations, where the dissolution rate increases with an increase in $\mathrm{pH}$ and temperature. Therefore, the same process was used to evaluate the data and extract the corresponding kinetic rate law parameters.

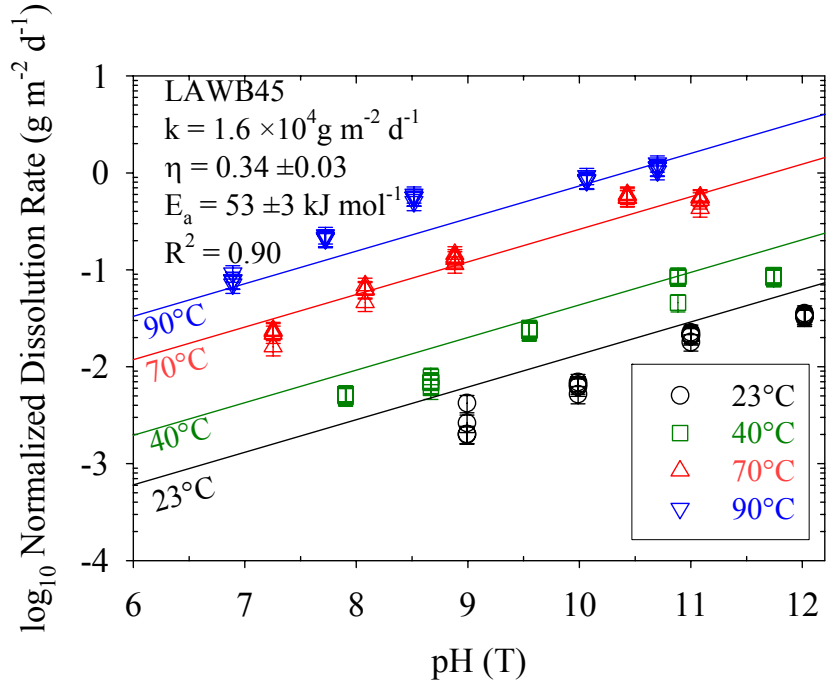

Figure 8. Normalized B Release Rate as a Function of $\mathrm{pH}$ and Temperature for LAWB45 Glass

Results from the linear regression at each temperature gave a slope $\eta=0.34 \pm 0.03$ indicating that $\eta$ does not depend on temperature within experimental error. Using the same non-linear regression technique as described in Section 3.1.5.1.3, the resulting regression coefficients are $\vec{k}=1.6 \times 10^{4} \mathrm{~g} \mathrm{~m}^{-2} \mathrm{~d}^{-1}, E_{a}=53 \pm 3 \mathrm{~kJ} \mathrm{~mol}^{-1}$ with a correlation coefficient $\left(\mathrm{R}^{2}\right)$ of 0.90 . The value for $E_{a}$ is slightly lower than other LAW glass formulations, but it still corresponds to a surface-controlled reaction process (LASAGA, 1981).

\subsection{Effect of Solution Saturation State}

As previously discussed in Section 3.1.5.1.5, experiments with input solutions doped with Si (ranging from 15 to $140 \mathrm{ppm}$ ) were conducted as a function of temperature at $\mathrm{pH}\left(23^{\circ} \mathrm{C}\right)=9$. Normalized release rates for $\mathrm{B}$ and $\mathrm{Na}$ as a function of $a\left[\mathrm{SiO}_{2}(\mathrm{aq})\right]$ are shown in Figure 9. Due to detection limit problems the Na results for $23^{\circ} \mathrm{C}$ are not displayed in Figure 9. The trend, a decrease in the dissolution rate with increasing $a\left[\mathrm{SiO}_{2}(\mathrm{aq})\right]$, is similar to those obtained for several LAW glass formulations (MCGRAIL et al., 2001a). Figure 9 also illustrates that LAWB45 has little to no alkali hydrogen exchange and suggest that matrix dissolution is the dominant mechanism of release. This is certainly due to the less than 6.5 weight \% sodium load for this glass formulation in comparison to the $20 \%$ and 14\% for LAWA44 and LAWC22, respectively. In comparison to LAWA44 and LAWC22, this glass formulation not only has lower alkali content but the $\mathrm{Al}$ and $\mathrm{B}$ content is higher, resulting in a ratio of $(\mathrm{Al}+\mathrm{B}) /(\mathrm{Na}+\mathrm{Li}+\mathrm{K})$ of 0.91 to 1 . Hence, almost all of the alkali ions are utilized in charge compensating $\mathrm{AlO}_{2}{ }^{-}$and $\mathrm{BO}_{2}{ }^{-}$groups in the glass, reducing the concentration of NBO sites that are susceptible to ion-exchange (MCGRAIL et al., 2001b). As a result, we assign a Na IEX rate of zero to LAWAB45 glass $\left(r_{X}=0\right)$.

The pseudo-equilibrium constant estimates are listed in Table 5 and displayed in Figure 10. The value for $\mathrm{K}_{\mathrm{g}}$ at the disposal system temperature of $15^{\circ} \mathrm{C}$ is $5.2 \times 10^{-4}$, with a corresponding reaction enthalpy estimate of $9.9 \pm 3 \mathrm{~kJ} \mathrm{~mol}^{-1}$. Kinetic rate law parameters for the Envelope $\mathrm{C}$ glass formulation LAWC22 will be discussed in the following section. 

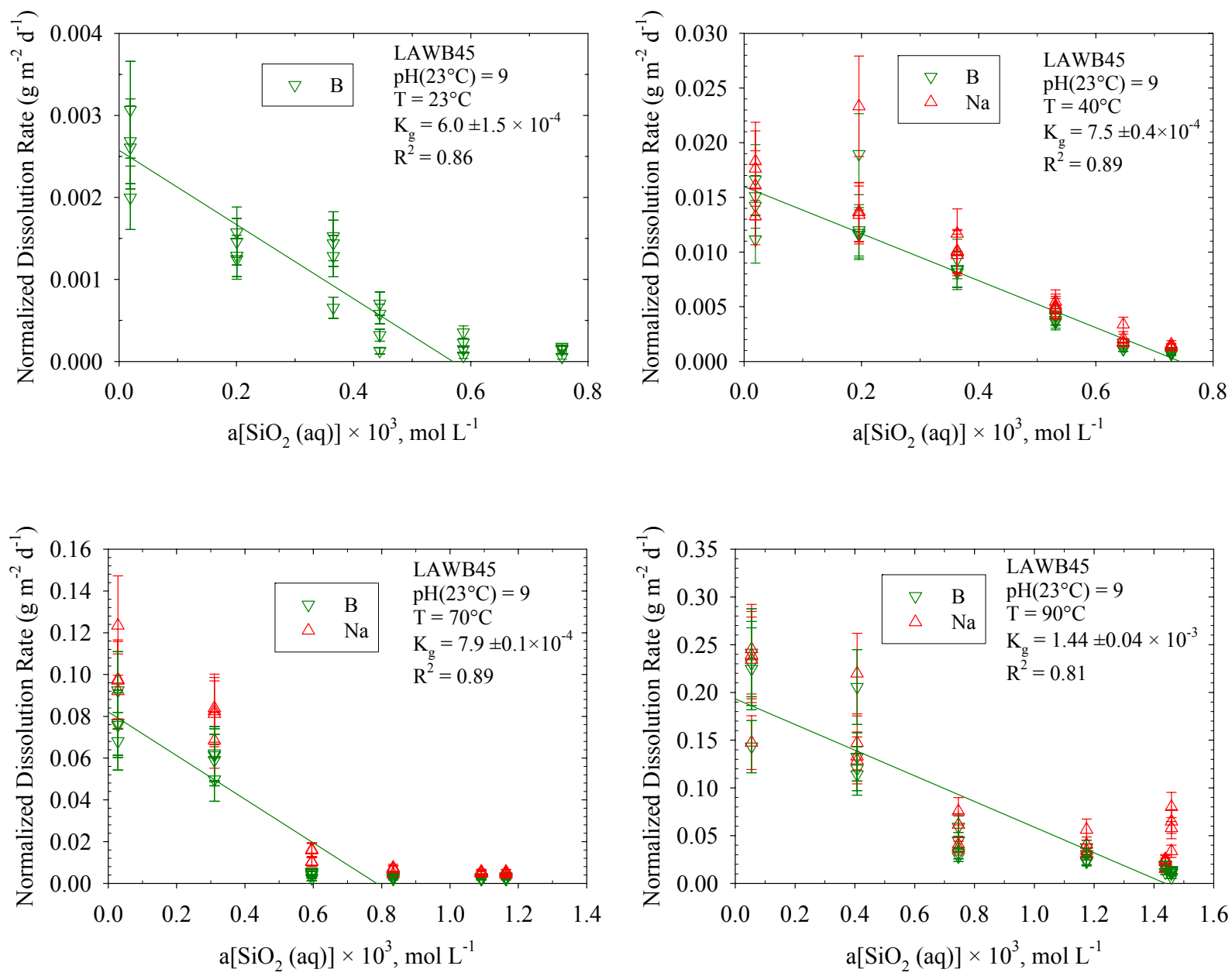

Figure 9. Normalized Release Rate with Respect to $\mathrm{B}$ and $\mathrm{Na}_{\text {Versus }} \mathrm{SiO}_{2}$ (aq) Activity at 23, 40, 70, and $90^{\circ} \mathrm{C}$ for LAWB45 Glass

Table 5. Estimate of the Pseudo-Equilibrium Constants for LAWB45 Glass as a Function of Temperature

\begin{tabular}{|c|c|c|c|}
\hline $\mathbf{T}\left({ }^{\mathbf{}} \mathbf{C}\right)$ & $\mathbf{K}_{\mathbf{g}}$ & Error & $\mathbf{R}^{2}$ \\
\hline 15 & $5.20 \mathrm{E}-04$ & - & - \\
23 & $6.0 \mathrm{E}-04$ & $\pm 1.5 \mathrm{E}-04$ & 0.86 \\
40 & $7.5 \mathrm{E}-04$ & $\pm 4.0 \mathrm{E}-05$ & 0.89 \\
70 & $7.9 \mathrm{E}-04$ & $\pm 1.0 \mathrm{E}-05$ & 0.89 \\
90 & $1.44 \mathrm{E}-03$ & $\pm 4.0 \mathrm{E}-05$ & 0.81 \\
\hline
\end{tabular}

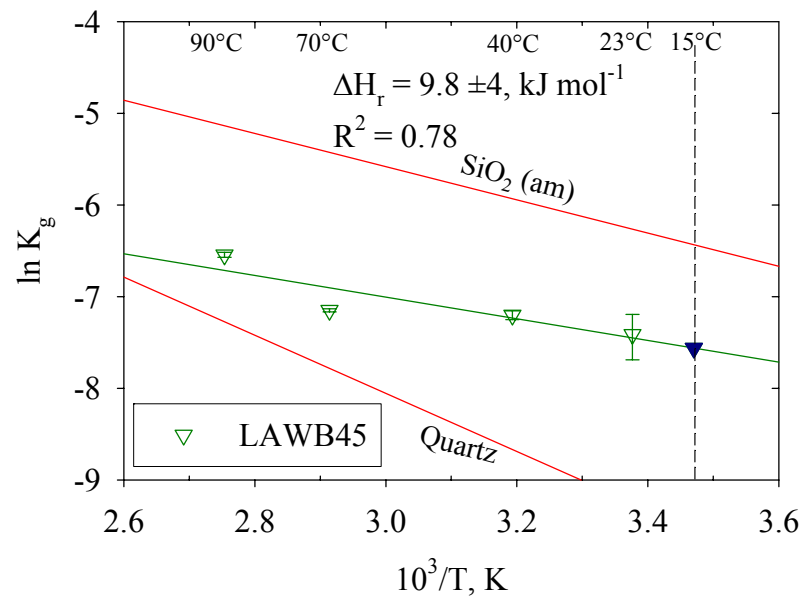

Figure 10. $\ln \mathrm{K}_{\mathrm{g}}$ vs. Inverse Temperature for LAWB45 Glass 


\subsubsection{SPFT Results For LAWC22 Glass}

\subsection{Effect of $p H$}

Like LAWA44 and LAWB45, the Envelope $\mathrm{C}$ glass formulation, LAWC22, also illustrates a strong temperature and $\mathrm{pH}$ dependence (Figure 11). Therefore, as $\mathrm{pH}$ increases from 7 to 12 , the overall glass dissolution rate also increases. As previously discussed for LAWA44 and LAWB45 a linear regression on the data at each temperature was conducted and we observed that $\eta, 0.42$ \pm 0.02 , does not depend on temperature within experimental error. Using this value for $\eta$ and conducting a non-linear regression on the entire data set shown in Figure 11, the resulting regression coefficients are $\vec{k}=1.0 \times 10^{5} \mathrm{~g} \mathrm{~m}^{-2} \mathrm{~d}^{-1}$, $E_{a}=64 \pm 2 \mathrm{~kJ} \mathrm{~mol}^{-1}$ with a correlation coefficient $\left(\mathrm{R}^{2}\right)$ of 0.96 . These values are similar to previous values that have been reported for other LAW glass formulations (MCGRAIL et al., 1997; 2001a), as well as the values contained in this report for LAWA44 and LAWB45.

\subsection{Effect of Alkali-Hydrogen Exchange}

As previously explained in Section 3.1.5.1.4, the rate of ion exchange (IEX) is computed by subtracting the rate of matrix dissolution from the Na release rate and converting the resulting value to moles of Na per square meter per second. Figure 12 shows the computed ion exchange rate from temperatures of 23 to $70^{\circ} \mathrm{C}$. These results show no ion-exchange rate dependence on $\mathrm{pH}$. This is not unexpected because surface layers on waste glasses have been found to be strongly $\mathrm{pH}$ buffered relative to the bulk aqueous phase (BUNKER, 1987).

Similar to LAWA44 glass, the effect of IEX was also observed in experiments where the concentration of $\mathrm{Si}$ in the influent solution was varied. Figure 13 illustrates the natural logarithm of the IEX rate versus $1 / \mathrm{T}$ for each $\mathrm{SiO}_{2}(\mathrm{aq})$ activity interrogated. Conducting a linear regression on the data resulted in an $E_{x}=45 \pm 4 \mathrm{~kJ} \mathrm{~mol}^{-1}$. The resulting $E_{x}$ correlates well with LAWABP1 $\left(E_{x}=52 \mathrm{~kJ} \mathrm{~mol}^{-1}\right)$ (MCGRAIL et al., 2001a) but is approximately $10 \mathrm{~kJ} \mathrm{~mol}^{-1}$ lower than LAWA44 $\left(E_{x}=65 \pm 6 \mathrm{~kJ} \mathrm{~mol}^{-1}\right)$. The rate of Na-IEX for LAWC22 glass was computed at $15^{\circ} \mathrm{C}$ using these regressed coefficients and is $r_{x}=1.2 \times 10^{-10} \mathrm{~mol} \mathrm{~m}^{-2} \mathrm{~s}^{-1}$. 


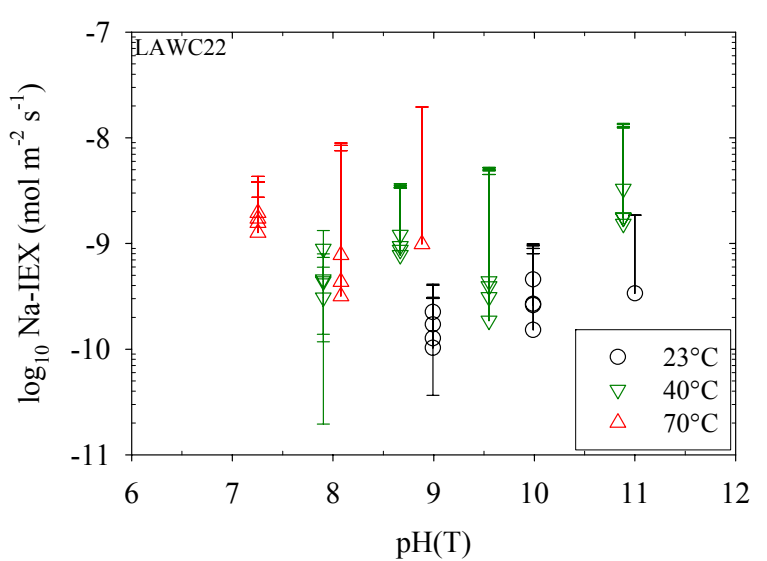

Figure 12. Na-IEX Rate as a Function of Solution $\mathrm{pH}$ and Temperature

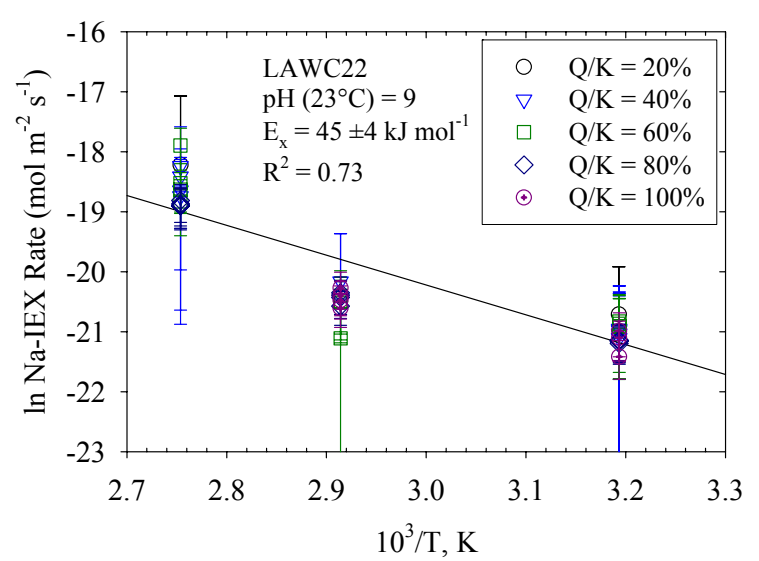

Figure 13. Na Ion Exchange Rate as a Function of Temperature with changing $a\left[\mathrm{SiO}_{2}\right.$ (aq) $]$ for LAWC22 Glass

\subsection{Effect of Solution Saturation State}

Using the same technique as previously described in Section 3.1.5.1.5, several experiments were conducted as a function of $a\left[\mathrm{SiO}_{2}(\mathrm{aq})\right]$ and temperature at a $\mathrm{pH}\left(23^{\circ} \mathrm{C}\right)$ of 9 on $\mathrm{LAWC} 22$ glass. Results shown in Figure 14 illustrate a typical trend, a decrease in the dissolution rate with increasing $\mathrm{SiO}_{2}(\mathrm{aq})$ activity and an increasing discrepancy between the $\mathrm{B}$ and $\mathrm{Na}$ release rate. In other words, as the activity of $\mathrm{SiO}_{2}(\mathrm{aq})$ increases the rate of glass dissolution decreases. As discussed in Section 3.1.5.1.5, this discrepancy has been assigned to a secondary reaction mechanism associated with $\mathrm{Na}$ ion exchange which is correlated to the concentration of NBO sites (MCGRAIL et al., 2001b).

By applying a linear fit to the normalized B release rates as they approached zero for the data shown in Figure 14, the $\mathrm{x}$-intercept was determined at each temperature, which is equivalent to the pseudo-equilibrium constant $\left(K_{g}\right)$. The estimated $K_{g}$ values are given in Table 6 and also plotted versus inverse temperature in Figure 15, along with the temperature-dependent solubility products for quartz and $\mathrm{SiO}_{2}(\mathrm{am})$. The results show the $\mathrm{K}_{\mathrm{g}}$ for BKV1 glass is intermediate between quartz and amorphous silica. The slope of a line regressed through the data also provides a crude estimate of the enthalpy of reaction, $\Delta \mathrm{H}_{\mathrm{r}}=12 \pm 2 \mathrm{~kJ} \mathrm{~mol}^{-1}$. Using the regression line shown in Figure 15, the value for $\mathrm{K}_{\mathrm{g}}$ at the disposal system temperature of $15^{\circ} \mathrm{C}$ was calculated and is provided in Table 6. 

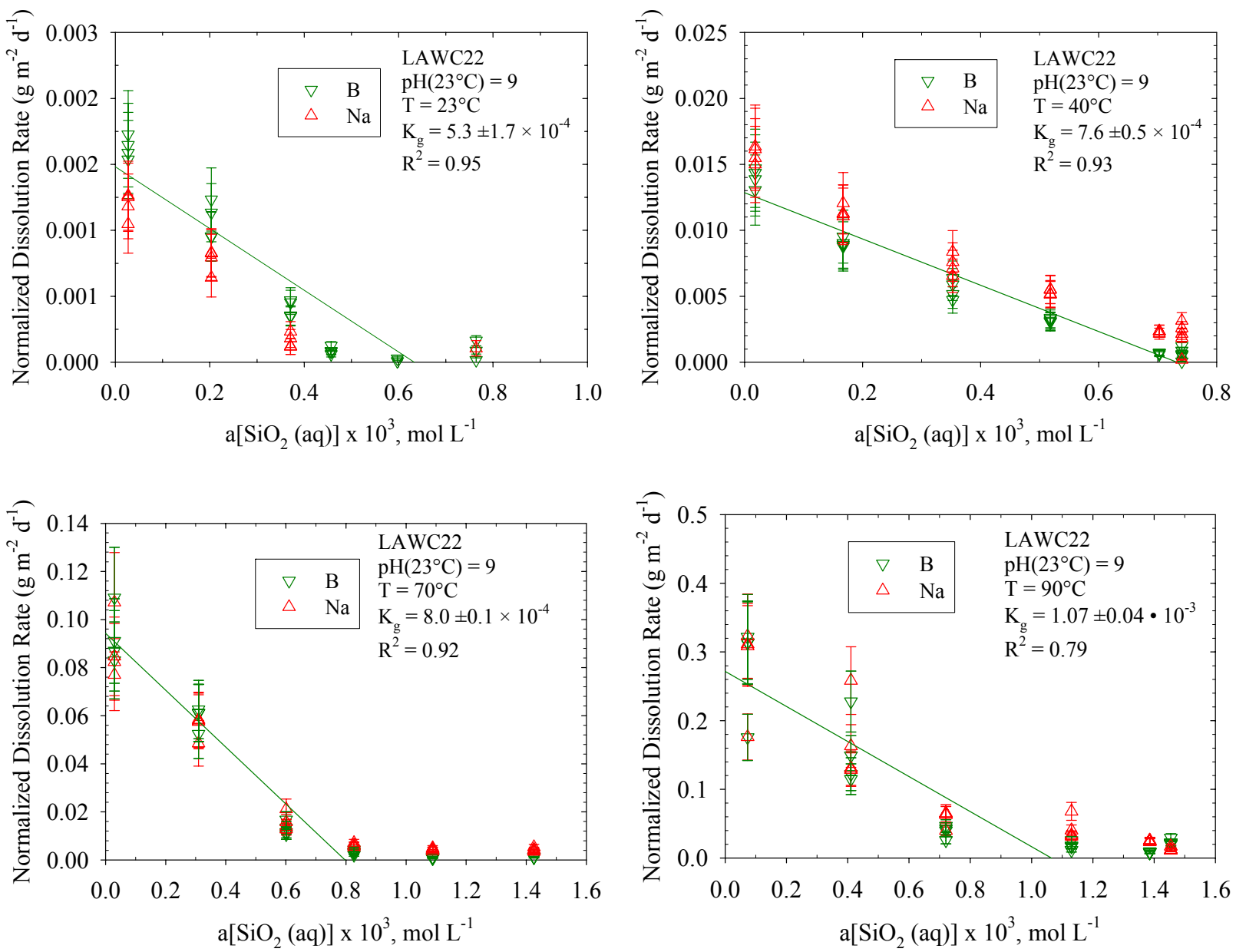

Figure 14. Normalized Release Rate with Respect to $\mathrm{B}$ and $\mathrm{Na}$ Versus $\mathrm{SiO}_{2}$ (aq) Activity at 23, 40, 70, and $90^{\circ} \mathrm{C}$ for LAWC22 Glass.

Table 6. Estimate of the Pseudo-Equilibrium Constants for LAWC22 Glass as a Function of Temperature

\begin{tabular}{|c|c|c|c|}
\hline $\left.\mathbf{T} \mathbf{~}^{\mathbf{}} \mathbf{C}\right)$ & $\mathbf{K}_{\mathbf{g}}$ & Error & $\mathbf{R}^{2}$ \\
\hline 15 & $4.96 \mathrm{E}-04$ & - & - \\
23 & $5.3 \mathrm{E}-04$ & $\pm 1.7 \mathrm{E}-04$ & 0.93 \\
40 & $7.6 \mathrm{E}-04$ & $\pm 5.0 \mathrm{E}-05$ & 0.93 \\
70 & $8.0 \mathrm{E}-04$ & $\pm 1.0 \mathrm{E}-05$ & 0.92 \\
90 & $1.07 \mathrm{E}-03$ & $\pm 4 \mathrm{E}-05$ & 0.83 \\
\hline
\end{tabular}

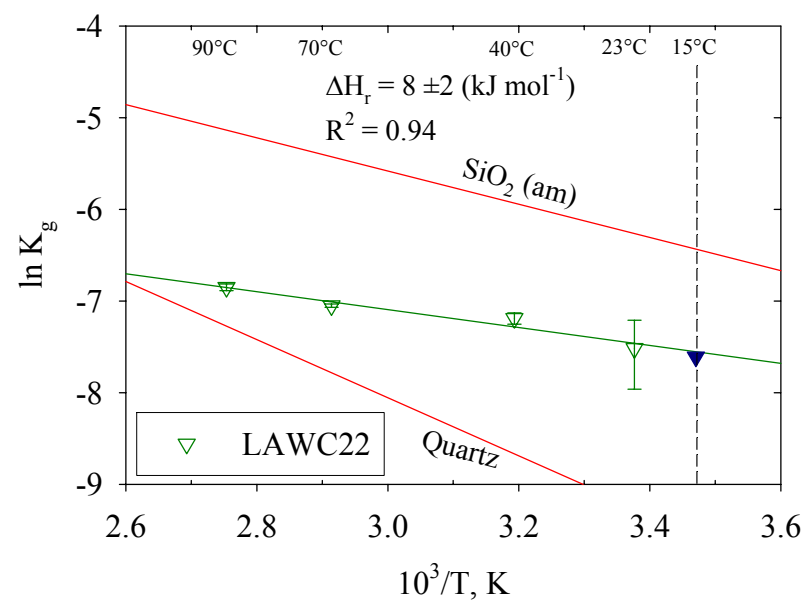

Figure 15. $\ln \mathrm{K}_{\mathrm{g}}$ vs. Inverse Temperature for LAWC22 Glass 


\subsection{Characterization of Glass Structure}

To gain a more detailed understanding of the relationship between the local coordination geometry around silicon atoms and the effect this has on glass dissolution magic angle spinning nuclear magnetic resonance (MAS-NMR) and Raman spectroscopy were collected for the three prototypic LAW glasses formulation being investigated.

\subsubsection{NMR Characterization}

The local coordination geometry around silicon atoms within the glass structure was investigated at room temperature for each glass formulation; LAWA44, LAWB45, and LAWC22, using ${ }^{29} \mathrm{Si}$ MAS-NMR. The ${ }^{29} \mathrm{Si}$ spectra were obtained under MAS conditions at a magnetic field strength of $100 \mathrm{MHz}$ frequency (e.g., 2.3T) using a Chemagnetics spectrometer. Each sample was analyzed with a spin speed of $4 \mathrm{kHz}$ using a Chemagentics 2-channel MAS probe.

Figure 16 shows the MAS-NMR spectra for each glass formulation. The observed chemical shifts were referenced against an internal standard Tetrakis (trimethylsilyl) silane (TMS), which gives sharp peaks at 0.0 and $-126 \mathrm{ppm}$. Broad ${ }^{29} \mathrm{Si}$ peaks were observed, which is typical for $\mathrm{Fe}$ bearing borosilicate glasses. Previous MAS-NMR results show that octahedrally coordinated $\mathrm{Si}$ $\left(\mathrm{Si}^{\mathrm{VI}}\right)$ has chemical shifts between -180 and -221 ppm (GRIMMER et al., 1986), where as tetrahedrally coordinated $\mathrm{Si}\left(\mathrm{Si}^{\mathrm{IV}}\right)$ has chemical shifts between -60 and $-126 \mathrm{ppm}$ (KIRKPATRICK, 1988). The ${ }^{29} \mathrm{Si}$ chemical shifts for LAWA44, -79.9 ppm, LAWB45, -87.3 ppm, and LAWC22, -75.8 ppm, confirm four-fold coordinated $\mathrm{Si}$ as the dominant local structure within each glass.

\subsubsection{Raman Characterization}

The Raman scattered light spectra was collected at room temperature in 180 mode with a fiber optic probe. Scattered laser light is passed through a holographic notch filter with an optical density of 4 but $80 \%$ transmissivity for Raman scattered light. The probe is coupled to a Holospec (Kaiser Optical Systems) spectrograph. The spectrograph features fast f/1.8 optics, HoloPlexTM transmission grating, and back illuminated CCD detector. Incident light was provided by a $532 \mathrm{~nm}$ diodepumped ND:YAG laser delivering approximately $150 \mathrm{~mW}$ at the sample surface.

Figure 17 shows the Raman spectra for each glass formulation; LAWA44, LAWB45, LAWC22, HAN28F, along with quartz refer-

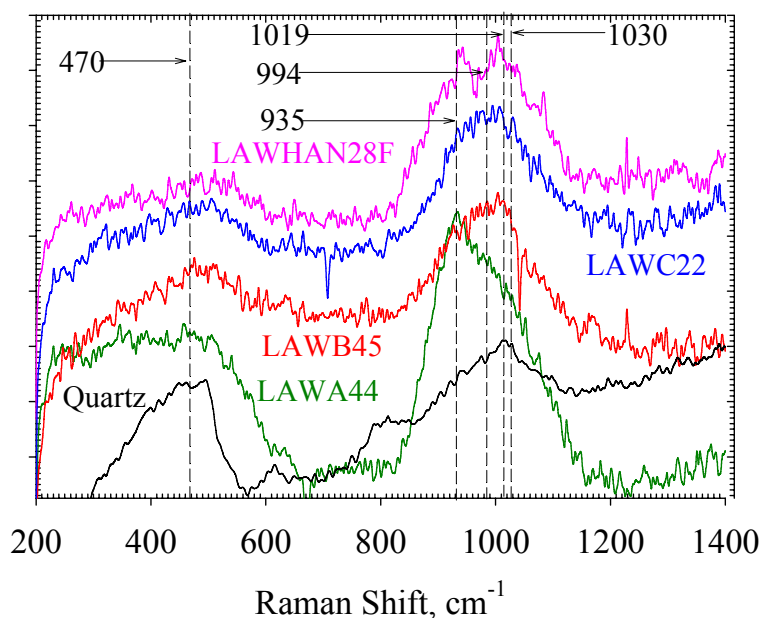

Figure 17. Raman Spectra of LAWA44, LAWB45, LAWC22 and Reference spectra for Quartz 
ence spectra. The main feature of the spectra is the broad feature between 800 and $1200 \mathrm{~cm}^{-1}$ that can be assigned to different structural groups associated with the silicate framework. For HAN28F glass, two remarkably sharp peaks are evident at 935 and $990 \mathrm{~cm}^{-1}$ that can be assigned (BUNKER et al., 1988) to $\mathrm{Q}_{1}$ and $\mathrm{Q}_{2}$ silicate units in the glass, i.e., $\mathrm{SiO}_{4}$ with only 1 or 2 bridging oxygens, respectively. The Raman spectra for LAWB45 is clearly shifted to the higher wave number region, at $\sim 1004 \mathrm{~cm}^{-1}$, suggesting that LAWB45 has a higher concentration of polymerized $\mathrm{Q}_{3}\left(\equiv \mathrm{Si}-\mathrm{O}^{-} \mathrm{Na}^{+}\right)$and $\mathrm{Q}_{4}(\equiv \mathrm{Si}-\mathrm{O}-\mathrm{Si})$ units. This conclusion correlates with the results obtained from SPFT tests conducted on LAWB45, where alkali-hydrogen ion exchange could not be quantified. In other words, LAWB45 has a higher polymerization state in comparison to the other LAW glasses; LAWA44, LAWC22, and LAWHAN28F, and is the result of a fewer NBO sites caused by the decreased Na load used for this glass formulation. LAWA44, at 935 $\mathrm{cm}^{-1}$, and LAWC22, at $994 \mathrm{~cm}^{-1}$, are shifted toward lower wave numbers in comparison to LAWB45 and the quartz reference spectra. This suggest that LAWA44 and LAWC22 contain less polymerized silicate units, caused by the excess alkali's contained within these glass compositions. Some caution is advised in interpreting these spectra because stretching modes associated with borate and borosilicate groups also appear in these same frequency bands (BRAY et al., 1980; DELL et al., 1983).

\subsection{Summary of SPFT Test Results}

A large body of SPFT data is provided in this section on three prototypic simulant glasses; LAWA44, LAWB45, and LAWC22, for LAW. Results from these experiments were used to derive the input parameters necessary to conduct long-term PA calculations with the STORM reactive transport computer code. A summary of the recommended best estimate rate law parameters is provided in Table 7.

Table 7. Summary of Best Estimate Rate Law Parameters for LAWA44, LAWB45, and LAWC22 Glasses at $15^{\circ} \mathrm{C}$.

\begin{tabular}{|c|c|c|c|c|c|}
\hline Parameter & Meaning & LAWA44 & LAWB45 & LAWC22 & Comments \\
\hline$\vec{k}$ & $\begin{array}{l}\text { forward rate } \\
\text { constant }\left(\mathrm{g} \mathrm{m}^{-2} \mathrm{~d}^{-1}\right)\end{array}$ & $1.3 \times 10^{4}$ & $1.6 \times 10^{4}$ & $1.0 \times 10^{5}$ & \\
\hline$K_{q}$ & $\begin{array}{l}\text { apparent equilibrium } \\
\text { constant for glass } \\
\text { based on activity } \\
\text { product a }\left[\mathrm{SiO}_{2}(\mathrm{aq})\right]\end{array}$ & $5.45 \times 10^{-4}$ & $5.24 \times 10^{-4}$ & $5.25 \times 10^{-4}$ & \\
\hline$\eta$ & $\begin{array}{l}\text { pH power law } \\
\text { coefficient }\end{array}$ & $0.49 \pm 0.08$ & $0.34 \pm 0.03$ & $0.42 \pm 0.02$ & \\
\hline$E_{a}$ & $\begin{array}{l}\text { activation energy of } \\
\text { glass dissolution } \\
\text { reaction }\left(\mathrm{kJ} \mathrm{mol}^{-1}\right)\end{array}$ & $60 \pm 7$ & $53 \pm 3$ & $64 \pm 2$ & \\
\hline$\sigma$ & Temkin coefficient & 1 & 1 & 1 & $\begin{array}{l}\text { Assigned } \\
\text { constant }\end{array}$ \\
\hline$r_{x}$ & $\begin{array}{l}\text { Na ion-exchange rate } \\
\left(\mathrm{mol} \mathrm{m}^{-2} \mathrm{~s}^{-1}\right)\end{array}$ & $5.3 \times 10^{-11}$ & 0 & $1.2 \times 10^{-10}$ & $\begin{array}{l}\text { No detectable } \\
\text { ion exchange } \\
\text { rate for } \\
\text { LAWB45 } \\
\end{array}$ \\
\hline
\end{tabular}




\subsection{Chemical Reaction Network}

Low-Activity Waste (LAW) performance assessment models must account for the long-term corrosion rate of each LAW glass formulation. This corrosion rate is a key parameter affecting the overall performance of the integrated disposal facility (IDF). Therefore, having determined the kinetic rate law parameters for LAWA44, LAWB45, and LAWC22 glass samples as described in Section 3.1.5, the next set of required data to conduct source-term calculations with the STORM code is 1) a set of secondary phases that form from the long-term corrosion of these glasses in the disposal system environment, and 2) the precipitation-dissolution rate and/or solubility product for each of these phases. Although the suite of weathering products that will form as a consequence of the glass-water reactions cannot be determined a priori at this time, discussed by McGrail et al. (MCGRAIL et al., 2000b), laboratory tests can be used to simulate and accelerate the weathering process. To address these and other issues, experiments were conducted to evaluate the corrosion rate on two simulant (LAWB45 [Envelope B] and LAWC22 [Envelope C]) and two radioactive glass formulations made with actual Hanford waste (LAWAP101 [Envelope A] and LAWAN102 [Envelope C]), using the PUF apparatus. In addition to these PUF tests, static PCT were conducted on each of the three simulant glasses; LAWA44, LAWB45, and LAWC22.

The following section will provide a description of the apparatus or technique, experimental materials and methods, data analysis, and results for the PUF and PCT tests, respectively.

\subsection{Pressurized Unsaturated Flow (PUF) Apparatus Experiments}

The PUF apparatus allows for accelerated weathering experiments to be conducted under hydraulically unsaturated conditions, thereby mimicking the vadose zone environment while allowing the corroding glass to achieve a final reaction state. The PUF apparatus provides the capability to vary the volumetric water content from saturation to $20 \%$ of saturation or less, minimize the flow rate to increase liquid residence time, and operate at a maximum temperature of $100^{\circ} \mathrm{C}$. The PUF column operates under a hydraulically unsaturated condition by creating a steady state vertical water flow, while maintaining uniform water content throughout the column, and by using gravity to assist in drainage.

The underlying principle for creating such conditions is Darcy's Law as modified by Rich$\operatorname{ards}(1931)$

$$
J_{w}=-K\left(\psi_{m}\right) \frac{\delta \psi}{\delta z}
$$

Where $J_{w}$ is the volumetric flux density; $\mathrm{m} \mathrm{s}^{-1}, \psi$ is the water potential (equal to the matric potential $\left[\psi_{m}\right]+$ gravitational potential $\left.\left[\psi_{g}\right]\right) ; \mathrm{m}, K\left(\psi_{m}\right)$ is the hydraulic conductivity as a function of matrix potential; $\mathrm{m} \mathrm{s}^{-1}$, and $\mathrm{z}$ is the length of the column; $\mathrm{m}$.

It can be shown that if uniform moisture content is established throughout the column equation reduces to:

$$
J_{w}=K\left(\psi_{m}\right) .
$$


Equation (10) simply states that under uniform water content conditions, the volumetric flux density of water is equal to the unsaturated hydraulic conductivity.

\subsubsection{Description of the PUF Apparatus}

This system has been previously described in other publications, and an interested reader should consult these references, as well as the references contained therein for more detail. Only a general description will be provided within this document. In general, the PUF system consists of a column (7.62-cm length and 1.91-cm diameter) fabricated from a chemically inert material, polyetheretherketone (PEEK), so that dissolution reactions are not influenced by interaction with the column material. A porous titanium plate with nominal pore size of $0.2 \mu \mathrm{m}$ is sealed in the bottom of the column to ensure an adequate pressure differential for the conductance of fluid while operating under unsaturated conditions (WIERENGA et al., 1993). Titanium (Ti) was chosen because it is highly resistant to corrosion and has excellent wetting properties. Once the porous titanium plate is water saturated, water but not air is allowed to flow through the $0.2 \mu \mathrm{m}$ pores, as long as the applied pressure differential does not exceed the air entry relief pressure or "bubble pressure" of the Ti plate. If the pressure differential is exceeded, air will escape through the plate and compromise the ability to maintain unsaturated flow conditions in the column.

The computer control system runs LabVIEW ${ }^{\top \mathrm{M}}$ (National Instruments Corporation) software for logging test data to a disk from several thermocouples, pressure sensors, in-line sensors for effluent $\mathrm{pH}$ and conductivity, and column weight from an electronic strain gauge to accurately track water mass balance and saturation level. The column also includes a "PUF port," which is an electronically actuated valve that periodically vents the column gases. The purpose of column venting is to prevent reduction in the partial pressure of important gases, especially $\mathrm{O}_{2}$ and $\mathrm{CO}_{2}$, which may be consumed in a variety of chemical reactions.

\subsubsection{Experimental Materials and Methods}

The materials and methods section provides information on the material preparation techniques, experimental setup, test conditions, and rate calculations that were used for the testing of several LAW glass compositions.

\subsubsection{Materials Preparation}

All glass samples used for these PUF tests were sieved into the $-40+60$ mesh (420 to $250-\mu \mathrm{m}$ diameter) size fraction. The sample preparation and surface area calculation process remained the same and is described in Section 3.1.1. 


\subsubsection{Experimental Setup}

As described in Section 4.1.1, the basic PUF apparatus consists of a column where glass particles (or other material) of a known size and density are compacted to a known bulk density ( $g$ $\mathrm{m}^{-3}$ ). The remaining void space (which is not filled by glass) represents the porosity $(\varepsilon)$. Volumetric water content $(\theta)$ is the percent volume of water within the total fixed column volume. For example, when a $20-\mathrm{cm}^{3}$ column is packed with glass leaving a $50 \%$ void space $(\varepsilon)$, the column is considered fully saturated when $10 \mathrm{~mL}$ of water $(\theta=50 \%)$ is in the column at any given point in time. Using these same parameters, a column is considered unsaturated when $\theta<\varepsilon$. The rate of water flow through the column is the pore water velocity $\left(U_{p}, \mathrm{~m} / \mathrm{s}\right)$, which is simply the influent flux $\left(\mathrm{m}^{3} / \mathrm{s}\right)$ divided by the cross-sectional area of the column $\left(\mathrm{m}^{2}\right)$ divided by $\theta$. To determine the residence time for an aliquot of water to move through the column, the length (m) of the column is divided by $\mathrm{U}_{\mathrm{p}}$.

These experiments were performed at nominal flow rate of $2.0 \mathrm{~mL} \mathrm{~d}^{-1}$ and a temperature of $90^{\circ} \mathrm{C}$. Each column was packed with the crushed and cleaned glass, giving an initial porosity of approximately $0.40 \pm 0.03$, and then vacuum saturated with water at ambient temperature. A temperature controller was programmed to heat the column to $99^{\circ} \mathrm{C}$ in approximately $1 \mathrm{~h}$ $\left(1^{\circ} \mathrm{C} / \mathrm{min}\right)$. The column was allowed to initially desaturate during heating by gravity drainage and was also vented periodically to maintain an internal pressure less than the bubble pressure of the porous plate. After reaching $99^{\circ} \mathrm{C}$, the influent valve was opened, and influent was set the appropriate flow rate. Column venting was set to occur once an hour, so that the partial pressure of $\mathrm{O}_{2}$ and $\mathrm{CO}_{2}$ could remain relatively constant. Effluent samples were collected in a receiving vessel, which was periodically drained into tared vials from which samples were extracted and acidified for elemental analysis by ICP-OES and inductively coupled plasma-mass spectrometry (ICP-MS).

\subsubsection{Release Rate and Error Calculations}

The results from chemical analyses on collected effluent samples are used to calculate a normalized release rate according to (MCGRAIL et al., 2002)

$$
r_{i}=\frac{4 \varepsilon Q\left(c_{i \mathrm{~L}}-c_{i \mathrm{~b}}\right)}{\theta s(1-\varepsilon) \rho \pi \mathrm{d}^{2} \mathrm{~L} f_{i}}
$$

where $r_{i}$ is the normalized rate of $i$ th element $\left(\mathrm{g} \mathrm{m}^{-2} \mathrm{~d}^{-1}\right), c_{i \mathrm{~L}}$ is the effluent concentration of $i$ th element $\left(\mathrm{g} \mathrm{m}^{-3}\right), c_{i b}$ is the background concentration of $i$ th element $\left(\mathrm{g} \mathrm{m}^{-3}\right), \mathrm{d}$ is the column diameter $(\mathrm{m}), f_{i}$ is the mass fraction of $i^{\text {th }}$ element in the glass (unitless), $\mathrm{L}$ is the column length (m), $Q$ is the volumetric flow rate $\left(\mathrm{m}^{3} \mathrm{~d}^{-1}\right), \mathrm{s}$ is the specific surface area of the glass sample $\left(\mathrm{m}^{2}\right.$

$\left.\mathrm{g}^{-1}\right), \varepsilon$ is the porosity (unitless), $\rho$ is the glass density $\left(\mathrm{g} \mathrm{m}^{-3}\right)$, and $\theta$ is the volumetric water content (unitless).

An estimate in the uncertainty associated with the normalized rate will be calculated using standard error propagation theory, assuming the variables in Equation (11) are uncorrelated. In this case, the standard deviation of a function $f\left(x_{1}, x_{2}, \ldots x_{n}\right)$ is given by Equation (4) and assuming that the error associated with the background concentration $\left(C_{i, b}\right)$, diameter $(d)$, and column length $(L)$ are negligible compared with the other variables, the relative standard deviation is given by 


$$
\sigma_{r_{i}}=r_{i} \sqrt{\left(\frac{\tilde{\sigma}_{\varepsilon}}{1-\varepsilon}\right)^{2}+\left(\frac{\tilde{\sigma}_{c_{i, L}}}{1-c_{i, B} / c_{i, L}}\right)^{2}+\tilde{\sigma}_{Q}^{2}+\tilde{\sigma}_{\theta}^{2}+\tilde{\sigma}_{S}^{2}+\tilde{\sigma}_{\rho}^{2}+\tilde{\sigma}_{f_{i}}^{2}}
$$

where the tilde over the $\sigma$ symbol signifies the relative standard deviation for the subscripted parameter. In calculating the error bounds with Equation (12), typical fixed relative standard deviations have been estimated based upon repeatability of laboratory measurements:

$$
\begin{array}{lll}
\tilde{\sigma}_{\varepsilon}=6 \%, & \tilde{\sigma}_{S}=20 \%, & \tilde{\sigma}_{Q}=2 \% \\
\tilde{\sigma}_{\rho}=5 \%, & \tilde{\sigma}_{c_{i, L}}=10 \%, & \tilde{\sigma}_{f_{i, L}}=10 \%
\end{array}
$$

The value of $\tilde{\sigma}_{\theta}$ is calculated from the variation in water content recorded by the data acquisition system over the discrete interval between each fluid sampling. A computer macro program is available to perform this calculation directly in the Excel $^{\mathrm{TM}}$ spreadsheet used to store the sensor data.

\subsubsection{PUF Test Results}

For ease of discussion, the PUF results are separated into three sections; section one discusses the results from PUF test on the simulant glass composition LAWA44, whereas section two and three provide a progress report on two additional simulant glasses, LAWB45 and LAWC22, and two radioactive glass samples; LAWAN102 and LAWAP101, respectively.

A comprehensive list of the experimental conditions, including temperature, solution $\mathrm{pH}$, volumetric water content, and the concentration of the major elements is given in Appendix B. As in the SPFT test, boron was considered as the primary element for determining the dissolution rate of the glass matrix. 


\subsubsection{PUF Results for LAWA44 Glass}

Results from the computer-monitored test metrics for LAWA44 glass are shown in Figure 18. At about approximately day 150 in the test with LAWA44 glass, an electrical problem developed with the conductivity sensor. The sensor was repaired at approximately day 350 . Because the sensor data are noisy, the data were smoothed using a bi-square weighting method where the smoothed data point, $y_{s}$, is given by $y_{s}=\left(1-\omega^{2}\right)^{2}$. The parameter $\omega$ is a weighting coefficient calculated from a window surrounding the smoothing location in the set of the independent variables. A low-order polynomial regression (order 2 in this case) is used to compute $\omega$ for each smoothed value. The smoothed data are provided as lines in Figure 18.

A comparison of normalized release rates for the major components in LAWA44 glass is shown in Figure 19. Over the 850day duration, the glass corrosion rate has slowed from an early-time rate of approximately $0.2 \mathrm{~g} \mathrm{~m}^{-2} \mathrm{~d}^{-1}$ to approximately 0.01 $\mathrm{g} \mathrm{m}^{-2} \mathrm{~d}^{-1}$. In comparison to previous PUF tests, the B release rate for LAWA44 glass is anywhere from 8 to $40 \mathrm{X}$ lower than the HLP glass series; HLP-9 glass (0.1 to $0.08 \mathrm{~g}$ $\left.\mathrm{m}^{-2} \mathrm{~d}^{-1}\right)$, HLP-10 glass $\left(0.1\right.$ to $0.08 \mathrm{~g} \mathrm{~m}^{-2} \mathrm{~d}^{-}$ $\left.{ }^{1}\right)$, and HLP-31 $\left(0.4 \mathrm{~g} \mathrm{~m}^{-2} \mathrm{~d}^{-1}\right)$, and 10X lower than LAWABP1 glass $\left(0.1 \mathrm{~g} \mathrm{~m}^{-2} \mathrm{~d}^{-1}\right)$ Therefore, these PUF test results indicate that LAWA44 glass performs well and is one of the more durable ILAW glasses tested to date.

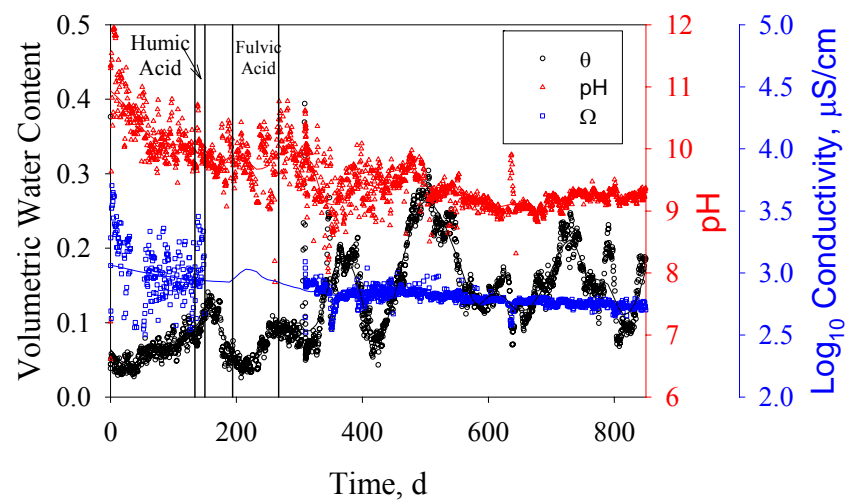

Figure 18. Computer Monitored Test Metrics From PUF Tests with LAWA44 Glass. Lines are bi-square smoothed fits to the raw data. The vertical lines give the periods where a $50 \mathrm{mg} / \mathrm{L}$ humic acid solution and a $10 \mathrm{mg} / \mathrm{L}$ fulvic acid solution was injected instead of deionized water.

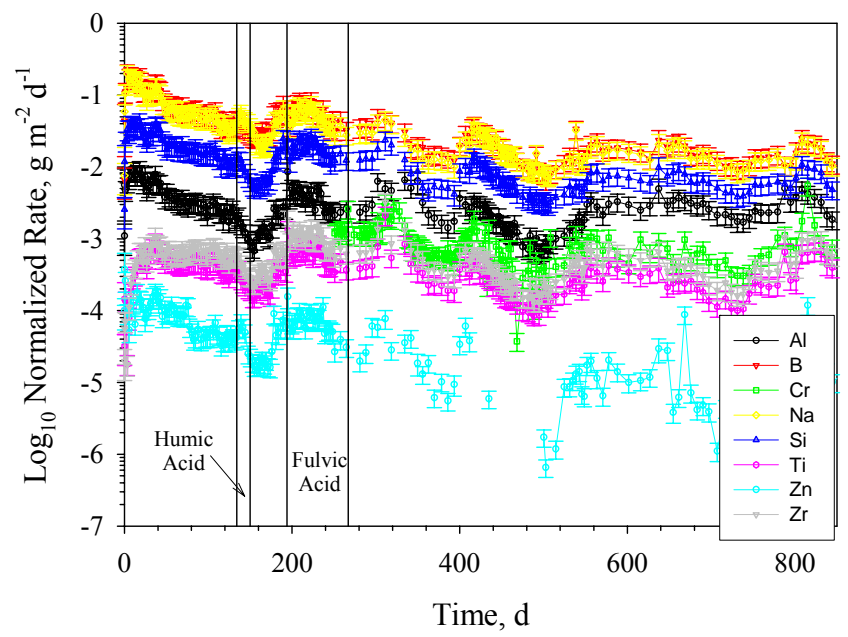

Figure 19. Normalized Release Rate for Selected Elements in PUF Tests with LAWA44 Glass

At approximately day 135, the DIW influent in the PUF test with LAWA44 glass was changed out for the $50 \mathrm{mg} / \mathrm{L}$ humic acid solution. As shown in Figure 18, no change in electrical conductivity or solution $\mathrm{pH}$ occurred immediately after the change to the humic acid solution. No change in the dissolution rate of the LAWA44 glass is evident either from the effluent chemical analysis, as shown in Figure 19, although the higher Na content of the humic acid solution is clearly detected over the injection period. Essentially identical results were obtained with the fulvic acid solution, i.e. no statistically significant change in dissolution rate was observed. These results are in accord with what was observed in SPFT experiments with the same organic acids (MCGRAIL et al., 2001a). 
After termination of the PUF test with LAWA44 glass, the reacted solids were subsampled as found (loose and moist particles) at 1 to $5 \mathrm{~mm}$ intervals. These samples were analyzed for moisture content; by drying in glass vials at room temperature in a vacuum desiccators with $\mathrm{CaSO}_{4}$ desiccant, and secondary alteration phases, using $\mathrm{X}$-ray diffraction (XRD) and scanning electron microscopy (SEM).

Figure 20 shows the post-test distribution of moisture in the PUF column as function of depth. The data are unusual as compared with other ILAW glasses we have tested in that no downstream peaks in water content were found. Peaks in water content have typically coincided with the onset of more extensive secondary phase formation (and consequent glass degradation). The lack of water content peaks suggests a more uniform and less extensive secondary phase formation with LAWA44 glass. This is indeed what is observed in scanning electron microscopy (SEM) images of the reacted solids from the PUF test, shown in Figure 21. The most extensive alteration is observed in sample S1 taken from the column inlet. As is typical of PUF reacted samples, glass alteration is observed only on portions of the grains that were in contact with water whereas other areas remain pristine. The background subtracted X-ray diffrac-
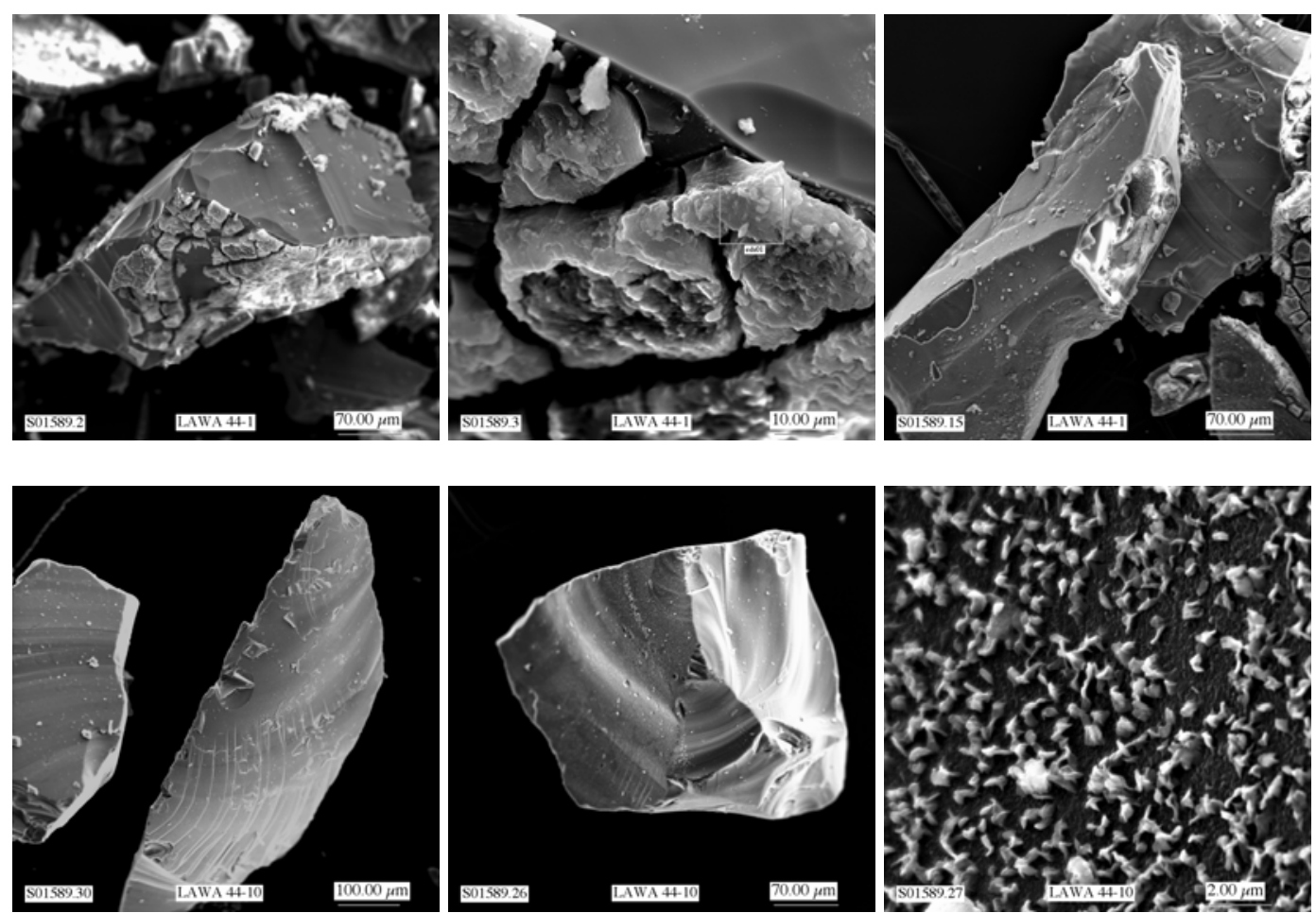

Figure 21. SEM Photographs of Reacted Grains of LAWA44 Glass After 858 Days in PUF Test at 2 $\mathrm{mL} / \mathrm{d}$ and $99^{\circ} \mathrm{C}$. The first row of pictures is from sample $\mathrm{S} 1$ at the column inlet. The second row is from sample S10, $44 \mathrm{~mm}$ downstream from the column inlet. 
tion (XRD) pattern of the reacted sample (see Figure 22) contains low intensity broad reflections typical of clay minerals. The diffraction peaks in the tracing appear to be based on a first order basal reflection of $6.2^{\circ} 2 \theta(14.1 \AA)$. Chlorite, a phyllosilicate mineral, has a basal series of diffractions peaks based on a first order reflection of $14.2 \AA$, with the odd ordered peaks having weak intensities as the iron content increases. Additionally, the diffraction peak located at $60.45^{\circ} 2 \theta(1.54 \AA)$ is similar to the 060 reflection characteristic of chlorite, which ranges between $1.538 \AA$ and $1.549 \AA$ (MOORE and REYNOLDS, 1989). Chlorite minerals commonly have a considerable range of substitutions for both trivalent and divalent ions, hence the phase ID of cli-

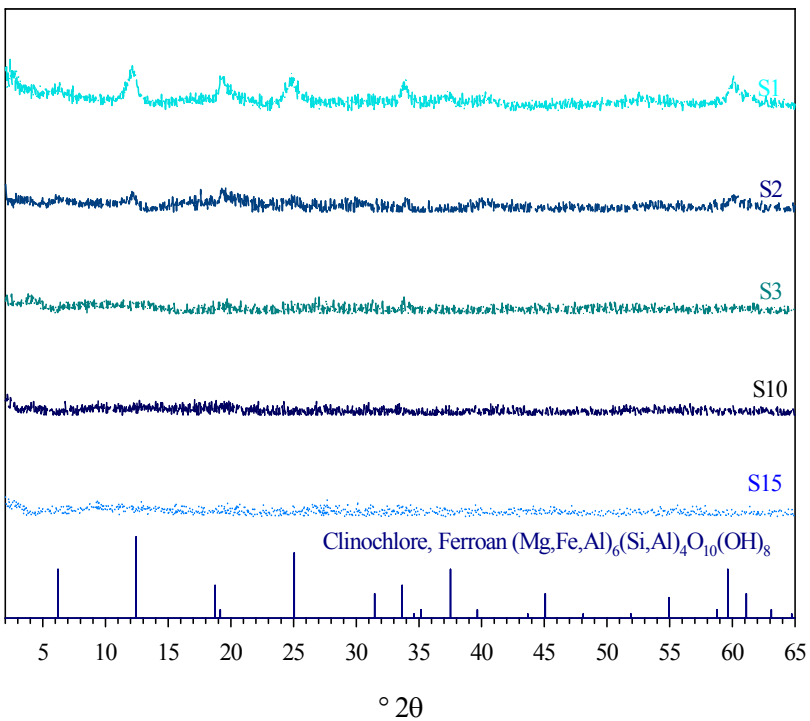

Figure 22. XRD Analyses of Reacted LAWA44 Glass Samples Taken from PUF Column After 859 days at 2 $\mathrm{mL} \mathrm{d}^{-1}$ and $99^{\circ} \mathrm{C}$. nochlore should be considered qualitative in terms of the chemical makeup of the clay mineral. In contrast with sample S1, sample S10 taken further downstream shows only very thin alteration layers. High magnification images show sparse precipitates located on portions of the layer but these were not identifiable crystalline phases in the XRD analysis. 


\subsubsection{PUF Results for LAWB45 and LAWC22 Glasses}

Results from the computer monitored test metrics (e.g., volumetric water content $[\theta], \mathrm{pH}$, and electrical conductivity $[\Omega]$ ), from the tests with LAWB45 and LAWC22 are shown in Figure 23. These test metrics, collected for more than 380 days (Figure 23), display that although periodic deviations in the volumetric water content occurred throughout the course of these test, an average of 12 and $15 \%$, respectively, was obtained for each experiment. Periodic deviations in the effluent $\mathrm{pH}$ and electrical conductivity mirror the volumetric water content, which usually suggest the formation of secondary reaction products. Figure 23 also illustrates that effluent $\mathrm{pH}$ and electrical conductivity are moderate for both glass formulations, suggesting moderate corrosion rates. The electrical conductivity is highest for LAWC22, suggesting it is dissolving fastest in comparison to LAWB45. This is consistent with the higher $\mathrm{Na}_{2} \mathrm{O}$ loading, 14 mass $\%$ for LAWC22, in comparison to 7 mass $\%$ for LAWB45.
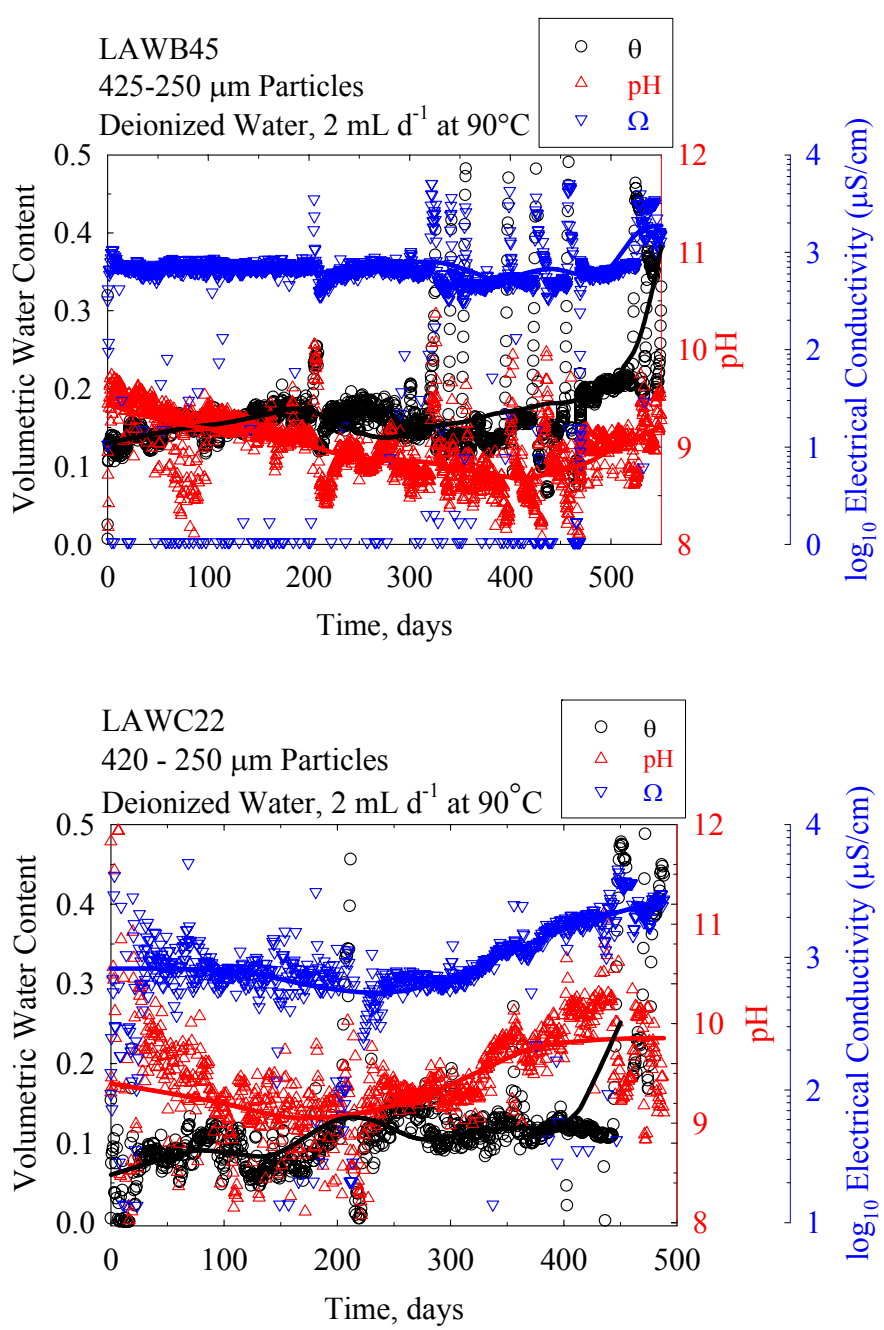

Figure 23. Computer Monitored Test Metrics from PUF Tests with LAWB45 (top) and LAWC22 (bottom) Glass Formulations. Lines are Bi-square Smoothed Fits to the Raw Data. 
Results from effluent chemical analyses are shown in Figure 24. The observed differential rates of release are typical and the result of the element's solubility behavior in water. These results suggest that release of $\mathrm{Al}, \mathrm{Ca}$, and $\mathrm{Si}$ is solubility controlled; whereas $\mathrm{B}, \mathrm{Li}, \mathrm{Na}$, and $\mathrm{S}$ release is not. As previously discussed, B is used to monitor the dissolution of the glass matrix, as no solid phases are expected to form that would affect its solution concentration. Therefore based on the $\mathrm{B}$ release data and as illustrated in Figure 24, the LAWC22 glass sample (from 0.08 to $0.1 \mathrm{~g} \mathrm{~m}^{-2}$ $\mathrm{d}^{-1}$ ), is reacting faster than the LAWB45 glass sample (from 0.06 to $0.07 \mathrm{~g} \mathrm{~m}^{-2} \mathrm{~d}^{-1}$ ). Again, these results are also consistent with the observed higher electrical conductivity and $\mathrm{Na}$ content of LAWC22.
LAWB45

420-250 $\mu \mathrm{m}$ Particles

Deionized Water, $2 \mathrm{~mL} \mathrm{~d}^{-1}$ at $90^{\circ} \mathrm{C}$
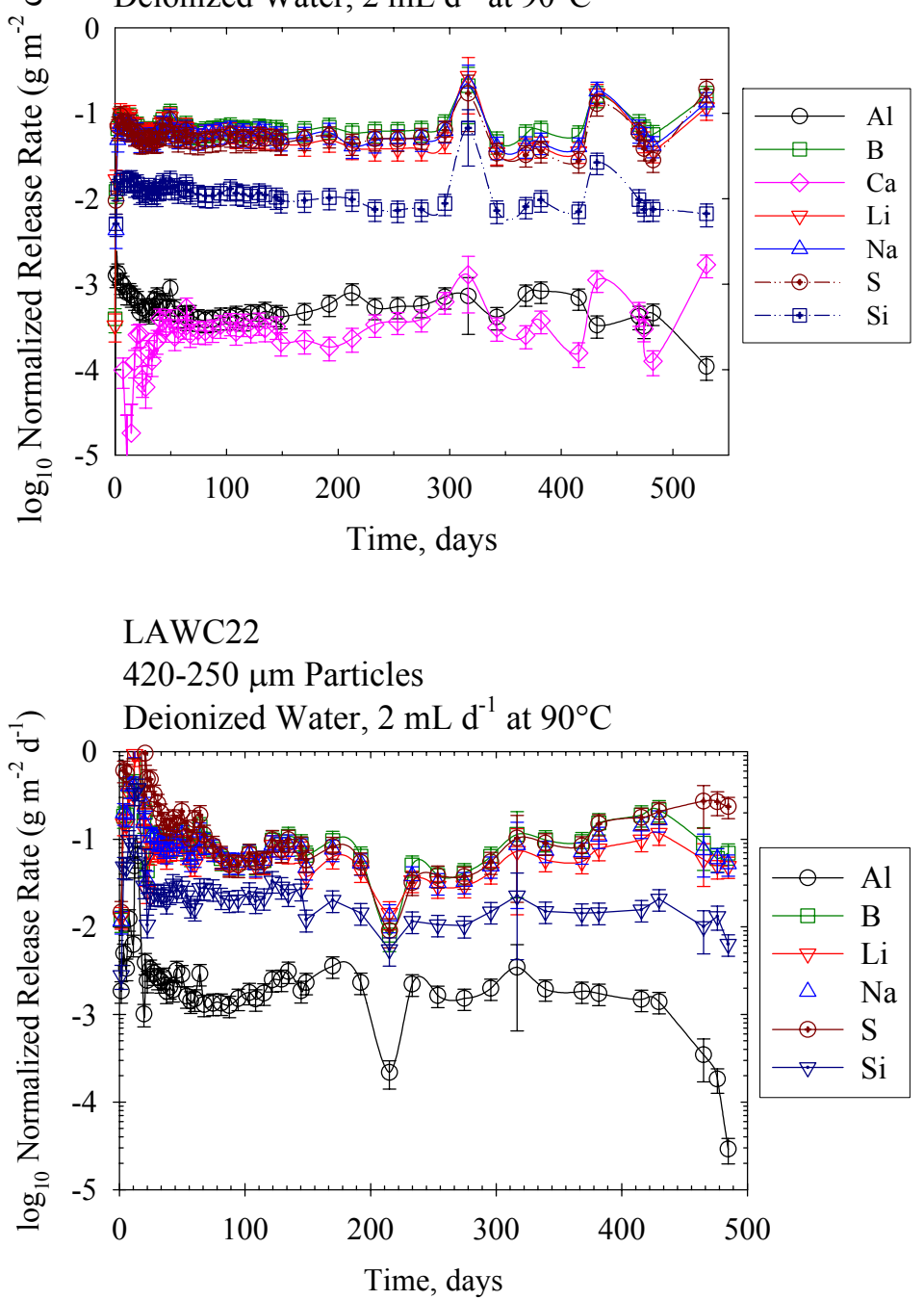

Figure 24. Normalized Release Rate for Selected Elements in PUF Test with LAWB45 (top) and LAWC22 (bottom) Glasses 
As described in Section 4.1.3.1, characterization of the reacted solids for LAWB45 and LAWC22 PUF test were conducted after each test was terminated. Figure 25 shows the post-test volumetric water content for the LAWB45 and LAWC22 PUF columns as a function of depth.

The volumetric water content distribution suggests that more extensive secondary phase formation has occurred within the first $10 \mathrm{~mm}$ of the inlet port for the LAWB45 test (Figure 25). Bulk powder XRD was used to confirm presence of and identify the secondary phase(s) that formed (Figure 26). The most intense reflection is for sample LAWB45-1 at $6^{\circ} 2 \theta$ as compared with the other 5 subsam-

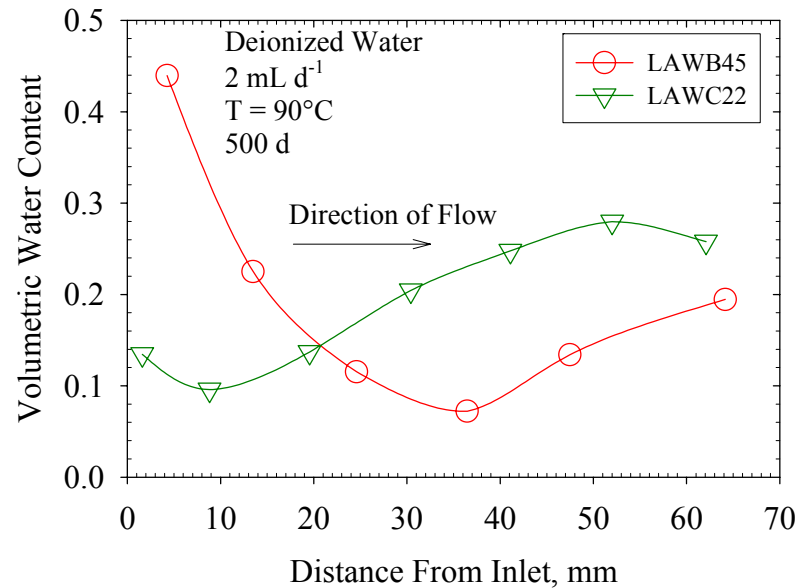

Figure 25. Volumetric Water Content as a Function of Distance from the PUF Column Inlet for LAWB45 and LAWC22.

ples. This subsample also showed reflections at 19.8 and $61.3^{\circ} 2 \theta$. These reflections are distinctive of a $14 \AA$ clay mineral and closely match nontronite, an Fe-rich smectite $\left[\mathrm{Na}_{0.3} \mathrm{Fe}_{2} \mathrm{Si}_{4} \mathrm{O}_{10}(\mathrm{OH})_{2} \bullet 4 \mathrm{H}_{2} \mathrm{O}\right]$. In addition to LAWWB45-1, possible nontronite reflections were also observe for the other five subsamples that were removed from various positions in the PUF column; LAWB45-2, -3, -4, -5, and -6.

Unlike LAWB45, LAWC22 had the highest volumetric water content within the last $10 \mathrm{~mm}$ of the column (Figure 25). XRD analysis of the reacted glass removed from this section, LAWC22-6, produced a single broad reflection at $6.9^{\circ} 2 \theta$, typical of the 2:1 layer silicate clay, most likely sepiolite (Figure 26). No additional crystalline phases were observed in the other six subsamples; LAWC22-1, -2, -3, -4, and -5.

In addition to these PUF test, two additional PUF test on LAW glass made with actual Hanford tank, LAWAN102 and LAWAP101 waste are still in progress and are discussed in the following section.
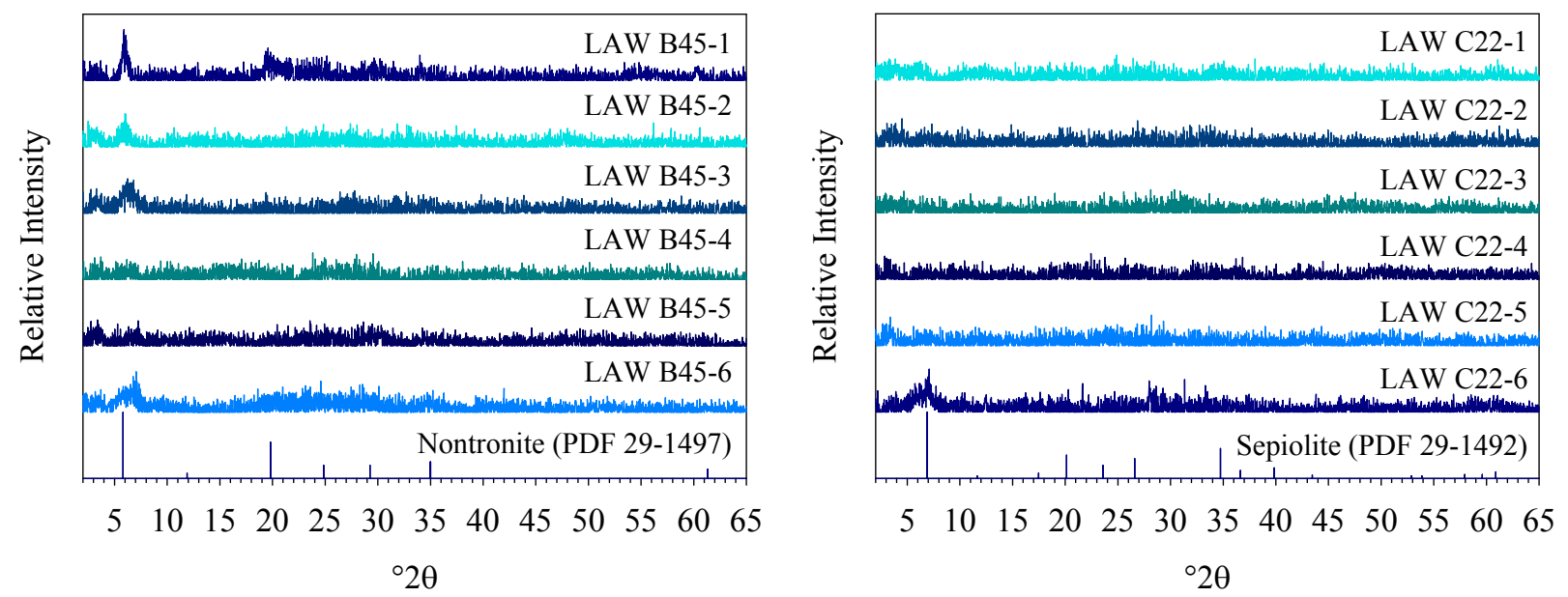

Figure 26. XRD Analyses of Reacted LAWB45 Glass Samples Taken from PUF Column After 530 days at $2 \mathrm{~mL} \mathrm{~d}^{-1}$ and $99^{\circ} \mathrm{C}$ 


\subsubsection{PUF Results for LAWAN102 and LAWAP101 Glasses}

The computer monitored test metrics results for the PUF tests with LAWAN102 and LAWAP101 are shown in Figure 27. The data were current as of the time this report was written; this test is still in progress. The LAWAP101 results show a rapid increase in $\mathrm{pH}$ along with a relatively high reading for electrical conductivity during the first 40 days of testing. The measured $\mathrm{pH}$ and electrical conductivity (Figure 27) combined with the B and $\mathrm{Na}$ release rate data (Figure 28) indicate a significant rate of glass corrosion in the early stages of the test. However, $\mathrm{pH}$, electrical conductivity, $\mathrm{B}$, and $\mathrm{Na}$ release rates have declined with time.
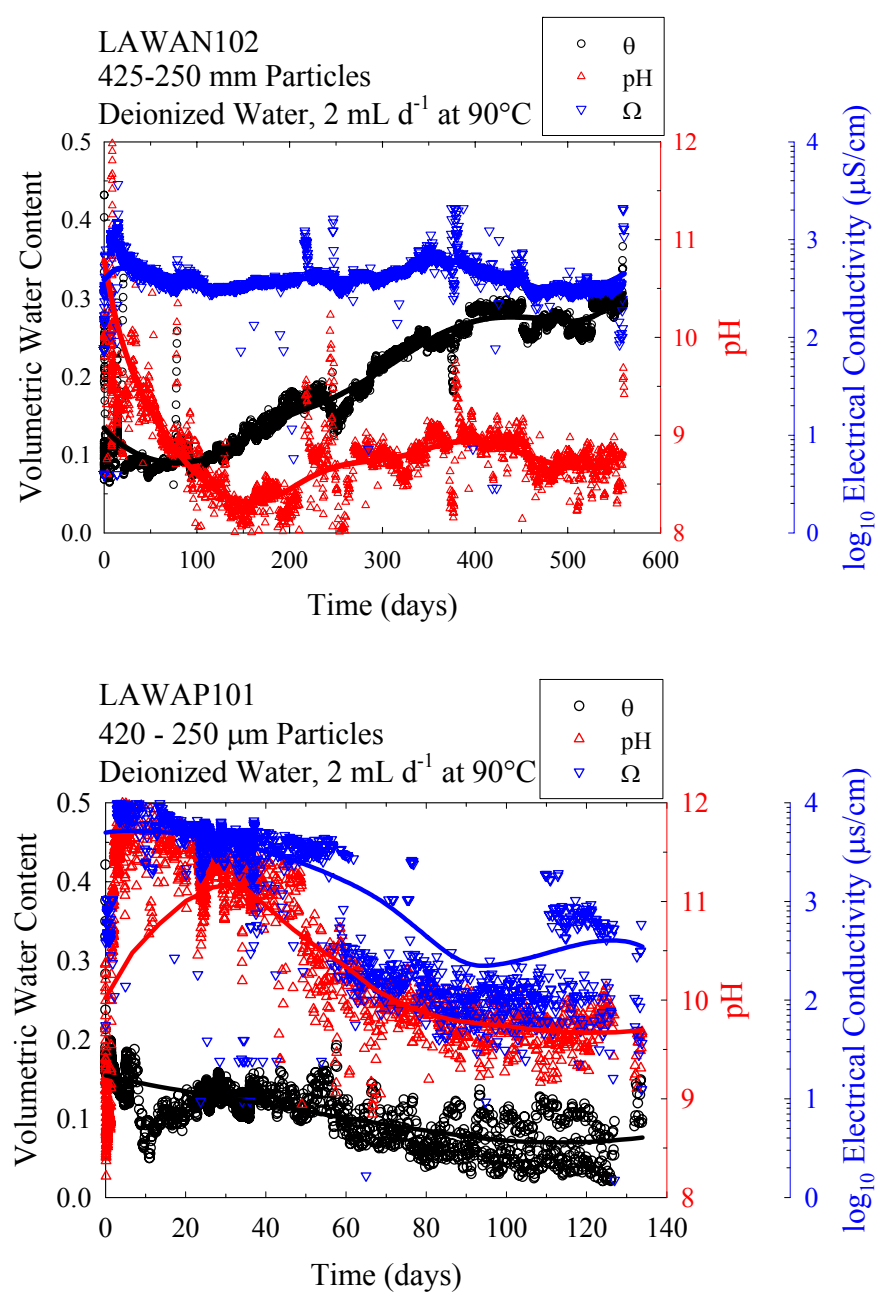

Figure 27. Computer Monitored Test Metrics from PUF Tests with LAWAN102 (top) and LAWAP101 (bottom) Glass Formulations. Lines are Bi-square Smoothed Fits to the Raw Data.
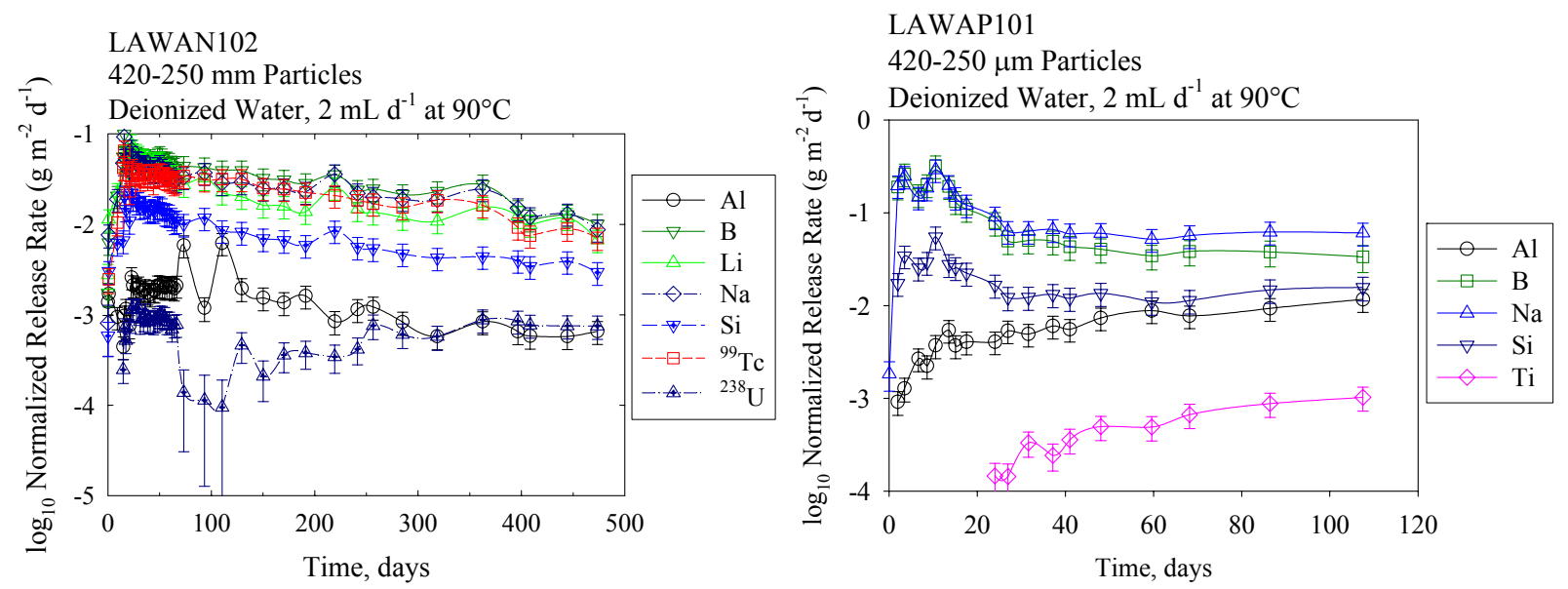

Figure 28. Normalized Release Rate for Selected Elements in PUF Test with LAWAN102 (left) and LAWAP101 (right) Glasses. 
The results from effluent chemical analyses on LAWAN102 are shown in Figure 28. As discussed in Section 4.1.3.2, differential rates of release are observed for each major glass component, which reflects their solubility behavior in water. Boron and $\mathrm{Na}$ are highly soluble, and so have the highest elemental release rates. Bulk dissolution behavior is typically indexed by the rate of $\mathrm{B}$ release, as no solid phases are expected to form that would affect its solution concentration. A comparison of ${ }^{99} \mathrm{Tc}$ to $\mathrm{B}$ release rates from LAWAN102 indicates that ${ }^{99} \mathrm{Tc}$ is being released congruently with $\mathrm{Na}$ and $\mathrm{B}$ within experimental measurement error. There is no evidence of significant incorporation of ${ }^{99} \mathrm{Tc}$ into alteration phases, as has been observed in static, watersaturated corrosion tests (MATTIGOD et al., 2002).

\subsubsection{Summary of PUF Results}

PUF test were conducted on three prototypic stimulant glasses; LAWA44, LAWB45, and LAWC22, as well as two LAW glasses produced with actual tank waste, LAWAN102 and LAWAP101. A summary of the steady state B release rates for these LAW glasses are provided in Table 8 along with the LAWABP1 for comparison. All the test glasses have good long-term performance indicators with LAWA44 being somewhat better than other tested glasses, factoring in the declining reaction rates observed with longer test durations.

Table 8. Summary of the Long-Term B Release Rates for PUF Tests on LAWA44, LAWB45, LAWC22, LAWAP101, and LAWAN102

\begin{tabular}{|c|c|c|}
\hline Sample ID & B Release Rate, $\mathrm{g} \mathrm{m}^{-2} \mathrm{~d}^{-1}$ & Test Duration, days \\
\hline LAWA44 & $0.0083 \pm 0.002$ & 850 \\
LAWB45 & $0.066 \pm 0.018$ & 500 \\
LAWC22 & $0.077 \pm 0.021$ & 500 \\
LAWAN102 & $0.048 \pm 0.013$ & 350 \\
LAWAP101 & $0.063 \pm 0.017$ & 250 \\
LAWABP1 & 0.1 & 188 \\
\hline
\end{tabular}

One consistent theme observed in each PUF test is the formation of mineral phases that range both in composition as well as the degree of crystallinity. We conclude that this observation is result of compositional differences between each LAW glass formulation as well as the dynamic nature of this test. In addition to PUF test, PCT experiments were conducted to determine the secondary phase paragenesis for each glass composition.

\subsection{Product Consistency Test (PCT) Experiments}

The PCT has been standardized as an American Society for Testing and Materials (ASTM) standard procedure (ASTM, 1994). The ASTM standard includes two methods: PCT Method A was developed specifically for verifying process control during production of vitrified high-level waste (HLW) forms and is conducted with specific values of test parameters; PCT Method B does not specify the values of test parameters. Because the PCT Method B encompasses commonly used variations of test parameters, PCT Method B was used in this work. 


\subsubsection{Experimental Materials and Methods}

The materials and methods section provides information on the material preparation techniques, experimental setup, test conditions, and rate calculations that were used for the testing of several LAW glass compositions.

Each of the glass samples used in PCT tests were sieved and washed using the same procedure as described in Section 3.1.1. The PCTs were conducted by placing a fixed amount of crushed glass with DIW in a Teflon reaction vessel at $90^{\circ} \mathrm{C}$. Two glass surface-area-to-solution volume ratios (S/V) were used: 1) $1 \mathrm{~g}$ of glass per $10 \mathrm{~mL}$ of DIW to give an S/V of $2000 \mathrm{~m}^{-1}$, and 2) $1 \mathrm{~g}$ of glass per $1 \mathrm{~mL}$ of DIW to give an S/V of 20,000 $\mathrm{m}^{-1}$. To limit water loss for longduration experiments, the Teflon PFA reactors were sealed inside a stainless steel Parr reactor. At the end of the test, the solution is analyzed for $\mathrm{pH}$ and the concentrations of dissolved glass components. The reacted glass surface was also analyzed to help characterize any alteration phases formed during the test.

\subsubsection{PCT Test Results}

\subsubsection{LAWA44 Glass}

The boron release data from the PCT experiments on each of the glass formulations was used to compute a reaction progress value as a function of test duration. Reaction progress is simply the moles of glass dissolved in $1 \mathrm{~kg}$ of water. The results are shown in Figure 29.

Using the $\mathrm{B}$ release data from the PCT experiments with LAWA44 glass, a reaction progress value was calculated as a function of test duration. Reaction progress is simply the moles of glass dissolved in $1 \mathrm{~kg}$ of water. The results are shown in Figure 29. Also shown on the figure is the predicted elemental solution concentration from the EQ3/6 version 8.0 code (WOLERY and DAVELER, 1992). These curves were obtained by allowing a paragenetic sequence of alteration phases to form in the simulation, as shown in Figure 30. Agreement with the experimental data is good. To adequately reproduce the PCT data, it was necessary to adjust the $\log \mathrm{K}$ upward for several of the phases (labeled as amorphous). This

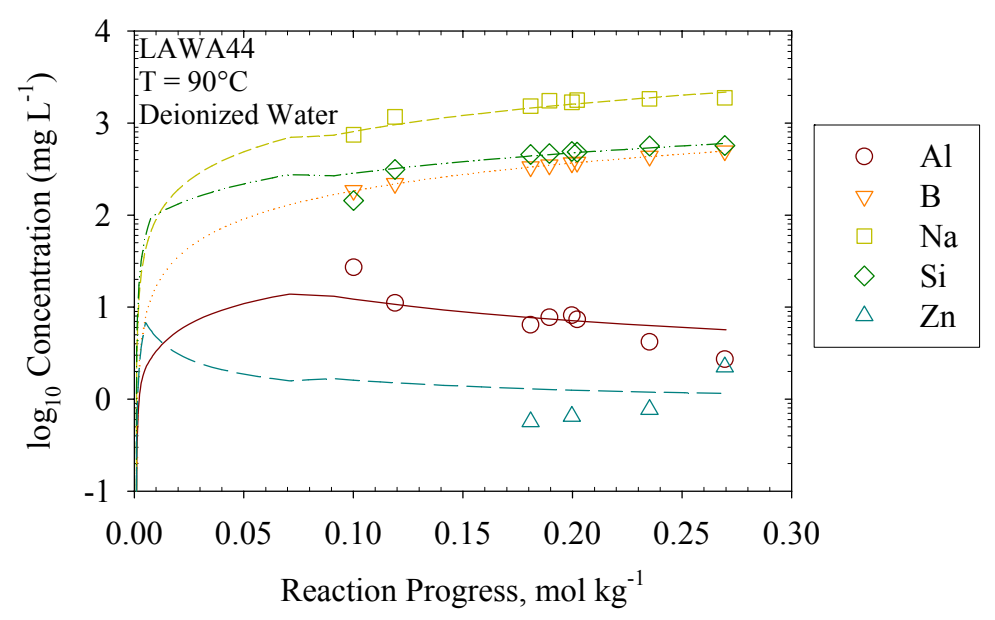

Figure 29. Comparison of PCT Solution Concentration Data (symbols) with the Solution Composition Calculated with the EQ3/6 Code (lines) for LAWA44 Glass

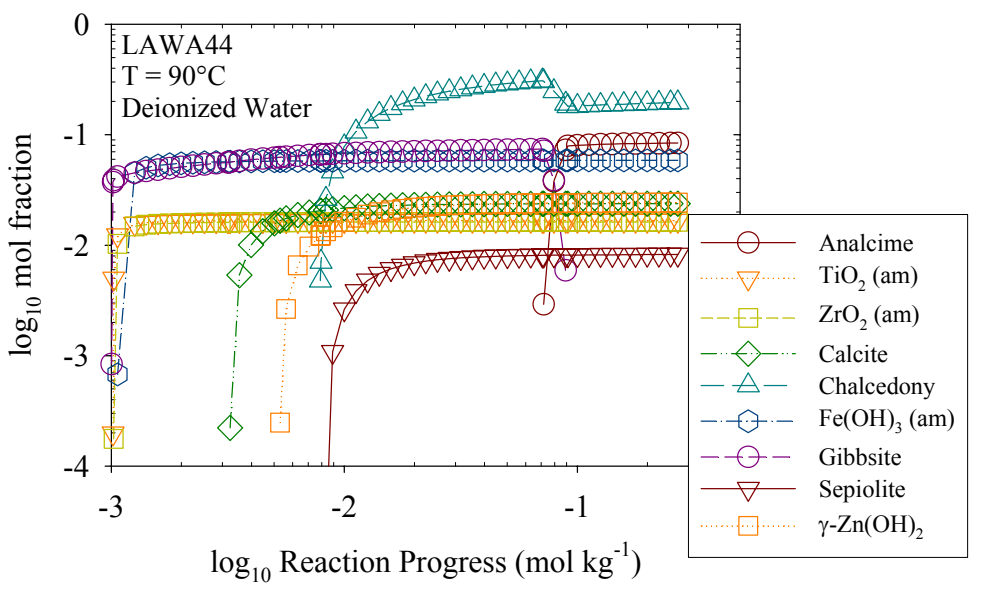

Figure 30. Predicted Paragenetic Sequence of Alteration Phases Formed During the Reaction of LAWA44 Glass in Deionized Water 
is a consequence of the fact that amorphous solids rather than their crystalline analogs often form in laboratory experiments with waste glasses. The amorphous solids are typically much more soluble and this is reflected in the equilibrium constant. The $\log \mathrm{K}$ values assigned to each of the phases used in the simulations are provided in Table 9.

Figure 31 and Figure 32 display the results from an X-ray diffraction and scanning electron microscopy analysis of the post-test reacted glass. The XRD analyses confirm the presence of the zeolite mineral, analcime

$\left(\mathrm{Na}_{0.96} \mathrm{Al}_{0.96} \mathrm{Si}_{2.04} \cdot \mathrm{H}_{2} \mathrm{O}\right)$ along with another zeolite phase; analcime was also predicted to form in the EQ3NR simulations. The SEM images of the reacted grains show needle-like crystalline phases, in the foreground, and a gel like-phase, in the background. Results from EDS analyses suggest that these phases are mainly composed of $\mathrm{Al}, \mathrm{Fe}, \mathrm{Na}$, and $\mathrm{Si}$, with minor amounts of $\mathrm{K}$.

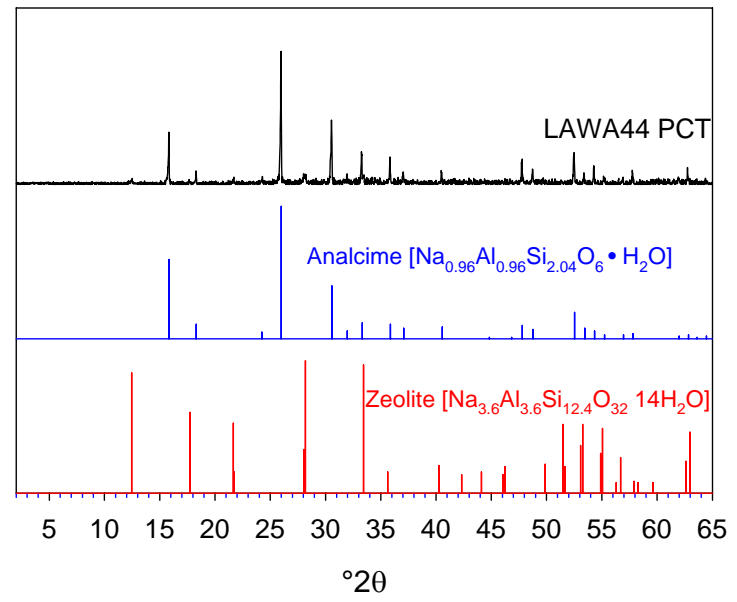

Figure 31. XRD Results of the PCT test reacted LAWA44

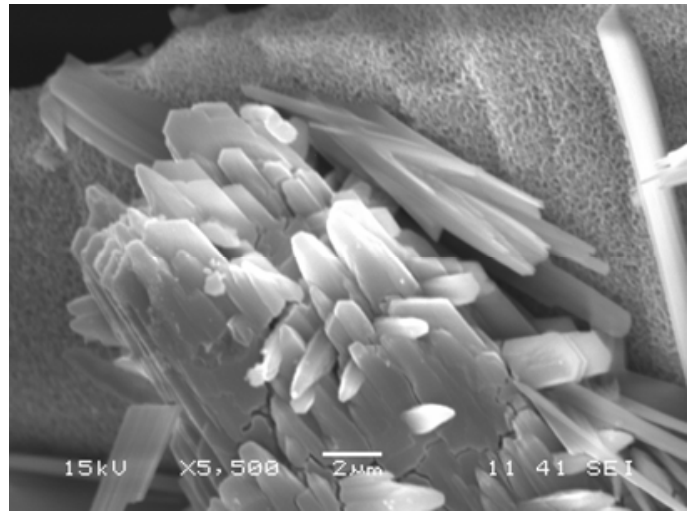

Figure 32. SEM Results of the Reacted LAWA44 Glass After 350 d PCT Test

Table 9. Secondary Phase Reaction Network for LAWA44 Glass. $\log \mathrm{K}$ is calculated at $15^{\circ} \mathrm{C}$

\begin{tabular}{|c|c|c|}
\hline Phase & Reaction & $\log K$ \\
\hline $\begin{array}{c}\text { Analcime } \\
\mathrm{Na}_{0.96} \mathrm{Al}_{0.96} \mathrm{Si}_{2.04} \mathrm{O}_{6} \cdot \mathrm{H}_{2} \mathrm{O}\end{array}$ & Analcime $=0.96 \mathrm{AlO}_{2}^{-}+0.96 \mathrm{Na}^{+}+2.04 \mathrm{SiO}_{2}(\mathrm{aq})$ & -13.47 \\
\hline $\mathrm{TiO}_{2}(\mathrm{am})$ & $\mathrm{TiO}_{2}(\mathrm{am})+2 \mathrm{H}_{2} \mathrm{O}=\mathrm{Ti}(\mathrm{OH})_{4}(\mathrm{aq})$ & -6.56 \\
\hline $\mathrm{ZrO}_{2}(\mathrm{am})$ & $\mathrm{ZrO}_{2}(\mathrm{am})+2 \mathrm{H}_{2} \mathrm{O}=\mathrm{Zr}(\mathrm{OH})_{4}(\mathrm{aq})$ & -6.73 \\
\hline $\begin{array}{l}\text { Calcite } \\
\mathrm{CaCO}_{3}\end{array}$ & Calcite $+\mathrm{H}^{+}=\mathrm{Ca}^{2+}+\mathrm{HCO}_{3}^{-}$ & 2.00 \\
\hline $\begin{array}{l}\text { Chalcedony } \\
\mathrm{SiO}_{2}\end{array}$ & Chalcedony $=\mathrm{SiO}_{2}(\mathrm{aq})$ & -3.64 \\
\hline $\mathrm{Fe}(\mathrm{OH})_{3}(\mathrm{am})$ & $\mathrm{Fe}(\mathrm{OH})_{3}(\mathrm{am})=\mathrm{Fe}(\mathrm{OH})_{3}(\mathrm{aq})$ & -2.33 \\
\hline $\begin{array}{l}\text { Gibbsite } \\
\mathrm{Al}(\mathrm{OH})_{3}\end{array}$ & Gibbsite $=\mathrm{AlO}_{2}^{-}+\mathrm{H}^{+}+\mathrm{H}_{2} \mathrm{O}$ & -15.61 \\
\hline $\begin{array}{c}\text { Sepiolite } \\
\mathrm{Mg}_{4} \mathrm{Si}_{6} \mathrm{O}_{15}(\mathrm{OH})_{2} \cdot 6 \mathrm{H}_{2} \mathrm{O}\end{array}$ & Sepiolite $+8 \mathrm{H}^{+}=4 \mathrm{Mg}^{2+}+6 \mathrm{SiO}_{2}(\mathrm{aq})+11 \mathrm{H}_{2} \mathrm{O}$ & 31.29 \\
\hline $\begin{array}{c}\text { Zinc Hydroxide } \\
\mathrm{Zn}(\mathrm{OH})_{2}(\text { gamma })\end{array}$ & $\mathrm{Zn}(\mathrm{OH})_{2}($ gamma $)+2 \mathrm{H}^{+}=2 \mathrm{H}_{2} \mathrm{O}+\mathrm{Zn}^{2+}$ & 11.88 \\
\hline
\end{tabular}




\subsubsection{LAWB45 and LAWC22 Glasses}

Figure 33 summarizes the available PCT data on LAWB45 and LAWC22 glasses to date. Using the $\mathrm{B}$ release data from these PCT experiments, a reaction progress value was calculated as a function of test duration. Reaction progress is simply the moles of glass dissolved in $1 \mathrm{~kg}$ of water. The results shown in Figure 33 suggest that $\mathrm{B}, \mathrm{Li}$, and $\mathrm{Na}$ are being released congruently, whereas $\mathrm{Al}$ and $\mathrm{Si}$ are not. Currently, no attempts have been made to model the solution composition data as additional, longer-duration tests with these glasses remain in progress. So far, the dissolution behavior of LAWB45 and LAWC22 glasses are entirely normal with no indications of reaction rate acceleration due to secondary phase formation.
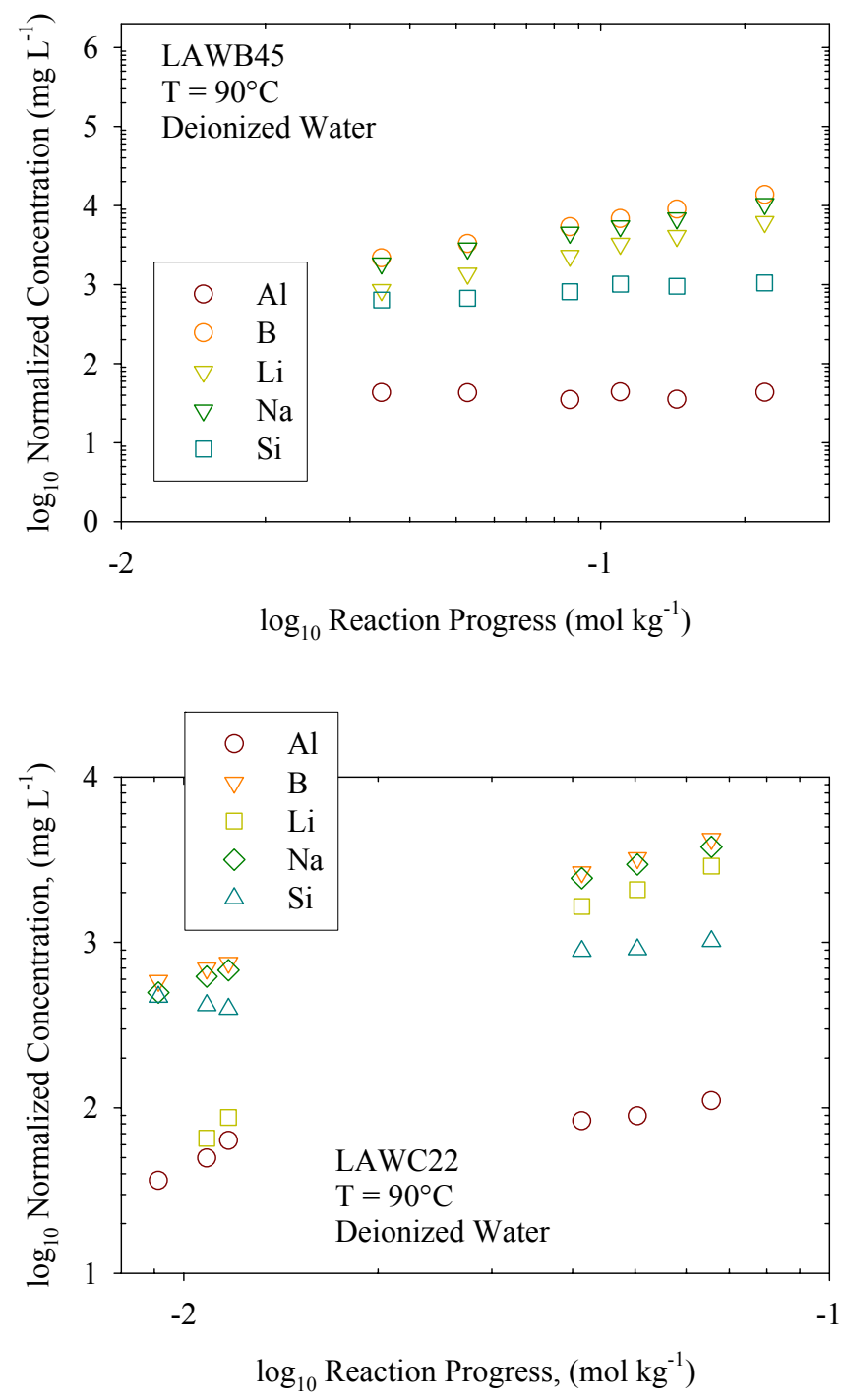

Figure 33. PCT-B Results for LAWB45 (top) and LAWC22 (bottom) Glasses 


\subsection{Microbial Degradation Experiments}

Microbes (bacteria, fungi and lichens) are widely recognized as playing an important role in numerous low-temperature geochemical processes. Weathering of silicates in nature is one of these processes. Microbes use the substrate as a source of energy or trace elements that enhances their survival and proliferation in a microbial community (EHRLICH, 1996).

Numerous studies on microbial-mediated dissolution of basaltic glasses have been conducted because of important role that alteration plays in marine chemistry (ALT and MATA, 2000). A few earlier investigations have focused on whether a direct attack by microbes can cause the breakdown of quartz and glass. Microbial attack on antique glasses at archaeological sites has shown to be much faster than abiotic corrosion processes alone (KRUMBEIN, 1983). Organic acids produced as metabolic byproducts are confined in biofilm microenvironments that have lower $\mathrm{pH}$ than the bulk fluid and thus generate locally enhanced rates of corrosion (LIERMANN et al., 2000). The organic acids (or base) may also directly enhance hydrolysis of $\mathrm{Si}-\mathrm{O}$ and $\mathrm{Al}-\mathrm{O}$ bonds or act as ligands that enhance silica solubility (EHRLICH, 1996).

Low-activity waste glasses contain $\mathrm{Cr}, \mathrm{F}, \mathrm{Mg}, \mathrm{P}, \mathrm{S}$, and $\mathrm{Zn}$ in much higher concentration than native Hanford soil. Microbial communities may therefore be attracted to the relatively large concentration of these important elements in the disposal system. Also, the transition to an IDF means that ILAW glass forms may be disposed in proximity to a variety of different wastes, including those that could supply a source of organic carbon. Clearly an investigation of LAW glass degradation due to microorganisms is needed.

Progress to date and the critical findings from the experimental investigation of the biodegradation of ILAW glass media is summarized in this section. Testing commenced in August 2001. An experimental procedure was developed during FY01 for the investigation of ILAW glass degradation due to Hanford microorganisms. The test design was developed with the following considerations: 1) avoid the use of glass containers, 2) separate chemical and microbial effects on degradation by statistical design of the experimental matrix, and 3) devise a sterile method for periodic analysis of the bacteria-doped fluids in contact with the glass. Sample preparation, equipment used, test matrix, and testing procedures used are described in this section. 


\subsection{Experimental Methods}

Summarized in Table 10 is the matrix of experimental variables used. The preparation and surface area calculation process for the LAWA44 glass used in these experiments remained the same and is described in Section 3.1.1.

Table 10. Matrix of Experimental Variable in the Glass Biodegradation Experiments

\begin{tabular}{|l|ll|}
\hline \multicolumn{1}{|c|}{ Variable } & \multicolumn{1}{|c|}{ Value/description } \\
\hline Glass type & 1 & LAWA44 $(75-150 \mu \mathrm{m})$ \\
Glass surface area & 1 & $500-1000 \mathrm{~cm}^{2} / \mathrm{g}$ \\
Glass/Solution Ratio & 1 & $1: 100$ \\
Carbon content & 2 & $0,0.1 \%$ \\
Microbial Culture & 3 & none, Hanford, Pure \\
pH & 1 & 7 \\
Temperature & 2 & 19 and $40^{\circ} \mathrm{C}$ \\
\hline
\end{tabular}

Microorganisms used in the tests were obtained from two sources: 1) solution extract from a composite of Hanford soils representative of the proposed ILAW disposal facility, and 2) a pure culture of Thiobacillus perometabolis (TPM) obtained from a commercial supplier. This bacteria strain is prescribed by ASTM G160-98 (ASTM, 2002) for similar degradation studies.

Solutions used in the glass corrosion experiments were the same as those used to culture the TPM or to extract microorganisms from the Hanford soil. A phosphate-buffered-saline (PBS) solution with a $\mathrm{pH}$ of 7 was used for suspension of the TPM. Hanford soil extract was prepared by adding $1.0 \mathrm{~g}$ of Hanford sediment to $20 \mathrm{~mL}$ DIW. The $\mathrm{pH}$ was adjusted to $\sim 8$ with $\mathrm{NaHCO}_{3}$ buffer. The slurry was shaken well for 10 to 15 minutes. After shaking, the slurry was sonicated for one hour. The supernatant was removed and transferred to a clean tube and sealed. After 24 hours, $5 \mathrm{~mL}$ of the supernatant was suspended directly into DIW or a $0.1 \%$ sodium pyrophosphate solution (SPS) at $\mathrm{pH} 7$. As will be demonstrated later, this procedure resulted in the generation of a suspension of colloid size particles of Hanford soil in addition to any microbes present in the sample. The bacteria were grown overnight in nutrient broth (ATCC Culture Medium 528) and resuspended in either DIW or their respective phosphate buffer solution prior to use. One set of experiments was also setup with an added carbon source, a $0.1 \%$ (by volume) yeast extract solution. All chemicals used in the experiments were of reagent grade. The cell density of the suspended bacterial culture used in all the experimental vials was determined on a Beckman DU-70 spectrophotometer, based on optical density measurements. 
Results from analysis of samples for key glass constituents in the original experimental solution prior to any contact with glass are shown in Table 11. High concentrations of $\mathrm{Na}$ in these solutions (except DIW) are due to the presence of $\mathrm{Na}$ in the buffer solutions.

An abridged test matrix, summarizing the experimental cells and the associated variation in the experimental parameters are listed in Appendix D. Appendix D also provides a list of the blanks and controls, some of which have glass powder without any bacterial culture present.

Table 11. Concentrations (ppb) of Constituents in Initial Solutions Without Glass Contact

\begin{tabular}{|c|c|c|c|c|}
\hline Sample Description & $\mathrm{Al}$ & $\mathrm{B}$ & $\mathrm{Na}$ & $\mathrm{Si}$ \\
\hline Distilled Water & $14 \pm 4$ & $12 \pm 11$ & $493 \pm 429$ & $402 \pm 161$ \\
Phosphate-Buffered-Saline & $27 \pm 7$ & $45 \pm 15$ & 3100000 & $682 \pm 283$ \\
& & & \pm 345000 & 301000 \\
Sodium Pyrophosphate Solution & $37 \pm 33$ & $16 \pm 11$ & \pm 33160 & $381 \pm 263$ \\
\hline
\end{tabular}

\subsection{Test Equipment}

The glass degradation experiments were set up under aerobic conditions using 50-mL Teflon flasks with air-tight screw caps. The caps were fitted with gas-tight valves (locking), which would allow removal of solution with a needle and sterile disposable syringe. The glass was weighed, placed in each flask, sealed, and then sterilized by autoclaving. In addition to autoclaving the glass sample, any equipment not sterilized previously by gamma irradiation was autoclaved. All preparation was done in a sterile hood. Each flask was inoculated with a known mass of bacterial culture and $50 \mathrm{~mL}$ of corresponding solution. After being inoculated, each flask was placed in a secure covered area on a bench top for the $19^{\circ} \mathrm{C}$ experiments and in an incubator for the $40^{\circ} \mathrm{C}$ experiments. After the initiation of incubation, glass degradation kinetics is monitored by a periodic measurement of the solution concentration of major glass components (Al, $\mathrm{B}, \mathrm{Na}, \mathrm{Si}$ ), $\mathrm{pH}$, and cell density in the vial solution. No monitoring of gases (including $\mathrm{CO}_{2}$ ) in the flasks was conducted. The reactor contents were not subjected to mixing or stirring.

\subsection{Sampling Procedure}

Solution samples were collected in a sterile hood. At sampling, each flask is unlocked, a needle inserted, $1 \mathrm{~mL}$ of solution removed approximately 25.4 to $38 \mathrm{~mm}$ from top of the flask. The $1 \mathrm{~mL}$ of solution is then placed in a sterile $5 \mathrm{~mL}$ falcon tube and diluted to a total volume of $5 \mathrm{~mL}$. The tubes were labeled and tightly sealed. Blanks and controls were sampled in the same manner and stored for later analysis. 


\subsection{Results}

Figure 34 shows a representative picture of the reactor flasks. Cloudiness of the solution is due to microbial growth. The concentration of $\mathrm{Al}, \mathrm{B}$ and $\mathrm{Si}$ in the flasks containing TPM, HSE, and no culture (blanks) for both the 19 and $40^{\circ} \mathrm{C}$ experiments are listed in Appendix D. Although the details will not be presented here, the majority of the data for the TPM culture show no statistically significant deviations from the control samples. In contrast, the data from flasks containing the Hanford soil microorganisms (HSE) yielded significantly higher concentrations of $\mathrm{Al}, \mathrm{B}$ and $\mathrm{Si}$ when compared with majority of the control samples. This does not appear to be $\mathrm{pH}$ related as the $\mathrm{pH}$ of all samples falls within a narrow range (5.5 to 7.5).

A comparison of the boron release data from the control experiments and the experiments conducted with HSE is given in Figure 35. The data clearly show enhanced glass corrosion (over $5 \mathrm{X}$ ) in the experiments with HSE. Similar effects were observed at $19^{\circ} \mathrm{C}$. However, we do not believe that these results represent evidence of microbial enhanced degradation of LAWA44 glass. A small portion of the reacted solids was removed from the bottom of one of the HSE vessels and analyzed by SEM and XRD. Figure 36 shows a SEM photograph taken on a sample removed from test MBD44-16. A grain of LAWA44 glass is clearly visible in the back of the photograph; in the foreground are colloid-size particles that appear very similar in morphology to minerals present in Hanford soil. XRD analyses of the MBD44-16 sample (see Figure 37) clearly

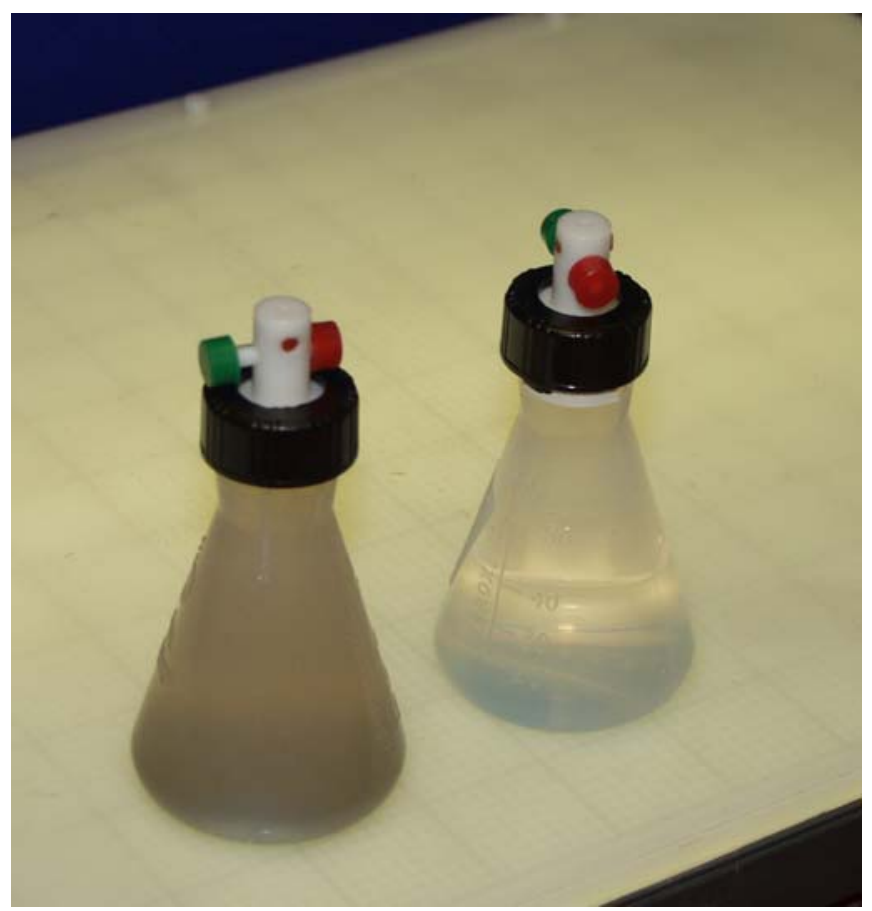

Figure 34. Visual Observation of Bacterial Growth After 14 Weeks. Right: Exp \# 31 DIW; Left: Exp \# 15 glass, HSE, added Carbon at $19^{\circ} \mathrm{C}$

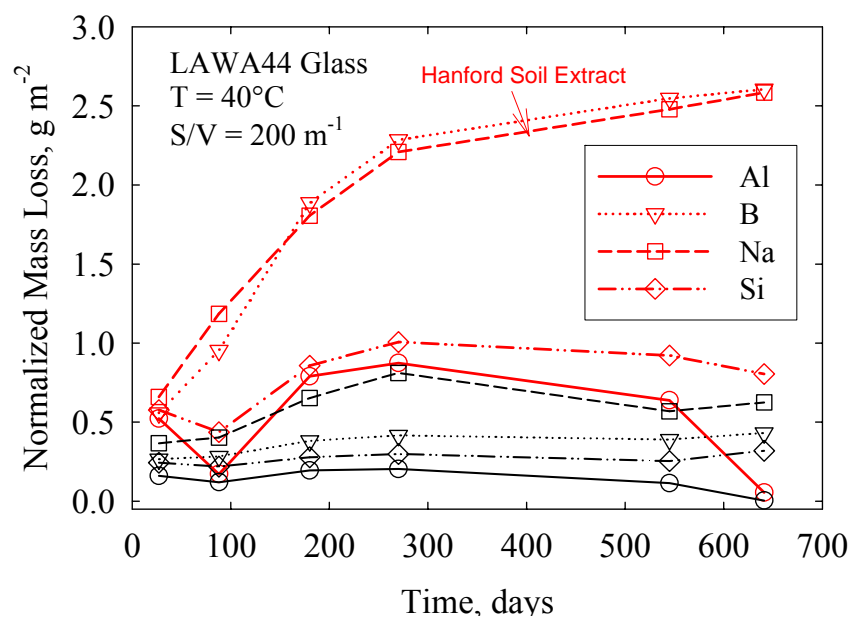

Figure 35. Comparison of Element Release Rates From LAWA44 Glass in Static Tests Conducted with DIW Only (black data points) versus Hanford Soil Extract (red data points) shows the major crystalline phases present are identical to those contained in Hanford soil. Based on the small amount of glass that has reacted, we believe that the large volume of mineral phases observed in these experiments was most likely introduced from the HSE solution. In addition to that lack of glass reaction, Figure 36 suggests that these phases settled out of solution and were not created as a reaction product at the glass/water interface. 
The introduction of Hanford soil minerals (plus any microbes present in the soil) was not considered during the initial planning for these experiments. Because of the high-surface area of these minerals in comparison with the glass, it is highly probable that they act as low surface-energy templates for additional precipitation, which causes the glass to dissolve faster to maintain stable concentrations of silicic acid. We believe this abiotic mechanism is the most probable cause of the increased glass degradation rate shown in Figure 35 , but acknowledge that it is impossible to rule out a biotic or bio-assisted mineralization process in these tests. Interestingly though, it was the interfaces between ILAW glass and Hanford soil that were predicted in reactive transport simulations to have the maximum glass dissolution rates in the ILAW disposal facility (MANN et al., 2001), again due to chemical effects (and hydraulic effects) at the glass/soil interfaces. These calculations were completed well before the experiments discussed here were even begun. Hence, the experimental results shown in Figure 35 represent a true (if accidental) validation of the computational chemical model being used for long-term performance evaluations of LAW glass.

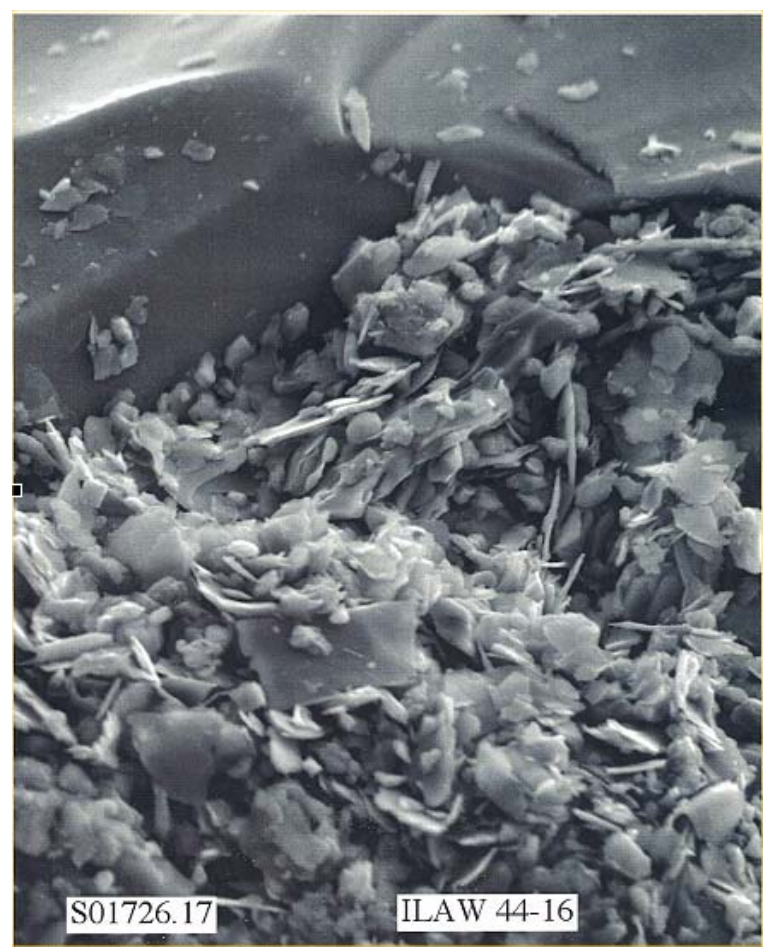

Figure 36. SEM Picture of Reacted Solids Removed From Static Corrosion Test with HSE Solution After $700 \mathrm{~d}$ at $40^{\circ} \mathrm{C}$. Solids in the foreground are minerals extracted from Hanford Soil during preparation of the HSE solution.

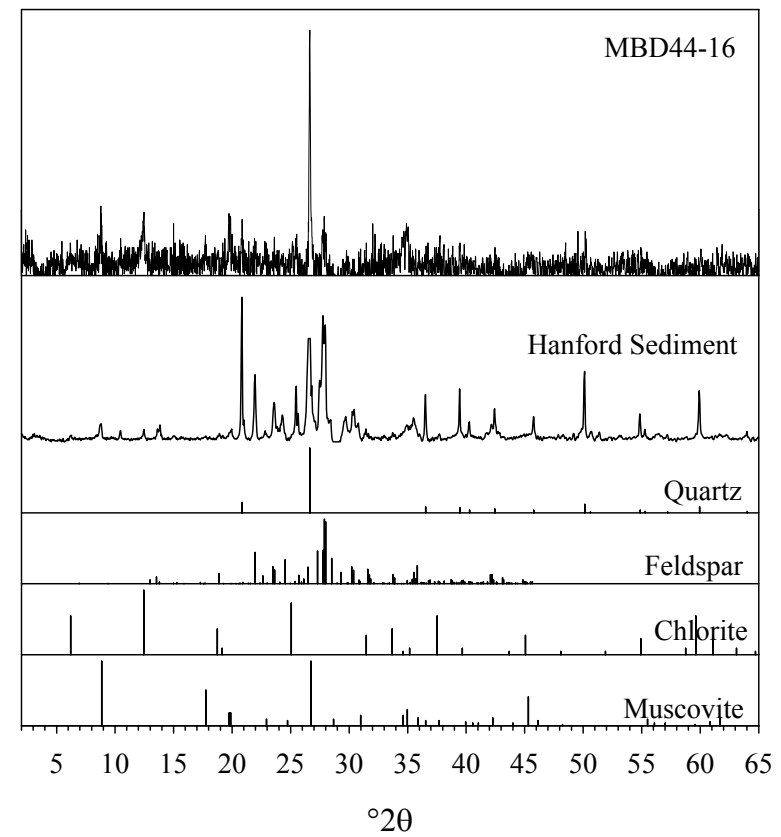

Figure 37. Comparison of XRD Patterns for Reacted Solids Removed After 700 days from Test MBD44-16 and Hanford Soil 


\subsection{Release of Contaminants from Secondary Waste}

Presently, no published data are available for quantifying the release of contaminants of concern from secondary waste streams that will be solidified in a likely cement-based waste form and disposed in the IDF. The secondary waste stream of most interest for the IDF PA is projected to be slurries generated from caustic scrubbing of off-gasses being vented from the WTP and any other alternative treatment technology (e.g., bulk vitrification and/or steam reformation) being evaluated. The projected composition of the caustic scrubber secondary waste stream is shown in Table 12. This recipe, which is normalized to a $5 \mathrm{M} \mathrm{Na}$ concentration, is being used in some preliminary waste solidification studies funded by CH2M-Hill Hanford Group (contract to Center for Laboratory Services) and by DOE Headquarters (contract to Vanderbilt University). Table 12 also shows that Na makes up $9.52 \mathrm{wt} \%$ of the stimulant. For comparison, the projected average caustic scrubber secondary waste effluent from the alkaline line effluent collection tanks is $4.14 \mathrm{wt} \%$ Na. Leanne Mahoney ${ }^{1}$ used the Environmental Simulation Program (ESP) model (OLI Corporation) to predict that all the chemicals listed in Table 12 will dissolve to make up a 5 $\mathrm{M} N a$ solution that has a solution $\mathrm{pH}$ of 13.5 and a specific gravity of $1.21 \mathrm{~g} \mathrm{~cm}^{-3}$.

As previously stated, contaminant release data for this specific waste stream after solidification in cement/grout are not currently available, but for the purpose of this data package we have elected to use release data obtained from the nuclear waste literature. The cement/grout-based solidified waste forms (e.g., Portland cement and mixed cement, slag, fly ash or other pozzolan etc.) used in these studies are mixed with highly saline and often caustic liquid wastes and are therefore expected to be similar to the expected waste form produced when mixed with secondary waste. By the next PA, more IDF site-specific data should be available to add technical defensibility to future performance predictions. We begin with a brief overview of key chemical processes important in production of cementitious waste forms.

\footnotetext{
${ }^{1}$ Personal Communication between the authors and Leanne Mahoney at Pacific Northwest National Laboratory, Richland, WA
} 


\subsection{Product Characteristics}

Production of cementitious waste forms is expected to be performed by mixing dry reagents with the waste feed. Typical dry reagents consist of 1) Portland cement, 2) fly ash, 3) blast furnace slag (BFS), and 4) ferrous sulfate monohydrate (1988; LANGTON, 1989). The BFS and ferrous sulfate are used in some formulations to reduce redox sensitive elements (such as Tc, $\mathrm{U}$, and $\mathrm{Cr}$ ), causing them to be precipitated as insoluble compounds and thereby lowering their release rate from the cement. Hydration and setting of the cement begins upon mixing water with the dry reagents. Each component contributes to a complex set of chemical reactions that consume water, produce heat, and form calcium-silicate-hydrate $(\mathrm{CSH})$ gel. A generalized reaction scheme is given by

$$
\begin{aligned}
& \mathrm{Ca}_{3} \mathrm{SiO}_{5}+3 \mathrm{H}_{2} \mathrm{O} \rightarrow x \mathrm{CaH}_{2} \mathrm{SiO}_{4} \cdot(1-x) \mathrm{SiO}_{2}+(3-x) \mathrm{Ca}(\mathrm{OH})_{2} \\
& \mathrm{Ca}_{2} \mathrm{SiO}_{4}+2 \mathrm{H}_{2} \mathrm{O} \rightarrow x \mathrm{CaH}_{2} \mathrm{SiO}_{4} \cdot(1-x) \mathrm{SiO}_{2}+(2-x) \mathrm{Ca}(\mathrm{OH})_{2}
\end{aligned}
$$

where $x$ is the $\mathrm{Ca} / \mathrm{Si}$ ratio of the $\mathrm{CSH}$ gel. The $\mathrm{CSH}$ can be considered a solid solution consisting of a non-ideal mixture of the end-member components $\mathrm{CaH}_{2} \mathrm{SiO}_{4}(\mathrm{~s})$ and $\mathrm{SiO}_{2}(\mathrm{~s})$ (RAHMAN et al., 1999). The calcium hydroxide produced from reactions (13) and (14) reacts with silica and calcium aluminates in reactions such as

$$
\begin{gathered}
\mathrm{Ca}_{4} \mathrm{Al}_{2} \mathrm{Fe}_{2} \mathrm{O}_{10}+4 \mathrm{Ca}(\mathrm{OH})_{2}+22 \mathrm{H}_{2} \mathrm{O} \rightarrow \mathrm{Ca}_{8} \mathrm{Al}_{2} \mathrm{Fe}_{2} \mathrm{O}_{14} \cdot 26 \mathrm{H}_{2} \mathrm{O} \\
\mathrm{Ca}_{3} \mathrm{Al}_{2} \mathrm{O}_{6}+\mathrm{Ca}(\mathrm{OH})_{2}+12 \mathrm{H}_{2} \mathrm{O} \rightarrow \mathrm{Ca}_{4} \mathrm{Al}_{2} \mathrm{O}_{7} \cdot 13 \mathrm{H}_{2} \mathrm{O}
\end{gathered}
$$

Reactions (13) thru (16) (along with many others) produce solid particles (e.g., portlandite phases) that continue to grow with time (PETERSON et al., 2002) and develop a macroscopic finescale pore structure which trap and limit the transport of contaminants contained within the cement matrix. Hydration of BFS initially proceeds much slower than Portland cement, but the products of hydration are similar in terms of chemical make-up, i.e. CSH. Hydration of BFS depends on the activation of the glass component by hydroxyl and alkali ions available from the Portland cement hydration. Activation of the glass is relatively slow and causes a delay in the hydration of slag, which is reflected in slower setting and lower early strength development compared to Portland cement. BFS hydration products are generally found to be more gel-like, as compared to cement, and tend to fill voids in the cement paste, increased strength, and enhanced durability.

A significant factor that affects long-term contaminant fate and transport predictions are the chemical reaction pathways that occur as cementitious waste forms interact with the atmosphere and water in contact with them within a subsurface burial ground. Most contaminants are metallike and thus their aqueous solution chemistry is quite sensitive to $\mathrm{pH}$ conditions. The composition of pore water that evolves during the degradation of cement in water has been studied extensively in the laboratory and with computer modeling techniques. The chemical reactions associated with the hydration of cement are described in detail in IAEA (1993), Atkins and Glasser (1992), Reardon (1992), and the references cited therein. The $\mathrm{pH}$ changes that occur as the result of cement and water reactions are shown schematically as a function of time in Figure 38. 
The dissolution of the $\mathrm{CSH}$ and portlandite phases, solids located on the right hand side of equations (15) and (16), which may constitute as much as $75 \mathrm{wt} \%$ of the hydrated cement, has an important role in buffering the $\mathrm{pH}$ of the resulting pore fluids. As groundwater reacts with the cement, dissolution of the alkali hydroxide phases present in relatively minor amounts can result in initially high $\mathrm{pH}$ values (approximately 13.5). As these phases are leached from the cement, the pore fluid $\mathrm{pH}$ decreases to approximately 12.5 and is buffered by the dissolution of free portlandite contained in the cement.

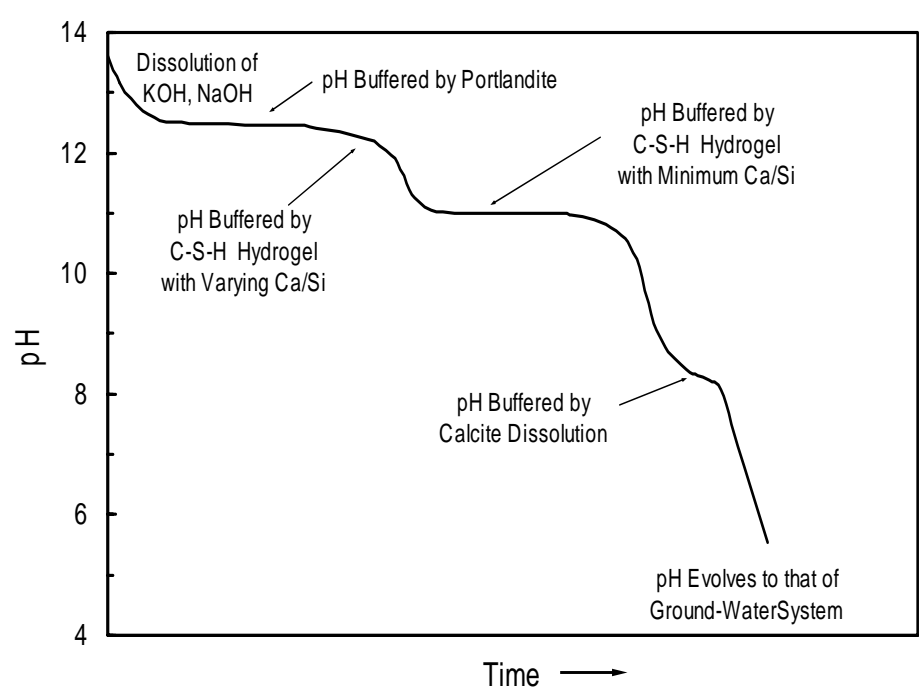

Figure 38. Change of Pore Water $\mathrm{pH}$ Resulting from Reactions of Cement Components

Eventually the portlandite is depleted and the pore fluid $\mathrm{pH}$ continues to decreases to approximately 10.5 , where it is controlled by the incongruent dissolution of $\mathrm{CSH}$. The solubility properties of $\mathrm{CSH}$, however, vary as a function of its calcium/silicon ratio $(\mathrm{Ca} / \mathrm{Si}$ ratio). The incongruent dissolution of the $\mathrm{CSH}$ produces mainly dissolved $\mathrm{Ca}(\mathrm{OH})_{2}$ and only traces of dissolved $\mathrm{SiO}_{2}$. During this process, the $\mathrm{Ca} / \mathrm{Si}$ ratio of the remaining CSH solid decreases depending on solid/solution ratio (BERNER, 1992). When the dissolution of CSH is complete, the $\mathrm{pH}$ of the cement pore fluid will continue to decrease to a value buffered by the host groundwater or vadose zone porewater. This continuous $\mathrm{pH}$ change will also be affected to a limited extent by the dissolution of any calcite that precipitated at the high $\mathrm{pH}$ conditions during the early stages of cement dissolution.

The timeframe required for the porewater $\mathrm{pH}$ to change from 13.5 to that of the groundwater is determined by the rate at which water migrates through the cement system. For example, calculations by Atkinson et al. (1989) indicate that the $\mathrm{pH}$ of the near-field pore water would remain above 10.5 for several hundred thousand years for designs of radioactive waste disposal systems being considered in the United Kingdom. Criscenti et al. (1996) performed calculations for three rows of 55-gallon drums stacked on top of each other in a shallow land burial ground in the arid Hanford environment for various scenarios. For all scenarios modeled, the system $\mathrm{pH}$ did not decrease below 10 for 10,000 years because CSH gel remained to buffer the $\mathrm{pH}$. For a scenario of one barrel filled only one-third with cement at the highest recharge rate $(5 \mathrm{~cm} / \mathrm{yr})$, the CSH gel would completely dissolve in 4,000 years, and the $\mathrm{pH}$ would drop below 10 .

Another parameter that can vary significantly in cement pore water and influence radionuclide adsorption potential is the solution redox potential, Eh. The major constituent that can influence the Eh of cement pore fluids is the sulfur contained in compounds found in slags that are often used in tailoring solidification of radioactive wastes. For details, the reader is referred to the discussions on this topic in Angus and Glasser (1985), Atkins and Glasser (1992), and references contained therein. The Eh conditions of the disposal facility may also be lowered by corrosion of iron containers (EWART et al., 1988). 
In summary, fresh cement/concrete is such a highly reactive and unstable assemblage of solids that care must be taken when predicting the release of contaminants because of wide swings in $\mathrm{pH}$ caused by the $\mathrm{Ca}(\mathrm{OH})_{2}$ and $\mathrm{CSH}$ components of hydrated cement. It is likely that some co-precipitation loss of metal-like contaminants occurs during short term laboratory leach testing that generally studies only the early-time high $\mathrm{pH}$ portion of the evolving system. Thus, the very long-term release of metal-like contaminants from cementitious solid waste forms for the later stages of weathering are not available and could be underestimated by available short-term empirical laboratory studies.

\subsection{Release Modeling}

The framework for modeling the long-term performance of vitrified waste (MCGRAIL et al., $2000 \mathrm{~b}$ ) is based on a mechanism in which matrix hydrolysis and contaminant release are controlled by the rate that chemical bonds are broken. While similar arguments can be made regarding the importance of modeling chemical reactions and transport in cement pore waters (BACON et al., 2002), with cementitious waste forms, a physical model of contaminant diffusion has been almost universally adopted (COOK, 2000). Empirical effective diffusion coefficients measured in short-term laboratory experiments are widely used to model the long-term performance of cementitious waste forms (ALBENESIUS, 2001). These diffusion measurements have changed little since the IAEA method was proposed by Hespe (1971) over 30 years ago. The effective diffusion coefficients measured for each contaminant are used for a diffusion-controlled transport analysis in the continuous pore network of the cement coupled with diffusive-advective transport in idealized fractures. Because waste-form specific data for secondary wastes is not available at this time, it is prudent to utilize the simpler diffusion-based modeling approach for the 2005 IDF PA. Further, no geochemical reaction pathway or mathematical constructs have been created to address the fate of trace contaminants bound in the cementitious solids as they weather/react over long time frames. The previous section summarizes the evolution of porewater $\mathrm{pH}$, one of the key variables that control the fate of metallic contaminants. Thus, there is a second reason for relying upon simple models for the 2005 IDF PA.

Diffusional transport of species through cement is best treated as a combination of physical transport and chemical interactions. The chemical interactions can have important retarding effects on final transport rates. The intrinsic diffusion coefficient $\left(D_{i}\right)$ is a measure of the physical contribution to diffusion and depends on the tortuosity $(\tau)$, constrictivity $(\delta)$, and porosity $(\varepsilon)$ of the cement, which influence the diffusion coefficient of free water, $\mathrm{D}_{\mathrm{f}}$, by

$$
D_{i}=D_{f} \frac{\varepsilon \delta}{\tau^{2}}
$$

Chemical interactions can be quite varied (ion exchange, precipitation, specific and irreversible adsorption and each process may have fast or slow kinetics). The simplest process that is mathematically readily tractable is ion exchange with fast kinetics and a linear isotherm. This simple chemical process gives rise to the following equation where the modified diffusion coefficient is called the effective diffusion coefficient, $D_{e}$, and is related to the intrinsic diffusion coefficient by a chemical capacity factor, $\alpha$

$$
D_{e}=\frac{D_{i}}{\alpha}
$$


The capacity factor is the ratio of the moles of contaminant per unit volume of water-saturated solid $\left(\mathrm{C}_{\mathrm{S}}\right)$ to the moles per unit volume of contaminant in the liquid, $\mathrm{C}_{\mathrm{L}}$. The capacity factor is related to the $K_{d}(\mathrm{~mL} / \mathrm{g})$ by the following equation:

$$
\alpha=\varepsilon+\rho K_{d}
$$

where $\rho$ is the is the bulk density of the porous solid. Again we stress that this relationship requires fast and reversible chemical reaction processes and that sorption satisfies the linear isotherm constraint (adsorption is independent of contaminant concentration). Few chemical reactions for contaminants meet these requirements.

Regardless, this simple construct is often applied in quantifying the release of contaminants from cementitious waste forms because it allows one to separate the physical and chemical processes that control transport. There are several experimental methods that one can use to measure the $K_{d}$ (and then compute $\alpha$ ) after also measuring the porosity and bulk density of the waste form. Conversely, one can measure the effective diffusion coefficient using through diffusion cells, penetration profiles of a contaminant into a solid porous medium, or out diffusion of contaminants (leaching tests). In Section 6.4.1, we review the relevant literature on iodine release from cementitious waste forms.

\subsection{Effective Diffusion Coefficients for Key Contaminants to be Disposed in IDF}

Table 13 contains "proxy" effective diffusion coefficients for key contaminants of concern for cementitious/grout solidified secondary wastes destined for disposal in IDF. These values are not site-specific or of the same pedigree as the release parameters tabulated for ILAW glass in other sections of this data package or for the $\mathrm{K}_{\mathrm{d}}$ values presented in the companion geochemistry data package (KRUPKA et al., 2004). By the next detailed IDF performance assessment, scheduled in 2010, site-specific release data for key contaminants from cement/grout solidified secondary waste will replace the "proxy" values shown in Table 13. It is also plausible that more sophisticated release conceptual models, more in line with the constructs used for glass as described within other sections of this data package, will be available for the 2010 PA activity.

Table 13 was mainly generated from a review of several previous data compilations for either leach results (effective diffusion coefficients), desorption $\mathrm{K}_{\mathrm{d}}$ results for release of contaminants from spiked grouts/cements or from adsorption $\mathrm{K}_{\mathrm{d}}$ results for uncontaminated grouts/cements placed in spiked solutions. Further, we searched two electronic data bases, on-line documents at DOE-OSTI at http://www.osti.gov/bridge/search.easy.jsp and Web of Science for journal manuscripts from 1980 to 2004. Only a few specific references were found with useful data beyond past compilations: Serne et al. (1995), Krupka and Serne (1996; 2001), Bradbury and Sarott (1995), and Bradbury and Van Loon (1998) and references cited within these compilations. All these sources were used to populate Table 13.

Two categories of effective diffusion coefficients are listed. The first column represents values that should be considered as most probable, meaning that the values represent projected releases of the contaminant under the baseline or most likely conditions to be found in the IDF. The second column represents higher release values that can be used to account for unexpected or adverse conditions and to allow "conservative" calculations of release. In addition, values are provided for different valence states/physical forms or species for some of the contaminants and 
for iodine and uranium the type of grout or cement is split into categories. In Section 6.4, it is shown that type of grout (oxidizing or reducing) can alter the speciation of iodate. Further, from geochemical principles and empirical data in the waste management literature it is known that uranium(VI) sequestration into cement/grout is highly sensitive to the $\mathrm{pH}$ and dissolved carbonate content of the porewater. As summarized in Section 6.1 and discussed in more detail within Krupka and Serne (1996), cement porewater evolves with time from a highly caustic and carbonate deficient solution towards a moderately caustic less carbonate deficient, and finally to a near neutral $\mathrm{pH}$ solution that is in equilibrium with atmospheric carbon dioxide. Therefore, the release properties for uranium that is solidified in cement/grout will change significantly over time as the solid weathers from contact with atmospheric carbon dioxide and recharge water.

Other considerations in using Table 13 are that for some listed contaminants either no data at all (e.g., for $\mathrm{Hg}$ ) or no data closely similar to projected IDF specific conditions were found (e.g., uranium in aged/weathered cements) such that the chosen values are qualified with the designation "guess." Assigning the "guess" attribution should be a flag that the value is a subjective choice based on the "expert opinion" of R. J. Serne, staff scientist at PNNL. For those values in Table 13 that are based on the generic literature a reference or rationale for choosing the value is identified. 
Table 13. Most Probable and Conservative Estimates for "Proxy" Effective Diffusion Coefficients $\left(\mathrm{cm}^{2} \mathrm{~s}^{-1}\right)$ for Key Contaminants in Secondary Waste Solidified in Cementitious Waste Forms.

\begin{tabular}{|c|c|c|c|c|c|}
\hline \multirow{3}{*}{ Element } & \multirow{3}{*}{$\begin{array}{l}\text { Waste Form } \\
\text { Species }\end{array}$} & \multirow{3}{*}{ Waste Form Type } & \multicolumn{2}{|c|}{ Effective Diffusion Coefficient } & \multirow{2}{*}{$\begin{array}{c}\text { Reference/ } \\
\text { Rationale }\end{array}$} \\
\hline & & & Most Probable & Conservative & \\
\hline & & & \multicolumn{2}{|c|}{ - } & \\
\hline \multirow{2}{*}{$\mathrm{N}$} & $\mathrm{NO}_{3}^{-}$ & any cement/grout & $5 \times 10^{-9}$ & $3 \times 10^{-8}$ & (SERNE et al., 1992) \\
\hline & $\mathrm{NO}_{2}^{-}$ & any cement/grout & $5 \times 10^{-9}$ & $3 \times 10^{-8}$ & (SERNE et al., 1992) \\
\hline \multirow{5}{*}{ I } & $\mathrm{I}^{-}$(free) & any cement/grout & $2.6 \times 10^{-9}$ & $1 \times 10^{-8}$ & (AtKINS et al., 1988) \\
\hline & $\mathrm{IO}_{3}^{-}$(free) & any cement/grout & $2.6 \times 10^{-9}$ & $1 \times 10^{-8}$ & (AtKINS et al., 1988) \\
\hline & $\mathrm{I}^{-}$(insoluble salt) & any cement/grout & $2.3 \times 10^{-10}$ & $1 \times 10^{-9}$ (guess) & (KALININ et al., 1983) \\
\hline & $\mathrm{IO}_{3}^{-}$(insoluble salt) & cement/oxidizing grout & $5.0 \times 10^{-11}$ & $3.1 \times 10^{-9}$ & $\begin{array}{c}\text { (CLARK, 1977), } \\
\text { (KALININ et al., 1983) }\end{array}$ \\
\hline & $\mathrm{IO}_{3}^{-}$(insoluble salt) & reducing grout & $2.6 \times 10^{-10}$ (guess) & $1 \times 10^{-9}$ (guess) & \\
\hline \multirow{2}{*}{$\mathrm{Tc}$} & $\mathrm{TcO}_{4}^{-}$ & any cement/grout & $5 \times 10^{-10}$ & $1 \times 10^{-8}$ & (SERNE et al., 1992) \\
\hline & $\mathrm{Tc}(\mathrm{IV})$ & any cement/grout & $5 \times 10^{-12}$ (guess) & $5 \times 10^{-11}$ (guess) & \\
\hline \multirow{2}{*}{$\mathrm{Cr}$} & $\mathrm{Cr}(\mathrm{VI})$ & any cement/grout & $5 \times 10^{-11}$ & $5 \times 10^{-10}$ (guess) & (SERNE et al., 1992) \\
\hline & $\mathrm{Cr}(\mathrm{III})$ & any cement/grout & $1 \times 10^{-12}$ (guess) & $1 \times 10^{-11}$ (guess) & \\
\hline \multirow{4}{*}{$\mathrm{Hg}$} & $\mathrm{Hg}(\mathrm{I})$ free & any cement/grout & $1 \times 10^{-11}$ (guess) & $1 \times 10^{-10}$ (guess) & \\
\hline & $\mathrm{Hg}(\mathrm{II})$ free & any cement/grout & $1 \times 10^{-11}$ (guess) & $1 \times 10^{-10}$ (guess) & \\
\hline & $\mathrm{Hg}(\mathrm{I})$ (insoluble salt) & any cement/grout & $1 \times 10^{-12}$ (guess) & $1 \times 10^{-11}$ (guess) & \\
\hline & $\mathrm{Hg}(\mathrm{Ii})$ (insoluble salt) & any cement/grout & $1 \times 10^{-12}$ (guess) & $1 \times 10^{-11}$ (guess) & \\
\hline \multirow{4}{*}{$\mathrm{U}$} & $\mathrm{U}(\mathrm{VI})$ & fresh cement/grout & $1 \times 10^{-12}$ & $1 \times 10^{-11}$ (guess) & (SERNE et al., 1992) \\
\hline & $\mathrm{U}(\mathrm{IV})$ & fresh cement/grout & $1 \times 10^{-13}$ (guess) & $1 \times 10^{-12}$ (guess) & \\
\hline & $\mathrm{U}(\mathrm{VI})$ & aged cement/grout & $1 \times 10^{-11}$ (guess) & $1 \times 10^{-10}$ (guess) & \\
\hline & $\mathrm{U}(\mathrm{IV})$ & aged cement/grout & $1 \times 10^{-12}$ (guess) & $1 \times 10^{-11}$ (guess) & \\
\hline
\end{tabular}




\subsection{Iodine Release From Secondary Waste}

The radionuclide ${ }^{129} \mathrm{I}$ is a key contaminant of concern because of its mobility in Hanford sediments and long half-life (MANN et al., 2001). A key factor affecting the distribution of ${ }^{129} \mathrm{I}$ in waste to be disposed in the IDF is volatilization during waste form processing. Mann et al. (MANN et al., 2003a) have estimated that as much as $100 \%$ of the ${ }^{129}$ I sent to the WTP or to supplemental treatment processes may be volatilized, captured in off-gas treatment systems, and sent to secondary waste treatment. Secondary waste streams are assumed to be encapsulated in a grouted waste form as Category 3 low-level waste (LLW) or mixed low-level waste (MLLW). Because the impact to groundwater from secondary waste was found to be much higher than calculated impacts for the other waste forms (e.g., ILAW and the proposed alternative waste technologies) disposed in the IDF (MANN et al., 2003b), it is important to develop the input data to assess ${ }^{129}$ I release rates from secondary waste. Unfortunately, no process-specific work has been performed to characterize the chemical form of ${ }^{129}$ I that would be sent to secondary waste treatment nor have ${ }^{129}$ I release studies been performed on secondary waste forms. Hence, the objective of this section is to review the available literature on iodine release from cementitious waste forms to provide recommendations for release modeling and the required input parameters. We begin with a brief overview of key chemical processes important in production of cementitious waste forms.

\subsubsection{Literature Review}

Although the literature on leaching of cementitious waste forms is extensive, studies specific to iodine are relatively sparse. Atkinson and Nickerson (1988) performed such tests using a pure Portland cement mixed with distilled water at a cement to water ratio of 0.4 . The reacted solids were cured for 2 days at room temperature and then for an additional 3 days at $56^{\circ} \mathrm{C}$. The batch $K_{d}$ for iodide was determined on crushed cement equilibrated with cement-equilibrated water $(\mathrm{pH} \sim 12.5)$. The $K_{d}$ for iodide was measured as a function of time at room temperature, solid particle size used, solid-to-solution ratio, and initial concentration of the iodide added. The behavior of the iodide was rather complicated in comparison to $\mathrm{Sr}$ and $\mathrm{Cs}$. The data suggested that the adsorption was highly dependent on the concentration of iodide present (non-linear isotherm), time (kinetics) and particle size of the crushed cement. The calculated capacity factor term, see Equation (18) and (19), varied from 3 to 2000 as the effective iodide concentration in the "equilibrium" solution in contact with the crushed cement decreased from $10^{-2}$ to $10^{-8} \mathrm{M}$. On a positive note, the iodide desorption $\mathrm{K}_{\mathrm{d}}$ appeared to be the same as the adsorption $\mathrm{K}_{\mathrm{d}}$ within experimental error so that adsorption was reversible.

Atkinson and Nickerson (1988) also performed diffusion tests on a slab of cement (5 mm thick) placed between two reservoirs of water; one reservoir was filled with a known concentration of iodide $\left(10^{-4} \mathrm{M}\right.$ as $\left.\mathrm{KI}\right)$ and the other reservoir with no iodide. The appearance of radioiodide in the clean reservoir was monitored as a function of time. From this type of test method, one can estimate both the intrinsic diffusion coefficient, $D_{i}$, and the capacity factor, $\alpha$, from the results. The steady state flux into the second reservoir is related to the physical term, $\mathrm{D}_{\mathrm{i}}$ and the rate of build up of contaminant in the second reservoir is related to the chemical term. Again, the capacity term was found to be highly sensitive to the amount of iodide present. At high concentrations or more correctly mass amounts, there was little interaction between the iodide and the cement so that the capacity term was about the same as the porosity $(0.3)$. The intrinsic diffusion coefficient for a case with high iodide mass being present varied from 0.7 to $1.2 \times 10^{-7} \mathrm{~cm}^{2} \mathrm{~s}^{-1}$. For the case where the initial iodide concentration in the "hot" reservoir was $10^{-4} \mathrm{M}$, the chemi- 
cal capacity term, $\alpha$, was found to be 2.6 and the intrinsic diffusion coefficient was $0.5 \times 10^{-7}$ $\mathrm{cm}^{2} \mathrm{~s}^{-1}$. The chemical capacity term at 2.6 is much lower than the value (30) calculated from the batch $K_{d}$ methodology for an equilibrium solution concentration of $10^{-4} \mathrm{M}$ iodide.

In a third type of test, Atkinson and Nickerson (1988) ran diffusion experiments on 50-mmdiameter by 10 -mm-thick pucks with the cylindrical edges coated with epoxy such that only the circular (axial) faces were exposed to contaminant-laden $\left[10^{-4} \mathrm{M}\right.$ iodide] equilibrated-cement water $\left[200 \mathrm{~mL}\right.$ ] for between 17 and 53 days. The test was performed at $30^{\circ} \mathrm{C}$ with the water stirred continuously. The change in radioiodide tracer with time in the solution was monitored. After the stated time periods, the contaminant laden solution was replaced by fresh equilibrated cement porewater and the out diffusion of iodide was monitored in the replacement solution versus time. Iodide results from this test yielded a capacity factor of 30 for iodide while diffusing into the cement and the resultant physically controlled instrinsic diffusion coefficient was $1.5 \times 10^{-7} \mathrm{~cm}^{2} \mathrm{~s}^{-1}$.

A final experiment was performed by Atkinson and Nickerson (1988) where the penetration profile was measured on a 50-mm-diameter by 45-mm "rod" of cement coated with epoxy on all but one of the cylindrical faces that was then submerged in iodide laden cement equilibrated solution $\left[10^{-4} \mathrm{M}\right.$ iodide] for 21 days at $25^{\circ} \mathrm{C}$. At the end of 21 days, the rod was sectioned into fine slices. Each slice was ground and the activity of ${ }^{131}$ I tracer was measured as a function of depth from the face. The iodide data for this test methodology was difficult to interpret because the penetration profile showed nearly constant iodide concentrations through the first $5 \mathrm{~mm}$ and then a rapid drop to zero. The highly non-linear nature of iodide sorption was assumed to be the cause of the atypical penetration profile. The data could not be fit to a simple diffusion model and so no valid diffusion parameters were obtained from this test.

Atkinson and Nickerson (1988) conclude that most contaminants solidified into cementitious waste forms do not abide by the assumptions used in simple diffusion models. The sorption processes of most contaminants do not conform to the simple conceptual models and mathematical models available. Thus only relatively crude agreement should be expected between the results of different testing methodologies. For the particular case of iodide, the authors believe that the factor of 20 difference in capacity factor (the chemical portion of the transport) is caused by a combination of the non-linear adsorption properties and the presence of two types of porosity within cement, a relatively low fraction of well connected "fast" and a larger portion of more restricted porosity "slow." Other rocks such as granite also exhibit this dual porosity. Atkinson and Nickerson (1988) recommended an intrinsic diffusion coefficient for pure Portland cement be set at $9 \pm 2 \times 10^{-12} \mathrm{~m}^{2} \mathrm{~s}^{-1}$ and the chemical capacity term at $35 \pm 15$ for iodide when present at $<$ $10^{-4} \mathrm{M}$ in solution. 
Table 14. Average Leach Rate of Four Iodine Bearing Salts From Portland Cement

\begin{tabular}{|c|c|c|c|c|}
\hline Salt & Initial & After 311 days & $\mathbf{D}_{\mathbf{e}}$ & $\mathbf{\mathbf { D } _ { \mathbf { e } }}$ \\
\hline Type & $\mathbf{c m} / \mathbf{d a y}$ & $\mathbf{c m} / \mathbf{d a y}$ & $\mathbf{c m}^{2} / \mathbf{d a y}$ & $\mathbf{c m}^{2} / \mathbf{s}$ \\
\hline $\mathrm{Ba}\left(\mathrm{IO}_{3}\right)_{2}$ & $6 \times 10^{-3}$ & $2 \times 10^{-6}$ & $6 \times 10^{-7}$ & $6.9 \mathrm{E}-12$ \\
\hline $\mathrm{Pb}\left(\mathrm{IO}_{3}\right)_{2}$ & $5 \times 10^{-2}$ & $2 \times 10^{-6}$ & $9 \times 10^{-7}$ & $1.0 \mathrm{E}-11$ \\
\hline $\mathrm{Cu}\left(\mathrm{IO}_{3}\right)_{2}$ & $3 \times 10^{-2}$ & $3 \times 10^{-6}$ & $6 \times 10^{-7}$ & $6.9 \mathrm{E}-12$ \\
\hline $\mathrm{PbI}_{2}$ & $3 \times 10^{-2}$ & $2 \times 10^{-5}$ & $2 \times 10^{-5}$ & $2.3 \mathrm{E}-10$ \\
\hline
\end{tabular}

Kalinin et al. (1983) solidified large quantities (9 wt. \%) of individual iodate and iodide salts $(\mathrm{Ba}, \mathrm{Pb}, \mathrm{Cu})$ into pure Portland cement and leached the resultant solids in distilled water. Iodate and/or iodine in the leachates were determined as a function of time and solution replacement frequency. The distilled water reacted with the cement solids to form a very alkaline $\mathrm{pH}$ system (11 to 12 , with long time average $\sim 11$ ). The leach rates $(\mathrm{R})$ of iodate and iodide were calculated and are shown in Table 14. The data in Table 14 shows the typical cement leaching trends where the rate for the first several days to a few weeks is larger than the leach rates after a few months to several years. Within experimental error, the authors suggest that initially only the barium iodate form leaches differently (more slowly) than the other forms. After about one year, all the iodate and iodide salts are leaching almost one hundred to one thousand times slower than the original leach rate. The lead iodide salt "instantaneous" leach rate after one year is about ten times faster than for the iodate salts. These data can be converted to apparent diffusion leach rates in the vein of the ANS16.1 protocol to produce effective diffusion coefficient values that can be used in long term PA calculations. The apparent diffusion coefficients for the year long test results have been converted in the fourth and fifth column of Table 14. The relevance of these data to secondary waste streams generated from vitrification processes at Hanford is unclear; these waste streams would contain orders of magnitude lower iodine concentrations than was used in this study and may have very low concentrations of heavy metals (barium, lead, or copper). The magnitude of the effective diffusivities is near those assumed in the IDF Risk Assessment (MANN et al., 2003a) but orders of magnitude smaller than those measured by Atkinson and Nickerson (1988).

Clark (1977) solidified iodate liquid wastes by first forming insoluble barium iodate (mixing iodic acid $\left[\mathrm{HIO}_{3}\right]$ with a slight excess of barium hydroxide), then mixed the resultant slurry (salt plus water formed upon mixing the acid and base) with Portland cement [Type I] at water to cement ratios of 0.76 to 0.87 . The final hardened cements contained between 2.9 to $9.07 \%$ wt iodine. After curing in closed containers maintained at $100 \%$ relative humidity [water saturated], the hardened waste forms [5-cm diameter by $5-\mathrm{cm}$ height] were leached in $300 \mathrm{~mL}$ DIW using a variant of the IAEA intermittent solution replacement test (HESPE, 1971). Leach tests were performed for up to 500 days with solution replacement starting with daily increments and ending with 28-day replacement increments.

The experimental data showed some deviation from the simple diffusion theory but the deviation (a slowing in cumulative mass leached versus square root of time) is observed in most leaching data for cement solidified waste. Clark (1977) presents two plots with the leach data however no effective diffusion coefficients are derived and when one takes data off the plots to 
calculate the effective diffusion coefficient the values are not realistic; values are at least four orders of magnitude too large. If we assume that the authors inverted their scale correction noted in the manuscript (they claim to have reduced the values on the Y axis by a factor of 100) such that the true scale correction should have been that they increased the values by 100 , then the effective diffusion coefficients calculated seem reasonable. Clark's data suggest that the leaching of iodate from solidified cement waste forms is dependent on the concentration of barium iodate salt present in the solid cement. For iodide concentrations between 5.4 and $11.9 \mathrm{wt} \%$ the leach rate is similar but for cements containing only $2.9 \% \mathrm{wt}$ iodate the leaching is significantly lower. For the higher range of iodide the effective diffusion coefficient (assuming our correction to the plotted data is accurate) was $3.6 \times 10^{-10} \mathrm{~cm}^{2} \mathrm{~s}^{-1}$ and for the cement that contained only $2.9 \% \mathrm{wt}$ iodate the corrected effective diffusion coefficient was $3.6 \times 10^{-11} \mathrm{~cm}^{2} \mathrm{~s}^{-1}$. These values seem reasonable for an moderately insoluble salt solidified into pure cement. The effective diffusion coefficient for barium iodate solidified into pure Portland cement Type I in Clark (1977) for high loading of iodine species is 60 times larger than the value found by Kalinin et al. (1983) for similarily high loadings. We suspect that the rather high water to solids ratio (0.8) used by Clark (1977) might account for some of the higher release, although no water to solids ratio information is available in Kalinin et al. (1983). In most instances a water to solids ratio of 0.4 to 0.6 by weight is more common.

Scheele et al. (1984) also solidified various iodine bearing salts in Portland Type III cements using a ratio of $1 \times 10^{-3} \mathrm{M}$ of iodine per gram of dry cement and a water to cement ratio of 0.3 . This is an effective loading of $\sim 13 \mathrm{wt} \%$, orders of magnitude higher than will occur in the secondary wastes disposed in the IDF. The article does not present quantitative information such as apparent diffusion coefficients that are readily usable for long-term PA calculations. Both static and modified IAEA tests (intermittent solution replenishment tests) using distilled water and in a few cases Columbia River and seawater were performed for up to 120 days. All the specimens show the typical trend of faster leach rates for the first several days to a few weeks and then a dramatic slowing down. Using some static leach test data, the authors suggest the best form of sequestering iodine is as AgI and that if solidified in a 55-g drum, only $1 \%$ of the iodide would be leached in 4,000 years. In other tests using barium and calcium iodate as the iodide product and dynamic leach tests where solutions are changed out, dynamic leaching was a factor of ten faster than static leaching. It would take 5 years for $1 \%$ of the iodine to be leached from this "scenario." The overall conclusions presented by the authors include "there is a considerable difference in the leach resistance among various iodine compounds in Portland cement, silver iodide showed the best leach resistance."

Toyohara et al. $(2000 ; 2002)$ used batch adsorption tests wherein various mixtures of calcium solids and alumina cement were hydrated and cured and then ground up. The crushed aluminacalcium "cement" product was then contacted with solutions with various concentrations of dissolved potassium iodide. A standard batch $K_{d}$ adsorption test was then performed to see which ground up "cement" removed the most iodide. The solid-to-solution ratio for the batch adsorption test was 1 part crushed cement to 10 parts iodide bearing solution. Initial iodide concentrations varied from $10^{-1}$ to $10^{-8} \mathrm{M}$. The contact time was 7 days, with shaking twice a day, at $25^{\circ} \mathrm{C}$ in most cases and $35^{\circ} \mathrm{C}$ for evaluating the effects of temperature. The leachates were filtered through 0.45 -micron membranes and iodide was measure by ICP-OES for tests where total I was $10^{-4} \mathrm{M}$ and higher and gamma counting of the radiotracer ${ }^{125} \mathrm{I}$ at the lower concentrations. Container and filter adsorption was determined to be variable but low 0.2 to $8 \%$ such that no correc- 
tions were made to the equation used to calculate the $K_{d}$. Note that this is not a very wise choice for situations where total adsorption is low and where $8 \%$ of the adsorbate is removed by the container walls and filters. The authors found that a mixture of 100 parts of alumina cement and 15.5 parts of gypsum $\left[\mathrm{CaSO}_{4} \cdot 2 \mathrm{H}_{2} \mathrm{O}\right]$ mixed with water at a ratio of two parts dry blend to one part water yielded the best solidification formulation. This formulation gave an iodide $K_{d}$ value of $200 \pm 20 \mathrm{~mL} \mathrm{~g}^{-1}$. The second paper also shows that the iodide adsorption is reversible when iodide-contacted crushed alumina cement was rinsed in fresh distilled water. Although the high $K_{d}$ is encouraging for iodine retention, the applicability of the information in these two manuscripts to the IDF PA is tenuous. Alumina cement is a mix of the oxides shown in Table 15 and is used commonly in Japan. The cement is highly enriched in alumina and significantly deficient in calcium oxide and silica in comparison to Portland cement. Unless the Hanford contractors widen formulations to be considered for secondary waste to include alumina cement mixtures the results indicated in this paper are not transferable.

Toyohara et al. $(2000 ; 2002)$ also describe detailed XRD and SEM characterization of the reaction products that suggest that the iodide substitutes for a hydroxyl into the structure of a tetracalcium aluminum hydrate $\left(4 \mathrm{CaO} \cdot \mathrm{Al}_{2} \mathrm{O}_{3} \cdot 13 \mathrm{H}_{2} \mathrm{O}\right)$ to form $\left(3 \mathrm{CaO} \cdot \mathrm{Al}_{2} \mathrm{O}_{3} \cdot \mathrm{CaI}_{2} \cdot 12 \mathrm{H}_{2} \mathrm{O}\right)$. The articles also described physical stability testing to ensure that the solidified product is mechanically robust. The detailed solid phase characterization is a valuable tool to use in attempting to elucidate the chemical reactions that control the removal of iodide from solution.

Bonhoure et al. (2002) used state-of-the-art X-ray absorption spectroscopy to study the molecular bonding environment of iodide and iodate with solids present in hardened cement paste (C-S-H gels) and one more crystalline end member of the gels, calcium silica hydrate. One technique that allows interrogation of the valence state of the sequestered iodine species showed that iodide remained iodide and iodate remained iodate upon their being sequestered in pure Portland cement or onto the calcium silica hydrate. No oxidation or reduction reactions changed the iodine speciation. Using a second technique, extended X-ray absorption fine structure (EXAFS) that interrogates the nearest neighbor atoms around the probed atom, it was found that the iodide EXAFS spectra were too weak to deconvolute any meaningful data. For the iodate, EXAFS shows the iodine-oxygen bonds within the iodate species $\left[\mathrm{IO}_{3}{ }^{-}\right]$remained typical of the bond lengths observed for iodate in aqueous solutions. Thus, no significant structural changes seem to occur when iodate is sequestered into the cement solids. This type of molecular probing of contaminants associated with solids may prove essential at determining the chemical processes that control the long-term fate of contaminants incorporated into cementitious waste forms. As the techniques evolve and instrumentation becomes more sensitive, our understanding of these complex interactions may progress at a faster pace and also become less expensive.

In an attempt to elucidate the chemical mechanisms that cause iodine species to associate with cementitious solids, Atkins et al. (1988) prepared iodide and iodate bearing cements. They used two types of cements, ordinary Portland cement Type I and a "grout" mix of 85\% blast furnace slag and $15 \%$ Portland cement Type I. Both dry blends were mixed with the iodine containing water (1300 $\mathrm{mg} \mathrm{L}^{-1}, 0.01 \mathrm{M}$ iodine as iodide and iodate from potassium salts) at a ratio of 0.5 solid to water ratio. The porewater of the curing solids were squeezed out at various times (tens 
of days to 300 days) and the speciation of dissolved iodine was measured. For the tests where iodide was originally present, iodide remained the species in the pore fluids regardless of which dry blend was used as a solidification agent. In other work referenced in the paper, a $10^{-4} \mathrm{M}$ solution of $\mathrm{KI}$ at $\mathrm{pH}=13$ was subjected to tens times normal oxygen concentrations and after four months no iodide had been oxidized to iodate as "theoretical" Eh-pH diagrams suggest could occur. Thus in the short term (months to a few years) the iodide oxidation at room temperature by dissolved oxygen does not appear to be kinetically favorable. After 300 days of curing, the iodide originally present is largely removed from the pore solution by reaction with the solids. For the pure Portland cement system, $\sim 98 \%$ of the added iodide is removed from the dissolved state and $\sim 77 \%$ is removed from the blast furnace slag "grout" system.

Thermodynamic calculations using the measured iodide concentrations and estimated concentrations of dissolved metals (silver, mercury and lead) suggest that no pure phase iodide compounds were likely forming. The removal of the iodide from solution must have been by incorporation into secondary mineral structures or adsorption. Adsorption seems unlikely because most mineral surfaces have a net negative charge at these high $\mathrm{pH}$ values. Perhaps the iodide anion is substituting for sulfate in cement forming minerals. Höglund et al. (1985) also found that pure Portland cement removed more iodide from solution than slag based cements in adsorption tests. No mechanisms that could explain the observations were apparent. Iodate added to the blast furnace slag cement was converted to iodide likely by reduction from dissolved sulfide. The tests with iodate doped pure Portland cement did not yield useable results because of detection limit problems. Iodate is readily removed from solution by both solidification agents (99\% removed by pure Portland cement and $86 \%$ removed by the blast furnace slag blend). At the high concentration of iodate used in the tests, precipitation of alkaline-earth iodates might have occurred initially but for waste solidification of more dilute iodine bearing wastes such direct precipitation is unlikely. Again, co-precipitation (incorporation of iodine species for another more common anion) into cement forming minerals is the more realistic process. Adsorption is another possibility but the surfaces of most minerals would tend to repel anions at the $\mathrm{pH}$ conditions in "young" cement.

Atkins et al. (1988) also performed adsorption tests using two "minerals," hydrotalcite and calcium silicate hydrogel. The former is the most abundant solid that forms as blast furnace slag blend hydrates and the latter forms when Portland cement hydrates. Hydrotalcite does adsorb anions, including carbonate and hydroxide. Hydrotalcite "adsorbed" less than $20 \%$ of either iodide or iodate when present at $\sim 10^{-3} \mathrm{M}$ and less than $5 \%$ was "adsorbed" when the iodine species concentration was $10^{-5} \mathrm{M}$. The calcium silicate hydrogel also did not adsorb much iodide present at the same concentrations after 14 to 42 days of contact. However, the calcium silicate hydrogel did "adsorb" iodate (when present between $10^{-4}$ and $10^{-3} \mathrm{M}$ ) perhaps via precipitation of calcium iodate. In practical waste solidification scenarios, iodate concentrations may never reach these values so direct precipitation (at least with $\mathrm{Ca}^{2+}$ ) is less likely. The authors also conclude, in agreement to the X-ray absorption spectroscopy studies of Bonhoure et al. (2002), that no oxidation-reduction reactions at the surfaces of the solids change the speciation of the iodide to iodate or vice-versa. 
It can be concluded from this and most of the other cited studies that iodide-iodate release from cement-containing solidification products is not well understood in terms of the underlying chemical reactions that cause iodine species to disappear from the pore fluids as the solids form during hydration of the dry blend. As a corollary, it is also not well understood what will happen to the sequestered iodine species as the solids continue to evolve and weather from further contact with recharge water, the gases in the partially saturated pores and with the vadose zone sediments.

Further, it would appear that solidification of free iodine species (soluble iodate or iodide) into pure Portland cement does not sequester the iodine species adequately unless perhaps the concentration of total iodine (stable and radioactive) is at trace concentrations $\left(<10^{-5} \mathrm{M}\right)$ in the waste stream. If the total iodine concentrations in the waste stream are greater we recommend that some pre-treatment to form a sparingly soluble salt be performed. One recommended salt is barium iodate. It is not clear whether barium iodide would be sequestered as readily as barium iodate, therefore some redox manipulation might be required. However, as shown by Atkins et al. (1988), if one solidifies aqueous solutions of iodate in a grout mixture that contains blast furnace slag iodate may be reduced to iodide by the sulfur species in the slag. Thus the pretreatment step to form insoluble barium iodates prior to solidification may be counteracted by using a dry blend that contains significant reductants (i.e., blast furnace slag). No one has studied the iodine speciation for insoluble salts being solidified into grout blends with significant masses of reductants, such as blast furnace slag. Thus it might be possible that iodate bound in an insoluble salt such as barium iodate may not be reduced to iodide.

\subsubsection{Iodine Parameter Recommendations}

In summary, the review of available literature has limited information on which one can make defensible recommendations on how to parameterize a release model for iodine species from cementitious waste forms. We recommend that experimental activities be started as soon as possible to determine a good waste form for secondary waste. One key technical issue will be whether the iodine species in the secondary waste stream should first be converted to an insoluble salt such as barium iodate before cement/grout solidification to assure adequately low releases from the waste form. Once representative types of solid waste has been prepared with iodine species (both aqueous (free) iodine species and insoluble iodine salts), laboratory experiments that combine leaching/diffusion techniques and detailed pre- and post-leach test solid phase characterization should be undertaken. Some added details on a rational testing and complementary geochemical and mass transport modeling efforts are found in McGrail et al. (2003). 
To accommodate the immediate need for parameters to allow computations of the impact from secondary waste for the 2005 IDF PA, we suggest using the results from Atkinson and Nickerson (1988) as representing upper bound or conservative values for effective diffusion coefficients, especially for waste forms containing only free iodide species. Their experiments were conducted with ordinary Portland cement and had no additives that could potentially attenuate iodine release rates. Effective diffusion coefficient values for waste forms in which the iodine species are first converted to an insoluble salt are represented by the data presented in Kalinin et al. (1983) and Clark et al. (1977) where iodine releases may have been attenuated by formation of sparingly soluble iodide or iodates are also shown in Table 16 and they are closer to the values used in the recent IDF Risk Assessment (MANN et al., 2003a). It should be noted that the mass of iodine species loaded into cement or grout impacts the leaching. Higher loadings of iodine species appears to release the iodine at faster rates, perhaps indicative of the non-linear adsorption effects of the minerals formed in the cement/grout gel. As a sensitivity case, we also recommend calculating iodine release rates that are controlled at a fixed concentration determined from the solubility product of silver iodide $\left(\mathrm{K}_{\mathrm{sp}}=9 \times 10^{-17}\right)$. Table 16 gives estimates of the conservative, most probable, and sensitivity case values.

Table 16. Recommended Values to Use in Simple Diffusion Controlled Release Conceptual Models for Iodine Solidified in Cement and Solubility-limited Release Model

\begin{tabular}{|l|c|}
\hline \multicolumn{1}{|c|}{ Diffusivity Values } & $\boldsymbol{D}_{\boldsymbol{e}} \mathbf{( \mathbf { c m } ^ { 2 } / \mathbf { s } )}$ \\
\hline $\begin{array}{l}\text { Conservative and/or Soluble Iodine (no attempts to sequester I be- } \\
\text { fore solidification) }\end{array}$ & $2.6 \times 10^{-9}$ \\
\hline $\begin{array}{l}\text { Iodine insoluble salt (e.g., barium iodate) } \\
\text { fied }\end{array}$ & $5 \times 10^{-11}$ \\
\hline \multicolumn{1}{|c|}{ Solubility Values } & Moading and then solidi- \\
\hline $\begin{array}{l}\text { Iodine insoluble salt (e.g., barium iodate) formed and then solidi- } \\
\text { fied. }<3 \% \text { loading }\end{array}$ & $3 \times 10^{-11} \mathrm{M}$ \\
\hline Solubility & $1 \times 10^{-8} \mathrm{M}$ \\
\hline
\end{tabular}

${ }^{(a)}$ value is geometric mean of Kalinin et al. (1983) and Clark (1977) for high iodate loading 


\subsection{Conclusion}

In this report, a large body of data is presented on the corrosion behavior of three prototypic simulant glasses for LAW: LAWA44, LAWB45, and LAWC22. In addition to these three simulant glass compositions, PUF test results on two glasses, LAWAN102 and LAWAP101, made with actual Hanford tank waste are also discussed. Four test methods; SPFT, PUF, PCT, and microbial degradation experiments, were used in combination to examine the corrosion behavior of the glass over a wide range of conditions.

Results from these experiments were used to develop the parameters necessary to conduct long-term PA calculations using the STORM reactive transport computer code. Table 17 provides the recommended parameters for three simulant glasses, plus LAWBP1 for comparison (2001a). Recommended values for the diffusion- and solubility-controlled release of key contaminants of concern from solidified cementitious secondary waste forms were derived from literature sources and are provided in Section 6.3, Table 13, and Table 16. Caution is advised on using generic literature values because of the wide variability in release data for contaminants of concern solidified in cement/grout. Therefore, the authors recommend that activities be initiated to generate IDF site-specific data on the release of these contaminants from secondary waste solidified in cement or grout waste forms. This site specific data will be a critical component in the evaluation of how secondary waste will impact contaminant release rates from the IDF.

Table 17. Summary of Best Estimate Rate Law Parameters for LAWA44, LAWB45, and LAWC22 Glasses at $15^{\circ} \mathrm{C}$.

\begin{tabular}{|c|c|c|c|c|c|c|}
\hline Parameter & Meaning & LAWABP1 & LAWA44 & LAWB45 & LAWC22 & Comments \\
\hline$\vec{k}$ & $\begin{array}{l}\text { forward rate } \\
\text { constant }\left(\mathrm{g} \mathrm{m}^{-2} \mathrm{~d}^{-1}\right)\end{array}$ & $3.4 \times 10^{6}$ & $1.3 \times 10^{4}$ & $1.6 \times 10^{4}$ & $1.0 \times 10^{5}$ & \\
\hline$K_{q}$ & $\begin{array}{l}\text { apparent equilibrium } \\
\text { constant for glass } \\
\text { based on activity } \\
\text { product } \mathrm{a}\left[\mathrm{SiO}_{2}(\mathrm{aq})\right]\end{array}$ & $4.9 \times 10^{-4}$ & $5.45 \times 10^{-4}$ & $5.24 \times 10^{-4}$ & $5.25 \times 10^{-4}$ & \\
\hline$\eta$ & $\begin{array}{l}\text { pH power law } \\
\text { coefficient }\end{array}$ & 0.35 & $0.49 \pm 0.08$ & $0.34 \pm 0.03$ & $0.42 \pm 0.02$ & \\
\hline$E_{a}$ & $\begin{array}{l}\text { activation energy of } \\
\text { glass dissolution } \\
\text { reaction }\left(\mathrm{kJ} \mathrm{mol}^{-1}\right)\end{array}$ & 68 & $60 \pm 7$ & $53 \pm 3$ & $64 \pm 2$ & \\
\hline$\sigma$ & Temkin coefficient & 1 & 1 & 1 & 1 & $\begin{array}{l}\text { Assigned } \\
\text { constant }\end{array}$ \\
\hline$r_{x}$ & $\begin{array}{l}\text { Na ion-exchange rate } \\
\left(\mathrm{mol} \mathrm{m}^{-2} \mathrm{~s}^{-1}\right)\end{array}$ & $3.4 \times 10^{-11}$ & $5.3 \times 10^{-11}$ & 0 & $1.2 \times 10^{-10}$ & $\begin{array}{l}\text { No detectable } \\
\text { ion exchange } \\
\text { rate for } \\
\text { LAWB45 }\end{array}$ \\
\hline
\end{tabular}




\subsection{References}

Aagaard, P. and H. C. Helgeson. 1982. "Thermodynamic and Kinetic Constraints on Reaction Rates Among Minerals and Aqueous Solutions. I. Theoretical Considerations." Am. J. Sci. 282:237-285.

Albenesius, E. L. 2001. Computer Modeling of Saltstone Landfills by Intera Environmental Consultants. DPST-83-529, Savannah River Site, Aiken, South Carolina.

Alt, J. C. and P. Mata. 2000. "On the Role of Microbes in the Alteration of Submarine Basaltic Glass: A TEM Study." Earth Planet. Sci. Let. 181:301-313.

Angus, M. J. and F. P. Glasser. 1985. "The Chemical Environment in Cement Matrices." Mat. Res. Soc. Symp. Proc. 50:547-556.

ASTM. 1994. Standard Test Methods for Determining Chemical Durability of Nuclear Waste Glasses: The Product Consistency Test (PCT). ASTM C1285, American Society for Testing and Materials, Philadelphia, Pennsylvania.

ASTM. 2002. Standard Practice for Evaluating Microbial Susceptibility of Nonmetallic Materials by Laboratory Soil Burial. G160-98, ASTM International, West Conshohocken, Pennsylvania.

Atkins, M., A. N. Beckley, and F. P. Glasser. 1988. "Influence of Cement on the Near-Field Environment and Its Specific Interactions with Uranium and Iodine." Radiochim. Acta 44-5:255261.

Atkins, M. and F. P. Glasser. 1992. "Application of Portland-Cement-Based Materials to Radioactive Waste Immobilization." Waste Management 12:105-131.

Atkinson, A. and A. K. Nickerson. 1988. "Diffusion and Sorption of Cesium, Strontium, and Iodine in Water-Saturated Cement." Nuc. Tech. 81(1):100-113.

Atkinson, A., N. M. Everitt, and R. M. Guppy. 1989. "Time Dependence of $\mathrm{pH}$ in a Cementitious Repository." Mat. Res. Soc. Symp. Proc. 127:439-446.

Bacon, D. H., B. P. McGrail, V. L. Freedman, G. Ventura, P. Risoluti, and K. M. Krupka. 2002. "Performance Assessment of Low-Level Waste Disposal Facilities Using Coupled Unsaturated Flow and Reactive Transport Simulators." Mat. Res. Soc. Symp. Proc. 713:267-274.

Berner, U. R. 1992. "Evolution of Pore Water Chemistry During Degradation of Cement in a Radioactive Waste Repository." Waste Management 12:201-219.

Bonhoure, I., A. M. Scheidegger, E. Wieland, and R. Dahn. 2002. "Iodine Species Uptake by Cement and CSH Studied by I K-edge X-ray Absorption Spectroscopy." Radiochim. Acta 90(911):647-651.

Bradbury, M. H. and F. A. Sarott. 1995. Sorption Databases for the Cementitious Near Field of a L/ILW Repository for Performance Assessment. CH-5232, PSI Bericht 95-06, Paul Scherrer Institut, Villigen PSI, Switzerland.

Bradbury, M. H. and L. R. Van Loon. 1998. Cementitious Near-Field Sorption Data Bases for Performance Assessment of a L/ILW Repository in a Palfris Marl Host Rock. CEM-94: Update I. CH-5232, PSI Bericht. 98-01, Paul Scherrer Institut, Villigen PSI, Switzerland. 
Bray, P. J., S. A. Feller, G. E. Jellison, and Y. H. Yun. 1980. "B-10 NMR-Studies of the Structure of Borate Glasses." J. Non-Cryst. Solids 38-9(MAY-):93-98.

Bunker, B. C. 1987. "Waste Glass Leaching: Chemistry and Kinetics." Mat. Res. Soc. Symp. Proc. 84:493-507.

Bunker, B. C., D. R. Tallant, T. J. Headley, G. L. Turner, and R. J. Kirkpatrick. 1988. "The Structure of Leached Sodium Borosilicate Glass." Phys. Chem. Glasses 29(3):106-120.

Clark, W. E. 1977. "The Isolation of Radioiodine with Portland Cement. Part I: Scoping Leach Studies." Nuc. Tech. 36:215-221.

Cook, J. R. 2000. Radiological Performance Assessment for the E-Area Vaults Disposal Facility. WSRC-RP-94-0218, Savannah River Site, Aiken, South Carolina.

Criscenti, L. J., R. J. Serne, K. M. Krupka, and M. I. Wood. 1996. Predictive Calculations to Assess the Long-Term Effect of Cementitious Materials on the pH and Solubility of Uranium(VI) in a Shallow-Land Disposal Environment. PNNL-11182, Pacific Northwest National Laboratory, Richland, WA.

Dell, W. J., P. J. Bray, and S. Z. Xiao. 1983. "B-11 NMR-Studies and Structural Modeling of $\mathrm{Na}_{2} \mathrm{O}-\mathrm{B}_{2} \mathrm{O}_{3}-\mathrm{SiO}_{2}$ Glasses of High Soda Content." J. Non-Cryst. Solids 58(1):1-16.

Dove, P. M. 1994. "The Dissolution Kinetics of Quartz in Sodium Chloride Solutions at $25^{\circ} \mathrm{C}$ to 300C." Am. J. Sci. 294:665-712.

Ehrlich, H. L. 1996. "How Microbes Influence Mineral Growth and Dissolution." Chem. Geol. 132:5-9.

Ewart, F. S., S. W. Pugh, and D. Woodwark. 1988. Chemical and Microbiological Effects in the Near-Field: Current Status. Report NSS/G103, U.K. Nirex Ltd., Hartwell, United Kingdom.

Fayer, M. J. and J. E. Szecsody. 2004. Recharge Data Package for the 2005 Integrated Disposal Facility Performance Assessment. PNNL-14744, Pacific Northwest National Laboratory, Richland, Washington.

Grimmer, A. R., F. Vonlampe, and M. Magi. 1986. "Solid-State High-Resolution Si-29 MAS NMR of Silicates with Sixfold Coordinated Silicon." Chem. Phys. Letters 132(6):549-553.

Hespe, E. D. 1971. Leach Testing of Immobilized Radioactive Waste Solids: A Proposal for a Standard Method. In Atomic Energy Review, Vol. 9, pp. 195-207. International Atomic Energy Agency, Vienna, Austria.

Höglund, S., L. Eliasson, B. Allard, K. Andersson, and B. Torstenfelt. 1985. "Sorption of Some Fission Products and Actinides in Concrete Systems." Mat. Res. Soc. Symp. Proc. 50:683-690.

IAEA. 1993. Improved Cement Solidification of Low- and Intermediate-Level Radioactive Wastes. Technical Reports Series No. 350, International Atomic Energy Agency (IAEA), Vienna.

Icenhower, J. P. and P. A. Dove. 2000. "The Dissolution Kinetics of Amorphous Silica Into Sodium Chloride Solutions: Effects of Temperature and Ionic Strength." Geochim. Cosmochim. Acta 64(24):4193-4203. 
Kalinin, N. N., A. N. Elizarova, V. N. Shchebetkovskii, Y. V. Kuznetsov, and V. K. Isupov. 1983. "Leaching of Iodine from Cement and Bitumen Compositions Containing Various Iodine Compounds." Soviet Radiochemistry 25(4):505-510.

Kirkpatrick, R. J. 1988. "MAS NMR-Spectroscopy of Minerals and Glasses." Reviews in Mineralogy 18:341-403.

Krumbein, W. E. 1983. Microbial Geochemistry. Blackwell Scientific Publications.

Krupka, K. M. and R. J. Serne. 1996. Performance Assessment of Low-Level Radioactive Waste Disposal Facilities: Effect on Radionuclide Concentrations by Cement/Ground-Water Interactions. NUREG/CR-6377, prepared for the Nuclear Regulatory Commission by Pacific Northwest National Laboratory, Washington, D. C.

Krupka, K. M. and R. J. Serne. 2001. Radionuclide $K_{d}$ Values for Cementitious Systems. PNWD-3127, prepared for the Italian National Agency for New Technology, Energy, and Environment (ENEA), Rome, Italy, by Battelle Pacific Northwest Division, Richland, Washington.

Krupka, K. M., R. J. Serne, and D. I. Kaplan. 2004. Geochemical Data Package for the 2005 Hanford Integrated Disposal Facility Performance Assessment (IDF PA). PNNL-13037, Rev. 2, Pacific Northwest National Laboratory, Richland, Washington.

Langton, C. A., S. B. Oblath, D. W. Pepper, and E. L. Wilhite. 1988. "Waste Salt Disposal at the Savannah River Plant." Chem. Eng. Comm. 66:189-199.

Langton, C. A. 1989. Slag-Based Materials for Toxic Metal and Radioactive Waste Stabilization. DP-MS-87-95, Rev. 2, E. I. du Pont de Nemours \& Co., Savannah River Laboratory, Aiken, South Carolina.

Lasaga, A. C. 1981. Transition State Theory. In Reviews in Mineralogy, Vol. 8 (ed. P. H. Ribbe), Washington D. C.

Lasaga, A. C. 1995. Fundamental Approaches in Describing Mineral Dissolution and Precipitation Rates. In Chemical Weathering Rates of Silicate Minerals, Vol. 31 (ed. A. F. White and S. L. Brantley), pp. 23-86. Mineralogical Society of America, Washington, D. C.

Liermann, L. J., A. S. Barnes, B. E. Kalinowski, X. Zhou, and S. L. Brantley. 2000. "Microenvironments of $\mathrm{pH}$ in Biofilms Grown on Dissolving Silicate Surfaces." Chem. Geol. 171:1-16.

Mann, F. M., R. J. Puigh, II, S. H. Finfrock, E. J. Freeman, R. Khaleel, D. H. Bacon, M. P. Bergeron, B. P. McGrail, S. K. Wurstner, K. Burgard, W. R. Root, and P. E. LaMont. 2001. Hanford Immobilized Low-Activity Tank Waste Performance Assessment: 2001 Version. DOE/ORP-2000-24 Rev. 0, U.S. Department of Energy, Richland, Washington.

Mann, F. M., R. J. Puigh, S. H. Finfrock, and R. Khaleel. 2003a. Integrated Disposal Facility Risk Assessment. RPP-15834, Rev. 0, CH2M Hill Hanford Group, Inc., Richland, Washington.

Mann, F. M., B. P. McGrail, D. H. Bacon, R. J. Serne, K. M. Krupka, R. J. Puigh, R. Khaleel, and S. H. Finfrock. 2003b. Risk Assessment Supporting the Decision on the Initial Selection of Supplemental ILAW Technologies. RPP-17675, Rev. 0, CH2M Hill Hanford Group, Inc., Richland, Washington. 
Mattigod, S. V., R. J. Serne, B. P. McGrail, and V. L. Legore. 2002. "Radionuclide Incorporation in Secondary Crystalline Minerals From Chemical Weathering of Waste Glasses." Mat. Res. Soc. Symp. Proc. 713:597-605.

McGrail, B. P., W. L. Ebert, A. J. Bakel, and D. K. Peeler. 1997. "Measurement of Kinetic Rate Law Parameters on a Na-Ca-Al Borosilicate Glass for Low-Activity Waste." J. Nuc. Mat. 249:175-189.

McGrail, B. P. and D. H. Bacon. 1998. Selection of a Computer Code for Hanford Low-Level Waste Engineered-System Performance Assessment. PNNL-10830, Rev. 1, Pacific Northwest National Laboratory, Richland, Washington.

McGrail, B. P., J. P. Icenhower, P. F. Martin, D. R. Rector, H. T. Schaef, E. A. Rodriguez, and J. L. Steele. 2000a. Low-Activity Waste Glass Studies: FY2000 Summary Report. PNNL-13381, Pacific Northwest National Laboratory, Richland, Wa.

McGrail, B. P., D. H. Bacon, W. L. Ebert, and K. P. Saripalli. 2000b. A Strategy to Conduct an Analysis of the Long-Term Performance of Low-Activity Waste Glass in a Shallow Subsurface Disposal System at Hanford. PNNL-11834 Rev. 1, Pacific Northwest National Laboratory, Richland, Washington.

McGrail, B. P., J. P. Icenhower, P. F. Martin, H. T. Schaef, M. J. O'Hara, E. A. Rodriguez, and J. L. Steele. 2001a. Waste Form Release Data Package for the 2001 Immobilized Low-Activity Waste Performance Assessment. PNNL-13043 Rev. 2, Pacific Northwest National Laboratory, Richland, Washington.

McGrail, B. P., J. P. Icenhower, D. K. Shuh, P. Liu, J. G. Darab, D. R. Baer, S. Thevuthasen, V. Shutthanandan, M. H. Engelhard, C. H. Booth, and P. Nachimuthu. 2001b. "The Structure of $\mathrm{Na}_{2} \mathrm{O}-\mathrm{Al}_{2} \mathrm{O}_{3}-\mathrm{SiO}_{2}$ Glass: Impact on Sodium Ion Exchange in $\mathrm{H}_{2} \mathrm{O}$ and $\mathrm{D}_{2} \mathrm{O}$." J. Non-Cryst. Solids 296(1-2):10-26.

McGrail, B. P., J. P. Icenhower, D. H. Bacon, J. D. Vienna, K. P. Saripalli, H. T. Schaef, P. F. Martin, R. D. Orr, E. A. Rodriguez, and J. L. Steele. 2002. Low-Activity Waste Glass Studies: FY2002 Summary Report. PNNL-14145, Pacific Northwest National Laboratory, Richland, Washington.

McGrail, B. P., D. H. Bacon, R. J. Serne, and E. M. Pierce. 2003. A Strategy to Assess Performance of Selected Low-Activity Waste Forms in an Integrated Disposal Facility. PNNL14362, Pacific Northwest National Laboratory, Richland, Washington.

Meyer, P. D., K. P. Saripalli, and V. L. Freedman. 2004. Near-Field Hydrology Data Package for the Integrated Disposal Facility 2005 Performance Assessment. PNNL-14700, Pacific Northwest National Laboratory, Richland, Washington.

Moore, D. M. and R. C. Reynolds. 1989. X-Ray Diffraction and the Identification and Analysis of Clay Minerals. Oxford University Press.

Muller, I. S., A. C. Buechele, and I. L. Pegg. 2001. Final Report: Glass Formulation and Testing with RPP-WTP LAW Simulants. VSL-01R3560-2, Vitreous State Laboratory, Catholic University of America, Washington, D.C. 
Peterson, V., B. Hunter, A. Ray, and L. P. Aldridge. 2002. "Rietveld Refinement of Neutron, Synchrotron and Combined Powder Diffraction Data of Cement Clinker." Appl. Phys. A-Mater. Sci. Process. 74:S1409-S1411.

Rahman, M. M., S. Nagasaki, and S. Tanaka. 1999. "A Model for Dissolution of CaO- $\mathrm{SiO}_{2}-\mathrm{H}_{2} \mathrm{O}$ $\mathrm{Gel}$ at $\mathrm{Ca} / \mathrm{Si}<1$ by Considering Disordered Structure." Material Research Symposium Proceedings 556:1237-1244.

Reardon, E. J. 1992. "Problems and Approaches to the Prediction of the Chemical Composition in Cement/Water Systems." Waste Management 12:221-239.

Renders, P. J. N., C. H. Gammons, and H. L. Barnes. 1995. "Precipitation and Dissolution Rate Constants for Cristobalite from $150^{\circ} \mathrm{C}$ to $300^{\circ} \mathrm{C}$." Geochim. Cosmochim. Acta 59(1):77-85.

Richards, L. A. 1931. "Capillary Conduction of Liquids Through Porous Mediums." Physics 1:318-333.

Scheele, R. D., L. L. Burger, and K. D. Wiemers. 1984. "Leach Resistance of Iodine Compounds in Portland-Cement." ACS Symposium Series 246:373-387.

Serne, R. J., R. O. Lokken, and L. J. Criscenti. 1992. "Chracterization of Grouted Low-Level Waste to Support Performance Assessment." Waste Management 12:217-287.

Serne, R. J., W. J. Martin, and V. L. Legore. 1995. Leach Test of Cladding Removal Waste Grout Using Hanford Groundwater. Pacific Northwest National Laboratory, Richland, WA.

Toyohara, M., M. Kaneko, H. Ueda, N. Mitsutsuka, H. Fujihara, T. Murase, and N. Saito. 2000. "Iodine Sorption Onto Mixed Solid Alumina Cement and Calcium Compounds." J. Nuc. Sci. Tech. 37(11):970-978.

Toyohara, M., M. Kaneko, N. Mitsutsuka, H. Fujihara, N. Saito, and T. Murase. 2002. "Contribution to Understanding Iodine Sorption Mechanism Onto Mixed Solid Alumina Cement and Calcium Compounds." J. Nuc. Sci. Tech. 39(9):950-956.

Wierenga, P. J., M. H. Young, G. W. Gee, R. G. Hills, C. T. Kincaid, T. J. Nicholson, and R. E. Cady. 1993. Soil Characterization Methods for Unsaturated Low-Level Waste Sites. PNL8480, Pacific Northwest Laboratory, Richland, Washington.

Wolery, T. J. 1992. EQ3NR, A Computer Program for Geochemical Aqueous SpeciationSolubility Calculations: Theoretical Manual, User's Guide, and Related Documentation (Version 7.0). UCRL-MA-110662 PT III, LLNL, Livermore, CA.

Wolery, T. J. and S. A. Daveler. 1992. EQ6, A Computer Program for Reaction Path Modeling of Aqueous Geochemical Systems: Theoretical Manual, User's Guide, and Related Documentation (Version 7.0). UCRL-MA-1 10662 PT IV, Lawrence Livermore National Laboratory, Livermore, California. 
Appendix A

Single-Pass Flow-Through Test Results 
Table A1. SPFT Results for LAWA44 Glasses.

\begin{tabular}{|c|c|c|c|c|c|c|c|c|c|c|c|c|c|c|c|c|}
\hline Sample ID & $\begin{array}{c}\text { Influent } \\
\text { [Si] }\end{array}$ & $\begin{array}{c}\mathrm{T} \\
\left({ }^{\circ} \mathrm{C}\right) \\
\end{array}$ & $\begin{array}{c}\text { Flow } \\
\text { Rate } \\
\left(\mathrm{m}^{3} / \mathrm{d}\right)\end{array}$ & $\begin{array}{l}\text { Time, } \\
\text { days }\end{array}$ & $\begin{array}{c}\mathrm{pH} \\
\left(23^{\circ} \mathrm{C}\right) \\
\end{array}$ & $\begin{array}{c}\text { Glass } \\
\text { Mass } \\
\text { (g) } \\
\end{array}$ & $\begin{array}{c}\text { SA } \\
\left(\mathrm{m}^{2}\right)\end{array}$ & {$[\mathrm{B}]$} & B Rate & {$[\mathrm{Al}]$} & Al Rate & {$[\mathrm{Na}]$} & Na Rate & {$[\mathrm{Si}]$} & Si Rate & IEX Rate \\
\hline \multicolumn{17}{|l|}{ LAWA44 } \\
\hline \multicolumn{17}{|l|}{ Exp.\#1 } \\
\hline LW44-1.0 & - & 40 & - & - & 9 & - & - & (2) & - & 57 & - & $(48)$ & - & (133) & - & - \\
\hline LW44-1.1 & - & 40 & - & - & 9 & - & - & (2) & - & 68 & - & (73) & - & (14) & - & - \\
\hline LW44-1.2 & - & 40 & - & - & 9 & - & - & (2) & - & 67 & - & (48) & - & (16) & - & - \\
\hline LW44-1.3 & 0 & 40 & $1.2 \mathrm{E}-05$ & 1.11 & 9 & 1.000 & 0.020 & 100 & $2.18 \mathrm{E}-03$ & 127 & 1.19E-03 & 3601 & $1.47 \mathrm{E}-02$ & ND & $1.25 \mathrm{E}-03$ & 5.02E-09 \\
\hline LW44-1.6 & 0 & 40 & 1.1E-05 & 5.09 & 9 & 1.000 & 0.020 & 249 & 5.19E-03 & 305 & $4.25 \mathrm{E}-03$ & 3288 & $1.26 \mathrm{E}-02$ & 1677 & $4.52 \mathrm{E}-03$ & 2.97E-09 \\
\hline LW44-1.9 & 0 & 40 & $1.1 \mathrm{E}-05$ & 10.95 & 9 & 0.999 & 0.020 & 279 & 5.81E-03 & 400 & 5.93E-03 & 2133 & 8.12E-03 & 2031 & 5.51E-03 & $9.24 \mathrm{E}-10$ \\
\hline LW44-1.12 & 0 & 40 & 1.2E-05 & 15.85 & 9 & 0.999 & 0.020 & 281 & $5.99 \mathrm{E}-03$ & 399 & $6.05 \mathrm{E}-03$ & 1814 & 7.04E-03 & 2081 & $5.78 \mathrm{E}-03$ & 4.19E-10 \\
\hline LW44-1.14 & 0 & 40 & 7.0E-06 & 19.05 & 9 & 0.999 & 0.020 & 334 & $4.26 \mathrm{E}-03$ & 455 & 4.22E-03 & 2063 & 4.80E-03 & 2435 & 4.06E-03 & $2.16 \mathrm{E}-10$ \\
\hline LW44-1.15 & 0 & 40 & $1.1 \mathrm{E}-05$ & 20.85 & 9 & 0.998 & 0.020 & 310 & $6.48 \mathrm{E}-03$ & 422 & 6.33E-03 & 1930 & 7.33E-03 & 2252 & 6.13E-03 & $3.41 \mathrm{E}-10$ \\
\hline LW44-1.16 & 0 & 40 & 1.1E-05 & 22.13 & 9 & 0.998 & 0.020 & 290 & 6.06E-03 & 418 & $6.27 \mathrm{E}-03$ & 1741 & 6.61E-03 & 2135 & 5.81E-03 & 2.17E-10 \\
\hline LW44-1.17 & 0 & 40 & $1.1 \mathrm{E}-05$ & 24.27 & 9 & 0.998 & 0.020 & 282 & 5.85E-03 & 377 & 5.51E-03 & 1639 & 6.17E-03 & 2069 & 5.59E-03 & $1.26 \mathrm{E}-10$ \\
\hline LW44-1.18 & 0 & 40 & $1.2 \mathrm{E}-05$ & 26.07 & 9 & 0.998 & 0.020 & 274 & 5.85E-03 & 392 & $5.96 \mathrm{E}-03$ & 1547 & 5.98E-03 & 2014 & 5.61E-03 & 5.23E-11 \\
\hline \multicolumn{17}{|l|}{ Exp. \#2 } \\
\hline LW44-2.0 & - & 40 & - & - & 9 & - & - & (3) & - & 75 & - & (138) & - & 9709 & - & - \\
\hline LW44-2.1 & - & 40 & - & - & 9 & - & - & (6) & - & 81 & - & (80) & - & 9900 & - & - \\
\hline LW44-2.2 & - & 40 & - & - & 9 & - & - & (3) & - & 171 & - & (237) & - & 9706 & - & - \\
\hline LW44-2.3 & $1.00 \mathrm{E}+01$ & 40 & $1.1 \mathrm{E}-05$ & 1.11 & 9 & 1.002 & 1.002 & ND & $1.94 \mathrm{E}-03$ & 150 & 7.14E-04 & 2838 & $1.05 \mathrm{E}-02$ & 10219 & $1.24 \mathrm{E}-03$ & 3.40E-09 \\
\hline LW44-2.6 & $1.00 \mathrm{E}+01$ & 40 & $1.1 \mathrm{E}-05$ & 5.09 & 9 & 1.002 & 1.002 & 315 & 6.16E-03 & 344 & 3.91E-03 & 3196 & $1.12 \mathrm{E}-02$ & 11591 & 4.79E-03 & 2.03E-09 \\
\hline LW44-2.9 & $1.00 \mathrm{E}+01$ & 40 & 1.1E-05 & 10.95 & 9 & 1.001 & 1.001 & 358 & 7.20E-03 & 412 & $5.18 \mathrm{E}-03$ & 2368 & 8.40E-03 & 11996 & $6.00 \mathrm{E}-03$ & 4.77E-10 \\
\hline LW44-2.12 & $1.00 \mathrm{E}+01$ & 40 & $1.1 \mathrm{E}-05$ & 15.85 & 9 & 1.001 & 1.001 & 346 & $7.12 \mathrm{E}-03$ & 401 & $5.11 \mathrm{E}-03$ & 2003 & 7.19E-03 & 11607 & $5.08 \mathrm{E}-03$ & 2.93E-11 \\
\hline LW44-2.14 & $1.00 \mathrm{E}+01$ & 40 & $1.1 \mathrm{E}-05$ & 19.05 & 9 & 1.000 & 1.000 & 349 & 7.12E-03 & 423 & $5.46 \mathrm{E}-03$ & 2016 & 7.18E-03 & 11887 & $5.80 \mathrm{E}-03$ & $2.41 \mathrm{E}-11$ \\
\hline LW44-2.15 & $1.00 \mathrm{E}+01$ & 40 & $1.1 \mathrm{E}-05$ & 20.85 & 9 & 1.000 & 1.000 & 339 & $6.81 \mathrm{E}-03$ & 414 & $5.22 \mathrm{E}-03$ & 1974 & $6.90 \mathrm{E}-03$ & 11754 & 5.35E-03 & 3.59E-11 \\
\hline LW44-2.16 & $1.00 \mathrm{E}+01$ & 40 & $1.1 \mathrm{E}-05$ & 22.13 & 9 & 1.000 & 1.000 & 333 & 6.71E-03 & 407 & 5.13E-03 & 1961 & 6.89E-03 & 11613 & 4.99E-03 & $6.91 \mathrm{E}-11$ \\
\hline LW44-2.17 & $1.00 \mathrm{E}+01$ & 40 & 1.1E-05 & 24.27 & 9 & 0.999 & 0.999 & 324 & 6.50E-03 & 391 & $4.82 \mathrm{E}-03$ & 1812 & $6.29 \mathrm{E}-03$ & 11784 & 5.43E-03 & - \\
\hline LW44-2.18 & $1.00 \mathrm{E}+01$ & 40 & $1.1 \mathrm{E}-05$ & 26.07 & 9 & 0.999 & 0.999 & 325 & $6.61 \mathrm{E}-03$ & 403 & $5.11 \mathrm{E}-03$ & 1860 & $6.56 \mathrm{E}-03$ & 11774 & $5.48 \mathrm{E}-03$ & - \\
\hline \multicolumn{17}{|l|}{ Exp. \#3 } \\
\hline LW44-3.0 & $1.61 \mathrm{E}+04$ & 40 & - & - & 9 & - & - & (4) & - & 57 & - & (35) & - & 17743 & - & - \\
\hline LW44-3.1 & $1.61 \mathrm{E}+04$ & 40 & - & - & 9 & - & - & (4) & - & 71 & - & $(72)$ & - & 18017 & - & - \\
\hline LW44-3.2 & $1.61 \mathrm{E}+04$ & 40 & - & - & 9 & - & - & (2) & - & 73 & - & (128) & - & 17946 & - & - \\
\hline LW44-3.3 & $1.61 \mathrm{E}+04$ & 40 & $1.2 \mathrm{E}-05$ & 1.11 & 9 & 1.002 & 0.020 & 119 & $2.45 \mathrm{E}-03$ & 140 & $1.31 \mathrm{E}-03$ & 3022 & $1.16 \mathrm{E}-02$ & 18427 & $1.48 \mathrm{E}-03$ & 3.66E-09 \\
\hline LW44-3.6 & $1.61 \mathrm{E}+04$ & 40 & $1.2 \mathrm{E}-05$ & 5.09 & 9 & 1.002 & 0.020 & 275 & 5.78E-03 & 296 & 4.11E-03 & 3051 & $1.18 \mathrm{E}-02$ & 19839 & $5.47 \mathrm{E}-03$ & $2.40 \mathrm{E}-09$ \\
\hline LW44-3.9 & $1.61 \mathrm{E}+04$ & 40 & $1.2 \mathrm{E}-05$ & 10.95 & 9 & 1.001 & 0.020 & 306 & $6.48 \mathrm{E}-03$ & 308 & 4.35E-03 & 2029 & 7.79E-03 & 19967 & 5.87E-03 & $5.20 \mathrm{E}-10$ \\
\hline LW44-3.12 & $1.61 \mathrm{E}+04$ & 40 & $1.2 \mathrm{E}-05$ & 15.85 & 9 & 1.001 & 0.020 & 290 & 6.34E-03 & 290 & 4.16E-03 & 1759 & 6.93E-03 & 19149 & $3.66 \mathrm{E}-03$ & 2.35E-10 \\
\hline LW44-3.14 & $1.61 \mathrm{E}+04$ & 40 & $1.2 \mathrm{E}-05$ & 19.05 & 9 & 1.001 & 0.020 & 296 & $6.49 \mathrm{E}-03$ & 318 & $4.68 \mathrm{E}-03$ & 1757 & 6.93E-03 & 19634 & 5.09E-03 & $1.73 \mathrm{E}-10$ \\
\hline LW44-3.15 & $1.61 \mathrm{E}+04$ & 40 & $1.1 \mathrm{E}-05$ & 20.85 & 9 & 1.000 & 0.020 & 294 & 5.69E-03 & 320 & $4.17 \mathrm{E}-03$ & 1640 & 5.69E-03 & 19631 & 4.49E-03 & - \\
\hline LW44-3.16 & $1.61 \mathrm{E}+04$ & 40 & $1.2 \mathrm{E}-05$ & 22.13 & 9 & 1.000 & 0.020 & 282 & $5.94 \mathrm{E}-03$ & 311 & $4.38 \mathrm{E}-03$ & 1726 & $6.54 \mathrm{E}-03$ & 19197 & $3.66 \mathrm{E}-03$ & $2.38 \mathrm{E}-10$ \\
\hline
\end{tabular}


Table A1. SPFT Results for LAWA44 Glasses.

\begin{tabular}{|c|c|c|c|c|c|c|c|c|c|c|c|c|c|c|c|c|}
\hline Sample ID & $\begin{array}{c}\text { Influent } \\
\text { [Si] }\end{array}$ & $\begin{array}{c}\mathrm{T} \\
\left({ }^{\circ} \mathrm{C}\right) \\
\end{array}$ & $\begin{array}{c}\text { Flow } \\
\text { Rate } \\
\left(\mathrm{m}^{3} / \mathrm{d}\right) \\
\end{array}$ & $\begin{array}{c}\text { Time, } \\
\text { days }\end{array}$ & $\begin{array}{c}\mathrm{pH} \\
\left(23^{\circ} \mathrm{C}\right) \\
\end{array}$ & $\begin{array}{c}\text { Glass } \\
\text { Mass } \\
(\mathrm{g}) \\
\end{array}$ & $\begin{array}{c}\text { SA } \\
\left(\mathrm{m}^{2}\right) \\
\end{array}$ & [B] & B Rate & {$[\mathrm{Al}]$} & Al Rate & {$[\mathrm{Na}]$} & Na Rate & {$[\mathrm{Si}]$} & Si Rate & IEX Rate \\
\hline LW44-3.17 & $1.61 \mathrm{E}+04$ & 40 & $1.2 \mathrm{E}-05$ & 24.27 & 9 & 1.000 & 0.020 & 276 & 5.85E-03 & 267 & 3.60E-03 & 1487 & 5.63E-03 & 19048 & 3.26E-03 & - \\
\hline LW44-3.18 & $1.61 \mathrm{E}+04$ & 40 & $1.2 \mathrm{E}-05$ & 26.07 & 9 & 0.999 & 0.020 & 275 & 5.92E-03 & 300 & $4.26 \mathrm{E}-03$ & 1502 & 5.77E-03 & 19133 & 3.56E-03 & - \\
\hline \multicolumn{17}{|l|}{ Exp. \#4 } \\
\hline LW44-4.0 & $3.21 \mathrm{E}+04$ & 40 & - & - & 9 & - & - & (2) & - & 73 & - & (62) & - & 38504 & - & - \\
\hline LW44-4.1 & $3.21 \mathrm{E}+04$ & 40 & - & - & 9 & - & - & (3) & - & 82 & - & (60) & - & 38812 & - & - \\
\hline LW44-4.2 & $3.21 \mathrm{E}+04$ & 40 & - & - & 9 & - & - & (3) & - & 72 & - & (262) & - & 38175 & - & - \\
\hline LW44-4.3 & $3.21 \mathrm{E}+04$ & 40 & $1.2 \mathrm{E}-05$ & 1.11 & 9 & 1.008 & 0.020 & 112 & 2.43E-03 & 144 & $1.27 \mathrm{E}-03$ & 2956 & 1.17E-02 & 39523 & 3.03E-03 & 3.72E-09 \\
\hline LW44-4.6 & $3.21 \mathrm{E}+04$ & 40 & $1.2 \mathrm{E}-05$ & 5.09 & 9 & 1.008 & 0.020 & 189 & 3.92E-03 & 185 & $1.94 \mathrm{E}-03$ & 2614 & $9.75 \mathrm{E}-03$ & 39739 & $3.47 \mathrm{E}-03$ & 2.33E-09 \\
\hline LW44-4.9 & $3.21 \mathrm{E}+04$ & 40 & $1.2 \mathrm{E}-05$ & 10.95 & 9 & 1.008 & 0.020 & 185 & 3.92E-03 & 166 & $1.64 \mathrm{E}-03$ & 1591 & $5.86 \mathrm{E}-03$ & 40076 & $4.50 \mathrm{E}-03$ & 7.75E-10 \\
\hline LW44-4.12 & $3.21 \mathrm{E}+04$ & 40 & $1.2 \mathrm{E}-05$ & 15.85 & 9 & 1.007 & 0.020 & 188 & $4.08 \mathrm{E}-03$ & 160 & $1.55 \mathrm{E}-03$ & 1276 & 4.69E-03 & 39503 & 2.93E-03 & $2.45 \mathrm{E}-10$ \\
\hline LW44-4.14 & $3.21 \mathrm{E}+04$ & 40 & $1.2 \mathrm{E}-05$ & 19.05 & 9 & 1.007 & 0.020 & 191 & $4.10 \mathrm{E}-03$ & 173 & $1.78 \mathrm{E}-03$ & 1253 & $4.56 \mathrm{E}-03$ & 39782 & 3.71E-03 & $1.85 \mathrm{E}-10$ \\
\hline LW44-4.15 & $3.21 \mathrm{E}+04$ & 40 & $1.2 \mathrm{E}-05$ & 20.85 & 9 & 1.007 & 0.020 & 184 & 3.87E-03 & 171 & $1.71 \mathrm{E}-03$ & 1189 & $4.21 \mathrm{E}-03$ & 39616 & 3.16E-03 & $1.32 \mathrm{E}-10$ \\
\hline LW44-4.16 & $3.21 \mathrm{E}+04$ & 40 & $1.2 \mathrm{E}-05$ & 22.13 & 9 & 1.007 & 0.020 & 181 & 3.82E-03 & 169 & $1.67 \mathrm{E}-03$ & 1218 & 4.33E-03 & 39629 & $3.20 \mathrm{E}-03$ & 2.05E-10 \\
\hline LW44-4.17 & $3.21 \mathrm{E}+04$ & 40 & $1.2 \mathrm{E}-05$ & 24.27 & 9 & 1.006 & 0.020 & 177 & 3.73E-03 & 149 & $1.31 \mathrm{E}-03$ & 1108 & 3.89E-03 & 39419 & 2.61E-03 & $6.55 \mathrm{E}-11$ \\
\hline LW44-4.18 & $3.21 \mathrm{E}+04$ & 40 & $1.2 \mathrm{E}-05$ & 26.07 & 9 & 1.006 & 0.020 & 174 & 3.67E-03 & 169 & $1.68 \mathrm{E}-03$ & 1076 & 3.79E-03 & 39996 & 4.27E-03 & $4.51 \mathrm{E}-11$ \\
\hline \multicolumn{17}{|l|}{ Exp. \#5 } \\
\hline LW44-5.0 & $4.78 \mathrm{E}+04$ & 40 & - & - & 9 & - & - & (2) & - & 67 & - & (13) & - & 54164 & - & - \\
\hline LW44-5.1 & $4.78 \mathrm{E}+04$ & 40 & - & - & 9 & - & - & (2) & - & 66 & - & $(57)$ & - & 54165 & - & - \\
\hline LW44-5.2 & $4.78 \mathrm{E}+04$ & 40 & - & - & 9 & - & - & (1) & - & 70 & - & (6) & - & 55688 & - & - \\
\hline LW44-5.3 & $4.78 \mathrm{E}+04$ & 40 & $1.3 \mathrm{E}-05$ & 1.11 & 9 & 1.001 & 0.020 & 115 & 2.62E-03 & 131 & $1.23 \mathrm{E}-03$ & 3249 & 1.39E-02 & 58101 & 1.05E-02 & 4.50E-09 \\
\hline LW44-5.6 & $4.78 \mathrm{E}+04$ & 40 & $1.2 \mathrm{E}-05$ & 5.09 & 9 & 1.001 & 0.020 & 150 & 3.13E-03 & 140 & $1.28 \mathrm{E}-03$ & 2508 & $9.75 \mathrm{E}-03$ & 58110 & $9.62 \mathrm{E}-03$ & 2.64E-09 \\
\hline LW44-5.9 & $4.78 \mathrm{E}+04$ & 40 & $1.2 \mathrm{E}-05$ & 10.95 & 9 & 1.001 & 0.020 & 113 & $2.40 \mathrm{E}-03$ & 107 & 7.14E-04 & 1268 & $5.01 \mathrm{E}-03$ & 57729 & 8.78E-03 & $1.04 \mathrm{E}-09$ \\
\hline LW44-5.12 & $4.78 \mathrm{E}+04$ & 40 & $1.2 \mathrm{E}-05$ & 15.85 & 9 & 1.001 & 0.020 & ND & $2.00 \mathrm{E}-03$ & 101 & $6.20 \mathrm{E}-04$ & ND & $3.91 \mathrm{E}-03$ & 57699 & 8.86E-03 & 7.62E-10 \\
\hline LW44-5.14 & $4.78 \mathrm{E}+04$ & 40 & $1.1 \mathrm{E}-05$ & 19.05 & 9 & 1.000 & 0.020 & ND & $1.71 \mathrm{E}-03$ & 105 & $6.20 \mathrm{E}-04$ & ND & $3.10 \mathrm{E}-03$ & 57284 & 6.89E-03 & $5.56 \mathrm{E}-10$ \\
\hline LW44-5.15 & $4.78 \mathrm{E}+04$ & 40 & $1.2 \mathrm{E}-05$ & 20.85 & 9 & 1.000 & 0.020 & ND & 1.84E-03 & 107 & 7.08E-04 & ND & $3.42 \mathrm{E}-03$ & 57921 & $9.19 \mathrm{E}-03$ & $6.32 \mathrm{E}-10$ \\
\hline LW44-5.16 & $4.78 \mathrm{E}+04$ & 40 & $1.2 \mathrm{E}-05$ & 22.13 & 9 & 1.000 & 0.020 & ND & $1.77 \mathrm{E}-03$ & 103 & $6.45 \mathrm{E}-04$ & ND & $3.21 \mathrm{E}-03$ & 56711 & 5.88E-03 & 5.77E-10 \\
\hline LW44-5.17 & $4.78 \mathrm{E}+04$ & 40 & $1.2 \mathrm{E}-05$ & 24.27 & 9 & 1.000 & 0.020 & ND & $1.68 \mathrm{E}-03$ & 94 & 4.74E-04 & ND & 2.88E-03 & 57956 & 9.37E-03 & 4.79E-10 \\
\hline LW44-5.18 & $4.78 \mathrm{E}+04$ & 40 & $1.2 \mathrm{E}-05$ & 26.07 & 9 & 1.000 & 0.020 & ND & $1.67 \mathrm{E}-03$ & 103 & $6.50 \mathrm{E}-04$ & ND & $2.74 \mathrm{E}-03$ & 57555 & 8.35E-03 & $4.28 \mathrm{E}-10$ \\
\hline \multicolumn{17}{|l|}{ Exp. \#6 } \\
\hline LW44-6.0 & $6.89 \mathrm{E}+04$ & 40 & - & - & 9 & - & - & $<100$ & - & 66 & - & (87) & - & 73730 & - & - \\
\hline LW44-6.1 & $6.89 \mathrm{E}+04$ & 40 & - & - & 9 & - & - & $<100$ & - & 55 & - & (21) & - & 74928 & - & - \\
\hline LW44-6.2 & $6.89 \mathrm{E}+04$ & 40 & - & - & 9 & - & - & $<100$ & - & 55 & - & (121) & - & 73461 & - & - \\
\hline LW44-6.9 & $6.89 \mathrm{E}+04$ & 40 & $1.2 \mathrm{E}-05$ & 10.95 & 9 & 1.001 & 0.020 & ND & - & 89 & $5.60 \mathrm{E}-04$ & 1314 & 4.96E-03 & 76963 & 8.34E-03 & $2.14 \mathrm{E}-09$ \\
\hline LW44-6.12 & $6.89 \mathrm{E}+04$ & 40 & $1.2 \mathrm{E}-05$ & 15.85 & 9 & 1.001 & 0.020 & ND & - & 85 & 4.91E-04 & 979 & 3.71E-03 & 78758 & $1.38 \mathrm{E}-02$ & 1.83E-09 \\
\hline LW44-6.14 & $6.89 \mathrm{E}+04$ & 40 & $1.2 \mathrm{E}-05$ & 19.05 & 9 & 1.001 & 0.020 & ND & - & 80 & $4.02 \mathrm{E}-04$ & 907 & 3.37E-03 & 77082 & 8.79E-03 & 1.75E-09 \\
\hline LW44-6.15 & $6.89 \mathrm{E}+04$ & 40 & $1.2 \mathrm{E}-05$ & 20.85 & 9 & 1.001 & 0.020 & ND & - & 77 & 3.27E-04 & 807 & 2.91E-03 & 74282 & 6.89E-04 & $1.58 \mathrm{E}-09$ \\
\hline LW44-6.16 & $6.89 \mathrm{E}+04$ & 40 & $1.2 \mathrm{E}-05$ & 22.13 & 9 & 1.001 & 0.020 & ND & - & 79 & 3.64E-04 & 775 & 2.81E-03 & 75959 & 5.50E-03 & $1.56 \mathrm{E}-09$ \\
\hline LW44-6.17 & $6.89 \mathrm{E}+04$ & 40 & $1.2 \mathrm{E}-05$ & 24.27 & 9 & 1.001 & 0.020 & ND & - & 70 & 2.05E-04 & 711 & 2.53E-03 & 75275 & 3.51E-03 & $1.46 \mathrm{E}-09$ \\
\hline LW44-6.18 & $6.89 \mathrm{E}+04$ & 40 & $1.2 \mathrm{E}-05$ & 26.07 & 9 & 1.001 & 0.020 & ND & - & 77 & 3.35E-04 & 681 & 2.44E-03 & 76507 & 7.09E-03 & $1.47 \mathrm{E}-09$ \\
\hline
\end{tabular}


Table A1. SPFT Results for LAWA44 Glasses.

\begin{tabular}{|c|c|c|c|c|c|c|c|c|c|c|c|c|c|c|c|c|}
\hline Sample ID & $\begin{array}{c}\text { Influent } \\
\text { [Si] } \\
\end{array}$ & $\begin{array}{c}\mathrm{T} \\
\left({ }^{\circ} \mathrm{C}\right) \\
\end{array}$ & $\begin{array}{c}\text { Flow } \\
\text { Rate } \\
\left(\mathrm{m}^{3} / \mathrm{d}\right) \\
\end{array}$ & $\begin{array}{c}\text { Time, } \\
\text { days }\end{array}$ & $\begin{array}{c}\mathrm{pH} \\
\left(23^{\circ} \mathrm{C}\right) \\
\end{array}$ & $\begin{array}{c}\text { Glass } \\
\text { Mass } \\
(\mathrm{g})\end{array}$ & $\begin{array}{c}\text { SA } \\
\left(\mathrm{m}^{2}\right) \\
\end{array}$ & {$[\mathrm{B}]$} & B Rate & [Al] & Al Rate & {$[\mathrm{Na}]$} & Na Rate & {$[\mathrm{Si}]$} & Si Rate & IEX Rate \\
\hline LW44-7.0 & 0 & 23 & - & - & 7 & - & - & $<50$ & - & $<25$ & - & $<50$ & - & $<100$ & - & - \\
\hline LW44-7.1 & 0 & 23 & - & - & 7 & - & - & $<50$ & - & $<25$ & - & 174 & - & 182 & - & - \\
\hline LW44-7.2 & 0 & 23 & - & - & 7 & - & - & $<50$ & - & $<25$ & - & $<50$ & - & $<100$ & - & - \\
\hline LW44-7.3 & 0 & 23 & 8.8E-06 & 2.01 & 7 & 1.013 & 0.020 & 244 & 3.11E-03 & ND & - & 4586 & $1.34 \mathrm{E}-02$ & 246 & $2.51 \mathrm{E}-04$ & 4.11E-09 \\
\hline LW44-7.7 & 0 & 23 & 9.7E-06 & 9.74 & 7 & 1.013 & 0.020 & 181 & $2.30 \mathrm{E}-03$ & ND & - & 1897 & $5.90 \mathrm{E}-03$ & 195 & $1.57 \mathrm{E}-04$ & $1.44 \mathrm{E}-09$ \\
\hline LW44-7.10 & 0 & 23 & $1.1 \mathrm{E}-05$ & 15.02 & 7 & 1.013 & 0.020 & 139 & $1.68 \mathrm{E}-03$ & ND & - & 1225 & 4.01E-03 & 147 & $4.83 \mathrm{E}-05$ & $9.29 \mathrm{E}-10$ \\
\hline LW44-7.13 & 0 & 23 & 9.7E-06 & 20.76 & 7 & 1.012 & 0.020 & 123 & $1.29 \mathrm{E}-03$ & ND & - & 1012 & $3.02 \mathrm{E}-03$ & 137 & 2.36E-05 & $6.91 \mathrm{E}-10$ \\
\hline LW44-7.16 & 0 & 23 & $9.6 \mathrm{E}-06$ & 25.90 & 7 & 1.012 & 0.020 & 115 & 1.12E-03 & ND & - & 849 & $2.44 \mathrm{E}-03$ & 122 & - & $5.28 \mathrm{E}-10$ \\
\hline LW44-7.18 & 0 & 23 & $9.6 \mathrm{E}-06$ & 29.92 & 7 & 1.012 & 0.020 & 102 & $9.06 \mathrm{E}-04$ & ND & - & 747 & $2.12 \mathrm{E}-03$ & 109 & - & $4.85 \mathrm{E}-10$ \\
\hline LW44-7.19 & 0 & 23 & 9.8E-06 & 31.85 & 7 & 1.012 & 0.020 & 95 & 8.06E-04 & ND & - & 708 & 2.04E-03 & 110 & - & 4.93E-10 \\
\hline LW44-7.20 & 0 & 23 & 9.7E-06 & 34.03 & 7 & 1.012 & 0.020 & 89 & $6.90 \mathrm{E}-04$ & ND & - & 675 & $1.90 \mathrm{E}-03$ & 106 & - & 4.85E-10 \\
\hline LW44-7.21 & 0 & 23 & $9.8 \mathrm{E}-06$ & 35.78 & 7 & 1.012 & 0.020 & 85 & $6.11 \mathrm{E}-04$ & ND & - & 656 & $1.86 \mathrm{E}-03$ & 101 & - & 4.98E-10 \\
\hline LW44-7.22 & 0 & 23 & 9.7E-06 & 37.78 & 7 & 1.012 & 0.020 & 86 & $6.29 \mathrm{E}-04$ & ND & - & 638 & 1.79E-03 & 103 & - & 4.63E-10 \\
\hline \multicolumn{17}{|l|}{ Exp. \#8 } \\
\hline LW44-8.0 & 0 & 23 & - & - & 7 & - & - & $<50$ & - & $<25$ & - & 109 & - & $<100$ & - & - \\
\hline LW44-8.1 & 0 & 23 & - & - & 7 & - & - & $<50$ & - & $<25$ & - & 56 & - & $<100$ & - & - \\
\hline LW44-8.2 & 0 & 23 & - & - & 7 & - & - & $<50$ & - & $<25$ & - & 61 & - & $<100$ & - & - \\
\hline LW44-8.0 & 0 & 23 & 2.0E-06 & 1.06 & 7 & 1.013 & 0.020 & ND & - & $\mathrm{ND}$ & - & 109 & - & $\mathrm{ND}$ & - & $5.88 \mathrm{E}-11$ \\
\hline LW44-8.1 & 0 & 23 & $1.8 \mathrm{E}-05$ & 2.21 & 7 & 1.013 & 0.020 & ND & - & ND & - & 56 & - & ND & - & 4.33E-10 \\
\hline LW44-8.2 & 0 & 23 & $1.8 \mathrm{E}-06$ & 5.06 & 7 & 1.013 & 0.020 & ND & - & ND & - & 61 & - & ND & - & 4.46E-11 \\
\hline LW44-8.3 & 0 & 23 & 8.9E-06 & 7.07 & 7 & 1.013 & 0.020 & 233 & $2.94 \mathrm{E}-03$ & ND & - & 4797 & $1.40 \mathrm{E}-02$ & 246 & $2.23 \mathrm{E}-04$ & 4.42E-09 \\
\hline LW44-8.7 & 0 & 23 & 9.7E-06 & 14.80 & 7 & 1.013 & 0.020 & 176 & $2.20 \mathrm{E}-03$ & ND & - & 2196 & 6.79E-03 & 207 & $1.54 \mathrm{E}-04$ & 1.83E-09 \\
\hline LW44-8.10 & 0 & 23 & $1.1 \mathrm{E}-05$ & 20.08 & 7 & 1.013 & 0.020 & 137 & $1.66 \mathrm{E}-03$ & ND & - & 1370 & 4.48E-03 & 172 & 7.87E-05 & 1.13E-09 \\
\hline LW44-8.13 & 0 & 23 & $9.8 \mathrm{E}-06$ & 25.82 & 7 & 1.012 & 0.020 & 117 & $1.18 \mathrm{E}-03$ & ND & - & 1082 & $3.20 \mathrm{E}-03$ & 142 & 3.09E-06 & 8.06E-10 \\
\hline LW44-8.16 & 0 & 23 & 9.6E-06 & 30.95 & 7 & 1.012 & 0.020 & 116 & $1.14 \mathrm{E}-03$ & ND & - & 965 & $2.76 \mathrm{E}-03$ & 142 & $3.14 \mathrm{E}-06$ & $6.47 \mathrm{E}-10$ \\
\hline LW44-8.18 & 0 & 23 & $9.7 \mathrm{E}-06$ & 34.98 & 7 & 1.012 & 0.020 & 99 & 8.52E-04 & ND & - & 789 & $2.21 \mathrm{E}-03$ & 121 & - & $5.42 \mathrm{E}-10$ \\
\hline LW44-8.19 & 0 & 23 & 9.9E-06 & 36.91 & 7 & 1.012 & 0.020 & 94 & 7.90E-04 & ND & - & 766 & 2.17E-03 & 113 & - & $5.52 \mathrm{E}-10$ \\
\hline LW44-8.20 & 0 & 23 & $9.8 \mathrm{E}-06$ & 39.09 & 7 & 1.012 & 0.020 & 90 & 7.09E-04 & ND & - & 754 & $2.12 \mathrm{E}-03$ & 114 & - & 5.61E-10 \\
\hline LW44-8.21 & 0 & 23 & 9.9E-06 & 40.84 & 7 & 1.012 & 0.020 & 88 & 6.82E-04 & ND & - & 723 & 2.03E-03 & 113 & - & 5.38E-10 \\
\hline LW44-8.22 & 0 & 23 & $9.8 \mathrm{E}-06$ & 42.84 & 7 & 1.012 & 0.020 & 88 & 6.67E-04 & ND & - & 695 & $1.92 \mathrm{E}-03$ & 116 & - & $4.98 \mathrm{E}-10$ \\
\hline \multicolumn{17}{|l|}{ Exp. \#9 } \\
\hline LW44-9.0 & 0 & 23 & - & - & 8 & - & - & $<50$ & - & $<25$ & - & 137 & - & $<100$ & - & - \\
\hline LW44-9.1 & 0 & 23 & - & - & 8 & - & - & $<50$ & - & $<25$ & - & $<50$ & - & 810 & - & - \\
\hline LW44-9.2 & 0 & 23 & - & - & 8 & - & - & $<50$ & - & $<25$ & - & $<50$ & - & $<100$ & - & - \\
\hline LW44-9.0 & 0 & 23 & 9.6E-06 & 1.06 & 8 & 1.016 & 0.020 & ND & - & ND & - & 137 & - & $\mathrm{ND}$ & - & $1.88 \mathrm{E}-10$ \\
\hline LW44-9.1 & 0 & 23 & $1.8 \mathrm{E}-05$ & 2.21 & 8 & 1.016 & 0.020 & ND & - & ND & - & ND & - & 810 & $1.79 \mathrm{E}-03$ & $6.81 \mathrm{E}-11$ \\
\hline LW44-9.2 & 0 & 23 & 6.1E-06 & 5.06 & 8 & 1.016 & 0.020 & ND & - & $\mathrm{ND}$ & - & ND & - & $\mathrm{ND}$ & - & $1.25 \mathrm{E}-11$ \\
\hline LW44-9.3 & 0 & 23 & $9.2 \mathrm{E}-06$ & 7.07 & 8 & 1.016 & 0.020 & 102 & $9.90 \mathrm{E}-04$ & ND & 5.38E-05 & 3140 & $9.05 \mathrm{E}-03$ & 284 & - & 3.22E-09 \\
\hline LW44-9.7 & 0 & 23 & 9.6E-06 & 14.80 & 8 & 1.016 & 0.020 & 87 & $7.88 \mathrm{E}-04$ & 69 & $5.21 \mathrm{E}-04$ & 1548 & 4.33E-03 & 406 & $1.30 \mathrm{E}-05$ & $1.42 \mathrm{E}-09$ \\
\hline LW44-9.10 & 0 & 23 & $1.1 \mathrm{E}-05$ & 20.08 & 8 & 1.016 & 0.020 & 65 & 4.50E-04 & 68 & 5.51E-04 & 978 & $2.75 \mathrm{E}-03$ & 368 & - & $9.17 \mathrm{E}-10$ \\
\hline
\end{tabular}


Table A1. SPFT Results for LAWA44 Glasses.

\begin{tabular}{|c|c|c|c|c|c|c|c|c|c|c|c|c|c|c|c|c|}
\hline Sample ID & $\begin{array}{c}\text { Influent } \\
\text { [Si] }\end{array}$ & $\begin{array}{c}\mathrm{T} \\
\left({ }^{\circ} \mathrm{C}\right) \\
\end{array}$ & $\begin{array}{c}\text { Flow } \\
\text { Rate } \\
\left(\mathrm{m}^{3} / \mathrm{d}\right) \\
\end{array}$ & $\begin{array}{c}\text { Time, } \\
\text { days }\end{array}$ & $\begin{array}{c}\mathrm{pH} \\
\left(23^{\circ} \mathrm{C}\right) \\
\end{array}$ & $\begin{array}{l}\text { Glass } \\
\text { Mass } \\
(\mathrm{g}) \\
\end{array}$ & $\begin{array}{c}\text { SA } \\
\left(\mathrm{m}^{2}\right) \\
\end{array}$ & {$[\mathrm{B}]$} & B Rate & {$[\mathrm{Al}]$} & Al Rate & {$[\mathrm{Na}]$} & Na Rate & {$[\mathrm{Si}]$} & Si Rate & IEX Rate \\
\hline LW44-9.13 & 0 & 23 & 9.7E-06 & 25.82 & 8 & 1.016 & 0.020 & 59 & 3.03E-04 & 68 & 5.08E-04 & 782 & $1.90 \mathrm{E}-03$ & 375 & - & 6.37E-10 \\
\hline LW44-9.16 & 0 & 23 & $9.6 \mathrm{E}-06$ & 30.95 & 8 & 1.016 & 0.020 & 54 & 2.17E-04 & 57 & 3.38E-04 & 661 & $1.48 \mathrm{E}-03$ & 345 & - & $5.04 \mathrm{E}-10$ \\
\hline LW44-9.18 & 0 & 23 & 9.6E-06 & 34.98 & 8 & 1.016 & 0.020 & 52 & $1.72 \mathrm{E}-04$ & 49 & 2.33E-04 & 583 & $1.23 \mathrm{E}-03$ & 317 & - & 4.24E-10 \\
\hline LW44-9.19 & 0 & 23 & 7.7E-06 & 36.91 & 8 & 1.016 & 0.020 & 53 & $1.57 \mathrm{E}-04$ & 49 & $1.78 \mathrm{E}-04$ & 581 & $9.80 \mathrm{E}-04$ & 318 & - & 3.29E-10 \\
\hline LW44-9.20 & 0 & 23 & 9.7E-06 & 39.09 & 8 & 1.015 & 0.020 & 54 & $2.07 \mathrm{E}-04$ & 55 & 3.13E-04 & 656 & $1.48 \mathrm{E}-03$ & 319 & - & $5.08 \mathrm{E}-10$ \\
\hline LW44-9.21 & 0 & 23 & $9.8 \mathrm{E}-06$ & 40.84 & 8 & 1.015 & 0.020 & 54 & 2.11E-04 & 54 & $3.05 \mathrm{E}-04$ & 579 & $1.24 \mathrm{E}-03$ & 322 & - & 4.12E-10 \\
\hline LW44-9.22 & 0 & 23 & 9.7E-06 & 42.84 & 8 & 1.015 & 0.020 & 53 & 2.03E-04 & 54 & 3.11E-04 & 552 & $1.14 \mathrm{E}-03$ & 324 & - & 3.76E-10 \\
\hline \multicolumn{17}{|l|}{ Exp. \#10 } \\
\hline LW44-10.0 & 0 & 23 & - & - & 8 & - & - & $<50$ & - & $<25$ & - & $<50$ & - & $<100$ & - & - \\
\hline LW44-10.1 & 0 & 23 & - & - & 8 & - & - & $<50$ & - & $<25$ & - & $<50$ & - & $<100$ & - & - \\
\hline LW44-10.2 & 0 & 23 & - & - & 8 & - & - & $<50$ & - & $<25$ & - & $<50$ & - & $<100$ & - & - \\
\hline LW44-10.0 & 0 & 23 & $9.4 \mathrm{E}-06$ & 1.06 & 8 & 1.015 & 0.020 & ND & 5.78E-04 & ND & - & ND & - & $\mathrm{ND}$ & - & 2.97E-10 \\
\hline LW44-10.1 & 0 & 23 & $1.8 \mathrm{E}-05$ & 2.21 & 8 & 1.015 & 0.020 & ND & $5.45 \mathrm{E}-04$ & ND & - & ND & - & ND & - & $6.24 \mathrm{E}-10$ \\
\hline LW44-10.2 & 0 & 23 & 6.3E-06 & 5.06 & 8 & 1.015 & 0.020 & ND & $2.03 \mathrm{E}-04$ & ND & - & ND & - & ND & - & $1.96 \mathrm{E}-10$ \\
\hline LW44-10.3 & 0 & 23 & 9.5E-06 & 7.07 & 8 & 1.015 & 0.020 & 84 & 5.65E-05 & 45 & $2.90 \mathrm{E}-04$ & 2933 & $9.17 \mathrm{E}-03$ & 236 & $3.08 \mathrm{E}-04$ & 3.43E-09 \\
\hline LW44-10.7 & 0 & 23 & 9.7E-06 & 14.80 & 8 & 1.015 & 0.020 & 81 & 7.75E-05 & 68 & $6.33 \mathrm{E}-04$ & 1505 & 4.75E-03 & 376 & $6.43 \mathrm{E}-04$ & $1.68 \mathrm{E}-09$ \\
\hline LW44-10.10 & 0 & 23 & 1.1E-05 & 20.08 & 8 & 1.015 & 0.020 & 61 & 8.54E-04 & 67 & $6.71 \mathrm{E}-04$ & 972 & $3.26 \mathrm{E}-03$ & 359 & 6.53E-04 & $1.22 \mathrm{E}-09$ \\
\hline LW44-10.13 & 0 & 23 & $9.8 \mathrm{E}-06$ & 25.82 & 8 & 1.015 & 0.020 & 53 & 8.58E-04 & 71 & $6.76 \mathrm{E}-04$ & 775 & 2.38E-03 & 353 & 5.92E-04 & $9.27 \mathrm{E}-10$ \\
\hline LW44-10.16 & 0 & 23 & $9.6 \mathrm{E}-06$ & 30.95 & 8 & 1.015 & 0.020 & 54 & 8.86E-04 & 60 & $5.16 \mathrm{E}-04$ & 676 & 2.02E-03 & 354 & 5.83E-04 & 7.74E-10 \\
\hline LW44-10.18 & 0 & 23 & 9.7E-06 & 34.98 & 8 & 1.015 & 0.020 & ND & 8.57E-04 & 53 & $4.06 \mathrm{E}-04$ & 702 & 2.13E-03 & 316 & 5.02E-04 & 8.57E-10 \\
\hline LW44-10.19 & 0 & 23 & $9.8 \mathrm{E}-06$ & 36.91 & 8 & 1.015 & 0.020 & ND & 6.95E-04 & 50 & 3.77E-04 & 611 & $1.85 \mathrm{E}-03$ & 311 & 4.97E-04 & 7.52E-10 \\
\hline LW44-10.20 & 0 & 23 & $9.8 \mathrm{E}-06$ & 39.09 & 8 & 1.015 & 0.020 & 50 & 5.49E-06 & 53 & 4.10E-04 & 564 & $1.69 \mathrm{E}-03$ & 328 & 5.33E-04 & $6.72 \mathrm{E}-10$ \\
\hline LW44-10.21 & 0 & 23 & $9.8 \mathrm{E}-06$ & 40.84 & 8 & 1.014 & 0.020 & ND & - & 51 & $3.90 \mathrm{E}-04$ & 538 & $1.61 \mathrm{E}-03$ & 317 & 5.11E-04 & $6.56 \mathrm{E}-10$ \\
\hline LW44-10.22 & 0 & 23 & 7.8E-06 & 42.84 & 8 & 1.014 & 0.020 & ND & - & 54 & $3.47 \mathrm{E}-04$ & 538 & $1.28 \mathrm{E}-03$ & 326 & 4.22E-04 & $5.14 \mathrm{E}-10$ \\
\hline \multicolumn{17}{|l|}{ Exp.\#11 } \\
\hline LW44-11.0 & 0 & 23 & - & - & 9 & - & - & $<50$ & - & $<25$ & - & $<50$ & - & $<100$ & - & - \\
\hline LW44-11.1 & 0 & 23 & - & - & 9 & - & - & $<50$ & - & $<25$ & - & $<50$ & - & $<100$ & - & - \\
\hline LW44-11.2 & 0 & 23 & - & - & 9 & - & - & $<50$ & - & $<25$ & - & $<50$ & - & $<100$ & - & - \\
\hline LW44-11.3 & 0 & 23 & 9.3E-06 & 2.01 & 9 & 1.005 & 0.020 & 60 & $1.74 \mathrm{E}-04$ & 76 & 7.33E-04 & 1910 & 5.86E-03 & 441 & 7.66E-04 & 2.27E-09 \\
\hline LW44-11.7 & 0 & 23 & 9.7E-06 & 7.73 & 9 & 1.005 & 0.020 & 299 & $4.40 \mathrm{E}-03$ & 341 & 4.72E-03 & 1999 & 6.43E-03 & 2140 & 4.79E-03 & 8.09E-10 \\
\hline LW44-11.10 & 0 & 23 & $1.0 \mathrm{E}-05$ & 13.01 & 9 & 1.004 & 0.020 & 338 & 5.47E-03 & 386 & 5.77E-03 & 1941 & $6.68 \mathrm{E}-03$ & 2384 & 5.75E-03 & 4.85E-10 \\
\hline LW44-11.13 & 0 & 23 & $9.8 \mathrm{E}-06$ & 18.75 & 9 & 1.004 & 0.020 & 316 & 4.73E-03 & 363 & $5.06 \mathrm{E}-03$ & 1768 & 5.69E-03 & 2251 & 5.07E-03 & 3.83E-10 \\
\hline LW44-11.16 & 0 & 23 & $9.6 \mathrm{E}-06$ & 23.89 & 9 & 1.004 & 0.020 & 354 & 5.34E-03 & 408 & 5.66E-03 & 1948 & $6.21 \mathrm{E}-03$ & 2456 & 5.49E-03 & $3.49 \mathrm{E}-10$ \\
\hline LW44-11.18 & 0 & 23 & 9.7E-06 & 27.91 & 9 & 1.003 & 0.020 & 371 & $5.68 \mathrm{E}-03$ & 427 & $6.00 \mathrm{E}-03$ & 1933 & $6.21 \mathrm{E}-03$ & 2577 & 5.82E-03 & $2.11 \mathrm{E}-10$ \\
\hline LW44-11.19 & 0 & 23 & $9.8 \mathrm{E}-06$ & 29.84 & 9 & 1.003 & 0.020 & 376 & 5.83E-03 & 431 & 6.12E-03 & 2027 & 6.59E-03 & 2603 & 5.95E-03 & 3.06E-10 \\
\hline LW44-11.20 & 0 & 23 & 9.7E-06 & 32.02 & 9 & 1.003 & 0.020 & 365 & $5.60 \mathrm{E}-03$ & 419 & 5.91E-03 & 2025 & $6.54 \mathrm{E}-03$ & 2524 & 5.72E-03 & 3.77E-10 \\
\hline LW44-11.21 & 0 & 23 & $9.8 \mathrm{E}-06$ & 33.77 & 9 & 1.002 & 0.020 & 377 & $5.86 \mathrm{E}-03$ & 428 & $6.08 \mathrm{E}-03$ & 2063 & 6.73E-03 & 2611 & $5.98 \mathrm{E}-03$ & $3.45 \mathrm{E}-10$ \\
\hline LW44-11.22 & 0 & 23 & 9.7E-06 & 35.77 & 9 & 1.002 & 0.020 & 377 & 5.81E-03 & 429 & $6.05 \mathrm{E}-03$ & 2105 & $6.81 \mathrm{E}-03$ & 2618 & 5.95E-03 & 3.99E-10 \\
\hline \multicolumn{17}{|l|}{ Exp. \#12 } \\
\hline LW44-12.0 & 0 & 23 & - & - & 9 & - & - & $<50$ & - & $<25$ & - & $<50$ & - & $<100$ & - & - \\
\hline
\end{tabular}


Table A1. SPFT Results for LAWA44 Glasses.

\begin{tabular}{|c|c|c|c|c|c|c|c|c|c|c|c|c|c|c|c|c|}
\hline Sample ID & $\begin{array}{c}\text { Influent } \\
\text { [Si] }\end{array}$ & $\begin{array}{c}\mathrm{T} \\
\left({ }^{\circ} \mathrm{C}\right) \\
\end{array}$ & $\begin{array}{c}\text { Flow } \\
\text { Rate } \\
\left(\mathrm{m}^{3} / \mathrm{d}\right) \\
\end{array}$ & $\begin{array}{l}\text { Time, } \\
\text { days }\end{array}$ & $\begin{array}{c}\mathrm{pH} \\
\left(23^{\circ} \mathrm{C}\right) \\
\end{array}$ & $\begin{array}{l}\text { Glass } \\
\text { Mass } \\
(\mathrm{g}) \\
\end{array}$ & $\begin{array}{l}\text { SA } \\
\left(\mathrm{m}^{2}\right) \\
\end{array}$ & {$[\mathrm{B}]$} & B Rate & {$[\mathrm{Al}]$} & Al Rate & {$[\mathrm{Na}]$} & Na Rate & {$[\mathrm{Si}]$} & Si Rate & IEX Rate \\
\hline LW44-12.1 & 0 & 23 & - & - & 9 & - & - & $<50$ & - & $<25$ & - & $<50$ & - & $<100$ & - & - \\
\hline LW44-12.2 & 0 & 23 & - & - & 9 & - & - & $<50$ & - & $<25$ & - & $<50$ & - & $<100$ & - & - \\
\hline LW44-12.3 & 0 & 23 & 9.5E-06 & 2.01 & 9 & 1.015 & 0.020 & 59 & $1.54 \mathrm{E}-04$ & 78 & 7.59E-04 & 1974 & $6.15 \mathrm{E}-03$ & 440 & 7.73E-04 & 2.39E-09 \\
\hline LW44-12.7 & 0 & 23 & $9.7 \mathrm{E}-06$ & 9.74 & 9 & 1.015 & 0.020 & 307 & $4.50 \mathrm{E}-03$ & 339 & 4.62E-03 & 2060 & $6.55 \mathrm{E}-03$ & 2200 & 4.87E-03 & 8.18E-10 \\
\hline LW44-12.10 & 0 & 23 & $1.0 \mathrm{E}-05$ & 15.02 & 9 & 1.014 & 0.020 & 304 & 4.79E-03 & 353 & $5.21 \mathrm{E}-03$ & 1801 & $6.14 \mathrm{E}-03$ & 2199 & 5.25E-03 & $5.41 \mathrm{E}-10$ \\
\hline LW44-12.13 & 0 & 23 & $9.8 \mathrm{E}-06$ & 20.76 & 9 & 1.014 & 0.020 & 258 & $3.66 \mathrm{E}-03$ & 293 & 3.99E-03 & 1542 & $4.90 \mathrm{E}-03$ & 1805 & 3.99E-03 & 4.94E-10 \\
\hline LW44-12.16 & 0 & 23 & $9.6 \mathrm{E}-06$ & 25.90 & 9 & 1.014 & 0.020 & 344 & 5.11E-03 & 403 & 5.53E-03 & 1866 & 5.88E-03 & 2397 & 5.30E-03 & $3.08 \mathrm{E}-10$ \\
\hline LW44-12.18 & 0 & 23 & $9.7 \mathrm{E}-06$ & 29.92 & 9 & 1.014 & 0.020 & 368 & 5.53E-03 & 430 & 5.94E-03 & 1951 & 6.17E-03 & 2566 & $5.70 \mathrm{E}-03$ & $2.55 \mathrm{E}-10$ \\
\hline LW44-12.19 & 0 & 23 & $9.9 \mathrm{E}-06$ & 31.85 & 9 & 1.013 & 0.020 & 383 & 5.94E-03 & 436 & 6.17E-03 & 2016 & $6.53 \mathrm{E}-03$ & 2585 & $5.88 \mathrm{E}-03$ & 2.39E-10 \\
\hline LW44-12.20 & 0 & 23 & $9.8 \mathrm{E}-06$ & 34.03 & 9 & 1.013 & 0.020 & 390 & $6.01 \mathrm{E}-03$ & 442 & $6.20 \mathrm{E}-03$ & 2001 & $6.41 \mathrm{E}-03$ & 2664 & 6.01E-03 & $1.63 \mathrm{E}-10$ \\
\hline LW44-12.21 & 0 & 23 & $9.8 \mathrm{E}-06$ & 35.78 & 9 & 1.012 & 0.020 & 378 & $5.80 \mathrm{E}-03$ & 428 & $6.01 \mathrm{E}-03$ & 2078 & $6.68 \mathrm{E}-03$ & 2592 & $5.85 \mathrm{E}-03$ & $3.51 \mathrm{E}-10$ \\
\hline LW44-12.22 & 0 & 23 & $9.8 \mathrm{E}-06$ & 37.78 & 9 & 1.012 & 0.020 & 382 & 5.89E-03 & 435 & 6.13E-03 & 2117 & 6.82E-03 & 2634 & 5.96E-03 & 3.73E-10 \\
\hline \multicolumn{17}{|l|}{ Exp.\#13 } \\
\hline LW44-13.0 & 0 & 23 & - & - & 10 & - & - & $<50$ & - & $<25$ & - & 138 & - & $<100$ & - & - \\
\hline LW44-13.1 & 0 & 23 & - & - & 10 & - & - & $<50$ & - & $<25$ & - & 147 & - & 175 & - & - \\
\hline LW44-13.2 & 0 & 23 & - & - & 10 & - & - & $<50$ & - & $<25$ & - & 110 & - & 159 & - & - \\
\hline LW44-13.3 & 0 & 23 & $9.3 \mathrm{E}-06$ & 2.01 & 10 & 1.012 & 0.020 & 166 & $1.96 \mathrm{E}-03$ & 295 & 3.85E-03 & 2290 & $6.80 \mathrm{E}-03$ & 1706 & 3.51E-03 & 1.93E-09 \\
\hline LW44-13.7 & 0 & 23 & $1.0 \mathrm{E}-05$ & 9.74 & 10 & 1.011 & 0.020 & 650 & 1.09E-02 & 798 & 1.18E-02 & 3922 & $1.28 \mathrm{E}-02$ & 4839 & 1.13E-02 & 7.66E-10 \\
\hline LW44-13.10 & 0 & 23 & $1.1 \mathrm{E}-05$ & 15.02 & 10 & 1.011 & 0.020 & 724 & $1.29 \mathrm{E}-02$ & 880 & $1.38 \mathrm{E}-02$ & 4039 & 1.39E-02 & 5479 & $1.35 \mathrm{E}-02$ & $4.14 \mathrm{E}-10$ \\
\hline LW44-13.13 & 0 & 23 & $9.7 \mathrm{E}-06$ & 20.76 & 10 & 1.010 & 0.020 & 605 & $9.74 \mathrm{E}-03$ & 699 & $9.97 \mathrm{E}-03$ & 3222 & $1.01 \mathrm{E}-02$ & 4282 & $9.65 \mathrm{E}-03$ & $1.47 \mathrm{E}-10$ \\
\hline LW44-13.16 & 0 & 23 & $9.6 \mathrm{E}-06$ & 25.90 & 10 & 1.010 & 0.020 & 644 & $1.03 \mathrm{E}-02$ & 752 & $1.06 \mathrm{E}-02$ & 3460 & 1.08E-02 & 4521 & $1.01 \mathrm{E}-02$ & $1.82 \mathrm{E}-10$ \\
\hline LW44-13.18 & 0 & 23 & $9.7 \mathrm{E}-06$ & 29.92 & 10 & 1.009 & 0.020 & 643 & $1.04 \mathrm{E}-02$ & 752 & $1.08 \mathrm{E}-02$ & 3426 & $1.08 \mathrm{E}-02$ & 4553 & 1.03E-02 & $1.47 \mathrm{E}-10$ \\
\hline LW44-13.19 & 0 & 23 & $9.9 \mathrm{E}-06$ & 31.85 & 10 & 1.008 & 0.020 & 630 & $1.04 \mathrm{E}-02$ & 738 & $1.07 \mathrm{E}-02$ & 3374 & $1.08 \mathrm{E}-02$ & 4496 & 1.03E-02 & $1.73 \mathrm{E}-10$ \\
\hline LW44-13.20 & 0 & 23 & $9.7 \mathrm{E}-06$ & 34.03 & 10 & 1.008 & 0.020 & 644 & $1.04 \mathrm{E}-02$ & 757 & $1.08 \mathrm{E}-02$ & 3351 & $1.05 \mathrm{E}-02$ & 4614 & $1.04 \mathrm{E}-02$ & 4.19E-11 \\
\hline LW44-13.21 & 0 & 23 & $9.9 \mathrm{E}-06$ & 35.78 & 10 & 1.007 & 0.020 & 652 & $1.08 \mathrm{E}-02$ & 767 & $1.12 \mathrm{E}-02$ & 3466 & $1.11 \mathrm{E}-02$ & 4698 & $1.08 \mathrm{E}-02$ & $1.38 \mathrm{E}-10$ \\
\hline LW44-13.22 & 0 & 23 & $9.7 \mathrm{E}-06$ & 37.78 & 10 & 1.006 & 0.020 & 663 & 1.09E-02 & 771 & $1.11 \mathrm{E}-02$ & 3545 & 1.13E-02 & 4794 & $1.09 \mathrm{E}-02$ & $1.63 \mathrm{E}-10$ \\
\hline \multicolumn{17}{|l|}{ Exp.\#14 } \\
\hline LW44-14.0 & 0 & 23 & - & - & 10 & - & - & $<50$ & - & $<25$ & - & 76 & - & $<100$ & - & - \\
\hline LW44-14.1 & 0 & 23 & - & - & 10 & - & - & $<50$ & - & $<25$ & - & 133 & - & 151 & - & - \\
\hline LW44-14.2 & 0 & 23 & - & - & 10 & - & - & $<50$ & - & $<25$ & - & 86 & - & 163 & - & - \\
\hline LW44-14.3 & 0 & 23 & $9.5 \mathrm{E}-06$ & 2.01 & 10 & 1.015 & 0.020 & 172 & 2.09E-03 & 300 & 3.97E-03 & 2214 & $6.75 \mathrm{E}-03$ & 1761 & 3.69E-03 & $1.86 \mathrm{E}-09$ \\
\hline LW44-14.7 & 0 & 23 & $9.7 \mathrm{E}-06$ & 9.74 & 10 & 1.014 & 0.020 & 643 & $1.03 \mathrm{E}-02$ & 807 & 1.15E-02 & 3770 & 1.19E-02 & 4821 & $1.08 \mathrm{E}-02$ & 6.34E-10 \\
\hline LW44-14.10 & 0 & 23 & $1.1 \mathrm{E}-05$ & 15.02 & 10 & 1.014 & 0.020 & 656 & $1.17 \mathrm{E}-02$ & 773 & $1.21 \mathrm{E}-02$ & 3731 & $1.30 \mathrm{E}-02$ & 5009 & $1.24 \mathrm{E}-02$ & $5.42 \mathrm{E}-10$ \\
\hline LW44-14.13 & 0 & 23 & $9.8 \mathrm{E}-06$ & 20.76 & 10 & 1.013 & 0.020 & 494 & $7.88 \mathrm{E}-03$ & 555 & 7.93E-03 & 2765 & 8.82E-03 & 3440 & 7.78E-03 & 3.72E-10 \\
\hline LW44-14.16 & 0 & 23 & $9.6 \mathrm{E}-06$ & 25.90 & 10 & 1.013 & 0.020 & 644 & $1.03 \mathrm{E}-02$ & 743 & $1.05 \mathrm{E}-02$ & 3288 & $1.03 \mathrm{E}-02$ & 4482 & $9.98 \mathrm{E}-03$ & - \\
\hline LW44-14.18 & 0 & 23 & $9.7 \mathrm{E}-06$ & 29.92 & 10 & 1.012 & 0.020 & 650 & $1.05 \mathrm{E}-02$ & 755 & $1.07 \mathrm{E}-02$ & 3329 & $1.05 \mathrm{E}-02$ & 4598 & 1.03E-02 & $1.55 \mathrm{E}-11$ \\
\hline LW44-14.19 & 0 & 23 & $9.8 \mathrm{E}-06$ & 31.85 & 10 & 1.011 & 0.020 & 660 & $1.09 \mathrm{E}-02$ & 775 & $1.12 \mathrm{E}-02$ & 3417 & $1.10 \mathrm{E}-02$ & 4711 & $1.08 \mathrm{E}-02$ & $5.55 \mathrm{E}-11$ \\
\hline LW44-14.20 & 0 & 23 & $9.8 \mathrm{E}-06$ & 34.03 & 10 & 1.011 & 0.020 & 640 & $1.04 \mathrm{E}-02$ & 760 & $1.09 \mathrm{E}-02$ & 3495 & $1.12 \mathrm{E}-02$ & 4579 & $1.04 \mathrm{E}-02$ & $2.99 \mathrm{E}-10$ \\
\hline LW44-14.21 & 0 & 23 & $9.9 \mathrm{E}-06$ & 35.78 & 10 & 1.010 & 0.020 & 643 & $1.06 \mathrm{E}-02$ & 783 & $1.14 \mathrm{E}-02$ & 3454 & $1.12 \mathrm{E}-02$ & 4682 & $1.08 \mathrm{E}-02$ & $2.26 \mathrm{E}-10$ \\
\hline LW44-14.22 & 0 & 23 & $9.8 \mathrm{E}-06$ & 37.78 & 10 & 1.009 & 0.020 & 666 & $1.09 \mathrm{E}-02$ & 789 & $1.14 \mathrm{E}-02$ & 3638 & 1.17E-02 & 4862 & $1.11 \mathrm{E}-02$ & 3.07E-10 \\
\hline
\end{tabular}


Table A1. SPFT Results for LAWA44 Glasses.

\begin{tabular}{|c|c|c|c|c|c|c|c|c|c|c|c|c|c|c|c|c|}
\hline Sample ID & $\begin{array}{c}\text { Influent } \\
\text { [Si] } \\
\end{array}$ & $\begin{array}{c}\mathrm{T} \\
\left({ }^{\circ} \mathrm{C}\right) \\
\end{array}$ & $\begin{array}{c}\text { Flow } \\
\text { Rate } \\
\left(\mathrm{m}^{3} / \mathrm{d}\right)\end{array}$ & $\begin{array}{c}\text { Time, } \\
\text { days }\end{array}$ & $\begin{array}{c}\mathrm{pH} \\
\left(23^{\circ} \mathrm{C}\right) \\
\end{array}$ & $\begin{array}{c}\text { Glass } \\
\text { Mass } \\
\text { (g) }\end{array}$ & $\begin{array}{c}\text { SA } \\
\left(\mathrm{m}^{2}\right) \\
\end{array}$ & {$[\mathrm{B}]$} & B Rate & {$[\mathrm{Al}]$} & Al Rate & {$[\mathrm{Na}]$} & Na Rate & {$[\mathrm{Si}]$} & Si Rate & IEX Rate \\
\hline \multicolumn{17}{|l|}{ Exp. \#15 } \\
\hline LW44-15.0 & 0 & 23 & - & - & 11 & - & - & $<50$ & - & $<25$ & - & 204 & - & 122 & - & - \\
\hline LW44-15.1 & 0 & 23 & - & - & 11 & - & - & $<50$ & - & $<25$ & - & 284 & - & 381 & - & - \\
\hline LW44-15.2 & 0 & 23 & - & - & 11 & - & - & $<50$ & - & $<25$ & - & 298 & - & 489 & - & - \\
\hline LW44-15.3 & 0 & 23 & $9.5 \mathrm{E}-06$ & 2.01 & 11 & 1.009 & 0.020 & 763 & $1.22 \mathrm{E}-02$ & 1050 & $1.48 \mathrm{E}-02$ & 5913 & $1.81 \mathrm{E}-02$ & 6604 & $1.43 \mathrm{E}-02$ & 2.33E-09 \\
\hline LW44-15.7 & 0 & 23 & 9.6E-06 & 9.74 & 11 & 1.008 & 0.020 & 2442 & 4.18E-02 & 2754 & 4.02E-02 & 14683 & 4.69E-02 & 17051 & 3.88E-02 & 2.06E-09 \\
\hline LW44-15.10 & 0 & 23 & $1.0 \mathrm{E}-05$ & 15.02 & 11 & 1.005 & 0.020 & 2869 & 5.37E-02 & 3212 & $5.12 \mathrm{E}-02$ & 16583 & $5.80 \mathrm{E}-02$ & 19781 & $4.92 \mathrm{E}-02$ & $1.69 \mathrm{E}-09$ \\
\hline LW44-15.13 & 0 & 23 & 9.7E-06 & 20.76 & 11 & 1.003 & 0.020 & 3078 & 5.36E-02 & 3395 & 5.03E-02 & 18941 & 6.16E-02 & 21194 & $4.90 \mathrm{E}-02$ & 3.20E-09 \\
\hline LW44-15.16 & 0 & 23 & $9.6 \mathrm{E}-06$ & 25.90 & 11 & 0.999 & 0.020 & 3202 & 5.53E-02 & 3522 & 5.17E-02 & 18710 & 6.03E-02 & 22061 & $5.06 \mathrm{E}-02$ & $1.99 \mathrm{E}-09$ \\
\hline LW44-15.18 & 0 & 23 & 9.6E-06 & 29.92 & 11 & 0.996 & 0.020 & 2776 & 4.83E-02 & 3007 & 4.45E-02 & 16009 & 5.19E-02 & 18931 & 4.37E-02 & $1.47 \mathrm{E}-09$ \\
\hline LW44-15.19 & 0 & 23 & $9.8 \mathrm{E}-06$ & 31.85 & 11 & 0.994 & 0.020 & 2314 & 4.09E-02 & 2447 & 3.69E-02 & 14100 & 4.66E-02 & 15535 & 3.65E-02 & 2.27E-09 \\
\hline LW44-15.20 & 0 & 23 & 9.7E-06 & 34.03 & 11 & 0.991 & 0.020 & 2691 & $4.72 \mathrm{E}-02$ & 2902 & 4.33E-02 & 15788 & $5.16 \mathrm{E}-02$ & 18272 & $4.25 \mathrm{E}-02$ & $1.79 \mathrm{E}-09$ \\
\hline LW44-15.21 & 0 & 23 & 9.9E-06 & 35.78 & 11 & 0.988 & 0.020 & 2630 & 4.71E-02 & 2846 & 4.33E-02 & 15319 & 5.12E-02 & 17836 & 4.24E-02 & $1.64 \mathrm{E}-09$ \\
\hline LW44-15.22 & 0 & 23 & $9.7 \mathrm{E}-06$ & 37.78 & 11 & 0.986 & 0.019 & 2637 & 4.66E-02 & 2831 & 4.26E-02 & 15795 & $5.21 \mathrm{E}-02$ & 17798 & 4.18E-02 & $2.20 \mathrm{E}-09$ \\
\hline \multicolumn{17}{|l|}{ Exp.\#16 } \\
\hline LW44-16.0 & 0 & 23 & - & - & 11 & - & - & $<50$ & - & $<25$ & - & 230 & - & 146 & - & - \\
\hline LW44-16.1 & 0 & 23 & - & - & 11 & - & - & $<50$ & - & $<25$ & - & 389 & - & 581 & - & - \\
\hline LW44-16.2 & 0 & 23 & - & - & 11 & - & - & $<50$ & - & $<25$ & - & 266 & - & 528 & - & - \\
\hline LW44-16.3 & 0 & 23 & 9.6E-06 & 2.01 & 11 & 1.000 & 0.020 & 769 & $1.26 \mathrm{E}-02$ & 1079 & $1.55 \mathrm{E}-02$ & 5733 & 1.77E-02 & 6660 & $1.45 \mathrm{E}-02$ & 2.05E-09 \\
\hline LW44-16.7 & 0 & 23 & $9.8 \mathrm{E}-06$ & 9.74 & 11 & 0.999 & 0.020 & 2143 & 3.74E-02 & 2396 & 3.57E-02 & 12668 & 4.12E-02 & 14895 & 3.44E-02 & $1.51 \mathrm{E}-09$ \\
\hline LW44-16.10 & 0 & 23 & $1.1 \mathrm{E}-05$ & 15.02 & 11 & 0.997 & 0.020 & 2668 & $5.09 \mathrm{E}-02$ & 2989 & 4.85E-02 & 15072 & 5.35E-02 & 18526 & 4.67E-02 & $1.05 \mathrm{E}-09$ \\
\hline LW44-16.13 & 0 & 23 & $9.8 \mathrm{E}-06$ & 20.76 & 11 & 0.994 & 0.020 & 3032 & 5.37E-02 & 3377 & $5.09 \mathrm{E}-02$ & 17319 & $5.71 \mathrm{E}-02$ & 21068 & 4.94E-02 & $1.36 \mathrm{E}-09$ \\
\hline LW44-16.16 & 0 & 23 & 9.6E-06 & 25.90 & 11 & 0.991 & 0.020 & 3039 & 5.30E-02 & 3337 & 4.95E-02 & 17594 & 5.71E-02 & 20847 & 4.81E-02 & $1.66 \mathrm{E}-09$ \\
\hline LW44-16.18 & 0 & 23 & 9.7E-06 & 29.92 & 11 & 0.988 & 0.020 & 2652 & 4.66E-02 & 2885 & 4.31E-02 & 15189 & 4.97E-02 & 18050 & 4.19E-02 & 1.23E-09 \\
\hline LW44-16.19 & 0 & 23 & $9.8 \mathrm{E}-06$ & 31.85 & 11 & 0.985 & 0.019 & 2491 & 4.46E-02 & 2675 & $4.08 \mathrm{E}-02$ & 14552 & 4.85E-02 & 16808 & 3.98E-02 & 1.57E-09 \\
\hline LW44-16.20 & 0 & 23 & $9.8 \mathrm{E}-06$ & 34.03 & 11 & 0.983 & 0.019 & 2402 & 4.27E-02 & 2588 & 3.92E-02 & 14176 & 4.69E-02 & 16168 & 3.79E-02 & $1.69 \mathrm{E}-09$ \\
\hline LW44-16.21 & 0 & 23 & $9.8 \mathrm{E}-06$ & 35.78 & 11 & 0.980 & 0.019 & 2498 & 4.49E-02 & 2674 & 4.10E-02 & 14753 & 4.94E-02 & 16848 & $4.00 \mathrm{E}-02$ & $1.80 \mathrm{E}-09$ \\
\hline LW44-16.22 & 0 & 23 & $9.8 \mathrm{E}-06$ & 37.78 & 11 & 0.978 & 0.019 & 2554 & 4.57E-02 & 2767 & $4.21 \mathrm{E}-02$ & 14908 & 4.97E-02 & 17338 & 4.10E-02 & $1.59 \mathrm{E}-09$ \\
\hline \multicolumn{17}{|l|}{ Exp.\#17 } \\
\hline LW44-17A & $8.67 \mathrm{E}+02$ & 70 & - & - & 9 & - & - & $<50$ & - & $<50$ & - & $<100$ & - & $<500$ & - & - \\
\hline LW44-17B & $8.67 \mathrm{E}+02$ & 70 & - & - & 9 & - & - & $<50$ & - & $<50$ & - & $<100$ & - & $<500$ & - & - \\
\hline LW44-17C & $8.67 \mathrm{E}+02$ & 70 & - & - & 9 & - & - & $<50$ & - & $<50$ & - & $<100$ & - & $<500$ & - & - \\
\hline LW44-17.3 & $8.67 \mathrm{E}+02$ & 70 & 6.3E-05 & 3.07 & 9 & 1.006 & 0.036 & 519 & $2.98 \mathrm{E}-02$ & 531 & $2.57 \mathrm{E}-02$ & 4822 & 5.59E-02 & (4272) & 3.18E-02 & $1.04 \mathrm{E}-08$ \\
\hline LW44-17.4 & $8.67 \mathrm{E}+02$ & 70 & 5.6E-05 & 4.00 & 9 & 1.004 & 0.020 & 814 & 7.84E-02 & 854 & 6.95E-02 & 5090 & $9.54 \mathrm{E}-02$ & (6512) & 8.19E-02 & 6.78E-09 \\
\hline LW44-17.6 & $8.67 \mathrm{E}+02$ & 70 & $6.0 \mathrm{E}-05$ & 5.23 & 9 & 1.002 & 0.020 & 792 & 8.09E-02 & 851 & 7.36E-02 & 4295 & 8.52E-02 & (6457) & 8.62E-02 & 1.73E-09 \\
\hline LW44-17.9 & $8.67 \mathrm{E}+02$ & 70 & $6.1 \mathrm{E}-05$ & 7.07 & 9 & 1.000 & 0.020 & 771 & 7.99E-02 & 827 & $7.25 \mathrm{E}-02$ & 4175 & $8.41 \mathrm{E}-02$ & (6327) & 8.57E-02 & $1.67 \mathrm{E}-09$ \\
\hline LW44-17.10 & $8.67 \mathrm{E}+02$ & 70 & 2.6E-05 & 7.92 & 9 & 0.998 & 0.020 & 700 & 3.11E-02 & 763 & $2.88 \mathrm{E}-02$ & 4091 & 3.56E-02 & (5841) & 3.40E-02 & 1.79E-09 \\
\hline LW44-17.11 & $8.67 \mathrm{E}+02$ & 70 & $6.0 \mathrm{E}-05$ & 8.18 & 9 & 0.997 & 0.020 & 677 & 6.92E-02 & 743 & $6.45 \mathrm{E}-02$ & 3847 & 7.71E-02 & (5617) & $7.50 \mathrm{E}-02$ & 3.13E-09 \\
\hline LW44-17.12 & $8.67 \mathrm{E}+02$ & 70 & 5.5E-05 & 8.97 & 9 & 0.996 & 0.020 & 689 & $6.43 \mathrm{E}-02$ & 764 & $6.05 \mathrm{E}-02$ & 3898 & 7.12E-02 & (5873) & 7.17E-02 & $2.74 \mathrm{E}-09$ \\
\hline LW44-17.13 & $8.67 \mathrm{E}+02$ & 70 & 5.3E-05 & 9.17 & 9 & 0.995 & 0.020 & 655 & 5.93E-02 & 723 & $5.56 \mathrm{E}-02$ & 3529 & $6.26 \mathrm{E}-02$ & (5404) & 6.38E-02 & $1.32 \mathrm{E}-09$ \\
\hline
\end{tabular}


Table A1. SPFT Results for LAWA44 Glasses.

\begin{tabular}{|c|c|c|c|c|c|c|c|c|c|c|c|c|c|c|c|c|}
\hline Sample ID & $\begin{array}{c}\text { Influent } \\
{[\mathrm{Si}]}\end{array}$ & $\begin{array}{c}\mathrm{T} \\
\left({ }^{\circ} \mathrm{C}\right)\end{array}$ & $\begin{array}{l}\text { Flow } \\
\text { Rate } \\
\left(\mathrm{m}^{3} / \mathrm{d}\right)\end{array}$ & $\begin{array}{l}\text { Time, } \\
\text { days }\end{array}$ & $\begin{array}{c}\mathrm{pH} \\
\left(23^{\circ} \mathrm{C}\right)\end{array}$ & $\begin{array}{c}\text { Glass } \\
\text { Mass } \\
\text { (g) }\end{array}$ & $\begin{array}{l}\text { SA } \\
\left(\mathrm{m}^{2}\right)\end{array}$ & [B] & B Rate & {$[\mathrm{Al}]$} & Al Rate & {$[\mathrm{Na}]$} & Na Rate & {$[\mathrm{Si}]$} & Si Rate & IEX Rate \\
\hline \multicolumn{17}{|l|}{ Exp.\#18 } \\
\hline LW44-18A & $1.00 \mathrm{E}+01$ & 70 & - & - & 9 & - & - & $<50$ & - & $<50$ & - & $<100$ & - & (20812) & - & - \\
\hline LW44-18B & $1.00 \mathrm{E}+01$ & 70 & - & - & 9 & - & - & $<50$ & - & $<50$ & - & 105 & - & (20815) & - & - \\
\hline LW44-18C & $1.00 \mathrm{E}+01$ & 70 & - & - & 9 & - & - & $<50$ & - & $<50$ & - & $<100$ & - & (21263) & - & - \\
\hline LW44-18.3 & $1.00 \mathrm{E}+01$ & 70 & $5.0 \mathrm{E}-05$ & 3.07 & 9 & 1.007 & 0.036 & 347 & $1.49 \mathrm{E}-02$ & 269 & $9.23 \mathrm{E}-03$ & 3681 & 3.34E-02 & (23238) & $1.51 \mathrm{E}-02$ & 7.39E-09 \\
\hline LW44-18.4 & $1.00 \mathrm{E}+01$ & 70 & 5.7E-05 & 4.00 & 9 & 1.006 & 0.020 & 556 & 5.25E-02 & 462 & $3.60 \mathrm{E}-02$ & 4307 & 8.13E-02 & (24669) & $5.10 \mathrm{E}-02$ & 1.15E-08 \\
\hline LW44-18.6 & $1.00 \mathrm{E}+01$ & 70 & $5.6 \mathrm{E}-05$ & 5.23 & 9 & 1.005 & 0.020 & 529 & 4.91E-02 & 485 & 3.75E-02 & 3534 & $6.54 \mathrm{E}-02$ & (24284) & 4.51E-02 & $6.54 \mathrm{E}-09$ \\
\hline LW44-18.9 & $1.00 \mathrm{E}+01$ & 70 & $6.1 \mathrm{E}-05$ & 7.07 & 9 & 1.004 & 0.020 & 498 & 4.94E-02 & 440 & 3.62E-02 & 3317 & 6.61E-02 & (23559) & 3.80E-02 & 6.67E-09 \\
\hline LW44-18.10 & $1.00 \mathrm{E}+01$ & 70 & 2.6E-05 & 7.92 & 9 & 1.003 & 0.020 & 399 & $1.64 \mathrm{E}-02$ & 401 & 1.39E-02 & 2908 & $2.46 \mathrm{E}-02$ & (23340) & $1.48 \mathrm{E}-02$ & $3.26 \mathrm{E}-09$ \\
\hline LW44-18.11 & $1.00 \mathrm{E}+01$ & 70 & 4.7E-05 & 8.18 & 9 & 1.002 & 0.020 & 385 & 2.90E-02 & 400 & $2.55 \mathrm{E}-02$ & 2717 & 4.22E-02 & (23211) & $2.58 \mathrm{E}-02$ & 5.27E-09 \\
\hline LW44-18.12 & $1.00 \mathrm{E}+01$ & 70 & $6.1 \mathrm{E}-05$ & 8.97 & 9 & 1.001 & 0.020 & 368 & $3.56 \mathrm{E}-02$ & 381 & 3.13E-02 & 2563 & $5.14 \mathrm{E}-02$ & (23617) & $3.95 \mathrm{E}-02$ & $6.30 \mathrm{E}-09$ \\
\hline LW44-18.13 & $1.00 \mathrm{E}+01$ & 70 & $6.4 \mathrm{E}-05$ & 9.17 & 9 & 1.001 & 0.020 & 350 & $3.51 \mathrm{E}-02$ & 377 & $3.21 \mathrm{E}-02$ & 2448 & $5.10 \mathrm{E}-02$ & (22972) & $3.11 \mathrm{E}-02$ & 6.37E-09 \\
\hline \multicolumn{17}{|l|}{ Exp. \#19 } \\
\hline LW44-19A & $2.93 \mathrm{E}+04$ & 70 & - & - & 9 & - & - & $<50$ & - & $<50$ & - & $<100$ & - & $(43280)$ & - & - \\
\hline LW44-19B & $2.93 \mathrm{E}+04$ & 70 & - & - & 9 & - & - & $<50$ & - & $<50$ & - & $<100$ & - & (43432) & - & - \\
\hline LW44-19C & $2.93 E+04$ & 70 & - & - & 9 & - & - & $<50$ & - & $<50$ & - & 219 & - & (43191) & - & - \\
\hline LW44-19.3 & $2.93 E+04$ & 70 & 5.7E-05 & 3.07 & 9 & 1.002 & 0.036 & 360 & $1.77 \mathrm{E}-02$ & 229 & 8.63E-03 & 4345 & 4.48E-02 & (45411) & $1.60 \mathrm{E}-02$ & $1.08 \mathrm{E}-08$ \\
\hline LW44-19.4 & $2.93 E+04$ & 70 & 5.9E-05 & 4.00 & 9 & 1.001 & 0.020 & 508 & 4.95E-02 & 327 & $2.52 \mathrm{E}-02$ & 3973 & 7.72E-02 & (46727) & 4.91E-02 & $1.10 \mathrm{E}-08$ \\
\hline LW44-19.6 & $2.93 \mathrm{E}+04$ & 70 & $6.1 \mathrm{E}-05$ & 5.23 & 9 & 1.000 & 0.020 & 480 & 4.79E-02 & 326 & $2.60 \mathrm{E}-02$ & 3085 & $6.12 \mathrm{E}-02$ & (46523) & 4.77E-02 & 5.31E-09 \\
\hline LW44-19.9 & $2.93 \mathrm{E}+04$ & 70 & 5.5E-05 & 7.07 & 9 & 0.999 & 0.020 & 495 & $4.48 \mathrm{E}-02$ & 323 & 2.32E-02 & 2971 & 5.31E-02 & (45915) & 3.49E-02 & 3.30E-09 \\
\hline LW44-19.10 & $2.93 \mathrm{E}+04$ & 70 & $2.5 \mathrm{E}-05$ & 7.92 & 9 & 0.998 & 0.020 & 424 & $1.70 \mathrm{E}-02$ & 246 & 7.50E-03 & 2863 & 2.30E-02 & $(47200)$ & 2.35E-02 & 2.42E-09 \\
\hline LW44-19.11 & $2.93 E+04$ & 70 & $6.2 \mathrm{E}-05$ & 8.18 & 9 & 0.997 & 0.020 & 383 & 3.79E-02 & 226 & $1.69 \mathrm{E}-02$ & 2620 & 5.26E-02 & (46492) & $4.82 \mathrm{E}-02$ & 5.85E-09 \\
\hline LW44-19.12 & $2.93 E+04$ & 70 & 5.8E-05 & 8.97 & 9 & 0.996 & 0.020 & 360 & 3.30E-02 & 222 & $1.54 \mathrm{E}-02$ & 2501 & 4.68E-02 & (47919) & $6.53 \mathrm{E}-02$ & 5.51E-09 \\
\hline LW44-19.13 & $2.93 \mathrm{E}+04$ & 70 & $6.1 \mathrm{E}-05$ & 9.17 & 9 & 0.996 & 0.020 & 338 & 3.23E-02 & 218 & 1.59E-02 & 2309 & 4.53E-02 & (46691) & $5.04 \mathrm{E}-02$ & 5.19E-09 \\
\hline \multicolumn{17}{|l|}{ Exp. \#20 } \\
\hline LW44-20A & $5.83 \mathrm{E}+04$ & 70 & - & - & 9 & - & - & $<50$ & - & $<50$ & - & $<100$ & - & (85181) & - & - \\
\hline LW44-20B & $5.83 \mathrm{E}+04$ & 70 & - & - & 9 & - & - & $<50$ & - & $<50$ & - & $<100$ & - & (86459) & - & - \\
\hline LW44-20C & $5.83 E+04$ & 70 & - & - & 9 & - & - & $<50$ & - & $<50$ & - & $<100$ & - & (86635) & - & - \\
\hline LW44-20.3 & $5.83 \mathrm{E}+04$ & 70 & $5.8 \mathrm{E}-05$ & 3.07 & 9 & 1.002 & 0.036 & 286 & $1.38 \mathrm{E}-02$ & 122 & 3.53E-03 & (4456) & 4.75E-02 & (87685) & $1.24 \mathrm{E}-02$ & $1.34 \mathrm{E}-08$ \\
\hline LW44-20.4 & $5.83 \mathrm{E}+04$ & 70 & $5.4 \mathrm{E}-05$ & 4.00 & 9 & 1.002 & 0.020 & 300 & $2.47 \mathrm{E}-02$ & 142 & 7.69E-03 & (3400) & $6.07 \mathrm{E}-02$ & (89053) & $3.88 \mathrm{E}-02$ & $1.44 \mathrm{E}-08$ \\
\hline LW44-20.6 & $5.83 \mathrm{E}+04$ & 70 & $5.6 \mathrm{E}-05$ & 5.23 & 9 & 1.001 & 0.020 & 264 & 2.19E-02 & 135 & $7.28 \mathrm{E}-03$ & (2335) & 4.25E-02 & (87782) & $2.29 \mathrm{E}-02$ & 8.23E-09 \\
\hline LW44-20.9 & $5.83 E+04$ & 70 & $5.4 \mathrm{E}-05$ & 7.07 & 9 & 1.001 & 0.020 & 245 & 1.93E-02 & 125 & $6.26 \mathrm{E}-03$ & (2124) & 3.73E-02 & (85607) & - & 7.19E-09 \\
\hline LW44-20.10 & $5.83 \mathrm{E}+04$ & 70 & $2.4 \mathrm{E}-05$ & 7.92 & 9 & 1.000 & 0.020 & 246 & 8.76E-03 & 124 & 2.79E-03 & (1930) & $1.53 \mathrm{E}-02$ & (89757) & $2.18 \mathrm{E}-02$ & $2.60 \mathrm{E}-09$ \\
\hline LW44-20.11 & $5.83 E+04$ & 70 & 7.0E-05 & 8.18 & 9 & 1.000 & 0.020 & 224 & 2.23E-02 & 111 & 6.64E-03 & (1764) & 3.98E-02 & (89946) & $6.57 \mathrm{E}-02$ & 6.99E-09 \\
\hline LW44-20.12 & $5.83 \mathrm{E}+04$ & 70 & 5.6E-05 & 8.97 & 9 & 0.999 & 0.020 & 225 & $1.79 \mathrm{E}-02$ & 115 & $5.64 \mathrm{E}-03$ & (1710) & $3.07 \mathrm{E}-02$ & (89929) & $5.21 \mathrm{E}-02$ & $5.10 \mathrm{E}-09$ \\
\hline LW44-20.13 & $5.83 \mathrm{E}+04$ & 70 & $4.8 \mathrm{E}-05$ & 9.17 & 9 & 0.999 & 0.020 & 214 & $1.45 \mathrm{E}-02$ & 119 & $5.10 \mathrm{E}-03$ & (1685) & $2.61 \mathrm{E}-02$ & (87735) & $1.93 \mathrm{E}-02$ & 4.62E-09 \\
\hline \multicolumn{17}{|l|}{ Exp. \#21 } \\
\hline LW44-21A & $8.84 \mathrm{E}+04$ & 70 & - & - & 9 & - & - & $<50$ & - & $<50$ & - & $<100$ & - & (131666) & - & - \\
\hline LW44-21B & $8.84 \mathrm{E}+04$ & 70 & - & - & 9 & - & - & $<50$ & - & $<50$ & - & $<100$ & - & (130926) & - & - \\
\hline LW44-21C & $8.84 \mathrm{E}+04$ & 70 & - & - & 9 & - & - & $<50$ & - & $<50$ & - & $<100$ & - & (130573) & - & - \\
\hline
\end{tabular}


Table A1. SPFT Results for LAWA44 Glasses.

\begin{tabular}{|c|c|c|c|c|c|c|c|c|c|c|c|c|c|c|c|c|}
\hline Sample ID & $\begin{array}{c}\text { Influent } \\
\text { [Si] }\end{array}$ & $\begin{array}{c}\mathrm{T} \\
\left({ }^{\circ} \mathrm{C}\right) \\
\end{array}$ & $\begin{array}{c}\text { Flow } \\
\text { Rate } \\
\left(\mathrm{m}^{3} / \mathrm{d}\right) \\
\end{array}$ & $\begin{array}{c}\text { Time, } \\
\text { days }\end{array}$ & $\begin{array}{c}\mathrm{pH} \\
\left(23^{\circ} \mathrm{C}\right) \\
\end{array}$ & $\begin{array}{l}\text { Glass } \\
\text { Mass } \\
(\mathrm{g}) \\
\end{array}$ & $\begin{array}{c}\text { SA } \\
\left(\mathrm{m}^{2}\right) \\
\end{array}$ & [B] & B Rate & {$[\mathrm{Al}]$} & Al Rate & {$[\mathrm{Na}]$} & Na Rate & [Si] & Si Rate & IEX Rate \\
\hline LW44-21.3 & $8.84 \mathrm{E}+04$ & 70 & $6.4 \mathrm{E}-05$ & 3.07 & 9 & 1.005 & 0.036 & 208 & $1.02 \mathrm{E}-02$ & 78.8 & $1.56 \mathrm{E}-03$ & (3913) & $4.56 \mathrm{E}-02$ & (131394) & 2.89E-03 & $1.42 \mathrm{E}-08$ \\
\hline LW44-21.4 & $8.84 \mathrm{E}+04$ & 70 & 5.9E-05 & 4.00 & 9 & 1.004 & 0.020 & 189 & $1.50 \mathrm{E}-02$ & 74.8 & $2.26 \mathrm{E}-03$ & (3090) & $6.01 \mathrm{E}-02$ & (132246) & 1.71E-02 & $1.80 \mathrm{E}-08$ \\
\hline LW44-21.6 & $8.84 \mathrm{E}+04$ & 70 & 5.9E-05 & 5.23 & 9 & 1.004 & 0.020 & 134 & $9.09 \mathrm{E}-03$ & 62.8 & 1.17E-03 & (1980) & 3.79E-02 & (131122) & $9.61 \mathrm{E}-04$ & $1.15 \mathrm{E}-08$ \\
\hline LW44-21.8 & $8.84 \mathrm{E}+04$ & 70 & 5.6E-05 & 7.07 & 9 & 1.003 & 0.020 & 138 & $9.04 \mathrm{E}-03$ & 57.9 & $6.78 \mathrm{E}-04$ & (1813) & 3.27E-02 & (129994) & - & $9.43 \mathrm{E}-09$ \\
\hline LW44-21.10 & $8.84 \mathrm{E}+04$ & 70 & 2.7E-05 & 7.92 & 9 & 1.003 & 0.020 & 118 & 3.29E-03 & 53.2 & $1.30 \mathrm{E}-04$ & (1397) & 1.17E-02 & (132240) & 7.63E-03 & 3.37E-09 \\
\hline LW44-21.11 & $8.84 \mathrm{E}+04$ & 70 & 6.3E-05 & 8.18 & 9 & 1.003 & 0.020 & 103 & 6.07E-03 & ND & - & (1260) & 2.48E-02 & (133043) & 3.02E-02 & 7.47E-09 \\
\hline LW44-21.12 & $8.84 \mathrm{E}+04$ & 70 & 5.8E-05 & 8.97 & 9 & 1.003 & 0.020 & 94.7 & 4.77E-03 & ND & - & (1212) & $2.21 \mathrm{E}-02$ & (133665) & 3.69E-02 & 6.91E-09 \\
\hline LW44-21.13 & $8.84 \mathrm{E}+04$ & 70 & $6.1 \mathrm{E}-05$ & 9.17 & 9 & 1.002 & 0.020 & 95.6 & $5.08 \mathrm{E}-03$ & ND & - & (1137) & $2.16 \mathrm{E}-02$ & (132910) & 2.75E-02 & 6.58E-09 \\
\hline \multicolumn{17}{|l|}{ Exp. \#22 } \\
\hline LW44-22-A & $1.14 \mathrm{E}+05$ & 70 & - & - & 9 & - & - & $<50$ & - & $<50$ & - & $<100$ & - & (167695) & - & - \\
\hline LW44-22-B & $1.14 \mathrm{E}+05$ & 70 & - & - & 9 & - & - & $<50$ & - & $<50$ & - & $<100$ & - & (159364) & - & - \\
\hline LW44-22-C & $1.14 \mathrm{E}+05$ & 70 & - & - & 9 & - & - & $<50$ & - & $<50$ & - & $<100$ & - & (165406) & - & - \\
\hline LW44-22.3 & $1.14 \mathrm{E}+05$ & 70 & 6.3E-05 & 3.07 & 9 & 1.006 & 0.036 & 215 & $1.05 \mathrm{E}-02$ & 64.2 & 7.61E-04 & (3951) & 4.56E-02 & (170624) & 5.46E-02 & $1.40 \mathrm{E}-08$ \\
\hline LW44-22.4 & $1.14 \mathrm{E}+05$ & 70 & $5.2 \mathrm{E}-05$ & 4.00 & 9 & 1.005 & 0.020 & 174 & $1.16 \mathrm{E}-02$ & 56.5 & 5.18E-04 & (2989) & 5.07E-02 & (168823) & 5.83E-02 & $1.56 \mathrm{E}-08$ \\
\hline LW44-22.6 & $1.14 \mathrm{E}+05$ & 70 & 5.9E-05 & 5.23 & 9 & 1.005 & 0.020 & 109 & $6.38 \mathrm{E}-03$ & ND & - & (1848) & $3.50 \mathrm{E}-02$ & (171600) & 1.06E-01 & $1.14 \mathrm{E}-08$ \\
\hline LW44-22.9 & $1.14 \mathrm{E}+05$ & 70 & $5.9 \mathrm{E}-05$ & 7.07 & 9 & 1.005 & 0.020 & 86.2 & 3.86E-03 & ND & - & (1653) & 3.09E-02 & (163795) & - & $1.08 \mathrm{E}-08$ \\
\hline LW44-22.10 & $1.14 \mathrm{E}+05$ & 70 & 2.6E-05 & 7.92 & 9 & 1.004 & 0.020 & 66.2 & 7.61E-04 & ND & - & (1275) & $1.03 \mathrm{E}-02$ & (165619) & $9.15 \mathrm{E}-03$ & 3.81E-09 \\
\hline LW44-22.11 & $1.14 \mathrm{E}+05$ & 70 & 5.8E-05 & 8.18 & 9 & 1.004 & 0.020 & ND & - & ND & - & (1141) & 2.06E-02 & (170599) & $9.11 \mathrm{E}-02$ & 8.26E-09 \\
\hline LW44-22.12 & $1.14 \mathrm{E}+05$ & 70 & $5.8 \mathrm{E}-05$ & 8.97 & 9 & 1.004 & 0.020 & ND & - & ND & - & (1082) & $1.93 \mathrm{E}-02$ & (171431) & $1.02 \mathrm{E}-01$ & 7.90E-09 \\
\hline LW44-22.13 & $1.14 \mathrm{E}+05$ & 70 & $6.4 \mathrm{E}-05$ & 9.17 & 9 & 1.004 & 0.020 & $\mathrm{ND}$ & - & ND & - & (1000) & $1.94 \mathrm{E}-02$ & (165652) & 2.30E-02 & 8.38E-09 \\
\hline \multicolumn{17}{|l|}{ Exp. \#23 } \\
\hline LW44-23A & - & 40 & - & - & 9 & - & - & $<25$ & - & $<50$ & - & $<100$ & - & $<100$ & - & - \\
\hline LW44-23B & - & 40 & - & - & 9 & - & - & $<25$ & - & $<50$ & - & $<100$ & - & $<100$ & - & - \\
\hline LW44-23C & - & 40 & - & - & 9 & - & - & $<25$ & - & $<50$ & - & $<100$ & - & $<100$ & - & - \\
\hline LW44-23.2 & - & 40 & $5.1 \mathrm{E}-06$ & 1.85 & 9 & 1.010 & 0.020 & 257 & 2.13E-03 & 195 & 1.13E-03 & 5,132 & 8.61E-03 & 1,470 & $1.67 \mathrm{E}-03$ & 2.59E-09 \\
\hline LW44-23.4 & - & 40 & 4.6E-06 & 4.05 & 9 & 1.010 & 0.020 & 471 & 3.74E-03 & 405 & $2.51 \mathrm{E}-03$ & 6,349 & $9.77 \mathrm{E}-03$ & 2,997 & 3.23E-03 & $2.40 \mathrm{E}-09$ \\
\hline LW44-23.6 & - & 40 & 4.8E-06 & 6.09 & 9 & 1.010 & 0.020 & 583 & $4.88 \mathrm{E}-03$ & 525 & $3.50 \mathrm{E}-03$ & 6,240 & $1.00 \mathrm{E}-02$ & 3,801 & 4.30E-03 & 2.04E-09 \\
\hline LW44-23.8 & - & 40 & $5.0 \mathrm{E}-06$ & 8.09 & 9 & 1.010 & 0.020 & 678 & $5.86 \mathrm{E}-03$ & 616 & $4.28 \mathrm{E}-03$ & 6,569 & $1.08 \mathrm{E}-02$ & 4,426 & 5.15E-03 & $1.98 \mathrm{E}-09$ \\
\hline LW44-23.10 & - & 40 & $4.8 \mathrm{E}-06$ & 11.09 & 9 & 1.009 & 0.020 & 652 & $5.47 \mathrm{E}-03$ & 636 & 4.30E-03 & 5,814 & $9.28 \mathrm{E}-03$ & 4,495 & $5.08 \mathrm{E}-03$ & $1.52 \mathrm{E}-09$ \\
\hline LW44-23.12 & - & 40 & 4.4E-06 & 14.95 & 9 & 1.009 & 0.020 & 651 & $5.01 \mathrm{E}-03$ & 669 & 4.17E-03 & 5,139 & 7.51E-03 & 4,512 & 4.69E-03 & $1.00 \mathrm{E}-09$ \\
\hline LW44-23.14 & - & 40 & 4.8E-06 & 18.84 & 9 & 1.009 & 0.020 & 651 & $5.45 \mathrm{E}-03$ & 704 & 4.79E-03 & 4,638 & 7.35E-03 & 4,669 & $5.27 \mathrm{E}-03$ & $7.60 \mathrm{E}-10$ \\
\hline LW44-23.16 & - & 40 & 4.6E-06 & 22.83 & 9 & 1.008 & 0.020 & 647 & $5.21 \mathrm{E}-03$ & 705 & 4.62E-03 & 4,157 & 6.33E-03 & 4,560 & $4.96 \mathrm{E}-03$ & $4.48 \mathrm{E}-10$ \\
\hline LW44-23.19 & - & 40 & $4.8 \mathrm{E}-06$ & 29.02 & 9 & 1.008 & 0.020 & 619 & $5.22 \mathrm{E}-03$ & 686 & $4.71 \mathrm{E}-03$ & 3,852 & $6.15 \mathrm{E}-03$ & 4,518 & 5.16E-03 & $3.67 \mathrm{E}-10$ \\
\hline LW44-23.21 & - & 40 & $5.0 \mathrm{E}-06$ & 33.00 & 9 & 1.008 & 0.020 & 610 & $5.27 \mathrm{E}-03$ & 679 & $4.78 \mathrm{E}-03$ & 3,764 & $6.15 \mathrm{E}-03$ & 4,597 & 5.38E-03 & 3.52E-10 \\
\hline LW44-23.24 & - & 40 & 4.6E-06 & 39.13 & 9 & 1.007 & 0.020 & 584 & 4.67E-03 & 666 & 4.33E-03 & 3,340 & $5.04 \mathrm{E}-03$ & 4,212 & $4.56 \mathrm{E}-03$ & $1.48 \mathrm{E}-10$ \\
\hline LW44-23.25 & - & 40 & $5.0 \mathrm{E}-06$ & 40.97 & 9 & 1.007 & 0.020 & 596 & $5.21 \mathrm{E}-03$ & 669 & $4.76 \mathrm{E}-03$ & 3,299 & $5.44 \mathrm{E}-03$ & 4,293 & $5.08 \mathrm{E}-03$ & $9.03 \mathrm{E}-11$ \\
\hline LW44-23.26 & - & 40 & 4.7E-06 & 43.98 & 9 & 1.007 & 0.020 & 590 & 4.83E-03 & 670 & 4.46E-03 & 3,311 & 5.11E-03 & 4,372 & 4.84E-03 & $1.12 \mathrm{E}-10$ \\
\hline LW44-23.27 & - & 40 & 4.7E-06 & 48.03 & 9 & 1.006 & 0.020 & 618 & $5.10 \mathrm{E}-03$ & 678 & 4.55E-03 & 3,400 & $5.29 \mathrm{E}-03$ & 4,412 & $4.92 \mathrm{E}-03$ & $7.64 \mathrm{E}-11$ \\
\hline LW44-23.28 & - & 40 & $4.9 \mathrm{E}-06$ & 52.05 & 9 & 1.005 & 0.020 & 616 & $5.24 \mathrm{E}-03$ & 664 & $4.58 \mathrm{E}-03$ & 3,453 & 5.53E-03 & 4,373 & 5.03E-03 & 1.17E-10 \\
\hline LW44-23.29 & - & 40 & $3.9 \mathrm{E}-06$ & 55.94 & 9 & 1.005 & 0.020 & 606 & 4.09E-03 & 658 & 3.61E-03 & 3,533 & $4.50 \mathrm{E}-03$ & 4,333 & $3.96 \mathrm{E}-03$ & $1.64 \mathrm{E}-10$ \\
\hline
\end{tabular}


Table A1. SPFT Results for LAWA44 Glasses.

\begin{tabular}{|c|c|c|c|c|c|c|c|c|c|c|c|c|c|c|c|c|}
\hline Sample ID & $\begin{array}{c}\text { Influent } \\
\text { [Si] }\end{array}$ & $\begin{array}{c}\mathrm{T} \\
\left({ }^{\circ} \mathrm{C}\right) \\
\end{array}$ & $\begin{array}{c}\text { Flow } \\
\text { Rate } \\
\left(\mathrm{m}^{3} / \mathrm{d}\right) \\
\end{array}$ & $\begin{array}{l}\text { Time, } \\
\text { days }\end{array}$ & $\begin{array}{c}\mathrm{pH} \\
\left(23^{\circ} \mathrm{C}\right) \\
\end{array}$ & $\begin{array}{l}\text { Glass } \\
\text { Mass } \\
(\mathrm{g}) \\
\end{array}$ & $\begin{array}{c}\text { SA } \\
\left(\mathrm{m}^{2}\right) \\
\end{array}$ & {$[\mathrm{B}]$} & B Rate & [Al] & Al Rate & {$[\mathrm{Na}]$} & Na Rate & [Si] & Si Rate & IEX Rate \\
\hline LW44-23.30 & - & 40 & $4.8 \mathrm{E}-06$ & 60.32 & 9 & 1.004 & 0.020 & 574 & 4.80E-03 & 632 & 4.29E-03 & 3,392 & 5.37E-03 & 4,057 & 4.59E-03 & $2.25 \mathrm{E}-10$ \\
\hline LW44-23.31 & - & 40 & $4.9 \mathrm{E}-06$ & 63.88 & 9 & 1.004 & 0.020 & 542 & 4.65E-03 & 603 & 4.19E-03 & 3,211 & $5.21 \mathrm{E}-03$ & 3,882 & $4.52 \mathrm{E}-03$ & $2.26 \mathrm{E}-10$ \\
\hline LW44-23.32 & - & 40 & 4.6E-06 & 67.95 & 9 & 1.003 & 0.020 & 504 & 4.05E-03 & 574 & 3.73E-03 & 3,108 & 4.73E-03 & 3,733 & 4.07E-03 & 2.73E-10 \\
\hline LW44-23.33 & - & 40 & 4.7E-06 & 71.86 & 9 & 1.003 & 0.020 & 483 & 3.90E-03 & 549 & 3.58E-03 & 3,037 & 4.66E-03 & 3,537 & 3.88E-03 & 3.02E-10 \\
\hline LW44-23.34 & - & 40 & $4.8 \mathrm{E}-06$ & 75.08 & 9 & 1.002 & 0.020 & 473 & 3.96E-03 & 546 & 3.70E-03 & 2,945 & 4.69E-03 & 3,554 & 4.06E-03 & $2.91 \mathrm{E}-10$ \\
\hline LW44-23.35 & - & 40 & $3.1 \mathrm{E}-06$ & 80.03 & 9 & 1.002 & 0.020 & 553 & $3.04 \mathrm{E}-03$ & 607 & $2.70 \mathrm{E}-03$ & 3,661 & 3.81E-03 & 4,108 & $3.06 \mathrm{E}-03$ & $3.11 \mathrm{E}-10$ \\
\hline LW44-23.36 & - & 40 & $5.5 \mathrm{E}-06$ & 83.42 & 9 & 1.001 & 0.020 & 491 & 4.70E-03 & 569 & 4.41E-03 & 3,243 & $5.90 \mathrm{E}-03$ & 3,685 & 4.80E-03 & $4.80 \mathrm{E}-10$ \\
\hline \multicolumn{17}{|l|}{ Exp. \#24 } \\
\hline LW44-24A & - & 40 & - & - & 9 & - & - & $<25$ & - & $<50$ & - & $<100$ & - & $<100$ & - & - \\
\hline LW44-24B & - & 40 & - & - & 9 & - & - & $<25$ & - & $<50$ & - & $<100$ & - & $<100$ & - & - \\
\hline LW44-24C & - & 40 & - & - & 9 & - & - & $<25$ & - & $<50$ & - & $<100$ & - & $<100$ & - & - \\
\hline LW44-24.2 & - & 40 & $1.0 \mathrm{E}-05$ & 1.85 & 9 & 0.750 & 0.016 & 216 & 4.32E-03 & 195 & 2.77E-03 & 3,999 & $1.65 \mathrm{E}-02$ & 1,308 & 3.64E-03 & 4.85E-09 \\
\hline LW44-24.4 & - & 40 & $9.5 \mathrm{E}-06$ & 4.05 & 9 & 0.750 & 0.015 & 327 & 7.02E-03 & 313 & 5.15E-03 & 3,720 & $1.57 \mathrm{E}-02$ & 2,200 & 6.47E-03 & 3.45E-09 \\
\hline LW44-24.6 & - & 40 & $9.8 \mathrm{E}-06$ & 6.09 & 9 & 0.750 & 0.015 & 375 & 8.38E-03 & 387 & 6.79E-03 & 3,197 & $1.38 \mathrm{E}-02$ & 2,659 & 8.14E-03 & 2.17E-09 \\
\hline LW44-24.8 & - & 40 & $9.5 \mathrm{E}-06$ & 8.09 & 9 & 0.749 & 0.015 & 390 & 8.47E-03 & 423 & 7.29E-03 & 2,978 & $1.24 \mathrm{E}-02$ & 2,808 & 8.34E-03 & $1.58 \mathrm{E}-09$ \\
\hline LW44-24.10 & - & 40 & $9.7 \mathrm{E}-06$ & 11.09 & 9 & 0.749 & 0.015 & 382 & $8.42 \mathrm{E}-03$ & 447 & 7.89E-03 & 2,665 & 1.13E-02 & 2,833 & 8.56E-03 & $1.14 \mathrm{E}-09$ \\
\hline LW44-24.12 & - & 40 & $9.4 \mathrm{E}-06$ & 14.95 & 9 & 0.749 & 0.015 & 382 & 8.17E-03 & 450 & 7.70E-03 & 2,368 & 9.67E-03 & 2,885 & 8.46E-03 & 5.99E-10 \\
\hline LW44-24.14 & - & 40 & $9.4 \mathrm{E}-06$ & 18.84 & 9 & 0.748 & 0.015 & 395 & 8.53E-03 & 471 & 8.18E-03 & 2,223 & $9.12 \mathrm{E}-03$ & 3,016 & 8.93E-03 & $2.38 \mathrm{E}-10$ \\
\hline LW44-24.16 & - & 40 & $9.9 \mathrm{E}-06$ & 22.83 & 9 & 0.748 & 0.015 & 395 & 8.97E-03 & 462 & $8.41 \mathrm{E}-03$ & 2,139 & $9.20 \mathrm{E}-03$ & 2,976 & $9.25 \mathrm{E}-03$ & $9.32 \mathrm{E}-11$ \\
\hline LW44-24.19 & - & 40 & $9.6 \mathrm{E}-06$ & 29.02 & 9 & 0.747 & 0.015 & 381 & 8.36E-03 & 435 & 7.61E-03 & 2,161 & $9.01 \mathrm{E}-03$ & 2,947 & 8.87E-03 & $2.58 \mathrm{E}-10$ \\
\hline LW44-24.21 & - & 40 & $1.0 \mathrm{E}-05$ & 33.00 & 9 & 0.747 & 0.015 & 365 & 8.36E-03 & 412 & 7.52E-03 & 2,117 & $9.25 \mathrm{E}-03$ & 2,950 & $9.32 \mathrm{E}-03$ & $3.57 \mathrm{E}-10$ \\
\hline LW44-24.24 & - & 40 & $9.7 \mathrm{E}-06$ & 39.13 & 9 & 0.747 & 0.015 & 366 & 8.12E-03 & 437 & 7.77E-03 & 1,874 & 7.88E-03 & 2,747 & 8.38E-03 & - \\
\hline LW44-24.25 & - & 40 & $1.0 \mathrm{E}-05$ & 40.97 & 9 & 0.746 & 0.015 & 370 & 8.48E-03 & 422 & 7.71E-03 & 1,921 & 8.35E-03 & 2,724 & 8.57E-03 & - \\
\hline \multicolumn{17}{|l|}{ Exp. \#25 } \\
\hline LW44-25A & - & 40 & - & - & 9 & - & - & $<25$ & - & $<50$ & - & $<100$ & - & $<100$ & - & - \\
\hline LW44-25B & - & 40 & - & - & 9 & - & - & $<25$ & - & $<50$ & - & $<100$ & - & $<100$ & - & - \\
\hline LW44-25C & - & 40 & - & - & 9 & - & - & $<25$ & - & $<50$ & - & $<100$ & - & $<100$ & - & - \\
\hline LW44-25.2 & - & 40 & $1.9 \mathrm{E}-05$ & 1.85 & 9 & 0.502 & 0.012 & 152 & 7.09E-03 & 149 & 4.63E-03 & 2,705 & 2.71E-02 & 950 & $6.29 \mathrm{E}-03$ & 7.97E-09 \\
\hline LW44-25.4 & - & 40 & $1.9 \mathrm{E}-05$ & 4.05 & 9 & 0.502 & 0.010 & 177 & $1.05 \mathrm{E}-02$ & 194 & 8.38E-03 & 1,631 & $1.98 \mathrm{E}-02$ & 1,287 & 1.09E-02 & 3.69E-09 \\
\hline LW44-25.6 & - & 40 & $1.9 \mathrm{E}-05$ & 6.09 & 9 & 0.502 & 0.010 & 190 & 1.13E-02 & 221 & $9.87 \mathrm{E}-03$ & 1,359 & $1.60 \mathrm{E}-02$ & 1,422 & $1.20 \mathrm{E}-02$ & $1.91 \mathrm{E}-09$ \\
\hline LW44-25.8 & - & 40 & $1.9 \mathrm{E}-05$ & 8.09 & 9 & 0.501 & 0.010 & 183 & 1.12E-02 & 218 & 9.99E-03 & 1,197 & $1.44 \mathrm{E}-02$ & 1,408 & 1.23E-02 & 1.30E-09 \\
\hline LW44-25.10 & - & 40 & $1.8 \mathrm{E}-05$ & 11.09 & 9 & 0.501 & 0.010 & 189 & $1.10 \mathrm{E}-02$ & 221 & $9.65 \mathrm{E}-03$ & 1,110 & $1.26 \mathrm{E}-02$ & 1,522 & $1.26 \mathrm{E}-02$ & $6.51 \mathrm{E}-10$ \\
\hline LW44-25.12 & - & 40 & $1.9 \mathrm{E}-05$ & 14.95 & 9 & 0.501 & 0.010 & 175 & $1.05 \mathrm{E}-02$ & 210 & $9.40 \mathrm{E}-03$ & 1,039 & $1.22 \mathrm{E}-02$ & 1,436 & $1.24 \mathrm{E}-02$ & $6.92 \mathrm{E}-10$ \\
\hline LW44-25.14 & - & 40 & $1.9 \mathrm{E}-05$ & 18.84 & 9 & 0.500 & 0.010 & 197 & 1.23E-02 & 209 & $9.50 \mathrm{E}-03$ & 1,040 & $1.25 \mathrm{E}-02$ & 1,761 & $1.57 \mathrm{E}-02$ & 7.93E-11 \\
\hline \multicolumn{17}{|l|}{ Exp. \#26 } \\
\hline LW44-26A & - & 40 & - & - & 9 & - & - & $<25$ & - & $<50$ & - & $<100$ & - & $<100$ & - & - \\
\hline LW44-26B & - & 40 & - & - & 9 & - & - & $<25$ & - & $<50$ & - & $<100$ & - & $<100$ & - & - \\
\hline LW44-26C & - & 40 & - & - & 9 & - & - & $<25$ & - & $<50$ & - & $<100$ & - & $<100$ & - & - \\
\hline LW44-26.2 & - & 40 & $3.8 \mathrm{E}-05$ & 1.85 & 9 & 0.251 & 0.008 & 56 & 5.53E-03 & 52 & $2.90 \mathrm{E}-04$ & 971 & $2.86 \mathrm{E}-02$ & 633 & $1.25 \mathrm{E}-02$ & $9.21 \mathrm{E}-09$ \\
\hline LW44-26.4 & - & 40 & 3.8E-05 & 4.05 & 9 & 0.251 & 0.005 & 55 & 8.25E-03 & 73 & 5.52E-03 & 429 & $1.71 \mathrm{E}-02$ & 428 & $1.21 \mathrm{E}-02$ & 3.53E-09 \\
\hline
\end{tabular}


Table A1. SPFT Results for LAWA44 Glasses.

\begin{tabular}{|c|c|c|c|c|c|c|c|c|c|c|c|c|c|c|c|c|}
\hline Sample ID & $\begin{array}{c}\text { Influent } \\
\text { [Si] }\end{array}$ & $\begin{array}{c}\mathrm{T} \\
\left({ }^{\circ} \mathrm{C}\right) \\
\end{array}$ & $\begin{array}{c}\text { Flow } \\
\text { Rate } \\
\left(\mathrm{m}^{3} / \mathrm{d}\right)\end{array}$ & $\begin{array}{l}\text { Time, } \\
\text { days }\end{array}$ & $\begin{array}{c}\mathrm{pH} \\
\left(23^{\circ} \mathrm{C}\right) \\
\end{array}$ & $\begin{array}{c}\text { Glass } \\
\text { Mass } \\
(\mathrm{g}) \\
\end{array}$ & $\begin{array}{c}\text { SA } \\
\left(\mathrm{m}^{2}\right) \\
\end{array}$ & {$[\mathrm{B}]$} & B Rate & {$[\mathrm{Al}]$} & Al Rate & {$[\mathrm{Na}]$} & Na Rate & {$[\mathrm{Si}]$} & Si Rate & IEX Rate \\
\hline LW44-26.6 & - & 40 & 3.9E-05 & 6.09 & 9 & 0.251 & 0.005 & 56 & 8.80E-03 & 75 & 5.81E-03 & 366 & 1.39E-02 & 448 & $1.30 \mathrm{E}-02$ & 2.04E-09 \\
\hline LW44-26.8 & - & 40 & 3.8E-05 & 8.09 & 9 & 0.251 & 0.005 & 55 & 8.37E-03 & 67 & 4.02E-03 & 340 & $1.25 \mathrm{E}-02$ & 559 & $1.71 \mathrm{E}-02$ & 1.65E-09 \\
\hline LW44-26.10 & - & 40 & 3.8E-05 & 11.09 & 9 & 0.250 & 0.005 & 57 & 9.07E-03 & 75 & 5.85E-03 & 319 & $1.14 \mathrm{E}-02$ & 509 & $1.52 \mathrm{E}-02$ & $9.47 \mathrm{E}-10$ \\
\hline \multicolumn{17}{|l|}{ Exp. \#27 } \\
\hline LW44-27.A & $8.79 \mathrm{E}+02$ & 90 & - & - & 9 & - & - & $<50$ & - & $<50$ & - & $<100$ & - & $<100$ & - & - \\
\hline LW44-27.B & $8.79 \mathrm{E}+02$ & 90 & - & - & & - & - & $<50$ & - & $<50$ & - & 728 & - & $<100$ & - & - \\
\hline LW44-27.C & $8.79 \mathrm{E}+02$ & 90 & - & - & & - & - & $<50$ & - & $<50$ & - & $<100$ & - & $<100$ & - & - \\
\hline LW44-27.2 & $8.79 \mathrm{E}+02$ & 90 & $8.8 \mathrm{E}-05$ & 2.11 & 9 & 0.995 & 0.020 & 1162 & $1.80 \mathrm{E}-01$ & 1200 & $1.56 \mathrm{E}-01$ & 7606 & 2.19E-01 & 7664 & $1.62 \mathrm{E}-01$ & 1.59E-08 \\
\hline LW44-27.3 & $8.79 \mathrm{E}+02$ & 90 & $8.2 \mathrm{E}-05$ & 3.01 & 9 & 0.990 & 0.020 & 1133 & $1.65 \mathrm{E}-01$ & 1190 & $1.46 \mathrm{E}-01$ & 6496 & $1.75 \mathrm{E}-01$ & 7467 & $1.49 \mathrm{E}-01$ & 4.22E-09 \\
\hline LW44-27.4 & $8.79 \mathrm{E}+02$ & 90 & 8.6E-05 & 4.07 & 9 & 0.985 & 0.020 & 1124 & $1.70 \mathrm{E}-01$ & 1206 & $1.55 \mathrm{E}-01$ & 6128 & 1.72E-01 & 7457 & $1.55 \mathrm{E}-01$ & $6.29 \mathrm{E}-10$ \\
\hline LW44-27.5 & 8.79E+02 & 90 & 8.7E-05 & 4.93 & 9 & 0.980 & 0.019 & 1167 & $1.81 \mathrm{E}-01$ & 1209 & 1.58E-01 & 5908 & 1.69E-01 & 7726 & 1.64E-01 & $-4.81 \mathrm{E}-09$ \\
\hline \multicolumn{17}{|l|}{ Exp. \#28 } \\
\hline LW44-28A & 10 & 90 & - & - & 9 & - & - & $<50$ & - & $<50$ & - & 72 & - & 21574 & - & - \\
\hline LW44-28B & 10 & 90 & - & - & 9 & - & - & $<50$ & - & $<50$ & - & 50 & - & 21891 & - & - \\
\hline LW44-28C & 10 & 90 & - & - & 9 & - & - & $<50$ & - & $<50$ & - & 54 & - & 21449 & - & - \\
\hline LW44-28.2 & 10 & 90 & 8.4E-05 & 2.11 & 9 & 0.999 & 0.020 & 804 & $1.16 \mathrm{E}-01$ & 706 & $8.50 \mathrm{E}-02$ & 6562 & $1.87 \mathrm{E}-01$ & 25882 & 8.67E-02 & 2.81E-08 \\
\hline LW44-28.3 & 10 & 90 & 8.1E-05 & 3.01 & 9 & 0.996 & 0.020 & 784 & $1.10 \mathrm{E}-01$ & 727 & 8.51E-02 & 5636 & $1.55 \mathrm{E}-01$ & 26179 & 8.99E-02 & $1.81 \mathrm{E}-08$ \\
\hline LW44-28.4 & 10 & 90 & 8.5E-05 & 4.07 & 9 & 0.993 & 0.020 & 718 & $1.04 \mathrm{E}-01$ & 690 & $8.41 \mathrm{E}-02$ & 4799 & $1.38 \mathrm{E}-01$ & 26140 & 9.33E-02 & $1.34 \mathrm{E}-08$ \\
\hline LW44-28.5 & 10 & 90 & 8.8E-05 & 4.93 & 9 & 0.989 & 0.020 & 707 & $1.06 \mathrm{E}-01$ & 670 & 8.44E-02 & 4537 & $1.35 \mathrm{E}-01$ & 25048 & 7.32E-02 & $1.14 \mathrm{E}-08$ \\
\hline \multicolumn{17}{|l|}{ Exp. \#29 } \\
\hline LW44-29A & $3.74 \mathrm{E}+04$ & 90 & - & - & 9 & - & - & $<50$ & - & $<50$ & - & 57 & - & 41897 & - & - \\
\hline LW44-29B & $3.74 \mathrm{E}+04$ & 90 & - & - & 9 & - & - & $<50$ & - & $<50$ & - & 50 & - & 42042 & - & - \\
\hline LW44-29C & $3.74 \mathrm{E}+04$ & 90 & - & - & 9 & - & - & $<50$ & - & $<50$ & - & 96 & - & 41179 & - & - \\
\hline LW44-29.2 & $3.74 \mathrm{E}+04$ & 90 & $8.8 \mathrm{E}-05$ & 2.11 & 9 & 0.994 & 0.020 & 741 & 1.12E-01 & 463 & 5.63E-02 & 6227 & 1.86E-01 & 45584 & 8.34E-02 & 2.95E-08 \\
\hline LW44-29.3 & $3.74 \mathrm{E}+04$ & 90 & 8.1E-05 & 3.01 & 9 & 0.991 & 0.020 & 677 & 9.38E-02 & 470 & $5.29 \mathrm{E}-02$ & 5110 & $1.40 \mathrm{E}-01$ & 45455 & $7.44 \mathrm{E}-02$ & 1.87E-08 \\
\hline LW44-29.4 & $3.74 \mathrm{E}+04$ & 90 & $9.0 \mathrm{E}-05$ & 4.07 & 9 & 0.988 & 0.020 & 592 & $9.00 \mathrm{E}-02$ & 441 & 5.47E-02 & 4256 & $1.29 \mathrm{E}-01$ & 45331 & 7.98E-02 & $1.58 \mathrm{E}-08$ \\
\hline LW44-29.5 & $3.74 \mathrm{E}+04$ & 90 & 7.4E-05 & 4.93 & 9 & 0.986 & 0.020 & 602 & 7.59E-02 & 459 & $4.74 \mathrm{E}-02$ & 4231 & $1.07 \mathrm{E}-01$ & 45279 & $6.51 \mathrm{E}-02$ & $1.22 \mathrm{E}-08$ \\
\hline \multicolumn{17}{|l|}{ Exp. \#30 } \\
\hline LW44-30A & $7.39 \mathrm{E}+04$ & 90 & - & - & 9 & - & - & $<50$ & - & $<50$ & - & 66 & - & 84873 & - & - \\
\hline LW44-30B & $7.39 \mathrm{E}+04$ & 90 & - & - & 9 & - & - & $<50$ & - & $<50$ & - & 65 & - & 81999 & - & - \\
\hline LW44-30C & $7.39 \mathrm{E}+04$ & 90 & - & - & 9 & - & - & $<50$ & - & $<50$ & - & 85 & - & 83677 & - & - \\
\hline LW44-30.2 & $7.39 \mathrm{E}+04$ & 90 & 7.8E-05 & 2.11 & 9 & 0.998 & 0.020 & 508 & 6.58E-02 & 201 & $1.83 \mathrm{E}-02$ & 5659 & 1.49E-01 & 87205 & 7.03E-02 & 3.34E-08 \\
\hline LW44-30.3 & $7.39 \mathrm{E}+04$ & 90 & 8.7E-05 & 3.01 & 9 & 0.996 & 0.020 & 495 & $7.08 \mathrm{E}-02$ & 198 & $1.98 \mathrm{E}-02$ & 4558 & $1.33 \mathrm{E}-01$ & 88947 & $1.15 \mathrm{E}-01$ & $2.48 \mathrm{E}-08$ \\
\hline LW44-30.4 & $7.39 \mathrm{E}+04$ & 90 & 7.9E-05 & 4.07 & 9 & 0.994 & 0.020 & 474 & $6.18 \mathrm{E}-02$ & 184 & $1.65 \mathrm{E}-02$ & 4034 & $1.08 \mathrm{E}-01$ & 91585 & $1.56 \mathrm{E}-01$ & $1.83 \mathrm{E}-08$ \\
\hline LW44-30.5 & $7.39 \mathrm{E}+04$ & 90 & $9.4 \mathrm{E}-05$ & 4.93 & 9 & 0.992 & 0.020 & 468 & 7.23E-02 & 176 & $1.84 \mathrm{E}-02$ & 3792 & $1.20 \mathrm{E}-01$ & 88498 & $1.14 \mathrm{E}-01$ & $1.90 \mathrm{E}-08$ \\
\hline \multicolumn{17}{|l|}{ Exp. \#31 } \\
\hline LW44-31A & $1.06 \mathrm{E}+05$ & 90 & - & - & 9 & - & - & $<50$ & - & $<50$ & - & 122 & - & 116232 & - & - \\
\hline LW44-31B & $1.06 \mathrm{E}+05$ & 90 & - & - & 9 & - & - & $<50$ & - & $<50$ & - & 104 & - & 120112 & - & - \\
\hline LW44-31C & $1.06 \mathrm{E}+05$ & 90 & - & - & 9 & - & - & $<50$ & - & $<50$ & - & 116 & - & 119886 & - & - \\
\hline LW44-31.2 & $1.06 \mathrm{E}+05$ & 90 & 7.5E-05 & 2.11 & 9 & 1.001 & 0.020 & 333 & 3.88E-02 & 54 & $5.20 \mathrm{E}-04$ & 4653 & $1.16 \mathrm{E}-01$ & 121467 & 4.97E-02 & 3.09E-08 \\
\hline
\end{tabular}


Table A1. SPFT Results for LAWA44 Glasses.

\begin{tabular}{|c|c|c|c|c|c|c|c|c|c|c|c|c|c|c|c|c|}
\hline Sample ID & $\begin{array}{c}\text { Influent } \\
\text { [Si] }\end{array}$ & $\begin{array}{c}\mathrm{T} \\
\left({ }^{\circ} \mathrm{C}\right) \\
\end{array}$ & $\begin{array}{c}\text { Flow } \\
\text { Rate } \\
\left(\mathrm{m}^{3} / \mathrm{d}\right) \\
\end{array}$ & $\begin{array}{l}\text { Time, } \\
\text { days }\end{array}$ & $\begin{array}{c}\mathrm{pH} \\
\left(23^{\circ} \mathrm{C}\right) \\
\end{array}$ & $\begin{array}{l}\text { Glass } \\
\text { Mass } \\
(\mathrm{g}) \\
\end{array}$ & $\begin{array}{c}\text { SA } \\
\left(\mathrm{m}^{2}\right) \\
\end{array}$ & {$[\mathrm{B}]$} & B Rate & {$[\mathrm{Al}]$} & Al Rate & {$[\mathrm{Na}]$} & Na Rate & [Si] & Si Rate & IEX Rate \\
\hline LW44-31.3 & $1.06 \mathrm{E}+05$ & 90 & $9.2 \mathrm{E}-05$ & 3.01 & 9 & 1.000 & 0.020 & 296 & 4.13E-02 & ND & - & 3752 & $1.14 \mathrm{E}-01$ & 121459 & 6.06E-02 & $2.90 \mathrm{E}-08$ \\
\hline LW44-31.4 & $1.06 \mathrm{E}+05$ & 90 & 7.6E-05 & 4.07 & 9 & 0.998 & 0.020 & 255 & 2.83E-02 & ND & - & 2989 & 7.42E-02 & 119895 & 2.12E-02 & $1.83 \mathrm{E}-08$ \\
\hline LW44-31.5 & $1.06 \mathrm{E}+05$ & 90 & 8.8E-05 & 4.93 & 9 & 0.997 & 0.020 & 244 & 3.15E-02 & ND & - & 2731 & 7.90E-02 & 120027 & 2.76E-02 & $1.90 \mathrm{E}-08$ \\
\hline \multicolumn{17}{|l|}{ Exp. \#32 } \\
\hline LW44-32.A & $1.22 \mathrm{E}+05$ & 90 & - & - & 9 & - & - & $<50$ & - & $<50$ & - & 53 & - & 129824 & - & - \\
\hline LW44-32.C & $1.22 \mathrm{E}+05$ & 90 & - & - & 9 & - & - & $<50$ & - & $<50$ & - & 101 & - & 145751 & - & - \\
\hline LW44-32.2 & $1.22 \mathrm{E}+05$ & 90 & $9.2 \mathrm{E}-05$ & 2.11 & 9 & 1.002 & 0.020 & 395 & 5.79E-02 & ND & - & 4924 & $1.52 \mathrm{E}-01$ & 131308.1 & - & 3.75E-08 \\
\hline LW44-32.3 & $1.22 \mathrm{E}+05$ & 90 & 7.1E-05 & 3.01 & 9 & 1.000 & 0.020 & 329 & 3.60E-02 & ND & - & 3838 & $9.04 \mathrm{E}-02$ & 137194.7 & - & 2.17E-08 \\
\hline LW44-32.4 & $1.22 \mathrm{E}+05$ & 90 & $9.1 \mathrm{E}-05$ & 4.07 & 9 & 0.999 & 0.020 & 303 & 4.23E-02 & ND & - & 3288 & $1.00 \mathrm{E}-01$ & 140705.6 & 6.49E-02 & 2.31E-08 \\
\hline LW44-32.5 & $1.22 \mathrm{E}+05$ & 90 & 4.7E-05 & 4.93 & 9 & 0.998 & 0.020 & 289 & $2.06 \mathrm{E}-02$ & ND & - & 3243 & $5.08 \mathrm{E}-02$ & 140491.1 & 3.09E-02 & $1.21 \mathrm{E}-08$ \\
\hline \multicolumn{17}{|l|}{ Exp.\#33 } \\
\hline LW44-33A & $8.97 \mathrm{E}+02$ & 23 & - & - & & - & - & $<50$ & - & $<10$ & - & $<100$ & - & (16) & - & - \\
\hline LW44-33B & $8.97 \mathrm{E}+02$ & 23 & - & - & 9 & - & - & $<50$ & - & $<10$ & - & $<100$ & - & (18) & - & - \\
\hline LW44-33C & $8.97 \mathrm{E}+02$ & 23 & - & - & 9 & - & - & $<50$ & - & $<10$ & - & $<100$ & - & (22) & - & - \\
\hline LW44-33.4 & $8.97 \mathrm{E}+02$ & 23 & 9.7E-06 & 7.12 & 9 & 4.014 & 0.050 & 321 & $1.91 \mathrm{E}-03$ & 362 & 2.09E-03 & 4,046 & 5.18E-03 & 2,255 & 2.09E-03 & $1.31 \mathrm{E}-09$ \\
\hline LW44-33.8 & $8.97 \mathrm{E}+02$ & 23 & 9.7E-06 & 14.25 & 9 & 4.013 & 0.079 & 311 & $1.15 \mathrm{E}-03$ & 300 & $1.08 \mathrm{E}-03$ & 2,755 & 2.19E-03 & 2,098 & $1.22 \mathrm{E}-03$ & 4.13E-10 \\
\hline LW44-33.12 & $8.97 \mathrm{E}+02$ & 23 & 9.6E-06 & 22.22 & 9 & 4.013 & 0.079 & 467 & $1.82 \mathrm{E}-03$ & 531 & $1.91 \mathrm{E}-03$ & 2,470 & $1.92 \mathrm{E}-03$ & 3,367 & $1.94 \mathrm{E}-03$ & 4.30E-11 \\
\hline LW44-33.16 & $8.97 \mathrm{E}+02$ & 23 & $9.5 \mathrm{E}-06$ & 33.09 & 9 & 4.012 & 0.079 & 498 & $1.95 \mathrm{E}-03$ & 515 & $1.85 \mathrm{E}-03$ & 2,514 & $1.96 \mathrm{E}-03$ & 3,336 & $1.92 \mathrm{E}-03$ & $2.54 \mathrm{E}-12$ \\
\hline LW44-33.20 & $8.97 \mathrm{E}+02$ & 23 & $9.6 \mathrm{E}-06$ & 42.48 & 9 & 4.012 & 0.079 & 447 & $1.73 \mathrm{E}-03$ & 440 & $1.58 \mathrm{E}-03$ & 2,448 & $1.91 \mathrm{E}-03$ & 2,944 & $1.70 \mathrm{E}-03$ & 7.03E-11 \\
\hline LW44-33.24 & $8.97 \mathrm{E}+02$ & 23 & 1.1E-05 & 52.10 & 9 & 4.011 & 0.079 & 362 & $1.54 \mathrm{E}-03$ & 380 & $1.54 \mathrm{E}-03$ & 2,054 & $1.80 \mathrm{E}-03$ & 2,457 & $1.60 \mathrm{E}-03$ & $1.03 \mathrm{E}-10$ \\
\hline LW44-33.28 & $8.97 \mathrm{E}+02$ & 23 & $9.4 \mathrm{E}-06$ & 68.08 & 9 & 4.011 & 0.079 & 311 & $1.11 \mathrm{E}-03$ & 388 & $1.36 \mathrm{E}-03$ & 1,658 & $1.24 \mathrm{E}-03$ & 2,292 & $1.29 \mathrm{E}-03$ & $5.06 \mathrm{E}-11$ \\
\hline LW44-33.32 & $8.97 \mathrm{E}+02$ & 23 & 9.3E-06 & 86.08 & 9 & 4.010 & 0.079 & 368 & $1.36 \mathrm{E}-03$ & 403 & $1.41 \mathrm{E}-03$ & 1,827 & 1.37E-03 & 2,570 & $1.44 \mathrm{E}-03$ & 5.87E-12 \\
\hline LW44-33.34 & $8.97 \mathrm{E}+02$ & 23 & $9.5 \mathrm{E}-06$ & 93.15 & 9 & 4.009 & 0.079 & 330 & $1.21 \mathrm{E}-03$ & 364 & $1.29 \mathrm{E}-03$ & 1,855 & $1.41 \mathrm{E}-03$ & 2,303 & $1.31 \mathrm{E}-03$ & $8.08 \mathrm{E}-11$ \\
\hline LW44-33.35 & $8.97 \mathrm{E}+02$ & 23 & 9.7E-06 & 96.01 & 9 & 4.009 & 0.079 & 369 & $1.41 \mathrm{E}-03$ & 474 & $1.73 \mathrm{E}-03$ & 1,821 & $1.42 \mathrm{E}-03$ & 2,773 & $1.61 \mathrm{E}-03$ & 3.55E-12 \\
\hline \multicolumn{17}{|l|}{ Exp. \#34 } \\
\hline LW44-34A & $1.51 \mathrm{E}+04$ & 23 & - & - & 9 & - & - & $<50$ & - & $<10$ & - & $<100$ & - & 16,543 & - & - \\
\hline LW44-34B & $1.51 \mathrm{E}+04$ & 23 & - & - & 9 & - & - & $<50$ & - & 12 & - & $<100$ & - & 16,797 & - & - \\
\hline LW44-34C & $1.51 \mathrm{E}+04$ & 23 & - & - & 9 & - & - & $<50$ & - & 13 & - & $<100$ & - & 16,703 & - & - \\
\hline LW44-34.4 & $1.51 \mathrm{E}+04$ & 23 & 9.7E-06 & 7.12 & 9 & 4.018 & 0.050 & 231 & $1.27 \mathrm{E}-03$ & 139 & 7.51E-04 & 3,800 & 4.82E-03 & 17,244 & 5.22E-04 & $1.42 \mathrm{E}-09$ \\
\hline LW44-34.8 & $1.51 \mathrm{E}+04$ & 23 & $9.6 \mathrm{E}-06$ & 14.25 & 9 & 4.018 & 0.079 & 177 & $5.56 \mathrm{E}-04$ & 124 & 4.13E-04 & 2,440 & $1.91 \mathrm{E}-03$ & 17,357 & 3.93E-04 & $5.40 \mathrm{E}-10$ \\
\hline LW44-34.12 & $1.51 \mathrm{E}+04$ & 23 & $9.4 \mathrm{E}-06$ & 22.22 & 9 & 4.017 & 0.079 & 263 & $9.13 \mathrm{E}-04$ & 267 & $9.24 \mathrm{E}-04$ & 1,913 & $1.45 \mathrm{E}-03$ & 19,006 & $1.33 \mathrm{E}-03$ & 2.15E-10 \\
\hline LW44-34.16 & $1.51 \mathrm{E}+04$ & 23 & $9.4 \mathrm{E}-06$ & 33.09 & 9 & 4.017 & 0.079 & 355 & $1.31 \mathrm{E}-03$ & 287 & 9.91E-04 & 1,903 & $1.44 \mathrm{E}-03$ & 18,935 & $1.28 \mathrm{E}-03$ & $5.24 \mathrm{E}-11$ \\
\hline LW44-34.20 & $1.51 \mathrm{E}+04$ & 23 & $9.5 \mathrm{E}-06$ & 42.48 & 9 & 4.017 & 0.079 & 298 & $1.07 \mathrm{E}-03$ & 197 & $6.75 \mathrm{E}-04$ & 1,589 & $1.20 \mathrm{E}-03$ & 17,798 & $6.42 \mathrm{E}-04$ & $5.09 \mathrm{E}-11$ \\
\hline LW44-34.24 & $1.51 \mathrm{E}+04$ & 23 & $1.1 \mathrm{E}-05$ & 52.10 & 9 & 4.016 & 0.079 & 239 & $9.24 \mathrm{E}-04$ & 152 & 5.79E-04 & 1,354 & $1.14 \mathrm{E}-03$ & 17,040 & 2.33E-04 & 8.74E-11 \\
\hline LW44-34.28 & $1.51 \mathrm{E}+04$ & 23 & $9.4 \mathrm{E}-06$ & 68.08 & 9 & 4.016 & 0.079 & 204 & 6.61E-04 & 133 & $4.41 \mathrm{E}-04$ & 1,285 & $9.50 \mathrm{E}-04$ & 17,061 & $2.17 \mathrm{E}-04$ & $1.16 \mathrm{E}-10$ \\
\hline LW44-34.32 & $1.51 \mathrm{E}+04$ & 23 & $9.4 \mathrm{E}-06$ & 86.08 & 9 & 4.015 & 0.079 & 216 & 7.15E-04 & 118 & 3.85E-04 & 1,295 & $9.58 \mathrm{E}-04$ & 17,240 & $3.20 \mathrm{E}-04$ & $9.71 \mathrm{E}-11$ \\
\hline LW44-34.34 & $1.51 \mathrm{E}+04$ & 23 & $9.5 \mathrm{E}-06$ & 93.15 & 9 & 4.015 & 0.079 & 182 & $5.71 \mathrm{E}-04$ & 100 & $3.21 \mathrm{E}-04$ & 1,377 & 1.03E-03 & 25,439 & $5.02 \mathrm{E}-03$ & $1.82 \mathrm{E}-10$ \\
\hline LW44-34.35 & $1.51 \mathrm{E}+04$ & 23 & $9.5 \mathrm{E}-06$ & 96.01 & 9 & 4.015 & 0.079 & 189 & $6.01 \mathrm{E}-04$ & 137 & 4.57E-04 & 1,252 & $9.26 \mathrm{E}-04$ & 21,709 & $2.88 \mathrm{E}-03$ & $1.30 \mathrm{E}-10$ \\
\hline \multicolumn{17}{|l|}{ Exp. \#35 } \\
\hline LW44-35A & $3.01 \mathrm{E}+04$ & 23 & - & - & 9 & - & - & $<50$ & - & $<10$ & - & $<100$ & - & 32,764 & - & - \\
\hline
\end{tabular}


Table A1. SPFT Results for LAWA44 Glasses.

\begin{tabular}{|c|c|c|c|c|c|c|c|c|c|c|c|c|c|c|c|c|}
\hline Sample ID & $\begin{array}{c}\text { Influent } \\
\text { [Si] }\end{array}$ & $\begin{array}{c}\mathrm{T} \\
\left({ }^{\circ} \mathrm{C}\right) \\
\end{array}$ & $\begin{array}{c}\text { Flow } \\
\text { Rate } \\
\left(\mathrm{m}^{3} / \mathrm{d}\right) \\
\end{array}$ & $\begin{array}{l}\text { Time, } \\
\text { days }\end{array}$ & $\begin{array}{c}\mathrm{pH} \\
\left(23^{\circ} \mathrm{C}\right) \\
\end{array}$ & $\begin{array}{l}\text { Glass } \\
\text { Mass } \\
(\mathrm{g}) \\
\end{array}$ & $\begin{array}{l}\text { SA } \\
\left(\mathrm{m}^{2}\right) \\
\end{array}$ & [B] & B Rate & [Al] & Al Rate & {$[\mathrm{Na}]$} & Na Rate & {$[\mathrm{Si}]$} & Si Rate & IEX Rate \\
\hline LW44-35B & $3.01 \mathrm{E}+04$ & 23 & - & - & 9 & - & - & $<50$ & - & $<10$ & - & $<100$ & - & 33,786 & - & - \\
\hline LW44-35C & $3.01 \mathrm{E}+04$ & 23 & - & - & 9 & - & - & $<50$ & - & $<10$ & - & $<100$ & - & 33,228 & - & - \\
\hline LW44-35.4 & $3.01 \mathrm{E}+04$ & 23 & $9.9 \mathrm{E}-06$ & 7.12 & 9 & 4.020 & 0.050 & 216 & 1.19E-03 & 107 & $5.80 \mathrm{E}-04$ & 3,797 & $4.90 \mathrm{E}-03$ & 34,511 & $1.18 \mathrm{E}-03$ & $1.49 \mathrm{E}-09$ \\
\hline LW44-35.8 & $3.01 \mathrm{E}+04$ & 23 & $9.6 \mathrm{E}-06$ & 14.25 & 9 & 4.020 & 0.079 & 144 & 4.11E-04 & 83 & $2.71 \mathrm{E}-04$ & 2,434 & $1.91 \mathrm{E}-03$ & 34,675 & 8.24E-04 & 5.97E-10 \\
\hline LW44-35.12 & $3.01 \mathrm{E}+04$ & 23 & $9.6 \mathrm{E}-06$ & 22.22 & 9 & 4.019 & 0.079 & 197 & $6.43 \mathrm{E}-04$ & 172 & 5.95E-04 & 1,855 & $1.43 \mathrm{E}-03$ & 35,721 & 1.43E-03 & 3.13E-10 \\
\hline LW44-35.16 & $3.01 \mathrm{E}+04$ & 23 & $9.4 \mathrm{E}-06$ & 33.09 & 9 & 4.019 & 0.079 & 276 & $9.68 \mathrm{E}-04$ & 195 & $6.68 \mathrm{E}-04$ & 1,722 & $1.30 \mathrm{E}-03$ & 34,627 & 7.78E-04 & $1.31 \mathrm{E}-10$ \\
\hline LW44-35.20 & $3.01 \mathrm{E}+04$ & 23 & $9.5 \mathrm{E}-06$ & 42.48 & 9 & 4.019 & 0.079 & 213 & 7.04E-04 & 116 & 3.87E-04 & 1,287 & $9.55 \mathrm{E}-04$ & 34,038 & 4.47E-04 & $1.00 \mathrm{E}-10$ \\
\hline LW44-35.24 & $3.01 \mathrm{E}+04$ & 23 & $1.1 \mathrm{E}-05$ & 52.10 & 9 & 4.019 & 0.079 & 153 & $5.08 \mathrm{E}-04$ & 85 & 3.13E-04 & 1,051 & 8.77E-04 & 33,488 & $1.51 \mathrm{E}-04$ & $1.47 \mathrm{E}-10$ \\
\hline LW44-35.28 & $3.01 \mathrm{E}+04$ & 23 & $9.4 \mathrm{E}-06$ & 68.08 & 9 & 4.019 & 0.079 & 112 & 2.66E-04 & 68 & $2.10 \mathrm{E}-04$ & 903 & $6.41 \mathrm{E}-04$ & 34,274 & 5.77E-04 & $1.50 \mathrm{E}-10$ \\
\hline LW44-35.32 & $3.01 \mathrm{E}+04$ & 23 & $9.4 \mathrm{E}-06$ & 86.08 & 9 & 4.018 & 0.079 & 125 & 3.22E-04 & 73 & 2.27E-04 & 909 & $6.48 \mathrm{E}-04$ & 34,203 & 5.38E-04 & $1.30 \mathrm{E}-10$ \\
\hline LW44-35.34 & $3.01 \mathrm{E}+04$ & 23 & $9.3 \mathrm{E}-06$ & 93.15 & 9 & 4.018 & 0.079 & 108 & $2.46 \mathrm{E}-04$ & 62 & $1.87 \mathrm{E}-04$ & 1,072 & 7.70E-04 & 43,846 & $5.98 \mathrm{E}-03$ & $2.09 \mathrm{E}-10$ \\
\hline LW44-35.35 & $3.01 \mathrm{E}+04$ & 23 & $9.3 \mathrm{E}-06$ & 96.01 & 9 & 4.018 & 0.079 & 110 & $2.56 \mathrm{E}-04$ & 77 & 2.39E-04 & 987 & 7.03E-04 & 37,698 & $2.51 \mathrm{E}-03$ & $1.78 \mathrm{E}-10$ \\
\hline \multicolumn{17}{|l|}{ Exp. \#36 } \\
\hline LW44-36A & $4.60 \mathrm{E}+04$ & 23 & - & - & 9 & - & - & $<50$ & - & $<10$ & - & $<100$ & - & 49,478 & - & - \\
\hline LW44-36B & $4.60 \mathrm{E}+04$ & 23 & - & - & 9 & - & - & $<50$ & - & $<10$ & - & $<100$ & - & 50,662 & - & - \\
\hline LW44-36C & $4.60 \mathrm{E}+04$ & 23 & - & - & 9 & - & - & $<50$ & - & $<10$ & - & $<100$ & - & 51,502 & - & - \\
\hline LW44-36.4 & $4.60 \mathrm{E}+04$ & 23 & $9.4 \mathrm{E}-06$ & 7.12 & 9 & 4.015 & 0.050 & 203 & $1.04 \mathrm{E}-03$ & 74 & 3.67E-04 & 3,931 & 4.88E-03 & 50,467 & - & 1.53E-09 \\
\hline LW44-36.8 & $4.60 \mathrm{E}+04$ & 23 & $9.6 \mathrm{E}-06$ & 14.25 & 9 & 4.015 & 0.079 & 124 & 3.24E-04 & 64 & 1.99E-04 & 2,829 & 2.22E-03 & 58,295 & 4.49E-03 & 7.56E-10 \\
\hline LW44-36.12 & $4.60 \mathrm{E}+04$ & 23 & $9.4 \mathrm{E}-06$ & 22.22 & 9 & 4.015 & 0.079 & 108 & $2.49 \mathrm{E}-04$ & 83 & 2.63E-04 & 1,782 & $1.34 \mathrm{E}-03$ & 53,038 & $1.41 \mathrm{E}-03$ & 4. $34 \mathrm{E}-10$ \\
\hline LW44-36.16 & $4.60 \mathrm{E}+04$ & 23 & 9.3E-06 & 33.09 & 9 & 4.014 & 0.079 & 137 & $3.70 \mathrm{E}-04$ & 96 & $3.08 \mathrm{E}-04$ & 1,315 & $9.58 \mathrm{E}-04$ & 50,161 & - & $2.35 \mathrm{E}-10$ \\
\hline LW44-36.20 & $4.60 \mathrm{E}+04$ & 23 & $9.3 \mathrm{E}-06$ & 42.48 & 9 & 4.014 & 0.079 & 110 & 2.53E-04 & 65 & $1.96 \mathrm{E}-04$ & 949 & $6.68 \mathrm{E}-04$ & 48,718 & - & $1.66 \mathrm{E}-10$ \\
\hline LW44-36.24 & $4.60 \mathrm{E}+04$ & 23 & $1.1 \mathrm{E}-05$ & 52.10 & 9 & 4.014 & 0.079 & 71 & 9.95E-05 & 40 & $1.24 \mathrm{E}-04$ & 699 & 5.42E-04 & 49,744 & - & $1.76 \mathrm{E}-10$ \\
\hline LW44-36.28 & $4.60 \mathrm{E}+04$ & 23 & $9.0 \mathrm{E}-06$ & 68.08 & 9 & 4.014 & 0.079 & 51 & 5.15E-06 & 48 & 1.32E-04 & 670 & 4.37E-04 & 47,362 & - & $1.72 \mathrm{E}-10$ \\
\hline LW44-36.32 & $4.60 \mathrm{E}+04$ & 23 & $9.1 \mathrm{E}-06$ & 86.08 & 9 & 4.014 & 0.079 & ND & $-6.74 \mathrm{E}-06$ & 33 & 7.96E-05 & 656 & $4.31 \mathrm{E}-04$ & 51,939 & 7.69E-04 & $1.75 \mathrm{E}-10$ \\
\hline LW44-36.34 & $4.60 \mathrm{E}+04$ & 23 & $9.2 \mathrm{E}-06$ & 93.15 & 9 & 4.014 & 0.079 & ND & $-2.76 \mathrm{E}-05$ & 26 & 5.51E-05 & 840 & 5.76E-04 & 43,225 & - & $2.41 \mathrm{E}-10$ \\
\hline LW44-36.35 & $4.60 \mathrm{E}+04$ & 23 & $9.2 \mathrm{E}-06$ & 96.01 & 9 & 4.014 & 0.079 & 53 & $1.21 \mathrm{E}-05$ & 28 & 6.36E-05 & 904 & $6.28 \mathrm{E}-04$ & 46,505 & - & $2.46 \mathrm{E}-10$ \\
\hline \multicolumn{17}{|l|}{ Exp. \#37 } \\
\hline LW44-36A & $6.04 \mathrm{E}+04$ & 23 & - & - & 9 & - & - & $<50$ & - & $<10$ & - & $<100$ & - & 65,880 & - & - \\
\hline LW44-36B & $6.04 \mathrm{E}+04$ & 23 & - & - & 9 & - & - & $<50$ & - & $<10$ & - & $<100$ & - & 69,250 & - & - \\
\hline LW44-36C & $6.04 \mathrm{E}+04$ & 23 & - & - & 9 & - & - & $<50$ & - & $<10$ & - & $<100$ & - & 67,086 & - & - \\
\hline LW44-37.4 & $6.04 \mathrm{E}+04$ & 23 & $9.8 \mathrm{E}-06$ & 7.12 & 9 & 4.021 & 0.050 & 183 & $9.44 \mathrm{E}-04$ & 54 & 2.61E-04 & 3,801 & 4.89E-03 & 65,178 & - & 1.57E-09 \\
\hline LW44-37.8 & $6.04 \mathrm{E}+04$ & 23 & $9.7 \mathrm{E}-06$ & 14.25 & 9 & 4.021 & 0.079 & 97 & 2.09E-04 & 39 & $1.07 \mathrm{E}-04$ & 2,373 & 1.87E-03 & 66,618 & - & 6.64E-10 \\
\hline LW44-37.12 & $6.04 \mathrm{E}+04$ & 23 & $9.5 \mathrm{E}-06$ & 22.22 & 9 & 4.021 & 0.079 & 73 & $1.01 \mathrm{E}-04$ & 50 & $1.46 \mathrm{E}-04$ & 1,680 & $1.27 \mathrm{E}-03$ & 67,027 & - & 4.66E-10 \\
\hline LW44-37.16 & $6.04 \mathrm{E}+04$ & 23 & $9.5 \mathrm{E}-06$ & 33.09 & 9 & 4.021 & 0.079 & 74 & $1.04 \mathrm{E}-04$ & 60 & $1.83 \mathrm{E}-04$ & 1,150 & $8.46 \mathrm{E}-04$ & 67,098 & - & $2.96 \mathrm{E}-10$ \\
\hline LW44-37.20 & $6.04 \mathrm{E}+04$ & 23 & $9.5 \mathrm{E}-06$ & 42.48 & 9 & 4.020 & 0.079 & 61 & 4.83E-05 & 40 & $1.09 \mathrm{E}-04$ & 749 & $5.25 \mathrm{E}-04$ & 63,845 & - & $1.90 \mathrm{E}-10$ \\
\hline LW44-37.24 & $6.04 \mathrm{E}+04$ & 23 & $1.1 \mathrm{E}-05$ & 52.10 & 9 & 4.020 & 0.079 & (35) & - & 23 & 5.50E-05 & 534 & 3.95E-04 & 70,172 & 1.79E-03 & $1.86 \mathrm{E}-10$ \\
\hline LW44-37.28 & $6.04 \mathrm{E}+04$ & 23 & $9.3 \mathrm{E}-06$ & 68.08 & 9 & 4.020 & 0.079 & (26) & - & 17 & 2.67E-05 & 754 & 5.17E-04 & 64,244 & - & $2.48 \mathrm{E}-10$ \\
\hline LW44-37.32 & $6.04 \mathrm{E}+04$ & 23 & $9.4 \mathrm{E}-06$ & 86.08 & 9 & 4.020 & 0.079 & (19) & - & 23 & $4.68 \mathrm{E}-05$ & 519 & 3.32E-04 & 63,348 & - & $1.86 \mathrm{E}-10$ \\
\hline LW44-37.34 & $6.04 \mathrm{E}+04$ & 23 & $9.1 \mathrm{E}-06$ & 93.15 & 9 & 4.020 & 0.079 & (20) & - & 18 & $2.96 \mathrm{E}-05$ & 532 & 3.35E-04 & 57,809 & - & $1.84 \mathrm{E}-10$ \\
\hline LW44-37.35 & $6.04 \mathrm{E}+04$ & 23 & $9.0 \mathrm{E}-06$ & 96.01 & 9 & 4.020 & 0.079 & (21) & - & 24 & $4.92 \mathrm{E}-05$ & 544 & 3.37E-04 & 62,078 & - & $1.83 \mathrm{E}-10$ \\
\hline
\end{tabular}


Table A1. SPFT Results for LAWA44 Glasses.

\begin{tabular}{|c|c|c|c|c|c|c|c|c|c|c|c|c|c|c|c|c|}
\hline Sample ID & $\begin{array}{c}\text { Influent } \\
\text { [Si] }\end{array}$ & $\begin{array}{c}\mathrm{T} \\
\left({ }^{\circ} \mathrm{C}\right) \\
\end{array}$ & $\begin{array}{c}\text { Flow } \\
\text { Rate } \\
\left(\mathrm{m}^{3} / \mathrm{d}\right)\end{array}$ & $\begin{array}{c}\text { Time, } \\
\text { days }\end{array}$ & $\begin{array}{c}\mathrm{pH} \\
\left(23^{\circ} \mathrm{C}\right) \\
\end{array}$ & $\begin{array}{c}\text { Glass } \\
\text { Mass } \\
\text { (g) }\end{array}$ & $\begin{array}{c}\mathrm{SA} \\
\left(\mathrm{m}^{2}\right) \\
\end{array}$ & {$[\mathrm{B}]$} & B Rate & [Al] & Al Rate & {$[\mathrm{Na}]$} & Na Rate & {$[\mathrm{Si}]$} & Si Rate & IEX Rate \\
\hline \multicolumn{17}{|l|}{ Exp. \#38 } \\
\hline LW44-38A & $5.24 \mathrm{E}+04$ & 23 & - & - & 9 & - & - & $<50$ & - & $<10$ & - & $<100$ & - & 52,022 & - & - \\
\hline LW44-38B & $5.24 \mathrm{E}+04$ & 23 & - & - & 9 & - & - & $<50$ & - & $<10$ & - & $<100$ & - & 57,400 & - & - \\
\hline LW44-38C & $5.24 \mathrm{E}+04$ & 23 & - & - & 9 & - & - & $<50$ & - & $<10$ & - & $<100$ & - & 61,722 & - & - \\
\hline LW44-38.4 & $5.24 \mathrm{E}+04$ & 23 & 9.7E-06 & 7.12 & 9 & 4.006 & 0.050 & 181 & $9.25 \mathrm{E}-04$ & 46 & $2.14 \mathrm{E}-04$ & 3,696 & 4.72E-03 & 76,634 & 1.83E-02 & $1.51 \mathrm{E}-09$ \\
\hline LW44-38.8 & $5.24 \mathrm{E}+04$ & 23 & 9.7E-06 & 14.25 & 9 & 4.006 & 0.079 & 101 & $2.26 \mathrm{E}-04$ & 37 & $1.01 \mathrm{E}-04$ & 2,735 & 2.16E-03 & 86,867 & $1.75 \mathrm{E}-02$ & 7.74E-10 \\
\hline LW44-38.12 & $5.24 \mathrm{E}+04$ & 23 & $9.5 \mathrm{E}-06$ & 22.22 & 9 & 4.006 & 0.079 & 65 & $6.71 \mathrm{E}-05$ & 35 & 9.15E-05 & 1,697 & $1.29 \mathrm{E}-03$ & 82,731 & $1.48 \mathrm{E}-02$ & $4.89 \mathrm{E}-10$ \\
\hline LW44-38.16 & $5.24 \mathrm{E}+04$ & 23 & $9.4 \mathrm{E}-06$ & 33.09 & 9 & 4.006 & 0.079 & (44) & - & 36 & $9.36 \mathrm{E}-05$ & 1,073 & 7.79E-04 & 82,997 & $1.48 \mathrm{E}-02$ & $3.22 \mathrm{E}-10$ \\
\hline LW44-38.20 & $5.24 \mathrm{E}+04$ & 23 & $9.5 \mathrm{E}-06$ & 42.48 & 9 & 4.006 & 0.079 & (30) & - & 26 & 5.88E-05 & 743 & $5.21 \mathrm{E}-04$ & 81,033 & $1.38 \mathrm{E}-02$ & $2.43 \mathrm{E}-10$ \\
\hline LW44-38.24 & $5.24 \mathrm{E}+04$ & 23 & 1.1E-05 & 52.10 & 9 & 4.006 & 0.079 & (16) & - & 17 & 3.05E-05 & 559 & $4.20 \mathrm{E}-04$ & 80,956 & $1.56 \mathrm{E}-02$ & 2.34E-10 \\
\hline LW44-38.28 & $5.24 \mathrm{E}+04$ & 23 & $9.2 \mathrm{E}-06$ & 68.08 & 9 & 4.006 & 0.079 & (9) & - & 13 & $1.04 \mathrm{E}-05$ & 509 & $3.21 \mathrm{E}-04$ & 74,205 & $9.58 \mathrm{E}-03$ & $1.97 \mathrm{E}-10$ \\
\hline LW44-38.32 & $5.24 \mathrm{E}+04$ & 23 & $9.3 \mathrm{E}-06$ & 86.08 & 9 & 4.005 & 0.079 & (6) & - & 14 & $1.30 \mathrm{E}-05$ & 433 & 2.64E-04 & 83,475 & $1.49 \mathrm{E}-02$ & $1.80 \mathrm{E}-10$ \\
\hline LW44-38.34 & $5.24 \mathrm{E}+04$ & 23 & $9.4 \mathrm{E}-06$ & 93.15 & 9 & 4.005 & 0.079 & (7) & - & 10 & - & 428 & 2.62E-04 & 73,591 & $9.41 \mathrm{E}-03$ & $1.78 \mathrm{E}-10$ \\
\hline LW44-38.35 & $5.24 \mathrm{E}+04$ & 23 & $9.0 \mathrm{E}-06$ & 96.01 & 9 & 4.005 & 0.079 & (7) & - & 12 & $8.42 \mathrm{E}-06$ & 448 & 2.67E-04 & 77,411 & $1.11 \mathrm{E}-02$ & $1.78 \mathrm{E}-10$ \\
\hline \multicolumn{17}{|l|}{ Exp. \#39 } \\
\hline LW44-47A & 0 & 40 & - & - & 7 & - & - & $<50$ & - & $<10$ & - & $<100$ & - & $<500$ & - & - \\
\hline LW44-47B & 0 & 40 & - & - & 7 & - & - & $<50$ & - & $<10$ & - & $<100$ & - & $<500$ & - & - \\
\hline LW44-47C & 0 & 40 & - & - & 7 & - & - & $<50$ & - & $<10$ & - & $<100$ & - & $<500$ & - & - \\
\hline LW44-47.1 & 0 & 40 & $1.0 \mathrm{E}-05$ & 1.98 & 7 & 1.005 & 0.020 & 480 & 7.92E-03 & 25 & 2.35E-04 & 6,014 & 2.03E-02 & 569 & $1.68 \mathrm{E}-04$ & 4.94E-09 \\
\hline LW44-47.2 & 0 & 40 & 8.6E-06 & 5.03 & 7 & 1.004 & 0.020 & 682 & 9.93E-03 & ND & - & 6,999 & 2.02E-02 & 1,134 & $1.32 \mathrm{E}-03$ & 4.10E-09 \\
\hline LW44-47.4 & 0 & 40 & 8.8E-06 & 9.10 & 7 & 1.003 & 0.020 & 590 & 8.69E-03 & 24 & $1.91 \mathrm{E}-04$ & 5,038 & $1.48 \mathrm{E}-02$ & 611 & $2.38 \mathrm{E}-04$ & 2.44E-09 \\
\hline LW44-47.6 & 0 & 40 & 8.7E-06 & 13.96 & 7 & 1.003 & 0.020 & 484 & $6.88 \mathrm{E}-03$ & 28 & $2.38 \mathrm{E}-04$ & 3,789 & $1.09 \mathrm{E}-02$ & ND & - & $1.60 \mathrm{E}-09$ \\
\hline LW44-47.9 & 0 & 40 & 9.5E-06 & 23.09 & 7 & 1.002 & 0.020 & 389 & 5.91E-03 & 30 & 2.92E-04 & 2,631 & $8.21 \mathrm{E}-03$ & ND & - & $9.19 \mathrm{E}-10$ \\
\hline LW44-47.12 & 0 & 40 & $1.1 \mathrm{E}-05$ & 33.15 & 7 & 1.002 & 0.020 & 345 & $6.08 \mathrm{E}-03$ & 29 & 3.32E-04 & 2,187 & 8.02E-03 & ND & - & 7.76E-10 \\
\hline LW44-47.14 & 0 & 40 & 9.3E-06 & 37.18 & 7 & 1.001 & 0.020 & 320 & 4.57E-03 & 31 & 2.95E-04 & 2,036 & $6.10 \mathrm{E}-03$ & ND & - & $6.14 \mathrm{E}-10$ \\
\hline \multicolumn{17}{|l|}{ Exp. \#40 } \\
\hline LW44-48A & 0 & 40 & - & - & 8 & - & - & $<50$ & - & $<10$ & - & $<100$ & - & $<500$ & - & - \\
\hline LW44-48B & 0 & 40 & - & - & 8 & - & - & $<50$ & - & $<10$ & - & $<100$ & - & $<500$ & - & - \\
\hline LW44-48C & 0 & 40 & - & - & 8 & - & - & $<50$ & - & $<10$ & - & $<100$ & - & $<500$ & - & - \\
\hline LW44-48.1 & 0 & 40 & $1.1 \mathrm{E}-05$ & 1.98 & 8 & 1.009 & 0.020 & 286 & 4.54E-03 & 82 & $1.17 \mathrm{E}-03$ & 4,871 & $1.71 \mathrm{E}-02$ & 744 & $6.22 \mathrm{E}-04$ & 5.01E-09 \\
\hline LW44-48.2 & 0 & 40 & $9.1 \mathrm{E}-06$ & 5.03 & 8 & 1.008 & 0.020 & 302 & 4.16E-03 & 92 & $1.13 \mathrm{E}-03$ & 4,918 & $1.48 \mathrm{E}-02$ & 1,049 & $1.20 \mathrm{E}-03$ & 4.26E-09 \\
\hline LW44-48.4 & 0 & 40 & $9.4 \mathrm{E}-06$ & 9.10 & 8 & 1.008 & 0.020 & 200 & $2.57 \mathrm{E}-03$ & 131 & $1.74 \mathrm{E}-03$ & 3,086 & 9.53E-03 & 817 & $7.21 \mathrm{E}-04$ & 2.78E-09 \\
\hline LW44-48.6 & 0 & 40 & $9.0 \mathrm{E}-06$ & 13.96 & 8 & 1.008 & 0.020 & 152 & $1.68 \mathrm{E}-03$ & 129 & $1.64 \mathrm{E}-03$ & 2,161 & 6.30E-03 & 691 & 4.16E-04 & 1.85E-09 \\
\hline LW44-48.9 & 0 & 40 & 9.9E-06 & 23.09 & 8 & 1.008 & 0.020 & 119 & $1.24 \mathrm{E}-03$ & 118 & $1.64 \mathrm{E}-03$ & 1,439 & 4.49E-03 & 587 & $2.08 \mathrm{E}-04$ & $1.30 \mathrm{E}-09$ \\
\hline LW44-48.12 & 0 & 40 & $1.3 \mathrm{E}-05$ & 33.15 & 8 & 1.008 & 0.020 & 112 & $1.44 \mathrm{E}-03$ & 109 & $1.94 \mathrm{E}-03$ & 1,216 & 4.82E-03 & 594 & 2.89E-04 & 1.35E-09 \\
\hline LW44-48.14 & 0 & 40 & $9.8 \mathrm{E}-06$ & 37.18 & 8 & 1.007 & 0.020 & 108 & 1.03E-03 & 108 & $1.47 \mathrm{E}-03$ & 1,104 & 3.33E-03 & 603 & $2.44 \mathrm{E}-04$ & $9.17 \mathrm{E}-10$ \\
\hline \multicolumn{17}{|l|}{ Exp. \#41 } \\
\hline LW44-49A & 0 & 40 & - & - & 9 & - & - & $<50$ & - & $<10$ & - & 104 & - & $<500$ & - & - \\
\hline LW44-49B & 0 & 40 & - & - & 9 & - & - & $<50$ & - & $<10$ & - & $<100$ & - & $<500$ & - & - \\
\hline LW44-49C & 0 & 40 & - & - & 9 & - & - & $<50$ & - & $<10$ & - & $<100$ & - & $<500$ & - & - \\
\hline
\end{tabular}


Table A1. SPFT Results for LAWA44 Glasses.

\begin{tabular}{|c|c|c|c|c|c|c|c|c|c|c|c|c|c|c|c|c|}
\hline Sample ID & $\begin{array}{c}\text { Influent } \\
\text { [Si] }\end{array}$ & $\begin{array}{c}\mathrm{T} \\
\left({ }^{\circ} \mathrm{C}\right) \\
\end{array}$ & $\begin{array}{c}\text { Flow } \\
\text { Rate } \\
\left(\mathrm{m}^{3} / \mathrm{d}\right) \\
\end{array}$ & $\begin{array}{c}\text { Time, } \\
\text { days }\end{array}$ & $\begin{array}{c}\mathrm{pH} \\
\left(23^{\circ} \mathrm{C}\right) \\
\end{array}$ & $\begin{array}{l}\text { Glass } \\
\text { Mass } \\
(\mathrm{g}) \\
\end{array}$ & $\begin{array}{c}\text { SA } \\
\left(\mathrm{m}^{2}\right) \\
\end{array}$ & [B] & B Rate & {$[\mathrm{Al}]$} & Al Rate & {$[\mathrm{Na}]$} & Na Rate & {$[\mathrm{Si}]$} & Si Rate & IEX Rate \\
\hline LW44-49.1 & 0 & 40 & $1.0 \mathrm{E}-05$ & 1.98 & 9 & 1.008 & 0.020 & 238 & 3.58E-03 & 232 & 3.56E-03 & 3,663 & $1.26 \mathrm{E}-02$ & 1,368 & 2.19E-03 & 3.62E-09 \\
\hline LW44-49.2 & 0 & 40 & $9.8 \mathrm{E}-06$ & 5.03 & 9 & 1.007 & 0.020 & 420 & 6.61E-03 & 480 & 7.06E-03 & 4,090 & 1.33E-02 & 2,923 & $5.74 \mathrm{E}-03$ & 2.65E-09 \\
\hline LW44-49.4 & 0 & 40 & 8.6E-06 & 9.10 & 9 & 1.007 & 0.020 & 485 & $6.80 \mathrm{E}-03$ & 597 & 7.72E-03 & 3,436 & $9.69 \mathrm{E}-03$ & 3,550 & $6.32 \mathrm{E}-03$ & 1.16E-09 \\
\hline LW44-49.6 & 0 & 40 & $9.2 \mathrm{E}-06$ & 13.96 & 9 & 1.006 & 0.020 & 496 & 7.44E-03 & 635 & 8.78E-03 & 3,142 & $9.45 \mathrm{E}-03$ & 3,669 & 7.02E-03 & 8.05E-10 \\
\hline LW44-49.9 & 0 & 40 & 9.9E-06 & 23.09 & 9 & 1.006 & 0.020 & 468 & 7.51E-03 & 619 & $9.22 \mathrm{E}-03$ & 2,803 & $9.05 \mathrm{E}-03$ & 3,425 & 6.98E-03 & $6.16 \mathrm{E}-10$ \\
\hline LW44-49.12 & 0 & 40 & $1.3 \mathrm{E}-05$ & 33.15 & 9 & 1.005 & 0.020 & 483 & $1.01 \mathrm{E}-02$ & 583 & $1.12 \mathrm{E}-02$ & 2,687 & $1.12 \mathrm{E}-02$ & 3,562 & $9.44 \mathrm{E}-03$ & $4.48 \mathrm{E}-10$ \\
\hline LW44-49.14 & 0 & 40 & $9.0 \mathrm{E}-06$ & 37.18 & 9 & 1.004 & 0.020 & 460 & 6.73E-03 & 578 & 7.85E-03 & 2,575 & 7.56E-03 & 3,375 & $6.26 \mathrm{E}-03$ & 3.33E-10 \\
\hline \multicolumn{17}{|l|}{ Exp. \#42 } \\
\hline LW44-50A & 0 & 40 & - & - & 10 & - & - & $<50$ & - & $<10$ & - & $<100$ & - & $<500$ & - & - \\
\hline LW44-50B & 0 & 40 & - & - & 10 & - & - & $<50$ & - & $<10$ & - & $<100$ & - & $<500$ & - & - \\
\hline LW44-50C & 0 & 40 & - & - & 10 & - & - & $<50$ & - & $<10$ & - & $<100$ & - & $<500$ & - & - \\
\hline LW44-50.1 & 0 & 40 & $1.1 \mathrm{E}-05$ & 1.98 & 10 & 1.005 & 0.020 & 467 & 8.15E-03 & 623 & $1.01 \mathrm{E}-02$ & 4,387 & $1.56 \mathrm{E}-02$ & 3,600 & 8.04E-03 & 2.98E-09 \\
\hline LW44-50.2 & 0 & 40 & $9.2 \mathrm{E}-06$ & 5.03 & 10 & 1.004 & 0.020 & 824 & 1.29E-02 & 1,028 & 1.43E-02 & 5,837 & $1.78 \mathrm{E}-02$ & 5,995 & $1.22 \mathrm{E}-02$ & 1.96E-09 \\
\hline LW44-50.4 & 0 & 40 & $9.4 \mathrm{E}-06$ & 9.10 & 10 & 1.003 & 0.020 & 844 & 1.37E-02 & 1,055 & $1.52 \mathrm{E}-02$ & 5,164 & 1.63E-02 & 6,019 & $1.26 \mathrm{E}-02$ & $1.02 \mathrm{E}-09$ \\
\hline LW44-50.6 & 0 & 40 & 8.9E-06 & 13.96 & 10 & 1.002 & 0.020 & 832 & $1.28 \mathrm{E}-02$ & 1,019 & 1.39E-02 & 4,883 & $1.46 \mathrm{E}-02$ & 5,866 & $1.16 \mathrm{E}-02$ & 7.12E-10 \\
\hline LW44-50.9 & 0 & 40 & $9.9 \mathrm{E}-06$ & 23.09 & 10 & 1.001 & 0.020 & 825 & $1.41 \mathrm{E}-02$ & 1,003 & $1.52 \mathrm{E}-02$ & 4,462 & $1.48 \mathrm{E}-02$ & 5,828 & $1.28 \mathrm{E}-02$ & $2.76 \mathrm{E}-10$ \\
\hline LW44-50.12 & 0 & 40 & $1.3 \mathrm{E}-05$ & 33.15 & 10 & 1.000 & 0.020 & 779 & $1.70 \mathrm{E}-02$ & 964 & $1.88 \mathrm{E}-02$ & 4,180 & $1.78 \mathrm{E}-02$ & 5,519 & $1.56 \mathrm{E}-02$ & $2.94 \mathrm{E}-10$ \\
\hline LW44-50.14 & 0 & 40 & $9.8 \mathrm{E}-06$ & 37.18 & 10 & 0.999 & 0.020 & 736 & $1.24 \mathrm{E}-02$ & 927 & 1.39E-02 & 3,993 & $1.31 \mathrm{E}-02$ & 5,228 & 1.13E-02 & $2.81 \mathrm{E}-10$ \\
\hline \multicolumn{17}{|l|}{ Exp. \#43 } \\
\hline LW44-51A & 0 & 40 & - & - & 11 & - & - & $<50$ & - & $<10$ & - & $<100$ & - & $<500$ & - & - \\
\hline LW44-51B & 0 & 40 & - & - & 11 & - & - & $<50$ & - & $<10$ & - & $<100$ & - & $<500$ & - & - \\
\hline LW44-51C & 0 & 40 & - & - & 11 & - & - & $<50$ & - & $<10$ & - & $<100$ & - & $<500$ & - & - \\
\hline LW44-51.1 & 0 & 40 & $1.0 \mathrm{E}-05$ & 1.98 & 11 & 1.003 & 0.020 & 1,213 & $2.14 \mathrm{E}-02$ & 1,611 & $2.48 \mathrm{E}-02$ & 7,859 & 2.66E-02 & 9,270 & 2.14E-02 & 2.07E-09 \\
\hline LW44-51.2 & 0 & 40 & $9.7 \mathrm{E}-06$ & 5.03 & 11 & 1.000 & 0.020 & 2,563 & 4.45E-02 & 2,982 & 4.43E-02 & 14,807 & $4.85 \mathrm{E}-02$ & 17,238 & 3.93E-02 & $1.60 \mathrm{E}-09$ \\
\hline LW44-51.4 & 0 & 40 & 9.4E-06 & 9.10 & 11 & 0.996 & 0.020 & 3,568 & 6.06E-02 & 4,052 & 5.86E-02 & 19,083 & 6.09E-02 & 23,146 & 5.18E-02 & $1.25 \mathrm{E}-10$ \\
\hline LW44-51.6 & 0 & 40 & 8.8E-06 & 13.96 & 11 & 0.994 & 0.020 & 3,282 & $5.26 \mathrm{E}-02$ & 3,500 & 4.78E-02 & 17,399 & $5.24 \mathrm{E}-02$ & 20,542 & 4.33E-02 & - \\
\hline LW44-51.9 & 0 & 40 & $9.8 \mathrm{E}-06$ & 23.09 & 11 & 0.990 & 0.020 & 4,011 & 7.20E-02 & 4,390 & $6.71 \mathrm{E}-02$ & 20,961 & 7.07E-02 & 25,643 & $6.07 \mathrm{E}-02$ & - \\
\hline LW44-51.12 & 0 & 40 & $1.3 \mathrm{E}-05$ & 33.15 & 11 & 0.984 & 0.019 & 3,449 & 8.03E-02 & 3,384 & $6.71 \mathrm{E}-02$ & 18,553 & $8.12 \mathrm{E}-02$ & 21,187 & $6.48 \mathrm{E}-02$ & 3.62E-10 \\
\hline LW44-51.14 & 0 & 40 & 9.7E-06 & 37.18 & 11 & 0.979 & 0.019 & 3,498 & $6.24 \mathrm{E}-02$ & 3,352 & 5.09E-02 & 18,364 & 6.16E-02 & 21,417 & 5.02E-02 & - \\
\hline \multicolumn{17}{|l|}{ Exp. \#44 } \\
\hline LW44-52A & 0 & 40 & - & - & 12 & - & - & $<50$ & - & 12 & - & $<100$ & - & $<500$ & - & - \\
\hline LW44-52B & 0 & 40 & - & - & 12 & - & - & $<50$ & - & 11 & - & $<100$ & - & $<500$ & - & - \\
\hline LW44-52C & 0 & 40 & - & - & 12 & - & - & $<50$ & - & 16 & - & $<100$ & - & $<500$ & - & - \\
\hline LW44-52.1 & 0 & 40 & $1.0 \mathrm{E}-05$ & 1.98 & 12 & 1.001 & 0.020 & 2,107 & 3.80E-02 & 2,824 & 4.37E-02 & 13,009 & 4.44E-02 & 15,343 & 3.64E-02 & 2.56E-09 \\
\hline LW44-52.2 & 0 & 40 & 9.3E-06 & 5.03 & 12 & 0.994 & 0.020 & 6,400 & 1.09E-01 & 7,689 & $1.11 \mathrm{E}-01$ & 34,393 & 1.09E-01 & 44,219 & 9.93E-02 & $2.64 \mathrm{E}-10$ \\
\hline LW44-52.4 & 0 & 40 & $9.1 \mathrm{E}-06$ & 9.10 & 12 & 0.985 & 0.020 & 8,859 & 1.49E-01 & 10,398 & $1.48 \mathrm{E}-01$ & 45,333 & 1.43E-01 & 57,223 & $1.27 \mathrm{E}-01$ & - \\
\hline LW44-52.6 & 0 & 40 & 8.9E-06 & 13.96 & 12 & 0.979 & 0.019 & 8,682 & 1.43E-01 & 9,989 & 1.39E-01 & 45,610 & $1.40 \mathrm{E}-01$ & 55,013 & $1.20 \mathrm{E}-01$ & - \\
\hline LW44-52.9 & 0 & 40 & 9.9E-06 & 23.09 & 12 & 0.971 & 0.019 & 8,826 & 1.63E-01 & 9,784 & $1.53 \mathrm{E}-01$ & 45,657 & $1.58 \mathrm{E}-01$ & 55,803 & $1.36 \mathrm{E}-01$ & - \\
\hline LW44-52.12 & 0 & 40 & $1.3 \mathrm{E}-05$ & 33.15 & 12 & 0.955 & 0.019 & 9,071 & 2.18E-01 & 9,652 & 1.96E-01 & 50,007 & 2.24E-01 & 57,314 & 1.82E-01 & 2.67E-09 \\
\hline LW44-52.14 & 0 & 40 & $9.7 \mathrm{E}-06$ & 37.18 & 12 & 0.942 & 0.019 & 8,391 & $1.57 \mathrm{E}-01$ & 9,078 & $1.44 \mathrm{E}-01$ & 46,504 & 1.63E-01 & 52,556 & $1.30 \mathrm{E}-01$ & 2.29E-09 \\
\hline
\end{tabular}


Table A1. SPFT Results for LAWA44 Glasses.

\begin{tabular}{|c|c|c|c|c|c|c|c|c|c|c|c|c|c|c|c|c|}
\hline Sample ID & $\begin{array}{c}\text { Influent } \\
\text { [Si] }\end{array}$ & $\begin{array}{c}\mathrm{T} \\
\left({ }^{\circ} \mathrm{C}\right) \\
\end{array}$ & $\begin{array}{c}\text { Flow } \\
\text { Rate } \\
\left(\mathrm{m}^{3} / \mathrm{d}\right) \\
\end{array}$ & $\begin{array}{c}\text { Time, } \\
\text { days }\end{array}$ & $\begin{array}{c}\mathrm{pH} \\
\left(23^{\circ} \mathrm{C}\right) \\
\end{array}$ & $\begin{array}{l}\text { Glass } \\
\text { Mass } \\
(\mathrm{g}) \\
\end{array}$ & $\begin{array}{c}\text { SA } \\
\left(\mathrm{m}^{2}\right) \\
\end{array}$ & [B] & B Rate & {$[\mathrm{Al}]$} & Al Rate & {$[\mathrm{Na}]$} & Na Rate & [Si] & Si Rate & IEX Rate \\
\hline \multicolumn{17}{|l|}{ Exp. \#45 } \\
\hline LW44-53.A & 0 & 90 & - & - & 7 & - & - & 50 & - & 10 & - & 100 & - & 500 & - & - \\
\hline LW44-53.1 & 0 & 90 & 7.2E-05 & 0.94 & 7 & 0.998 & 0.020 & 4,083 & 5.34E-01 & 51 & 4.62E-03 & 26,604 & $6.53 \mathrm{E}-01$ & 1,939 & $2.53 \mathrm{E}-02$ & $4.78 \mathrm{E}-08$ \\
\hline LW44-53.2 & 0 & 90 & $8.5 \mathrm{E}-05$ & 1.17 & 7 & 0.989 & 0.020 & 6,224 & $9.64 \mathrm{E}-01$ & 91 & $1.07 \mathrm{E}-02$ & 34,929 & $1.01 \mathrm{E}+00$ & 2,095 & 3.30E-02 & 1.96E-08 \\
\hline LW44-53.4 & 0 & 90 & 5.9E-05 & 2.19 & 7 & 0.983 & 0.019 & 4,891 & 5.34E-01 & 89 & 7.32E-03 & 26,724 & 5.47E-01 & 1,194 & 1.02E-02 & 5.22E-09 \\
\hline LW44-53.6 & 0 & 90 & 7.3E-05 & 5.18 & 7 & 0.973 & 0.019 & 3,399 & 4.59E-01 & 82 & $8.26 \mathrm{E}-03$ & 18,703 & 4.75E-01 & 934 & 7.89E-03 & 6.37E-09 \\
\hline LW44-53.8 & 0 & 90 & $8.0 \mathrm{E}-05$ & 7.02 & 7 & 0.960 & 0.019 & 3,077 & 4.62E-01 & 79 & 8.84E-03 & 16,491 & 4.66E-01 & 945 & $9.01 \mathrm{E}-03$ & $1.60 \mathrm{E}-09$ \\
\hline LW44-53.9 & 0 & 90 & 7.5E-05 & 8.05 & 7 & 0.948 & 0.019 & 2,929 & 4.13E-01 & 74 & 7.78E-03 & 15,967 & $4.24 \mathrm{E}-01$ & 906 & 7.74E-03 & 4.43E-09 \\
\hline \multicolumn{17}{|l|}{ Exp. \#46 } \\
\hline LW44-54.A & 0 & 90 & - & - & 8 & - & - & 50 & - & 10 & - & 100 & - & 500 & - & - \\
\hline LW44-54.1 & 0 & 90 & $7.4 \mathrm{E}-05$ & 0.94 & 8 & 0.998 & 0.020 & 1,481 & 1.93E-01 & 260 & 2.84E-02 & 14,465 & 3.61E-01 & 2,258 & 3.15E-02 & $6.70 \mathrm{E}-08$ \\
\hline LW44-54.2 & 0 & 90 & 7.1E-05 & 1.17 & 8 & 0.995 & 0.020 & 1,943 & 2.47E-01 & 404 & 4.33E-02 & 15,706 & $3.80 \mathrm{E}-01$ & 2,821 & 4.02E-02 & 5.29E-08 \\
\hline LW44-54.4 & 0 & 90 & 3.3E-05 & 2.19 & 8 & 0.994 & 0.020 & 1,509 & 8.83E-02 & 367 & 1.82E-02 & 10,496 & 1.17E-01 & 2,303 & $1.45 \mathrm{E}-02$ & 1.15E-08 \\
\hline LW44-54.6 & 0 & 90 & 7.5E-05 & 5.18 & 8 & 0.991 & 0.020 & 941 & $1.24 \mathrm{E}-01$ & 337 & 3.82E-02 & 5,612 & $1.43 \mathrm{E}-01$ & 2,121 & 2.99E-02 & 7.55E-09 \\
\hline LW44-54.8 & 0 & 90 & $7.8 \mathrm{E}-05$ & 7.02 & 8 & 0.988 & 0.020 & 817 & $1.10 \mathrm{E}-01$ & 319 & $3.74 \mathrm{E}-02$ & 5,047 & 1.33E-01 & 2,071 & $3.00 \mathrm{E}-02$ & 8.89E-09 \\
\hline LW44-54.9 & 0 & 90 & 7.2E-05 & 8.05 & 8 & 0.985 & 0.019 & 812 & $1.01 \mathrm{E}-01$ & 326 & 3.53E-02 & 4,821 & $1.17 \mathrm{E}-01$ & 2,013 & $2.67 \mathrm{E}-02$ & $6.23 \mathrm{E}-09$ \\
\hline \multicolumn{17}{|l|}{ Exp. \#47 } \\
\hline LW44-55.A & 0 & 9 & - & - & 9 & - & - & 50 & - & 10 & - & 100 & - & 500 & - & - \\
\hline LW44-55.1 & 0 & 90 & 7.1E-05 & 0.94 & 9 & 1.000 & 0.020 & 846 & $1.03 \mathrm{E}-01$ & 928 & $9.99 \mathrm{E}-02$ & 8,155 & $1.94 \mathrm{E}-01$ & 5,795 & $9.08 \mathrm{E}-02$ & 3.63E-08 \\
\hline LW44-55.2 & 0 & 90 & $5.2 \mathrm{E}-05$ & 1.17 & 9 & 0.998 & 0.020 & 1,284 & 1.18E-01 & 1,458 & 1.17E-01 & 10,400 & $1.84 \mathrm{E}-01$ & 8,913 & $1.07 \mathrm{E}-01$ & 2.62E-08 \\
\hline LW44-55.4 & 0 & 90 & $4.8 \mathrm{E}-05$ & 2.19 & 9 & 0.998 & 0.020 & 1,204 & $1.02 \mathrm{E}-01$ & 1,391 & $1.03 \mathrm{E}-01$ & 7,755 & $1.26 \mathrm{E}-01$ & 8,423 & $9.32 \mathrm{E}-02$ & $9.64 \mathrm{E}-09$ \\
\hline LW44-55.6 & 0 & 90 & 7.2E-05 & 5.18 & 9 & 0.994 & 0.020 & 1,313 & 1.67E-01 & 1,518 & $1.68 \mathrm{E}-01$ & 6,704 & 1.63E-01 & 8,916 & $1.48 \mathrm{E}-01$ & - \\
\hline LW44-55.8 & 0 & 90 & 7.6E-05 & 7.02 & 9 & 0.989 & 0.020 & 1,300 & 1.77E-01 & 1,497 & $1.77 \mathrm{E}-01$ & 6,938 & $1.80 \mathrm{E}-01$ & 8,960 & 1.59E-01 & 1.33E-09 \\
\hline LW44-55.9 & 0 & 90 & 7.5E-05 & 8.05 & 9 & 0.984 & 0.019 & 1,234 & $1.65 \mathrm{E}-01$ & 1,419 & $1.65 \mathrm{E}-01$ & 6,783 & $1.73 \mathrm{E}-01$ & 8,574 & 1.49E-01 & 3.40E-09 \\
\hline \multicolumn{17}{|l|}{ Exp. \#48 } \\
\hline LW44-56.A & 0 & 90 & - & - & 10 & - & - & 50 & - & 10 & - & 100 & $5.00 \mathrm{E}+02$ & 500 & - & \\
\hline LW44-56.1 & 0 & 90 & $7.5 \mathrm{E}-05$ & 0.94 & 10 & 0.499 & 0.010 & 1,040 & 2.72E-01 & 1,182 & 2.72E-01 & 6,681 & 3.37E-01 & 6,757 & $2.28 \mathrm{E}-01$ & $2.59 \mathrm{E}-08$ \\
\hline LW44-56.2 & 0 & 90 & $8.2 \mathrm{E}-05$ & 1.17 & 10 & 0.497 & 0.010 & 1,788 & 5.25E-01 & 2,006 & 5.08E-01 & 10,184 & 5.67E-01 & 11,300 & 4.33E-01 & $1.70 \mathrm{E}-08$ \\
\hline LW44-56.4 & 0 & 90 & $5.5 \mathrm{E}-05$ & 2.19 & 10 & 0.495 & 0.010 & 1,910 & 3.79E-01 & 2,030 & 3.47E-01 & 10,101 & $3.80 \mathrm{E}-01$ & 11,975 & 3.11E-01 & 2.73E-10 \\
\hline LW44-56.6 & 0 & 90 & 7.7E-05 & 5.18 & 10 & 0.488 & 0.010 & 2,390 & $6.72 \mathrm{E}-01$ & 2,514 & $6.06 \mathrm{E}-01$ & 12,424 & $6.60 \mathrm{E}-01$ & 14,986 & 5.53E-01 & - \\
\hline LW44-56.8 & 0 & 90 & 7.1E-05 & 7.02 & 10 & 0.479 & 0.010 & 2,319 & 6.11E-01 & 2,283 & 5.16E-01 & 12,391 & $6.17 \mathrm{E}-01$ & 14,469 & 4.99E-01 & 2.27E-09 \\
\hline LW44-56.9 & 0 & 90 & 4.5E-05 & 8.05 & 10 & 0.473 & 0.009 & 2,270 & 3.82E-01 & 2,244 & 3.24E-01 & 12,155 & 3.86E-01 & 14,133 & 3.11E-01 & $1.77 \mathrm{E}-09$ \\
\hline \multicolumn{17}{|l|}{ Exp. \#49 } \\
\hline LW44.57.A & 0 & 90 & - & - & 11 & - & - & 50 & - & 10 & - & 100 & - & 500 & - & - \\
\hline LW44-57.1 & 0 & 90 & 7.2E-05 & 0.94 & 11 & 0.494 & 0.010 & 3,527 & $9.17 \mathrm{E}-01$ & 3,545 & 7.85E-01 & 19,269 & $9.42 \mathrm{E}-01$ & 22,054 & 7.55E-01 & $9.90 \mathrm{E}-09$ \\
\hline LW44-57.2 & 0 & 90 & $5.1 \mathrm{E}-05$ & 1.17 & 11 & 0.487 & 0.010 & 6,346 & $1.19 \mathrm{E}+00$ & 5,825 & $9.25 \mathrm{E}-01$ & 33,830 & $1.19 \mathrm{E}+00$ & 37,710 & 9.32E-01 & - \\
\hline LW44-57.4 & 0 & 90 & 5.7E-05 & 2.19 & 11 & 0.482 & 0.010 & 6,615 & $1.43 \mathrm{E}+00$ & 5,244 & $9.58 \mathrm{E}-01$ & 34,345 & $1.39 \mathrm{E}+00$ & 37,940 & $1.08 \mathrm{E}+00$ & - \\
\hline LW44-57.6 & 0 & 90 & 7.5E-05 & 5.18 & 11 & 0.462 & 0.009 & 6,486 & $1.89 \mathrm{E}+00$ & 4,896 & $1.21 \mathrm{E}+00$ & 33,638 & $1.84 \mathrm{E}+00$ & 38,207 & $1.47 \mathrm{E}+00$ & - \\
\hline LW44-57.8 & 0 & 90 & $8.0 \mathrm{E}-05$ & 7.02 & 11 & 0.441 & 0.009 & 4,852 & $1.57 \mathrm{E}+00$ & 3,670 & $1.01 \mathrm{E}+00$ & 24,805 & $1.50 \mathrm{E}+00$ & 28,786 & $1.23 \mathrm{E}+00$ & - \\
\hline LW44-57.9 & 0 & 90 & 7.5E-05 & 8.05 & 11 & 0.423 & 0.008 & 4,197 & $1.33 \mathrm{E}+00$ & 3,050 & 8.19E-01 & 21,594 & $1.28 \mathrm{E}+00$ & 24,863 & $1.03 \mathrm{E}+00$ & - \\
\hline
\end{tabular}


Table A1. SPFT Results for LAWA44 Glasses.

\begin{tabular}{|c|c|c|c|c|c|c|c|c|c|c|c|c|c|c|c|c|}
\hline Sample ID & $\begin{array}{c}\text { Influent } \\
\text { [Si] }\end{array}$ & $\begin{array}{c}\mathrm{T} \\
\left({ }^{\circ} \mathrm{C}\right) \\
\end{array}$ & $\begin{array}{c}\text { Flow } \\
\text { Rate } \\
\left(\mathrm{m}^{3} / \mathrm{d}\right) \\
\end{array}$ & $\begin{array}{l}\text { Time, } \\
\text { days }\end{array}$ & $\begin{array}{c}\mathrm{pH} \\
\left(23^{\circ} \mathrm{C}\right) \\
\end{array}$ & $\begin{array}{c}\text { Glass } \\
\text { Mass } \\
(\mathrm{g}) \\
\end{array}$ & $\begin{array}{c}\text { SA } \\
\left(\mathrm{m}^{2}\right) \\
\end{array}$ & [B] & B Rate & {$[\mathrm{Al}]$} & Al Rate & {$[\mathrm{Na}]$} & Na Rate & {$[\mathrm{Si}]$} & Si Rate & IEX Rate \\
\hline \multicolumn{17}{|l|}{ Exp. \#50 } \\
\hline LW44-58.A & 0 & 90 & - & - & 12 & - & - & 50 & - & 10 & - & 100 & - & 500 & - & - \\
\hline LW44-58.1 & 0 & 90 & 7.0E-05 & 0.94 & 12 & 0.484 & 0.010 & 9,098 & $2.37 \mathrm{E}+00$ & 9,720 & $2.14 \mathrm{E}+00$ & 47,454 & $2.31 \mathrm{E}+00$ & 57,168 & $1.97 \mathrm{E}+00$ & - \\
\hline LW44-58.2 & 0 & 90 & $8.2 \mathrm{E}-05$ & 1.17 & 12 & 0.462 & 0.009 & 16,900 & $5.36 \mathrm{E}+00$ & 15,460 & $4.14 \mathrm{E}+00$ & 83,899 & $4.97 \mathrm{E}+00$ & 98,609 & $4.15 \mathrm{E}+00$ & - \\
\hline LW44-58.4 & 0 & 90 & $6.3 \mathrm{E}-05$ & 2.19 & 12 & 0.446 & 0.009 & 15,178 & $3.85 E+00$ & 12,693 & $2.72 \mathrm{E}+00$ & 75,478 & $3.58 \mathrm{E}+00$ & 87,323 & $2.94 \mathrm{E}+00$ & - \\
\hline LW44-58.6 & 0 & 90 & 7.2E-05 & 5.18 & 12 & 0.407 & 0.008 & 13,067 & $4.08 \mathrm{E}+00$ & 9,970 & $2.63 \mathrm{E}+00$ & 64,959 & $3.78 \mathrm{E}+00$ & 72,152 & $2.98 \mathrm{E}+00$ & - \\
\hline LW44-58.8 & 0 & 90 & 7.5E-05 & 7.02 & 12 & 0.362 & 0.007 & 11,338 & $4.10 \mathrm{E}+00$ & 8,524 & $2.61 \mathrm{E}+00$ & 52,648 & $3.56 \mathrm{E}+00$ & 62,210 & $2.98 \mathrm{E}+00$ & - \\
\hline LW44-58.9 & 0 & 90 & 7.5E-05 & 8.05 & 12 & 0.315 & 0.007 & 11,773 & $4.87 \mathrm{E}+00$ & 8,911 & $3.11 \mathrm{E}+00$ & 54,671 & $4.22 \mathrm{E}+00$ & 64,730 & $3.54 \mathrm{E}+00$ & - \\
\hline \multicolumn{17}{|l|}{ Exp. \#51 } \\
\hline LW44-59A & 0 & 70 & - & - & 7 & - & - & $<50$ & - & $<25$ & - & $<100$ & - & $<500$ & - & - \\
\hline LW44-59.1 & 0 & 70 & - & - & 7 & - & - & $<50$ & - & $<25$ & - & $<100$ & - & $<500$ & - & - \\
\hline LW44-59.2 & 0 & 70 & $6.1 \mathrm{E}-05$ & 0.85 & 7 & 1.008 & 0.036 & 864 & 4.94E-02 & ND & - & 6,682 & 7.44E-02 & 568 & 5.51E-04 & 9.99E-09 \\
\hline LW44-59.4 & 0 & 70 & 5.7E-05 & 2.99 & 7 & 1.004 & 0.020 & 1,449 & $1.46 \mathrm{E}-01$ & 29 & 3.77E-04 & 8,602 & 1.65E-01 & 562 & 8.59E-04 & 7.69E-09 \\
\hline LW44-59.6 & 0 & 70 & 9.4E-05 & 4.85 & 7 & 0.999 & 0.020 & 1,168 & $1.91 \mathrm{E}-01$ & 41 & $2.31 \mathrm{E}-03$ & 6,596 & 2.07E-01 & ND & - & $6.30 \mathrm{E}-09$ \\
\hline LW44-59.8 & 0 & 70 & 5.1E-05 & 6.86 & 7 & 0.996 & 0.020 & 1,062 & 9.53E-02 & 43 & $1.43 \mathrm{E}-03$ & 5,966 & 1.03E-01 & ND & - & 3.03E-09 \\
\hline LW44-59.9 & 0 & 70 & $5.8 \mathrm{E}-05$ & 7.77 & 7 & 0.993 & 0.020 & 1,011 & $1.02 \mathrm{E}-01$ & 44 & $1.71 \mathrm{E}-03$ & 5,467 & 1.07E-01 & ND & - & 1.64E-09 \\
\hline LW44-59.10 & 0 & 70 & $5.8 \mathrm{E}-05$ & 8.07 & 7 & 0.991 & 0.020 & 1,056 & $1.08 \mathrm{E}-01$ & 50 & $2.28 \mathrm{E}-03$ & 6,051 & 1.19E-01 & ND & - & 4.41E-09 \\
\hline LW44-59.11 & 0 & 70 & $1.3 \mathrm{E}-04$ & 8.36 & 7 & 0.989 & 0.020 & 962 & $2.14 \mathrm{E}-01$ & 47 & 4.33E-03 & 5,122 & 2.19E-01 & ND & - & 2.20E-09 \\
\hline \multicolumn{17}{|l|}{ Exp. \#52 } \\
\hline LW44-60A & 0 & 70 & - & - & 8 & - & - & $<50$ & - & $<25$ & - & $<100$ & - & $<500$ & - & - \\
\hline LW44-60.1 & 0 & 70 & - & - & 8 & - & - & $<50$ & - & $<25$ & - & $<100$ & - & $<500$ & - & - \\
\hline LW44-60.2 & 0 & 70 & 5.7E-05 & 0.85 & 8 & 1.008 & 0.036 & 279 & $1.31 \mathrm{E}-02$ & 93 & 3.30E-03 & 3,914 & 4.07E-02 & 766 & 2.02E-03 & $1.10 \mathrm{E}-08$ \\
\hline LW44-60.4 & 0 & 70 & 5.7E-05 & 2.99 & 8 & 1.006 & 0.020 & 407 & 3.73E-02 & 178 & $1.35 \mathrm{E}-02$ & 3,876 & 7.34E-02 & 1,096 & $8.25 \mathrm{E}-03$ & $1.44 \mathrm{E}-08$ \\
\hline LW44-60.6 & 0 & 70 & $9.0 \mathrm{E}-05$ & 4.85 & 8 & 1.005 & 0.020 & 369 & 5.23E-02 & 154 & $1.78 \mathrm{E}-02$ & 2,862 & 8.44E-02 & 921 & $9.15 \mathrm{E}-03$ & $1.28 \mathrm{E}-08$ \\
\hline LW44-60.8 & 0 & 70 & 5.1E-05 & 6.86 & 8 & 1.004 & 0.020 & 357 & 2.87E-02 & 152 & $9.97 \mathrm{E}-03$ & 2,470 & 4.13E-02 & 886 & 4.79E-03 & 5.03E-09 \\
\hline LW44-60.9 & 0 & 70 & $5.8 \mathrm{E}-05$ & 7.77 & 8 & 1.003 & 0.020 & 324 & 2.90E-02 & 134 & $9.68 \mathrm{E}-03$ & 2,133 & $4.00 \mathrm{E}-02$ & 819 & 4.47E-03 & 4.43E-09 \\
\hline LW44-60.10 & 0 & 70 & $5.8 \mathrm{E}-05$ & 8.07 & 8 & 1.002 & 0.020 & 310 & 2.75E-02 & 133 & 9.63E-03 & 2,051 & 3.85E-02 & 792 & 4.11E-03 & 4.37E-09 \\
\hline LW44-60.11 & 0 & 70 & $1.3 \mathrm{E}-04$ & 8.36 & 8 & 1.002 & 0.020 & 305 & 5.91E-02 & 131 & 2.07E-02 & 1,991 & 8.16E-02 & 779 & 8.58E-03 & 8.99E-09 \\
\hline \multicolumn{17}{|l|}{ Exp. \#53 } \\
\hline LW44-61A & 0 & 70 & - & - & 9 & - & - & $<50$ & - & $<25$ & - & $<100$ & - & $<500$ & - & - \\
\hline LW44-61.1 & 0 & 70 & - & - & 9 & - & - & $<50$ & - & $<25$ & - & $<100$ & - & $<500$ & - & - \\
\hline LW44-61.2 & 0 & 70 & 5.7E-05 & 0.85 & 9 & 1.005 & 0.036 & 308 & $1.47 \mathrm{E}-02$ & 428 & $1.94 \mathrm{E}-02$ & 3,197 & 3.29E-02 & 2,217 & $1.30 \mathrm{E}-02$ & 7.25E-09 \\
\hline LW44-61.4 & 0 & 70 & 5.7E-05 & 2.99 & 9 & 1.004 & 0.020 & 624 & 5.95E-02 & 706 & 5.94E-02 & 4,071 & 7.67E-02 & 4,457 & $5.44 \mathrm{E}-02$ & 6.84E-09 \\
\hline LW44-61.6 & 0 & 70 & 8.9E-05 & 4.85 & 9 & 1.001 & 0.020 & 630 & $9.48 \mathrm{E}-02$ & 739 & $9.82 \mathrm{E}-02$ & 3,460 & $1.02 \mathrm{E}-01$ & 4,437 & 8.53E-02 & 2.98E-09 \\
\hline LW44-61.8 & 0 & 70 & $5.1 \mathrm{E}-05$ & 6.86 & 9 & 0.999 & 0.020 & 742 & $6.44 \mathrm{E}-02$ & 864 & 6.57E-02 & 3,949 & 6.67E-02 & 5,099 & 5.68E-02 & $9.21 \mathrm{E}-10$ \\
\hline LW44-61.9 & 0 & 70 & $5.8 \mathrm{E}-05$ & 7.77 & 9 & 0.997 & 0.020 & 750 & 7.39E-02 & 871 & 7.52E-02 & 3,931 & 7.53E-02 & 5,066 & 6.39E-02 & $5.71 \mathrm{E}-10$ \\
\hline LW44-61.10 & 0 & 70 & $5.8 \mathrm{E}-05$ & 8.07 & 9 & 0.996 & 0.020 & 725 & 7.15E-02 & 846 & 7.33E-02 & 3,894 & 7.48E-02 & 5,068 & $6.42 \mathrm{E}-02$ & 1.32E-09 \\
\hline LW44-61.11 & 0 & 70 & $1.2 \mathrm{E}-04$ & 8.36 & 9 & 0.995 & 0.020 & 721 & $1.52 \mathrm{E}-01$ & 838 & $1.55 \mathrm{E}-01$ & 3,850 & $1.58 \mathrm{E}-01$ & 4,910 & 1.33E-01 & 2.47E-09 \\
\hline \multicolumn{17}{|l|}{ Exp. \#54 } \\
\hline LW44-62A & 0 & 70 & - & - & 10 & - & - & $<50$ & - & $<25$ & - & $<100$ & - & $<500$ & - & - \\
\hline
\end{tabular}


Table A1. SPFT Results for LAWA44 Glasses.

\begin{tabular}{|c|c|c|c|c|c|c|c|c|c|c|c|c|c|c|c|c|}
\hline Sample ID & $\begin{array}{c}\text { Influent } \\
{[\mathrm{Si}]}\end{array}$ & $\begin{array}{c}\mathrm{T} \\
\left({ }^{\circ} \mathrm{C}\right) \\
\end{array}$ & $\begin{array}{c}\text { Flow } \\
\text { Rate } \\
\left(\mathrm{m}^{3} / \mathrm{d}\right) \\
\end{array}$ & $\begin{array}{c}\text { Time, } \\
\text { days }\end{array}$ & $\begin{array}{c}\mathrm{pH} \\
\left(23^{\circ} \mathrm{C}\right) \\
\end{array}$ & $\begin{array}{c}\text { Glass } \\
\text { Mass } \\
(\mathrm{g}) \\
\end{array}$ & $\begin{array}{c}\text { SA } \\
\left(\mathrm{m}^{2}\right) \\
\end{array}$ & {$[\mathrm{B}]$} & B Rate & {$[\mathrm{Al}]$} & Al Rate & {$[\mathrm{Na}]$} & Na Rate & [Si] & Si Rate & IEX Rate \\
\hline LW44-62.1 & 0 & 70 & - & - & 10 & - & - & $<50$ & - & $<25$ & - & $<100$ & - & $<500$ & - & - \\
\hline LW44-62.2 & 0 & 70 & 5.6E-05 & 0.85 & 10 & 0.501 & 0.023 & 389 & 3.01E-02 & 476 & 3.36E-02 & 2,562 & 4.06E-02 & 2,677 & $2.56 \mathrm{E}-02$ & 4.22E-09 \\
\hline LW44-62.4 & 0 & 70 & 5.7E-05 & 2.99 & 10 & 0.499 & 0.010 & 956 & 1.89E-01 & 1,148 & 1.97E-01 & 5,184 & $1.98 \mathrm{E}-01$ & 6,507 & $1.66 \mathrm{E}-01$ & 3.39E-09 \\
\hline LW44-62.6 & 0 & 70 & $9.0 \mathrm{E}-05$ & 4.85 & 10 & 0.495 & 0.010 & 908 & 2.84E-01 & 1,069 & 2.92E-01 & 4,791 & 2.90E-01 & 6,148 & 2.49E-01 & 2.13E-09 \\
\hline LW44-62.8 & 0 & 70 & 5.1E-05 & 6.86 & 10 & 0.492 & 0.010 & 828 & $1.47 \mathrm{E}-01$ & 996 & 1.55E-01 & 4,342 & $1.50 \mathrm{E}-01$ & 5,670 & $1.30 \mathrm{E}-01$ & $9.07 \mathrm{E}-10$ \\
\hline LW44-62.9 & 0 & 70 & 5.8E-05 & 7.77 & 10 & 0.490 & 0.010 & 814 & $1.64 \mathrm{E}-01$ & 980 & 1.73E-01 & 4,208 & $1.64 \mathrm{E}-01$ & 5,512 & 1.43E-01 & $1.20 \mathrm{E}-10$ \\
\hline LW44-62.10 & 0 & 70 & 5.8E-05 & 8.07 & 10 & 0.489 & 0.010 & 802 & 1.62E-01 & 974 & 1.72E-01 & 4,158 & 1.63E-01 & 5,490 & 1.43E-01 & 3.83E-10 \\
\hline LW44-62.11 & 0 & 70 & 1.3E-04 & 8.36 & 10 & 0.487 & 0.010 & 803 & 3.55E-01 & 951 & 3.68E-01 & 4,202 & 3.60E-01 & 5,462 & 3.11E-01 & 2.02E-09 \\
\hline \multicolumn{17}{|l|}{ Exp. \#55 } \\
\hline LW44-63A & 0 & 70 & - & - & 11 & - & - & $<50$ & - & $<25$ & - & $<100$ & - & $<500$ & - & - \\
\hline LW44-63.1 & 0 & 70 & - & - & 11 & - & - & $<50$ & - & $<25$ & - & $<100$ & - & $<500$ & - & - \\
\hline LW44-63.2 & 0 & 70 & 6.6E-05 & 0.85 & 11 & 0.502 & 0.023 & 1,066 & $1.07 \mathrm{E}-01$ & 1,252 & $1.08 \mathrm{E}-01$ & 6,162 & 1.19E-01 & 7,137 & $9.24 \mathrm{E}-02$ & 4.76E-09 \\
\hline LW44-63.4 & 0 & 70 & 5.7E-05 & 2.99 & 11 & 0.493 & 0.010 & 2,942 & $6.06 \mathrm{E}-01$ & 2,910 & $5.10 \mathrm{E}-01$ & 15,083 & 5.85E-01 & 17,977 & 4.86E-01 & - \\
\hline LW44-63.6 & 0 & 70 & 8.9E-05 & 4.85 & 11 & 0.482 & 0.010 & 3,372 & $1.11 \mathrm{E}+00$ & 3,432 & 9.63E-01 & 17,537 & $1.09 \mathrm{E}+00$ & 20,380 & $8.86 \mathrm{E}-01$ & - \\
\hline LW44-63.8 & 0 & 70 & 5.1E-05 & 6.86 & 11 & 0.470 & 0.009 & 3,678 & 7.12E-01 & 3,221 & 5.28E-01 & 19,165 & 6.97E-01 & 21,821 & 5.55E-01 & - \\
\hline LW44-63.9 & 0 & 70 & 5.7E-05 & 7.77 & 11 & 0.460 & 0.009 & 3,546 & 7.91E-01 & 3,054 & 5.77E-01 & 18,096 & 7.59E-01 & 21,037 & 6.17E-01 & - \\
\hline LW44-63.10 & 0 & 70 & 5.9E-05 & 8.07 & 11 & 0.454 & 0.009 & 3,518 & 8.23E-01 & 3,054 & 6.06E-01 & 19,709 & 8.67E-01 & 20,763 & 6.38E-01 & 1.76E-08 \\
\hline LW44-63.11 & 0 & 70 & $1.1 \mathrm{E}-04$ & 8.36 & 11 & 0.449 & 0.009 & 3,394 & $1.54 \mathrm{E}+00$ & 2,871 & $1.10 \mathrm{E}+00$ & 17,585 & $1.50 \mathrm{E}+00$ & 19,942 & $1.19 \mathrm{E}+00$ & - \\
\hline \multicolumn{17}{|l|}{ Exp. \#56 } \\
\hline LW44-64A & 0 & 70 & - & - & 12 & - & - & $<50$ & - & 32 & - & $<100$ & - & $<500$ & - & - \\
\hline LW44-64.1 & 0 & 70 & - & - & 12 & - & - & $<50$ & - & 50 & - & $<100$ & - & $<500$ & - & - \\
\hline LW44-64.2 & 0 & 70 & 5.7E-05 & 0.85 & 12 & 0.505 & 0.023 & 2,496 & 2.21E-01 & 3,033 & 2.28E-01 & 13,523 & 2.26E-01 & 16,699 & 1.95E-01 & 1.97E-09 \\
\hline LW44-64.4 & 0 & 70 & 5.7E-05 & 2.99 & 12 & 0.483 & 0.010 & 7,728 & $1.63 \mathrm{E}+00$ & 8,355 & $1.49 \mathrm{E}+00$ & 40,528 & $1.60 \mathrm{E}+00$ & 47,843 & $1.34 \mathrm{E}+00$ & - \\
\hline LW44-64.6 & 0 & 70 & 9.1E-05 & 4.85 & 12 & 0.451 & 0.009 & 9,100 & $3.28 \mathrm{E}+00$ & 8,908 & $2.70 \mathrm{E}+00$ & 47,491 & $3.20 \mathrm{E}+00$ & 54,462 & $2.59 \mathrm{E}+00$ & - \\
\hline LW44-64.8 & 0 & 70 & 4.6E-05 & 6.86 & 12 & 0.416 & 0.008 & 12,794 & $2.50 \mathrm{E}+00$ & 10,711 & $1.76 \mathrm{E}+00$ & 65,487 & $2.39 \mathrm{E}+00$ & 73,531 & $1.90 \mathrm{E}+00$ & - \\
\hline LW44-64.9 & 0 & 70 & $5.9 \mathrm{E}-05$ & 7.77 & 12 & 0.387 & 0.008 & 9,167 & $2.47 \mathrm{E}+00$ & 8,344 & $1.90 \mathrm{E}+00$ & 47,554 & $2.40 \mathrm{E}+00$ & 53,386 & $1.90 \mathrm{E}+00$ & - \\
\hline LW44-64.10 & 0 & 70 & 5.3E-05 & 8.07 & 12 & 0.373 & 0.007 & 8,519 & $2.19 \mathrm{E}+00$ & 8,003 & $1.74 \mathrm{E}+00$ & 43,527 & $2.09 \mathrm{E}+00$ & 50,790 & $1.73 \mathrm{E}+00$ & - \\
\hline LW44-64.11 & 0 & 70 & $1.2 \mathrm{E}-04$ & 8.36 & 12 & 0.360 & 0.007 & 8,350 & $5.13 \mathrm{E}+00$ & 7,645 & $3.96 \mathrm{E}+00$ & 43,298 & $4.97 \mathrm{E}+00$ & 48,693 & $3.95 E+00$ & - \\
\hline
\end{tabular}

[] $-\mu \mathrm{g} \mathrm{L}^{-1}$

Rate $-\mathrm{g} \mathrm{m}^{-2} \mathrm{~d}^{-1}$

IEX Rate $-\mathrm{mol} \mathrm{m}^{-2} \mathrm{~s}^{-1}$ 
Table A2. SPFT Results for LAWB45 Glasses.

\begin{tabular}{|c|c|c|c|c|c|c|c|c|c|c|c|c|c|c|c|c|}
\hline Sample ID & $\begin{array}{c}\text { Influent } \\
\text { [Si] } \\
\end{array}$ & $\mathrm{T}\left({ }^{\circ} \mathrm{C}\right)$ & $\begin{array}{c}\text { Flow } \\
\text { Rate } \\
\left(\mathrm{m}^{3} / \mathrm{d}\right)\end{array}$ & $\begin{array}{c}\text { Time, } \\
\text { days }\end{array}$ & $\begin{array}{c}\mathrm{pH} \\
\left(23^{\circ} \mathrm{C}\right) \\
\end{array}$ & $\begin{array}{c}\text { Glass } \\
\text { Mass } \\
\text { (g) }\end{array}$ & $\mathrm{SA}\left(\mathrm{m}^{2}\right)$ & [B] & B Rate & {$[\mathrm{Al}]$} & Al Rate & {$[\mathrm{Na}]$} & Na Rate & {$[\mathrm{Si}]$} & Si Rate & $\begin{array}{l}\text { IEX } \\
\text { Rate } \\
\end{array}$ \\
\hline \multicolumn{17}{|l|}{ LAWB45 } \\
\hline \multicolumn{17}{|l|}{ Exp.\#1 } \\
\hline LB45-1B & 0 & 40 & - & - & 7 & - & - & $<100$ & - & $<10$ & - & $<500$ & - & $<500$ & - & - \\
\hline LB45-1C & 0 & 40 & - & - & 7 & - & - & $<100$ & - & 10 & - & $<500$ & - & $<500$ & - & - \\
\hline LB45-1.1 & 0 & 40 & 4.2E-05 & 0.73 & 7 & 1.004 & 0.020 & 531 & 2.33E-02 & 14 & 2.27E-04 & 1,121 & 2.67E-02 & 698 & 1.83E-03 & 1.35E-09 \\
\hline LB45-1.2 & 0 & 40 & 4.0E-05 & 2.08 & 7 & 1.003 & 0.020 & 285 & $9.54 \mathrm{E}-03$ & 11 & 7.03E-05 & 536 & $1.47 \mathrm{E}-03$ & (497) & - & - \\
\hline LB45-1.3 & 0 & 40 & $4.0 \mathrm{E}-05$ & 2.74 & 7 & 1.003 & 0.020 & 157 & $2.95 \mathrm{E}-03$ & 10 & 1.13E-05 & (292) & - & (357) & - & - \\
\hline LB45-1.4 & 0 & 40 & 4.0E-05 & 3.77 & 7 & 1.002 & 0.020 & 110 & $5.12 \mathrm{E}-04$ & 13 & $1.61 \mathrm{E}-04$ & (202) & - & (241) & - & - \\
\hline LB45-1.5 & 0 & 40 & $3.9 \mathrm{E}-05$ & 4.91 & 7 & 1.002 & 0.020 & ND & 5.03E-03 & 10 & - & (162) & - & (235) & - & - \\
\hline LB45-1.6 & 0 & 40 & $4.0 \mathrm{E}-05$ & 5.82 & 7 & 1.002 & 0.020 & ND & 5.23E-03 & 13 & $2.08 \mathrm{E}-04$ & (120) & - & (163) & - & - \\
\hline LB45-1.7 & 0 & 40 & 4.0E-05 & 6.81 & 7 & 1.002 & 0.020 & ND & 5.18E-03 & 14 & 2.12E-04 & (116) & - & (145) & - & - \\
\hline LB45-1.8 & 0 & 40 & $4.0 \mathrm{E}-05$ & 7.80 & 7 & 1.002 & 0.020 & ND & $5.20 \mathrm{E}-03$ & 19 & 5.19E-04 & (110) & - & (125) & - & - \\
\hline LB45-1.9 & 0 & 40 & 4.0E-05 & 9.06 & 7 & 1.002 & 0.020 & ND & $5.21 \mathrm{E}-03$ & 16 & 3.79E-04 & (92) & - & (124) & - & - \\
\hline LB45-1.10 & 0 & 40 & 4.0E-05 & 9.94 & 7 & 1.002 & 0.020 & ND & $5.22 \mathrm{E}-03$ & 15 & 3.25E-04 & (77) & - & (114) & - & - \\
\hline LB45-1.11 & 0 & 40 & 4.0E-05 & 10.86 & 7 & 1.001 & 0.020 & ND & 5.15E-03 & 18 & 4.55E-04 & (80) & - & (116) & - & - \\
\hline Exp.\#2 & & & & & & - & & & & & & & & & & \\
\hline LB45-2A & 0 & 40 & - & - & 8 & - & - & $<100$ & - & $<10$ & - & $<500$ & - & $<500$ & - & - \\
\hline LB45-2B & 0 & 40 & - & - & 8 & - & - & $<100$ & - & $<10$ & - & $<500$ & - & $<500$ & - & - \\
\hline LB45-2C & 0 & 40 & - & - & 8 & - & - & $<100$ & - & $<10$ & - & $<500$ & - & $<500$ & - & - \\
\hline LB45-2.1 & 0 & 40 & 4.1E-05 & 0.73 & 8 & 1.005 & 0.020 & 389 & $1.53 \mathrm{E}-02$ & 43 & 2.07E-03 & 718 & $9.16 \mathrm{E}-03$ & 950 & 4.07E-03 & - \\
\hline LB45-2.2 & 0 & 40 & 4.0E-05 & 2.08 & 8 & 1.004 & 0.020 & 255 & 7.97E-03 & 87 & 4.66E-03 & ND & - & 873 & 3.29E-03 & - \\
\hline LB45-2.3 & 0 & 40 & 4.0E-05 & 2.74 & 8 & 1.004 & 0.020 & 166 & $3.46 \mathrm{E}-03$ & 85 & 4.64E-03 & ND & - & 664 & $1.47 \mathrm{E}-03$ & - \\
\hline LB45-2.4 & 0 & 40 & 4.0E-05 & 3.77 & 8 & 1.004 & 0.020 & 136 & $1.87 \mathrm{E}-03$ & 79 & 4.20E-03 & ND & - & 589 & 7.90E-04 & - \\
\hline LB45-2.5 & 0 & 40 & 4.0E-05 & 4.91 & 8 & 1.003 & 0.020 & 115 & 7.72E-04 & 77 & 4.15E-03 & ND & - & 501 & $1.01 \mathrm{E}-05$ & - \\
\hline LB45-2.6 & 0 & 40 & 4.0E-05 & 5.82 & 8 & 1.003 & 0.020 & 101 & $4.12 \mathrm{E}-05$ & 70 & 3.68E-03 & ND & - & ND & - & - \\
\hline LB45-2.7 & 0 & 40 & 4.0E-05 & 6.81 & 8 & 1.003 & 0.020 & ND & $5.23 \mathrm{E}-03$ & 70 & 3.73E-03 & ND & - & ND & - & - \\
\hline LB45-2.8 & 0 & 40 & 4.0E-05 & 7.80 & 8 & 1.003 & 0.020 & ND & $5.20 \mathrm{E}-03$ & 60 & $3.08 \mathrm{E}-03$ & ND & - & ND & - & - \\
\hline LB45-2.9 & 0 & 40 & $4.0 \mathrm{E}-05$ & 9.06 & 8 & 1.003 & 0.020 & ND & 5.16E-03 & 65 & 3.38E-03 & ND & - & ND & - & - \\
\hline LB45-2.10 & 0 & 40 & 3.9E-05 & 9.94 & 8 & 1.003 & 0.020 & ND & 5.11E-03 & 61 & 3.11E-03 & ND & - & ND & - & - \\
\hline LB45-2.11 & 0 & 40 & 3.8E-05 & 10.86 & 8 & 1.003 & 0.020 & ND & 4.96E-03 & 65 & 3.24E-03 & ND & - & ND & - & - \\
\hline \multicolumn{17}{|l|}{ Exp. \#3 } \\
\hline LB45-3A & 0 & 40 & - & - & 9 & - & - & $<100$ & - & $<10$ & - & $<500$ & - & $<500$ & - & - \\
\hline LB45-3B & 0 & 40 & - & - & 9 & - & - & $<100$ & - & $<10$ & - & $<500$ & - & $<500$ & - & - \\
\hline LB45-3C & 0 & 40 & - & - & 9 & - & - & $<100$ & - & $<10$ & - & $<500$ & - & $<500$ & - & - \\
\hline LB45-3.1 & 0 & 40 & 3.5E-05 & 0.73 & 9 & 1.007 & 0.020 & 206 & 4.87E-03 & 109 & 5.35E-03 & ND & - & 1,527 & 8.08E-03 & - \\
\hline LB45-3.2 & 0 & 40 & 3.6E-05 & 2.08 & 9 & 1.006 & 0.020 & 267 & 7.92E-03 & 197 & $1.05 \mathrm{E}-02$ & ND & - & 1,391 & 7.22E-03 & - \\
\hline LB45-3.3 & 0 & 40 & 3.6E-05 & 2.74 & 9 & 1.006 & 0.020 & 285 & 8.74E-03 & 223 & 1.19E-02 & ND & - & 1,504 & 8.11E-03 & - \\
\hline LB45-3.4 & 0 & 40 & 3.7E-05 & 3.77 & 9 & 1.006 & 0.020 & 285 & 8.79E-03 & 235 & $1.27 \mathrm{E}-02$ & ND & - & 1,525 & 8.36E-03 & - \\
\hline LB45-3.5 & 0 & 40 & 3.7E-05 & 4.91 & 9 & 1.005 & 0.020 & 272 & 8.30E-03 & 229 & $1.24 \mathrm{E}-02$ & ND & - & 1,475 & $8.04 \mathrm{E}-03$ & - \\
\hline LB45-3.6 & 0 & 40 & 3.7E-05 & 5.82 & 9 & 1.005 & 0.020 & 264 & 7.83E-03 & 216 & $1.16 \mathrm{E}-02$ & ND & - & 1,461 & 7.85E-03 & - \\
\hline
\end{tabular}


Table A2. SPFT Results for LAWB45 Glasses.

\begin{tabular}{|c|c|c|c|c|c|c|c|c|c|c|c|c|c|c|c|c|}
\hline Sample ID & $\begin{array}{c}\text { Influent } \\
\text { [Si] }\end{array}$ & $\mathrm{T}\left({ }^{\circ} \mathrm{C}\right)$ & $\begin{array}{l}\text { Flow } \\
\text { Rate } \\
\left(\mathrm{m}^{3} / \mathrm{d}\right) \\
\end{array}$ & $\begin{array}{l}\text { Time, } \\
\text { days }\end{array}$ & $\begin{array}{c}\mathrm{pH} \\
\left(23^{\circ} \mathrm{C}\right) \\
\end{array}$ & $\begin{array}{l}\text { Glass } \\
\text { Mass } \\
\text { (g) }\end{array}$ & $\mathrm{SA}\left(\mathrm{m}^{2}\right)$ & [B] & B Rate & {$[\mathrm{Al}]$} & Al Rate & {$[\mathrm{Na}]$} & Na Rate & {$[\mathrm{Si}]$} & Si Rate & $\begin{array}{l}\text { IEX } \\
\text { Rate }\end{array}$ \\
\hline LB45-3.7 & 0 & 40 & $3.7 \mathrm{E}-05$ & 6.81 & 9 & 1.005 & 0.020 & 243 & 6.83E-03 & 208 & 1.12E-02 & ND & - & 1,333 & 6.81E-03 & - \\
\hline LB45-3.8 & 0 & 40 & 3.7E-05 & 7.80 & 9 & 1.004 & 0.020 & 247 & 6.96E-03 & 202 & $1.08 \mathrm{E}-02$ & ND & - & 1,376 & 7.13E-03 & - \\
\hline LB45-3.9 & 0 & 40 & 2.9E-05 & 9.06 & 9 & 1.004 & 0.020 & 260 & 6.03E-03 & 226 & $9.61 \mathrm{E}-03$ & ND & - & 1,445 & $6.10 \mathrm{E}-03$ & - \\
\hline LB45-3.10 & 0 & 40 & $6.2 \mathrm{E}-06$ & 9.94 & 9 & 1.004 & 0.020 & 314 & 1.72E-03 & 262 & $2.40 \mathrm{E}-03$ & ND & - & 1,720 & $1.68 \mathrm{E}-03$ & - \\
\hline LB45-3.11 & 0 & 40 & 3.9E-05 & 10.86 & 9 & 1.003 & 0.020 & 356 & $1.28 \mathrm{E}-02$ & 289 & $1.66 \mathrm{E}-02$ & 614 & $4.55 \mathrm{E}-03$ & 1,952 & $1.25 \mathrm{E}-02$ & - \\
\hline \multicolumn{17}{|l|}{ Exp. \#4 } \\
\hline LB45-4A & 0 & 40 & - & - & 10 & - & - & $<100$ & - & 10 & - & $<500$ & - & $<500$ & - & - \\
\hline LB45-4B & 0 & 40 & - & - & 10 & - & - & $<100$ & - & $<10$ & - & $<500$ & - & $<500$ & - & - \\
\hline LB45-4C & 0 & 40 & - & - & 10 & - & - & $<100$ & - & $<10$ & - & $<500$ & - & $<500$ & - & - \\
\hline LB45-4.1 & 0 & 40 & $4.0 \mathrm{E}-05$ & 0.73 & 10 & 0.509 & 0.013 & 228 & $1.06 \mathrm{E}-02$ & 221 & $2.06 \mathrm{E}-02$ & $\mathrm{ND}$ & - & 1,494 & $1.40 \mathrm{E}-02$ & - \\
\hline LB45-4.2 & 0 & 40 & 3.9E-05 & 2.08 & 10 & 0.508 & 0.010 & 346 & $2.49 \mathrm{E}-02$ & 319 & 3.69E-02 & ND & - & 1,935 & $2.48 \mathrm{E}-02$ & - \\
\hline LB45-4.3 & 0 & 40 & $4.0 \mathrm{E}-05$ & 2.74 & 10 & 0.508 & 0.010 & 345 & $2.49 \mathrm{E}-02$ & 289 & 3.36E-02 & ND & - & 2,026 & $2.66 \mathrm{E}-02$ & - \\
\hline LB45-4.4 & 0 & 40 & 3.9E-05 & 3.77 & 10 & 0.507 & 0.010 & 343 & $2.45 \mathrm{E}-02$ & 291 & 3.35E-02 & ND & - & 1,986 & $2.56 \mathrm{E}-02$ & - \\
\hline LB45-4.5 & 0 & 40 & $4.0 \mathrm{E}-05$ & 4.91 & 10 & 0.507 & 0.010 & 344 & $2.50 \mathrm{E}-02$ & 298 & $3.49 \mathrm{E}-02$ & ND & - & 1,985 & $2.61 \mathrm{E}-02$ & - \\
\hline LB45-4.6 & 0 & 40 & 3.9E-05 & 5.82 & 10 & 0.506 & 0.010 & 338 & 2.39E-02 & 294 & 3.37E-02 & ND & - & 1,898 & 2.41E-02 & - \\
\hline LB45-4.7 & 0 & 40 & $3.9 \mathrm{E}-05$ & 6.81 & 10 & 0.506 & 0.010 & 338 & 2.39E-02 & 291 & 3.34E-02 & ND & - & 1,901 & $2.41 \mathrm{E}-02$ & - \\
\hline LB45-4.8 & 0 & 40 & $4.0 \mathrm{E}-05$ & 7.80 & 10 & 0.505 & 0.010 & 342 & $2.47 \mathrm{E}-02$ & 303 & $3.55 \mathrm{E}-02$ & ND & - & 1,899 & $2.45 \mathrm{E}-02$ & - \\
\hline LB45-4.9 & 0 & 40 & 3.9E-05 & 9.06 & 10 & 0.505 & 0.010 & 336 & $2.40 \mathrm{E}-02$ & 297 & 3.44E-02 & ND & - & 1,874 & 2.39E-02 & - \\
\hline LB45-4.10 & 0 & 40 & 4.0E-05 & 9.94 & 10 & 0.504 & 0.010 & 328 & 2.35E-02 & 283 & 3.32E-02 & ND & - & 1,837 & 2.36E-02 & - \\
\hline LB45-4.11 & 0 & 40 & 3.9E-05 & 10.86 & 10 & 0.504 & 0.010 & 308 & 2.09E-02 & 278 & 3.17E-02 & 1,210 & 5.65E-02 & 1,721 & $2.10 \mathrm{E}-02$ & - \\
\hline \multicolumn{17}{|l|}{ Exp.\#5 } \\
\hline LB45-5A & 0 & 40 & - & - & 11 & - & - & $<100$ & - & 12 & - & $<500$ & - & $<500$ & - & - \\
\hline LB45-5B & 0 & 40 & - & - & 11 & - & - & $<100$ & - & 11 & - & $<500$ & - & $<500$ & - & - \\
\hline LB45-5C & 0 & 40 & - & - & 11 & - & - & $<100$ & - & 13 & - & $<500$ & - & $<500$ & - & - \\
\hline LB45-5.1 & 0 & 40 & 3.8E-05 & 0.73 & 11 & 0.504 & 0.013 & 330 & $1.80 \mathrm{E}-02$ & 366 & 3.29E-02 & 626 & 7.85E-03 & 2,210 & 2.30E-02 & - \\
\hline LB45-5.2 & 0 & 40 & 3.8E-05 & 2.08 & 11 & 0.503 & 0.010 & 784 & $6.68 \mathrm{E}-02$ & 762 & 8.65E-02 & 1,127 & 4.87E-02 & 4,539 & $6.76 \mathrm{E}-02$ & - \\
\hline LB45-5.3 & 0 & 40 & $4.0 \mathrm{E}-05$ & 2.74 & 11 & 0.501 & 0.010 & 875 & 8.13E-02 & 807 & $9.85 \mathrm{E}-02$ & 1,213 & $5.94 \mathrm{E}-02$ & 4,969 & 8.03E-02 & - \\
\hline LB45-5.4 & 0 & 40 & $4.0 \mathrm{E}-05$ & 3.77 & 11 & 0.500 & 0.010 & 917 & 8.53E-02 & 832 & $1.01 \mathrm{E}-01$ & 1,235 & $6.10 \mathrm{E}-02$ & 5,093 & $8.21 \mathrm{E}-02$ & - \\
\hline LB45-5.5 & 0 & 40 & $4.0 \mathrm{E}-05$ & 4.91 & 11 & 0.499 & 0.010 & 909 & 8.55E-02 & 826 & $1.02 \mathrm{E}-01$ & 1,213 & $5.98 \mathrm{E}-02$ & 5,073 & $8.27 \mathrm{E}-02$ & - \\
\hline LB45-5.6 & 0 & 40 & $4.0 \mathrm{E}-05$ & 5.82 & 11 & 0.497 & 0.010 & 899 & 8.43E-02 & 813 & $9.98 \mathrm{E}-02$ & 1,231 & 6.13E-02 & 5,223 & 8.54E-02 & - \\
\hline LB45-5.7 & 0 & 40 & $4.0 \mathrm{E}-05$ & 6.81 & 11 & 0.496 & 0.010 & 895 & $8.40 \mathrm{E}-02$ & 809 & $9.94 \mathrm{E}-02$ & 1,222 & $6.06 \mathrm{E}-02$ & 4,991 & $8.12 \mathrm{E}-02$ & - \\
\hline LB45-5.8 & 0 & 40 & 4.0E-05 & 7.80 & 11 & 0.494 & 0.010 & 898 & $8.41 \mathrm{E}-02$ & 815 & $9.99 \mathrm{E}-02$ & 1,233 & $6.13 \mathrm{E}-02$ & 5,001 & 8.12E-02 & - \\
\hline LB45-5.9 & 0 & 40 & $2.1 \mathrm{E}-05$ & 9.06 & 11 & 0.493 & 0.010 & 916 & 4.57E-02 & 830 & $5.42 \mathrm{E}-02$ & 1,249 & 3.34E-02 & 5,098 & 4.41E-02 & - \\
\hline LB45-5.10 & 0 & 40 & $4.0 \mathrm{E}-05$ & 9.94 & 11 & 0.492 & 0.010 & 919 & 8.65E-02 & 840 & 1.03E-01 & 1,274 & $6.50 \mathrm{E}-02$ & 5,744 & 9.49E-02 & - \\
\hline LB45-5.11 & 0 & 40 & $4.0 \mathrm{E}-05$ & 10.86 & 11 & 0.491 & 0.010 & 899 & 8.43E-02 & 802 & $9.85 \mathrm{E}-02$ & 1,237 & $6.18 \mathrm{E}-02$ & 5,456 & 8.95E-02 & - \\
\hline \multicolumn{17}{|l|}{ Exp. \#6 } \\
\hline LB45-6A & 0 & 40 & - & - & 12 & - & - & $<100$ & - & $<10$ & - & $<500$ & - & 516 & - & - \\
\hline LB45-6B & 0 & 40 & - & - & 12 & - & - & $<100$ & - & $<10$ & - & $<500$ & - & 529 & - & - \\
\hline LB45-6C & 0 & 40 & - & - & 12 & - & - & $<100$ & - & $<10$ & - & $<500$ & - & 524 & - & - \\
\hline LB45-6.1 & 0 & 40 & 3.9E-05 & 0.73 & 12 & 0.509 & 0.013 & 503 & 3.19E-02 & 560 & 5.13E-02 & 976 & 2.99E-02 & 3,388 & $3.88 \mathrm{E}-02$ & - \\
\hline
\end{tabular}


Table A2. SPFT Results for LAWB45 Glasses.

\begin{tabular}{|c|c|c|c|c|c|c|c|c|c|c|c|c|c|c|c|c|}
\hline Sample ID & $\begin{array}{c}\text { Influent } \\
\text { [Si] }\end{array}$ & $\mathrm{T}\left({ }^{\circ} \mathrm{C}\right)$ & $\begin{array}{c}\text { Flow } \\
\text { Rate } \\
\left(\mathrm{m}^{3} / \mathrm{d}\right)\end{array}$ & $\begin{array}{c}\text { Time, } \\
\text { days }\end{array}$ & $\begin{array}{c}\mathrm{pH} \\
\left(23^{\circ} \mathrm{C}\right) \\
\end{array}$ & $\begin{array}{c}\text { Glass } \\
\text { Mass } \\
(\mathrm{g})\end{array}$ & $\mathrm{SA}\left(\mathrm{m}^{2}\right)$ & [B] & B Rate & {$[\mathrm{Al}]$} & Al Rate & {$[\mathrm{Na}]$} & Na Rate & {$[\mathrm{Si}]$} & Si Rate & $\begin{array}{l}\text { IEX } \\
\text { Rate }\end{array}$ \\
\hline LB45-6.2 & 0 & 40 & 4.0E-05 & 2.08 & 12 & 0.507 & 0.010 & 922 & 8.47E-02 & 897 & $1.08 \mathrm{E}-01$ & 1,426 & 7.59E-02 & 5,292 & 8.42E-02 & - \\
\hline LB45-6.3 & 0 & 40 & 4.0E-05 & 2.74 & 12 & 0.506 & 0.010 & 978 & 9.03E-02 & 931 & 1.12E-01 & 1,438 & 7.67E-02 & 5,599 & 8.94E-02 & - \\
\hline LB45-6.4 & 0 & 40 & 3.9E-05 & 3.77 & 12 & 0.504 & 0.010 & 966 & 8.81E-02 & 906 & $1.08 \mathrm{E}-01$ & 1,447 & 7.66E-02 & 5,420 & 8.54E-02 & - \\
\hline LB45-6.5 & 0 & 40 & $4.0 \mathrm{E}-05$ & 4.91 & 12 & 0.503 & 0.010 & 962 & 8.95E-02 & 898 & $1.09 \mathrm{E}-01$ & 1,511 & 8.34E-02 & 5,418 & 8.71E-02 & - \\
\hline LB45-6.6 & 0 & 40 & $4.0 \mathrm{E}-05$ & 5.82 & 12 & 0.501 & 0.010 & 963 & 8.97E-02 & 913 & $1.11 \mathrm{E}-01$ & 1,454 & 7.88E-02 & 5,419 & 8.72E-02 & - \\
\hline LB45-6.7 & 0 & 40 & 3.9E-05 & 6.81 & 12 & 0.500 & 0.010 & 944 & 8.68E-02 & 884 & $1.06 \mathrm{E}-01$ & 1,517 & 8.31E-02 & 5,572 & 8.89E-02 & - \\
\hline LB45-6.8 & 0 & 40 & $4.0 \mathrm{E}-05$ & 7.80 & 12 & 0.498 & 0.010 & 912 & $8.42 \mathrm{E}-02$ & 858 & $1.04 \mathrm{E}-01$ & 1,451 & 7.83E-02 & 5,149 & $8.22 \mathrm{E}-02$ & - \\
\hline LB45-6.9 & 0 & 40 & 4.0E-05 & 9.06 & 12 & 0.497 & 0.010 & 898 & $8.28 \mathrm{E}-02$ & 849 & 1.03E-01 & 1,466 & 7.97E-02 & 5,132 & 8.19E-02 & - \\
\hline LB45-6.10 & 0 & 40 & 3.9E-05 & 9.94 & 12 & 0.495 & 0.010 & 932 & 8.55E-02 & 883 & $1.06 \mathrm{E}-01$ & 1,464 & 7.87E-02 & 5,282 & 8.37E-02 & - \\
\hline LB45-6.11 & 0 & 40 & $3.8 \mathrm{E}-05$ & 10.86 & 12 & 0.494 & 0.010 & 988 & 8.81E-02 & 952 & $1.10 \mathrm{E}-01$ & 1,514 & $8.00 \mathrm{E}-02$ & 5,896 & $9.13 \mathrm{E}-02$ & - \\
\hline \multicolumn{17}{|l|}{ Exp.\#7 } \\
\hline LB45-7.0 & 0 & 90 & - & - & 7 & - & - & $<100$ & - & 23 & - & $<5000$ & - & $<5000$ & - & - \\
\hline LB45-7.1 & 0 & 90 & - & - & 7 & - & - & $<100$ & - & $<10$ & - & $<5000$ & - & $<5000$ & - & - \\
\hline LB45-7.2 & 0 & 90 & - & - & 7 & - & - & $<100$ & - & $<10$ & - & $<5000$ & - & $<5000$ & - & - \\
\hline LB45-7.3 & 0 & 90 & 1.6E-05 & 2.05 & 7 & 0.754 & 0.015 & 2,404 & 6.51E-02 & 290 & $9.20 \mathrm{E}-03$ & ND & - & ND & - & - \\
\hline LB45-7.4 & 0 & 90 & 4.5E-05 & 2.87 & 7 & 0.749 & 0.015 & 4,369 & 3.32E-01 & 104 & 8.25E-03 & 5,947 & - & ND & - & - \\
\hline LB45-7.5 & 0 & 90 & $5.4 \mathrm{E}-05$ & 3.92 & 7 & 0.743 & 0.015 & 2,629 & 2.39E-01 & 101 & 9.69E-03 & ND & - & ND & - & - \\
\hline LB45-7.6 & 0 & 90 & 5.7E-05 & 4.89 & 7 & 0.738 & 0.015 & 2,043 & $1.95 \mathrm{E}-01$ & 103 & $1.05 \mathrm{E}-02$ & ND & - & ND & - & - \\
\hline LB45-7.7 & 0 & 90 & 5.3E-05 & 5.90 & 7 & 0.734 & 0.015 & 1,915 & $1.70 \mathrm{E}-01$ & 85 & $7.80 \mathrm{E}-03$ & ND & - & ND & - & - \\
\hline LB45-7.8 & 0 & 90 & 5.5E-05 & 6.90 & 7 & 0.730 & 0.015 & 1,704 & $1.58 \mathrm{E}-01$ & 99 & $9.85 \mathrm{E}-03$ & ND & - & ND & - & - \\
\hline LB45-7.9 & 0 & 90 & 5.5E-05 & 8.16 & 7 & 0.726 & 0.015 & 1,638 & $1.50 \mathrm{E}-01$ & 72 & $6.65 E-03$ & ND & - & ND & - & - \\
\hline LB45-7.10 & 0 & 90 & $5.0 \mathrm{E}-05$ & 9.10 & 7 & 0.722 & 0.014 & 1,794 & $1.51 \mathrm{E}-01$ & 87 & 7.67E-03 & ND & - & ND & - & - \\
\hline \multicolumn{17}{|l|}{ Exp. \#8 } \\
\hline LB45-8.0 & 0 & 90 & - & - & 8 & - & - & $<100$ & - & 10 & - & $<5000$ & - & $<5000$ & - & - \\
\hline LB45-8.1 & 0 & 90 & - & - & 8 & - & - & $<100$ & - & $<10$ & - & $<5000$ & - & $<5000$ & - & - \\
\hline LB45-8.2 & 0 & 90 & - & - & 8 & - & - & $<100$ & - & $<10$ & - & $<5000$ & - & $<5000$ & - & - \\
\hline LB45-8.3 & 0 & 90 & 4.3E-05 & 2.05 & 8 & 0.749 & 0.015 & 1,135 & 7.72E-02 & 553 & 4.79E-02 & ND & - & 5,344 & 4.39E-03 & - \\
\hline LB45-8.4 & 0 & 90 & $4.4 \mathrm{E}-05$ & 2.87 & 8 & 0.747 & 0.015 & 1,214 & 8.47E-02 & 764 & 6.77E-02 & ND & - & 6,413 & $1.84 \mathrm{E}-02$ & - \\
\hline LB45-8.5 & 0 & 90 & 3.9E-05 & 3.92 & 8 & 0.745 & 0.015 & 1,153 & 7.26E-02 & 791 & $6.37 \mathrm{E}-02$ & ND & - & 6,249 & $1.48 \mathrm{E}-02$ & - \\
\hline LB45-8.6 & 0 & 90 & $5.2 \mathrm{E}-05$ & 4.89 & 8 & 0.743 & 0.015 & 1,081 & $9.00 \mathrm{E}-02$ & 728 & 7.78E-02 & ND & - & 5,887 & 1.39E-02 & - \\
\hline LB45-8.7 & 0 & 90 & $5.8 \mathrm{E}-05$ & 5.90 & 8 & 0.741 & 0.015 & 1,003 & $9.22 \mathrm{E}-02$ & 657 & 7.81E-02 & ND & - & 5,468 & $8.18 \mathrm{E}-03$ & - \\
\hline LB45-8.8 & 0 & 90 & 5.1E-05 & 6.90 & 8 & 0.738 & 0.015 & 964 & 7.78E-02 & 674 & 7.07E-02 & ND & - & 5,285 & 4.39E-03 & - \\
\hline LB45-8.9 & 0 & 90 & $5.4 \mathrm{E}-05$ & 8.16 & 8 & 0.736 & 0.015 & 922 & 7.88E-02 & 648 & 7.23E-02 & ND & - & 5,088 & $1.44 \mathrm{E}-03$ & - \\
\hline LB45-8.10 & 0 & 90 & $5.0 \mathrm{E}-05$ & 9.10 & 8 & 0.734 & 0.015 & 903 & 7.11E-02 & 615 & $6.33 \mathrm{E}-02$ & ND & - & ND & - & - \\
\hline \multicolumn{17}{|l|}{ Exp. \#9 } \\
\hline LB45-9.0 & 0 & 90 & - & - & 9 & - & - & $<100$ & - & $<10$ & - & $<5000$ & - & $<5000$ & - & - \\
\hline LB45-9.1 & 0 & 90 & - & - & 9 & - & - & $<100$ & - & $<10$ & - & $<5000$ & - & $<5000$ & - & - \\
\hline LB45-9.2 & 0 & 90 & - & - & 9 & - & - & $<100$ & - & 17 & - & $<5000$ & - & $<5000$ & - & - \\
\hline LB45-9.3 & 0 & 90 & 5.6E-05 & 2.05 & 9 & 0.500 & - & 1,409 & $1.92 \mathrm{E}-01$ & 1,057 & $1.82 \mathrm{E}-01$ & ND & - & 7,720 & 6.85E-02 & - \\
\hline LB45-9.4 & 0 & 90 & $5.0 \mathrm{E}-05$ & 2.87 & 9 & 0.497 & 0.010 & 1,708 & 2.09E-01 & 1,278 & $1.94 \mathrm{E}-01$ & ND & - & 8,916 & $8.71 \mathrm{E}-02$ & - \\
\hline
\end{tabular}


Table A2. SPFT Results for LAWB45 Glasses.

\begin{tabular}{|c|c|c|c|c|c|c|c|c|c|c|c|c|c|c|c|c|}
\hline Sample ID & $\begin{array}{c}\text { Influent } \\
\text { [Si] } \\
\end{array}$ & $\mathrm{T}\left({ }^{\circ} \mathrm{C}\right)$ & $\begin{array}{c}\text { Flow } \\
\text { Rate } \\
\left(\mathrm{m}^{3} / \mathrm{d}\right)\end{array}$ & $\begin{array}{c}\text { Time, } \\
\text { days }\end{array}$ & $\begin{array}{c}\mathrm{pH} \\
\left(23^{\circ} \mathrm{C}\right) \\
\end{array}$ & $\begin{array}{c}\text { Glass } \\
\text { Mass } \\
\text { (g) }\end{array}$ & $\mathrm{SA}\left(\mathrm{m}^{2}\right)$ & {$[\mathrm{B}]$} & B Rate & {$[\mathrm{Al}]$} & Al Rate & {$[\mathrm{Na}]$} & Na Rate & {$[\mathrm{Si}]$} & Si Rate & $\begin{array}{l}\text { IEX } \\
\text { Rate }\end{array}$ \\
\hline LB45-9.5 & 0 & 90 & 5.7E-05 & 3.92 & 9 & 0.493 & 0.010 & 1,773 & $2.53 \mathrm{E}-01$ & 1,349 & 2.39E-01 & ND & - & 9,256 & $1.10 \mathrm{E}-01$ & - \\
\hline LB45-9.6 & 0 & 90 & 5.5E-05 & 4.89 & 9 & 0.489 & 0.010 & 1,762 & 2.42E-01 & 1,322 & 2.25E-01 & ND & - & 9,238 & $1.06 \mathrm{E}-01$ & - \\
\hline LB45-9.7 & 0 & 90 & 5.1E-05 & 5.90 & 9 & 0.486 & 0.010 & 1,669 & 2.15E-01 & 1,278 & 2.04E-01 & ND & - & 8,902 & $9.14 \mathrm{E}-02$ & - \\
\hline LB45-9.8 & 0 & 90 & 5.3E-05 & 6.90 & 9 & 0.482 & 0.010 & 1,586 & $2.14 \mathrm{E}-01$ & 1,225 & 2.07E-01 & ND & - & 8,481 & $8.60 \mathrm{E}-02$ & - \\
\hline LB45-9.9 & 0 & 90 & 5.5E-05 & 8.16 & 9 & 0.478 & 0.010 & 1,619 & 2.29E-01 & 1,232 & 2.17E-01 & ND & - & 8,692 & 9.54E-02 & - \\
\hline LB45-9.10 & 0 & 90 & $4.8 \mathrm{E}-05$ & 9.10 & 9 & 0.475 & 0.010 & 1,675 & 2.09E-01 & 1,312 & 2.03E-01 & ND & - & 8,996 & $9.06 \mathrm{E}-02$ & - \\
\hline \multicolumn{17}{|l|}{ Exp. \#10 } \\
\hline LB45-10.0 & 0 & 90 & - & - & 10 & - & - & $<100$ & - & $<10$ & - & $<5000$ & - & $<5000$ & - & - \\
\hline LB45-10.1 & 0 & 90 & - & - & 10 & - & - & $<100$ & - & $<10$ & - & $<5000$ & - & $<5000$ & - & - \\
\hline LB45-10.2 & 0 & 90 & - & - & 10 & - & - & $<100$ & - & $<10$ & - & $<5000$ & - & $<5000$ & - & - \\
\hline LB45-10.3 & 0 & 90 & $5.4 \mathrm{E}-05$ & 2.05 & 10 & 0.497 & 0.010 & 2,487 & 3.38E-01 & 1,504 & $2.50 \mathrm{E}-01$ & $(3,271)$ & - & 11,068 & $1.47 \mathrm{E}-01$ & - \\
\hline LB45-10.4 & 0 & 90 & 5.3E-05 & 2.87 & 10 & 0.490 & 0.010 & 3,922 & $5.41 \mathrm{E}-01$ & 1,946 & $3.24 \mathrm{E}-01$ & 5,113 & $1.27 \mathrm{E}-02$ & 15,991 & 2.66E-01 & - \\
\hline LB45-10.5 & 0 & 90 & 2.0E-05 & 3.92 & 10 & 0.486 & 0.010 & 4,550 & $2.41 \mathrm{E}-01$ & 1,991 & $1.27 \mathrm{E}-01$ & 6,040 & $4.48 \mathrm{E}-02$ & 18,034 & $1.21 \mathrm{E}-01$ & - \\
\hline LB45-10.6 & 0 & 90 & 5.1E-05 & 4.89 & 10 & 0.478 & 0.010 & 4,908 & $6.60 \mathrm{E}-01$ & 1,913 & 3.09E-01 & 6,513 & 1.65E-01 & 18,769 & $3.24 \mathrm{E}-01$ & - \\
\hline LB45-10.7 & 0 & 90 & 5.5E-05 & 5.90 & 10 & 0.469 & 0.009 & 4,066 & $6.00 \mathrm{E}-01$ & 1,750 & 3.11E-01 & 5,422 & 5.07E-02 & 16,471 & 2.97E-01 & - \\
\hline LB45-10.8 & 0 & 90 & 5.6E-05 & 6.90 & 10 & 0.461 & 0.009 & 3,677 & 5.64E-01 & 1,644 & 3.04E-01 & $(4,628)$ & - & 15,209 & 2.76E-01 & - \\
\hline LB45-10.9 & 0 & 90 & 5.5E-05 & 8.16 & 10 & 0.451 & 0.009 & 3,627 & 5.59E-01 & 1,535 & 2.85E-01 & $(4,722)$ & - & 14,851 & 2.67E-01 & - \\
\hline LB45-10.10 & 0 & 90 & 4.9E-05 & 9.10 & 10 & 0.444 & 0.009 & 3,616 & 5.03E-01 & 1,708 & 2.87E-01 & $(4,584)$ & - & 15,551 & 2.59E-01 & - \\
\hline \multicolumn{17}{|l|}{ Exp. \#11 } \\
\hline LB45-11.0 & 0 & 90 & - & - & 11 & - & - & $<100$ & - & 37 & - & $<5000$ & - & $<5000$ & - & - \\
\hline LB45-11.1 & 0 & 90 & - & - & 11 & - & - & $<100$ & - & 75 & - & $<5000$ & - & $<5000$ & - & - \\
\hline LB45-11.2 & 0 & 90 & - & - & 11 & - & - & $<100$ & - & 45 & - & $<5000$ & - & $<5000$ & - & - \\
\hline LB45-11.3 & 0 & 90 & 5.3E-05 & 2.05 & 11 & 0.495 & 0.010 & 4,670 & 6.31E-01 & 2,541 & 4.06E-01 & 6,009 & $1.11 \mathrm{E}-01$ & 21,378 & 3.87E-01 & - \\
\hline LB45-11.4 & 0 & 90 & 5.6E-05 & 2.87 & 11 & 0.484 & 0.010 & 6,639 & $9.82 \mathrm{E}-01$ & 2,915 & 5.08E-01 & 8,672 & 4.38E-01 & 27,660 & 5.83E-01 & - \\
\hline LB45-11.5 & 0 & 90 & 5.7E-05 & 3.92 & 11 & 0.469 & 0.009 & 6,813 & $1.06 \mathrm{E}+00$ & 2,703 & 4.93E-01 & 8,546 & 4.44E-01 & 27,245 & $6.00 \mathrm{E}-01$ & - \\
\hline LB45-11.6 & 0 & 90 & $5.4 \mathrm{E}-05$ & 4.89 & 11 & 0.455 & 0.009 & 6,456 & $9.68 \mathrm{E}-01$ & 2,448 & 4.31E-01 & 8,291 & $3.98 \mathrm{E}-01$ & 26,007 & $5.48 \mathrm{E}-01$ & - \\
\hline LB45-11.7 & 0 & 90 & 5.6E-05 & 5.90 & 11 & 0.442 & 0.009 & 5,788 & $9.33 \mathrm{E}-01$ & 2,107 & 3.98E-01 & 7,367 & 3.08E-01 & 23,146 & 5.10E-01 & - \\
\hline LB45-11.8 & 0 & 90 & 5.3E-05 & 6.90 & 11 & 0.430 & 0.009 & 5,455 & 8.52E-01 & 1,997 & 3.65E-01 & 6,790 & $2.26 \mathrm{E}-01$ & 21,945 & 4.62E-01 & - \\
\hline LB45-11.9 & 0 & 90 & 5.1E-05 & 8.16 & 11 & 0.417 & 0.008 & 5,359 & 8.38E-01 & 1,934 & 3.54E-01 & 6,968 & 2.49E-01 & 21,534 & 4.51E-01 & - \\
\hline LB45-11.10 & 0 & 90 & $5.2 \mathrm{E}-05$ & 9.10 & 11 & 0.406 & 0.008 & 5,086 & 8.32E-01 & 1,965 & 3.77E-01 & 6,407 & $1.87 \mathrm{E}-01$ & 20,733 & 4.50E-01 & - \\
\hline \multicolumn{17}{|l|}{ Exp. \#12 } \\
\hline LB45-12.0 & 0 & 90 & - & - & 12 & - & - & $<100$ & - & 139 & - & $<5000$ & - & $<5000$ & - & - \\
\hline LB45-12.1 & 0 & 90 & - & - & 12 & - & - & $<100$ & - & 278 & - & $<5000$ & - & $<5000$ & - & - \\
\hline LB45-12.2 & 0 & 90 & - & - & 12 & - & - & $<100$ & - & 296 & - & $<5000$ & - & $<5000$ & - & - \\
\hline LB45-12.3 & 0 & 90 & 5.6E-05 & 2.05 & 12 & 0.496 & 0.010 & 3,502 & 4.95E-01 & 2,918 & 4.61E-01 & 5,324 & 3.75E-02 & 18,782 & 3.44E-01 & - \\
\hline LB45-12.4 & 0 & 90 & 5.5E-05 & 2.87 & 12 & 0.488 & 0.010 & 4,583 & $6.56 \mathrm{E}-01$ & 3,523 & $5.68 \mathrm{E}-01$ & 6,709 & $1.99 \mathrm{E}-01$ & 22,616 & $4.41 \mathrm{E}-01$ & - \\
\hline LB45-12.5 & 0 & 90 & $2.5 \mathrm{E}-05$ & 3.92 & 12 & 0.480 & 0.010 & 7,274 & 4.92E-01 & 5,036 & 3.89E-01 & 9,993 & 2.72E-01 & 33,834 & 3.39E-01 & - \\
\hline LB45-12.6 & 0 & 90 & $5.2 \mathrm{E}-05$ & 4.89 & 12 & 0.468 & 0.009 & 6,937 & $9.75 \mathrm{E}-01$ & 4,305 & 6.85E-01 & 9,494 & $5.09 \mathrm{E}-01$ & 30,979 & 6.35E-01 & - \\
\hline LB45-12.7 & 0 & 90 & 5.3E-05 & 5.90 & 12 & 0.454 & 0.009 & 6,977 & $1.04 \mathrm{E}+00$ & 3,858 & 6.50E-01 & 9,227 & 5.10E-01 & 29,953 & 6.49E-01 & - \\
\hline LB45-12.8 & 0 & 90 & $5.8 \mathrm{E}-05$ & 6.90 & 12 & 0.438 & 0.009 & 7,522 & $1.26 \mathrm{E}+00$ & 3,902 & 7.34E-01 & 9,830 & 6.51E-01 & 31,350 & 7.65E-01 & - \\
\hline
\end{tabular}


Table A2. SPFT Results for LAWB45 Glasses.

\begin{tabular}{|c|c|c|c|c|c|c|c|c|c|c|c|c|c|c|c|c|}
\hline Sample ID & $\begin{array}{c}\text { Influent } \\
\text { [Si] }\end{array}$ & $\mathrm{T}\left({ }^{\circ} \mathrm{C}\right)$ & $\begin{array}{c}\text { Flow } \\
\text { Rate } \\
\left(\mathrm{m}^{3} / \mathrm{d}\right) \\
\end{array}$ & $\begin{array}{c}\text { Time, } \\
\text { days }\end{array}$ & $\begin{array}{c}\mathrm{pH} \\
\left(23^{\circ} \mathrm{C}\right) \\
\end{array}$ & $\begin{array}{l}\text { Glass } \\
\text { Mass } \\
\text { (g) }\end{array}$ & $\mathrm{SA}\left(\mathrm{m}^{2}\right)$ & [B] & B Rate & {$[\mathrm{Al}]$} & Al Rate & {$[\mathrm{Na}]$} & Na Rate & {$[\mathrm{Si}]$} & Si Rate & $\begin{array}{l}\text { IEX } \\
\text { Rate }\end{array}$ \\
\hline LB45-12.9 & 0 & 90 & $5.1 \mathrm{E}-05$ & 8.16 & 12 & 0.420 & 0.009 & 7,384 & $1.13 E+00$ & 3,795 & $6.54 \mathrm{E}-01$ & 9,533 & 5.61E-01 & 30,855 & 6.89E-01 & - \\
\hline LB45-12.10 & 0 & 90 & $5.0 \mathrm{E}-05$ & 9.10 & 12 & 0.405 & 0.008 & 7,280 & $1.15 \mathrm{E}+00$ & 3,735 & $6.60 \mathrm{E}-01$ & 9,116 & 5.23E-01 & 30,271 & 6.92E-01 & - \\
\hline \multicolumn{17}{|l|}{ Exp.\#13 } \\
\hline LB45-13A & $8.97 E+02$ & 23 & - & - & 9 & - & - & $<25$ & - & $<75$ & - & $<300$ & - & $<1500$ & - & - \\
\hline LB45-13B & $8.97 \mathrm{E}+02$ & 23 & - & - & 9 & - & - & $<25$ & - & $<75$ & - & $<300$ & - & $<1500$ & - & - \\
\hline LB45-13C & $8.97 \mathrm{E}+02$ & 23 & - & - & 9 & - & - & $<25$ & - & $<75$ & - & $<300$ & - & $<1500$ & - & - \\
\hline LB45-13.4 & $8.97 \mathrm{E}+02$ & 23 & $9.8 \mathrm{E}-06$ & 7.12 & 9 & 2.006 & 0.032 & 515 & 3.93E-03 & 325 & $2.37 \mathrm{E}-03$ & 720 & $2.68 \mathrm{E}-03$ & 2,506 & $1.38 \mathrm{E}-03$ & - \\
\hline LB45-13.8 & $8.97 \mathrm{E}+02$ & 23 & 9.6E-06 & 14.25 & 9 & 2.005 & 0.040 & 465 & $2.75 \mathrm{E}-03$ & 323 & 1.83E-03 & 596 & $1.47 \mathrm{E}-03$ & 2,306 & 8.62E-04 & - \\
\hline LB45-13.12 & $8.97 \mathrm{E}+02$ & 23 & $9.5 \mathrm{E}-06$ & 22.22 & 9 & 2.005 & 0.040 & 532 & $3.14 \mathrm{E}-03$ & 472 & $2.90 \mathrm{E}-03$ & 641 & $1.68 \mathrm{E}-03$ & 2,921 & $1.51 \mathrm{E}-03$ & - \\
\hline LB45-13.16 & $8.97 \mathrm{E}+02$ & 23 & $9.5 \mathrm{E}-06$ & 33.09 & 9 & 2.005 & 0.040 & 523 & 3.07E-03 & 439 & $2.65 \mathrm{E}-03$ & 694 & 1.93E-03 & 2,864 & 1.44E-03 & - \\
\hline LB45-13.20 & $8.97 \mathrm{E}+02$ & 23 & 9.5E-06 & 42.48 & 9 & 2.004 & 0.040 & 461 & 2.69E-03 & 355 & 2.03E-03 & 607 & 1.50E-03 & 2,430 & $9.81 \mathrm{E}-04$ & - \\
\hline LB45-13.24 & $8.97 \mathrm{E}+02$ & 23 & $1.1 \mathrm{E}-05$ & 52.10 & 9 & 2.004 & 0.040 & 392 & 2.61E-03 & 311 & $1.98 \mathrm{E}-03$ & 492 & $1.08 \mathrm{E}-03$ & 2,061 & $6.82 \mathrm{E}-04$ & - \\
\hline LB45-13.28 & $8.97 \mathrm{E}+02$ & 23 & $9.7 \mathrm{E}-06$ & 68.08 & 9 & 2.003 & 0.040 & 341 & $2.00 \mathrm{E}-03$ & 316 & $1.79 \mathrm{E}-03$ & 419 & 5.95E-04 & 1,970 & $5.08 \mathrm{E}-04$ & - \\
\hline LB45-13.32 & $8.97 \mathrm{E}+02$ & 23 & $9.9 \mathrm{E}-06$ & 86.08 & 9 & 2.003 & 0.040 & 369 & $2.21 \mathrm{E}-03$ & 307 & $1.76 \mathrm{E}-03$ & 438 & 7.05E-04 & 2,010 & 5.61E-04 & - \\
\hline LB45-13.34 & $8.97 \mathrm{E}+02$ & 23 & $1.0 \mathrm{E}-05$ & 93.15 & 9 & 2.002 & 0.040 & 351 & $2.12 \mathrm{E}-03$ & 292 & $1.66 \mathrm{E}-03$ & 440 & 7.25E-04 & 1,948 & 4.99E-04 & - \\
\hline LB45-13.35 & $8.97 E+02$ & 23 & 9.7E-06 & 96.01 & 9 & 2.002 & 0.040 & 374 & $2.22 \mathrm{E}-03$ & 360 & 2.13E-03 & 464 & 8.26E-04 & 2,196 & 7.57E-04 & - \\
\hline \multicolumn{17}{|l|}{ Exp. \#14 } \\
\hline LB45-14A & $1.51 \mathrm{E}+04$ & 23 & - & - & 9 & - & - & $<25$ & - & $<75$ & - & $<300$ & - & 16,485 & - & - \\
\hline LB45-14B & $1.51 \mathrm{E}+04$ & 23 & - & - & 9 & - & - & $<25$ & - & $<75$ & - & $<300$ & - & 16,890 & - & - \\
\hline LB45-14C & $1.51 \mathrm{E}+04$ & 23 & - & - & 9 & - & - & $<25$ & - & $<75$ & - & $<300$ & - & 17,003 & - & - \\
\hline LB45-14.4 & $1.51 \mathrm{E}+04$ & 23 & $9.8 \mathrm{E}-06$ & 7.12 & 9 & 2.002 & 0.032 & 377 & 2.84E-03 & 96 & $1.96 \mathrm{E}-04$ & 515 & $1.38 \mathrm{E}-03$ & 17,725 & $1.29 \mathrm{E}-03$ & - \\
\hline LB45-14.8 & $1.51 \mathrm{E}+04$ & 23 & $9.6 \mathrm{E}-06$ & 14.25 & 9 & 2.002 & 0.040 & 332 & $1.91 \mathrm{E}-03$ & 87 & 8.73E-05 & 434 & 6.66E-04 & 17,717 & $9.88 \mathrm{E}-04$ & - \\
\hline LB45-14.12 & $1.51 \mathrm{E}+04$ & 23 & $9.4 \mathrm{E}-06$ & 22.22 & 9 & 2.001 & 0.040 & 362 & 2.07E-03 & 192 & $8.48 \mathrm{E}-04$ & 465 & 8.06E-04 & 19,086 & 2.41E-03 & - \\
\hline LB45-14.16 & $1.51 \mathrm{E}+04$ & 23 & $9.5 \mathrm{E}-06$ & 33.09 & 9 & 2.001 & 0.040 & 340 & $1.95 \mathrm{E}-03$ & 190 & $8.41 \mathrm{E}-04$ & 466 & 8.14E-04 & 18,936 & 2.27E-03 & - \\
\hline LB45-14.20 & $1.51 \mathrm{E}+04$ & 23 & 9.4E-06 & 42.48 & 9 & 2.001 & 0.040 & 330 & $1.88 \mathrm{E}-03$ & 131 & 4.07E-04 & 368 & 3.32E-04 & 17,956 & $1.23 \mathrm{E}-03$ & - \\
\hline LB45-14.24 & $1.51 \mathrm{E}+04$ & 23 & $1.1 \mathrm{E}-05$ & 52.10 & 9 & 2.000 & 0.040 & 294 & $1.88 \mathrm{E}-03$ & 110 & $2.86 \mathrm{E}-04$ & 354 & 2.99E-04 & 16,837 & 5.34E-05 & - \\
\hline LB45-14.28 & $1.51 \mathrm{E}+04$ & 23 & $9.5 \mathrm{E}-06$ & 68.08 & 9 & 2.000 & 0.040 & 260 & $1.46 \mathrm{E}-03$ & 94 & $1.41 \mathrm{E}-04$ & 374 & $3.68 \mathrm{E}-04$ & 17,407 & $6.55 \mathrm{E}-04$ & - \\
\hline LB45-14.32 & $1.51 \mathrm{E}+04$ & 23 & $9.9 \mathrm{E}-06$ & 86.08 & 9 & 2.000 & 0.040 & 269 & $1.57 \mathrm{E}-03$ & 98 & $1.74 \mathrm{E}-04$ & 361 & 3.13E-04 & 17,408 & $6.81 \mathrm{E}-04$ & - \\
\hline LB45-14.34 & $1.51 \mathrm{E}+04$ & 23 & $9.7 \mathrm{E}-06$ & 93.15 & 9 & 1.999 & 0.040 & 223 & $1.25 \mathrm{E}-03$ & ND & - & 323 & $1.16 \mathrm{E}-04$ & 25,967 & 9.92E-03 & - \\
\hline LB45-14.35 & $1.51 \mathrm{E}+04$ & 23 & $9.7 \mathrm{E}-06$ & 96.01 & 9 & 1.999 & 0.040 & 229 & $1.29 \mathrm{E}-03$ & 94 & $1.43 \mathrm{E}-04$ & 323 & 1.17E-04 & 21,097 & 4.66E-03 & - \\
\hline \multicolumn{17}{|l|}{ Exp. \#15 } \\
\hline LB45-15A & $3.01 \mathrm{E}+04$ & 23 & - & - & 9 & - & - & $<25$ & - & $<75$ & - & $<300$ & - & 33,259 & - & - \\
\hline LB45-15B & $3.01 \mathrm{E}+04$ & 23 & - & - & 9 & - & - & $<25$ & - & $<75$ & - & $<300$ & - & 33,415 & - & - \\
\hline LB45-15C & $3.01 \mathrm{E}+04$ & 23 & - & - & 9 & - & - & $<25$ & - & $<75$ & - & $<300$ & - & 33,339 & - & - \\
\hline LB45-15.4 & $3.01 \mathrm{E}+04$ & 23 & $9.8 \mathrm{E}-06$ & 7.12 & 9 & 2.003 & 0.032 & 296 & 2.17E-03 & ND & - & 415 & 7.32E-04 & 33,599 & $3.60 \mathrm{E}-04$ & - \\
\hline LB45-15.8 & $3.01 \mathrm{E}+04$ & 23 & 9.6E-06 & 14.25 & 9 & 2.003 & 0.040 & 222 & $1.24 \mathrm{E}-03$ & ND & - & 332 & $1.57 \mathrm{E}-04$ & 34,277 & $1.01 \mathrm{E}-03$ & - \\
\hline LB45-15.12 & $3.01 \mathrm{E}+04$ & 23 & $9.4 \mathrm{E}-06$ & 22.22 & 9 & 2.002 & 0.040 & 259 & $1.44 \mathrm{E}-03$ & 101 & $1.89 \mathrm{E}-04$ & 359 & 2.87E-04 & 35,368 & 2.14E-03 & - \\
\hline LB45-15.16 & $3.01 \mathrm{E}+04$ & 23 & $9.4 \mathrm{E}-06$ & 33.09 & 9 & 2.002 & 0.040 & 273 & $1.53 \mathrm{E}-03$ & 106 & $2.25 \mathrm{E}-04$ & 390 & $4.42 \mathrm{E}-04$ & 34,034 & 7.34E-04 & - \\
\hline LB45-15.20 & $3.01 E+04$ & 23 & $9.5 \mathrm{E}-06$ & 42.48 & 9 & 2.002 & 0.040 & 232 & $1.29 \mathrm{E}-03$ & ND & - & ND & - & 33,969 & 6.72E-04 & - \\
\hline LB45-15.24 & $3.01 \mathrm{E}+04$ & 23 & $6.2 \mathrm{E}-06$ & 52.10 & 9 & 2.002 & 0.040 & 188 & $6.54 \mathrm{E}-04$ & ND & - & ND & - & 33,837 & $3.44 \mathrm{E}-04$ & - \\
\hline
\end{tabular}


Table A2. SPFT Results for LAWB45 Glasses.

\begin{tabular}{|c|c|c|c|c|c|c|c|c|c|c|c|c|c|c|c|c|}
\hline Sample ID & $\begin{array}{c}\text { Influent } \\
\text { [Si] }\end{array}$ & $\mathrm{T}\left({ }^{\circ} \mathrm{C}\right)$ & $\begin{array}{c}\text { Flow } \\
\text { Rate } \\
\left(\mathrm{m}^{3} / \mathrm{d}\right)\end{array}$ & $\begin{array}{c}\text { Time, } \\
\text { days }\end{array}$ & $\begin{array}{c}\mathrm{pH} \\
\left(23^{\circ} \mathrm{C}\right) \\
\end{array}$ & $\begin{array}{c}\text { Glass } \\
\text { Mass } \\
(\mathrm{g})\end{array}$ & $\mathrm{SA}\left(\mathrm{m}^{2}\right)$ & {$[\mathrm{B}]$} & B Rate & {$[\mathrm{Al}]$} & Al Rate & {$[\mathrm{Na}]$} & Na Rate & {$[\mathrm{Si}]$} & Si Rate & $\begin{array}{l}\text { IEX } \\
\text { Rate }\end{array}$ \\
\hline LB45-15.28 & $3.01 \mathrm{E}+04$ & 23 & 9.5E-06 & 68.08 & 9 & 2.002 & 0.040 & 132 & $6.61 \mathrm{E}-04$ & ND & - & ND & - & 34,562 & $1.29 \mathrm{E}-03$ & - \\
\hline LB45-15.32 & $3.01 E+04$ & 23 & 9.8E-06 & 86.08 & 9 & 2.001 & 0.040 & 136 & 7.09E-04 & ND & - & ND & - & 35,083 & $1.91 \mathrm{E}-03$ & - \\
\hline LB45-15.34 & $3.01 \mathrm{E}+04$ & 23 & 9.7E-06 & 93.15 & 9 & 2.001 & 0.040 & 95 & 4.39E-04 & ND & - & ND & - & 44,644 & $1.22 \mathrm{E}-02$ & - \\
\hline LB45-15.35 & $3.01 \mathrm{E}+04$ & 23 & 9.7E-06 & 96.01 & 9 & 2.001 & 0.040 & 104 & $5.00 \mathrm{E}-04$ & ND & - & ND & - & 37,721 & $4.75 \mathrm{E}-03$ & - \\
\hline \multicolumn{17}{|l|}{ Exp.\#16 } \\
\hline LB45-16A & $4.60 \mathrm{E}+04$ & 23 & - & - & 9 & - & - & $<25$ & - & $<75$ & - & $<300$ & - & 50,267 & - & - \\
\hline LB45-16B & $4.60 \mathrm{E}+04$ & 23 & - & - & 9 & - & - & $<25$ & - & $<75$ & - & $<300$ & - & 50,834 & - & - \\
\hline LB45-16C & $4.60 \mathrm{E}+04$ & 23 & - & - & 9 & - & - & $<25$ & - & $<75$ & - & $<300$ & - & 51,232 & - & - \\
\hline LB45-16.4 & $4.60 \mathrm{E}+04$ & 23 & $9.8 \mathrm{E}-06$ & 7.12 & 9 & 1.999 & 0.032 & 229 & $1.64 \mathrm{E}-03$ & ND & - & 376 & - & 53,035 & $3.12 \mathrm{E}-03$ & - \\
\hline LB45-16.8 & $4.60 \mathrm{E}+04$ & 23 & $9.6 \mathrm{E}-06$ & 14.25 & 9 & 1.999 & 0.040 & 138 & 7.06E-04 & ND & - & ND & - & 51,930 & $1.23 \mathrm{E}-03$ & - \\
\hline LB45-16.12 & $4.60 \mathrm{E}+04$ & 23 & $9.4 \mathrm{E}-06$ & 22.22 & 9 & 1.999 & 0.040 & 129 & $6.43 \mathrm{E}-04$ & ND & - & ND & - & 53,608 & 2.99E-03 & - \\
\hline LB45-16.16 & $4.60 \mathrm{E}+04$ & 23 & $9.4 \mathrm{E}-06$ & 33.09 & 9 & 1.999 & 0.040 & 140 & 7.04E-04 & ND & - & ND & - & 51,552 & 8.13E-04 & - \\
\hline LB45-16.20 & $4.60 \mathrm{E}+04$ & 23 & 9.5E-06 & 42.48 & 9 & 1.998 & 0.040 & 118 & $5.80 \mathrm{E}-04$ & ND & - & ND & - & 50,058 & - & - \\
\hline LB45-16.24 & $4.60 \mathrm{E}+04$ & 23 & $1.1 \mathrm{E}-05$ & 52.10 & 9 & 1.998 & 0.040 & 71 & $3.21 \mathrm{E}-04$ & ND & - & ND & - & 51,174 & 4.75E-04 & - \\
\hline LB45-16.28 & $4.60 \mathrm{E}+04$ & 23 & $9.4 \mathrm{E}-06$ & 68.08 & 9 & 1.998 & 0.040 & 46 & $1.30 \mathrm{E}-04$ & ND & - & ND & - & 48,606 & - & - \\
\hline LB45-16.32 & $4.60 \mathrm{E}+04$ & 23 & $9.8 \mathrm{E}-06$ & 86.08 & 9 & 1.998 & 0.040 & 35 & $6.42 \mathrm{E}-05$ & ND & - & ND & - & 52,713 & 2.11E-03 & - \\
\hline LB45-16.34 & $4.60 \mathrm{E}+04$ & 23 & $9.6 \mathrm{E}-06$ & 93.15 & 9 & 1.998 & 0.040 & 30 & $3.17 \mathrm{E}-05$ & ND & - & ND & - & 42,823 & - & - \\
\hline LB45-16.35 & $4.60 \mathrm{E}+04$ & 23 & $9.8 \mathrm{E}-06$ & 96.01 & 9 & 1.998 & 0.040 & 38 & 8.17E-05 & ND & - & ND & - & 47,424 & - & - \\
\hline \multicolumn{17}{|l|}{ Exp. \#17 } \\
\hline LB45-17A & $6.04 \mathrm{E}+04$ & 23 & - & - & 9 & - & - & $<25$ & - & $<75$ & - & $<300$ & - & 66,580 & - & - \\
\hline LB45-17B & $6.04 \mathrm{E}+04$ & 23 & - & - & 9 & - & - & $<25$ & - & $<75$ & - & $<300$ & - & 67,154 & - & - \\
\hline LB45-17C & $6.04 \mathrm{E}+04$ & 23 & - & - & 9 & - & - & $<25$ & - & $<75$ & - & $<300$ & - & 72,215 & - & - \\
\hline LB45-17.4 & $6.04 \mathrm{E}+04$ & 23 & 9.7E-06 & 7.12 & 9 & 2.005 & 0.032 & 179 & $1.23 \mathrm{E}-03$ & ND & - & 302 & - & 67,752 & - & - \\
\hline LB45-17.8 & $6.04 \mathrm{E}+04$ & 23 & $9.8 \mathrm{E}-06$ & 14.25 & 9 & 2.005 & 0.040 & 99 & 4.73E-04 & ND & - & ND & - & 66,233 & - & - \\
\hline LB45-17.12 & $6.04 \mathrm{E}+04$ & 23 & $9.7 \mathrm{E}-06$ & 22.22 & 9 & 2.005 & 0.040 & 87 & 3.92E-04 & ND & - & ND & - & 73,018 & $4.72 \mathrm{E}-03$ & - \\
\hline LB45-17.16 & $6.04 \mathrm{E}+04$ & 23 & $9.5 \mathrm{E}-06$ & 33.09 & 9 & 2.005 & 0.040 & 82 & 3.54E-04 & ND & - & ND & - & 68,361 & - & - \\
\hline LB45-17.20 & $6.04 \mathrm{E}+04$ & 23 & $9.6 \mathrm{E}-06$ & 42.48 & 9 & 2.005 & 0.040 & 62 & $2.29 \mathrm{E}-04$ & ND & - & ND & - & 64,796 & - & - \\
\hline LB45-17.24 & $6.04 \mathrm{E}+04$ & 23 & $1.1 \mathrm{E}-05$ & 52.10 & 9 & 2.005 & 0.040 & 35 & $6.80 \mathrm{E}-05$ & ND & - & ND & - & 72,839 & $5.10 \mathrm{E}-03$ & - \\
\hline LB45-17.28 & $6.04 \mathrm{E}+04$ & 23 & $9.5 \mathrm{E}-06$ & 68.08 & 9 & 2.005 & 0.040 & ND & $1.49 \mathrm{E}-04$ & ND & - & ND & - & 65,809 & - & - \\
\hline LB45-17.32 & $6.04 \mathrm{E}+04$ & 23 & $9.8 \mathrm{E}-06$ & 86.08 & 9 & 2.004 & 0.040 & ND & $1.59 \mathrm{E}-04$ & ND & - & ND & - & 65,110 & - & - \\
\hline LB45-17.34 & $6.04 \mathrm{E}+04$ & 23 & 9.7E-06 & 93.15 & 9 & 2.004 & 0.040 & ND & $1.58 \mathrm{E}-04$ & ND & - & ND & - & 59,263 & - & - \\
\hline LB45-17.35 & $6.04 \mathrm{E}+04$ & 23 & 9.7E-06 & 96.01 & 9 & 2.004 & 0.040 & ND & $1.58 \mathrm{E}-04$ & ND & - & ND & - & 64,366 & - & - \\
\hline \multicolumn{17}{|l|}{ Exp. \#18 } \\
\hline LB45-18A & $5.24 \mathrm{E}+04$ & 23 & - & - & 9 & - & - & $<25$ & - & $<75$ & - & $<300$ & - & 52,429 & - & - \\
\hline LB45-18B & $5.24 \mathrm{E}+04$ & 23 & - & - & 9 & - & - & $<25$ & - & $<75$ & - & $<300$ & - & 59,118 & - & - \\
\hline LB45-18C & $5.24 \mathrm{E}+04$ & 23 & - & - & 9 & - & - & $<25$ & - & $<75$ & - & $<300$ & - & 67,153 & - & - \\
\hline LB45-18.4 & $5.24 \mathrm{E}+04$ & 23 & $9.9 \mathrm{E}-06$ & 7.12 & 9 & 2.014 & 0.032 & 169 & $1.16 \mathrm{E}-03$ & ND & - & 302 & $1.07 \mathrm{E}-05$ & 80,462 & 2.89E-02 & - \\
\hline LB45-18.8 & $5.24 \mathrm{E}+04$ & 23 & $9.7 \mathrm{E}-06$ & 14.25 & 9 & 2.014 & 0.040 & 95 & 4.40E-04 & ND & - & ND & - & 82,510 & $2.47 \mathrm{E}-02$ & - \\
\hline LB45-18.12 & $5.24 \mathrm{E}+04$ & 23 & $9.5 \mathrm{E}-06$ & 22.22 & 9 & 2.014 & 0.040 & 69 & 2.74E-04 & ND & - & ND & - & 87,955 & $3.00 \mathrm{E}-02$ & - \\
\hline LB45-18.16 & $5.24 \mathrm{E}+04$ & 23 & $9.6 \mathrm{E}-06$ & 33.09 & 9 & 2.014 & 0.040 & 48 & $1.44 \mathrm{E}-04$ & ND & - & ND & - & 84,683 & $2.68 \mathrm{E}-02$ & - \\
\hline
\end{tabular}


Table A2. SPFT Results for LAWB45 Glasses.

\begin{tabular}{|c|c|c|c|c|c|c|c|c|c|c|c|c|c|c|c|c|}
\hline Sample ID & $\begin{array}{c}\text { Influent } \\
\text { [Si] }\end{array}$ & $\mathrm{T}\left({ }^{\circ} \mathrm{C}\right)$ & $\begin{array}{l}\text { Flow } \\
\text { Rate } \\
\left(\mathrm{m}^{3} / \mathrm{d}\right) \\
\end{array}$ & $\begin{array}{l}\text { Time, } \\
\text { days }\end{array}$ & $\begin{array}{c}\mathrm{pH} \\
\left(23^{\circ} \mathrm{C}\right) \\
\end{array}$ & $\begin{array}{l}\text { Glass } \\
\text { Mass } \\
\text { (g) }\end{array}$ & $\mathrm{SA}\left(\mathrm{m}^{2}\right)$ & {$[\mathrm{B}]$} & B Rate & {$[\mathrm{Al}]$} & Al Rate & {$[\mathrm{Na}]$} & Na Rate & {$[\mathrm{Si}]$} & Si Rate & $\begin{array}{l}\text { IEX } \\
\text { Rate }\end{array}$ \\
\hline LB45-18.20 & $5.24 \mathrm{E}+04$ & 23 & $9.6 \mathrm{E}-06$ & 42.48 & 9 & 2.014 & 0.040 & 34 & 5.54E-05 & ND & - & ND & - & 83,648 & 2.55E-02 & - \\
\hline LB45-18.24 & $5.24 \mathrm{E}+04$ & 23 & $1.1 \mathrm{E}-05$ & 52.10 & 9 & 2.014 & 0.040 & ND & $1.78 \mathrm{E}-04$ & ND & - & ND & - & 83,189 & 2.88E-02 & - \\
\hline LB45-18.28 & $5.24 \mathrm{E}+04$ & 23 & 9.7E-06 & 68.08 & 9 & 2.014 & 0.040 & ND & $1.57 \mathrm{E}-04$ & ND & - & ND & - & 77,066 & 1.89E-02 & - \\
\hline LB45-18.32 & $5.24 \mathrm{E}+04$ & 23 & $9.9 \mathrm{E}-06$ & 86.08 & 9 & 2.014 & 0.040 & ND & $1.60 \mathrm{E}-04$ & ND & - & ND & - & 85,851 & 2.87E-02 & - \\
\hline LB45-18.34 & $5.24 \mathrm{E}+04$ & 23 & 9.7E-06 & 93.15 & 9 & 2.014 & 0.040 & ND & 1.56E-04 & ND & - & ND & - & 76,518 & 1.82E-02 & - \\
\hline LB45-18.35 & $5.24 \mathrm{E}+04$ & 23 & $9.8 \mathrm{E}-06$ & 96.01 & 9 & 2.013 & 0.040 & ND & 1.59E-04 & ND & - & ND & - & 80,466 & 2.27E-02 & - \\
\hline \multicolumn{17}{|l|}{ Exp. \#19 } \\
\hline LB45-19.0 & 0 & 23 & - & - & 7 & - & - & $<50$ & - & $<50$ & - & $<100$ & - & $<500$ & - & - \\
\hline LB45-19.1 & 0 & 23 & - & - & 7 & - & - & $<50$ & - & $<50$ & - & $<100$ & - & $<500$ & - & - \\
\hline LB45-19.4 & 0 & 23 & $8.8 \mathrm{E}-06$ & 7.07 & 7 & 1.007 & 0.020 & 325 & 3.16E-03 & ND & - & 673 & $5.22 \mathrm{E}-03$ & ND & - & $8.23 \mathrm{E}-10$ \\
\hline LB45-19.5 & 0 & 23 & $9.0 \mathrm{E}-06$ & 9.03 & 7 & 1.006 & 0.020 & 231 & $2.10 \mathrm{E}-03$ & ND & - & 464 & 3.36E-03 & ND & - & $5.02 \mathrm{E}-10$ \\
\hline LB45-19.7 & 0 & 23 & $9.2 \mathrm{E}-06$ & 16.97 & 7 & 1.006 & 0.020 & 114 & 7.56E-04 & ND & - & 210 & $1.04 \mathrm{E}-03$ & ND & - & $1.12 \mathrm{E}-10$ \\
\hline LB45-19.9 & 0 & 23 & $1.0 \mathrm{E}-05$ & 28.88 & 7 & 1.006 & 0.020 & 83 & 4.39E-04 & ND & - & 174 & $7.86 \mathrm{E}-04$ & ND & - & $1.38 \mathrm{E}-10$ \\
\hline LB45-19.10 & 0 & 23 & $8.2 \mathrm{E}-06$ & 33.88 & 7 & 1.006 & 0.020 & 68 & $1.87 \mathrm{E}-04$ & ND & - & 133 & 2.83E-04 & ND & - & $3.81 \mathrm{E}-11$ \\
\hline LB45-19.11 & 0 & 23 & $5.1 \mathrm{E}-07$ & 37.99 & 7 & 1.006 & 0.020 & ND & 2.37E-05 & ND & - & ND & 3.58E-05 & ND & - & 4.87E-12 \\
\hline LB45-19.12 & 0 & 23 & $9.6 \mathrm{E}-06$ & 40.86 & 7 & 1.006 & 0.020 & 96 & $5.70 \mathrm{E}-04$ & ND & - & 195 & $9.41 \mathrm{E}-04$ & ND & - & $1.48 \mathrm{E}-10$ \\
\hline LB45-19.13 & 0 & 23 & 8.9E-06 & 41.90 & 7 & 1.006 & 0.020 & 77 & 3.06E-04 & ND & - & 167 & 6.12E-04 & ND & - & $1.22 \mathrm{E}-10$ \\
\hline \multicolumn{17}{|l|}{ Exp. \#20 } \\
\hline LB45-20.0 & 0 & 23 & - & - & 8 & - & - & $<50$ & - & $<50$ & - & $<100$ & - & $<500$ & - & - \\
\hline LB45-20.1 & 0 & 23 & - & - & 8 & - & - & $<50$ & - & $<50$ & - & $<100$ & - & $<500$ & - & - \\
\hline LB45-20.4 & 0 & 23 & $9.8 \mathrm{E}-06$ & 7.07 & 8 & 1.003 & 0.020 & 192 & $1.81 \mathrm{E}-03$ & ND & - & 442 & $3.48 \mathrm{E}-03$ & ND & - & $6.66 \mathrm{E}-10$ \\
\hline LB45-20.5 & 0 & 23 & 9.6E-06 & 9.03 & 8 & 1.003 & 0.020 & 141 & 1.13E-03 & ND & - & 302 & $2.00 \mathrm{E}-03$ & ND & - & $3.50 \mathrm{E}-10$ \\
\hline LB45-20.7 & 0 & 23 & $9.8 \mathrm{E}-06$ & 16.97 & 8 & 1.003 & 0.020 & 76 & 3.31E-04 & ND & - & 152 & $5.28 \mathrm{E}-04$ & ND & - & 7.86E-11 \\
\hline LB45-20.9 & 0 & 23 & $1.1 \mathrm{E}-05$ & 28.88 & 8 & 1.003 & 0.020 & ND & 6.83E-04 & ND & - & ND & - & ND & - & - \\
\hline LB45-20.10 & 0 & 23 & $9.7 \mathrm{E}-06$ & 33.88 & 8 & 1.002 & 0.020 & ND & $6.29 \mathrm{E}-04$ & ND & - & ND & - & ND & - & - \\
\hline LB45-20.11 & 0 & 23 & $1.0 \mathrm{E}-05$ & 37.99 & 8 & 1.002 & 0.020 & ND & $6.68 \mathrm{E}-04$ & ND & - & ND & - & ND & - & - \\
\hline LB45-20.12 & 0 & 23 & $1.0 \mathrm{E}-05$ & 40.86 & 8 & 1.002 & 0.020 & ND & $6.49 \mathrm{E}-04$ & ND & - & ND & - & ND & - & - \\
\hline LB45-20.13 & 0 & 23 & $9.3 \mathrm{E}-06$ & 41.90 & 8 & 1.002 & 0.020 & ND & $6.05 \mathrm{E}-04$ & ND & - & ND & - & ND & - & - \\
\hline \multicolumn{17}{|l|}{ Exp. \#21 } \\
\hline LB45-21.0 & 0 & 23 & - & - & 9 & - & - & $<50$ & - & $<50$ & - & $<100$ & - & $<500$ & - & - \\
\hline LB45-21.1 & 0 & 23 & - & - & 9 & - & - & $<50$ & - & $<50$ & - & $<100$ & - & $<500$ & - & - \\
\hline LB45-21.4 & 0 & 23 & $9.6 \mathrm{E}-06$ & 7.07 & 9 & 1.004 & 0.020 & 227 & $2.21 \mathrm{E}-03$ & 140 & $1.33 \mathrm{E}-03$ & 438 & 3.36E-03 & 1,073 & $1.23 \mathrm{E}-03$ & $4.60 \mathrm{E}-10$ \\
\hline LB45-21.5 & 0 & 23 & $9.8 \mathrm{E}-06$ & 9.03 & 9 & 1.004 & 0.020 & 249 & 2.53E-03 & 164 & $1.71 \mathrm{E}-03$ & 419 & 3.23E-03 & 1,210 & 1.55E-03 & $2.80 \mathrm{E}-10$ \\
\hline LB45-21.7 & 0 & 23 & $9.9 \mathrm{E}-06$ & 16.97 & 9 & 1.003 & 0.020 & 242 & $2.48 \mathrm{E}-03$ & 167 & $1.78 \mathrm{E}-03$ & 364 & $2.71 \mathrm{E}-03$ & 1,224 & $1.60 \mathrm{E}-03$ & $9.26 \mathrm{E}-11$ \\
\hline LB45-21.9 & 0 & 23 & $1.0 \mathrm{E}-05$ & 28.88 & 9 & 1.003 & 0.020 & 178 & $1.72 \mathrm{E}-03$ & 196 & 2.33E-03 & 269 & $1.81 \mathrm{E}-03$ & 1,083 & $1.35 \mathrm{E}-03$ & 3.66E-11 \\
\hline LB45-21.10 & 0 & 23 & $9.6 \mathrm{E}-06$ & 33.88 & 9 & 1.003 & 0.020 & 260 & 2.63E-03 & 265 & 3.17E-03 & 388 & 2.87E-03 & 1,575 & 2.30E-03 & $9.46 \mathrm{E}-11$ \\
\hline LB45-21.11 & 0 & 23 & $6.9 \mathrm{E}-06$ & 37.99 & 9 & 1.002 & 0.020 & 271 & $1.99 \mathrm{E}-03$ & 253 & 2.16E-03 & 404 & 2.17E-03 & 1,573 & $1.65 \mathrm{E}-03$ & $7.45 \mathrm{E}-11$ \\
\hline LB45-21.12 & 0 & 23 & $6.5 \mathrm{E}-06$ & 40.86 & 9 & 1.002 & 0.020 & 287 & 2.02E-03 & 232 & 1.83E-03 & 428 & 2.22E-03 & 1,665 & $1.70 \mathrm{E}-03$ & 8.04E-11 \\
\hline LB45-21.13 & 0 & 23 & $1.4 \mathrm{E}-05$ & 41.90 & 9 & 1.002 & 0.020 & 281 & 4.20E-03 & 251 & 4.31E-03 & 425 & 4.70E-03 & 1,610 & $3.45 \mathrm{E}-03$ & $1.97 \mathrm{E}-10$ \\
\hline
\end{tabular}


Table A2. SPFT Results for LAWB45 Glasses.

\begin{tabular}{|c|c|c|c|c|c|c|c|c|c|c|c|c|c|c|c|c|}
\hline Sample ID & $\begin{array}{c}\text { Influent } \\
\text { [Si] }\end{array}$ & $\mathrm{T}\left({ }^{\circ} \mathrm{C}\right)$ & $\begin{array}{l}\text { Flow } \\
\text { Rate } \\
\left(\mathrm{m}^{3} / \mathrm{d}\right) \\
\end{array}$ & $\begin{array}{l}\text { Time, } \\
\text { days }\end{array}$ & $\begin{array}{c}\mathrm{pH} \\
\left(23^{\circ} \mathrm{C}\right) \\
\end{array}$ & $\begin{array}{l}\text { Glass } \\
\text { Mass } \\
\text { (g) }\end{array}$ & $\mathrm{SA}\left(\mathrm{m}^{2}\right)$ & [B] & B Rate & {$[\mathrm{Al}]$} & Al Rate & {$[\mathrm{Na}]$} & Na Rate & {$[\mathrm{Si}]$} & Si Rate & $\begin{array}{l}\text { IEX } \\
\text { Rate }\end{array}$ \\
\hline LB45-22.0 & 0 & 23 & - & - & 10 & - & - & $<50$ & - & $<50$ & - & $<100$ & - & $<500$ & - & - \\
\hline LB45-22.1 & 0 & 23 & - & - & 10 & - & - & $<50$ & - & $<50$ & - & $<100$ & - & $<500$ & - & - \\
\hline LB45-22.4 & 0 & 23 & $9.7 \mathrm{E}-06$ & 7.07 & 10 & 0.508 & 0.013 & 249 & 3.93E-03 & 257 & 4.83E-03 & 410 & 4.88E-03 & 1,534 & 3.50E-03 & 3.79E-10 \\
\hline LB45-22.5 & 0 & 23 & $9.8 \mathrm{E}-06$ & 9.03 & 10 & 0.507 & 0.010 & 292 & $6.08 \mathrm{E}-03$ & 273 & 6.62E-03 & 462 & 7.22E-03 & 1,694 & 5.14E-03 & $4.56 \mathrm{E}-10$ \\
\hline LB45-22.7 & 0 & 23 & 9.9E-06 & 16.97 & 10 & 0.507 & 0.010 & 239 & 4.79E-03 & 205 & 4.66E-03 & 365 & 5.35E-03 & 1,296 & 3.46E-03 & $2.24 \mathrm{E}-10$ \\
\hline LB45-22.9 & 0 & 23 & $1.0 \mathrm{E}-05$ & 28.88 & 10 & 0.507 & 0.010 & 266 & 5.79E-03 & 283 & $7.40 \mathrm{E}-03$ & 379 & 5.96E-03 & 1,753 & 5.77E-03 & $6.58 \mathrm{E}-11$ \\
\hline LB45-22.10 & 0 & 23 & $9.0 \mathrm{E}-06$ & 33.88 & 10 & 0.507 & 0.010 & 331 & 6.52E-03 & 310 & 7.15E-03 & 453 & $6.51 \mathrm{E}-03$ & 2,064 & 6.23E-03 & - \\
\hline LB45-22.11 & 0 & 23 & $1.0 \mathrm{E}-05$ & 37.99 & 10 & 0.506 & 0.010 & 314 & 6.93E-03 & 303 & 7.84E-03 & 471 & 7.76E-03 & 1,844 & 6.05E-03 & 3.32E-10 \\
\hline LB45-22.12 & 0 & 23 & $1.0 \mathrm{E}-05$ & 40.86 & 10 & 0.506 & 0.010 & 292 & $6.21 \mathrm{E}-03$ & 256 & $6.27 \mathrm{E}-03$ & 431 & $6.76 \mathrm{E}-03$ & 1,656 & 5.09E-03 & $2.20 \mathrm{E}-10$ \\
\hline LB45-22.13 & 0 & 23 & $9.1 \mathrm{E}-06$ & 41.90 & 10 & 0.506 & 0.010 & 271 & 5.19E-03 & 231 & $5.04 \mathrm{E}-03$ & 390 & $5.42 \mathrm{E}-03$ & 1,516 & 4.10E-03 & $9.16 \mathrm{E}-11$ \\
\hline \multicolumn{17}{|l|}{ Exp. \#23 } \\
\hline LB45-23.0 & 0 & 23 & - & - & 11 & - & - & $<50$ & - & $<50$ & - & $<100$ & - & $<500$ & - & - \\
\hline LB45-23.1 & 0 & 23 & - & - & 11 & - & - & $<50$ & - & $<50$ & - & $<100$ & - & $<500$ & - & - \\
\hline LB45-23.4 & 0 & 23 & $9.6 \mathrm{E}-06$ & 7.07 & 11 & 0.505 & 0.013 & 452 & $7.90 \mathrm{E}-03$ & 478 & $9.94 \mathrm{E}-03$ & 724 & $9.74 \mathrm{E}-03$ & 2,943 & $8.22 \mathrm{E}-03$ & 7.38E-10 \\
\hline LB45-23.5 & 0 & 23 & $9.8 \mathrm{E}-06$ & 9.03 & 11 & 0.504 & 0.010 & 588 & $1.37 \mathrm{E}-02$ & 574 & $1.58 \mathrm{E}-02$ & 869 & $1.56 \mathrm{E}-02$ & 3,623 & $1.36 \mathrm{E}-02$ & $7.42 \mathrm{E}-10$ \\
\hline LB45-23.7 & 0 & 23 & $9.9 \mathrm{E}-06$ & 16.97 & 11 & 0.504 & 0.010 & 515 & 1.19E-02 & 466 & $1.26 \mathrm{E}-02$ & 804 & 1.43E-02 & 2,848 & 1.03E-02 & $9.61 \mathrm{E}-10$ \\
\hline LB45-23.9 & 0 & 23 & $1.0 \mathrm{E}-05$ & 28.88 & 11 & 0.503 & 0.010 & 602 & $1.48 \mathrm{E}-02$ & 588 & $1.70 \mathrm{E}-02$ & 885 & $1.67 \mathrm{E}-02$ & 3,783 & $1.51 \mathrm{E}-02$ & $7.68 \mathrm{E}-10$ \\
\hline LB45-23.10 & 0 & 23 & $9.6 \mathrm{E}-06$ & 33.88 & 11 & 0.502 & 0.010 & 908 & $2.14 \mathrm{E}-02$ & 823 & $2.28 \mathrm{E}-02$ & 1,217 & $2.21 \mathrm{E}-02$ & 5,587 & 2.17E-02 & $2.95 \mathrm{E}-10$ \\
\hline LB45-23.11 & 0 & 23 & $1.0 \mathrm{E}-05$ & 37.99 & 11 & 0.500 & 0.010 & 901 & $2.25 \mathrm{E}-02$ & 798 & 2.34E-02 & 1,376 & 2.69E-02 & 5,521 & $2.28 \mathrm{E}-02$ & 1.73E-09 \\
\hline LB45-23.12 & 0 & 23 & $9.9 \mathrm{E}-06$ & 40.86 & 11 & 0.499 & 0.010 & 848 & $2.06 \mathrm{E}-02$ & 750 & $2.14 \mathrm{E}-02$ & 1,275 & $2.42 \mathrm{E}-02$ & 5,094 & 2.04E-02 & $1.41 \mathrm{E}-09$ \\
\hline LB45-23.13 & 0 & 23 & $9.1 \mathrm{E}-06$ & 41.90 & 11 & 0.499 & 0.010 & 800 & $1.79 \mathrm{E}-02$ & 720 & $1.89 \mathrm{E}-02$ & 1,151 & $2.00 \mathrm{E}-02$ & 4,746 & $1.74 \mathrm{E}-02$ & 8.13E-10 \\
\hline \multicolumn{17}{|l|}{ Exp. \#24 } \\
\hline LB45-24.0 & 0 & 23 & - & - & 12 & - & - & $<50$ & - & $<50$ & - & $<100$ & - & $<500$ & - & - \\
\hline LB45-24.1 & 0 & 23 & - & - & 12 & - & - & $<50$ & - & $<50$ & - & $<100$ & - & $<500$ & - & - \\
\hline LB45-24.4 & 0 & 23 & $1.0 \mathrm{E}-05$ & 7.07 & 12 & 0.503 & 0.013 & 746 & $1.45 \mathrm{E}-02$ & 791 & $1.82 \mathrm{E}-02$ & 1,157 & $1.75 \mathrm{E}-02$ & 5,323 & $1.72 \mathrm{E}-02$ & $1.20 \mathrm{E}-09$ \\
\hline LB45-24.5 & 0 & 23 & $1.1 \mathrm{E}-05$ & 9.03 & 12 & 0.502 & 0.010 & 966 & $2.52 \mathrm{E}-02$ & 967 & $2.98 \mathrm{E}-02$ & 1,466 & 2.99E-02 & 5,958 & $2.57 \mathrm{E}-02$ & $1.86 \mathrm{E}-09$ \\
\hline LB45-24.7 & 0 & 23 & $9.9 \mathrm{E}-06$ & 16.97 & 12 & 0.501 & 0.010 & 1,262 & 3.13E-02 & 1,240 & 3.63E-02 & 1,864 & 3.62E-02 & 7,681 & $3.18 \mathrm{E}-02$ & 1.95E-09 \\
\hline LB45-24.9 & 0 & 23 & $6.4 \mathrm{E}-06$ & 28.88 & 12 & 0.501 & 0.010 & 1,181 & $1.89 \mathrm{E}-02$ & 1,192 & $2.25 \mathrm{E}-02$ & 1,815 & $2.27 \mathrm{E}-02$ & 7,176 & $1.91 \mathrm{E}-02$ & $1.54 \mathrm{E}-09$ \\
\hline LB45-24.10 & 0 & 23 & $9.7 \mathrm{E}-06$ & 33.88 & 12 & 0.499 & 0.010 & 1,318 & $3.20 \mathrm{E}-02$ & 1,271 & 3.64E-02 & 1,954 & $3.72 \mathrm{E}-02$ & 8,363 & $3.40 \mathrm{E}-02$ & 2.07E-09 \\
\hline LB45-24.11 & 0 & 23 & $1.0 \mathrm{E}-05$ & 37.99 & 12 & 0.496 & 0.010 & 1,306 & 3.38E-02 & 1,236 & 3.77E-02 & 1,902 & 3.85E-02 & 8,373 & 3.63E-02 & $1.89 \mathrm{E}-09$ \\
\hline LB45-24.12 & 0 & 23 & $1.0 \mathrm{E}-05$ & 40.86 & 12 & 0.495 & 0.010 & 1,396 & 3.55E-02 & 1,309 & 3.93E-02 & 1,995 & $3.98 \mathrm{E}-02$ & 9,031 & $3.86 \mathrm{E}-02$ & $1.69 \mathrm{E}-09$ \\
\hline LB45-24.13 & 0 & 23 & 9.3E-06 & 41.90 & 12 & 0.494 & 0.010 & 1,411 & 3.34E-02 & 1,348 & $3.76 \mathrm{E}-02$ & 2,048 & $3.80 \mathrm{E}-02$ & 9,015 & $3.58 \mathrm{E}-02$ & $1.83 \mathrm{E}-09$ \\
\hline \multicolumn{17}{|l|}{ Exp. \#25 } \\
\hline LB45-25A & 0 & 70 & - & - & 7 & - & - & $<50$ & - & $<50$ & - & $<100$ & - & $<500$ & - & - \\
\hline LB45-25.1 & 0 & 70 & - & - & 7 & - & - & $<50$ & - & $<50$ & - & $<100$ & - & $<500$ & - & - \\
\hline LB45-25.2 & 0 & 70 & 5.6E-05 & 2.02 & 7 & 1.002 & 0.036 & 1,602 & $6.20 \mathrm{E}-02$ & ND & - & 2,673 & 8.17E-02 & 1,243 & 5.09E-03 & 7.86E-09 \\
\hline LB45-25.4 & 0 & 70 & $5.7 \mathrm{E}-05$ & 4.16 & 7 & 0.998 & 0.020 & 1,850 & $1.34 \mathrm{E}-01$ & ND & - & 2,698 & $1.53 \mathrm{E}-01$ & 729 & $2.92 \mathrm{E}-03$ & 7.86E-09 \\
\hline LB45-25.6 & 0 & 70 & 5.5E-05 & 6.02 & 7 & 0.994 & 0.020 & 1,400 & $9.71 \mathrm{E}-02$ & ND & - & 2,016 & $1.10 \mathrm{E}-01$ & ND & - & 4.95E-09 \\
\hline LB45-25.8 & 0 & 70 & $5.2 \mathrm{E}-05$ & 8.03 & 7 & 0.990 & 0.020 & 1,249 & 8.23E-02 & 52 & $1.44 \mathrm{E}-04$ & 1,806 & 9.31E-02 & ND & - & 4.31E-09 \\
\hline LB45-25.9 & 0 & 70 & $6.1 \mathrm{E}-05$ & 8.91 & 7 & 0.988 & 0.020 & 1,202 & $9.25 \mathrm{E}-02$ & ND & - & 1,752 & $1.05 \mathrm{E}-01$ & ND & - & 5.18E-09 \\
\hline
\end{tabular}


Table A2. SPFT Results for LAWB45 Glasses.

\begin{tabular}{|c|c|c|c|c|c|c|c|c|c|c|c|c|c|c|c|c|}
\hline Sample ID & $\begin{array}{c}\text { Influent } \\
\text { [Si] } \\
\end{array}$ & $\mathrm{T}\left({ }^{\circ} \mathrm{C}\right)$ & $\begin{array}{c}\text { Flow } \\
\text { Rate } \\
\left(\mathrm{m}^{3} / \mathrm{d}\right)\end{array}$ & $\begin{array}{c}\text { Time, } \\
\text { days }\end{array}$ & $\begin{array}{c}\mathrm{pH} \\
\left(23^{\circ} \mathrm{C}\right) \\
\end{array}$ & $\begin{array}{c}\text { Glass } \\
\text { Mass } \\
\text { (g) }\end{array}$ & $\mathrm{SA}\left(\mathrm{m}^{2}\right)$ & {$[\mathrm{B}]$} & B Rate & {$[\mathrm{Al}]$} & Al Rate & {$[\mathrm{Na}]$} & Na Rate & {$[\mathrm{Si}]$} & Si Rate & $\begin{array}{l}\text { IEX } \\
\text { Rate } \\
\end{array}$ \\
\hline LB45-25.10 & 0 & 70 & $5.4 \mathrm{E}-05$ & 9.24 & 7 & 0.986 & 0.020 & 1,120 & 7.61E-02 & 51 & 7.74E-05 & 1,665 & 8.85E-02 & ND & - & 4.95E-09 \\
\hline LB45-25.11 & 0 & 70 & 5.9E-05 & 9.88 & 7 & 0.985 & 0.020 & 1,157 & 8.67E-02 & 52 & 2.02E-04 & 1,850 & $1.09 \mathrm{E}-01$ & ND & - & 8.90E-09 \\
\hline \multicolumn{17}{|l|}{ Exp. \#26 } \\
\hline LB45-26A & 0 & 70 & - & - & 8 & - & - & $<50$ & - & $<50$ & - & $<100$ & - & $<500$ & - & - \\
\hline LB45-26.1 & 0 & 70 & - & - & 8 & - & - & $<50$ & - & $<50$ & - & $<100$ & - & $<500$ & - & - \\
\hline LB45-26.2 & 0 & 70 & 5.6E-05 & 2.02 & 8 & 1.004 & 0.036 & 618 & 2.29E-02 & 128 & 3.71E-03 & 1,253 & 3.69E-02 & 1,789 & 8.89E-03 & 5.61E-09 \\
\hline LB45-26.4 & 0 & 70 & 5.7E-05 & 4.16 & 8 & 1.003 & 0.020 & 423 & 2.76E-02 & 210 & $1.40 \mathrm{E}-02$ & 684 & 3.43E-02 & 1,433 & $1.18 \mathrm{E}-02$ & 2.69E-09 \\
\hline LB45-26.6 & 0 & 70 & $5.4 \mathrm{E}-05$ & 6.02 & 8 & 1.002 & 0.020 & 366 & $2.24 \mathrm{E}-02$ & 185 & 1.13E-02 & 535 & $2.45 \mathrm{E}-02$ & 1,160 & 8.02E-03 & 8.37E-10 \\
\hline LB45-26.8 & 0 & 70 & 5.5E-05 & 8.03 & 8 & 1.001 & 0.020 & 376 & 2.32E-02 & 173 & $1.03 \mathrm{E}-02$ & 628 & $2.98 \mathrm{E}-02$ & 1,180 & $8.28 \mathrm{E}-03$ & 2.63E-09 \\
\hline LB45-26.9 & 0 & 70 & 6.1E-05 & 8.91 & 8 & 1.000 & 0.020 & 351 & 2.39E-02 & 168 & 1.10E-02 & 503 & $2.54 \mathrm{E}-02$ & 1,097 & 8.11E-03 & $6.01 \mathrm{E}-10$ \\
\hline LB45-26.10 & 0 & 70 & 4.2E-05 & 9.24 & 8 & 1.000 & 0.020 & 342 & $1.61 \mathrm{E}-02$ & 167 & 7.64E-03 & 510 & 1.79E-02 & 1,077 & $5.44 \mathrm{E}-03$ & 7.30E-10 \\
\hline LB45-26.11 & 0 & 70 & 5.9E-05 & 9.88 & 8 & 1.000 & 0.020 & 332 & 2.18E-02 & 159 & $9.95 \mathrm{E}-03$ & 463 & 2.22E-02 & 1,051 & 7.29E-03 & $1.79 \mathrm{E}-10$ \\
\hline \multicolumn{17}{|l|}{ Exp. \#27 } \\
\hline LB45-27A & 0 & 70 & - & - & 9 & - & - & $<50$ & - & $<50$ & - & $<100$ & - & $<500$ & - & - \\
\hline LB45-27.1 & 0 & 70 & - & - & 9 & - & - & $<50$ & - & $<50$ & - & $<100$ & - & $<500$ & - & - \\
\hline LB45-27.2 & 0 & 70 & 5.7E-05 & 2.02 & 9 & 1.006 & 0.037 & 750 & 2.86E-02 & 493 & 2.13E-02 & 1,377 & 4.14E-02 & 3,876 & 2.36E-02 & 5.13E-09 \\
\hline LB45-27.4 & 0 & 70 & 5.7E-05 & 4.16 & 9 & 1.004 & 0.020 & 788 & $5.41 \mathrm{E}-02$ & 706 & 5.69E-02 & 1,159 & $6.17 \mathrm{E}-02$ & 4,488 & 5.01E-02 & 3.03E-09 \\
\hline LB45-27.6 & 0 & 70 & 5.5E-05 & 6.02 & 9 & 1.002 & 0.020 & 854 & 5.75E-02 & 825 & $6.55 \mathrm{E}-02$ & 1,280 & $6.71 \mathrm{E}-02$ & 4,729 & $5.18 \mathrm{E}-02$ & 3.83E-09 \\
\hline LB45-27.8 & 0 & 70 & 5.5E-05 & 8.03 & 9 & 1.000 & 0.020 & 920 & 6.19E-02 & 840 & 6.64E-02 & 1,342 & 7.02E-02 & 5,023 & 5.51E-02 & 3.32E-09 \\
\hline LB45-27.9 & 0 & 70 & $6.1 \mathrm{E}-05$ & 8.91 & 9 & 0.998 & 0.020 & 914 & $6.86 \mathrm{E}-02$ & 825 & 7.27E-02 & 1,317 & 7.67E-02 & 4,925 & 6.01E-02 & 3.26E-09 \\
\hline LB45-27.10 & 0 & 70 & 4.3E-05 & 9.24 & 9 & 0.997 & 0.020 & 866 & 4.59E-02 & 807 & 5.03E-02 & 1,308 & $5.40 \mathrm{E}-02$ & 4,817 & 4.16E-02 & 3.23E-09 \\
\hline LB45-27.11 & 0 & 70 & 5.7E-05 & 9.88 & 9 & 0.996 & 0.020 & 894 & 6.35E-02 & 802 & 6.69E-02 & 1,296 & 7.15E-02 & 4,877 & 5.64E-02 & $3.21 \mathrm{E}-09$ \\
\hline \multicolumn{17}{|l|}{ Exp. \#28 } \\
\hline LB45-28A & 0 & 70 & - & - & 10 & - & - & $<50$ & - & $<50$ & - & $<100$ & - & $<500$ & - & - \\
\hline LB45-28.1 & 0 & 70 & - & - & 10 & - & - & $<50$ & - & $<50$ & - & $<100$ & - & $<500$ & - & - \\
\hline LB45-28.2 & 0 & 70 & 5.7E-05 & 2.02 & 10 & 0.508 & 0.023 & 698 & 4.16E-02 & 634 & 4.43E-02 & 1,143 & $5.32 \mathrm{E}-02$ & 3,770 & $3.60 \mathrm{E}-02$ & 4.63E-09 \\
\hline LB45-28.4 & 0 & 70 & 5.8E-05 & 4.16 & 10 & 0.506 & 0.010 & 1,148 & $1.64 \mathrm{E}-01$ & 999 & 1.67E-01 & 1,688 & $1.88 \mathrm{E}-01$ & 5,979 & $1.40 \mathrm{E}-01$ & $9.74 \mathrm{E}-09$ \\
\hline LB45-28.6 & 0 & 70 & 5.5E-05 & 6.02 & 10 & 0.503 & 0.010 & 1,056 & $1.44 \mathrm{E}-01$ & 931 & $1.49 \mathrm{E}-01$ & 1,504 & $1.59 \mathrm{E}-01$ & 5,550 & 1.23E-01 & $6.25 \mathrm{E}-09$ \\
\hline LB45-28.8 & 0 & 70 & 5.4E-05 & 8.03 & 10 & 0.500 & 0.010 & 960 & $1.29 \mathrm{E}-01$ & 900 & $1.42 \mathrm{E}-01$ & 1,375 & $1.44 \mathrm{E}-01$ & 5,162 & 1.13E-01 & 5.85E-09 \\
\hline LB45-28.9 & 0 & 70 & $6.1 \mathrm{E}-05$ & 8.91 & 10 & 0.498 & 0.010 & 959 & $1.45 \mathrm{E}-01$ & 910 & 1.62E-01 & 1,415 & 1.67E-01 & 5,127 & $1.26 \mathrm{E}-01$ & 8.67E-09 \\
\hline LB45-28.10 & 0 & 70 & 4.8E-05 & 9.24 & 10 & 0.497 & 0.010 & 956 & $1.14 \mathrm{E}-01$ & 875 & $1.22 \mathrm{E}-01$ & 1,394 & $1.29 \mathrm{E}-01$ & 5,078 & $9.84 \mathrm{E}-02$ & $6.14 \mathrm{E}-09$ \\
\hline LB45-28.11 & 0 & 70 & 5.6E-05 & 9.88 & 10 & 0.496 & 0.010 & 968 & $1.35 \mathrm{E}-01$ & 826 & 1.35E-01 & 1,408 & $1.53 \mathrm{E}-01$ & 5,229 & 1.19E-01 & $7.14 \mathrm{E}-09$ \\
\hline \multicolumn{17}{|l|}{ Exp. \#29 } \\
\hline LB45-29A & 0 & 70 & - & - & 11 & - & - & $<50$ & - & $<50$ & - & $<100$ & - & $<500$ & - & - \\
\hline LB45-29.1 & 0 & 70 & - & - & 11 & - & - & $<50$ & - & $<50$ & - & $<100$ & - & $<500$ & - & - \\
\hline LB45-29.2 & 0 & 70 & 7.2E-05 & 2.02 & 11 & 0.502 & 0.023 & 1,256 & $9.86 \mathrm{E}-02$ & 1,116 & $1.03 \mathrm{E}-01$ & 2,037 & $1.26 \mathrm{E}-01$ & 6,624 & 8.58E-02 & $1.09 \mathrm{E}-08$ \\
\hline LB45-29.4 & 0 & 70 & $5.8 \mathrm{E}-05$ & 4.16 & 11 & 0.495 & 0.010 & 3,319 & 4.95E-01 & 2,298 & 4.02E-01 & 5,045 & 5.95E-01 & 15,550 & 3.90E-01 & $4.00 \mathrm{E}-08$ \\
\hline LB45-29.6 & 0 & 70 & $5.4 \mathrm{E}-05$ & 6.02 & 11 & 0.486 & 0.010 & 3,348 & 4.77E-01 & 2,073 & 3.45E-01 & 5,140 & 5.79E-01 & 15,132 & 3.62E-01 & 4.09E-08 \\
\hline LB45-29.8 & 0 & 70 & 5.1E-05 & 8.03 & 11 & 0.477 & 0.010 & 3,997 & 5.49E-01 & 2,322 & 3.73E-01 & 6,047 & 6.57E-01 & 18,037 & 4.18E-01 & 4.33E-08 \\
\hline LB45-29.9 & 0 & 70 & 5.7E-05 & 8.91 & 11 & 0.469 & 0.009 & 3,735 & 5.83E-01 & 2,204 & 4.03E-01 & 5,674 & 7.01E-01 & 16,971 & 4.46E-01 & $4.71 \mathrm{E}-08$ \\
\hline
\end{tabular}


Table A2. SPFT Results for LAWB45 Glasses.

\begin{tabular}{|c|c|c|c|c|c|c|c|c|c|c|c|c|c|c|c|c|}
\hline Sample ID & $\begin{array}{c}\text { Influent } \\
{[\mathrm{Si}]}\end{array}$ & $\mathrm{T}\left({ }^{\circ} \mathrm{C}\right)$ & $\begin{array}{c}\text { Flow } \\
\text { Rate } \\
\left(\mathrm{m}^{3} / \mathrm{d}\right)\end{array}$ & $\begin{array}{c}\text { Time, } \\
\text { days }\end{array}$ & $\begin{array}{c}\mathrm{pH} \\
\left(23^{\circ} \mathrm{C}\right) \\
\end{array}$ & $\begin{array}{c}\text { Glass } \\
\text { Mass } \\
\text { (g) }\end{array}$ & $\mathrm{SA}\left(\mathrm{m}^{2}\right)$ & [B] & B Rate & {$[\mathrm{Al}]$} & Al Rate & {$[\mathrm{Na}]$} & Na Rate & {$[\mathrm{Si}]$} & Si Rate & $\begin{array}{l}\text { IEX } \\
\text { Rate } \\
\end{array}$ \\
\hline LB45-29.10 & 0 & 70 & $5.4 \mathrm{E}-05$ & 9.24 & 11 & 0.465 & 0.009 & 3,706 & $5.54 \mathrm{E}-01$ & 2,172 & $3.80 \mathrm{E}-01$ & 5,587 & $6.61 \mathrm{E}-01$ & 16,733 & $4.21 \mathrm{E}-01$ & $4.26 \mathrm{E}-08$ \\
\hline LB45-29.11 & 0 & 70 & 5.9E-05 & 9.88 & 11 & 0.461 & 0.009 & 3,677 & $6.00 \mathrm{E}-01$ & 2,117 & 4.04E-01 & 5,579 & 7.21E-01 & 16,508 & 4.54E-01 & 4.81E-08 \\
\hline \multicolumn{17}{|l|}{ Exp. \#30 } \\
\hline LB45-30A & 0 & 70 & - & - & 12 & - & - & $<50$ & - & 53 & - & $<100$ & - & $<500$ & - & - \\
\hline LB45-30.1 & 0 & 70 & - & - & 12 & - & - & $<50$ & - & 58 & - & $<100$ & - & 510 & - & - \\
\hline LB45-30.2 & 0 & 70 & 5.8E-05 & 2.02 & 12 & 0.507 & 0.023 & 1,786 & 1.13E-01 & 1,866 & 1.39E-01 & 2,983 & $1.49 \mathrm{E}-01$ & 10,156 & $1.08 \mathrm{E}-01$ & $1.44 \mathrm{E}-08$ \\
\hline LB45-30.4 & 0 & 70 & 5.9E-05 & 4.16 & 12 & 0.500 & 0.010 & 2,991 & 4.48E-01 & 2,911 & 5.13E-01 & 4,932 & 5.84E-01 & 16,041 & 4.05E-01 & $5.46 \mathrm{E}-08$ \\
\hline LB45-30.6 & 0 & 70 & $5.4 \mathrm{E}-05$ & 6.02 & 12 & 0.492 & 0.010 & 3,191 & 4.45E-01 & 3,240 & 5.33E-01 & 5,161 & 5.69E-01 & 16,891 & 3.97E-01 & 4.98E-08 \\
\hline LB45-30.8 & 0 & 70 & 4.7E-05 & 8.03 & 12 & 0.483 & 0.010 & 4,195 & $5.22 \mathrm{E}-01$ & 3,976 & 5.84E-01 & 6,699 & $6.61 \mathrm{E}-01$ & 21,360 & 4.50E-01 & 5.53E-08 \\
\hline LB45-30.9 & 0 & 70 & 6.2E-05 & 8.91 & 12 & 0.476 & 0.010 & 3,310 & $5.51 \mathrm{E}-01$ & 3,207 & 6.29E-01 & 5,416 & 7.14E-01 & 17,338 & 4.87E-01 & $6.51 \mathrm{E}-08$ \\
\hline LB45-30.10 & 0 & 70 & $4.9 \mathrm{E}-05$ & 9.24 & 12 & 0.472 & 0.009 & 3,265 & 4.30E-01 & 3,154 & 4.89E-01 & 5,329 & 5.56E-01 & 17,194 & 3.82E-01 & $5.02 \mathrm{E}-08$ \\
\hline LB45-30.11 & 0 & 70 & $6.0 \mathrm{E}-05$ & 9.88 & 12 & 0.468 & 0.009 & 3,423 & 5.64E-01 & 3,311 & $6.43 \mathrm{E}-01$ & 5,289 & $6.89 \mathrm{E}-01$ & 17,925 & 4.99E-01 & $5.01 \mathrm{E}-08$ \\
\hline \multicolumn{17}{|l|}{ Exp. \#31 } \\
\hline LB45-31.A & $8.82 \mathrm{E}+02$ & 40 & - & - & 9 & - & - & $<25$ & - & $<10$ & - & $<50$ & - & $<1000$ & - & - \\
\hline LB45-31.2 & $8.82 \mathrm{E}+02$ & 40 & $1.8 \mathrm{E}-05$ & 3.02 & 9 & 0.508 & 0.013 & 401 & $1.37 \mathrm{E}-02$ & 313 & $1.31 \mathrm{E}-02$ & 641 & $1.72 \mathrm{E}-02$ & 2,114 & 6.98E-03 & 1.37E-09 \\
\hline LB45-31.4 & $8.82 \mathrm{E}+02$ & 40 & $1.8 \mathrm{E}-05$ & 5.48 & 9 & 0.507 & 0.010 & 413 & $1.75 \mathrm{E}-02$ & 353 & $1.83 \mathrm{E}-02$ & 606 & $1.99 \mathrm{E}-02$ & 2,302 & $1.01 \mathrm{E}-02$ & $9.62 \mathrm{E}-10$ \\
\hline LB45-31.7 & $8.82 \mathrm{E}+02$ & 40 & $1.7 \mathrm{E}-05$ & 8.14 & 9 & 0.507 & 0.010 & 407 & $1.71 \mathrm{E}-02$ & 356 & $1.83 \mathrm{E}-02$ & 592 & $1.93 \mathrm{E}-02$ & 2,292 & $9.92 \mathrm{E}-03$ & $8.76 \mathrm{E}-10$ \\
\hline LB45-31.13 & $8.82 \mathrm{E}+02$ & 40 & 1.7E-05 & 16.27 & 9 & 0.507 & 0.010 & 373 & $1.54 \mathrm{E}-02$ & 333 & $1.68 \mathrm{E}-02$ & 549 & $1.75 \mathrm{E}-02$ & 2,134 & 8.58E-03 & 8.56E-10 \\
\hline LB45-31.16 & $8.82 \mathrm{E}+02$ & 40 & $1.4 \mathrm{E}-05$ & 21.94 & 9 & 0.507 & 0.010 & 370 & $1.26 \mathrm{E}-02$ & 326 & $1.37 \mathrm{E}-02$ & 546 & $1.44 \mathrm{E}-02$ & 2,105 & 6.93E-03 & $7.21 \mathrm{E}-10$ \\
\hline LB45-31.20 & $8.82 \mathrm{E}+02$ & 40 & 1.7E-05 & 29.05 & 9 & 0.506 & 0.010 & 359 & $1.42 \mathrm{E}-02$ & 315 & $1.53 \mathrm{E}-02$ & 525 & $1.61 \mathrm{E}-02$ & 2,040 & 7.59E-03 & $7.46 \mathrm{E}-10$ \\
\hline LB45-31.21 & $8.82 \mathrm{E}+02$ & 40 & 1.3E-05 & 30.17 & 9 & 0.506 & 0.010 & 359 & $1.12 \mathrm{E}-02$ & 317 & $1.21 \mathrm{E}-02$ & 550 & $1.33 \mathrm{E}-02$ & 2,025 & $5.86 \mathrm{E}-03$ & $8.41 \mathrm{E}-10$ \\
\hline LB45-31.22 & $8.82 \mathrm{E}+02$ & 40 & 1.7E-05 & 31.08 & 9 & 0.506 & 0.010 & 403 & $1.66 \mathrm{E}-02$ & 342 & 1.73E-02 & 573 & $1.83 \mathrm{E}-02$ & 2,227 & $9.25 \mathrm{E}-03$ & $6.73 \mathrm{E}-10$ \\
\hline LB45-31.23 & $8.82 \mathrm{E}+02$ & 40 & $1.8 \mathrm{E}-05$ & 34.07 & 9 & 0.505 & 0.010 & 350 & $1.51 \mathrm{E}-02$ & 305 & $1.62 \mathrm{E}-02$ & 527 & $1.76 \mathrm{E}-02$ & 2,010 & 8.05E-03 & $1.01 \mathrm{E}-09$ \\
\hline \multicolumn{17}{|l|}{ Exp. \#32 } \\
\hline LB45-32.A & $1.61 \mathrm{E}+04$ & 40 & - & - & 9 & - & - & $<25$ & - & 25 & - & $<50$ & - & 19,567 & - & - \\
\hline LB45-32.2 & $1.61 \mathrm{E}+04$ & 40 & $1.9 \mathrm{E}-05$ & 3.02 & 9 & 0.504 & 0.013 & 321 & 1.19E-02 & 183 & 7.46E-03 & 525 & $1.52 \mathrm{E}-02$ & 20,525 & 6.58E-03 & $1.31 \mathrm{E}-09$ \\
\hline LB45-32.4 & $1.61 \mathrm{E}+04$ & 40 & $1.9 \mathrm{E}-05$ & 5.48 & 9 & 0.504 & 0.010 & 321 & $1.44 \mathrm{E}-02$ & 208 & $1.04 \mathrm{E}-02$ & 501 & $1.74 \mathrm{E}-02$ & 20,857 & $1.07 \mathrm{E}-02$ & $1.21 \mathrm{E}-09$ \\
\hline LB45-32.7 & $1.61 \mathrm{E}+04$ & 40 & $1.9 \mathrm{E}-05$ & 8.14 & 9 & 0.503 & 0.010 & 306 & $1.38 \mathrm{E}-02$ & 218 & $1.12 \mathrm{E}-02$ & 457 & $1.59 \mathrm{E}-02$ & 21,110 & $1.30 \mathrm{E}-02$ & 8.34E-10 \\
\hline LB45-32.13 & $1.61 \mathrm{E}+04$ & 40 & 1.9E-05 & 16.27 & 9 & 0.503 & 0.010 & 286 & $1.30 \mathrm{E}-02$ & 227 & 1.19E-02 & 435 & $1.53 \mathrm{E}-02$ & 21,264 & $1.45 \mathrm{E}-02$ & 8.93E-10 \\
\hline LB45-32.16 & $1.61 \mathrm{E}+04$ & 40 & $1.4 \mathrm{E}-05$ & 21.94 & 9 & 0.503 & 0.010 & 275 & $9.34 \mathrm{E}-03$ & 219 & 8.55E-03 & 432 & $1.13 \mathrm{E}-02$ & 21,178 & $1.03 \mathrm{E}-02$ & 7.93E-10 \\
\hline LB45-32.19 & $1.61 \mathrm{E}+04$ & 40 & 2.9E-05 & 29.05 & 9 & 0.502 & 0.010 & 274 & $1.90 \mathrm{E}-02$ & 215 & $1.70 \mathrm{E}-02$ & 436 & 2.33E-02 & 21,829 & 2.94E-02 & $1.75 \mathrm{E}-09$ \\
\hline LB45-32.21 & $1.61 \mathrm{E}+04$ & 40 & $1.9 \mathrm{E}-05$ & 30.17 & 9 & 0.502 & 0.010 & 268 & $1.20 \mathrm{E}-02$ & 210 & 1.07E-02 & 398 & $1.36 \mathrm{E}-02$ & 21,463 & $1.60 \mathrm{E}-02$ & $6.57 \mathrm{E}-10$ \\
\hline LB45-32.22 & $1.61 \mathrm{E}+04$ & 40 & $1.9 \mathrm{E}-05$ & 31.08 & 9 & 0.502 & 0.010 & 265 & 1.16E-02 & 209 & 1.05E-02 & 399 & $1.34 \mathrm{E}-02$ & 20,928 & $1.13 \mathrm{E}-02$ & $7.24 \mathrm{E}-10$ \\
\hline LB45-32.23 & $1.61 \mathrm{E}+04$ & 40 & 1.9E-05 & 34.07 & 9 & 0.501 & 0.010 & 263 & $1.18 \mathrm{E}-02$ & 204 & $1.04 \mathrm{E}-02$ & 397 & $1.37 \mathrm{E}-02$ & 21,621 & $1.74 \mathrm{E}-02$ & $7.59 \mathrm{E}-10$ \\
\hline \multicolumn{17}{|l|}{ Exp. \#33 } \\
\hline LB45-33.A & $3.21 \mathrm{E}+04$ & 40 & - & - & 9 & - & - & $<25$ & - & $<10$ & - & $<50$ & - & 37,385 & - & - \\
\hline LB45-33.2 & $3.21 \mathrm{E}+04$ & 40 & $1.9 \mathrm{E}-05$ & 3.02 & 9 & 1.007 & 0.020 & 486 & $1.15 \mathrm{E}-02$ & 228 & $6.42 \mathrm{E}-03$ & 894 & $1.67 \mathrm{E}-02$ & 40,040 & $1.13 \mathrm{E}-02$ & 2.09E-09 \\
\hline LB45-33.4 & $3.21 \mathrm{E}+04$ & 40 & $1.8 \mathrm{E}-05$ & 5.48 & 9 & 1.006 & 0.020 & 484 & $1.10 \mathrm{E}-02$ & 225 & $6.07 \mathrm{E}-03$ & 780 & $1.38 \mathrm{E}-02$ & 38,995 & 6.59E-03 & $1.15 \mathrm{E}-09$ \\
\hline LB45-33.7 & $3.21 \mathrm{E}+04$ & 40 & $1.9 \mathrm{E}-05$ & 8.14 & 9 & 1.006 & 0.020 & 444 & $1.02 \mathrm{E}-02$ & 219 & 6.01E-03 & 684 & $1.22 \mathrm{E}-02$ & 38,531 & 4.77E-03 & 8.23E-10 \\
\hline LB45-33.13 & $3.21 \mathrm{E}+04$ & 40 & $1.9 \mathrm{E}-05$ & 16.27 & 9 & 1.006 & 0.020 & 405 & $9.36 \mathrm{E}-03$ & 205 & $5.68 \mathrm{E}-03$ & 636 & $1.15 \mathrm{E}-02$ & 38,528 & 4.82E-03 & 8.36E-10 \\
\hline
\end{tabular}


Table A2. SPFT Results for LAWB45 Glasses.

\begin{tabular}{|c|c|c|c|c|c|c|c|c|c|c|c|c|c|c|c|c|}
\hline Sample ID & $\begin{array}{c}\text { Influent } \\
\text { [Si] }\end{array}$ & $\mathrm{T}\left({ }^{\circ} \mathrm{C}\right)$ & $\begin{array}{c}\text { Flow } \\
\text { Rate } \\
\left(\mathrm{m}^{3} / \mathrm{d}\right)\end{array}$ & $\begin{array}{l}\text { Time, } \\
\text { days }\end{array}$ & $\begin{array}{c}\mathrm{pH} \\
\left(23^{\circ} \mathrm{C}\right) \\
\end{array}$ & $\begin{array}{c}\text { Glass } \\
\text { Mass } \\
(\mathrm{g})\end{array}$ & $\mathrm{SA}\left(\mathrm{m}^{2}\right)$ & {$[\mathrm{B}]$} & B Rate & {$[\mathrm{Al}]$} & Al Rate & {$[\mathrm{Na}]$} & Na Rate & {$[\mathrm{Si}]$} & Si Rate & $\begin{array}{l}\text { IEX } \\
\text { Rate }\end{array}$ \\
\hline LB45-33.16 & $3.21 E+04$ & 40 & $1.4 \mathrm{E}-05$ & 21.94 & 9 & 1.005 & 0.020 & 412 & 7.14E-03 & 218 & $4.54 \mathrm{E}-03$ & 662 & 8.97E-03 & 39,231 & 5.83E-03 & 7.33E-10 \\
\hline LB45-33.20 & $3.21 E+04$ & 40 & $1.9 \mathrm{E}-05$ & 29.05 & 9 & 1.005 & 0.020 & 397 & 9.37E-03 & 203 & 5.73E-03 & 634 & 1.17E-02 & 39,829 & 1.05E-02 & $9.24 \mathrm{E}-10$ \\
\hline LB45-33.21 & $3.21 E+04$ & 40 & $1.8 \mathrm{E}-05$ & 30.17 & 9 & 1.004 & 0.020 & 383 & 8.14E-03 & 186 & 4.73E-03 & 604 & $1.00 \mathrm{E}-02$ & 40,119 & $1.06 \mathrm{E}-02$ & 7.43E-10 \\
\hline LB45-33.22 & $3.21 \mathrm{E}+04$ & 40 & $1.8 \mathrm{E}-05$ & 31.08 & 9 & 1.004 & 0.020 & 377 & 8.44E-03 & 181 & 4.85E-03 & 579 & $1.01 \mathrm{E}-02$ & 39,319 & 7.96E-03 & 6.61E-10 \\
\hline $\begin{array}{c}\text { LB45-33.23 } \\
\text { Exp. \#34 }\end{array}$ & \multicolumn{15}{|c|}{ Exp. \#34 } & $5.45 \mathrm{E}-10$ \\
\hline LB45-34.A & $4.78 \mathrm{E}+04$ & 40 & - & - & 9 & - & - & $<25$ & - & $<10$ & - & $<50$ & - & 55,203 & - & - \\
\hline LB45-34.2 & $4.78 \mathrm{E}+04$ & 40 & $2.0 \mathrm{E}-05$ & 3.02 & 9 & 1.006 & 0.020 & 357 & $8.46 \mathrm{E}-03$ & 125 & 3.45E-03 & 679 & $1.27 \mathrm{E}-02$ & 56,183 & $4.27 \mathrm{E}-03$ & $1.70 \mathrm{E}-09$ \\
\hline LB45-34.4 & $4.78 \mathrm{E}+04$ & 40 & $1.9 \mathrm{E}-05$ & 5.48 & 9 & 1.006 & 0.020 & 318 & 7.09E-03 & 116 & 3.01E-03 & 546 & $9.53 \mathrm{E}-03$ & 55,813 & 2.53E-03 & $9.73 \mathrm{E}-10$ \\
\hline LB45-34.7 & $4.78 E+04$ & 40 & 1.9E-05 & 8.14 & 9 & 1.005 & 0.020 & 273 & 6.05E-03 & 108 & 2.82E-03 & 446 & 7.70E-03 & 56,397 & $5.00 \mathrm{E}-03$ & 6.57E-10 \\
\hline LB45-34.13 & $4.78 E+04$ & 40 & 1.9E-05 & 16.27 & 9 & 1.005 & 0.020 & 235 & $5.20 \mathrm{E}-03$ & 105 & $2.78 \mathrm{E}-03$ & 381 & 6.51E-03 & 58,283 & $1.31 \mathrm{E}-02$ & 5.23E-10 \\
\hline LB45-34.16 & $4.78 \mathrm{E}+04$ & 40 & $1.5 \mathrm{E}-05$ & 21.94 & 9 & 1.005 & 0.020 & 219 & $3.68 \mathrm{E}-03$ & 105 & $2.12 \mathrm{E}-03$ & 367 & $4.77 \mathrm{E}-03$ & 58,188 & $9.68 \mathrm{E}-03$ & 4.34E-10 \\
\hline LB45-34.20 & $4.78 \mathrm{E}+04$ & 40 & $1.9 \mathrm{E}-05$ & 29.05 & 9 & 1.005 & 0.020 & 193 & $4.22 \mathrm{E}-03$ & 96 & $2.54 \mathrm{E}-03$ & 323 & $5.45 \mathrm{E}-03$ & 57,639 & $1.05 \mathrm{E}-02$ & $4.95 \mathrm{E}-10$ \\
\hline LB45-34.21 & $4.78 \mathrm{E}+04$ & 40 & $1.9 \mathrm{E}-05$ & 30.17 & 9 & 1.004 & 0.020 & 189 & 4.07E-03 & 91 & 2.39E-03 & 309 & 5.13E-03 & 57,617 & $1.03 \mathrm{E}-02$ & 4.23E-10 \\
\hline LB45-34.22 & $4.78 \mathrm{E}+04$ & 40 & $1.9 \mathrm{E}-05$ & 31.08 & 9 & 1.004 & 0.020 & 182 & 3.79E-03 & 93 & 2.37E-03 & 308 & 4.95E-03 & 57,349 & 8.87E-03 & $4.62 \mathrm{E}-10$ \\
\hline LB45-34.23 & $4.78 \mathrm{E}+04$ & 40 & 1.9E-05 & 34.07 & 9 & 1.004 & 0.020 & 170 & 3.59E-03 & 87 & 2.26E-03 & 293 & 4.79E-03 & 58,702 & $1.49 \mathrm{E}-02$ & $4.78 \mathrm{E}-10$ \\
\hline $\begin{array}{c}\text { Exp. \#35 } \\
\text { LB45-35.A }\end{array}$ & $6.89 \mathrm{E}+04$ & 40 & - & - & 9 & - & - & $<25$ & - & $<10$ & - & $<50$ & - & 73,953 & - & - \\
\hline LB45-35.2 & $6.89 \mathrm{E}+04$ & 40 & $1.9 \mathrm{E}-05$ & 3.02 & 9 & 2.004 & 0.032 & 473 & 7.09E-03 & 114 & $1.94 \mathrm{E}-03$ & 979 & 1.17E-02 & 66,656 & - & 1.83E-09 \\
\hline LB45-35.4 & $6.89 \mathrm{E}+04$ & 40 & 1.9E-05 & 5.48 & 9 & 2.003 & 0.040 & 352 & 3.96E-03 & 91 & $1.16 \mathrm{E}-03$ & 651 & 5.77E-03 & 66,216 & - & $7.24 \mathrm{E}-10$ \\
\hline LB45-35.7 & $6.89 E+04$ & 40 & $1.9 \mathrm{E}-05$ & 8.14 & 9 & 2.003 & 0.040 & 270 & $3.00 \mathrm{E}-03$ & 84 & $1.07 \mathrm{E}-03$ & 493 & 4.32E-03 & 66,765 & - & $5.25 \mathrm{E}-10$ \\
\hline LB45-35.13 & $6.89 \mathrm{E}+04$ & 40 & $1.8 \mathrm{E}-05$ & 16.27 & 9 & 2.003 & 0.040 & 189 & $1.93 \mathrm{E}-03$ & 65 & 7.60E-04 & 330 & $2.61 \mathrm{E}-03$ & 69,520 & - & $2.74 \mathrm{E}-10$ \\
\hline LB45-35.16 & $6.89 \mathrm{E}+04$ & 40 & $1.4 \mathrm{E}-05$ & 21.94 & 9 & 2.003 & 0.040 & 158 & $1.23 \mathrm{E}-03$ & 57 & 5.13E-04 & 300 & $1.85 \mathrm{E}-03$ & 68,273 & - & $2.46 \mathrm{E}-10$ \\
\hline LB45-35.20 & $6.89 \mathrm{E}+04$ & 40 & $1.9 \mathrm{E}-05$ & 29.05 & 9 & 2.003 & 0.040 & 139 & $1.42 \mathrm{E}-03$ & 54 & $6.54 \mathrm{E}-04$ & 259 & $2.07 \mathrm{E}-03$ & 70,899 & - & $2.59 \mathrm{E}-10$ \\
\hline LB45-35.21 & $6.89 \mathrm{E}+04$ & 40 & 1.7E-05 & 30.17 & 9 & 2.003 & 0.040 & 178 & $1.73 \mathrm{E}-03$ & 110 & $1.34 \mathrm{E}-03$ & 428 & 3.38E-03 & 70,636 & - & $6.61 \mathrm{E}-10$ \\
\hline LB45-35.22 & $6.89 \mathrm{E}+04$ & 40 & $1.8 \mathrm{E}-05$ & 31.08 & 9 & 2.002 & 0.040 & 123 & $1.17 \mathrm{E}-03$ & 51 & $5.83 \mathrm{E}-04$ & 232 & $1.73 \mathrm{E}-03$ & 69,358 & - & $2.24 \mathrm{E}-10$ \\
\hline LB45-35.23 & $6.89 \mathrm{E}+04$ & 40 & $1.9 \mathrm{E}-05$ & 34.07 & 9 & 2.002 & 0.040 & 116 & $1.12 \mathrm{E}-03$ & 48 & $5.48 \mathrm{E}-04$ & 224 & $1.70 \mathrm{E}-03$ & 71,428 & - & 2.33E-10 \\
\hline \multicolumn{17}{|l|}{ Exp. \#36 } \\
\hline LB45-36.A & $7.64 \mathrm{E}+04$ & 40 & - & - & 9 & - & - & $<25$ & - & $<10$ & - & $<50$ & - & 82,270 & - & - \\
\hline LB45-36.2 & $7.64 \mathrm{E}+04$ & 40 & $1.9 \mathrm{E}-05$ & 3.02 & 9 & 2.002 & 0.032 & 494 & 7.48E-03 & 53 & 8.02E-04 & 950 & $1.14 \mathrm{E}-02$ & 74,004 & - & 1.57E-09 \\
\hline LB45-36.4 & $7.64 \mathrm{E}+04$ & 40 & $1.9 \mathrm{E}-05$ & 5.48 & 9 & 2.001 & 0.040 & 361 & $4.12 \mathrm{E}-03$ & 61 & 7.38E-04 & 649 & $5.84 \mathrm{E}-03$ & 68,044 & - & $6.88 \mathrm{E}-10$ \\
\hline LB45-36.7 & $7.64 \mathrm{E}+04$ & 40 & $1.9 \mathrm{E}-05$ & 8.14 & 9 & 2.001 & 0.040 & 284 & $3.20 \mathrm{E}-03$ & 65 & 7.95E-04 & 491 & 4.33E-03 & 68,998 & - & $4.51 \mathrm{E}-10$ \\
\hline LB45-36.13 & $7.64 \mathrm{E}+04$ & 40 & $1.9 \mathrm{E}-05$ & 16.27 & 9 & 2.001 & 0.040 & 171 & $1.77 \mathrm{E}-03$ & 56 & $6.54 \mathrm{E}-04$ & 314 & $2.54 \mathrm{E}-03$ & 72,008 & - & $3.09 \mathrm{E}-10$ \\
\hline LB45-36.16 & $7.64 \mathrm{E}+04$ & 40 & $1.4 \mathrm{E}-05$ & 21.94 & 9 & 2.001 & 0.040 & 131 & $9.75 \mathrm{E}-04$ & 54 & 4.79E-04 & 261 & $1.55 \mathrm{E}-03$ & 74,845 & - & $2.28 \mathrm{E}-10$ \\
\hline LB45-36.20 & $7.64 \mathrm{E}+04$ & 40 & $1.9 \mathrm{E}-05$ & 29.05 & 9 & 2.001 & 0.040 & 102 & $9.66 \mathrm{E}-04$ & 42 & 4.72E-04 & 206 & $1.56 \mathrm{E}-03$ & 77,243 & - & $2.38 \mathrm{E}-10$ \\
\hline LB45-36.21 & $7.64 \mathrm{E}+04$ & 40 & 1.7E-05 & 30.17 & 9 & 2.001 & 0.040 & 98 & 8.30E-04 & 42 & 4.35E-04 & 200 & $1.35 \mathrm{E}-03$ & 81,183 & - & $2.09 \mathrm{E}-10$ \\
\hline LB45-36.22 & $7.64 \mathrm{E}+04$ & 40 & $1.9 \mathrm{E}-05$ & 31.08 & 9 & 2.001 & 0.040 & 90 & 7.85E-04 & 39 & $4.21 \mathrm{E}-04$ & 189 & $1.34 \mathrm{E}-03$ & 77,979 & - & $2.22 \mathrm{E}-10$ \\
\hline LB45-36.23 & $7.64 \mathrm{E}+04$ & 40 & $1.9 \mathrm{E}-05$ & 34.07 & 9 & 2.000 & 0.040 & 79 & $6.75 \mathrm{E}-04$ & 39 & 4.37E-04 & 179 & $1.29 \mathrm{E}-03$ & 78,933 & - & $2.46 \mathrm{E}-10$ \\
\hline \multicolumn{17}{|l|}{ Exp. \#37 } \\
\hline LB45-43.A & $8.79 \mathrm{E}+02$ & 90 & - & - & 9 & - & - & $<25$ & - & $<10$ & - & $<50$ & - & $<1000$ & - & - \\
\hline
\end{tabular}


Table A2. SPFT Results for LAWB45 Glasses.

\begin{tabular}{|c|c|c|c|c|c|c|c|c|c|c|c|c|c|c|c|c|}
\hline Sample ID & $\begin{array}{c}\text { Influent } \\
\text { [Si] }\end{array}$ & $\mathrm{T}\left({ }^{\circ} \mathrm{C}\right)$ & $\begin{array}{c}\text { Flow } \\
\text { Rate } \\
\left(\mathrm{m}^{3} / \mathrm{d}\right)\end{array}$ & $\begin{array}{c}\text { Time, } \\
\text { days }\end{array}$ & $\begin{array}{c}\mathrm{pH} \\
\left(23^{\circ} \mathrm{C}\right) \\
\end{array}$ & $\begin{array}{c}\text { Glass } \\
\text { Mass } \\
\text { (g) }\end{array}$ & $\mathrm{SA}\left(\mathrm{m}^{2}\right)$ & [B] & B Rate & {$[\mathrm{Al}]$} & Al Rate & {$[\mathrm{Na}]$} & Na Rate & {$[\mathrm{Si}]$} & Si Rate & $\begin{array}{l}\text { IEX } \\
\text { Rate } \\
\end{array}$ \\
\hline LB45-43.1 & $8.79 \mathrm{E}+02$ & 90 & 1.7E-05 & 0.79 & 9 & 0.506 & 0.010 & 529 & $2.25 \mathrm{E}-02$ & 378 & $1.94 \mathrm{E}-02$ & 899 & $3.01 \mathrm{E}-02$ & 2,735 & $1.33 \mathrm{E}-02$ & 3.05E-09 \\
\hline LB45-43.2 & $8.79 \mathrm{E}+02$ & 90 & 8.1E-05 & 1.89 & 9 & 0.503 & 0.010 & 1,201 & 2.47E-01 & 916 & 2.25E-01 & 1,755 & 2.85E-01 & 6,224 & $1.88 \mathrm{E}-01$ & $1.50 \mathrm{E}-08$ \\
\hline LB45-43.3 & $8.79 \mathrm{E}+02$ & 90 & 1.9E-05 & 2.90 & 9 & 0.501 & 0.010 & 1,180 & $5.85 \mathrm{E}-02$ & 916 & 5.42E-02 & 1,586 & $6.18 \mathrm{E}-02$ & 6,100 & 4.42E-02 & $1.34 \mathrm{E}-09$ \\
\hline LB45-43.6 & $8.79 \mathrm{E}+02$ & 90 & 7.6E-05 & 5.84 & 9 & 0.498 & 0.010 & 1,494 & 2.93E-01 & 865 & 2.02E-01 & 1,965 & $3.04 \mathrm{E}-01$ & 7,120 & 2.09E-01 & 4.26E-09 \\
\hline LB45-43.8 & $8.79 \mathrm{E}+02$ & 90 & 4.1E-05 & 7.74 & 9 & 0.494 & 0.010 & 1,337 & 1.43E-01 & 791 & $1.01 \mathrm{E}-01$ & 1,749 & 1.47E-01 & 6,562 & $1.04 \mathrm{E}-01$ & $1.68 \mathrm{E}-09$ \\
\hline LB45-43.9 & $8.79 \mathrm{E}+02$ & 90 & 8.0E-05 & 9.06 & 9 & 0.489 & 0.010 & 1,079 & $2.25 \mathrm{E}-01$ & 686 & $1.70 \mathrm{E}-01$ & 1,432 & 2.34E-01 & 5,574 & $1.67 \mathrm{E}-01$ & 3.74E-09 \\
\hline LB45-43.10 & $8.79 \mathrm{E}+02$ & 90 & 7.7E-05 & 9.79 & 9 & 0.486 & 0.010 & 1,148 & $2.30 \mathrm{E}-01$ & 754 & $1.80 \mathrm{E}-01$ & 1,516 & 2.39E-01 & 5,884 & $1.72 \mathrm{E}-01$ & $3.47 \mathrm{E}-09$ \\
\hline LB45-43.11 & $8.79 \mathrm{E}+02$ & 90 & 7.7E-05 & 10.83 & 9 & 0.483 & 0.010 & 1,183 & 2.42E-01 & 782 & $1.90 \mathrm{E}-01$ & 1,530 & $2.45 \mathrm{E}-01$ & 6,014 & $1.79 \mathrm{E}-01$ & $1.50 \mathrm{E}-09$ \\
\hline $\begin{array}{c}\text { LB45-43.12 } \\
\text { Exp. \#38 }\end{array}$ & $8.79 \mathrm{E}+02$ & 90 & 1.4E-04 & 10.93 & 9 & 0.481 & 0.010 & 1,179 & 4.45E-01 & 794 & 3.57E-01 & 1,565 & 4.64E-01 & 5,973 & 3.29E-01 & $7.69 \mathrm{E}-09$ \\
\hline LB45-44.A & $3.74 \mathrm{E}+04$ & 90 & - & - & 9 & - & - & $<25$ & - & $<10$ & - & $<50$ & - & 39,061 & - & - \\
\hline LB45-44.1 & $3.74 \mathrm{E}+04$ & 90 & 5.9E-05 & 0.79 & 9 & 0.501 & 0.010 & 647 & $9.60 \mathrm{E}-02$ & 299 & 5.28E-02 & 1,083 & $1.27 \mathrm{E}-01$ & 43,706 & $1.23 \mathrm{E}-01$ & $1.23 \mathrm{E}-08$ \\
\hline LB45-44.2 & $3.74 \mathrm{E}+04$ & 90 & 8.3E-05 & 1.89 & 9 & 0.498 & 0.010 & 1,221 & $2.60 \mathrm{E}-01$ & 391 & $9.78 \mathrm{E}-02$ & 1,847 & 3.10E-01 & 45,423 & 2.37E-01 & $2.01 \mathrm{E}-08$ \\
\hline LB45-44.3 & $3.74 \mathrm{E}+04$ & 90 & 4.6E-05 & 2.90 & 9 & 0.495 & 0.010 & 1,542 & $1.85 \mathrm{E}-01$ & 379 & 5.32E-02 & 2,072 & $1.96 \mathrm{E}-01$ & 46,400 & $1.54 \mathrm{E}-01$ & 4.41E-09 \\
\hline LB45-44.6 & $3.74 \mathrm{E}+04$ & 90 & 7.3E-05 & 5.84 & 9 & 0.491 & 0.010 & 1,882 & 3.57E-01 & 360 & 7.95E-02 & 2,575 & 3.86E-01 & 45,688 & 2.18E-01 & $1.14 \mathrm{E}-08$ \\
\hline LB45-44.8 & $3.74 \mathrm{E}+04$ & 90 & $3.9 \mathrm{E}-05$ & 7.74 & 9 & 0.487 & 0.010 & 1,119 & $1.14 \mathrm{E}-01$ & 232 & 2.73E-02 & 1,604 & $1.29 \mathrm{E}-01$ & 46,251 & $1.28 \mathrm{E}-01$ & 5.85E-09 \\
\hline LB45-44.9 & $3.74 \mathrm{E}+04$ & 90 & 8.1E-05 & 9.06 & 9 & 0.484 & 0.010 & 574 & $1.20 \mathrm{E}-01$ & 262 & 6.51E-02 & 815 & $1.33 \mathrm{E}-01$ & 41,443 & 8.92E-02 & $5.10 \mathrm{E}-09$ \\
\hline LB45-44.10 & $3.74 \mathrm{E}+04$ & 90 & 7.1E-05 & 9.79 & 9 & 0.482 & 0.010 & 716 & $1.32 \mathrm{E}-01$ & 359 & 7.92E-02 & 1,015 & $1.47 \mathrm{E}-01$ & 41,865 & $9.22 \mathrm{E}-02$ & $5.86 \mathrm{E}-09$ \\
\hline LB45-44.11 & $3.74 \mathrm{E}+04$ & 90 & 8.1E-05 & 10.83 & 9 & 0.480 & 0.010 & 963 & 2.06E-01 & 390 & 9.83E-02 & 1,311 & 2.20E-01 & 44,296 & 1.97E-01 & 5.63E-09 \\
\hline $\begin{array}{c}\text { LB45-44.12 } \\
\text { Exp. \#39 }\end{array}$ & $3.74 \mathrm{E}+04$ & 90 & 1.4E-04 & 10.93 & 9 & 0.478 & 0.010 & 1,269 & 4.63E-01 & 418 & $1.80 \mathrm{E}-01$ & 1,694 & 4.87E-01 & 47,414 & 5.33E-01 & $9.31 \mathrm{E}-09$ \\
\hline LB45-45.A & $7.39 \mathrm{E}+04$ & 90 & - & - & 9 & - & - & $<25$ & - & $<10$ & - & $<50$ & - & 80,560 & - & - \\
\hline LB45-45.1 & $7.39 \mathrm{E}+04$ & 90 & $6.4 \mathrm{E}-05$ & 0.79 & 9 & 1.000 & 0.020 & 446 & 3.51E-02 & 141 & $1.29 \mathrm{E}-02$ & 1,159 & 7.36E-02 & 88,206 & $1.09 \mathrm{E}-01$ & $1.54 \mathrm{E}-08$ \\
\hline LB45-45.2 & $7.39 \mathrm{E}+04$ & 90 & 6.7E-05 & 1.89 & 9 & 0.999 & 0.020 & 672 & 5.65E-02 & 169 & $1.64 \mathrm{E}-02$ & 1,300 & 8.68E-02 & 87,791 & $1.08 \mathrm{E}-01$ & $1.21 \mathrm{E}-08$ \\
\hline LB45-45.3 & $7.39 \mathrm{E}+04$ & 90 & 3.8E-05 & 2.90 & 9 & 0.997 & 0.020 & 1,125 & $5.48 \mathrm{E}-02$ & 198 & $1.10 \mathrm{E}-02$ & 1,844 & $7.10 \mathrm{E}-02$ & 87,409 & 5.84E-02 & $6.48 \mathrm{E}-09$ \\
\hline LB45-45.6 & $7.39 \mathrm{E}+04$ & 90 & 7.6E-05 & 5.84 & 9 & 0.992 & 0.020 & 2,754 & $2.74 \mathrm{E}-01$ & 303 & $3.47 \mathrm{E}-02$ & 4,242 & 3.34E-01 & 82,533 & 3.39E-02 & $2.41 \mathrm{E}-08$ \\
\hline LB45-45.8 & $7.39 \mathrm{E}+04$ & 90 & 4.0E-05 & 7.74 & 9 & 0.987 & 0.020 & 1,159 & $5.92 \mathrm{E}-02$ & 161 & $9.30 \mathrm{E}-03$ & 1,868 & 7.54E-02 & 82,926 & 2.12E-02 & 6.47E-09 \\
\hline LB45-45.9 & $7.39 \mathrm{E}+04$ & 90 & 8.2E-05 & 9.06 & 9 & 0.984 & 0.020 & 436 & $4.48 \mathrm{E}-02$ & 123 & $1.46 \mathrm{E}-02$ & 759 & 6.13E-02 & 81,691 & $2.11 \mathrm{E}-02$ & $6.62 \mathrm{E}-09$ \\
\hline LB45-45.10 & $7.39 \mathrm{E}+04$ & 90 & 6.9E-05 & 9.79 & 9 & 0.983 & 0.020 & 334 & $2.81 \mathrm{E}-02$ & 150 & $1.50 \mathrm{E}-02$ & 560 & 3.68E-02 & 82,391 & 2.85E-02 & 3.47E-09 \\
\hline LB45-45.11 & $7.39 \mathrm{E}+04$ & 90 & 7.8E-05 & 10.83 & 9 & 0.982 & 0.020 & 330 & 3.17E-02 & 161 & $1.85 \mathrm{E}-02$ & 541 & 4.05E-02 & 81,142 & $1.04 \mathrm{E}-02$ & 3.53E-09 \\
\hline $\begin{array}{c}\text { LB45-45.12 } \\
\text { Exp. \#40 }\end{array}$ & $7.39 \mathrm{E}+04$ & 90 & 2.1E-04 & 10.93 & 9 & 0.982 & 0.020 & 381 & $9.81 \mathrm{E}-02$ & 173 & 5.29E-02 & 704 & 1.43E-01 & 81,160 & 2.83E-02 & $1.80 \mathrm{E}-08$ \\
\hline LB45-46.A & $1.06 \mathrm{E}+05$ & 90 & - & - & 9 & - & - & $<25$ & - & $<10$ & - & $<50$ & - & 108,234 & - & - \\
\hline LB45-46.1 & $1.06 \mathrm{E}+05$ & 90 & 4.7E-05 & 0.79 & 9 & 1.002 & 0.020 & 337 & $1.89 \mathrm{E}-02$ & 78 & 4.86E-03 & 992 & 4.54E-02 & 131,385 & 2.40E-01 & $1.06 \mathrm{E}-08$ \\
\hline LB45-46.2 & $1.06 \mathrm{E}+05$ & 90 & $6.8 \mathrm{E}-05$ & 1.89 & 9 & 1.001 & 0.020 & 418 & 3.49E-02 & 81 & 7.44E-03 & 980 & 6.56E-02 & 127,829 & 2.98E-01 & $1.23 \mathrm{E}-08$ \\
\hline LB45-46.3 & $1.06 \mathrm{E}+05$ & 90 & 2.2E-05 & 2.90 & 9 & 1.000 & 0.020 & 457 & $1.25 \mathrm{E}-02$ & 85 & $2.57 \mathrm{E}-03$ & 891 & $1.94 \mathrm{E}-02$ & 135,397 & $1.35 \mathrm{E}-01$ & 2.74E-09 \\
\hline LB45-46.6 & $1.06 \mathrm{E}+05$ & 90 & 7.6E-05 & 5.84 & 9 & 0.999 & 0.020 & 352 & $3.24 \mathrm{E}-02$ & 82 & 8.43E-03 & 664 & 4.84E-02 & 133,190 & 4.24E-01 & $6.38 \mathrm{E}-09$ \\
\hline LB45-46.8 & $1.06 \mathrm{E}+05$ & 90 & 3.8E-05 & 7.74 & 9 & 0.998 & 0.020 & 238 & $1.06 \mathrm{E}-02$ & 49 & 2.33E-03 & 428 & $1.50 \mathrm{E}-02$ & 136,781 & $2.45 \mathrm{E}-01$ & $1.75 \mathrm{E}-09$ \\
\hline LB45-46.9 & $1.06 \mathrm{E}+05$ & 90 & 8.4E-05 & 9.06 & 9 & 0.998 & 0.020 & 233 & $2.28 \mathrm{E}-02$ & 48 & 4.91E-03 & 402 & 3.07E-02 & 118,565 & $1.94 \mathrm{E}-01$ & 3.17E-09 \\
\hline LB45-46.10 & $1.06 \mathrm{E}+05$ & 90 & 7.9E-05 & 9.79 & 9 & 0.997 & 0.020 & 321 & 3.05E-02 & 73 & 7.67E-03 & 546 & 4.07E-02 & 122,243 & 2.47E-01 & 4.03E-09 \\
\hline
\end{tabular}


Table A2. SPFT Results for LAWB45 Glasses.

\begin{tabular}{|c|c|c|c|c|c|c|c|c|c|c|c|c|c|c|c|c|}
\hline Sample ID & $\begin{array}{c}\text { Influent } \\
\text { [Si] }\end{array}$ & $\mathrm{T}\left({ }^{\circ} \mathrm{C}\right)$ & $\begin{array}{c}\text { Flow } \\
\text { Rate } \\
\left(\mathrm{m}^{3} / \mathrm{d}\right)\end{array}$ & $\begin{array}{c}\text { Time, } \\
\text { days }\end{array}$ & $\begin{array}{c}\mathrm{pH} \\
\left(23^{\circ} \mathrm{C}\right) \\
\end{array}$ & $\begin{array}{c}\text { Glass } \\
\text { Mass } \\
\text { (g) }\end{array}$ & $\mathrm{SA}\left(\mathrm{m}^{2}\right)$ & [B] & B Rate & {$[\mathrm{Al}]$} & Al Rate & {$[\mathrm{Na}]$} & Na Rate & [Si] & Si Rate & $\begin{array}{l}\text { IEX } \\
\text { Rate } \\
\end{array}$ \\
\hline LB45-46.11 & $1.06 \mathrm{E}+05$ & 90 & 7.3E-05 & 10.83 & 9 & 0.996 & 0.020 & 277 & 2.42E-02 & 69 & 6.64E-03 & 499 & 3.43E-02 & 131,522 & 3.83E-01 & 4.03E-09 \\
\hline $\begin{array}{c}\text { LB45-46.12 } \\
\text { Exp. \#41 }\end{array}$ & $1.06 \mathrm{E}+05$ & 90 & $1.4 \mathrm{E}-04$ & 10.93 & 9 & 0.996 & 0.020 & 231 & 3.78E-02 & 62 & 1.13E-02 & 436 & $5.62 \mathrm{E}-02$ & 131,499 & 7.31E-01 & 7.36E-09 \\
\hline LB45-47.A & $1.22 \mathrm{E}+05$ & 90 & - & - & 9 & - & - & $<25$ & - & $<10$ & - & $<50$ & - & 125,733 & - & - \\
\hline LB45-47.1 & $1.22 \mathrm{E}+05$ & 90 & 7.6E-05 & 0.79 & 9 & 2.003 & 0.040 & 601 & 2.84E-02 & 58 & 2.79E-03 & 1,988 & 7.59E-02 & 150,975 & 2.13E-01 & $1.90 \mathrm{E}-08$ \\
\hline LB45-47.2 & $1.22 \mathrm{E}+05$ & 90 & 7.0E-05 & 1.89 & 9 & 2.001 & 0.040 & 711 & 3.12E-02 & 64 & 2.90E-03 & 1,450 & 5.06E-02 & 152,385 & 2.08E-01 & 7.74E-09 \\
\hline LB45-47.3 & $1.22 \mathrm{E}+05$ & 90 & 4.6E-05 & 2.90 & 9 & 2.000 & 0.040 & 742 & 2.15E-02 & 66 & $1.98 \mathrm{E}-03$ & 1,320 & 3.03E-02 & 150,681 & $1.28 \mathrm{E}-01$ & 3.49E-09 \\
\hline LB45-47.6 & $1.22 \mathrm{E}+05$ & 90 & 7.2E-05 & 5.84 & 9 & 1.998 & 0.040 & 530 & $2.38 \mathrm{E}-02$ & 31 & $1.14 \mathrm{E}-03$ & 942 & 3.34E-02 & 160,668 & 2.82E-01 & 3.83E-09 \\
\hline LB45-47.8 & $1.22 \mathrm{E}+05$ & 90 & 4.4E-05 & 7.74 & 9 & 1.997 & 0.040 & 424 & 1.15E-02 & 20 & 3.43E-04 & 712 & $1.52 \mathrm{E}-02$ & 144,520 & $9.28 \mathrm{E}-02$ & $1.46 \mathrm{E}-09$ \\
\hline LB45-47.9 & $1.22 \mathrm{E}+05$ & 90 & 8.1E-05 & 9.06 & 9 & 1.995 & 0.040 & 386 & $1.91 \mathrm{E}-02$ & 17 & 4.54E-04 & 626 & $2.42 \mathrm{E}-02$ & 143,230 & 1.59E-01 & 2.04E-09 \\
\hline LB45-47.10 & $1.22 \mathrm{E}+05$ & 90 & 7.6E-05 & 9.79 & 9 & 1.994 & 0.040 & 414 & $1.94 \mathrm{E}-02$ & 26 & $9.54 \mathrm{E}-04$ & 687 & $2.52 \mathrm{E}-02$ & 150,162 & $2.08 \mathrm{E}-01$ & 2.33E-09 \\
\hline LB45-47.11 & $1.22 \mathrm{E}+05$ & 90 & 7.1E-05 & 10.83 & 9 & 1.993 & 0.040 & 373 & $1.61 \mathrm{E}-02$ & 20 & $5.47 \mathrm{E}-04$ & 658 & $2.23 \mathrm{E}-02$ & 161,611 & 2.84E-01 & $2.50 \mathrm{E}-09$ \\
\hline $\begin{array}{c}\text { LB45-47.12 } \\
\text { Exp. \#42 }\end{array}$ & $1.22 \mathrm{E}+05$ & 90 & 2.1E-04 & 10.93 & 9 & 1.993 & 0.040 & 341 & 4.26E-02 & 20 & $1.53 \mathrm{E}-03$ & 592 & 5.79E-02 & 159,822 & 7.86E-01 & 6.13E-09 \\
\hline LB45-48.A & $1.39 \mathrm{E}+05$ & 90 & - & - & 9 & - & - & $<25$ & - & $<10$ & - & $<50$ & - & 137,926 & - & - \\
\hline LB45-48.1 & $1.39 \mathrm{E}+05$ & 90 & 4.4E-05 & 0.79 & 9 & 2.008 & 0.040 & 637 & $1.76 \mathrm{E}-02$ & 117 & 3.62E-03 & 6,684 & $1.51 \mathrm{E}-01$ & 160,320 & $1.10 \mathrm{E}-01$ & 5.33E-08 \\
\hline LB45-48.2 & $1.39 \mathrm{E}+05$ & 90 & 1.9E-06 & 1.89 & 9 & 2.008 & 0.040 & 801 & $9.73 \mathrm{E}-04$ & 151 & 2.09E-04 & 9,183 & $9.10 \mathrm{E}-03$ & 171,368 & 7.18E-03 & $3.24 \mathrm{E}-09$ \\
\hline LB45-48.3 & $1.39 \mathrm{E}+05$ & 90 & 7.2E-05 & 2.90 & 9 & 2.007 & 0.040 & 688 & $3.08 \mathrm{E}-02$ & 91 & 4.47E-03 & 7,193 & $2.64 \mathrm{E}-01$ & 167,591 & 2.36E-01 & $9.31 \mathrm{E}-08$ \\
\hline LB45-48.6 & $1.39 \mathrm{E}+05$ & 90 & 7.3E-05 & 5.84 & 9 & 2.006 & 0.040 & 320 & 1.39E-02 & 53 & $2.41 \mathrm{E}-03$ & 2,183 & 8.00E-02 & 171,882 & 2.75E-01 & 2.64E-08 \\
\hline LB45-48.8 & $1.39 \mathrm{E}+05$ & 90 & 3.7E-05 & 7.74 & 9 & 2.005 & 0.040 & 290 & $6.45 \mathrm{E}-03$ & 40 & 8.67E-04 & 1,784 & 3.36E-02 & 163,466 & 1.07E-01 & $1.08 \mathrm{E}-08$ \\
\hline LB45-48.9 & $1.39 \mathrm{E}+05$ & 90 & 8.0E-05 & 9.06 & 9 & 2.004 & 0.040 & 260 & $1.22 \mathrm{E}-02$ & 44 & 2.07E-03 & 1,618 & $6.47 \mathrm{E}-02$ & 155,100 & 1.53E-01 & $2.10 \mathrm{E}-08$ \\
\hline LB45-48.10 & $1.39 \mathrm{E}+05$ & 90 & 6.5E-05 & 9.79 & 9 & 2.003 & 0.040 & 273 & $1.06 \mathrm{E}-02$ & 60 & 2.52E-03 & 1,759 & 5.78E-02 & 157,371 & $1.42 \mathrm{E}-01$ & $1.89 \mathrm{E}-08$ \\
\hline $\begin{array}{c}\text { LB45-48.11 } \\
\text { Exp. \#43 }\end{array}$ & $1.39 \mathrm{E}+05$ & 90 & $6.8 \mathrm{E}-05$ & 10.83 & 9 & 2.002 & 0.040 & 234 & $9.23 \mathrm{E}-03$ & 42 & $1.67 \mathrm{E}-03$ & 1,552 & $5.28 \mathrm{E}-02$ & 165,768 & $2.11 \mathrm{E}-01$ & $1.74 \mathrm{E}-08$ \\
\hline LB45-49.A & $8.67 \mathrm{E}+02$ & 70 & - & - & 9 & - & - & $<100$ & - & $<50$ & - & $<50$ & - & $<500$ & - & - \\
\hline LB45-49.1 & $8.67 \mathrm{E}+02$ & 70 & $6.4 \mathrm{E}-05$ & 0.90 & 9 & 0.501 & 0.023 & 528 & $3.12 \mathrm{E}-02$ & 399 & $3.00 \mathrm{E}-02$ & 866 & 4.73E-02 & 2,763 & 2.83E-02 & 6.43E-09 \\
\hline LB45-49.3 & $8.67 \mathrm{E}+02$ & 70 & 6.6E-05 & 1.83 & 9 & 0.500 & 0.010 & 718 & $1.07 \mathrm{E}-01$ & 603 & 1.13E-01 & 1,038 & $1.36 \mathrm{E}-01$ & 3,851 & $9.95 \mathrm{E}-02$ & $1.16 \mathrm{E}-08$ \\
\hline LB45-49.4 & $8.67 \mathrm{E}+02$ & 70 & 6.6E-05 & 2.87 & 9 & 0.498 & 0.010 & 703 & $1.03 \mathrm{E}-01$ & 587 & 1.09E-01 & 978 & $1.27 \mathrm{E}-01$ & 3,719 & $9.46 \mathrm{E}-02$ & $9.19 \mathrm{E}-09$ \\
\hline LB45-49.7 & $8.67 \mathrm{E}+02$ & 70 & 6.3E-05 & 5.18 & 9 & 0.496 & 0.010 & 602 & 8.31E-02 & 514 & $9.06 \mathrm{E}-02$ & 834 & $1.03 \mathrm{E}-01$ & 3,295 & 7.92E-02 & 7.96E-09 \\
\hline LB45-49.9 & $8.67 \mathrm{E}+02$ & 70 & $6.4 \mathrm{E}-05$ & 7.95 & 9 & 0.494 & 0.010 & 556 & 7.69E-02 & 478 & 8.53E-02 & 774 & $9.71 \mathrm{E}-02$ & 3,063 & 7.41E-02 & 8.06E-09 \\
\hline LB45-49.10 & $8.67 \mathrm{E}+02$ & 70 & 6.6E-05 & 8.89 & 9 & 0.492 & 0.010 & 537 & 7.58E-02 & 435 & $7.88 \mathrm{E}-02$ & 759 & $9.77 \mathrm{E}-02$ & 3,000 & 7.43E-02 & 8.74E-09 \\
\hline LB45-49.11 & $8.67 \mathrm{E}+02$ & 70 & 5.6E-05 & 10.11 & 9 & 0.491 & 0.010 & 561 & $6.80 \mathrm{E}-02$ & 533 & 8.42E-02 & 834 & $9.20 \mathrm{E}-02$ & 3,074 & 6.51E-02 & $9.59 \mathrm{E}-09$ \\
\hline $\begin{array}{c}\text { LB45-49.12 } \\
\text { Exp. \#44 }\end{array}$ & $8.67 \mathrm{E}+02$ & 70 & $6.6 \mathrm{E}-05$ & 10.98 & 9 & 0.490 & 0.010 & 623 & $9.24 \mathrm{E}-02$ & 573 & $1.09 \mathrm{E}-01$ & 930 & $1.23 \mathrm{E}-01$ & 3,341 & 8.59E-02 & $1.24 \mathrm{E}-08$ \\
\hline LB45-50.A & $2.93 \mathrm{E}+04$ & 70 & - & - & 9 & - & - & $<100$ & - & $<50$ & - & $<50$ & - & 33,080 & - & - \\
\hline LB45-50.1 & $2.93 \mathrm{E}+04$ & 70 & 7.2E-05 & 0.90 & 9 & 0.498 & 0.023 & 260 & $1.32 \mathrm{E}-02$ & 96 & $4.52 \mathrm{E}-03$ & 469 & $2.75 \mathrm{E}-02$ & 33,763 & $9.67 \mathrm{E}-03$ & $5.70 \mathrm{E}-09$ \\
\hline LB45-50.3 & $2.93 \mathrm{E}+04$ & 70 & $6.6 \mathrm{E}-05$ & 1.83 & 9 & 0.497 & 0.010 & 475 & $6.52 \mathrm{E}-02$ & 172 & $2.50 \mathrm{E}-02$ & 773 & $9.99 \mathrm{E}-02$ & 34,488 & $4.20 \mathrm{E}-02$ & $1.38 \mathrm{E}-08$ \\
\hline LB45-50.4 & $2.93 \mathrm{E}+04$ & 70 & 6.6E-05 & 2.87 & 9 & 0.496 & 0.010 & 477 & $6.57 \mathrm{E}-02$ & 176 & 2.60E-02 & 729 & $9.39 \mathrm{E}-02$ & 34,284 & 3.59E-02 & $1.13 \mathrm{E}-08$ \\
\hline LB45-50.7 & $2.93 \mathrm{E}+04$ & 70 & $6.4 \mathrm{E}-05$ & 5.18 & 9 & 0.494 & 0.010 & 454 & $5.96 \mathrm{E}-02$ & 203 & 3.05E-02 & 652 & 8.06E-02 & 34,593 & 4.37E-02 & 8.39E-09 \\
\hline LB45-50.9 & $2.93 \mathrm{E}+04$ & 70 & 6.6E-05 & 7.95 & 9 & 0.492 & 0.010 & 449 & 6.13E-02 & 202 & 3.15E-02 & 640 & $8.25 \mathrm{E}-02$ & 34,515 & 4.32E-02 & 8.45E-09 \\
\hline
\end{tabular}


Table A2. SPFT Results for LAWB45 Glasses.

\begin{tabular}{|c|c|c|c|c|c|c|c|c|c|c|c|c|c|c|c|c|}
\hline Sample ID & $\begin{array}{c}\text { Influent } \\
\text { [Si] }\end{array}$ & $\mathrm{T}\left({ }^{\circ} \mathrm{C}\right)$ & $\begin{array}{c}\text { Flow } \\
\text { Rate } \\
\left(\mathrm{m}^{3} / \mathrm{d}\right) \\
\end{array}$ & $\begin{array}{c}\text { Time, } \\
\text { days }\end{array}$ & $\begin{array}{c}\mathrm{pH} \\
\left(23^{\circ} \mathrm{C}\right) \\
\end{array}$ & $\begin{array}{c}\text { Glass } \\
\text { Mass } \\
\text { (g) }\end{array}$ & $\mathrm{SA}\left(\mathrm{m}^{2}\right)$ & {$[\mathrm{B}]$} & B Rate & {$[\mathrm{Al}]$} & Al Rate & {$[\mathrm{Na}]$} & Na Rate & {$[\mathrm{Si}]$} & Si Rate & $\begin{array}{l}\text { IEX } \\
\text { Rate } \\
\end{array}$ \\
\hline LB45-50.10 & $2.93 E+04$ & 70 & $6.6 \mathrm{E}-05$ & 8.89 & 9 & 0.491 & 0.010 & 437 & 5.90E-02 & 193 & $2.96 \mathrm{E}-02$ & 633 & $8.11 \mathrm{E}-02$ & 34,189 & 3.33E-02 & 8.84E-09 \\
\hline LB45-50.11 & $2.93 \mathrm{E}+04$ & 70 & $5.6 \mathrm{E}-05$ & 10.11 & 9 & 0.490 & 0.010 & 433 & 4.97E-02 & 209 & 2.81E-02 & 627 & 6.85E-02 & 34,386 & 3.34E-02 & 7.50E-09 \\
\hline $\begin{array}{c}\text { LB45-50.12 } \\
\text { Exp. \#45 }\end{array}$ & $2.93 \mathrm{E}+04$ & 70 & 6.6E-05 & 10.98 & 9 & 0.489 & 0.010 & 452 & $6.22 \mathrm{E}-02$ & 232 & $3.80 \mathrm{E}-02$ & 647 & 8.39E-02 & 34,702 & 4.91E-02 & 8.66E-09 \\
\hline LB45-51.A & $5.83 \mathrm{E}+04$ & 70 & - & - & 9 & - & - & $<100$ & - & $<50$ & - & 57 & - & 66,179 & - & - \\
\hline LB45-51.1 & $5.83 E+04$ & 70 & $6.6 \mathrm{E}-05$ & 0.90 & 9 & 0.998 & 0.036 & 251 & 7.15E-03 & 57 & $3.80 \mathrm{E}-04$ & 568 & 1.92E-02 & 65,652 & - & 4.80E-09 \\
\hline LB45-51.3 & $5.83 \mathrm{E}+04$ & 70 & 6.6E-05 & 1.83 & 9 & 0.997 & 0.020 & 257 & $1.36 \mathrm{E}-02$ & 58 & $8.61 \mathrm{E}-04$ & 503 & $3.06 \mathrm{E}-02$ & 65,750 & - & $6.82 \mathrm{E}-09$ \\
\hline LB45-51.4 & $5.83 \mathrm{E}+04$ & 70 & $6.6 \mathrm{E}-05$ & 2.87 & 9 & 0.997 & 0.020 & 232 & $1.14 \mathrm{E}-02$ & 59 & 8.86E-04 & 463 & $2.78 \mathrm{E}-02$ & 65,864 & - & $6.56 \mathrm{E}-09$ \\
\hline LB45-51.7 & $5.83 \mathrm{E}+04$ & 70 & $6.2 \mathrm{E}-05$ & 5.18 & 9 & 0.996 & 0.020 & 191 & $7.40 \mathrm{E}-03$ & 61 & $1.04 \mathrm{E}-03$ & 329 & $1.75 \mathrm{E}-02$ & 66,742 & 7.82E-03 & 4.04E-09 \\
\hline LB45-51.9 & $5.83 \mathrm{E}+04$ & 70 & 2.4E-05 & 7.95 & 9 & 0.995 & 0.020 & 275 & 5.59E-03 & 70 & 7.64E-04 & 460 & 1.02E-02 & 66,843 & 3.63E-03 & 1.86E-09 \\
\hline LB45-51.10 & $5.83 \mathrm{E}+04$ & 70 & $6.6 \mathrm{E}-05$ & 8.89 & 9 & 0.995 & 0.020 & 156 & 4.82E-03 & 51 & $1.25 \mathrm{E}-04$ & 287 & $1.58 \mathrm{E}-02$ & 66,052 & - & 4.38E-09 \\
\hline LB45-51.11 & $5.83 E+04$ & 70 & $5.6 \mathrm{E}-05$ & 10.11 & 9 & 0.995 & 0.020 & 134 & $2.50 \mathrm{E}-03$ & 53 & 2.88E-04 & 232 & $1.02 \mathrm{E}-02$ & 66,096 & - & 3.09E-09 \\
\hline $\begin{array}{c}\text { LB45-51.12 } \\
\text { Exp. \#46 }\end{array}$ & $5.83 \mathrm{E}+04$ & 70 & 6.6E-05 & 10.98 & 9 & 0.994 & 0.020 & 146 & 4.00E-03 & 62 & $1.18 \mathrm{E}-03$ & 292 & $1.62 \mathrm{E}-02$ & 65,968 & - & 4.86E-09 \\
\hline LB45-52.A & $8.84 \mathrm{E}+04$ & 70 & - & - & 9 & - & - & $<25$ & - & $<50$ & - & $<50$ & - & 97,505 & - & - \\
\hline LB45-52.1 & $8.84 \mathrm{E}+04$ & 70 & 6.6E-05 & 0.90 & 9 & 1.004 & 0.036 & 217 & $9.06 \mathrm{E}-03$ & ND & - & 538 & $1.83 \mathrm{E}-02$ & 96,536 & - & 3.67E-09 \\
\hline LB45-52.3 & $8.84 \mathrm{E}+04$ & 70 & 6.6E-05 & 1.83 & 9 & 1.003 & 0.020 & 188 & $1.40 \mathrm{E}-02$ & ND & - & 417 & $2.50 \mathrm{E}-02$ & 96,756 & - & 4.41E-09 \\
\hline LB45-52.4 & $8.84 \mathrm{E}+04$ & 70 & $6.6 \mathrm{E}-05$ & 2.87 & 9 & 1.003 & 0.020 & 138 & $9.70 \mathrm{E}-03$ & ND & - & 293 & $1.65 \mathrm{E}-02$ & 97,212 & - & 2.73E-09 \\
\hline LB45-52.7 & $8.84 \mathrm{E}+04$ & 70 & 6.3E-05 & 5.18 & 9 & 1.003 & 0.020 & 75 & 4.15E-03 & ND & - & 180 & 8.51E-03 & 95,890 & - & $1.74 \mathrm{E}-09$ \\
\hline LB45-52.9 & $8.84 \mathrm{E}+04$ & 70 & 6.6E-05 & 7.95 & 9 & 1.002 & 0.020 & 60 & $2.98 \mathrm{E}-03$ & ND & - & 151 & 6.91E-03 & 98,611 & 1.63E-02 & 1.57E-09 \\
\hline LB45-52.10 & $8.84 \mathrm{E}+04$ & 70 & 6.6E-05 & 8.89 & 9 & 1.002 & 0.020 & 62 & 3.15E-03 & ND & - & 160 & $7.48 \mathrm{E}-03$ & 97,131 & - & 1.73E-09 \\
\hline LB45-52.11 & $8.84 \mathrm{E}+04$ & 70 & 5.6E-05 & 10.11 & 9 & 1.002 & 0.020 & 55 & 2.17E-03 & ND & - & 127 & 4.42E-03 & 90,515 & - & 8.99E-10 \\
\hline $\begin{array}{c}\text { LB45-52.12 } \\
\text { Exp. \#47 }\end{array}$ & $8.84 \mathrm{E}+04$ & 70 & $6.6 \mathrm{E}-05$ & 10.98 & 9 & 1.002 & 0.020 & 68 & 3.73E-03 & ND & - & 149 & $6.76 \mathrm{E}-03$ & 89,611 & - & $1.21 \mathrm{E}-09$ \\
\hline LB45-53.A & $1.14 \mathrm{E}+05$ & 70 & - & - & 9 & - & - & $<25$ & - & $<50$ & - & $<50$ & - & 114,657 & - & - \\
\hline LB45-53.1 & $1.14 \mathrm{E}+05$ & 70 & 6.7E-05 & 0.90 & 9 & 2.004 & 0.058 & 353 & $9.88 \mathrm{E}-03$ & ND & - & 869 & $1.96 \mathrm{E}-02$ & 116,163 & 7.76E-03 & $3.88 \mathrm{E}-09$ \\
\hline LB45-53.3 & $1.14 \mathrm{E}+05$ & 70 & 6.6E-05 & 1.83 & 9 & 2.004 & 0.040 & 321 & $1.26 \mathrm{E}-02$ & ND & - & 681 & $2.14 \mathrm{E}-02$ & 114,534 & - & 3.51E-09 \\
\hline LB45-53.4 & $1.14 \mathrm{E}+05$ & 70 & 6.6E-05 & 2.87 & 9 & 2.003 & 0.040 & 235 & $8.98 \mathrm{E}-03$ & ND & - & 504 & $1.54 \mathrm{E}-02$ & 114,075 & - & 2.56E-09 \\
\hline LB45-53.7 & $1.14 \mathrm{E}+05$ & 70 & 6.3E-05 & 5.18 & 9 & 2.003 & 0.040 & 138 & 4.67E-03 & ND & - & 307 & 8.43E-03 & 123,428 & 6.19E-02 & $1.50 \mathrm{E}-09$ \\
\hline LB45-53.9 & $1.14 \mathrm{E}+05$ & 70 & $6.7 \mathrm{E}-05$ & 7.95 & 9 & 2.002 & 0.040 & 93 & 2.93E-03 & ND & - & 212 & 5.57E-03 & 124,089 & 7.01E-02 & 1.05E-09 \\
\hline LB45-53.10 & $1.14 \mathrm{E}+05$ & 70 & 6.6E-05 & 8.89 & 9 & 2.002 & 0.040 & 87 & 2.64E-03 & ND & - & 205 & $5.27 \mathrm{E}-03$ & 125,525 & 7.96E-02 & 1.05E-09 \\
\hline LB45-53.11 & $1.14 \mathrm{E}+05$ & 70 & 5.6E-05 & 10.11 & 9 & 2.002 & 0.040 & 83 & 2.13E-03 & ND & - & 209 & 4.63E-03 & 120,926 & 3.95E-02 & $1.00 \mathrm{E}-09$ \\
\hline $\begin{array}{c}\text { LB45-53.12 } \\
\text { Exp. \#48 }\end{array}$ & $1.14 \mathrm{E}+05$ & 70 & 6.6E-05 & 10.98 & 9 & 2.002 & 0.040 & 75 & $2.13 \mathrm{E}-03$ & ND & - & 191 & $4.80 \mathrm{E}-03$ & 116,554 & 1.39E-02 & $1.06 \mathrm{E}-09$ \\
\hline LB45-54.A & $1.37 \mathrm{E}+05$ & 70 & - & - & 9 & - & - & $<25$ & - & $<50$ & - & 58 & - & 120,313 & - & - \\
\hline LB45-54.1 & $1.37 \mathrm{E}+05$ & 70 & $6.8 \mathrm{E}-05$ & 0.90 & 9 & 2.002 & 0.058 & 395 & $1.14 \mathrm{E}-02$ & ND & - & 1,019 & 2.35E-02 & 121,984 & 8.81E-03 & 4.83E-09 \\
\hline LB45-54.3 & $1.37 \mathrm{E}+05$ & 70 & 6.7E-05 & 1.83 & 9 & 2.002 & 0.040 & 323 & $1.30 \mathrm{E}-02$ & ND & - & 704 & 2.23E-02 & 120,405 & $6.86 \mathrm{E}-04$ & 3.73E-09 \\
\hline LB45-54.4 & $1.37 \mathrm{E}+05$ & 70 & 6.6E-05 & 2.87 & 9 & 2.001 & 0.040 & 231 & $8.88 \mathrm{E}-03$ & ND & - & 490 & $1.48 \mathrm{E}-02$ & 121,411 & $8.12 \mathrm{E}-03$ & 2.36E-09 \\
\hline LB45-54.7 & $1.37 \mathrm{E}+05$ & 70 & 6.4E-05 & 5.18 & 9 & 2.001 & 0.040 & 138 & 4.66E-03 & ND & - & 831 & $2.54 \mathrm{E}-02$ & 136,064 & 1.12E-01 & 8.29E-09 \\
\hline LB45-54.9 & $1.37 \mathrm{E}+05$ & 70 & $6.5 \mathrm{E}-05$ & 7.95 & 9 & 2.000 & 0.040 & 103 & 3.30E-03 & ND & - & 222 & $5.49 \mathrm{E}-03$ & 134,735 & $1.04 \mathrm{E}-01$ & 8.75E-10 \\
\hline
\end{tabular}


Table A2. SPFT Results for LAWB45 Glasses.

\begin{tabular}{|c|c|c|c|c|c|c|c|c|c|c|c|c|c|c|c|c|}
\hline Sample ID & $\begin{array}{c}\text { Influent } \\
\text { [Si] }\end{array}$ & $\mathrm{T}\left({ }^{\circ} \mathrm{C}\right)$ & $\begin{array}{c}\text { Flow } \\
\text { Rate } \\
\left(\mathrm{m}^{3} / \mathrm{d}\right) \\
\end{array}$ & $\begin{array}{l}\text { Time, } \\
\text { days }\end{array}$ & $\begin{array}{c}\mathrm{pH} \\
\left(23^{\circ} \mathrm{C}\right) \\
\end{array}$ & $\begin{array}{c}\text { Glass } \\
\text { Mass } \\
\text { (g) } \\
\end{array}$ & $\mathrm{SA}\left(\mathrm{m}^{2}\right)$ & [B] & B Rate & [Al] & Al Rate & {$[\mathrm{Na}]$} & Na Rate & {$[\mathrm{Si}]$} & Si Rate & $\begin{array}{l}\text { IEX } \\
\text { Rate } \\
\end{array}$ \\
\hline LB45-54.10 & $1.37 \mathrm{E}+05$ & 70 & $6.5 \mathrm{E}-05$ & 8.89 & 9 & 2.000 & 0.040 & 95 & 2.96E-03 & ND & - & 216 & 5.33E-03 & 135,545 & $1.11 \mathrm{E}-01$ & $9.45 \mathrm{E}-10$ \\
\hline LB45-54.11 & $1.37 \mathrm{E}+05$ & 70 & $5.6 \mathrm{E}-05$ & 10.11 & 9 & 2.000 & 0.040 & 84 & 2.15E-03 & ND & - & 201 & $4.16 \mathrm{E}-03$ & 128,716 & $5.28 \mathrm{E}-02$ & $8.01 \mathrm{E}-10$ \\
\hline LB45-54.12 & $1.37 \mathrm{E}+05$ & 70 & $6.2 \mathrm{E}-05$ & 10.98 & 9 & 1.999 & 0.040 & 79 & $2.21 \mathrm{E}-03$ & ND & - & 199 & $4.54 \mathrm{E}-03$ & 122,769 & $1.71 \mathrm{E}-02$ & $9.29 \mathrm{E}-10$ \\
\hline
\end{tabular}

[] $-\mu \mathrm{g} \mathrm{L}^{-1}$

Rate $-\mathrm{g} \mathrm{m}^{-2} \mathrm{~d}^{-1}$

IEX Rate $-\mathrm{mol} \mathrm{m}^{-2} \mathrm{~s}^{-1}$ 
Table A3. SPFT Results for LAWC22 Glasses.

\begin{tabular}{|c|c|c|c|c|c|c|c|c|c|c|c|c|c|c|c|c|}
\hline Sample ID & $\begin{array}{c}\text { Influent } \\
{[\mathrm{Si}]}\end{array}$ & $\mathrm{T}\left({ }^{\circ} \mathrm{C}\right)$ & $\begin{array}{c}\text { Flow } \\
\text { Rate } \\
\left(\mathrm{m}^{3} / \mathrm{d}\right)\end{array}$ & $\begin{array}{l}\text { Time, } \\
\text { days }\end{array}$ & $\begin{array}{c}\mathrm{pH} \\
\left(23^{\circ} \mathrm{C}\right) \\
\end{array}$ & $\begin{array}{c}\text { Glass } \\
\text { Mass (g) }\end{array}$ & $\mathrm{SA}\left(\mathrm{m}^{2}\right)$ & {$[\mathrm{B}]$} & B Rate & {$[\mathrm{Al}]$} & Al Rate & {$[\mathrm{Na}]$} & Na Rate & {$[\mathrm{Si}]$} & Si Rate & IEX Rate \\
\hline \multicolumn{17}{|l|}{ LAWC22 } \\
\hline \multicolumn{17}{|l|}{ Exp.\#1 } \\
\hline LC22-1A & 0 & 40 & - & - & 7 & - & - & $<10$ & - & $<25$ & - & 106 & - & $<100$ & - & - \\
\hline LC22-1B & 0 & 40 & - & - & 7 & - & - & $<10$ & - & $<25$ & - & 107 & - & $<100$ & - & - \\
\hline LC22-1C & 0 & 40 & - & - & 7 & - & - & $<10$ & - & $<25$ & - & $<100$ & - & $<100$ & - & - \\
\hline LC22-1.1 & 0 & 40 & 4.3E-05 & 0.73 & 7 & 1.002 & 0.020 & 346 & 2.22E-02 & $<25$ & - & 2,337 & 4.51E-02 & 406 & 3.02E-03 & $9.15 \mathrm{E}-09$ \\
\hline LC22-1.2 & 0 & 40 & 4.1E-05 & 2.08 & 7 & 1.001 & 0.020 & 248 & $1.48 \mathrm{E}-02$ & $<25$ & - & 1,539 & 2.77E-02 & 552 & $4.28 \mathrm{E}-03$ & 5.18E-09 \\
\hline LC22-1.3 & 0 & 40 & 4.1E-05 & 2.74 & 7 & 1.001 & 0.020 & 155 & 8.64E-03 & 11 & $9.39 \mathrm{E}-05$ & 951 & 1.65E-02 & 505 & 3.86E-03 & $3.14 \mathrm{E}-09$ \\
\hline LC22-1.4 & 0 & 40 & 4.1E-05 & 3.77 & 7 & 1.001 & 0.020 & 124 & 6.52E-03 & 12 & $1.40 \mathrm{E}-04$ & 688 & 1.13E-02 & 245 & $1.37 \mathrm{E}-03$ & $1.89 \mathrm{E}-09$ \\
\hline LC22-1.5 & 0 & 40 & 4.1E-05 & 4.91 & 7 & 1.000 & 0.020 & 104 & $5.24 \mathrm{E}-03$ & 41 & $1.98 \mathrm{E}-03$ & 524 & 8.17E-03 & 197 & $9.26 \mathrm{E}-04$ & 1.17E-09 \\
\hline LC22-1.6 & 0 & 40 & 4.1E-05 & 5.82 & 7 & 1.000 & 0.020 & 90 & $4.38 \mathrm{E}-03$ & 17 & 4.52E-04 & 438 & 6.53E-03 & 160 & 5.77E-04 & 8.58E-10 \\
\hline LC22-1.7 & 0 & 40 & 4.1E-05 & 6.81 & 7 & 1.000 & 0.020 & 86 & $4.01 \mathrm{E}-03$ & 15 & $3.06 \mathrm{E}-04$ & 416 & 6.03E-03 & 154 & 5.13E-04 & 8.05E-10 \\
\hline LC22-1.8 & 0 & 40 & 4.1E-05 & 7.80 & 7 & 1.000 & 0.020 & 79 & $3.60 \mathrm{E}-03$ & 21 & $6.83 \mathrm{E}-04$ & 378 & 5.32E-03 & 123 & 2.22E-04 & $6.86 \mathrm{E}-10$ \\
\hline LC22-1.9 & 0 & 40 & 4.1E-05 & 9.06 & 7 & 1.000 & 0.020 & 77 & $3.46 \mathrm{E}-03$ & 17 & 4.63E-04 & 350 & 4.79E-03 & 112 & $1.18 \mathrm{E}-04$ & $5.31 \mathrm{E}-10$ \\
\hline LC22-1.10 & 0 & 40 & 4.1E-05 & 9.94 & 7 & 0.999 & 0.020 & 75 & 3.31E-03 & 18 & $5.24 \mathrm{E}-04$ & 331 & 4.42E-03 & 108 & 7.71E-05 & $4.42 \mathrm{E}-10$ \\
\hline LC22-1.11 & 0 & 40 & 4.1E-05 & 10.86 & 7 & 0.999 & 0.020 & 72 & 3.12E-03 & 16 & 3.76E-04 & 317 & 4.12E-03 & $<100$ & - & 3.96E-10 \\
\hline \multicolumn{17}{|l|}{ Exp.\#2 } \\
\hline LC22-2A & 0 & 40 & - & - & 8 & - & - & $<10$ & - & $<25$ & - & $<100$ & - & $<100$ & - & - \\
\hline LC22-2B & 0 & 40 & - & - & 8 & - & - & $<10$ & - & $<25$ & - & $<100$ & - & $<100$ & - & - \\
\hline LC22-2C & 0 & 40 & - & - & 8 & - & - & $<10$ & - & $<25$ & - & $<100$ & - & $<100$ & - & - \\
\hline LC22-2.1 & 0 & 40 & 3.7E-05 & 0.73 & 8 & 1.006 & 0.020 & 416 & 2.33E-02 & 83 & $4.20 \mathrm{E}-03$ & 2,863 & 4.82E-02 & 1,187 & $9.28 \mathrm{E}-03$ & $9.92 \mathrm{E}-09$ \\
\hline LC22-2.2 & 0 & 40 & $3.8 \mathrm{E}-05$ & 2.08 & 8 & 1.005 & 0.020 & 183 & $9.79 \mathrm{E}-03$ & 67 & $3.45 \mathrm{E}-03$ & 1,259 & $2.10 \mathrm{E}-02$ & 659 & 4.97E-03 & 4.49E-09 \\
\hline LC22-2.3 & 0 & 40 & 4.1E-05 & 2.74 & 8 & 1.005 & 0.020 & 108 & $5.48 \mathrm{E}-03$ & 67 & 3.65E-03 & 712 & $1.18 \mathrm{E}-02$ & 544 & 4.19E-03 & 2.52E-09 \\
\hline LC22-2.4 & 0 & 40 & $4.0 \mathrm{E}-05$ & 3.77 & 8 & 1.005 & 0.020 & 85 & 3.92E-03 & 68 & $3.71 \mathrm{E}-03$ & 538 & 8.36E-03 & 456 & 3.33E-03 & $1.77 \mathrm{E}-09$ \\
\hline LC22-2.5 & 0 & 40 & 4.1E-05 & 4.91 & 8 & 1.005 & 0.020 & 71 & $3.04 \mathrm{E}-03$ & 59 & 3.17E-03 & 411 & 6.03E-03 & 431 & 3.15E-03 & $1.20 \mathrm{E}-09$ \\
\hline LC22-2.6 & 0 & 40 & 4.1E-05 & 5.82 & 8 & 1.005 & 0.020 & 63 & $2.52 \mathrm{E}-03$ & 58 & 3.07E-03 & 347 & 4.79E-03 & 388 & 2.73E-03 & $9.06 \mathrm{E}-10$ \\
\hline LC22-2.7 & 0 & 40 & 3.6E-05 & 6.81 & 8 & 1.004 & 0.020 & 61 & $2.11 \mathrm{E}-03$ & 66 & 3.19E-03 & 342 & 4.16E-03 & 351 & $2.11 \mathrm{E}-03$ & 8.16E-10 \\
\hline LC22-2.8 & 0 & 40 & 4.1E-05 & 7.80 & 8 & 1.004 & 0.020 & 56 & 2.03E-03 & 56 & $2.94 \mathrm{E}-03$ & 322 & 4.27E-03 & 331 & $2.18 \mathrm{E}-03$ & 8.92E-10 \\
\hline LC22-2.9 & 0 & 40 & 3.3E-05 & 9.06 & 8 & 1.004 & 0.020 & 55 & $1.60 \mathrm{E}-03$ & 52 & 2.16E-03 & 274 & 2.70E-03 & 317 & $1.66 \mathrm{E}-03$ & 4.38E-10 \\
\hline LC22-2.10 & 0 & 40 & 4.1E-05 & 9.94 & 8 & 1.004 & 0.020 & 52 & $1.79 \mathrm{E}-03$ & 55 & $2.91 \mathrm{E}-03$ & 252 & $2.94 \mathrm{E}-03$ & 313 & 2.02E-03 & $4.58 \mathrm{E}-10$ \\
\hline LC22-2.11 & 0 & 40 & 4.1E-05 & 10.86 & 8 & 1.004 & 0.020 & 47 & $1.48 \mathrm{E}-03$ & 32 & $1.42 \mathrm{E}-03$ & 217 & $2.25 \mathrm{E}-03$ & 354 & 2.39E-03 & $3.08 \mathrm{E}-10$ \\
\hline \multicolumn{17}{|l|}{ Exp.\#3 } \\
\hline LC22-3A & 0 & 40 & - & - & 9 & - & - & $<10$ & - & $<25$ & - & $<100$ & - & 121 & - & - \\
\hline LC22-3B & 0 & 40 & - & - & 9 & - & - & $<10$ & - & $<25$ & - & $<100$ & - & 108 & - & - \\
\hline LC22-3C & 0 & 40 & - & - & 9 & - & - & $<10$ & - & $<25$ & - & $<100$ & - & $<100$ & - & - \\
\hline LC22-3.1 & 0 & 40 & 4.3E-05 & 0.73 & 9 & 0.503 & 0.013 & 139 & $1.25 \mathrm{E}-02$ & 100 & $9.52 \mathrm{E}-03$ & 886 & 2.52E-02 & 772 & $1.04 \mathrm{E}-02$ & 5.05E-09 \\
\hline LC22-3.2 & 0 & 40 & 4.1E-05 & 2.08 & 9 & 0.502 & 0.010 & 219 & $2.56 \mathrm{E}-02$ & 204 & $2.48 \mathrm{E}-02$ & 943 & $3.25 \mathrm{E}-02$ & 1,477 & $2.58 \mathrm{E}-02$ & 2.75E-09 \\
\hline LC22-3.3 & 0 & 40 & 4.1E-05 & 2.74 & 9 & 0.502 & 0.010 & 222 & $2.60 \mathrm{E}-02$ & 228 & $2.80 \mathrm{E}-02$ & 850 & 2.89E-02 & 1,448 & 2.53E-02 & $1.16 \mathrm{E}-09$ \\
\hline LC22-3.4 & 0 & 40 & 4.1E-05 & 3.77 & 9 & 0.502 & 0.010 & 219 & $2.56 \mathrm{E}-02$ & 222 & $2.71 \mathrm{E}-02$ & 816 & $2.76 \mathrm{E}-02$ & 1,427 & 2.49E-02 & $8.08 \mathrm{E}-10$ \\
\hline LC22-3.5 & 0 & 40 & 4.1E-05 & 4.91 & 9 & 0.501 & 0.010 & 217 & $2.55 \mathrm{E}-02$ & 206 & 2.53E-02 & 811 & 2.77E-02 & 1,459 & 2.57E-02 & 8.62E-10 \\
\hline
\end{tabular}


Table A3. SPFT Results for LAWC22 Glasses.

\begin{tabular}{|c|c|c|c|c|c|c|c|c|c|c|c|c|c|c|c|c|}
\hline Sample ID & $\begin{array}{c}\text { Influent } \\
\text { [Si] }\end{array}$ & $\mathrm{T}\left({ }^{\circ} \mathrm{C}\right)$ & $\begin{array}{c}\text { Flow } \\
\text { Rate } \\
\left(\mathrm{m}^{3} / \mathrm{d}\right) \\
\end{array}$ & $\begin{array}{l}\text { Time, } \\
\text { days }\end{array}$ & $\begin{array}{c}\mathrm{pH} \\
\left(23^{\circ} \mathrm{C}\right) \\
\end{array}$ & $\begin{array}{c}\text { Glass } \\
\text { Mass (g) }\end{array}$ & $\mathrm{SA}\left(\mathrm{m}^{2}\right)$ & {$[\mathrm{B}]$} & B Rate & {$[\mathrm{Al}]$} & Al Rate & {$[\mathrm{Na}]$} & Na Rate & {$[\mathrm{Si}]$} & Si Rate & IEX Rate \\
\hline LC22-3.6 & 0 & 40 & $4.1 \mathrm{E}-05$ & 5.82 & 9 & 0.501 & 0.010 & 205 & $2.40 \mathrm{E}-02$ & 204 & 2.51E-02 & 739 & 2.49E-02 & 1,353 & 2.37E-02 & 3.38E-10 \\
\hline LC22-3.7 & 0 & 40 & $4.1 \mathrm{E}-05$ & 6.81 & 9 & 0.500 & 0.010 & 194 & 2.23E-02 & 193 & 2.35E-02 & 723 & 2.41E-02 & 1,282 & 2.22E-02 & 7.06E-10 \\
\hline LC22-3.8 & 0 & 40 & 4.1E-05 & 7.80 & 9 & 0.500 & 0.010 & 190 & $2.18 \mathrm{E}-02$ & 192 & 2.33E-02 & 726 & $2.41 \mathrm{E}-02$ & 1,247 & 2.15E-02 & $9.47 \mathrm{E}-10$ \\
\hline LC22-3.9 & 0 & 40 & 4.1E-05 & 9.06 & 9 & 0.500 & 0.010 & 193 & 2.23E-02 & 192 & 2.35E-02 & 725 & 2.43E-02 & 1,300 & 2.27E-02 & 7.79E-10 \\
\hline LC22-3.10 & 0 & 40 & 3.8E-05 & 9.94 & 9 & 0.499 & 0.010 & 187 & 2.03E-02 & 181 & 2.07E-02 & 737 & 2.33E-02 & 1,224 & $2.00 \mathrm{E}-02$ & $1.21 \mathrm{E}-09$ \\
\hline LC22-3.11 & 0 & 40 & 4.0E-05 & 10.86 & 9 & 0.499 & 0.010 & 184 & 2.09E-02 & 175 & 2.10E-02 & 701 & 2.31E-02 & 1,205 & 2.06E-02 & 8.72E-10 \\
\hline \multicolumn{17}{|l|}{ Exp. \#4 } \\
\hline LC22-4A & 0 & 40 & - & - & 10 & - & - & $<10$ & - & $<25$ & - & $<100$ & - & $<100$ & - & - \\
\hline LC22-4B & 0 & 40 & - & - & 10 & - & - & $<10$ & - & $<25$ & - & 299 & - & $<100$ & - & - \\
\hline LC22-4C & 0 & 40 & - & - & 10 & - & - & $<10$ & - & $<25$ & - & $<100$ & - & $<100$ & - & - \\
\hline LC22-4.1 & 0 & 40 & $4.0 \mathrm{E}-05$ & 0.73 & 10 & 0.503 & 0.013 & 204 & 1.82E-02 & 256 & 2.43E-02 & 1,065 & 2.67E-02 & 1,657 & 2.27E-02 & 3.42E-09 \\
\hline LC22-4.2 & 0 & 40 & 4.1E-05 & 2.08 & 10 & 0.502 & 0.010 & 348 & 4.25E-02 & 378 & 4.70E-02 & 1,352 & 4.56E-02 & 2,365 & 4.27E-02 & $1.24 \mathrm{E}-09$ \\
\hline LC22-4.3 & 0 & 40 & 4.1E-05 & 2.74 & 10 & 0.502 & 0.010 & 341 & 4.17E-02 & 366 & 4.58E-02 & 1,277 & 4.30E-02 & 2,243 & 4.06E-02 & $4.88 \mathrm{E}-10$ \\
\hline LC22-4.4 & 0 & 40 & 4.1E-05 & 3.77 & 10 & 0.501 & 0.010 & 347 & 4.23E-02 & 366 & 4.54E-02 & 1,293 & 4.33E-02 & 2,290 & 4.12E-02 & 3.65E-10 \\
\hline LC22-4.5 & 0 & 40 & 4.1E-05 & 4.91 & 10 & 0.500 & 0.010 & 362 & 4.47E-02 & 384 & 4.82E-02 & 1,320 & $4.48 \mathrm{E}-02$ & 2,361 & 4.30E-02 & $3.88 \mathrm{E}-11$ \\
\hline LC22-4.6 & 0 & 40 & 4.1E-05 & 5.82 & 10 & 0.499 & 0.010 & 342 & $4.18 \mathrm{E}-02$ & 359 & 4.46E-02 & 1,263 & $4.22 \mathrm{E}-02$ & 2,242 & 4.04E-02 & $1.67 \mathrm{E}-10$ \\
\hline LC22-4.7 & 0 & 40 & $4.0 \mathrm{E}-05$ & 6.81 & 10 & 0.499 & 0.010 & 337 & 4.05E-02 & 340 & 4.16E-02 & 1,243 & 4.09E-02 & 2,332 & 4.15E-02 & $1.51 \mathrm{E}-10$ \\
\hline LC22-4.8 & 0 & 40 & $3.9 \mathrm{E}-05$ & 7.80 & 10 & 0.498 & 0.010 & 350 & 4.16E-02 & 369 & 4.45E-02 & 1,304 & $4.25 \mathrm{E}-02$ & 2,303 & 4.03E-02 & $3.93 \mathrm{E}-10$ \\
\hline LC22-4.9 & 0 & 40 & 4.2E-05 & 9.06 & 10 & 0.497 & 0.010 & 339 & $4.30 \mathrm{E}-02$ & 366 & 4.73E-02 & 1,268 & 4.41E-02 & 2,242 & 4.19E-02 & 4.39E-10 \\
\hline LC22-4.10 & 0 & 40 & $4.0 \mathrm{E}-05$ & 9.94 & 10 & 0.497 & 0.010 & 350 & 4.21E-02 & 336 & 4.10E-02 & 1,290 & 4.26E-02 & 2,309 & 4.10E-02 & $1.86 \mathrm{E}-10$ \\
\hline LC22-4.11 & 0 & 40 & $3.8 \mathrm{E}-05$ & 10.86 & 10 & 0.496 & 0.010 & 328 & 3.73E-02 & 339 & 3.94E-02 & 1,222 & $3.80 \mathrm{E}-02$ & 2,180 & 3.67E-02 & $3.10 \mathrm{E}-10$ \\
\hline \multicolumn{17}{|l|}{ Exp. \#5 } \\
\hline LC22-5A & 0 & 40 & - & - & 11 & - & - & 14 & - & $<25$ & - & 138 & - & $<100$ & - & - \\
\hline LC22-5B & 0 & 40 & - & - & 11 & - & - & $<10$ & - & $<25$ & - & $<100$ & - & $<100$ & - & - \\
\hline LC22-5C & 0 & 40 & - & - & 11 & - & - & $<10$ & - & $<25$ & - & $<100$ & - & $<100$ & - & - \\
\hline LC22-5.1 & 0 & 40 & 4.2E-05 & 0.73 & 11 & 0.507 & 0.013 & 407 & $4.06 \mathrm{E}-02$ & 510 & $5.14 \mathrm{E}-02$ & 1,928 & 5.63E-02 & 2,939 & $4.31 \mathrm{E}-02$ & $6.29 \mathrm{E}-09$ \\
\hline LC22-5.2 & 0 & 40 & 4.1E-05 & 2.08 & 11 & 0.505 & 0.010 & 640 & 8.00E-02 & 703 & 8.74E-02 & 2,451 & 8.90E-02 & 4,338 & 7.90E-02 & 3.58E-09 \\
\hline LC22-5.3 & 0 & 40 & 4.1E-05 & 2.74 & 11 & 0.504 & 0.010 & 818 & $1.04 \mathrm{E}-01$ & 898 & 1.13E-01 & 3,005 & $1.11 \mathrm{E}-01$ & 5,385 & 9.97E-02 & 2.80E-09 \\
\hline LC22-5.4 & 0 & 40 & 4.1E-05 & 3.77 & 11 & 0.503 & 0.010 & 727 & $9.18 \mathrm{E}-02$ & 791 & $9.90 \mathrm{E}-02$ & 2,695 & $9.88 \mathrm{E}-02$ & 4,750 & 8.71E-02 & 2.79E-09 \\
\hline LC22-5.5 & 0 & 40 & 4.1E-05 & 4.91 & 11 & 0.501 & 0.010 & 721 & $9.34 \mathrm{E}-02$ & 779 & $1.00 \mathrm{E}-01$ & 2,650 & $9.96 \mathrm{E}-02$ & 5,119 & $9.65 \mathrm{E}-02$ & $2.46 \mathrm{E}-09$ \\
\hline LC22-5.6 & 0 & 40 & $4.1 \mathrm{E}-05$ & 5.82 & 11 & 0.500 & 0.010 & 674 & 8.66E-02 & 731 & $9.32 \mathrm{E}-02$ & 2,482 & $9.24 \mathrm{E}-02$ & 4,336 & 8.09E-02 & 2.34E-09 \\
\hline LC22-5.7 & 0 & 40 & 4.1E-05 & 6.81 & 11 & 0.499 & 0.010 & 647 & 8.30E-02 & 698 & 8.89E-02 & 2,431 & 9.04E-02 & 4,149 & 7.73E-02 & 2.95E-09 \\
\hline LC22-5.8 & 0 & 40 & 4.1E-05 & 7.80 & 11 & 0.497 & 0.010 & 625 & 7.99E-02 & 669 & 8.49E-02 & 2,378 & 8.81E-02 & 4,267 & 7.94E-02 & 3.30E-09 \\
\hline LC22-5.9 & 0 & 40 & 3.9E-05 & 9.06 & 11 & 0.496 & 0.010 & 796 & $9.85 \mathrm{E}-02$ & 872 & 1.07E-01 & 2,865 & 1.03E-01 & 5,188 & $9.32 \mathrm{E}-02$ & 1.75E-09 \\
\hline LC22-5.10 & 0 & 40 & 4.1E-05 & 9.94 & 11 & 0.494 & 0.010 & 834 & $1.08 \mathrm{E}-01$ & 907 & $1.16 \mathrm{E}-01$ & 2,977 & $1.11 \mathrm{E}-01$ & 5,385 & $1.01 \mathrm{E}-01$ & $1.54 \mathrm{E}-09$ \\
\hline LC22-5.11 & 0 & 40 & 4.0E-05 & 10.86 & 11 & 0.493 & 0.010 & 837 & $1.08 \mathrm{E}-01$ & 908 & 1.16E-01 & 3,004 & 1.12E-01 & 5,420 & $1.01 \mathrm{E}-01$ & $1.77 \mathrm{E}-09$ \\
\hline \multicolumn{17}{|l|}{ Exp. \#6 } \\
\hline LC22-6A & 0 & 40 & - & - & 12 & - & - & $<10$ & - & $<25$ & - & 116 & - & 128 & - & - \\
\hline LC22-6B & 0 & 40 & - & - & 12 & - & - & $<10$ & - & $<25$ & - & 122 & - & 126 & - & - \\
\hline LC22-6C & 0 & 40 & - & - & 12 & - & - & $<10$ & - & $<25$ & - & 139 & - & 132 & - & - \\
\hline
\end{tabular}


Table A3. SPFT Results for LAWC22 Glasses.

\begin{tabular}{|c|c|c|c|c|c|c|c|c|c|c|c|c|c|c|c|c|}
\hline Sample ID & $\begin{array}{c}\text { Influent } \\
{[\mathrm{Si}]}\end{array}$ & $\mathrm{T}\left({ }^{\circ} \mathrm{C}\right)$ & $\begin{array}{c}\text { Flow } \\
\text { Rate } \\
\left(\mathrm{m}^{3} / \mathrm{d}\right) \\
\end{array}$ & $\begin{array}{l}\text { Time, } \\
\text { days }\end{array}$ & $\begin{array}{c}\mathrm{pH} \\
\left(23^{\circ} \mathrm{C}\right) \\
\end{array}$ & $\begin{array}{c}\text { Glass } \\
\text { Mass (g) }\end{array}$ & $\mathrm{SA}\left(\mathrm{m}^{2}\right)$ & {$[\mathrm{B}]$} & B Rate & {$[\mathrm{Al}]$} & Al Rate & {$[\mathrm{Na}]$} & Na Rate & [Si] & Si Rate & IEX Rate \\
\hline LC22-6.1 & 0 & 40 & $4.0 \mathrm{E}-05$ & 0.73 & 12 & 0.506 & 0.013 & 629 & 6.23E-02 & 831 & 8.22E-02 & 2,736 & 7.87E-02 & 5,143 & 7.41E-02 & 6.56E-09 \\
\hline LC22-6.2 & 0 & 40 & $4.0 \mathrm{E}-05$ & 2.08 & 12 & 0.504 & 0.010 & 1,092 & $1.37 \mathrm{E}-01$ & 1,247 & $1.54 \mathrm{E}-01$ & 4,264 & 1.55E-01 & 7,417 & $1.34 \mathrm{E}-01$ & 7.33E-09 \\
\hline LC22-6.3 & 0 & 40 & $4.2 \mathrm{E}-05$ & 2.74 & 12 & 0.502 & 0.010 & 1,183 & $1.57 \mathrm{E}-01$ & 1,345 & $1.75 \mathrm{E}-01$ & 4,480 & 1.72E-01 & 8,067 & $1.54 \mathrm{E}-01$ & $6.25 \mathrm{E}-09$ \\
\hline LC22-6.4 & 0 & 40 & $4.0 \mathrm{E}-05$ & 3.77 & 12 & 0.500 & 0.010 & 1,065 & 1.36E-01 & 1,210 & $1.53 \mathrm{E}-01$ & 4,133 & $1.54 \mathrm{E}-01$ & 7,032 & $1.30 \mathrm{E}-01$ & 6.90E-09 \\
\hline LC22-6.5 & 0 & 40 & 4.1E-05 & 4.91 & 12 & 0.498 & 0.010 & 1,076 & $1.40 \mathrm{E}-01$ & 1,233 & $1.58 \mathrm{E}-01$ & 4,136 & $1.56 \mathrm{E}-01$ & 7,140 & $1.34 \mathrm{E}-01$ & 6.47E-09 \\
\hline LC22-6.6 & 0 & 40 & 4.1E-05 & 5.82 & 12 & 0.496 & 0.010 & 1,056 & 1.37E-01 & 1,201 & $1.54 \mathrm{E}-01$ & 4,115 & 1.55E-01 & 6,946 & $1.30 \mathrm{E}-01$ & 7.21E-09 \\
\hline LC22-6.7 & 0 & 40 & 3.8E-05 & 6.81 & 12 & 0.494 & 0.010 & 1,084 & $1.34 \mathrm{E}-01$ & 1,248 & 1.52E-01 & 4,185 & $1.50 \mathrm{E}-01$ & 7,202 & $1.28 \mathrm{E}-01$ & 6.44E-09 \\
\hline LC22-6.8 & 0 & 40 & 4.1E-05 & 7.80 & 12 & 0.492 & 0.010 & 987 & $1.29 \mathrm{E}-01$ & 1,116 & $1.44 \mathrm{E}-01$ & 3,762 & 1.42E-01 & 6,949 & $1.31 \mathrm{E}-01$ & 5.38E-09 \\
\hline LC22-6.9 & 0 & 40 & 4.1E-05 & 9.06 & 12 & 0.489 & 0.010 & 1,220 & $1.60 \mathrm{E}-01$ & 1,386 & 1.79E-01 & 4,548 & 1.73E-01 & 8,126 & $1.54 \mathrm{E}-01$ & 5.23E-09 \\
\hline LC22-6.10 & 0 & 40 & 4.1E-05 & 9.94 & 12 & 0.487 & 0.010 & 1,223 & 1.62E-01 & 1,381 & $1.80 \mathrm{E}-01$ & 4,607 & $1.77 \mathrm{E}-01$ & 8,116 & $1.54 \mathrm{E}-01$ & 6.02E-09 \\
\hline $\begin{array}{c}\text { LC22-6.11 } \\
\text { Exp.\#7 }\end{array}$ & 0 & 40 & $4.0 \mathrm{E}-05$ & 10.86 & 12 & 0.485 & 0.010 & 1,215 & $1.61 \mathrm{E}-01$ & 1,414 & $1.84 \mathrm{E}-01$ & 4,580 & 1.76E-01 & 8,096 & $1.54 \mathrm{E}-01$ & $6.04 \mathrm{E}-09$ \\
\hline LC22-7.0 & 0 & 90 & - & - & 7 & - & - & 13 & - & $<50$ & - & $<5000$ & - & $<5000$ & - & - \\
\hline LC22-7.1 & 0 & 90 & - & - & 7 & - & - & $<10$ & - & $<50$ & - & $<5000$ & - & $<5000$ & - & - \\
\hline LC22-7.2 & 0 & 90 & - & - & 7 & - & - & $<10$ & - & $<50$ & - & $<5000$ & - & $<5000$ & - & - \\
\hline LC22-7.3 & 0 & 90 & $1.7 \mathrm{E}-05$ & 2.05 & 7 & 0.751 & 0.015 & 2,785 & $9.82 \mathrm{E}-02$ & 223 & 7.40E-03 & 11,878 & 7.22E-02 & ND & - & - \\
\hline LC22-7.4 & 0 & 90 & 4.6E-05 & 2.87 & 7 & 0.742 & 0.015 & 6,696 & 6.72E-01 & 158 & $1.44 \mathrm{E}-02$ & 24,997 & 5.91E-01 & ND & - & - \\
\hline LC22-7.5 & 0 & 90 & $5.4 \mathrm{E}-05$ & 3.92 & 7 & 0.731 & 0.015 & 4,141 & 4.84E-01 & 110 & 1.13E-02 & 15,027 & 3.47E-01 & ND & - & - \\
\hline LC22-7.6 & 0 & 90 & $5.9 \mathrm{E}-05$ & 4.89 & 7 & 0.721 & 0.014 & 3,415 & 4.45E-01 & 119 & 1.38E-02 & 12,224 & 2.79E-01 & ND & - & - \\
\hline LC22-7.7 & 0 & 90 & $5.2 \mathrm{E}-05$ & 5.90 & 7 & 0.712 & 0.014 & 3,147 & 3.65E-01 & 121 & $1.26 \mathrm{E}-02$ & 11,221 & $2.15 \mathrm{E}-01$ & ND & - & - \\
\hline LC22-7.8 & 0 & 90 & 5.3E-05 & 6.90 & 7 & 0.705 & 0.014 & 2,989 & 3.58E-01 & 126 & 1.37E-02 & 10,942 & 2.12E-01 & ND & - & - \\
\hline LC22-7.9 & 0 & 90 & 5.3E-05 & 8.16 & 7 & 0.696 & 0.014 & 2,843 & 3.47E-01 & 118 & 1.29E-02 & 10,153 & $1.87 \mathrm{E}-01$ & ND & - & - \\
\hline $\begin{array}{c}\text { LC22-7.10 } \\
\text { Exp. \#8 }\end{array}$ & 0 & 90 & 4.8E-05 & 9.10 & 7 & 0.688 & 0.014 & 3,083 & 3.42E-01 & 97 & $9.44 \mathrm{E}-03$ & 11,001 & $1.98 \mathrm{E}-01$ & ND & - & - \\
\hline LC22-8.0 & 0 & 90 & - & - & 8 & - & - & $<10$ & - & $<50$ & - & $<5000$ & - & $<5000$ & - & - \\
\hline LC22-8.1 & 0 & 90 & - & - & 8 & - & - & $<10$ & - & $<50$ & - & $<5000$ & - & $<5000$ & - & - \\
\hline LC22-8.2 & 0 & 90 & - & - & 8 & - & - & $<10$ & - & $<50$ & - & $<5000$ & - & $<5000$ & - & - \\
\hline LC22-8.3 & 0 & 90 & 5.7E-05 & 2.05 & 8 & 0.750 & 0.015 & 779 & 8.91E-02 & 459 & 5.32E-02 & ND & - & ND & - & - \\
\hline LC22-8.4 & 0 & 90 & 4.8E-05 & 2.87 & 8 & 0.748 & 0.015 & 869 & $8.60 \mathrm{E}-02$ & 679 & 6.82E-02 & ND & - & ND & - & - \\
\hline LC22-8.5 & 0 & 90 & $5.2 \mathrm{E}-05$ & 3.92 & 8 & 0.746 & 0.015 & 825 & 8.83E-02 & 695 & 7.57E-02 & ND & - & ND & - & - \\
\hline LC22-8.6 & 0 & 90 & 5.7E-05 & 4.89 & 8 & 0.744 & 0.015 & 803 & 9.39E-02 & 687 & 8.19E-02 & ND & - & ND & - & - \\
\hline LC22-8.7 & 0 & 90 & 5.3E-05 & 5.90 & 8 & 0.742 & 0.015 & 713 & 7.73E-02 & 595 & 6.63E-02 & ND & - & ND & - & - \\
\hline LC22-8.8 & 0 & 90 & $5.4 \mathrm{E}-05$ & 6.90 & 8 & 0.740 & 0.015 & 736 & 8.12E-02 & 638 & 7.21E-02 & ND & - & ND & - & - \\
\hline LC22-8.9 & 0 & 90 & $5.4 \mathrm{E}-05$ & 8.16 & 8 & 0.738 & 0.015 & 720 & 8.02E-02 & 627 & 7.17E-02 & ND & - & ND & - & - \\
\hline $\begin{array}{c}\text { LC22-8.10 } \\
\text { Exp. \#9 }\end{array}$ & 0 & 90 & $6.0 \mathrm{E}-05$ & 9.10 & 8 & 0.736 & 0.015 & 705 & $8.64 \mathrm{E}-02$ & 627 & $7.90 \mathrm{E}-02$ & ND & - & ND & - & - \\
\hline LC22-9.0 & 0 & 90 & - & - & 9 & - & - & 10 & - & $<50$ & - & $<5000$ & - & $<5000$ & - & - \\
\hline LC22-9.1 & 0 & 90 & - & - & 9 & - & - & $<10$ & - & $<50$ & - & $<5000$ & - & $<5000$ & - & - \\
\hline LC22-9.2 & 0 & 90 & - & - & 9 & - & - & $<10$ & - & $<50$ & - & $<5000$ & - & $<5000$ & - & - \\
\hline LC22-9.3 & 0 & 90 & 5.6E-05 & 2.05 & 9 & 0.500 & 0.010 & 1,268 & $2.21 \mathrm{E}-01$ & 1,138 & $1.98 \mathrm{E}-01$ & 5,455 & $2.41 \mathrm{E}-02$ & 8,076 & 7.98E-02 & - \\
\hline
\end{tabular}


Table A3. SPFT Results for LAWC22 Glasses.

\begin{tabular}{|c|c|c|c|c|c|c|c|c|c|c|c|c|c|c|c|c|}
\hline Sample ID & $\begin{array}{c}\text { Influent } \\
\text { [Si] }\end{array}$ & $\mathrm{T}\left({ }^{\circ} \mathrm{C}\right)$ & $\begin{array}{c}\text { Flow } \\
\text { Rate } \\
\left(\mathrm{m}^{3} / \mathrm{d}\right) \\
\end{array}$ & $\begin{array}{l}\text { Time, } \\
\text { days }\end{array}$ & $\begin{array}{c}\mathrm{pH} \\
\left(23^{\circ} \mathrm{C}\right) \\
\end{array}$ & $\begin{array}{c}\text { Glass } \\
\text { Mass (g) }\end{array}$ & $\mathrm{SA}\left(\mathrm{m}^{2}\right)$ & [B] & B Rate & {$[\mathrm{Al}]$} & Al Rate & {$[\mathrm{Na}]$} & Na Rate & {$[\mathrm{Si}]$} & Si Rate & IEX Rate \\
\hline LC22-9.4 & 0 & 90 & $5.8 \mathrm{E}-05$ & 2.87 & 9 & 0.497 & 0.010 & 1,631 & 3.00E-01 & 1,457 & 2.67E-01 & 6,130 & 6.28E-02 & 10,094 & 1.39E-01 & - \\
\hline LC22-9.5 & 0 & 90 & $5.4 \mathrm{E}-05$ & 3.92 & 9 & 0.492 & 0.010 & 1,632 & 2.79E-01 & 1,493 & 2.54E-01 & 5,787 & 4.06E-02 & 10,141 & $1.30 \mathrm{E}-01$ & - \\
\hline LC22-9.6 & 0 & 90 & 5.3E-05 & 4.89 & 9 & 0.488 & 0.010 & 1,716 & $2.94 \mathrm{E}-01$ & 1,584 & 2.70E-01 & 6,112 & $5.74 \mathrm{E}-02$ & 10,771 & $1.46 \mathrm{E}-01$ & - \\
\hline LC22-9.7 & 0 & 90 & 5.7E-05 & 5.90 & 9 & 0.484 & 0.010 & 1,532 & 2.83E-01 & 1,391 & 2.56E-01 & 5,524 & 2.92E-02 & 9,740 & 1.30E-01 & - \\
\hline LC22-9.8 & 0 & 90 & 5.3E-05 & 6.90 & 9 & 0.480 & 0.009 & 1,500 & 2.59E-01 & 1,420 & 2.44E-01 & 5,303 & 1.58E-02 & 9,696 & $1.20 \mathrm{E}-01$ & - \\
\hline LC22-9.9 & 0 & 90 & 5.3E-05 & 8.16 & 9 & 0.476 & 0.009 & 1,383 & 2.41E-01 & 1,286 & $2.24 \mathrm{E}-01$ & ND & - & 8,837 & 9.95E-02 & - \\
\hline LC22-9.10 & 0 & 90 & 4.7E-05 & 9.10 & 9 & 0.472 & 0.009 & 1,558 & 2.42E-01 & 1,471 & $2.28 \mathrm{E}-01$ & 5,629 & 2.95E-02 & 10,129 & 1.18E-01 & - \\
\hline \multicolumn{17}{|l|}{ Exp. \#10 } \\
\hline LC22-10.0 & 0 & 90 & - & - & 10 & - & - & 115 & - & $<50$ & - & $<5000$ & - & $<5000$ & - & - \\
\hline LC22-10.1 & 0 & 90 & - & - & 10 & - & - & 80 & - & $<50$ & - & $<5000$ & - & $<5000$ & - & - \\
\hline LC22-10.2 & 0 & 90 & - & - & 10 & - & - & 40 & - & $<50$ & - & $<5000$ & - & $<5000$ & - & - \\
\hline LC22-10.3 & 0 & 90 & 5.3E-05 & 2.05 & 10 & 0.498 & 0.010 & 2,938 & 5.01E-01 & 2,308 & $3.76 \mathrm{E}-01$ & 11,478 & 3.29E-01 & 15,556 & 2.62E-01 & - \\
\hline LC22-10.4 & 0 & 90 & $5.6 \mathrm{E}-05$ & 2.87 & 10 & 0.490 & 0.010 & 3,606 & 6.59E-01 & 2,539 & 4.42E-01 & 12,632 & 4.13E-01 & 18,406 & 3.55E-01 & - \\
\hline LC22-10.5 & 0 & 90 & $1.8 \mathrm{E}-05$ & 3.92 & 10 & 0.484 & 0.010 & 4,426 & 2.69E-01 & 2,625 & $1.52 \mathrm{E}-01$ & 15,235 & $1.84 \mathrm{E}-01$ & 21,214 & $1.43 \mathrm{E}-01$ & - \\
\hline LC22-10.6 & 0 & 90 & $5.1 \mathrm{E}-05$ & 4.89 & 10 & 0.477 & 0.009 & 3,868 & 6.59E-01 & 2,391 & 3.87E-01 & 13,419 & 4.25E-01 & 19,311 & 3.54E-01 & - \\
\hline LC22-10.7 & 0 & 90 & $5.2 \mathrm{E}-05$ & 5.90 & 10 & 0.470 & 0.009 & 2,117 & 3.70E-01 & 1,768 & 2.93E-01 & ND & - & 11,478 & $1.66 \mathrm{E}-01$ & - \\
\hline LC22-10.8 & 0 & 90 & 5.6E-05 & 6.90 & 10 & 0.463 & 0.009 & 3,089 & 5.95E-01 & 2,158 & 3.95E-01 & 10,677 & 3.25E-01 & 16,591 & 3.25E-01 & - \\
\hline LC22-10.9 & 0 & 90 & $5.4 \mathrm{E}-05$ & 8.16 & 10 & 0.454 & 0.009 & 2,907 & 5.53E-01 & 2,023 & $3.66 \mathrm{E}-01$ & 10,196 & 2.94E-01 & 15,836 & 3.00E-01 & - \\
\hline LC22-10.10 & 0 & 90 & $5.6 \mathrm{E}-05$ & 9.10 & 10 & 0.445 & 0.009 & 3,180 & 6.30E-01 & 2,598 & 4.92E-01 & 11,047 & 3.56E-01 & 17,975 & 3.74E-01 & - \\
\hline \multicolumn{17}{|l|}{ Exp.\#11 } \\
\hline LC22-11.0 & 0 & 90 & - & - & 11 & - & - & 21 & - & $<50$ & - & $<5000$ & - & $<5000$ & - & - \\
\hline LC22-11.1 & 0 & 90 & - & - & 11 & - & - & 40 & - & $<50$ & - & $<5000$ & - & $<5000$ & - & - \\
\hline LC22-11.2 & 0 & 90 & - & - & 11 & - & - & 56 & - & $<50$ & - & $<5000$ & - & $<5000$ & - & - \\
\hline LC22-11.3 & 0 & 90 & $5.6 \mathrm{E}-05$ & 2.05 & 11 & 0.495 & 0.010 & 4,233 & 7.67E-01 & 3,015 & $5.29 \mathrm{E}-01$ & 15,088 & $5.41 \mathrm{E}-01$ & 23,231 & 4.78E-01 & - \\
\hline LC22-11.4 & 0 & 90 & $5.4 \mathrm{E}-05$ & 2.87 & 11 & 0.483 & 0.010 & 5,623 & $1.01 \mathrm{E}+00$ & 3,325 & 5.76E-01 & 19,758 & $7.80 \mathrm{E}-01$ & 28,473 & $6.07 \mathrm{E}-01$ & - \\
\hline LC22-11.5 & 0 & 90 & $5.4 \mathrm{E}-05$ & 3.92 & 11 & 0.467 & 0.009 & 6,064 & $1.13 \mathrm{E}+00$ & 3,305 & 5.94E-01 & 20,605 & 8.54E-01 & 30,337 & 6.79E-01 & - \\
\hline LC22-11.6 & 0 & 90 & $5.1 \mathrm{E}-05$ & 4.89 & 11 & 0.452 & 0.009 & 6,313 & $1.13 \mathrm{E}+00$ & 3,287 & 5.67E-01 & 21,449 & 8.65E-01 & 31,500 & 6.82E-01 & - \\
\hline LC22-11.7 & 0 & 90 & $5.7 \mathrm{E}-05$ & 5.90 & 11 & 0.436 & 0.009 & 6,140 & $1.28 \mathrm{E}+00$ & 3,003 & $6.07 \mathrm{E}-01$ & 21,133 & $9.94 \mathrm{E}-01$ & 29,990 & $7.54 \mathrm{E}-01$ & - \\
\hline LC22-11.8 & 0 & 90 & 5.3E-05 & 6.90 & 11 & 0.419 & 0.008 & 6,241 & $1.26 \mathrm{E}+00$ & 2,933 & 5.74E-01 & 22,141 & $1.02 \mathrm{E}+00$ & 29,885 & $7.28 \mathrm{E}-01$ & - \\
\hline LC22-11.9 & 0 & 90 & 5.5E-05 & 8.16 & 11 & 0.401 & 0.008 & 5,840 & $1.27 \mathrm{E}+00$ & 2,638 & 5.51E-01 & 19,936 & $9.54 \mathrm{E}-01$ & 28,022 & $7.20 \mathrm{E}-01$ & - \\
\hline LC22-11.10 & 0 & 90 & 5.7E-05 & 9.10 & 11 & 0.385 & 0.008 & 5,842 & $1.37 \mathrm{E}+00$ & 2,699 & 6.13E-01 & 20,207 & $1.05 \mathrm{E}+00$ & 28,282 & 7.91E-01 & - \\
\hline \multicolumn{17}{|l|}{ Exp. \#12 } \\
\hline LC22-12.0 & 0 & 90 & - & - & 12 & - & - & 89 & - & $<50$ & - & $<5000$ & - & $<5000$ & - & - \\
\hline LC22-12.1 & 0 & 90 & - & - & 12 & - & - & 116 & - & $<50$ & - & $<5000$ & - & $<5000$ & - & - \\
\hline LC22-12.2 & 0 & 90 & - & - & 12 & - & - & 144 & - & $<50$ & - & $<5000$ & - & $<5000$ & - & - \\
\hline LC22-12.3 & 0 & 90 & 5.3E-05 & 2.05 & 12 & 0.491 & 0.010 & 6,231 & $1.08 \mathrm{E}+00$ & 5,242 & 8.69E-01 & 25,151 & $1.03 \mathrm{E}+00$ & 35,259 & 7.57E-01 & - \\
\hline LC22-12.4 & 0 & 90 & $5.4 \mathrm{E}-05$ & 2.87 & 12 & 0.464 & 0.009 & 14,544 & $2.68 \mathrm{E}+00$ & 8,926 & $1.58 \mathrm{E}+00$ & 51,960 & $2.54 \mathrm{E}+00$ & 70,659 & $1.74 \mathrm{E}+00$ & - \\
\hline LC22-12.5 & 0 & 90 & $2.4 \mathrm{E}-05$ & 3.92 & 12 & 0.442 & 0.009 & 14,927 & $1.27 \mathrm{E}+00$ & 8,462 & $6.93 \mathrm{E}-01$ & 52,193 & $1.18 \mathrm{E}+00$ & 70,376 & $8.01 \mathrm{E}-01$ & - \\
\hline LC22-12.6 & 0 & 90 & 5.6E-05 & 4.89 & 12 & 0.405 & 0.008 & 17,559 & $3.82 \mathrm{E}+00$ & 9,084 & $1.90 \mathrm{E}+00$ & 60,967 & $3.57 \mathrm{E}+00$ & 80,760 & $2.37 \mathrm{E}+00$ & - \\
\hline LC22-12.7 & 0 & 90 & $5.4 \mathrm{E}-05$ & 5.90 & 12 & 0.370 & 0.008 & 11,283 & $2.58 \mathrm{E}+00$ & 6,332 & $1.38 \mathrm{E}+00$ & 38,804 & $2.27 \mathrm{E}+00$ & 54,004 & $1.61 \mathrm{E}+00$ & - \\
\hline
\end{tabular}


Table A3. SPFT Results for LAWC22 Glasses.

\begin{tabular}{|c|c|c|c|c|c|c|c|c|c|c|c|c|c|c|c|c|}
\hline Sample ID & $\begin{array}{c}\text { Influent } \\
\text { [Si] }\end{array}$ & $\mathrm{T}\left({ }^{\circ} \mathrm{C}\right)$ & $\begin{array}{c}\text { Flow } \\
\text { Rate } \\
\left(\mathrm{m}^{3} / \mathrm{d}\right) \\
\end{array}$ & $\begin{array}{l}\text { Time, } \\
\text { days }\end{array}$ & $\begin{array}{c}\mathrm{pH} \\
\left(23^{\circ} \mathrm{C}\right) \\
\end{array}$ & $\begin{array}{c}\text { Glass } \\
\text { Mass (g) }\end{array}$ & $\mathrm{SA}\left(\mathrm{m}^{2}\right)$ & [B] & B Rate & {$[\mathrm{Al}]$} & Al Rate & {$[\mathrm{Na}]$} & Na Rate & [Si] & Si Rate & IEX Rate \\
\hline LC22-12.8 & 0 & 90 & 5.3E-05 & 6.90 & 12 & 0.344 & 0.007 & 9,825 & $2.38 \mathrm{E}+00$ & 5,843 & $1.36 \mathrm{E}+00$ & 33,779 & $2.05 E+00$ & 48,938 & $1.53 \mathrm{E}+00$ & - \\
\hline LC22-12.9 & 0 & 90 & $5.5 \mathrm{E}-05$ & 8.16 & 12 & 0.316 & 0.006 & 8,767 & $2.42 \mathrm{E}+00$ & 5,259 & $1.38 \mathrm{E}+00$ & 29,844 & $2.01 \mathrm{E}+00$ & 43,639 & $1.53 \mathrm{E}+00$ & - \\
\hline LC22-12.10 & 0 & 90 & 4.4E-05 & 9.10 & 12 & 0.294 & 0.006 & 9,275 & $2.18 \mathrm{E}+00$ & 5,597 & $1.26 \mathrm{E}+00$ & 31,357 & $1.82 \mathrm{E}+00$ & 46,167 & $1.39 \mathrm{E}+00$ & - \\
\hline \multicolumn{17}{|l|}{ Exp. \#13 } \\
\hline LC22-13A & $8.97 E+02$ & 23 & - & - & 9 & - & - & $<75$ & - & $<25$ & - & $<300$ & - & $<1500$ & - & - \\
\hline LC22-13B & $8.97 \mathrm{E}+02$ & 23 & - & - & 9 & - & - & $<75$ & - & $<25$ & - & $<300$ & - & $<1500$ & - & - \\
\hline LC22-13C & $8.97 \mathrm{E}+02$ & 23 & - & - & 9 & - & - & $<75$ & - & $<25$ & - & $<300$ & - & $<1500$ & - & - \\
\hline LC22-13.4 & $8.97 E+02$ & 23 & $9.9 \mathrm{E}-06$ & 7.12 & 9 & 4.019 & 0.050 & 583 & 3.53E-03 & 343 & 1.64E-03 & 2,857 & 4.73E-03 & 3,169 & $1.51 \mathrm{E}-03$ & $4.79 \mathrm{E}-10$ \\
\hline LC22-13.8 & $8.97 E+02$ & 23 & $9.7 \mathrm{E}-06$ & 14.25 & 9 & 4.018 & 0.079 & 550 & 2.06E-03 & 376 & 1.15E-03 & 2,187 & $2.16 \mathrm{E}-03$ & 3,120 & $9.09 \mathrm{E}-04$ & $4.79 \mathrm{E}-10$ \\
\hline LC22-13.12 & $8.97 E+02$ & 23 & $9.5 \mathrm{E}-06$ & 22.22 & 9 & 4.018 & 0.079 & 615 & 2.27E-03 & 563 & $1.82 \mathrm{E}-03$ & 1,962 & 1.87E-03 & 3,930 & 1.34E-03 & 4.79E-10 \\
\hline LC22-13.16 & $8.97 \mathrm{E}+02$ & 23 & 9.5E-06 & 33.09 & 9 & 4.017 & 0.079 & 635 & 2.34E-03 & 542 & $1.74 \mathrm{E}-03$ & 2,041 & $1.95 \mathrm{E}-03$ & 3,888 & $1.31 \mathrm{E}-03$ & $4.79 \mathrm{E}-10$ \\
\hline LC22-13.20 & $8.97 \mathrm{E}+02$ & 23 & 9.6E-06 & 42.48 & 9 & 4.016 & 0.079 & 561 & 2.07E-03 & 458 & $1.44 \mathrm{E}-03$ & 1,923 & 1.84E-03 & 3,368 & $1.04 \mathrm{E}-03$ & 4.79E-10 \\
\hline LC22-13.24 & $8.97 \mathrm{E}+02$ & 23 & $1.1 \mathrm{E}-05$ & 52.10 & 9 & 4.016 & 0.079 & 463 & 1.93E-03 & 408 & $1.43 \mathrm{E}-03$ & 1,527 & $1.58 \mathrm{E}-03$ & 2,948 & $9.15 \mathrm{E}-04$ & 4.79E-10 \\
\hline LC22-13.28 & $8.97 \mathrm{E}+02$ & 23 & $9.6 \mathrm{E}-06$ & 68.08 & 9 & 4.015 & 0.079 & 419 & $1.54 \mathrm{E}-03$ & 417 & $1.30 \mathrm{E}-03$ & ND & $1.05 \mathrm{E}-03$ & 2,734 & $6.89 \mathrm{E}-04$ & 4.79E-10 \\
\hline LC22-13.32 & $8.97 E+02$ & 23 & $9.8 \mathrm{E}-06$ & 86.08 & 9 & 4.014 & 0.079 & 440 & 1.65E-03 & 414 & $1.30 \mathrm{E}-03$ & ND & $1.26 \mathrm{E}-03$ & 2,844 & 7.63E-04 & 4.79E-10 \\
\hline LC22-13.34 & $8.97 \mathrm{E}+02$ & 23 & 9.7E-06 & 93.15 & 9 & 4.013 & 0.079 & 429 & $1.59 \mathrm{E}-03$ & 391 & $1.21 \mathrm{E}-03$ & ND & $1.25 \mathrm{E}-03$ & 2,757 & 7.07E-04 & $4.79 \mathrm{E}-10$ \\
\hline LC22-13.35 & $8.97 E+02$ & 23 & $9.6 \mathrm{E}-06$ & 96.01 & 9 & 4.012 & 0.079 & 470 & 1.73E-03 & 496 & $1.59 \mathrm{E}-03$ & ND & 1.18E-03 & 3,105 & 8.92E-04 & $4.79 \mathrm{E}-10$ \\
\hline Exp. \#14 & & & & & & & & & & & & & & 16,562 & & \\
\hline LC22-14A & $1.51 \mathrm{E}+04$ & 23 & - & - & 9 & - & - & $<75$ & - & $<25$ & - & $<300$ & - & 16,737 & - & - \\
\hline LC22-14B & $1.51 \mathrm{E}+04$ & 23 & - & - & 9 & - & - & $<75$ & - & $<25$ & - & $<300$ & - & 16,820 & - & - \\
\hline LC22-14C & $1.51 \mathrm{E}+04$ & 23 & - & - & 9 & - & - & $<75$ & - & $<25$ & - & $<300$ & - & & - & - \\
\hline LC22-14.4 & $1.51 \mathrm{E}+04$ & 23 & $9.8 \mathrm{E}-06$ & 7.12 & 9 & 4.019 & 0.050 & 403 & 2.38E-03 & 112 & 2.27E-04 & 2,306 & 3.70E-03 & 18,118 & $1.27 \mathrm{E}-03$ & $5.25 \mathrm{E}-10$ \\
\hline LC22-14.8 & $1.51 \mathrm{E}+04$ & 23 & $9.7 \mathrm{E}-06$ & 14.25 & 9 & 4.018 & 0.079 & 366 & $1.34 \mathrm{E}-03$ & 99 & 9.27E-05 & 1,674 & 1.57E-03 & 18,102 & 7.83E-04 & $9.43 \mathrm{E}-11$ \\
\hline LC22-14.12 & $1.51 \mathrm{E}+04$ & 23 & $9.4 \mathrm{E}-06$ & 22.22 & 9 & 4.018 & 0.079 & 456 & $1.64 \mathrm{E}-03$ & 237 & 5.97E-04 & 1,534 & $1.37 \mathrm{E}-03$ & 19,608 & $1.58 \mathrm{E}-03$ & - \\
\hline LC22-14.16 & $1.51 \mathrm{E}+04$ & 23 & $9.5 \mathrm{E}-06$ & 33.09 & 9 & 4.018 & 0.079 & 475 & $1.73 \mathrm{E}-03$ & 226 & $5.66 \mathrm{E}-04$ & 1,580 & $1.44 \mathrm{E}-03$ & 19,591 & $1.59 \mathrm{E}-03$ & - \\
\hline LC22-14.20 & $1.51 \mathrm{E}+04$ & 23 & 9.6E-06 & 42.48 & 9 & 4.017 & 0.079 & 409 & $1.49 \mathrm{E}-03$ & 154 & 2.99E-04 & ND & $1.16 \mathrm{E}-03$ & 18,310 & 8.94E-04 & - \\
\hline LC22-14.24 & $1.51 \mathrm{E}+04$ & 23 & $1.1 \mathrm{E}-05$ & 52.10 & 9 & 4.017 & 0.079 & 367 & $1.52 \mathrm{E}-03$ & 126 & 2.18E-04 & ND & 1.12E-03 & 17,791 & 6.89E-04 & - \\
\hline LC22-14.28 & $1.51 \mathrm{E}+04$ & 23 & 9.7E-06 & 68.08 & 9 & 4.016 & 0.079 & 315 & $1.13 \mathrm{E}-03$ & 109 & $1.29 \mathrm{E}-04$ & ND & $8.31 \mathrm{E}-04$ & 17,828 & $6.28 \mathrm{E}-04$ & - \\
\hline LC22-14.32 & $1.51 \mathrm{E}+04$ & 23 & $9.9 \mathrm{E}-06$ & 86.08 & 9 & 4.015 & 0.079 & 335 & $1.23 \mathrm{E}-03$ & 107 & $1.25 \mathrm{E}-04$ & ND & 8.25E-04 & 17,813 & $6.31 \mathrm{E}-04$ & - \\
\hline LC22-14.34 & $1.51 \mathrm{E}+04$ & 23 & $9.9 \mathrm{E}-06$ & 93.15 & 9 & 4.015 & 0.079 & 263 & $9.54 \mathrm{E}-04$ & ND & - & ND & $7.94 \mathrm{E}-04$ & 26,008 & 5.33E-03 & - \\
\hline LC22-14.35 & $1.51 \mathrm{E}+04$ & 23 & $9.8 \mathrm{E}-06$ & 96.01 & 9 & 4.014 & 0.079 & 266 & $9.51 \mathrm{E}-04$ & 113 & $1.46 \mathrm{E}-04$ & ND & $6.41 \mathrm{E}-04$ & 21,511 & 2.72E-03 & - \\
\hline \multicolumn{17}{|l|}{ Exp. \#15 } \\
\hline LC22-15A & $3.01 E+04$ & 23 & - & - & 9 & - & - & $<75$ & - & $<25$ & - & $<300$ & - & 34,050 & - & - \\
\hline LC22-15B & $3.01 \mathrm{E}+04$ & 23 & - & - & 9 & - & - & $<75$ & - & $<25$ & - & $<300$ & - & 33,267 & - & - \\
\hline LC22-15C & $3.01 \mathrm{E}+04$ & 23 & - & - & 9 & - & - & $<75$ & - & $<25$ & - & $<300$ & - & 33,880 & - & - \\
\hline LC22-15.4 & $3.01 \mathrm{E}+04$ & 23 & $9.8 \mathrm{E}-06$ & 7.12 & 9 & 4.029 & 0.050 & 319 & $1.84 \mathrm{E}-03$ & 75 & $3.00 \mathrm{E}-06$ & 2,002 & 3.12E-03 & 34,851 & $1.00 \mathrm{E}-03$ & $5.10 \mathrm{E}-10$ \\
\hline LC22-15.8 & $3.01 \mathrm{E}+04$ & 23 & $9.7 \mathrm{E}-06$ & 14.25 & 9 & 4.029 & 0.079 & 257 & $9.05 \mathrm{E}-04$ & ND & - & ND & $1.22 \mathrm{E}-03$ & 35,190 & 8.16E-04 & $1.27 \mathrm{E}-10$ \\
\hline LC22-15.12 & $3.01 \mathrm{E}+04$ & 23 & $9.4 \mathrm{E}-06$ & 22.22 & 9 & 4.028 & 0.079 & 310 & $1.08 \mathrm{E}-03$ & 120 & $1.66 \mathrm{E}-04$ & ND & $1.02 \mathrm{E}-03$ & 36,441 & $1.47 \mathrm{E}-03$ & - \\
\hline LC22-15.16 & $3.01 \mathrm{E}+04$ & 23 & $9.5 \mathrm{E}-06$ & 33.09 & 9 & 4.028 & 0.079 & 367 & $1.31 \mathrm{E}-03$ & 130 & 2.04E-04 & ND & $1.09 \mathrm{E}-03$ & 35,755 & $1.11 \mathrm{E}-03$ & - \\
\hline LC22-15.20 & $3.01 \mathrm{E}+04$ & 23 & $9.5 \mathrm{E}-06$ & 42.48 & 9 & 4.028 & 0.079 & 283 & $9.90 \mathrm{E}-04$ & 78 & $1.04 \mathrm{E}-05$ & ND & 7.19E-04 & 34,858 & $6.19 \mathrm{E}-04$ & - \\
\hline
\end{tabular}


Table A3. SPFT Results for LAWC22 Glasses.

\begin{tabular}{|c|c|c|c|c|c|c|c|c|c|c|c|c|c|c|c|c|}
\hline Sample ID & $\begin{array}{c}\text { Influent } \\
\text { [Si] }\end{array}$ & $\mathrm{T}\left({ }^{\circ} \mathrm{C}\right)$ & $\begin{array}{c}\text { Flow } \\
\text { Rate } \\
\left(\mathrm{m}^{3} / \mathrm{d}\right) \\
\end{array}$ & $\begin{array}{c}\text { Time, } \\
\text { days }\end{array}$ & $\begin{array}{c}\mathrm{pH} \\
\left(23^{\circ} \mathrm{C}\right) \\
\end{array}$ & $\begin{array}{c}\text { Glass } \\
\text { Mass (g) }\end{array}$ & $\mathrm{SA}\left(\mathrm{m}^{2}\right)$ & [B] & B Rate & {$[\mathrm{Al}]$} & Al Rate & {$[\mathrm{Na}]$} & Na Rate & [Si] & Si Rate & IEX Rate \\
\hline LC22-15.24 & $3.01 E+04$ & 23 & $1.1 \mathrm{E}-05$ & 52.10 & 9 & 4.027 & 0.079 & 197 & $7.52 \mathrm{E}-04$ & ND & - & ND & $4.68 \mathrm{E}-04$ & 34,285 & $3.46 \mathrm{E}-04$ & - \\
\hline LC22-15.28 & $3.01 E+04$ & 23 & $9.6 \mathrm{E}-06$ & 68.08 & 9 & 4.027 & 0.079 & 143 & 4.54E-04 & ND & - & ND & $1.80 \mathrm{E}-04$ & 34,928 & $6.60 \mathrm{E}-04$ & - \\
\hline LC22-15.32 & $3.01 E+04$ & 23 & $9.7 \mathrm{E}-06$ & 86.08 & 9 & 4.027 & 0.079 & 146 & $4.70 \mathrm{E}-04$ & ND & - & ND & $1.21 \mathrm{E}-04$ & 35,765 & 1.13E-03 & - \\
\hline LC22-15.34 & $3.01 E+04$ & 23 & $9.6 \mathrm{E}-06$ & 93.15 & 9 & 4.027 & 0.079 & 114 & $3.48 \mathrm{E}-04$ & ND & - & ND & 2.32E-04 & 44,486 & $5.99 \mathrm{E}-03$ & - \\
\hline LC22-15.35 & $3.01 \mathrm{E}+04$ & 23 & $9.5 \mathrm{E}-06$ & 96.01 & 9 & 4.026 & 0.079 & 117 & 3.54E-04 & $\mathrm{ND}$ & - & ND & $1.19 \mathrm{E}-04$ & 38,972 & 2.89E-03 & - \\
\hline \multicolumn{17}{|l|}{ Exp. \#16 } \\
\hline LC22-16A & $4.60 \mathrm{E}+04$ & 23 & - & - & 9 & - & - & $<75$ & - & $<25$ & - & $<300$ & - & 50,494 & - & - \\
\hline LC22-16B & $4.60 \mathrm{E}+04$ & 23 & - & - & 9 & - & - & $<75$ & - & $<25$ & - & $<300$ & - & 51,318 & - & - \\
\hline LC22-16C & $4.60 \mathrm{E}+04$ & 23 & - & - & 9 & - & - & $<75$ & - & $<25$ & - & $<300$ & - & 50,956 & - & - \\
\hline LC22-16.4 & $4.60 \mathrm{E}+04$ & 23 & $9.9 \mathrm{E}-06$ & 7.12 & 9 & 4.043 & 0.050 & 252 & $1.43 \mathrm{E}-03$ & ND & - & 1,869 & 2.89E-03 & 52,219 & 1.17E-03 & $5.84 \mathrm{E}-10$ \\
\hline LC22-16.8 & $4.60 \mathrm{E}+04$ & 23 & $9.9 \mathrm{E}-06$ & 14.25 & 9 & 4.043 & 0.080 & 172 & 5.81E-04 & ND & - & ND & 8.76E-04 & 52,641 & $9.76 \mathrm{E}-04$ & $1.17 \mathrm{E}-10$ \\
\hline LC22-16.12 & $4.60 \mathrm{E}+04$ & 23 & $9.4 \mathrm{E}-06$ & 22.22 & 9 & 4.043 & 0.080 & 155 & 4.92E-04 & ND & - & ND & 5.53E-04 & 52,679 & $9.54 \mathrm{E}-04$ & $2.45 \mathrm{E}-11$ \\
\hline LC22-16.16 & $4.60 \mathrm{E}+04$ & 23 & $9.6 \mathrm{E}-06$ & 33.09 & 9 & 4.042 & 0.080 & 179 & 5.98E-04 & ND & - & ND & 4.62E-04 & 52,155 & 6.83E-04 & - \\
\hline LC22-16.20 & $4.60 \mathrm{E}+04$ & 23 & 9.7E-06 & 42.48 & 9 & 4.042 & 0.080 & 133 & $4.20 \mathrm{E}-04$ & ND & - & ND & $1.55 \mathrm{E}-04$ & 50,432 & - & - \\
\hline LC22-16.24 & $4.60 \mathrm{E}+04$ & 23 & $1.1 \mathrm{E}-05$ & 52.10 & 9 & 4.042 & 0.080 & 85 & 2.65E-04 & $\mathrm{ND}$ & - & ND & ND & 51,732 & 5.12E-04 & - \\
\hline LC22-16.28 & $4.60 \mathrm{E}+04$ & 23 & 9.7E-06 & 68.08 & 9 & 4.042 & 0.080 & 57 & $1.25 \mathrm{E}-04$ & ND & - & ND & ND & 49,389 & - & - \\
\hline LC22-16.32 & $4.60 \mathrm{E}+04$ & 23 & $9.7 \mathrm{E}-06$ & 86.08 & 9 & 4.042 & 0.080 & 45 & 7.95E-05 & ND & - & ND & ND & 53,499 & $1.44 \mathrm{E}-03$ & - \\
\hline LC22-16.34 & $4.60 \mathrm{E}+04$ & 23 & $9.8 \mathrm{E}-06$ & 93.15 & 9 & 4.042 & 0.080 & 41 & $6.11 \mathrm{E}-05$ & ND & - & ND & ND & 45,589 & - & - \\
\hline LC22-16.35 & $4.60 \mathrm{E}+04$ & 23 & $9.6 \mathrm{E}-06$ & 96.01 & 9 & 4.042 & 0.080 & 47 & 8.53E-05 & ND & - & ND & ND & 47,787 & - & - \\
\hline \multicolumn{17}{|l|}{ Exp. \#17 } \\
\hline LC22-17A & $6.04 \mathrm{E}+04$ & 23 & - & - & 9 & - & - & $<25$ & - & $<75$ & - & $<300$ & - & 66,537 & - & - \\
\hline LC22-17B & $6.04 \mathrm{E}+04$ & 23 & - & - & 9 & - & - & $<25$ & - & $<75$ & - & $<300$ & - & 67,719 & - & - \\
\hline LC22-17C & $6.04 \mathrm{E}+04$ & 23 & - & - & 9 & - & - & $<25$ & - & $<75$ & - & $<300$ & - & 68,493 & - & - \\
\hline LC22-17.4 & $6.04 \mathrm{E}+04$ & 23 & $9.9 \mathrm{E}-06$ & 7.12 & 9 & 4.024 & 0.050 & 219 & $1.23 \mathrm{E}-03$ & ND & - & 1,652 & $2.51 \mathrm{E}-03$ & 67,528 & - & $5.10 \mathrm{E}-10$ \\
\hline LC22-17.8 & $6.04 \mathrm{E}+04$ & 23 & 9.7E-06 & 14.25 & 9 & 4.024 & 0.079 & 129 & 4.07E-04 & ND & - & ND & $6.95 \mathrm{E}-04$ & 67,729 & $8.21 \mathrm{E}-05$ & 1.15E-10 \\
\hline LC22-17.12 & $6.04 \mathrm{E}+04$ & 23 & $9.7 \mathrm{E}-06$ & 22.22 & 9 & 4.024 & 0.079 & 110 & 3.33E-04 & ND & - & ND & $4.20 \mathrm{E}-04$ & 69,279 & $9.50 \mathrm{E}-04$ & $3.47 \mathrm{E}-11$ \\
\hline LC22-17.16 & $6.04 \mathrm{E}+04$ & 23 & 9.5E-06 & 33.09 & 9 & 4.024 & 0.079 & 108 & $3.16 \mathrm{E}-04$ & ND & - & ND & $1.91 \mathrm{E}-04$ & 69,906 & $1.27 \mathrm{E}-03$ & - \\
\hline LC22-17.20 & $6.04 \mathrm{E}+04$ & 23 & 9.6E-06 & 42.48 & 9 & 4.023 & 0.079 & 79 & $2.10 \mathrm{E}-04$ & ND & - & ND & - & 65,455 & - & - \\
\hline LC22-17.24 & $6.04 \mathrm{E}+04$ & 23 & $1.1 \mathrm{E}-05$ & 52.10 & 9 & 4.023 & 0.079 & 49 & $1.08 \mathrm{E}-04$ & ND & - & ND & - & 73,149 & $3.54 \mathrm{E}-03$ & - \\
\hline LC22-17.28 & $6.04 \mathrm{E}+04$ & 23 & $9.5 \mathrm{E}-06$ & 68.08 & 9 & 4.023 & 0.079 & 32 & 2.84E-05 & ND & - & ND & - & 66,828 & - & - \\
\hline LC22-17.32 & $6.04 \mathrm{E}+04$ & 23 & 9.7E-06 & 86.08 & 9 & 4.023 & 0.079 & 25 & - & ND & - & ND & - & 66,252 & - & - \\
\hline LC22-17.34 & $6.04 \mathrm{E}+04$ & 23 & $9.7 \mathrm{E}-06$ & 93.15 & 9 & 4.023 & 0.079 & ND & - & $\mathrm{ND}$ & - & ND & - & 60,505 & - & - \\
\hline LC22-17.35 & $6.04 \mathrm{E}+04$ & 23 & $1.1 \mathrm{E}-05$ & 96.01 & 9 & 4.023 & 0.079 & 27 & 7.59E-06 & ND & - & ND & - & 65,206 & - & - \\
\hline \multicolumn{17}{|l|}{ Exp. \#18 } \\
\hline LC22-18A & $5.24 \mathrm{E}+04$ & 23 & - & - & 9 & - & - & $<25$ & - & $<75$ & - & $<300$ & - & 52,478 & - & - \\
\hline LC22-18B & $5.24 \mathrm{E}+04$ & 23 & - & - & 9 & - & - & $<25$ & - & $<75$ & - & $<300$ & - & 58,366 & - & - \\
\hline LC22-18C & $5.24 \mathrm{E}+04$ & 23 & - & - & 9 & - & - & $<25$ & - & $<75$ & - & $<300$ & - & 64,021 & - & - \\
\hline LC22-18.4 & $5.24 \mathrm{E}+04$ & 23 & $9.8 \mathrm{E}-06$ & 7.12 & 9 & 4.006 & 0.050 & 219 & $1.22 \mathrm{E}-03$ & ND & - & 1,709 & $2.59 \mathrm{E}-03$ & 80,716 & $2.02 \mathrm{E}-02$ & $5.49 \mathrm{E}-10$ \\
\hline LC22-18.8 & $5.24 \mathrm{E}+04$ & 23 & 9.7E-06 & 14.25 & 9 & 4.006 & 0.079 & 126 & $3.96 \mathrm{E}-04$ & ND & - & ND & 7.72E-04 & 83,342 & $1.41 \mathrm{E}-02$ & $1.50 \mathrm{E}-10$ \\
\hline LC22-18.12 & $5.24 \mathrm{E}+04$ & 23 & $9.5 \mathrm{E}-06$ & 22.22 & 9 & 4.006 & 0.079 & 94 & 2.64E-04 & ND & - & ND & $4.09 \mathrm{E}-04$ & 87,968 & $1.64 \mathrm{E}-02$ & $5.76 \mathrm{E}-11$ \\
\hline
\end{tabular}


Table A3. SPFT Results for LAWC22 Glasses.

\begin{tabular}{|c|c|c|c|c|c|c|c|c|c|c|c|c|c|c|c|c|}
\hline Sample ID & $\begin{array}{c}\text { Influent } \\
\text { [Si] }\end{array}$ & $\mathrm{T}\left({ }^{\circ} \mathrm{C}\right)$ & $\begin{array}{c}\text { Flow } \\
\text { Rate } \\
\left(\mathrm{m}^{3} / \mathrm{d}\right) \\
\end{array}$ & $\begin{array}{c}\text { Time, } \\
\text { days }\end{array}$ & $\begin{array}{c}\mathrm{pH} \\
\left(23^{\circ} \mathrm{C}\right) \\
\end{array}$ & $\begin{array}{c}\text { Glass } \\
\text { Mass (g) }\end{array}$ & $\mathrm{SA}\left(\mathrm{m}^{2}\right)$ & {$[\mathrm{B}]$} & B Rate & {$[\mathrm{Al}]$} & Al Rate & {$[\mathrm{Na}]$} & Na Rate & {$[\mathrm{Si}]$} & Si Rate & IEX Rate \\
\hline LC22-18.16 & $5.24 \mathrm{E}+04$ & 23 & $9.6 \mathrm{E}-06$ & 33.09 & 9 & 4.006 & 0.079 & 67 & 1.63E-04 & ND & - & ND & 1.05E-04 & 86,660 & $1.57 \mathrm{E}-02$ & - \\
\hline LC22-18.20 & $5.24 \mathrm{E}+04$ & 23 & 9.6E-06 & 42.48 & 9 & 4.006 & 0.079 & 47 & 8.68E-05 & ND & - & ND & - & 84,554 & 1.47E-02 & - \\
\hline LC22-18.24 & $5.24 \mathrm{E}+04$ & 23 & $1.1 \mathrm{E}-05$ & 52.10 & 9 & 4.005 & 0.079 & 28 & $1.51 \mathrm{E}-05$ & ND & - & ND & - & 83,996 & 1.65E-02 & - \\
\hline LC22-18.28 & $5.24 \mathrm{E}+04$ & 23 & $9.6 \mathrm{E}-06$ & 68.08 & 9 & 4.005 & 0.079 & ND & - & ND & - & ND & - & 79,439 & 1.17E-02 & - \\
\hline LC22-18.32 & $5.24 \mathrm{E}+04$ & 23 & $9.8 \mathrm{E}-06$ & 86.08 & 9 & 4.005 & 0.079 & ND & - & ND & - & ND & - & 87,437 & 1.65E-02 & - \\
\hline LC22-18.34 & $5.24 \mathrm{E}+04$ & 23 & $9.8 \mathrm{E}-06$ & 93.15 & 9 & 4.005 & 0.079 & ND & - & ND & - & ND & - & 77,134 & 1.07E-02 & - \\
\hline LC22-18.35 & $5.24 \mathrm{E}+04$ & 23 & 9.7E-06 & 96.01 & 9 & 4.005 & 0.079 & ND & - & ND & - & ND & - & 80,981 & $1.28 \mathrm{E}-02$ & - \\
\hline \multicolumn{17}{|l|}{ Exp. \#19 } \\
\hline LC22-19A & 0 & 23 & - & - & 7 & - & - & $<50$ & - & $<10$ & - & $<100$ & - & $<500$ & - & - \\
\hline LC22-19B & 0 & 23 & - & - & 7 & - & - & $<50$ & - & $<10$ & - & $<100$ & - & $<500$ & - & - \\
\hline LC22-19C & 0 & 23 & - & - & 7 & - & - & $<50$ & - & 11 & - & $<100$ & - & $<500$ & - & - \\
\hline LC22-19.1 & 0 & 23 & 7.4E-06 & 2.05 & 7 & 1.004 & 0.020 & 261 & $2.51 \mathrm{E}-03$ & 42 & 3.71E-04 & 1,956 & $6.47 \mathrm{E}-03$ & ND & - & $1.58 \mathrm{E}-09$ \\
\hline LC22-19.2 & 0 & 23 & $8.8 \mathrm{E}-06$ & 3.84 & 7 & 1.004 & 0.020 & 245 & $2.78 \mathrm{E}-03$ & ND & - & 1,760 & $6.90 \mathrm{E}-03$ & ND & - & 1.65E-09 \\
\hline LC22-19.4 & 0 & 23 & $9.2 \mathrm{E}-06$ & 8.85 & 7 & 1.004 & 0.020 & 160 & 1.63E-03 & 10 & - & 1,044 & $4.12 \mathrm{E}-03$ & ND & - & $9.92 \mathrm{E}-10$ \\
\hline LC22-19.6 & 0 & 23 & 7.9E-06 & 15.82 & 7 & 1.003 & 0.020 & ND & - & 41 & 3.81E-04 & 372 & $1.01 \mathrm{E}-03$ & ND & - & 4.32E-10 \\
\hline LC22-19.9 & 0 & 23 & $9.6 \mathrm{E}-06$ & 22.81 & 7 & 1.003 & 0.020 & ND & - & 40 & 4.42E-04 & 204 & $4.75 \mathrm{E}-04$ & ND & - & 3.15E-10 \\
\hline LC22-19.12 & 0 & 23 & 9.7E-06 & 30.98 & 7 & 1.003 & 0.020 & ND & - & 34 & 3.57E-04 & 159 & $2.72 \mathrm{E}-04$ & ND & - & $2.88 \mathrm{E}-10$ \\
\hline LC22-19.14 & 0 & 23 & $9.8 \mathrm{E}-06$ & 38.92 & 7 & 1.003 & 0.020 & ND & - & 32 & 3.36E-04 & 146 & $2.11 \mathrm{E}-04$ & ND & - & $2.64 \mathrm{E}-10$ \\
\hline \multicolumn{17}{|l|}{ Exp. \#20 } \\
\hline LC22-20A & 0 & 23 & - & - & 8 & - & - & $<50$ & - & $<10$ & - & $<100$ & - & $<500$ & - & - \\
\hline LC22-20B & 0 & 23 & - & - & 8 & - & - & $<50$ & - & $<10$ & - & $<100$ & - & $<500$ & - & - \\
\hline LC22-20C & 0 & 23 & - & - & 8 & - & - & $<50$ & - & $<10$ & - & $<100$ & - & $<500$ & - & - \\
\hline LC22-20.1 & 0 & 23 & $9.2 \mathrm{E}-06$ & 2.05 & 8 & 1.005 & 0.020 & 153 & 1.53E-03 & 21 & $1.58 \mathrm{E}-04$ & 1,359 & $1.36 \mathrm{E}+03$ & ND & - & $1.58 \mathrm{E}-09$ \\
\hline LC22-20.2 & 0 & 23 & $9.6 \mathrm{E}-06$ & 3.84 & 8 & 1.005 & 0.020 & 133 & $1.28 \mathrm{E}-03$ & 34 & 3.59E-04 & 1,099 & $1.10 \mathrm{E}+03$ & ND & - & $1.30 \mathrm{E}-09$ \\
\hline LC22-20.4 & 0 & 23 & $1.0 \mathrm{E}-05$ & 8.85 & 8 & 1.005 & 0.020 & 79 & 4.74E-04 & 43 & 5.19E-04 & 611 & $6.11 \mathrm{E}+02$ & ND & - & 7.70E-10 \\
\hline LC22-20.6 & 0 & 23 & 4.7E-06 & 15.82 & 8 & 1.005 & 0.020 & 83 & $2.56 \mathrm{E}-04$ & ND & - & 543 & $5.43 \mathrm{E}+02$ & ND & - & $2.94 \mathrm{E}-10$ \\
\hline LC22-20.9 & 0 & 23 & 8.6E-06 & 22.81 & 8 & 1.005 & 0.020 & ND & - & ND & - & 287 & $2.87 \mathrm{E}+02$ & ND & - & $3.31 \mathrm{E}-10$ \\
\hline LC22-20.12 & 0 & 23 & $9.1 \mathrm{E}-06$ & 30.98 & 8 & 1.005 & 0.020 & ND & - & ND & - & 220 & $2.20 \mathrm{E}+02$ & ND & - & $2.99 \mathrm{E}-10$ \\
\hline LC22-20.14 & 0 & 23 & 8.9E-06 & 38.92 & 8 & 1.005 & 0.020 & ND & - & ND & 4.60E-06 & 185 & $1.85 \mathrm{E}+02$ & ND & - & $2.51 \mathrm{E}-10$ \\
\hline \multicolumn{17}{|l|}{ Exp.\#21 } \\
\hline LC22-21A & 0 & 23 & - & - & 9 & - & - & $<50$ & - & 14 & - & $<100$ & - & $<500$ & - & - \\
\hline LC22-21B & 0 & 23 & - & - & 9 & - & - & $<50$ & - & 152 & - & $<100$ & - & $<500$ & - & - \\
\hline LC22-21C & 0 & 23 & - & - & 9 & - & - & $<50$ & - & 14 & - & $<100$ & - & $<500$ & - & - \\
\hline LC22-21.1 & 0 & 23 & $9.0 \mathrm{E}-06$ & 2.05 & 9 & 1.004 & 0.020 & 132 & $1.20 \mathrm{E}-03$ & 64 & 5.54E-05 & 1,231 & 4.82E-03 & 500 & 8.13E-07 & 1.45E-09 \\
\hline LC22-21.2 & 0 & 23 & $9.7 \mathrm{E}-06$ & 3.84 & 9 & 1.004 & 0.020 & 157 & $1.67 \mathrm{E}-03$ & 112 & 7.92E-04 & 1,116 & $4.66 \mathrm{E}-03$ & 830 & 7.42E-04 & 1.19E-09 \\
\hline LC22-21.4 & 0 & 23 & $9.9 \mathrm{E}-06$ & 8.85 & 9 & 1.004 & 0.020 & 171 & $1.95 \mathrm{E}-03$ & 167 & $1.68 \mathrm{E}-03$ & 799 & $3.28 \mathrm{E}-03$ & 1,114 & $1.41 \mathrm{E}-03$ & $5.32 \mathrm{E}-10$ \\
\hline LC22-21.6 & 0 & 23 & 7.7E-06 & 15.82 & 9 & 1.003 & 0.020 & 154 & $1.29 \mathrm{E}-03$ & 166 & $1.28 \mathrm{E}-03$ & 610 & $1.85 \mathrm{E}-03$ & 1,082 & $1.03 \mathrm{E}-03$ & $2.25 \mathrm{E}-10$ \\
\hline LC22-21.9 & 0 & 23 & 9.6E-06 & 22.81 & 9 & 1.003 & 0.020 & 131 & $1.25 \mathrm{E}-03$ & 171 & $1.67 \mathrm{E}-03$ & 447 & $1.57 \mathrm{E}-03$ & 1,007 & $1.12 \mathrm{E}-03$ & $1.27 \mathrm{E}-10$ \\
\hline LC22-21.12 & 0 & 23 & $9.1 \mathrm{E}-06$ & 30.98 & 9 & 1.003 & 0.020 & 158 & $1.59 \mathrm{E}-03$ & 184 & $1.78 \mathrm{E}-03$ & 530 & $1.85 \mathrm{E}-03$ & 1,156 & $1.38 \mathrm{E}-03$ & 1.03E-10 \\
\hline LC22-21.14 & 0 & 23 & $9.2 \mathrm{E}-06$ & 38.92 & 9 & 1.003 & 0.020 & 168 & $1.75 \mathrm{E}-03$ & 176 & $1.67 \mathrm{E}-03$ & 601 & $2.18 \mathrm{E}-03$ & 1,186 & $1.46 \mathrm{E}-03$ & $1.71 \mathrm{E}-10$ \\
\hline
\end{tabular}


Table A3. SPFT Results for LAWC22 Glasses.

\begin{tabular}{|c|c|c|c|c|c|c|c|c|c|c|c|c|c|c|c|c|}
\hline Sample ID & $\begin{array}{c}\text { Influent } \\
\text { [Si] }\end{array}$ & $\mathrm{T}\left({ }^{\circ} \mathrm{C}\right)$ & $\begin{array}{c}\text { Flow } \\
\text { Rate } \\
\left(\mathrm{m}^{3} / \mathrm{d}\right)\end{array}$ & $\begin{array}{l}\text { Time, } \\
\text { days }\end{array}$ & $\begin{array}{c}\mathrm{pH} \\
\left(23^{\circ} \mathrm{C}\right) \\
\end{array}$ & $\begin{array}{c}\text { Glass } \\
\text { Mass (g) }\end{array}$ & $\mathrm{SA}\left(\mathrm{m}^{2}\right)$ & [B] & B Rate & {$[\mathrm{Al}]$} & Al Rate & {$[\mathrm{Na}]$} & Na Rate & {$[\mathrm{Si}]$} & Si Rate & IEX Rate \\
\hline \multicolumn{17}{|l|}{ Exp. \#22 } \\
\hline LC22-22A & 0 & 23 & - & - & 10 & - & - & $<50$ & - & 14 & - & $<100$ & - & $<500$ & - & - \\
\hline LC22-22B & 0 & 23 & - & - & 10 & - & - & $<50$ & - & 12 & - & $<100$ & - & $<500$ & - & - \\
\hline LC22-22C & 0 & 23 & - & - & 10 & - & - & $<50$ & - & 12 & - & $<100$ & - & $<500$ & - & - \\
\hline LC22-22.1 & 0 & 23 & $9.6 \mathrm{E}-06$ & 2.05 & 10 & 0.506 & 0.013 & 140 & $2.20 \mathrm{E}-03$ & 191 & $4.24 \mathrm{E}-03$ & 752 & $4.66 \mathrm{E}-03$ & 1,111 & $2.14 \mathrm{E}-03$ & $9.83 \mathrm{E}-10$ \\
\hline LC22-22.2 & 0 & 23 & 9.6E-06 & 3.84 & 10 & 0.506 & 0.010 & 235 & $5.68 \mathrm{E}-03$ & 300 & 8.59E-03 & 939 & 7.55E-03 & 1,846 & 5.92E-03 & $7.45 \mathrm{E}-10$ \\
\hline LC22-22.4 & 0 & 23 & 9.7E-06 & 8.85 & 10 & 0.506 & 0.010 & 288 & 7.42E-03 & 330 & $9.60 \mathrm{E}-03$ & 1,021 & $8.40 \mathrm{E}-03$ & 2,084 & 7.07E-03 & $3.91 \mathrm{E}-10$ \\
\hline LC22-22.6 & 0 & 23 & 7.8E-06 & 15.82 & 10 & 0.505 & 0.010 & 261 & 5.30E-03 & 285 & $6.65 \mathrm{E}-03$ & 910 & $5.96 \mathrm{E}-03$ & 1,826 & 4.78E-03 & $2.61 \mathrm{E}-10$ \\
\hline LC22-22.9 & 0 & 23 & $9.5 \mathrm{E}-06$ & 22.81 & 10 & 0.505 & 0.010 & 229 & $5.49 \mathrm{E}-03$ & 265 & $7.50 \mathrm{E}-03$ & 756 & $5.87 \mathrm{E}-03$ & 1,685 & 5.19E-03 & $1.52 \mathrm{E}-10$ \\
\hline LC22-22.12 & 0 & 23 & $9.9 \mathrm{E}-06$ & 30.98 & 10 & 0.505 & 0.010 & 226 & 5.62E-03 & 245 & 7.19E-03 & 776 & $6.29 \mathrm{E}-03$ & 1,605 & 5.04E-03 & $2.68 \mathrm{E}-10$ \\
\hline LC22-22.14 & 0 & 23 & $9.9 \mathrm{E}-06$ & 38.92 & 10 & 0.504 & 0.010 & 173 & 3.95E-03 & 180 & 5.18E-03 & 645 & $5.09 \mathrm{E}-03$ & 1,174 & $3.08 \mathrm{E}-03$ & 4.57E-10 \\
\hline \multicolumn{17}{|l|}{ Exp. \#23 } \\
\hline LC22-23A & 0 & 23 & - & - & 11 & - & - & $<50$ & - & 24 & - & $<100$ & - & 747 & - & - \\
\hline LC22-23B & 0 & 23 & - & - & 11 & - & - & $<50$ & - & 179 & - & $<100$ & - & 820 & - & - \\
\hline LC22-23C & 0 & 23 & - & - & 11 & - & - & $<50$ & - & 27 & - & $<100$ & - & 789 & - & - \\
\hline LC22-23.1 & 0 & 23 & $9.2 \mathrm{E}-06$ & 2.05 & 11 & 0.503 & 0.013 & 285 & $5.56 \mathrm{E}-03$ & 355 & $6.38 \mathrm{E}-03$ & 1,065 & 6.67E-03 & 2,916 & $7.22 \mathrm{E}-03$ & 4.43E-10 \\
\hline LC22-23.2 & 0 & 23 & $9.8 \mathrm{E}-06$ & 3.84 & 11 & 0.502 & 0.010 & 595 & $1.72 \mathrm{E}-02$ & 689 & $1.88 \mathrm{E}-02$ & 1,928 & $1.69 \mathrm{E}-02$ & 4,941 & $1.88 \mathrm{E}-02$ & - \\
\hline LC22-23.4 & 0 & 23 & 9.7E-06 & 8.85 & 11 & 0.502 & 0.010 & 760 & 2.23E-02 & 830 & $2.30 \mathrm{E}-02$ & 2,441 & $2.15 \mathrm{E}-02$ & 5,699 & $2.21 \mathrm{E}-02$ & - \\
\hline LC22-23.6 & 0 & 23 & 7.9E-06 & 15.82 & 11 & 0.501 & 0.010 & 729 & $1.74 \mathrm{E}-02$ & 784 & $1.76 \mathrm{E}-02$ & 2,369 & $1.70 \mathrm{E}-02$ & 5,349 & $1.68 \mathrm{E}-02$ & - \\
\hline LC22-23.9 & 0 & 23 & 9.3E-06 & 22.81 & 11 & 0.500 & 0.010 & 727 & 2.05E-02 & 777 & 2.06E-02 & 2,351 & $2.00 \mathrm{E}-02$ & 5,302 & $1.96 \mathrm{E}-02$ & - \\
\hline LC22-23.12 & 0 & 23 & $9.2 \mathrm{E}-06$ & 30.98 & 11 & 0.499 & 0.010 & 663 & $1.84 \mathrm{E}-02$ & 704 & 1.83E-02 & 2,115 & $1.77 \mathrm{E}-02$ & 4,836 & $1.74 \mathrm{E}-02$ & - \\
\hline LC22-23.14 & 0 & 23 & $9.1 \mathrm{E}-06$ & 38.92 & 11 & 0.499 & 0.010 & 502 & $1.34 \mathrm{E}-02$ & 485 & $1.18 \mathrm{E}-02$ & 1,742 & $1.43 \mathrm{E}-02$ & 3,403 & $1.11 \mathrm{E}-02$ & - \\
\hline \multicolumn{17}{|l|}{ Exp. \#24 } \\
\hline LC22-24A & 0 & 23 & - & - & 12 & - & - & 53 & - & 24 & - & $<100$ & - & 1,141 & - & - \\
\hline LC22-24B & 0 & 23 & - & - & 12 & - & - & $<50$ & - & 26 & - & $<100$ & - & 1,135 & - & - \\
\hline LC22-24C & 0 & 23 & - & - & 12 & - & - & 54 & - & 40 & - & $<100$ & - & 1,215 & - & - \\
\hline LC22-24.1 & 0 & 23 & $9.5 \mathrm{E}-06$ & 2.05 & 12 & 0.503 & 0.013 & 501 & $1.10 \mathrm{E}-02$ & 630 & $1.42 \mathrm{E}-02$ & 1,735 & 1.17E-02 & 4,882 & $1.30 \mathrm{E}-02$ & - \\
\hline LC22-24.2 & 0 & 23 & $9.4 \mathrm{E}-06$ & 3.84 & 12 & 0.502 & 0.010 & 983 & $2.84 \mathrm{E}-02$ & 1,155 & 3.33E-02 & 3,304 & $2.86 \mathrm{E}-02$ & 8,146 & 3.05E-02 & - \\
\hline LC22-24.4 & 0 & 23 & $9.9 \mathrm{E}-06$ & 8.85 & 12 & 0.501 & 0.010 & 1,226 & $3.75 \mathrm{E}-02$ & 1,380 & 4.19E-02 & 4,017 & $3.66 \mathrm{E}-02$ & 9,420 & $3.78 \mathrm{E}-02$ & - \\
\hline LC22-24.6 & 0 & 23 & 7.9E-06 & 15.82 & 12 & 0.499 & 0.010 & 1,171 & 2.89E-02 & 1,319 & 3.23E-02 & 3,763 & $2.76 \mathrm{E}-02$ & 8,927 & 2.87E-02 & - \\
\hline LC22-24.9 & 0 & 23 & $9.1 \mathrm{E}-06$ & 22.81 & 12 & 0.498 & 0.010 & 1,282 & $3.66 \mathrm{E}-02$ & 1,404 & 3.96E-02 & 4,102 & $3.48 \mathrm{E}-02$ & 9,616 & $3.60 \mathrm{E}-02$ & - \\
\hline LC22-24.12 & 0 & 23 & $7.8 \mathrm{E}-06$ & 30.98 & 12 & 0.497 & 0.010 & 1,340 & $3.28 \mathrm{E}-02$ & 1,465 & $3.55 \mathrm{E}-02$ & 4,192 & 3.05E-02 & 10,084 & $3.26 \mathrm{E}-02$ & - \\
\hline LC22-24.14 & 0 & 23 & $9.1 \mathrm{E}-06$ & 38.92 & 12 & 0.495 & 0.010 & 1,428 & $4.08 \mathrm{E}-02$ & 1,564 & 4.42E-02 & 4,545 & 3.85E-02 & 10,650 & 4.03E-02 & - \\
\hline \multicolumn{17}{|l|}{ Exp. \#25 } \\
\hline LC22-25A & 0 & 70 & - & - & 7 & - & - & $<50$ & - & $<25$ & - & $<100$ & - & $<500$ & - & - \\
\hline LC22-25.1 & 0 & 70 & - & - & 7 & - & - & $<50$ & - & $<25$ & - & $<100$ & - & $<500$ & - & - \\
\hline LC22-25.2 & 0 & 70 & 5.7E-05 & 2.02 & 7 & 1.004 & 0.036 & 1,158 & 5.61E-02 & ND & - & 5,392 & 7.83E-02 & 1,137 & $4.62 \mathrm{E}-03$ & 8.87E-09 \\
\hline LC22-25.4 & 0 & 70 & 5.7E-05 & 4.16 & 7 & 1.001 & 0.020 & 1,259 & $1.13 \mathrm{E}-01$ & ND & - & 4,667 & $1.24 \mathrm{E}-01$ & 603 & $1.37 \mathrm{E}-03$ & 4.69E-09 \\
\hline LC22-25.6 & 0 & 70 & 5.5E-05 & 6.02 & 7 & 0.997 & 0.020 & 1,009 & 8.52E-02 & 49 & 2.08E-03 & 3,434 & 8.66E-02 & ND & - & $5.73 \mathrm{E}-10$ \\
\hline LC22-25.8 & 0 & 70 & $4.8 \mathrm{E}-05$ & 8.03 & 7 & 0.994 & 0.020 & 992 & 7.35E-02 & 50 & $1.88 \mathrm{E}-03$ & 3,393 & 7.51E-02 & ND & - & $6.47 \mathrm{E}-10$ \\
\hline
\end{tabular}


Table A3. SPFT Results for LAWC22 Glasses.

\begin{tabular}{|c|c|c|c|c|c|c|c|c|c|c|c|c|c|c|c|c|}
\hline Sample ID & $\begin{array}{c}\text { Influent } \\
\text { [Si] }\end{array}$ & $\mathrm{T}\left({ }^{\circ} \mathrm{C}\right)$ & $\begin{array}{c}\text { Flow } \\
\text { Rate } \\
\left(\mathrm{m}^{3} / \mathrm{d}\right) \\
\end{array}$ & $\begin{array}{l}\text { Time, } \\
\text { days }\end{array}$ & $\begin{array}{c}\mathrm{pH} \\
\left(23^{\circ} \mathrm{C}\right) \\
\end{array}$ & $\begin{array}{c}\text { Glass } \\
\text { Mass (g) }\end{array}$ & $\mathrm{SA}\left(\mathrm{m}^{2}\right)$ & [B] & B Rate & [Al] & Al Rate & {$[\mathrm{Na}]$} & Na Rate & [Si] & Si Rate & IEX Rate \\
\hline LC22-25.9 & 0 & 70 & $6.1 \mathrm{E}-05$ & 8.91 & 7 & 0.992 & 0.020 & 875 & $8.25 E-02$ & 41 & $1.54 \mathrm{E}-03$ & 2,983 & 8.43E-02 & ND & - & 7.07E-10 \\
\hline LC22-25.10 & 0 & 70 & 5.3E-05 & 9.24 & 7 & 0.991 & 0.020 & 859 & 6.97E-02 & 36 & $9.18 \mathrm{E}-04$ & 2,992 & 7.28E-02 & ND & - & $1.26 \mathrm{E}-09$ \\
\hline LC22-25.11 & 0 & 70 & $5.9 \mathrm{E}-05$ & 9.88 & 7 & 0.989 & 0.020 & 852 & 7.76E-02 & 66 & 3.81E-03 & 2,967 & 8.12E-02 & ND & - & $1.42 \mathrm{E}-09$ \\
\hline \multicolumn{17}{|l|}{ Exp. \#26 } \\
\hline LC22-26A & 0 & 70 & - & - & 8 & - & - & $<50$ & - & $<25$ & - & $<100$ & - & $<500$ & - & - \\
\hline LC22-26.1 & 0 & 70 & - & - & 8 & - & - & $<50$ & - & $<25$ & - & $<100$ & - & $<500$ & - & - \\
\hline LC22-26.2 & 0 & 70 & $6.0 \mathrm{E}-05$ & 2.02 & 8 & 1.001 & 0.036 & 481 & 2.29E-02 & 159 & $6.92 \mathrm{E}-03$ & 3,298 & 4.97E-02 & 1,825 & $1.01 \mathrm{E}-02$ & 1.07E-08 \\
\hline LC22-26.4 & 0 & 70 & 5.7E-05 & 4.16 & 8 & 1.000 & 0.020 & 308 & $2.40 \mathrm{E}-02$ & 228 & 1.83E-02 & 1,557 & 3.97E-02 & 1,512 & 1.35E-02 & 6.25E-09 \\
\hline LC22-26.6 & 0 & 70 & 5.3E-05 & 6.02 & 8 & 0.992 & 0.020 & 3,760 & 3.22E-01 & 4,109 & 3.45E-01 & 13,706 & $3.46 \mathrm{E}-01$ & 23,638 & 2.88E-01 & 9.33E-09 \\
\hline LC22-26.8 & 0 & 70 & $5.1 \mathrm{E}-05$ & 8.03 & 8 & 0.987 & 0.020 & 263 & $1.78 \mathrm{E}-02$ & 200 & $1.42 \mathrm{E}-02$ & 988 & 2.17E-02 & 1,328 & 9.93E-03 & $1.57 \mathrm{E}-09$ \\
\hline LC22-26.9 & 0 & 70 & $6.1 \mathrm{E}-05$ & 8.91 & 8 & 0.987 & 0.020 & 234 & $1.84 \mathrm{E}-02$ & 187 & $1.58 \mathrm{E}-02$ & 896 & 2.33E-02 & 1,251 & $1.08 \mathrm{E}-02$ & 1.95E-09 \\
\hline LC22-26.10 & 0 & 70 & $4.1 \mathrm{E}-05$ & 9.24 & 8 & 0.986 & 0.019 & 216 & 1.12E-02 & 179 & $1.01 \mathrm{E}-02$ & 827 & $1.44 \mathrm{E}-02$ & 1,167 & $6.48 \mathrm{E}-03$ & 1.27E-09 \\
\hline LC22-26.11 & 0 & 70 & $5.9 \mathrm{E}-05$ & 9.88 & 8 & 0.986 & 0.019 & 219 & 1.63E-02 & 186 & $1.51 \mathrm{E}-02$ & 831 & 2.07E-02 & 1,196 & 9.63E-03 & $1.72 \mathrm{E}-09$ \\
\hline \multicolumn{17}{|l|}{ Exp. \#27 } \\
\hline LC22-27A & 0 & 70 & - & - & 9 & - & - & $<50$ & - & $<25$ & - & $<100$ & - & $<500$ & - & - \\
\hline LC22-27.1 & 0 & 70 & - & - & 9 & - & - & $<50$ & - & $<25$ & - & $<100$ & - & $<500$ & - & - \\
\hline LC22-27.2 & 0 & 70 & $5.5 \mathrm{E}-05$ & 2.02 & 9 & 1.001 & 0.036 & 639 & $2.88 \mathrm{E}-02$ & 503 & 2.27E-02 & 503 & 4.60E-02 & 4,049 & 2.49E-02 & 6.87E-09 \\
\hline LC22-27.4 & 0 & 70 & 5.7E-05 & 4.16 & 9 & 0.999 & 0.020 & 762 & $6.60 \mathrm{E}-02$ & 754 & 6.56E-02 & 754 & 7.65E-02 & 5,109 & 6.12E-02 & 4.19E-09 \\
\hline LC22-27.6 & 0 & 70 & $5.4 \mathrm{E}-05$ & 6.02 & 9 & 0.996 & 0.020 & 830 & 6.86E-02 & 868 & 7.19E-02 & 868 & 7.14E-02 & 5,427 & $6.20 \mathrm{E}-02$ & $1.11 \mathrm{E}-09$ \\
\hline LC22-27.8 & 0 & 70 & 5.1E-05 & 8.03 & 9 & 0.994 & 0.020 & 884 & 6.95E-02 & 888 & $6.98 \mathrm{E}-02$ & 888 & $6.94 \mathrm{E}-02$ & 5,584 & $6.07 \mathrm{E}-02$ & - \\
\hline LC22-27.9 & 0 & 70 & $6.0 \mathrm{E}-05$ & 8.91 & 9 & 0.992 & 0.020 & 835 & 7.77E-02 & 862 & 8.04E-02 & 862 & $7.88 \mathrm{E}-02$ & 5,367 & $6.89 \mathrm{E}-02$ & $4.34 \mathrm{E}-10$ \\
\hline LC22-27.10 & 0 & 70 & $5.2 \mathrm{E}-05$ & 9.24 & 9 & 0.990 & 0.020 & 827 & 6.61E-02 & 832 & 6.67E-02 & 832 & 6.69E-02 & 5,269 & $5.82 \mathrm{E}-02$ & 3.17E-10 \\
\hline LC22-27.11 & 0 & 70 & 5.6E-05 & 9.88 & 9 & 0.989 & 0.020 & 808 & $7.00 \mathrm{E}-02$ & 825 & 7.17E-02 & 825 & $7.20 \mathrm{E}-02$ & 5,265 & $6.30 \mathrm{E}-02$ & 7.77E-10 \\
\hline \multicolumn{17}{|l|}{ Exp. \#28 } \\
\hline LC22-28A & 0 & 70 & - & - & 10 & - & - & $<50$ & - & $<25$ & - & $<100$ & - & $<500$ & - & - \\
\hline LC22-28.1 & 0 & 70 & - & - & 10 & - & - & $<50$ & - & $<25$ & - & $<100$ & - & $<500$ & - & - \\
\hline LC22-28.2 & 0 & 70 & 5.6E-05 & 2.02 & 10 & 0.506 & 0.023 & 730 & 5.35E-02 & 768 & 5.67E-02 & 2,958 & 6.57E-02 & 4,675 & $4.70 \mathrm{E}-02$ & 4.89E-09 \\
\hline LC22-28.4 & 0 & 70 & 5.7E-05 & 4.16 & 10 & 0.503 & 0.010 & 1,106 & $1.95 \mathrm{E}-01$ & 1,115 & $1.95 \mathrm{E}-01$ & 3,845 & $2.02 \mathrm{E}-01$ & 6,842 & $1.68 \mathrm{E}-01$ & $2.88 \mathrm{E}-09$ \\
\hline LC22-28.6 & 0 & 70 & $5.4 \mathrm{E}-05$ & 6.02 & 10 & 0.499 & 0.010 & 1,015 & $1.70 \mathrm{E}-01$ & 1,030 & $1.72 \mathrm{E}-01$ & 3,415 & $1.71 \mathrm{E}-01$ & 6,386 & $1.49 \mathrm{E}-01$ & $3.06 \mathrm{E}-10$ \\
\hline LC22-28.8 & 0 & 70 & 5.3E-05 & 8.03 & 10 & 0.497 & 0.010 & 944 & $1.54 \mathrm{E}-01$ & 1,005 & 1.63E-01 & 3,135 & $1.53 \mathrm{E}-01$ & 6,001 & $1.35 \mathrm{E}-01$ & - \\
\hline LC22-28.9 & 0 & 70 & 5.6E-05 & 8.91 & 10 & 0.494 & 0.010 & 965 & $1.69 \mathrm{E}-01$ & 1,026 & $1.80 \mathrm{E}-01$ & 3,205 & $1.68 \mathrm{E}-01$ & 6,088 & $1.48 \mathrm{E}-01$ & - \\
\hline LC22-28.10 & 0 & 70 & $5.2 \mathrm{E}-05$ & 9.24 & 10 & 0.493 & 0.010 & 914 & $1.47 \mathrm{E}-01$ & 941 & $1.51 \mathrm{E}-01$ & 3,050 & $1.46 \mathrm{E}-01$ & 5,725 & $1.27 \mathrm{E}-01$ & - \\
\hline LC22-28.11 & 0 & 70 & $5.9 \mathrm{E}-05$ & 9.88 & 10 & 0.492 & 0.010 & 922 & $1.70 \mathrm{E}-01$ & 936 & $1.72 \mathrm{E}-01$ & 3,127 & $1.72 \mathrm{E}-01$ & 5,822 & $1.48 \mathrm{E}-01$ & $9.86 \mathrm{E}-10$ \\
\hline \multicolumn{17}{|l|}{ Exp.\#29 } \\
\hline LC22-29A & 0 & 70 & - & - & 11 & - & - & $<50$ & - & $<25$ & - & $<100$ & - & $<500$ & - & - \\
\hline LC22-29.1 & 0 & 70 & - & - & 11 & - & - & $<50$ & - & $<25$ & - & $<100$ & - & $<500$ & - & - \\
\hline LC22-29.2 & 0 & 70 & 6.6E-05 & 2.02 & 11 & 0.502 & 0.023 & 1,266 & $1.14 \mathrm{E}-01$ & 1,323 & $1.18 \mathrm{E}-01$ & 4,588 & $1.23 \mathrm{E}-01$ & 7,923 & 9.94E-02 & $3.60 \mathrm{E}-09$ \\
\hline LC22-29.4 & 0 & 70 & $5.7 \mathrm{E}-05$ & 4.16 & 11 & 0.494 & 0.010 & 2,856 & $5.20 \mathrm{E}-01$ & 2,525 & $4.50 \mathrm{E}-01$ & 9,740 & $5.22 \mathrm{E}-01$ & 16,275 & 4.19E-01 & $9.64 \mathrm{E}-10$ \\
\hline LC22-29.6 & 0 & 70 & $5.5 \mathrm{E}-05$ & 6.02 & 11 & 0.485 & 0.010 & 2,958 & 5.35E-01 & 2,619 & 4.63E-01 & 9,861 & $5.25 \mathrm{E}-01$ & 16,829 & 4.30E-01 & - \\
\hline LC22-29.8 & 0 & 70 & $5.2 \mathrm{E}-05$ & 8.03 & 11 & 0.475 & 0.009 & 3,320 & 5.75E-01 & 2,673 & 4.52E-01 & 11,230 & 5.73E-01 & 18,525 & 4.54E-01 & - \\
\hline
\end{tabular}


Table A3. SPFT Results for LAWC22 Glasses.

\begin{tabular}{|c|c|c|c|c|c|c|c|c|c|c|c|c|c|c|c|c|}
\hline Sample ID & $\begin{array}{c}\text { Influent } \\
\text { [Si] }\end{array}$ & $\mathrm{T}\left({ }^{\circ} \mathrm{C}\right)$ & $\begin{array}{c}\text { Flow } \\
\text { Rate } \\
\left(\mathrm{m}^{3} / \mathrm{d}\right) \\
\end{array}$ & $\begin{array}{l}\text { Time, } \\
\text { days }\end{array}$ & $\begin{array}{c}\mathrm{pH} \\
\left(23^{\circ} \mathrm{C}\right) \\
\end{array}$ & $\begin{array}{c}\text { Glass } \\
\text { Mass (g) }\end{array}$ & $\mathrm{SA}\left(\mathrm{m}^{2}\right)$ & {$[\mathrm{B}]$} & B Rate & {$[\mathrm{Al}]$} & Al Rate & {$[\mathrm{Na}]$} & Na Rate & [Si] & Si Rate & IEX Rate \\
\hline LC22-29.9 & 0 & 70 & $5.6 \mathrm{E}-05$ & 8.91 & 11 & 0.467 & 0.009 & 3,162 & $6.05 \mathrm{E}-01$ & 2,564 & 4.79E-01 & 10,546 & $5.94 \mathrm{E}-01$ & 17,717 & 4.79E-01 & - \\
\hline LC22-29.10 & 0 & 70 & $5.2 \mathrm{E}-05$ & 9.24 & 11 & 0.463 & 0.009 & 3,122 & 5.59E-01 & 2,469 & 4.32E-01 & 10,515 & $5.54 \mathrm{E}-01$ & 17,365 & 4.40E-01 & - \\
\hline LC22-29.11 & 0 & 70 & $5.8 \mathrm{E}-05$ & 9.88 & 11 & 0.459 & 0.009 & 3,104 & 6.30E-01 & 2,361 & 4.68E-01 & 10,343 & 6.18E-01 & 17,042 & 4.89E-01 & - \\
\hline \multicolumn{17}{|l|}{ Exp. \#30 } \\
\hline LC22-30A & 0 & 70 & - & - & 12 & - & - & $<50$ & - & 39 & - & $<100$ & - & $<500$ & - & - \\
\hline LC22-30.1 & 0 & 70 & - & - & 12 & - & - & $<50$ & - & 50 & - & $<100$ & - & $<500$ & - & - \\
\hline LC22-30.2 & 0 & 70 & 5.7E-05 & 2.02 & 12 & 0.505 & 0.023 & 2,299 & $1.80 \mathrm{E}-01$ & 2,620 & 2.01E-01 & 8,323 & 1.93E-01 & 15,137 & $1.68 \mathrm{E}-01$ & 4.99E-09 \\
\hline LC22-30.4 & 0 & 70 & 5.7E-05 & 4.16 & 12 & 0.496 & 0.010 & 3,581 & 6.57E-01 & 3,824 & 6.82E-01 & 13,278 & 7.17E-01 & 22,492 & 5.86E-01 & 2.39E-08 \\
\hline LC22-30.6 & 0 & 70 & 5.5E-05 & 6.02 & 12 & 0.484 & 0.010 & 3,718 & 6.68E-01 & 4,067 & 7.11E-01 & 13,599 & 7.18E-01 & 23,374 & 5.96E-01 & 2.03E-08 \\
\hline LC22-30.8 & 0 & 70 & 4.5E-05 & 8.03 & 12 & 0.471 & 0.009 & 5,591 & 8.53E-01 & 5,905 & 8.75E-01 & 20,830 & 9.33E-01 & 33,414 & 7.25E-01 & 3.20E-08 \\
\hline LC22-30.9 & 0 & 70 & $6.1 \mathrm{E}-05$ & 8.91 & 12 & 0.459 & 0.009 & 4,272 & $9.10 \mathrm{E}-01$ & 4,609 & $9.55 \mathrm{E}-01$ & 15,764 & $9.88 \mathrm{E}-01$ & 26,340 & 7.98E-01 & $3.08 \mathrm{E}-08$ \\
\hline LC22-30.10 & 0 & 70 & $5.3 \mathrm{E}-05$ & 9.24 & 12 & 0.453 & 0.009 & 4,344 & 8.06E-01 & 4,639 & 8.38E-01 & 16,082 & 8.78E-01 & 26,395 & $6.96 \mathrm{E}-01$ & $2.84 \mathrm{E}-08$ \\
\hline LC22-30.11 & 0 & 70 & $5.2 \mathrm{E}-05$ & 9.88 & 12 & 0.447 & 0.009 & 4,400 & 8.25E-01 & 4,727 & 8.62E-01 & 16,115 & 8.88E-01 & 27,155 & 7.24E-01 & 2.52E-08 \\
\hline \multicolumn{17}{|l|}{ Exp.\#31 } \\
\hline LC22-31.A & $8.82 E+02$ & 40 & - & - & 9 & - & - & $<50$ & - & $<10$ & - & $<50$ & - & $<1000$ & - & - \\
\hline LC22-31.2 & $8.82 E+02$ & 40 & $1.9 \mathrm{E}-05$ & 0.89 & 9 & 0.504 & 0.013 & 218 & 8.22E-03 & 206 & 9.32E-03 & 944 & $1.28 \mathrm{E}-02$ & 1,399 & 2.79E-03 & $1.82 \mathrm{E}-09$ \\
\hline LC22-31.4 & $8.82 \mathrm{E}+02$ & 40 & $1.9 \mathrm{E}-05$ & 3.34 & 9 & 0.504 & 0.010 & 260 & $1.26 \mathrm{E}-02$ & 261 & $1.46 \mathrm{E}-02$ & 923 & $1.53 \mathrm{E}-02$ & 1,761 & $6.53 \mathrm{E}-03$ & $1.08 \mathrm{E}-09$ \\
\hline LC22-31.7 & $8.82 \mathrm{E}+02$ & 40 & $1.8 \mathrm{E}-05$ & 6.01 & 9 & 0.503 & 0.010 & 278 & $1.36 \mathrm{E}-02$ & 293 & 1.63E-02 & 930 & 1.53E-02 & 1,905 & 7.71E-03 & $7.00 \mathrm{E}-10$ \\
\hline LC22-31.13 & $8.82 E+02$ & 40 & $1.8 \mathrm{E}-05$ & 14.14 & 9 & 0.503 & 0.010 & 279 & 1.35E-02 & 293 & $1.62 \mathrm{E}-02$ & 965 & 1.57E-02 & 1,929 & 7.82E-03 & 8.98E-10 \\
\hline LC22-31.16 & $8.82 E+02$ & 40 & $1.2 \mathrm{E}-05$ & 19.80 & 9 & 0.503 & 0.010 & 332 & 1.12E-02 & 344 & 1.29E-02 & 1,124 & $1.25 \mathrm{E}-02$ & 2,288 & 7.32E-03 & $5.05 \mathrm{E}-10$ \\
\hline LC22-31.20 & $8.82 \mathrm{E}+02$ & 40 & $1.8 \mathrm{E}-05$ & 26.92 & 9 & 0.502 & 0.010 & 293 & $1.39 \mathrm{E}-02$ & 306 & $1.64 \mathrm{E}-02$ & 976 & $1.55 \mathrm{E}-02$ & 2,011 & $8.28 \mathrm{E}-03$ & $6.40 \mathrm{E}-10$ \\
\hline LC22-31.21 & $8.82 E+02$ & 40 & $1.8 \mathrm{E}-05$ & 28.03 & 9 & 0.502 & 0.010 & 296 & 1.47E-02 & 307 & $1.72 \mathrm{E}-02$ & 985 & 1.63E-02 & 2,012 & 8.67E-03 & $6.58 \mathrm{E}-10$ \\
\hline LC22-31.22 & $8.82 E+02$ & 40 & $1.8 \mathrm{E}-05$ & 28.95 & 9 & 0.502 & 0.010 & 293 & 1.43E-02 & 307 & $1.70 \mathrm{E}-02$ & 984 & 1.61E-02 & 2,026 & 8.68E-03 & 7.19E-10 \\
\hline LC22-31.23 & $8.82 \mathrm{E}+02$ & 40 & $1.8 \mathrm{E}-05$ & 31.94 & 9 & 0.501 & 0.010 & 269 & $1.30 \mathrm{E}-02$ & 280 & $1.56 \mathrm{E}-02$ & 911 & $1.50 \mathrm{E}-02$ & 1,864 & 7.37E-03 & 7.77E-10 \\
\hline \multicolumn{17}{|l|}{ Exp. \#32 } \\
\hline LC22-32.A & $1.61 \mathrm{E}+04$ & 40 & - & - & 9 & - & - & $<50$ & - & $<10$ & - & $<50$ & - & 16,581 & - & - \\
\hline LC22-32.2 & $1.61 \mathrm{E}+04$ & 40 & $1.7 \mathrm{E}-05$ & 0.89 & 9 & 0.507 & 0.013 & 207 & 6.64E-03 & 164 & 6.34E-03 & 891 & $1.04 \mathrm{E}-02$ & 17,475 & $5.41 \mathrm{E}-03$ & $1.50 \mathrm{E}-09$ \\
\hline LC22-32.4 & $1.61 \mathrm{E}+04$ & 40 & $1.9 \mathrm{E}-05$ & 3.34 & 9 & 0.507 & 0.010 & 220 & 1.02E-02 & 201 & $1.11 \mathrm{E}-02$ & 803 & 1.32E-02 & 18,087 & $1.29 \mathrm{E}-02$ & 1.19E-09 \\
\hline LC22-32.7 & $1.61 \mathrm{E}+04$ & 40 & $1.9 \mathrm{E}-05$ & 6.01 & 9 & 0.507 & 0.010 & 208 & $9.51 \mathrm{E}-03$ & 194 & $1.08 \mathrm{E}-02$ & 717 & $1.18 \mathrm{E}-02$ & 17,868 & $1.11 \mathrm{E}-02$ & 8.94E-10 \\
\hline LC22-32.13 & $1.61 \mathrm{E}+04$ & 40 & $1.9 \mathrm{E}-05$ & 14.14 & 9 & 0.506 & 0.010 & 212 & $9.69 \mathrm{E}-03$ & 211 & 1.17E-02 & 726 & $1.18 \mathrm{E}-02$ & 18,201 & 1.39E-02 & $8.54 \mathrm{E}-10$ \\
\hline LC22-32.16 & $1.61 \mathrm{E}+04$ & 40 & $1.5 \mathrm{E}-05$ & 19.80 & 9 & 0.506 & 0.010 & 216 & 7.75E-03 & 211 & $9.12 \mathrm{E}-03$ & 733 & $9.34 \mathrm{E}-03$ & 18,548 & $1.32 \mathrm{E}-02$ & 6.35E-10 \\
\hline LC22-32.20 & $1.61 \mathrm{E}+04$ & 40 & $1.9 \mathrm{E}-05$ & 26.92 & 9 & 0.506 & 0.010 & 206 & 9.52E-03 & 203 & $1.14 \mathrm{E}-02$ & 725 & $1.21 \mathrm{E}-02$ & 18,156 & 1.38E-02 & $1.01 \mathrm{E}-09$ \\
\hline LC22-32.21 & $1.61 \mathrm{E}+04$ & 40 & $1.9 \mathrm{E}-05$ & 28.03 & 9 & 0.505 & 0.010 & 201 & 9.03E-03 & 200 & 1.11E-02 & 692 & 1.13E-02 & 18,196 & 1.39E-02 & $8.88 \mathrm{E}-10$ \\
\hline LC22-32.22 & $1.61 \mathrm{E}+04$ & 40 & $1.8 \mathrm{E}-05$ & 28.95 & 9 & 0.505 & 0.010 & 202 & 8.91E-03 & 204 & 1.11E-02 & 705 & 1.13E-02 & 18,135 & $1.31 \mathrm{E}-02$ & $9.38 \mathrm{E}-10$ \\
\hline LC22-32.23 & $1.61 \mathrm{E}+04$ & 40 & $1.9 \mathrm{E}-05$ & 31.94 & 9 & 0.505 & 0.010 & 196 & $8.78 \mathrm{E}-03$ & 199 & $1.10 \mathrm{E}-02$ & 678 & $1.11 \mathrm{E}-02$ & 18,301 & $1.48 \mathrm{E}-02$ & $9.11 \mathrm{E}-10$ \\
\hline \multicolumn{17}{|l|}{ Exp. \#33 } \\
\hline LC22-33.A & $3.21 \mathrm{E}+04$ & 40 & - & - & 9 & - & - & $<50$ & - & $<10$ & - & $<50$ & - & 37,072 & - & - \\
\hline LC22-33.2 & $3.21 E+04$ & 40 & $1.9 \mathrm{E}-05$ & 0.89 & 9 & 1.006 & 0.020 & 264 & 6.73E-03 & 148 & $4.20 \mathrm{E}-03$ & 1,402 & $1.24 \mathrm{E}-02$ & 38,024 & $4.28 \mathrm{E}-03$ & 2.27E-09 \\
\hline LC22-33.4 & $3.21 E+04$ & 40 & $1.9 \mathrm{E}-05$ & 3.34 & 9 & 1.006 & 0.020 & 252 & 6.16E-03 & 153 & 4.22E-03 & 1,109 & $9.44 \mathrm{E}-03$ & 38,096 & 4.47E-03 & $1.31 \mathrm{E}-09$ \\
\hline LC22-33.7 & $3.21 E+04$ & 40 & $1.9 \mathrm{E}-05$ & 6.01 & 9 & 1.005 & 0.020 & 228 & 5.36E-03 & 153 & 4.19E-03 & 916 & 7.64E-03 & 38,397 & 5.73E-03 & $9.08 \mathrm{E}-10$ \\
\hline
\end{tabular}


Table A3. SPFT Results for LAWC22 Glasses.

\begin{tabular}{|c|c|c|c|c|c|c|c|c|c|c|c|c|c|c|c|c|}
\hline Sample ID & $\begin{array}{c}\text { Influent } \\
\text { [Si] }\end{array}$ & $\mathrm{T}\left({ }^{\circ} \mathrm{C}\right)$ & $\begin{array}{c}\text { Flow } \\
\text { Rate } \\
\left(\mathrm{m}^{3} / \mathrm{d}\right)\end{array}$ & $\begin{array}{l}\text { Time, } \\
\text { days }\end{array}$ & $\begin{array}{c}\mathrm{pH} \\
\left(23^{\circ} \mathrm{C}\right) \\
\end{array}$ & $\begin{array}{c}\text { Glass } \\
\text { Mass (g) }\end{array}$ & $\mathrm{SA}\left(\mathrm{m}^{2}\right)$ & {$[\mathrm{B}]$} & B Rate & {$[\mathrm{Al}]$} & Al Rate & {$[\mathrm{Na}]$} & Na Rate & [Si] & Si Rate & IEX Rate \\
\hline LC22-33.13 & $3.21 E+04$ & 40 & $1.9 \mathrm{E}-05$ & 14.14 & 9 & 1.005 & 0.020 & 229 & 5.36E-03 & 164 & 4.48E-03 & 871 & 7.19E-03 & 38,504 & $6.14 \mathrm{E}-03$ & 7.30E-10 \\
\hline LC22-33.16 & $3.21 \mathrm{E}+04$ & 40 & $1.5 \mathrm{E}-05$ & 19.80 & 9 & 1.005 & 0.020 & 213 & $3.81 \mathrm{E}-03$ & 152 & $3.24 \mathrm{E}-03$ & 812 & $5.23 \mathrm{E}-03$ & 38,439 & 4.59E-03 & $5.64 \mathrm{E}-10$ \\
\hline LC22-33.20 & $3.21 \mathrm{E}+04$ & 40 & 1.9E-05 & 26.92 & 9 & 1.004 & 0.020 & 256 & 6.37E-03 & 167 & 4.70E-03 & 977 & 8.37E-03 & 38,121 & 4.64E-03 & 7.97E-10 \\
\hline LC22-33.21 & $3.21 E+04$ & 40 & 1.9E-05 & 28.03 & 9 & 1.004 & 0.020 & 241 & 5.89E-03 & 172 & 4.85E-03 & 894 & 7.60E-03 & 38,394 & 5.82E-03 & $6.81 \mathrm{E}-10$ \\
\hline LC22-33.22 & $3.21 E+04$ & 40 & $1.8 \mathrm{E}-05$ & 28.95 & 9 & 1.004 & 0.020 & 224 & 5.16E-03 & 152 & 4.11E-03 & 868 & 7.11E-03 & 38,404 & 5.67E-03 & 7.78E-10 \\
\hline LC22-33.23 & $3.21 \mathrm{E}+04$ & 40 & 1.9E-05 & 31.94 & 9 & 1.004 & 0.020 & 204 & $4.71 \mathrm{E}-03$ & 141 & 3.87E-03 & 784 & $6.55 \mathrm{E}-03$ & 38,449 & $6.02 \mathrm{E}-03$ & 7.35E-10 \\
\hline \multicolumn{17}{|l|}{ Exp. \#34 } \\
\hline LC22-34.A & $4.78 \mathrm{E}+04$ & 40 & - & - & 9 & - & - & $<50$ & - & $<10$ & - & $<50$ & - & 55,922 & - & - \\
\hline LC22-34.2 & $4.78 \mathrm{E}+04$ & 40 & $1.7 \mathrm{E}-05$ & 0.89 & 9 & 1.006 & 0.020 & 246 & 5.37E-03 & 136 & 3.35E-03 & 1,452 & $1.12 \mathrm{E}-02$ & 51,344 & - & 2.34E-09 \\
\hline LC22-34.4 & $4.78 E+04$ & 40 & $1.8 \mathrm{E}-05$ & 3.34 & 9 & 1.006 & 0.020 & 231 & $5.40 \mathrm{E}-03$ & 139 & 3.74E-03 & 1,147 & $9.55 \mathrm{E}-03$ & 54,958 & - & $1.66 \mathrm{E}-09$ \\
\hline LC22-34.7 & $4.78 \mathrm{E}+04$ & 40 & $1.8 \mathrm{E}-05$ & 6.01 & 9 & 1.005 & 0.020 & 198 & 4.39E-03 & 128 & $3.41 \mathrm{E}-03$ & 918 & 7.54E-03 & 54,642 & - & $1.26 \mathrm{E}-09$ \\
\hline LC22-34.13 & $4.78 \mathrm{E}+04$ & 40 & 1.9E-05 & 14.14 & 9 & 1.005 & 0.020 & 172 & 3.65E-03 & 134 & 3.60E-03 & 733 & 5.98E-03 & 55,362 & - & $9.30 \mathrm{E}-10$ \\
\hline LC22-34.16 & $4.78 \mathrm{E}+04$ & 40 & $1.4 \mathrm{E}-05$ & 19.80 & 9 & 1.005 & 0.020 & 178 & 2.99E-03 & 133 & 2.79E-03 & 746 & 4.75E-03 & 55,586 & - & 6.99E-10 \\
\hline LC22-34.20 & $4.78 \mathrm{E}+04$ & 40 & $1.9 \mathrm{E}-05$ & 26.92 & 9 & 1.005 & 0.020 & 160 & 3.35E-03 & 118 & $3.21 \mathrm{E}-03$ & 670 & 5.52E-03 & 55,678 & - & 8.65E-10 \\
\hline LC22-34.21 & $4.78 \mathrm{E}+04$ & 40 & $1.8 \mathrm{E}-05$ & 28.03 & 9 & 1.005 & 0.020 & 159 & $3.25 \mathrm{E}-03$ & 125 & 3.32E-03 & 684 & $5.50 \mathrm{E}-03$ & 55,776 & - & 8.98E-10 \\
\hline LC22-34.22 & $4.78 \mathrm{E}+04$ & 40 & $1.8 \mathrm{E}-05$ & 28.95 & 9 & 1.004 & 0.020 & 156 & 3.11E-03 & 119 & 3.10E-03 & 656 & 5.19E-03 & 55,935 & 5.73E-05 & $8.30 \mathrm{E}-10$ \\
\hline LC22-34.23 & $4.78 \mathrm{E}+04$ & 40 & $1.9 \mathrm{E}-05$ & 31.94 & 9 & 1.004 & 0.020 & 151 & 3.05E-03 & 115 & 3.06E-03 & 633 & 5.12E-03 & 57,610 & 7.27E-03 & $8.28 \mathrm{E}-10$ \\
\hline \multicolumn{17}{|l|}{ Exp. \#35 } \\
\hline LC22-35.A & $6.89 \mathrm{E}+04$ & 40 & - & - & 9 & - & - & $<50$ & - & $<10$ & - & $<50$ & - & 73,508 & - & - \\
\hline LC22-35.2 & $6.89 \mathrm{E}+04$ & 40 & $-6.5 \mathrm{E}-05$ & 0.89 & 9 & 2.004 & 0.031 & 334 & - & 129 & - & 2,275 & - & 71,175 & 2.23E-02 & - \\
\hline LC22-35.4 & $6.89 \mathrm{E}+04$ & 40 & $1.9 \mathrm{E}-05$ & 3.34 & 9 & 2.004 & 0.040 & 272 & 3.36E-03 & 206 & 2.89E-03 & 1,562 & $6.70 \mathrm{E}-03$ & 72,088 & - & 1.33E-09 \\
\hline LC22-35.7 & $6.89 E+04$ & 40 & 1.9E-05 & 6.01 & 9 & 2.004 & 0.040 & 225 & 2.64E-03 & 104 & 1.38E-03 & 1,189 & 5.03E-03 & 73,844 & 7.27E-04 & $9.55 \mathrm{E}-10$ \\
\hline LC22-35.13 & $6.89 E+04$ & 40 & 1.9E-05 & 14.14 & 9 & 2.003 & 0.040 & 161 & 1.67E-03 & 83 & $1.07 \mathrm{E}-03$ & 823 & $3.41 \mathrm{E}-03$ & 76,453 & 6.37E-03 & 6.95E-10 \\
\hline LC22-35.16 & $6.89 \mathrm{E}+04$ & 40 & $1.4 \mathrm{E}-05$ & 19.80 & 9 & 2.003 & 0.040 & 158 & $1.27 \mathrm{E}-03$ & 84 & 8.49E-04 & 832 & 2.69E-03 & 76,413 & 4.89E-03 & $5.65 \mathrm{E}-10$ \\
\hline LC22-35.20 & $6.89 \mathrm{E}+04$ & 40 & $1.8 \mathrm{E}-05$ & 26.92 & 9 & 2.003 & 0.040 & 99 & 7.15E-04 & 62 & 7.45E-04 & 596 & 2.34E-03 & 76,073 & 5.39E-03 & $6.50 \mathrm{E}-10$ \\
\hline LC22-35.21 & $6.89 \mathrm{E}+04$ & 40 & $1.9 \mathrm{E}-05$ & 28.03 & 9 & 2.003 & 0.040 & 97 & 7.04E-04 & 62 & 7.69E-04 & 582 & $2.36 \mathrm{E}-03$ & 76,011 & $5.42 \mathrm{E}-03$ & $6.60 \mathrm{E}-10$ \\
\hline LC22-35.22 & $6.89 \mathrm{E}+04$ & 40 & $1.8 \mathrm{E}-05$ & 28.95 & 9 & 2.003 & 0.040 & 90 & $6.00 \mathrm{E}-04$ & 59 & 7.04E-04 & 549 & $2.16 \mathrm{E}-03$ & 76,268 & 5.86E-03 & $6.24 \mathrm{E}-10$ \\
\hline LC22-35.23 & $6.89 \mathrm{E}+04$ & 40 & $1.9 \mathrm{E}-05$ & 31.94 & 9 & 2.003 & 0.040 & 84 & $5.22 \mathrm{E}-04$ & 55 & 6.59E-04 & 536 & $2.15 \mathrm{E}-03$ & 77,351 & 8.34E-03 & $6.51 \mathrm{E}-10$ \\
\hline \multicolumn{17}{|l|}{ Exp. \#36 } \\
\hline LC22-36.A & $7.64 \mathrm{E}+04$ & 40 & - & - & 9 & - & - & $<50$ & - & $<10$ & - & $<50$ & - & 88,085 & - & - \\
\hline LC22-36.2 & $7.64 \mathrm{E}+04$ & 40 & $1.9 \mathrm{E}-05$ & 0.89 & 9 & 2.005 & 0.031 & 418 & 7.13E-03 & 36 & 4.83E-04 & 2,585 & $1.43 \mathrm{E}-02$ & 79,782 & - & 2.88E-09 \\
\hline LC22-36.4 & $7.64 \mathrm{E}+04$ & 40 & $1.9 \mathrm{E}-05$ & 3.34 & 9 & 2.004 & 0.040 & 341 & $4.40 \mathrm{E}-03$ & 67 & 8.38E-04 & 1,885 & 8.11E-03 & 74,783 & - & $1.48 \mathrm{E}-09$ \\
\hline LC22-36.7 & $7.64 \mathrm{E}+04$ & 40 & $1.8 \mathrm{E}-05$ & 6.01 & 9 & 2.004 & 0.040 & 259 & $3.11 \mathrm{E}-03$ & 89 & $1.15 \mathrm{E}-03$ & 1,371 & $5.76 \mathrm{E}-03$ & 72,786 & - & 1.06E-09 \\
\hline LC22-36.13 & $7.64 \mathrm{E}+04$ & 40 & $1.8 \mathrm{E}-05$ & 14.14 & 9 & 2.004 & 0.040 & 172 & $1.78 \mathrm{E}-03$ & 90 & 1.13E-03 & 927 & $3.74 \mathrm{E}-03$ & 78,454 & - & $7.85 \mathrm{E}-10$ \\
\hline LC22-36.16 & $7.64 \mathrm{E}+04$ & 40 & $1.4 \mathrm{E}-05$ & 19.80 & 9 & 2.004 & 0.040 & 139 & $1.04 \mathrm{E}-03$ & 78 & 7.73E-04 & 771 & $2.45 \mathrm{E}-03$ & 79,265 & - & 5.65E-10 \\
\hline LC22-36.20 & $7.64 \mathrm{E}+04$ & 40 & $1.2 \mathrm{E}-05$ & 26.92 & 9 & 2.004 & 0.040 & 112 & 6.03E-04 & 70 & 5.63E-04 & 705 & $1.85 \mathrm{E}-03$ & 86,193 & - & 4.99E-10 \\
\hline LC22-36.21 & $7.64 \mathrm{E}+04$ & 40 & $1.9 \mathrm{E}-05$ & 28.03 & 9 & 2.003 & 0.040 & 131 & $1.22 \mathrm{E}-03$ & 74 & $9.42 \mathrm{E}-04$ & 762 & $3.14 \mathrm{E}-03$ & 81,897 & - & $7.68 \mathrm{E}-10$ \\
\hline LC22-36.22 & $7.64 \mathrm{E}+04$ & 40 & $1.8 \mathrm{E}-05$ & 28.95 & 9 & 2.003 & 0.040 & 109 & 8.65E-04 & 64 & 7.68E-04 & 649 & $2.58 \mathrm{E}-03$ & 80,436 & - & $6.85 \mathrm{E}-10$ \\
\hline LC22-36.23 & $7.64 \mathrm{E}+04$ & 40 & 1.3E-06 & 31.94 & 9 & 2.003 & 0.040 & 100 & $5.42 \mathrm{E}-05$ & 61 & 5.34E-05 & 655 & $1.93 \mathrm{E}-04$ & 79,823 & - & 5.53E-11 \\
\hline
\end{tabular}


Table A3. SPFT Results for LAWC22 Glasses.

\begin{tabular}{|c|c|c|c|c|c|c|c|c|c|c|c|c|c|c|c|c|}
\hline Sample ID & $\begin{array}{c}\text { Influent } \\
\text { [Si] }\end{array}$ & $\mathrm{T}\left({ }^{\circ} \mathrm{C}\right)$ & $\begin{array}{c}\text { Flow } \\
\text { Rate } \\
\left(\mathrm{m}^{3} / \mathrm{d}\right) \\
\end{array}$ & $\begin{array}{c}\text { Time, } \\
\text { days }\end{array}$ & $\begin{array}{c}\mathrm{pH} \\
\left(23^{\circ} \mathrm{C}\right) \\
\end{array}$ & $\begin{array}{c}\text { Glass } \\
\text { Mass (g) }\end{array}$ & $\mathrm{SA}\left(\mathrm{m}^{2}\right)$ & {$[\mathrm{B}]$} & B Rate & {$[\mathrm{Al}]$} & Al Rate & {$[\mathrm{Na}]$} & Na Rate & {$[\mathrm{Si}]$} & Si Rate & IEX Rate \\
\hline SS030804B1-A & $8.79 E+02$ & 90 & - & - & 9 & - & - & $<50$ & - & $<10$ & - & $<50$ & - & $<1000$ & - & - \\
\hline SS030804B1-B & $8.79 E+02$ & 90 & - & - & 9 & - & - & $<50$ & - & $<10$ & - & $<50$ & - & $<1000$ & - & - \\
\hline LC22-43.1 & $8.79 \mathrm{E}+02$ & 90 & 3.7E-05 & 0.79 & 9 & 0.501 & 0.010 & 818 & $9.27 \mathrm{E}-02$ & 846 & $9.80 \mathrm{E}-02$ & 3,736 & $1.30 \mathrm{E}-01$ & 6,448 & $9.41 \mathrm{E}-02$ & 1.49E-08 \\
\hline LC22-43.2 & $8.79 \mathrm{E}+02$ & 90 & 7.6E-05 & 1.89 & 9 & 0.497 & 0.010 & 1,473 & 3.54E-01 & 1,538 & 3.69E-01 & 5,555 & $4.00 \mathrm{E}-01$ & 9,347 & 2.97E-01 & $1.85 \mathrm{E}-08$ \\
\hline LC22-43.3 & $8.79 E+02$ & 90 & 2.2E-05 & 2.90 & 9 & 0.494 & 0.010 & 1,318 & 8.95E-02 & 1,358 & $9.24 \mathrm{E}-02$ & 4,511 & $9.21 \mathrm{E}-02$ & 8,398 & 7.48E-02 & $1.04 \mathrm{E}-09$ \\
\hline LC22-43.6 & $8.79 E+02$ & 90 & 7.8E-05 & 5.84 & 9 & 0.491 & 0.010 & 1,322 & 3.26E-01 & 1,254 & 3.10E-01 & 4,319 & 3.20E-01 & 8,405 & 2.72E-01 & - \\
\hline LC22-43.8 & $8.79 \mathrm{E}+02$ & 90 & 4.2E-05 & 7.74 & 9 & 0.486 & 0.010 & 1,294 & $1.76 \mathrm{E}-01$ & 1,179 & $1.60 \mathrm{E}-01$ & 4,320 & $1.76 \mathrm{E}-01$ & 8,219 & $1.46 \mathrm{E}-01$ & $2.32 \mathrm{E}-10$ \\
\hline LC22-43.9 & $8.79 \mathrm{E}+02$ & 90 & $8.0 \mathrm{E}-05$ & 9.06 & 9 & 0.480 & 0.010 & 1,219 & 3.14E-01 & 1,146 & 2.96E-01 & 4,014 & 3.11E-01 & 7,997 & 2.69E-01 & - \\
\hline LC22-43.10 & $8.79 \mathrm{E}+02$ & 90 & $8.1 \mathrm{E}-05$ & 9.79 & 9 & 0.476 & 0.009 & 1,220 & 3.22E-01 & 1,198 & 3.18E-01 & 4,064 & 3.23E-01 & 7,902 & 2.72E-01 & $4.40 \mathrm{E}-10$ \\
\hline LC22-43.11 & $8.79 \mathrm{E}+02$ & 90 & 7.6E-05 & 10.83 & 9 & 0.471 & 0.009 & 1,244 & 3.13E-01 & 1,199 & 3.03E-01 & 4,075 & 3.09E-01 & 8,003 & 2.63E-01 & - \\
\hline $\begin{array}{c}\text { LC22-43.12 } \\
\text { Exp. \#38 }\end{array}$ & $8.79 \mathrm{E}+02$ & 90 & $1.8 \mathrm{E}-04$ & 10.93 & 9 & 0.469 & 0.009 & 1,280 & 7.52E-01 & 1,217 & 7.16E-01 & 4,177 & 7.38E-01 & 8,149 & 6.26E-01 & - \\
\hline SS030804B2-A & $3.74 \mathrm{E}+04$ & 90 & - & - & 9 & - & - & $<50$ & - & $<10$ & - & $<50$ & - & 46,369 & - & - \\
\hline SS030804B2-B & $3.74 \mathrm{E}+04$ & 90 & - & - & 9 & - & - & $<50$ & - & $<10$ & - & $<50$ & - & 38,308 & - & - \\
\hline LC22-44.1 & $3.74 \mathrm{E}+04$ & 90 & 7.0E-05 & 0.79 & 9 & 0.504 & 0.010 & 617 & $1.27 \mathrm{E}-01$ & 402 & 8.55E-02 & 2,980 & $1.92 \mathrm{E}-01$ & 44,944 & 8.38E-02 & $2.60 \mathrm{E}-08$ \\
\hline LC22-44.2 & $3.74 \mathrm{E}+04$ & 90 & 8.3E-05 & 1.89 & 9 & 0.501 & 0.010 & 888 & 2.25E-01 & 486 & $1.24 \mathrm{E}-01$ & 3,493 & $2.71 \mathrm{E}-01$ & 46,317 & $1.53 \mathrm{E}-01$ & $1.82 \mathrm{E}-08$ \\
\hline LC22-44.3 & $3.74 \mathrm{E}+04$ & 90 & 4.4E-05 & 2.90 & 9 & 0.498 & 0.010 & 830 & $1.11 \mathrm{E}-01$ & 436 & 5.86E-02 & 3,078 & $1.25 \mathrm{E}-01$ & 46,204 & 7.84E-02 & 5.94E-09 \\
\hline LC22-44.6 & $3.74 \mathrm{E}+04$ & 90 & 7.6E-05 & 5.84 & 9 & 0.496 & 0.010 & 839 & $1.95 \mathrm{E}-01$ & 504 & 1.19E-01 & 2,846 & 2.02E-01 & 46,181 & $1.36 \mathrm{E}-01$ & 2.83E-09 \\
\hline LC22-44.8 & $3.74 \mathrm{E}+04$ & 90 & $4.0 \mathrm{E}-05$ & 7.74 & 9 & 0.494 & 0.010 & 589 & 7.05E-02 & 275 & 3.36E-02 & 2,145 & 8.00E-02 & 45,001 & 4.98E-02 & 3.82E-09 \\
\hline LC22-44.9 & $3.74 \mathrm{E}+04$ & 90 & 7.8E-05 & 9.06 & 9 & 0.491 & 0.010 & 498 & $1.15 \mathrm{E}-01$ & 334 & 8.05E-02 & 1,769 & $1.29 \mathrm{E}-01$ & 42,231 & - & 5.63E-09 \\
\hline LC22-44.10 & $3.74 \mathrm{E}+04$ & 90 & 7.1E-05 & 9.79 & 9 & 0.489 & 0.010 & 566 & $1.22 \mathrm{E}-01$ & 456 & $1.02 \mathrm{E}-01$ & 1,941 & $1.31 \mathrm{E}-01$ & 42,078 & - & 3.46E-09 \\
\hline LC22-44.11 & $3.74 \mathrm{E}+04$ & 90 & 8.5E-05 & 10.83 & 9 & 0.487 & 0.010 & 577 & 1.49E-01 & 490 & 1.32E-01 & 2,022 & $1.63 \mathrm{E}-01$ & 45,154 & $1.14 \mathrm{E}-01$ & 5.65E-09 \\
\hline $\begin{array}{c}\text { LC22-44.12 } \\
\text { Exp. \#39 }\end{array}$ & $3.74 \mathrm{E}+04$ & 90 & $1.2 \mathrm{E}-04$ & 10.93 & 9 & 0.486 & 0.010 & 599 & $2.28 \mathrm{E}-01$ & 566 & $2.24 \mathrm{E}-01$ & 2,178 & $2.58 \mathrm{E}-01$ & 47,445 & $3.04 \mathrm{E}-01$ & $1.22 \mathrm{E}-08$ \\
\hline SS030804B3-A & $7.39 \mathrm{E}+04$ & 90 & - & - & 9 & - & - & $<50$ & - & $<10$ & - & $<50$ & - & 83,074 & - & - \\
\hline SS030804B3-B & $7.39 \mathrm{E}+04$ & 90 & - & - & 9 & - & - & $<50$ & - & $<10$ & - & $<50$ & - & 74,762 & - & - \\
\hline LC22-45.1 & $7.39 \mathrm{E}+04$ & 90 & $5.8 \mathrm{E}-05$ & 0.79 & 9 & 0.998 & 0.020 & 494 & $4.21 \mathrm{E}-02$ & 213 & $1.87 \mathrm{E}-02$ & 3,746 & $1.02 \mathrm{E}-01$ & 86,976 & 1.09E-01 & $2.41 \mathrm{E}-08$ \\
\hline LC22-45.2 & $7.39 \mathrm{E}+04$ & 90 & 7.2E-05 & 1.89 & 9 & 0.996 & 0.020 & 641 & $6.92 \mathrm{E}-02$ & 246 & $2.68 \mathrm{E}-02$ & 3,896 & $1.32 \mathrm{E}-01$ & 85,728 & $1.14 \mathrm{E}-01$ & $2.49 \mathrm{E}-08$ \\
\hline LC22-45.3 & $7.39 \mathrm{E}+04$ & 90 & 4.3E-05 & 2.90 & 9 & 0.995 & 0.020 & 600 & 3.89E-02 & 239 & $1.57 \mathrm{E}-02$ & 3,223 & 6.57E-02 & 85,684 & 6.86E-02 & 1.07E-08 \\
\hline LC22-45.6 & $7.39 E+04$ & 90 & 7.3E-05 & 5.84 & 9 & 0.993 & 0.020 & 736 & 8.15E-02 & 314 & 3.51E-02 & 3,300 & 1.13E-01 & 82,351 & 5.84E-02 & $1.25 \mathrm{E}-08$ \\
\hline LC22-45.8 & $7.39 \mathrm{E}+04$ & 90 & $4.0 \mathrm{E}-05$ & 7.74 & 9 & 0.991 & 0.020 & 444 & $2.58 \mathrm{E}-02$ & 165 & 9.83E-03 & 2,135 & 3.99E-02 & 80,554 & $1.53 \mathrm{E}-02$ & $5.62 \mathrm{E}-09$ \\
\hline LC22-45.9 & $7.39 \mathrm{E}+04$ & 90 & $8.2 \mathrm{E}-05$ & 9.06 & 9 & 0.989 & 0.020 & 344 & 3.97E-02 & 126 & $1.51 \mathrm{E}-02$ & 1,699 & $6.50 \mathrm{E}-02$ & 80,997 & 4.01E-02 & $1.01 \mathrm{E}-08$ \\
\hline LC22-45.10 & $7.39 \mathrm{E}+04$ & 90 & 7.6E-05 & 9.79 & 9 & 0.988 & 0.020 & 394 & 4.28E-02 & 148 & $1.67 \mathrm{E}-02$ & 1,777 & $6.28 \mathrm{E}-02$ & 80,205 & $2.29 \mathrm{E}-02$ & 7.99E-09 \\
\hline LC22-45.11 & $7.39 \mathrm{E}+04$ & 90 & 7.7E-05 & 10.83 & 9 & 0.986 & 0.020 & 415 & 4.66E-02 & 164 & 1.91E-02 & 1,786 & 6.47E-02 & 79,068 & 2.74E-03 & 7.24E-09 \\
\hline $\begin{array}{c}\text { LC22-45.12 } \\
\text { Exp. \#40 }\end{array}$ & $7.39 \mathrm{E}+04$ & 90 & $1.3 \mathrm{E}-04$ & 10.93 & 9 & 0.986 & 0.019 & 458 & 8.61E-02 & 197 & 3.82E-02 & 1,930 & $1.16 \mathrm{E}-01$ & 76,956 & - & $1.20 \mathrm{E}-08$ \\
\hline SS030804B4-A & $1.06 \mathrm{E}+05$ & 90 & - & - & 9 & - & - & $<50$ & - & 11 & - & $<50$ & - & 113,351 & - & - \\
\hline SS030804B4-B & $1.06 \mathrm{E}+05$ & 90 & - & - & 9 & - & - & $<50$ & - & $<10$ & - & $<50$ & - & 101,114 & - & - \\
\hline LC22-46.1 & $1.06 \mathrm{E}+05$ & 90 & 4.5E-05 & 0.79 & 9 & 0.995 & 0.020 & 279 & $1.66 \mathrm{E}-02$ & 91 & 5.72E-03 & 3,008 & $6.29 \mathrm{E}-02$ & 131,009 & $2.48 \mathrm{E}-01$ & $1.85 \mathrm{E}-08$ \\
\hline LC22-46.2 & $1.06 \mathrm{E}+05$ & 90 & $6.9 \mathrm{E}-05$ & 1.89 & 9 & 0.994 & 0.020 & 245 & 2.19E-02 & 80 & 7.60E-03 & 2,764 & 8.91E-02 & 126,600 & 3.11E-01 & $2.68 \mathrm{E}-08$ \\
\hline
\end{tabular}


Table A3. SPFT Results for LAWC22 Glasses.

\begin{tabular}{|c|c|c|c|c|c|c|c|c|c|c|c|c|c|c|c|c|}
\hline Sample ID & $\begin{array}{c}\text { Influent } \\
\text { [Si] }\end{array}$ & $\mathrm{T}\left({ }^{\circ} \mathrm{C}\right)$ & $\begin{array}{c}\text { Flow } \\
\text { Rate } \\
\left(\mathrm{m}^{3} / \mathrm{d}\right) \\
\end{array}$ & $\begin{array}{l}\text { Time, } \\
\text { days }\end{array}$ & $\begin{array}{c}\mathrm{pH} \\
\left(23^{\circ} \mathrm{C}\right) \\
\end{array}$ & $\begin{array}{c}\text { Glass } \\
\text { Mass (g) }\end{array}$ & $\mathrm{SA}\left(\mathrm{m}^{2}\right)$ & [B] & B Rate & {$[\mathrm{Al}]$} & Al Rate & {$[\mathrm{Na}]$} & Na Rate & {$[\mathrm{Si}]$} & Si Rate & IEX Rate \\
\hline LC22-46.3 & $1.06 \mathrm{E}+05$ & 90 & $2.1 \mathrm{E}-05$ & 2.90 & 9 & 0.994 & 0.020 & 228 & 6.18E-03 & 93 & 2.79E-03 & 2,164 & 2.15E-02 & 127,261 & $9.96 \mathrm{E}-02$ & 6.10E-09 \\
\hline LC22-46.6 & $1.06 \mathrm{E}+05$ & 90 & 7.4E-05 & 5.84 & 9 & 0.993 & 0.020 & 167 & $1.41 \mathrm{E}-02$ & 72 & 7.24E-03 & 1,307 & 4.42E-02 & 128,446 & 3.65E-01 & $1.20 \mathrm{E}-08$ \\
\hline LC22-46.8 & $1.06 \mathrm{E}+05$ & 90 & 4.1E-05 & 7.74 & 9 & 0.993 & 0.020 & 130 & 5.34E-03 & 50 & 2.57E-03 & 957 & 1.76E-02 & 125,074 & $1.70 \mathrm{E}-01$ & 4.89E-09 \\
\hline LC22-46.9 & $1.06 \mathrm{E}+05$ & 90 & $8.1 \mathrm{E}-05$ & 9.06 & 9 & 0.992 & 0.020 & 135 & 1.13E-02 & 51 & 5.25E-03 & 861 & 3.15E-02 & 121,302 & 2.68E-01 & 8.09E-09 \\
\hline LC22-46.10 & $1.06 \mathrm{E}+05$ & 90 & $6.4 \mathrm{E}-05$ & 9.79 & 9 & 0.991 & 0.020 & 207 & $1.65 \mathrm{E}-02$ & 77 & $6.84 \mathrm{E}-03$ & 1,130 & 3.32E-02 & 119,039 & $1.77 \mathrm{E}-01$ & 6.65E-09 \\
\hline LC22-46.11 & $1.06 \mathrm{E}+05$ & 90 & 8.3E-05 & 10.83 & 9 & 0.991 & 0.020 & 181 & $1.78 \mathrm{E}-02$ & 73 & $8.24 \mathrm{E}-03$ & 1,069 & 4.04E-02 & 123,737 & $3.20 \mathrm{E}-01$ & $9.03 \mathrm{E}-09$ \\
\hline LC22-46.12 & $1.06 \mathrm{E}+05$ & 90 & $1.5 \mathrm{E}-04$ & 10.93 & 9 & 0.990 & 0.020 & 154 & 2.55E-02 & 70 & $1.42 \mathrm{E}-02$ & 993 & $6.78 \mathrm{E}-02$ & 127,881 & $7.28 \mathrm{E}-01$ & $1.69 \mathrm{E}-08$ \\
\hline \multicolumn{17}{|l|}{ Exp. \#41 } \\
\hline SS030804B5-A & $1.22 \mathrm{E}+05$ & 90 & - & - & 9 & - & - & $<50$ & - & $<10$ & - & $<50$ & - & 123,534 & - & - \\
\hline SS030804B5-B & $1.22 \mathrm{E}+05$ & 90 & - & - & 9 & - & - & $<50$ & - & $<10$ & - & $<50$ & - & 103,000 & - & - \\
\hline LC22-47.1 & $1.22 \mathrm{E}+05$ & 90 & $6.8 \mathrm{E}-05$ & 0.79 & 9 & 2.002 & 0.040 & 481 & 2.38E-02 & 73 & 3.38E-03 & 5,368 & 8.59E-02 & 151,639 & 3.04E-01 & $2.48 \mathrm{E}-08$ \\
\hline LC22-47.2 & $1.22 \mathrm{E}+05$ & 90 & 7.5E-05 & 1.89 & 9 & 2.001 & 0.040 & 306 & $1.56 \mathrm{E}-02$ & 54 & 2.62E-03 & 4,060 & 7.15E-02 & 150,048 & $3.21 \mathrm{E}-01$ & 2.23E-08 \\
\hline LC22-47.3 & $1.22 \mathrm{E}+05$ & 90 & $5.2 \mathrm{E}-05$ & 2.90 & 9 & 2.000 & 0.039 & 224 & 7.31E-03 & 59 & 1.98E-03 & 3,041 & 3.68E-02 & 155,807 & $2.56 \mathrm{E}-01$ & $1.18 \mathrm{E}-08$ \\
\hline LC22-47.6 & $1.22 \mathrm{E}+05$ & 90 & 7.3E-05 & 5.84 & 9 & 2.000 & 0.039 & 232 & $1.08 \mathrm{E}-02$ & 46 & 2.09E-03 & 1,818 & $3.08 \mathrm{E}-02$ & 157,657 & 3.78E-01 & 7.95E-09 \\
\hline LC22-47.8 & $1.22 \mathrm{E}+05$ & 90 & $4.0 \mathrm{E}-05$ & 7.74 & 9 & 1.999 & 0.039 & 206 & 5.07E-03 & 40 & $9.40 \mathrm{E}-04$ & 1,445 & 1.33E-02 & 145,069 & $1.48 \mathrm{E}-01$ & 3.28E-09 \\
\hline LC22-47.9 & $1.22 \mathrm{E}+05$ & 90 & 8.1E-05 & 9.06 & 9 & 1.998 & 0.039 & 193 & $9.40 \mathrm{E}-03$ & 46 & $2.28 \mathrm{E}-03$ & 1,347 & 2.49E-02 & 140,813 & 2.59E-01 & 6.19E-09 \\
\hline LC22-47.10 & $1.22 \mathrm{E}+05$ & 90 & 7.5E-05 & 9.79 & 9 & 1.997 & 0.039 & 183 & 8.13E-03 & 47 & 2.20E-03 & 1,401 & $2.41 \mathrm{E}-02$ & 149,069 & 3.13E-01 & 6.38E-09 \\
\hline LC22-47.11 & $1.22 \mathrm{E}+05$ & 90 & 7.7E-05 & 10.83 & 9 & 1.997 & 0.039 & 177 & 7.91E-03 & 51 & 2.47E-03 & 1,331 & 2.33E-02 & 153,754 & 3.61E-01 & 6.16E-09 \\
\hline LC22-47.12 & $1.22 \mathrm{E}+05$ & 90 & $9.1 \mathrm{E}-05$ & 10.93 & 9 & 1.996 & 0.039 & 163 & 8.39E-03 & 41 & 2.22E-03 & 1,214 & 2.53E-02 & 151,487 & 4.07E-01 & 6.76E-09 \\
\hline \multicolumn{17}{|l|}{ Exp. \#42 } \\
\hline SS030804B6-A & $1.39 \mathrm{E}+05$ & 90 & - & - & 9 & - & - & $<50$ & - & $<10$ & - & $<50$ & - & 129,572 & - & - \\
\hline SS030804B6-B & $1.39 \mathrm{E}+05$ & 90 & - & - & 9 & - & - & $<50$ & - & $<10$ & - & $<50$ & - & 97,300 & - & - \\
\hline LC22-48.1 & $1.39 \mathrm{E}+05$ & 90 & 4.7E-05 & 0.79 & 9 & 1.993 & 0.039 & 489 & $1.68 \mathrm{E}-02$ & 60 & $1.85 \mathrm{E}-03$ & 1,686 & 1.83E-02 & 155,190 & 2.29E-01 & $6.05 \mathrm{E}-10$ \\
\hline LC22-48.2 & $1.39 \mathrm{E}+05$ & 90 & $1.1 \mathrm{E}-06$ & 1.89 & 9 & 1.993 & 0.039 & 975 & 8.51E-04 & 120 & 9.83E-05 & 2,521 & $6.64 \mathrm{E}-04$ & 143,025 & 3.89E-03 & - \\
\hline LC22-48.3 & $1.39 \mathrm{E}+05$ & 90 & 6.7E-05 & 2.90 & 9 & 1.990 & 0.039 & 1,528 & 8.05E-02 & 96 & 4.56E-03 & 2,795 & 4.37E-02 & 157,120 & $3.41 \mathrm{E}-01$ & - \\
\hline LC22-48.6 & $1.39 \mathrm{E}+05$ & 90 & 7.4E-05 & 5.84 & 9 & 1.987 & 0.039 & 521 & 2.84E-02 & 21 & 6.53E-04 & 947 & $1.58 \mathrm{E}-02$ & 166,825 & 4.61E-01 & - \\
\hline LC22-48.8 & $1.39 \mathrm{E}+05$ & 90 & $4.0 \mathrm{E}-05$ & 7.74 & 9 & 1.985 & 0.039 & 440 & $1.28 \mathrm{E}-02$ & 17 & 2.13E-04 & 758 & $6.80 \mathrm{E}-03$ & 155,252 & 1.97E-01 & - \\
\hline LC22-48.9 & $1.39 \mathrm{E}+05$ & 90 & 7.9E-05 & 9.06 & 9 & 1.984 & 0.039 & 383 & 2.14E-02 & 16 & 3.71E-04 & 672 & 1.17E-02 & 148,936 & 3.27E-01 & - \\
\hline LC22-48.10 & $1.39 \mathrm{E}+05$ & 90 & 7.5E-05 & 9.79 & 9 & 1.982 & 0.039 & 415 & $2.24 \mathrm{E}-02$ & 25 & 8.97E-04 & 709 & 1.19E-02 & 151,889 & 3.39E-01 & - \\
\hline LC22-48.11 & $1.39 \mathrm{E}+05$ & 90 & 7.3E-05 & 10.83 & 9 & 1.981 & 0.039 & 380 & $1.99 \mathrm{E}-02$ & 18 & 4.67E-04 & 674 & $1.10 \mathrm{E}-02$ & 158,612 & $3.90 \mathrm{E}-01$ & - \\
\hline LC22-48.12 & $1.39 \mathrm{E}+05$ & 90 & $1.3 \mathrm{E}-04$ & 10.93 & 9 & 1.980 & 0.039 & 335 & 2.94E-02 & 17 & 7.42E-04 & 607 & $1.68 \mathrm{E}-02$ & 166,449 & 7.83E-01 & - \\
\hline \multicolumn{17}{|l|}{ Exp. \#43 } \\
\hline LC22-49.A & $8.67 E+02$ & 70 & - & - & 9 & - & - & $<25$ & - & $<10$ & - & $<100$ & - & $<500$ & - & - \\
\hline LC22-49.1 & $8.67 \mathrm{E}+02$ & 70 & $6.2 \mathrm{E}-05$ & 0.90 & 9 & 0.506 & 0.023 & 359 & 2.92E-02 & 360 & 2.97E-02 & 1,403 & 3.33E-02 & 2,416 & $2.40 \mathrm{E}-02$ & 1.63E-09 \\
\hline LC22-49.3 & $8.67 \mathrm{E}+02$ & 70 & 6.6E-05 & 1.83 & 9 & 0.505 & 0.010 & 566 & $1.15 \mathrm{E}-01$ & 565 & $1.15 \mathrm{E}-01$ & 1,838 & $1.08 \mathrm{E}-01$ & 3,771 & $9.98 \mathrm{E}-02$ & - \\
\hline LC22-49.4 & $8.67 \mathrm{E}+02$ & 70 & 6.6E-05 & 2.87 & 9 & 0.504 & 0.010 & 556 & 1.12E-01 & 565 & $1.14 \mathrm{E}-01$ & 1,798 & $1.05 \mathrm{E}-01$ & 3,704 & $9.69 \mathrm{E}-02$ & - \\
\hline LC22-49.7 & $8.67 \mathrm{E}+02$ & 70 & 6.3E-05 & 5.18 & 9 & 0.502 & 0.010 & 472 & $9.13 \mathrm{E}-02$ & 481 & 9.34E-02 & 1,548 & 8.66E-02 & 3,155 & 7.77E-02 & - \\
\hline LC22-49.9 & $8.67 E+02$ & 70 & 6.6E-05 & 7.95 & 9 & 0.500 & 0.010 & 450 & $9.11 \mathrm{E}-02$ & 462 & 9.39E-02 & 1,416 & 8.24E-02 & 3,013 & 7.70E-02 & - \\
\hline LC22-49.10 & $8.67 \mathrm{E}+02$ & 70 & $6.2 \mathrm{E}-05$ & 8.89 & 9 & 0.498 & 0.010 & 433 & 8.30E-02 & 438 & 8.46E-02 & 1,395 & 7.71E-02 & 2,936 & $7.10 \mathrm{E}-02$ & - \\
\hline LC22-49.11 & $8.67 \mathrm{E}+02$ & 70 & $5.8 \mathrm{E}-05$ & 10.11 & 9 & 0.496 & 0.010 & 483 & $8.70 \mathrm{E}-02$ & 522 & $9.44 \mathrm{E}-02$ & 1,626 & $8.47 \mathrm{E}-02$ & 3,257 & 7.49E-02 & - \\
\hline
\end{tabular}


Table A3. SPFT Results for LAWC22 Glasses.

\begin{tabular}{|c|c|c|c|c|c|c|c|c|c|c|c|c|c|c|c|c|}
\hline Sample ID & $\begin{array}{c}\text { Influent } \\
\text { [Si] }\end{array}$ & $\mathrm{T}\left({ }^{\circ} \mathrm{C}\right)$ & $\begin{array}{c}\text { Flow } \\
\text { Rate } \\
\left(\mathrm{m}^{3} / \mathrm{d}\right) \\
\end{array}$ & $\begin{array}{l}\text { Time, } \\
\text { days }\end{array}$ & $\begin{array}{c}\mathrm{pH} \\
\left(23^{\circ} \mathrm{C}\right) \\
\end{array}$ & $\begin{array}{c}\text { Glass } \\
\text { Mass (g) }\end{array}$ & $\mathrm{SA}\left(\mathrm{m}^{2}\right)$ & {$[\mathrm{B}]$} & B Rate & {$[\mathrm{Al}]$} & Al Rate & {$[\mathrm{Na}]$} & Na Rate & [Si] & Si Rate & IEX Rate \\
\hline LC22-49.12 & $8.67 \mathrm{E}+02$ & 70 & 6.3E-05 & 10.98 & 9 & 0.495 & 0.010 & 553 & 1.09E-01 & 770 & $1.53 \mathrm{E}-01$ & 1,872 & $1.07 \mathrm{E}-01$ & 3,657 & 9.35E-02 & - \\
\hline \multicolumn{17}{|l|}{ Exp. \#44 } \\
\hline LC22-50.A & $2.93 \mathrm{E}+04$ & 70 & - & - & 9 & - & - & $<25$ & - & $<10$ & - & $<100$ & - & 32,850 & - & - \\
\hline LC22-50.1 & $2.93 E+04$ & 70 & 6.3E-05 & 0.90 & 9 & 0.507 & 0.023 & 171 & $1.29 \mathrm{E}-02$ & 101 & 7.85E-03 & 783 & $1.77 \mathrm{E}-02$ & 33,449 & 7.59E-03 & $1.89 \mathrm{E}-09$ \\
\hline LC22-50.3 & $2.93 E+04$ & 70 & 6.6E-05 & 1.83 & 9 & 0.506 & 0.010 & 321 & $6.22 \mathrm{E}-02$ & 201 & 3.90E-02 & 1,206 & 6.80E-02 & 34,340 & 4.49E-02 & 2.32E-09 \\
\hline LC22-50.4 & $2.93 \mathrm{E}+04$ & 70 & 6.6E-05 & 2.87 & 9 & 0.505 & 0.010 & 316 & $6.12 \mathrm{E}-02$ & 201 & 3.89E-02 & 1,137 & $6.38 \mathrm{E}-02$ & 33,729 & 2.65E-02 & 1.05E-09 \\
\hline LC22-50.7 & $2.93 E+04$ & 70 & 6.3E-05 & 5.18 & 9 & 0.504 & 0.010 & 316 & 5.90E-02 & 232 & 4.37E-02 & 1,048 & 5.61E-02 & 34,179 & 3.85E-02 & - \\
\hline LC22-50.9 & $2.93 E+04$ & 70 & $6.5 \mathrm{E}-05$ & 7.95 & 9 & 0.502 & 0.010 & 316 & 6.12E-02 & 235 & 4.59E-02 & 1,048 & 5.83E-02 & 34,697 & 5.57E-02 & - \\
\hline LC22-50.10 & $2.93 E+04$ & 70 & $6.5 \mathrm{E}-05$ & 8.89 & 9 & 0.501 & 0.010 & 314 & 6.11E-02 & 230 & 4.51E-02 & 1,030 & 5.75E-02 & 34,478 & 4.93E-02 & - \\
\hline LC22-50.11 & $2.93 E+04$ & 70 & 5.6E-05 & 10.11 & 9 & 0.500 & 0.010 & 314 & $5.24 \mathrm{E}-02$ & 237 & 4.00E-02 & 1,015 & 4.85E-02 & 33,947 & 2.85E-02 & - \\
\hline LC22-50.12 & $2.93 \mathrm{E}+04$ & 70 & 6.6E-05 & 10.98 & 9 & 0.499 & 0.010 & 318 & $6.25 \mathrm{E}-02$ & 251 & 4.99E-02 & 1,029 & $5.80 \mathrm{E}-02$ & 34,495 & 5.03E-02 & - \\
\hline \multicolumn{17}{|l|}{ Exp. \#45 } \\
\hline LC22-51.A & $5.83 \mathrm{E}+04$ & 70 & - & - & 9 & - & - & $<25$ & - & 10 & - & $<100$ & - & 66,285 & - & - \\
\hline LC22-51.1 & $5.83 \mathrm{E}+04$ & 70 & 6.6E-05 & 0.90 & 9 & 1.006 & 0.036 & 155 & 7.60E-03 & 62 & 2.96E-03 & 1,012 & $1.55 \mathrm{E}-02$ & 64,690 & - & 3.17E-09 \\
\hline LC22-51.3 & $5.83 E+04$ & 70 & $6.5 \mathrm{E}-05$ & 1.83 & 9 & 1.005 & 0.020 & 217 & 2.03E-02 & 86 & 7.90E-03 & 1,105 & 3.11E-02 & 65,107 & - & 4.32E-09 \\
\hline LC22-51.4 & $5.83 \mathrm{E}+04$ & 70 & 6.6E-05 & 2.87 & 9 & 1.005 & 0.020 & 209 & 1.95E-02 & 84 & 7.63E-03 & 978 & 2.72E-02 & 65,143 & - & 3.06E-09 \\
\hline LC22-51.7 & $5.83 E+04$ & 70 & 6.3E-05 & 5.18 & 9 & 1.004 & 0.020 & 189 & $1.67 \mathrm{E}-02$ & 86 & 7.52E-03 & 800 & 2.08E-02 & 66,681 & 5.77E-03 & $1.66 \mathrm{E}-09$ \\
\hline LC22-51.9 & $5.83 \mathrm{E}+04$ & 70 & $2.4 \mathrm{E}-05$ & 7.95 & 9 & 1.003 & 0.020 & 295 & $1.06 \mathrm{E}-02$ & 114 & 3.99E-03 & 1,209 & $1.28 \mathrm{E}-02$ & 67,861 & 8.88E-03 & $8.61 \mathrm{E}-10$ \\
\hline LC22-51.10 & $5.83 \mathrm{E}+04$ & 70 & $6.5 \mathrm{E}-05$ & 8.89 & 9 & 1.003 & 0.020 & 184 & $1.67 \mathrm{E}-02$ & 81 & 7.25E-03 & 787 & $2.11 \mathrm{E}-02$ & 67,495 & $1.82 \mathrm{E}-02$ & 1.75E-09 \\
\hline LC22-51.11 & $5.83 E+04$ & 70 & 5.6E-05 & 10.11 & 9 & 1.002 & 0.020 & 151 & $1.15 \mathrm{E}-02$ & 80 & $6.27 \mathrm{E}-03$ & 622 & 1.39E-02 & 66,541 & 3.33E-03 & $9.69 \mathrm{E}-10$ \\
\hline LC22-51.12 & $5.83 E+04$ & 70 & $6.6 \mathrm{E}-05$ & 10.98 & 9 & 1.002 & 0.020 & 151 & $1.34 \mathrm{E}-02$ & 82 & 7.53E-03 & 606 & $1.57 \mathrm{E}-02$ & 65,858 & - & $9.42 \mathrm{E}-10$ \\
\hline \multicolumn{17}{|l|}{ Exp. \#46 } \\
\hline LC22-52.A & $8.84 \mathrm{E}+04$ & 70 & - & - & 9 & - & - & $<25$ & - & $<10$ & - & $<100$ & - & 96,748 & - & - \\
\hline LC22-52.1 & $8.84 \mathrm{E}+04$ & 70 & 6.6E-05 & 0.90 & 9 & 1.005 & 0.036 & 113 & $5.16 \mathrm{E}-03$ & 35 & $1.42 \mathrm{E}-03$ & 863 & $1.30 \mathrm{E}-02$ & 96,200 & - & 3.15E-09 \\
\hline LC22-52.3 & $8.84 \mathrm{E}+04$ & 70 & 6.6E-05 & 1.83 & 9 & 1.005 & 0.020 & 104 & 8.45E-03 & 35 & $2.56 \mathrm{E}-03$ & 747 & $2.02 \mathrm{E}-02$ & 97,171 & $6.45 \mathrm{E}-03$ & 4.67E-09 \\
\hline LC22-52.4 & $8.84 \mathrm{E}+04$ & 70 & $6.5 \mathrm{E}-05$ & 2.87 & 9 & 1.004 & 0.020 & 78 & $5.60 \mathrm{E}-03$ & 28 & $1.87 \mathrm{E}-03$ & 594 & 1.53E-02 & 95,799 & - & 3.86E-09 \\
\hline LC22-52.7 & $8.84 \mathrm{E}+04$ & 70 & 6.3E-05 & 5.18 & 9 & 1.004 & 0.020 & 56 & 3.13E-03 & 32 & 2.17E-03 & 373 & 8.16E-03 & 94,898 & - & 2.01E-09 \\
\hline LC22-52.9 & $8.84 \mathrm{E}+04$ & 70 & 6.6E-05 & 7.95 & 9 & 1.004 & 0.020 & 59 & 3.59E-03 & 33 & $2.34 \mathrm{E}-03$ & 325 & 7.04E-03 & 96,380 & - & $1.38 \mathrm{E}-09$ \\
\hline LC22-52.10 & $8.84 \mathrm{E}+04$ & 70 & $6.5 \mathrm{E}-05$ & 8.89 & 9 & 1.004 & 0.020 & 52 & 2.89E-03 & 29 & $1.97 \mathrm{E}-03$ & 296 & $6.04 \mathrm{E}-03$ & 96,603 & - & $1.26 \mathrm{E}-09$ \\
\hline LC22-52.11 & $8.84 \mathrm{E}+04$ & 70 & 5.7E-05 & 10.11 & 9 & 1.003 & 0.020 & 48 & $2.08 \mathrm{E}-03$ & 28 & $1.58 \mathrm{E}-03$ & 295 & $5.23 \mathrm{E}-03$ & 91,341 & - & $1.26 \mathrm{E}-09$ \\
\hline LC22-52.12 & $8.84 \mathrm{E}+04$ & 70 & 6.6E-05 & 10.98 & 9 & 1.003 & 0.020 & 65 & $4.28 \mathrm{E}-03$ & 36 & 2.66E-03 & 292 & 5.98E-03 & 86,958 & - & $6.78 \mathrm{E}-10$ \\
\hline \multicolumn{17}{|l|}{ Exp. \#47 } \\
\hline LC22-53.A & $1.14 \mathrm{E}+05$ & 70 & - & - & 9 & - & - & $<25$ & - & 12 & - & $<100$ & - & 115,042 & - & - \\
\hline LC22-53.1 & $1.14 \mathrm{E}+05$ & 70 & $6.5 \mathrm{E}-05$ & 0.90 & 9 & 2.006 & 0.057 & 200 & $6.42 \mathrm{E}-03$ & 30 & 6.49E-04 & 1,667 & $1.68 \mathrm{E}-02$ & 115,633 & $3.10 \mathrm{E}-03$ & 4.14E-09 \\
\hline LC22-53.3 & $1.14 \mathrm{E}+05$ & 70 & 6.7E-05 & 1.83 & 9 & 2.005 & 0.040 & 172 & $7.98 \mathrm{E}-03$ & 24 & $6.41 \mathrm{E}-04$ & 1,397 & 2.05E-02 & 115,685 & 4.98E-03 & $5.01 \mathrm{E}-09$ \\
\hline LC22-53.4 & $1.14 \mathrm{E}+05$ & 70 & 6.6E-05 & 2.87 & 9 & 2.005 & 0.040 & 121 & $5.10 \mathrm{E}-03$ & 19 & 3.93E-04 & 1,014 & $1.42 \mathrm{E}-02$ & 116,053 & $7.70 \mathrm{E}-03$ & 3.64E-09 \\
\hline LC22-53.7 & $1.14 \mathrm{E}+05$ & 70 & $6.4 \mathrm{E}-05$ & 5.18 & 9 & 2.005 & 0.040 & 66 & $2.11 \mathrm{E}-03$ & 13 & 7.74E-05 & 598 & 7.49E-03 & 125,049 & 7.37E-02 & 2.15E-09 \\
\hline LC22-53.9 & $1.14 \mathrm{E}+05$ & 70 & $6.6 \mathrm{E}-05$ & 7.95 & 9 & 2.004 & 0.040 & 49 & $1.30 \mathrm{E}-03$ & 11 & - & 414 & 4.93E-03 & 124,853 & 7.55E-02 & $1.45 \mathrm{E}-09$ \\
\hline LC22-53.10 & $1.14 \mathrm{E}+05$ & 70 & 6.6E-05 & 8.89 & 9 & 2.004 & 0.040 & 45 & $1.06 \mathrm{E}-03$ & 14 & $1.40 \mathrm{E}-04$ & 385 & 4.43E-03 & 125,303 & 7.81E-02 & $1.34 \mathrm{E}-09$ \\
\hline LC22-53.11 & $1.14 \mathrm{E}+05$ & 70 & $5.5 \mathrm{E}-05$ & 10.11 & 9 & 2.004 & 0.040 & 40 & $6.66 \mathrm{E}-04$ & 15 & $1.34 \mathrm{E}-04$ & 373 & $3.58 \mathrm{E}-03$ & 119,790 & 3.05E-02 & $1.16 \mathrm{E}-09$ \\
\hline
\end{tabular}


Table A3. SPFT Results for LAWC22 Glasses.

\begin{tabular}{|c|c|c|c|c|c|c|c|c|c|c|c|c|c|c|c|c|}
\hline Sample ID & $\begin{array}{c}\text { Influent } \\
\text { [Si] }\end{array}$ & $\mathrm{T}\left({ }^{\circ} \mathrm{C}\right)$ & $\begin{array}{c}\text { Flow } \\
\text { Rate } \\
\left(\mathrm{m}^{3} / \mathrm{d}\right)\end{array}$ & $\begin{array}{c}\text { Time, } \\
\text { days }\end{array}$ & $\begin{array}{c}\mathrm{pH} \\
\left(23^{\circ} \mathrm{C}\right)\end{array}$ & $\begin{array}{c}\text { Glass } \\
\text { Mass (g) }\end{array}$ & $\mathrm{SA}\left(\mathrm{m}^{2}\right)$ & {$[\mathrm{B}]$} & B Rate & {$[\mathrm{Al}]$} & Al Rate & {$[\mathrm{Na}]$} & Na Rate & [Si] & Si Rate & IEX Rate \\
\hline $\begin{array}{c}\text { LC22-53.12 } \\
\text { Exp. \#48 }\end{array}$ & $1.14 \mathrm{E}+05$ & 70 & 6.6E-05 & 10.98 & 9 & 2.004 & 0.040 & 40 & 8.12E-04 & 24 & $6.48 \mathrm{E}-04$ & 375 & $4.30 \mathrm{E}-03$ & 116,901 & $1.43 \mathrm{E}-02$ & 1.39E-09 \\
\hline LC22-54.A & $1.37 \mathrm{E}+05$ & 70 & - & - & 9 & - & - & $<25$ & - & $<10$ & - & $<100$ & - & 120,577 & - & - \\
\hline LC22-54.1 & $1.37 \mathrm{E}+05$ & 70 & 7.1E-05 & 0.90 & 9 & 2.005 & 0.057 & 187 & 6.47E-03 & 28 & 7.05E-04 & 1,620 & $1.77 \mathrm{E}-02$ & 122,530 & $1.12 \mathrm{E}-02$ & 4.50E-09 \\
\hline LC22-54.3 & $1.37 \mathrm{E}+05$ & 70 & 6.6E-05 & 1.83 & 9 & 2.004 & 0.040 & 151 & 6.73E-03 & 23 & 6.59E-04 & 1,329 & $1.92 \mathrm{E}-02$ & 123,281 & 2.07E-02 & 4.99E-09 \\
\hline LC22-54.4 & $1.37 \mathrm{E}+05$ & 70 & 6.5E-05 & 2.87 & 9 & 2.004 & 0.040 & 100 & 3.99E-03 & 15 & 2.33E-04 & 909 & $1.25 \mathrm{E}-02$ & 122,903 & $1.76 \mathrm{E}-02$ & $3.40 \mathrm{E}-09$ \\
\hline LC22-54.7 & $1.37 \mathrm{E}+05$ & 70 & $6.4 \mathrm{E}-05$ & 5.18 & 9 & 2.004 & 0.040 & 60 & $1.82 \mathrm{E}-03$ & ND & - & 1,045 & $1.43 \mathrm{E}-02$ & 135,455 & $1.10 \mathrm{E}-01$ & 4.97E-09 \\
\hline LC22-54.9 & $1.37 \mathrm{E}+05$ & 70 & $6.5 \mathrm{E}-05$ & 7.95 & 9 & 2.003 & 0.040 & 52 & $1.42 \mathrm{E}-03$ & 12 & $1.01 \mathrm{E}-04$ & 449 & 5.36E-03 & 134,901 & $1.08 \mathrm{E}-01$ & 1.57E-09 \\
\hline LC22-54.10 & $1.37 \mathrm{E}+05$ & 70 & 6.5E-05 & 8.89 & 9 & 2.003 & 0.040 & 41 & 8.60E-04 & ND & - & 378 & $4.30 \mathrm{E}-03$ & 135,775 & $1.15 \mathrm{E}-01$ & 1.37E-09 \\
\hline LC22-54.11 & $1.37 \mathrm{E}+05$ & 70 & 5.6E-05 & 10.11 & 9 & 2.003 & 0.040 & 38 & $6.10 \mathrm{E}-04$ & 10 & - & 358 & $3.42 \mathrm{E}-03$ & 128,951 & 5.43E-02 & $1.12 \mathrm{E}-09$ \\
\hline LC22-54.12 & $1.37 \mathrm{E}+05$ & 70 & 6.6E-05 & 10.98 & 9 & 2.003 & 0.040 & 35 & 5.64E-04 & 16 & 3.31E-04 & 340 & 3.77E-03 & 121,693 & 8.59E-03 & $1.28 \mathrm{E}-09$ \\
\hline
\end{tabular}

[] $-\mu \mathrm{g} \mathrm{L}^{-1}$

Rate $-\mathrm{g} \mathrm{m}^{-2} \mathrm{~d}^{-1}$

IEX Rate $-\mathrm{mol} \mathrm{m}^{-2} \mathrm{~s}^{-1}$ 
Appendix B

Pressurized Unsaturated Flow Test Results 
Table B1. LAWA44 PUF Test Results

\begin{tabular}{|c|c|c|c|c|c|c|c|c|c|c|c|c|c|}
\hline Sample ID & Vial \# & Time, days & $\theta$ & $\sigma \theta$ & pH & [Al] & Al Rate & [B] & B Rate & [Cr] & Cr Rate & [Mg] & Mg Rate \\
\hline LAWA44-01 & 1 & 0.07 & 0.31 & 0.12 & - & $6.0 \mathrm{E}+03$ & $1.1 \mathrm{E}-03$ & $3.1 \mathrm{E}+04$ & $6.6 \mathrm{E}-03$ & - & - & $2.1 \mathrm{E}+02$ & 1.1E-04 \\
\hline LAWA44-02 & 2 & 0.18 & 0.07 & 0.05 & - & $7.1 \mathrm{E}+03$ & 5.6E-03 & $4.7 \mathrm{E}+04$ & 4.4E-02 & - & - & $7.9 \mathrm{E}+02$ & 1.7E-03 \\
\hline LAWA44-03 & 3 & 1.19 & 0.05 & 0.01 & - & $4.6 \mathrm{E}+03$ & 5.3E-03 & $9.1 \mathrm{E}+04$ & $1.2 \mathrm{E}-01$ & - & - & $1.5 \mathrm{E}+02$ & 4.6E-04 \\
\hline LAWA44-04 & 4 & 3.41 & 0.04 & 0.01 & - & $6.2 \mathrm{E}+03$ & 8.2E-03 & $1.6 \mathrm{E}+05$ & 2.6E-01 & - & - & $6.3 \mathrm{E}+00$ & 2.3E-05 \\
\hline LAWA44-05 & 5 & 5.74 & 0.03 & 0.01 & - & $6.2 \mathrm{E}+03$ & $1.1 \mathrm{E}-02$ & $1.2 \mathrm{E}+05$ & $2.5 \mathrm{E}-01$ & - & - & $6.5 \mathrm{E}+00$ & 3.1E-05 \\
\hline LAWA44-06 & 6 & 7.91 & 0.02 & 0.00 & - & $6.1 \mathrm{E}+03$ & $1.4 \mathrm{E}-02$ & $1.1 \mathrm{E}+05$ & $3.0 \mathrm{E}-01$ & - & - & $4.3 \mathrm{E}+00$ & 2.7E-05 \\
\hline LAWA44-07 & 7 & 10.37 & 0.03 & 0.01 & - & $6.2 \mathrm{E}+03$ & 1.3E-02 & $1.0 \mathrm{E}+05$ & 2.6E-01 & - & - & $9.0 \mathrm{E}+00$ & 5.2E-05 \\
\hline LAWA44-08 & 8 & 12.78 & 0.03 & 0.01 & - & $5.4 \mathrm{E}+03$ & $9.0 \mathrm{E}-03$ & $1.0 \mathrm{E}+05$ & $2.0 \mathrm{E}-01$ & - & - & $5.9 \mathrm{E}+00$ & 2.7E-05 \\
\hline LAWA44-09 & 9 & 15.39 & 0.03 & 0.01 & - & $5.2 \mathrm{E}+03$ & 8.7E-03 & $9.0 \mathrm{E}+04$ & $1.8 \mathrm{E}-01$ & - & - & $5.2 \mathrm{E}+00$ & 2.3E-05 \\
\hline LAWA44-10 & 10 & 17.90 & 0.03 & 0.00 & - & $5.2 E+03$ & $1.0 \mathrm{E}-02$ & $8.6 E+04$ & 2.1E-01 & - & - & $3.5 \mathrm{E}+00$ & 1.9E-05 \\
\hline LAWA44-11 & 11 & 20.05 & 0.03 & 0.01 & - & $5.2 \mathrm{E}+03$ & $9.2 \mathrm{E}-03$ & $8.6 \mathrm{E}+04$ & $1.8 \mathrm{E}-01$ & - & - & $8.6 \mathrm{E}+00$ & 4.1E-05 \\
\hline LAWA44-12 & 12 & 22.50 & 0.03 & 0.01 & - & $4.9 \mathrm{E}+03$ & 8.0E-03 & $7.8 \mathrm{E}+04$ & $1.5 \mathrm{E}-01$ & - & - & $2.5 \mathrm{E}+01$ & 1.1E-04 \\
\hline LAWA44-13 & 13 & 24.75 & 0.02 & 0.01 & - & $5.3 \mathrm{E}+03$ & $1.6 \mathrm{E}-02$ & $7.5 \mathrm{E}+04$ & $2.8 \mathrm{E}-01$ & - & - & $7.0 \mathrm{E}+00$ & $6.0 \mathrm{E}-05$ \\
\hline LAWA44-14 & 14 & 26.82 & 0.04 & 0.01 & - & $4.6 \mathrm{E}+03$ & $5.8 \mathrm{E}-03$ & $7.9 \mathrm{E}+04$ & $1.2 \mathrm{E}-01$ & - & - & $1.2 \mathrm{E}+01$ & 4.2E-05 \\
\hline LAWA44-15 & 15 & 29.01 & 0.05 & 0.01 & - & $4.4 \mathrm{E}+03$ & 5.5E-03 & $8.0 \mathrm{E}+04$ & $1.2 \mathrm{E}-01$ & - & - & $5.1 \mathrm{E}+00$ & 1.7E-05 \\
\hline LAWA44-16 & 16 & 31.40 & 0.04 & 0.01 & - & $4.5 \mathrm{E}+03$ & 6.3E-03 & $7.1 \mathrm{E}+04$ & $1.2 \mathrm{E}-01$ & - & - & $3.8 \mathrm{E}+00$ & 1.4E-05 \\
\hline LAWA44-17 & 17 & 34.27 & 0.05 & 0.01 & - & $4.3 E+03$ & 4.8E-03 & $6.6 \mathrm{E}+04$ & $8.8 \mathrm{E}-02$ & - & - & $3.9 \mathrm{E}+00$ & 1.2E-05 \\
\hline LAWA44-18 & 18 & 36.80 & 0.05 & 0.00 & - & $4.4 \mathrm{E}+03$ & $5.4 \mathrm{E}-03$ & $7.0 \mathrm{E}+04$ & $1.0 \mathrm{E}-01$ & - & - & $5.1 \mathrm{E}+00$ & 1.7E-05 \\
\hline LAWA44-19 & 19 & 38.76 & 0.05 & 0.00 & - & $3.8 \mathrm{E}+03$ & 4.3E-03 & $7.4 \mathrm{E}+04$ & $1.0 \mathrm{E}-01$ & - & - & $8.7 \mathrm{E}+00$ & 2.7E-05 \\
\hline LAWA44-20 & 20 & 40.87 & 0.05 & 0.01 & - & $4.1 \mathrm{E}+03$ & 4.2E-03 & $7.1 \mathrm{E}+04$ & $8.8 \mathrm{E}-02$ & - & - & $2.4 \mathrm{E}+00$ & 6.9E-06 \\
\hline LAWA44-21 & 21 & 43.02 & 0.05 & 0.00 & - & $4.1 \mathrm{E}+03$ & 4.8E-03 & $6.9 \mathrm{E}+04$ & $9.6 \mathrm{E}-02$ & - & - & $8.8 \mathrm{E}+00$ & 2.8E-05 \\
\hline LAWA44-22 & 22 & 45.38 & 0.05 & 0.01 & - & $4.1 \mathrm{E}+03$ & 4.3E-03 & $6.7 \mathrm{E}+04$ & 8.3E-02 & - & - & $6.4 \mathrm{E}+00$ & 1.8E-05 \\
\hline LAWA44-23 & 23 & 48.28 & 0.05 & 0.01 & - & $3.9 \mathrm{E}+03$ & 4.0E-03 & $6.7 \mathrm{E}+04$ & 8.3E-02 & - & - & $6.0 \mathrm{E}+00$ & 1.7E-05 \\
\hline LAWA44-24 & 24 & 50.83 & 0.05 & 0.01 & - & $4.3 \mathrm{E}+03$ & 4.7E-03 & $5.5 \mathrm{E}+04$ & 7.1E-02 & - & - & $5.0 \mathrm{E}+00$ & 1.5E-05 \\
\hline LAWA44-25 & 25 & 53.26 & 0.06 & 0.01 & - & $4.1 \mathrm{E}+03$ & 3.8E-03 & $6.2 \mathrm{E}+04$ & $6.9 \mathrm{E}-02$ & - & - & $6.4 \mathrm{E}+00$ & 1.6E-05 \\
\hline LAWA44-26 & 26 & 56.38 & 0.06 & 0.01 & - & $3.9 \mathrm{E}+03$ & 3.6E-03 & $6.5 \mathrm{E}+04$ & 7.2E-02 & - & - & $6.1 \mathrm{E}+00$ & 1.6E-05 \\
\hline LAWA44-27 & 27 & 59.42 & 0.06 & 0.01 & - & $3.6 \mathrm{E}+03$ & 3.6E-03 & $6.1 \mathrm{E}+04$ & 7.1E-02 & - & - & $4.1 \mathrm{E}+00$ & 1.1E-05 \\
\hline LAWA44-28 & 28 & 61.76 & 0.06 & 0.01 & - & $3.7 \mathrm{E}+03$ & 3.8E-03 & $6.0 \mathrm{E}+04$ & 7.3E-02 & - & - & $3.9 \mathrm{E}+00$ & 1.1E-05 \\
\hline LAWA44-29 & 29 & 63.91 & 0.06 & 0.01 & - & $3.5 E+03$ & 3.5E-03 & $5.6 \mathrm{E}+04$ & $6.5 \mathrm{E}-02$ & - & - & $5.0 \mathrm{E}+00$ & 1.4E-05 \\
\hline LAWA44-30 & 30 & 66.40 & 0.06 & 0.01 & - & $3.6 \mathrm{E}+03$ & $3.2 \mathrm{E}-03$ & $6.0 \mathrm{E}+04$ & $6.4 \mathrm{E}-02$ & - & - & $1.5 \mathrm{E}+01$ & 3.7E-05 \\
\hline LAWA44-31 & 31 & 68.76 & 0.07 & 0.01 & - & $3.7 \mathrm{E}+03$ & $3.2 \mathrm{E}-03$ & $6.1 \mathrm{E}+04$ & $6.2 \mathrm{E}-02$ & - & - & $5.5 \mathrm{E}+00$ & 1.3E-05 \\
\hline LAWA44-32 & 32 & 70.93 & 0.06 & 0.01 & - & $3.4 \mathrm{E}+03$ & $3.0 \mathrm{E}-03$ & $5.3 \mathrm{E}+04$ & 5.6E-02 & - & - & $3.8 \mathrm{E}+00$ & 9.3E-06 \\
\hline LAWA44-33 & 33 & 73.41 & 0.06 & 0.01 & - & $3.4 \mathrm{E}+03$ & 3.5E-03 & $5.3 \mathrm{E}+04$ & $6.4 \mathrm{E}-02$ & - & - & $3.9 \mathrm{E}+00$ & 1.1E-05 \\
\hline LAWA44-34 & 34 & 75.83 & 0.07 & 0.01 & - & $3.6 \mathrm{E}+03$ & 3.1E-03 & $6.0 \mathrm{E}+04$ & $6.1 \mathrm{E}-02$ & - & - & $5.0 \mathrm{E}+00$ & 1.2E-05 \\
\hline LAWA44-35 & 35 & 77.99 & 0.05 & 0.01 & - & $3.6 \mathrm{E}+03$ & 3.9E-03 & $5.5 \mathrm{E}+04$ & 7.1E-02 & - & - & - & - \\
\hline LAWA44-36 & 36 & 80.40 & 0.05 & 0.01 & - & $3.2 \mathrm{E}+03$ & 3.6E-03 & $5.2 \mathrm{E}+04$ & 7.0E-02 & - & - & - & - \\
\hline LAWA44-37 & 37 & 82.77 & 0.05 & 0.01 & - & $3.4 \mathrm{E}+03$ & 3.6E-03 & $5.6 \mathrm{E}+04$ & $7.0 \mathrm{E}-02$ & - & - & - & - \\
\hline
\end{tabular}


Table B1. LAWA44 PUF Test Results

\begin{tabular}{|c|c|c|c|c|c|c|c|c|c|c|c|c|c|}
\hline Sample ID & Vial \# & Time, days & $\theta$ & $\sigma \theta$ & pH & [Al] & Al Rate & [B] & B Rate & [Cr] & Cr Rate & [Mg] & Mg Rate \\
\hline LAWA44-38 & 38 & 84.78 & 0.06 & 0.01 & - & $3.7 \mathrm{E}+03$ & $3.8 \mathrm{E}-03$ & $6.0 \mathrm{E}+04$ & 7.3E-02 & - & - & - & - \\
\hline LAWA44-39 & 39 & 87.92 & 0.06 & 0.01 & - & $3.4 \mathrm{E}+03$ & $3.4 \mathrm{E}-03$ & $5.2 \mathrm{E}+04$ & $6.2 \mathrm{E}-02$ & - & - & - & - \\
\hline LAWA44-40 & 40 & 91.56 & 0.07 & 0.01 & - & $3.3 \mathrm{E}+03$ & $2.8 \mathrm{E}-03$ & $5.7 \mathrm{E}+04$ & $5.8 \mathrm{E}-02$ & - & - & - & - \\
\hline LAWA44-41 & 41 & 94.49 & 0.05 & 0.01 & - & $3.3 \mathrm{E}+03$ & 3.7E-03 & $4.7 \mathrm{E}+04$ & $6.4 \mathrm{E}-02$ & - & - & - & - \\
\hline LAWA44-42 & 42 & 96.99 & 0.05 & 0.01 & - & $3.0 \mathrm{E}+03$ & $3.5 \mathrm{E}-03$ & $5.3 \mathrm{E}+04$ & $7.2 \mathrm{E}-02$ & - & - & - & - \\
\hline LAWA44-43 & 43 & 98.95 & 0.07 & 0.00 & - & $3.2 \mathrm{E}+03$ & 2.7E-03 & $6.7 \mathrm{E}+04$ & 6.6E-02 & - & - & - & - \\
\hline LAWA44-44 & 44 & 102.33 & 0.07 & 0.01 & - & $3.6 \mathrm{E}+03$ & $3.1 \mathrm{E}-03$ & $5.4 \mathrm{E}+04$ & $5.6 \mathrm{E}-02$ & - & - & - & - \\
\hline LAWA44-45 & 45 & 105.95 & 0.07 & 0.00 & - & $3.6 \mathrm{E}+03$ & $3.0 \mathrm{E}-03$ & $5.1 \mathrm{E}+04$ & 5.0E-02 & - & - & - & - \\
\hline LAWA44-46 & 46 & 108.41 & 0.07 & 0.01 & - & $3.3 \mathrm{E}+03$ & $2.8 \mathrm{E}-03$ & $5.6 \mathrm{E}+04$ & 5.7E-02 & - & - & - & - \\
\hline LAWA44-47 & 47 & 110.82 & 0.07 & 0.01 & - & $3.8 \mathrm{E}+03$ & 3.3E-03 & $5.2 \mathrm{E}+04$ & 5.3E-02 & - & - & - & - \\
\hline LAWA44-48 & 48 & 112.98 & 0.07 & 0.01 & - & $3.5 \mathrm{E}+03$ & $2.9 \mathrm{E}-03$ & $5.4 \mathrm{E}+04$ & 5.3E-02 & - & - & - & - \\
\hline LAWA44-49 & 49 & 115.44 & 0.06 & 0.01 & - & $3.4 \mathrm{E}+03$ & $3.0 \mathrm{E}-03$ & $4.4 \mathrm{E}+04$ & 4.6E-02 & - & - & - & - \\
\hline LAWA44-50 & 50 & 117.82 & 0.07 & 0.01 & - & $2.9 \mathrm{E}+03$ & 2.3E-03 & $5.9 \mathrm{E}+04$ & 5.5E-02 & - & - & - & - \\
\hline LAWA44-51 & 51 & 119.93 & 0.07 & 0.01 & - & $3.4 \mathrm{E}+03$ & $2.8 \mathrm{E}-03$ & $5.1 \mathrm{E}+04$ & 4.9E-02 & - & - & - & - \\
\hline LAWA44-52 & 52 & 122.35 & 0.07 & 0.01 & - & $3.7 \mathrm{E}+03$ & $2.8 \mathrm{E}-03$ & $4.3 E+04$ & $4.0 \mathrm{E}-02$ & - & - & - & - \\
\hline LAWA44-53 & 53 & 124.75 & 0.10 & 0.01 & - & $3.1 \mathrm{E}+03$ & $1.8 \mathrm{E}-03$ & $5.1 \mathrm{E}+04$ & $3.4 \mathrm{E}-02$ & - & - & - & - \\
\hline LAWA44-54 & 54 & 126.90 & 0.09 & 0.01 & - & $3.7 \mathrm{E}+03$ & 2.4E-03 & $4.9 \mathrm{E}+04$ & 3.7E-02 & - & - & - & - \\
\hline LAWA44-55 & 55 & 129.36 & 0.08 & 0.00 & - & $3.7 \mathrm{E}+03$ & $2.5 \mathrm{E}-03$ & $4.1 \mathrm{E}+04$ & $3.4 \mathrm{E}-02$ & - & - & - & - \\
\hline LAWA44-56 & 56 & 131.75 & 0.09 & 0.01 & - & $2.7 \mathrm{E}+03$ & $1.7 \mathrm{E}-03$ & $4.7 \mathrm{E}+04$ & 3.5E-02 & - & - & - & - \\
\hline LAWA44-57 & 57 & 133.86 & 0.08 & 0.01 & - & $2.6 \mathrm{E}+03$ & $1.8 \mathrm{E}-03$ & $5.3 \mathrm{E}+04$ & $4.2 \mathrm{E}-02$ & - & - & - & - \\
\hline LAWA44-58 & 58 & 136.34 & 0.08 & 0.00 & - & $2.6 \mathrm{E}+03$ & $1.9 \mathrm{E}-03$ & $4.7 \mathrm{E}+04$ & $4.0 \mathrm{E}-02$ & - & - & - & - \\
\hline LAWA44-59 & 59 & 139.20 & 0.08 & 0.00 & - & $2.3 \mathrm{E}+03$ & $1.6 \mathrm{E}-03$ & $4.9 \mathrm{E}+04$ & $4.0 \mathrm{E}-02$ & - & - & - & - \\
\hline LAWA44-60 & 60 & 141.26 & 0.08 & 0.00 & - & $2.2 \mathrm{E}+03$ & $1.6 \mathrm{E}-03$ & $4.5 \mathrm{E}+04$ & 3.7E-02 & - & - & - & - \\
\hline LAWA44-61 & 61 & 143.82 & 0.08 & 0.00 & - & $2.1 \mathrm{E}+03$ & $1.5 \mathrm{E}-03$ & $4.7 \mathrm{E}+04$ & 3.9E-02 & - & - & - & - \\
\hline LAWA44-62 & 62 & 147.44 & 0.08 & 0.01 & - & $1.9 \mathrm{E}+03$ & $1.3 \mathrm{E}-03$ & $4.9 \mathrm{E}+04$ & 3.9E-02 & - & - & $2.4 \mathrm{E}+01$ & 4.5E-05 \\
\hline LAWA44-63 & 63 & 150.33 & 0.07 & 0.00 & - & $1.7 \mathrm{E}+03$ & $1.3 \mathrm{E}-03$ & $4.6 \mathrm{E}+04$ & 4.2E-02 & - & - & $2.9 \mathrm{E}+01$ & $6.1 \mathrm{E}-05$ \\
\hline LAWA44-64 & 64 & 152.73 & 0.08 & 0.00 & - & $1.6 \mathrm{E}+03$ & $1.2 \mathrm{E}-03$ & $4.6 \mathrm{E}+04$ & $4.0 \mathrm{E}-02$ & - & - & $3.1 \mathrm{E}+01$ & 6.3E-05 \\
\hline LAWA44-65 & 65 & 154.98 & 0.08 & 0.01 & - & $1.5 \mathrm{E}+03$ & $1.0 \mathrm{E}-03$ & $4.8 \mathrm{E}+04$ & 3.9E-02 & - & - & $3.8 \mathrm{E}+00$ & 7.1E-06 \\
\hline LAWA44-66 & 66 & 157.41 & 0.07 & 0.00 & - & $2.1 \mathrm{E}+03$ & $1.7 \mathrm{E}-03$ & $4.6 \mathrm{E}+04$ & 4.3E-02 & - & - & $6.3 \mathrm{E}+02$ & 1.3E-03 \\
\hline LAWA44-67 & 67 & 159.82 & 0.08 & 0.01 & - & $2.7 \mathrm{E}+03$ & $2.0 \mathrm{E}-03$ & $5.2 \mathrm{E}+04$ & 4.6E-02 & - & - & $1.8 \mathrm{E}+01$ & 3.7E-05 \\
\hline LAWA44-68 & 68 & 161.96 & 0.08 & 0.01 & - & $2.6 \mathrm{E}+03$ & $2.0 \mathrm{E}-03$ & $4.7 \mathrm{E}+04$ & $4.2 \mathrm{E}-02$ & - & - & $1.5 \mathrm{E}+01$ & 3.1E-05 \\
\hline LAWA44-69 & 69 & 164.35 & 0.07 & 0.01 & - & $2.6 \mathrm{E}+03$ & 2.0E-03 & $4.9 \mathrm{E}+04$ & 4.7E-02 & - & - & $1.4 \mathrm{E}+01$ & 3.1E-05 \\
\hline LAWA44-70 & 70 & 166.86 & 0.07 & 0.01 & - & $2.7 \mathrm{E}+03$ & $2.1 \mathrm{E}-03$ & $4.4 \mathrm{E}+04$ & $4.1 \mathrm{E}-02$ & - & - & $6.3 \mathrm{E}+02$ & $1.3 \mathrm{E}-03$ \\
\hline LAWA44-71 & 71 & 169.03 & 0.08 & 0.01 & - & $2.3 \mathrm{E}+03$ & $1.6 \mathrm{E}-03$ & $5.4 \mathrm{E}+04$ & 4.4E-02 & - & - & $1.1 \mathrm{E}+01$ & 2.1E-05 \\
\hline LAWA44-72 & 72 & 171.35 & 0.09 & 0.00 & - & $2.2 \mathrm{E}+03$ & $1.4 \mathrm{E}-03$ & $4.7 \mathrm{E}+04$ & 3.7E-02 & - & - & $2.5 \mathrm{E}+01$ & 4.4E-05 \\
\hline LAWA44-73 & 73 & 173.85 & 0.08 & 0.01 & - & $2.2 \mathrm{E}+03$ & $1.5 \mathrm{E}-03$ & $4.9 \mathrm{E}+04$ & 3.9E-02 & - & - & $6.3 \mathrm{E}+02$ & $1.2 \mathrm{E}-03$ \\
\hline LAWA44-74 & 74 & 176.00 & 0.06 & 0.01 & - & $2.2 \mathrm{E}+03$ & 2.0E-03 & $4.2 \mathrm{E}+04$ & 4.6E-02 & - & - & $6.3 \mathrm{E}+02$ & $1.6 \mathrm{E}-03$ \\
\hline
\end{tabular}


Table B1. LAWA44 PUF Test Results

\begin{tabular}{|c|c|c|c|c|c|c|c|c|c|c|c|c|c|}
\hline Sample ID & Vial \# & Time, days & $\theta$ & $\sigma \theta$ & pH & [Al] & Al Rate & [B] & B Rate & [Cr] & Cr Rate & [Mg] & Mg Rate \\
\hline LAWA44-75 & 75 & 178.33 & 0.06 & 0.01 & - & $2.8 \mathrm{E}+03$ & $2.8 \mathrm{E}-03$ & $4.9 \mathrm{E}+04$ & $5.8 \mathrm{E}-02$ & - & - & $3.4 \mathrm{E}+01$ & $9.4 \mathrm{E}-05$ \\
\hline LAWA44-76 & 76 & 180.80 & 0.06 & 0.02 & - & $2.6 \mathrm{E}+03$ & $2.5 \mathrm{E}-03$ & $4.8 \mathrm{E}+04$ & $5.4 \mathrm{E}-02$ & - & - & $1.8 \mathrm{E}+00$ & 4.6E-06 \\
\hline LAWA44-77 & 77 & 183.45 & 0.08 & 0.01 & - & $2.4 \mathrm{E}+03$ & $1.8 \mathrm{E}-03$ & $4.9 \mathrm{E}+04$ & 4.4E-02 & - & - & $5.0 \mathrm{E}+02$ & $1.0 \mathrm{E}-03$ \\
\hline LAWA44-78 & 78 & 186.47 & 0.05 & 0.02 & - & $2.1 \mathrm{E}+03$ & 2.6E-03 & $5.1 \mathrm{E}+04$ & 7.5E-02 & - & - & $1.3 \mathrm{E}+01$ & 4.4E-05 \\
\hline LAWA44-79 & 79 & 189.53 & 0.04 & 0.01 & - & $2.3 E+03$ & 3.1E-03 & $5.3 E+04$ & 8.3E-02 & - & - & $3.8 \mathrm{E}+01$ & 1.4E-04 \\
\hline LAWA44-80 & 80 & 192.41 & 0.05 & 0.01 & - & $2.8 \mathrm{E}+03$ & 3.2E-03 & $4.8 \mathrm{E}+04$ & $6.4 \mathrm{E}-02$ & - & - & $4.7 \mathrm{E}+01$ & 1.5E-04 \\
\hline LAWA44-81 & 81 & 194.83 & 0.04 & 0.02 & - & $9.3 \mathrm{E}+03$ & 1.3E-02 & $5.1 \mathrm{E}+04$ & $8.5 \mathrm{E}-02$ & - & - & $3.3 \mathrm{E}+01$ & 1.2E-04 \\
\hline LAWA44-82 & 82 & 197.50 & 0.03 & 0.00 & - & $3.3 E+03$ & 6.3E-03 & $2.9 \mathrm{E}+04$ & $6.4 \mathrm{E}-02$ & - & - & $5.9 \mathrm{E}+01$ & 3.0E-04 \\
\hline LAWA44-83 & 83 & 199.86 & 0.02 & 0.00 & - & $3.6 \mathrm{E}+03$ & 8.7E-03 & $3.9 \mathrm{E}+04$ & $1.1 \mathrm{E}-01$ & - & - & $3.9 \mathrm{E}+01$ & 2.6E-04 \\
\hline LAWA44-84 & 84 & 201.73 & 0.04 & 0.01 & - & $3.7 \mathrm{E}+03$ & $5.6 \mathrm{E}-03$ & $4.5 \mathrm{E}+04$ & $8.1 \mathrm{E}-02$ & - & - & $2.3 \mathrm{E}+01$ & 9.6E-05 \\
\hline LAWA44-85 & 85 & 203.92 & 0.03 & 0.00 & - & $3.3 E+03$ & $6.2 \mathrm{E}-03$ & $4.5 \mathrm{E}+04$ & $9.9 \mathrm{E}-02$ & - & - & $1.6 \mathrm{E}+01$ & 8.3E-05 \\
\hline LAWA44-86 & 86 & 206.37 & 0.02 & 0.00 & - & $3.2 E+03$ & 8.0E-03 & $4.3 E+04$ & $1.3 \mathrm{E}-01$ & - & - & $8.7 \mathrm{E}+00$ & 6.0E-05 \\
\hline LAWA44-87 & 87 & 208.77 & 0.02 & 0.00 & - & $3.1 \mathrm{E}+03$ & 7.6E-03 & $4.4 \mathrm{E}+04$ & $1.3 \mathrm{E}-01$ & - & - & $5.0 \mathrm{E}+02$ & 3.4E-03 \\
\hline LAWA44-88 & 88 & 210.97 & 0.03 & 0.01 & - & $3.1 \mathrm{E}+03$ & $6.4 \mathrm{E}-03$ & $4.6 \mathrm{E}+04$ & $1.1 \mathrm{E}-01$ & - & - & $2.9 \mathrm{E}+01$ & 1.6E-04 \\
\hline LAWA44-89 & 89 & 213.40 & 0.02 & 0.01 & - & $3.0 \mathrm{E}+03$ & 7.1E-03 & $4.8 \mathrm{E}+04$ & $1.3 \mathrm{E}-01$ & - & - & $2.7 \mathrm{E}+01$ & 1.7E-04 \\
\hline LAWA44-90 & 90 & 215.80 & 0.02 & 0.01 & - & $2.9 \mathrm{E}+03$ & 7.2E-03 & $4.7 \mathrm{E}+04$ & $1.4 \mathrm{E}-01$ & - & - & $3.5 \mathrm{E}+01$ & 2.4E-04 \\
\hline LAWA44-91 & 91 & 217.93 & 0.02 & 0.01 & - & $3.0 \mathrm{E}+03$ & $9.4 \mathrm{E}-03$ & $4.3 E+04$ & $1.6 \mathrm{E}-01$ & - & - & $4.5 \mathrm{E}+01$ & 3.9E-04 \\
\hline LAWA44-92 & 92 & 220.36 & 0.02 & 0.00 & - & $3.0 \mathrm{E}+03$ & 7.2E-03 & $4.2 \mathrm{E}+04$ & $1.2 \mathrm{E}-01$ & - & - & $2.7 \mathrm{E}+01$ & 1.8E-04 \\
\hline LAWA44-93 & 93 & 222.84 & 0.03 & 0.00 & - & $3.0 \mathrm{E}+03$ & $6.1 \mathrm{E}-03$ & $4.5 \mathrm{E}+04$ & $1.1 \mathrm{E}-01$ & - & - & $5.0 \mathrm{E}+02$ & 2.8E-03 \\
\hline LAWA44-94 & 94 & 225.00 & 0.04 & 0.02 & - & $2.8 \mathrm{E}+03$ & 3.5E-03 & $4.4 \mathrm{E}+04$ & 6.6E-02 & - & - & $5.0 \mathrm{E}+02$ & 1.7E-03 \\
\hline LAWA44-95 & 95 & 227.50 & 0.07 & 0.00 & - & $2.5 \mathrm{E}+03$ & 2.0E-03 & $5.6 \mathrm{E}+04$ & $5.1 \mathrm{E}-02$ & - & - & $5.0 \mathrm{E}+02$ & 1.1E-03 \\
\hline LAWA44-96 & 96 & 230.01 & 0.04 & 0.00 & - & $4.2 \mathrm{E}+03$ & $5.6 \mathrm{E}-03$ & $3.8 \mathrm{E}+04$ & $6.1 \mathrm{E}-02$ & - & - & $4.1 \mathrm{E}+00$ & 1.5E-05 \\
\hline LAWA44-97 & 97 & 232.10 & 0.04 & 0.01 & - & $4.1 \mathrm{E}+03$ & $6.0 \mathrm{E}-03$ & $3.5 E+04$ & $6.0 \mathrm{E}-02$ & - & - & $3.0 \mathrm{E}+01$ & $1.2 \mathrm{E}-04$ \\
\hline LAWA44-98 & 98 & 234.46 & 0.03 & 0.02 & - & $3.1 \mathrm{E}+03$ & 5.0E-03 & $3.1 E+04$ & $6.0 \mathrm{E}-02$ & - & - & $8.0 \mathrm{E}+00$ & 3.6E-05 \\
\hline LAWA44-99 & 99 & 236.86 & 0.09 & 0.00 & - & $2.6 \mathrm{E}+03$ & $1.7 \mathrm{E}-03$ & $4.7 \mathrm{E}+04$ & 3.6E-02 & - & - & $3.3 \mathrm{E}+01$ & 5.9E-05 \\
\hline LAWA44-100 & 100 & 238.96 & 0.10 & 0.00 & - & $2.9 \mathrm{E}+03$ & 1.7E-03 & $4.9 \mathrm{E}+04$ & $3.4 \mathrm{E}-02$ & - & - & $3.7 \mathrm{E}+01$ & 6.0E-05 \\
\hline LAWA44-101 & 101 & 241.37 & 0.10 & 0.00 & - & $3.2 E+03$ & 1.7E-03 & $4.8 \mathrm{E}+04$ & $3.1 \mathrm{E}-02$ & - & - & $1.8 \mathrm{E}+01$ & 2.6E-05 \\
\hline LAWA44-102 & 102 & 243.81 & 0.06 & 0.02 & - & $3.0 \mathrm{E}+03$ & 2.7E-03 & $4.0 \mathrm{E}+04$ & 4.2E-02 & - & - & $9.3 \mathrm{E}+00$ & 2.3E-05 \\
\hline LAWA44-103 & 103 & 245.97 & 0.06 & 0.00 & - & $2.9 \mathrm{E}+03$ & $2.6 \mathrm{E}-03$ & $3.3 \mathrm{E}+04$ & $3.5 \mathrm{E}-02$ & - & - & $2.3 \mathrm{E}+01$ & 5.6E-05 \\
\hline LAWA44-104 & 104 & 248.43 & 0.07 & 0.00 & - & $3.1 \mathrm{E}+03$ & $2.4 \mathrm{E}-03$ & $4.9 \mathrm{E}+04$ & 4.6E-02 & - & - & 9.4E-01 & 2.0E-06 \\
\hline LAWA44-105 & 105 & 250.91 & 0.07 & 0.00 & - & $3.4 \mathrm{E}+03$ & 2.6E-03 & $4.3 \mathrm{E}+04$ & 3.9E-02 & $7.9 \mathrm{E}+00$ & $1.5 \mathrm{E}-03$ & - & - \\
\hline LAWA44-106 & 106 & 253.43 & 0.07 & 0.01 & - & - & - & - & - & $8.8 \mathrm{E}+00$ & $1.8 \mathrm{E}-03$ & - & - \\
\hline LAWA44-107 & 107 & 255.80 & 0.07 & 0.00 & - & - & - & - & - & $7.5 \mathrm{E}+00$ & $1.5 \mathrm{E}-03$ & - & - \\
\hline LAWA44-108 & 108 & 257.88 & 0.06 & 0.03 & - & $3.7 \mathrm{E}+03$ & $3.5 \mathrm{E}-03$ & $6.1 \mathrm{E}+04$ & $6.9 \mathrm{E}-02$ & $9.1 \mathrm{E}+00$ & $2.1 \mathrm{E}-03$ & - & - \\
\hline LAWA44-109 & 109 & 260.34 & 0.05 & 0.01 & - & - & - & - & - & $8.5 \mathrm{E}+00$ & $2.4 \mathrm{E}-03$ & - & - \\
\hline LAWA44-110 & 110 & 262.74 & 0.05 & 0.01 & - & - & - & - & - & $9.0 \mathrm{E}+00$ & $2.6 \mathrm{E}-03$ & - & - \\
\hline LAWA44-111 & 111 & 264.82 & 0.05 & 0.01 & - & $4.2 E+03$ & 4.7E-03 & $4.5 \mathrm{E}+04$ & $5.9 \mathrm{E}-02$ & $7.9 \mathrm{E}+00$ & $2.1 \mathrm{E}-03$ & - & - \\
\hline
\end{tabular}


Table B1. LAWA44 PUF Test Results

\begin{tabular}{|c|c|c|c|c|c|c|c|c|c|c|c|c|c|}
\hline Sample ID & Vial \# & Time, days & $\theta$ & $\sigma \theta$ & pH & [Al] & Al Rate & [B] & B Rate & [Cr] & Cr Rate & {$[\mathrm{Mg}]$} & Mg Rate \\
\hline LAWA44-112 & 112 & 266.94 & 0.05 & 0.01 & - & - & - & - & - & $1.7 \mathrm{E}+01$ & $4.5 \mathrm{E}-03$ & - & - \\
\hline LAWA44-113 & 113 & 273.90 & 0.04 & 0.01 & - & - & - & - & - & $7.6 \mathrm{E}+00$ & $2.4 \mathrm{E}-03$ & - & - \\
\hline LAWA44-114 & 114 & 280.95 & 0.04 & 0.01 & - & $3.8 \mathrm{E}+03$ & $5.4 \mathrm{E}-03$ & $4.8 \mathrm{E}+04$ & $8.2 \mathrm{E}-02$ & $7.5 \mathrm{E}+00$ & $2.6 \mathrm{E}-03$ & - & - \\
\hline LAWA44-115 & 115 & 283.39 & 0.03 & 0.00 & - & - & - & - & - & $6.2 \mathrm{E}+00$ & $3.1 \mathrm{E}-03$ & - & - \\
\hline LAWA44-116 & 116 & 285.88 & 0.05 & 0.01 & - & - & - & - & - & $8.9 \mathrm{E}+00$ & 2.5E-03 & - & - \\
\hline LAWA44-117 & 117 & 288.04 & 0.04 & 0.01 & - & $3.6 \mathrm{E}+03$ & $5.1 \mathrm{E}-03$ & $4.3 \mathrm{E}+04$ & 7.2E-02 & $6.9 \mathrm{E}+00$ & 2.3E-03 & - & - \\
\hline LAWA44-118 & 118 & 290.44 & 0.05 & 0.01 & - & - & - & - & - & $7.4 \mathrm{E}+00$ & $1.9 \mathrm{E}-03$ & - & - \\
\hline LAWA44-119 & 119 & 292.95 & 0.05 & 0.01 & - & - & - & - & - & $8.8 \mathrm{E}+00$ & $2.2 \mathrm{E}-03$ & - & - \\
\hline LAWA44-120 & 120 & 295.50 & 0.05 & 0.01 & - & $4.3 \mathrm{E}+03$ & 4.9E-03 & $4.1 \mathrm{E}+04$ & $5.6 \mathrm{E}-02$ & $6.8 \mathrm{E}+00$ & $1.9 \mathrm{E}-03$ & - & - \\
\hline LAWA44-121 & 121 & 297.94 & 0.05 & 0.01 & - & - & - & - & - & $7.2 \mathrm{E}+00$ & $2.1 \mathrm{E}-03$ & - & - \\
\hline LAWA44-122 & 122 & 300.00 & 0.05 & 0.01 & - & - & - & - & - & $7.8 \mathrm{E}+00$ & $2.2 \mathrm{E}-03$ & - & - \\
\hline LAWA44-123 & 123 & 302.12 & 0.04 & 0.00 & - & $8.1 \mathrm{E}+03$ & $1.1 \mathrm{E}-02$ & $5.3 \mathrm{E}+04$ & 8.7E-02 & $9.7 \mathrm{E}+00$ & $3.2 \mathrm{E}-03$ & - & - \\
\hline LAWA44-124 & 124 & 304.50 & 0.08 & 0.03 & - & - & - & - & - & $1.1 \mathrm{E}+01$ & $1.9 \mathrm{E}-03$ & - & - \\
\hline LAWA44-125 & 125 & 307.77 & 0.27 & 0.08 & - & - & - & - & - & $3.2 \mathrm{E}+01$ & $1.6 \mathrm{E}-03$ & - & - \\
\hline LAWA44-126 & 126 & 311.25 & 0.16 & 0.01 & - & $5.4 \mathrm{E}+03$ & $1.9 \mathrm{E}-03$ & $4.0 \mathrm{E}+04$ & $1.7 \mathrm{E}-02$ & $1.4 \mathrm{E}+01$ & $1.2 \mathrm{E}-03$ & - & - \\
\hline LAWA44-127 & 127 & 313.84 & 0.17 & 0.01 & - & - & - & - & - & $1.0 \mathrm{E}+01$ & 8.1E-04 & - & - \\
\hline LAWA44-128 & 128 & 316.01 & 0.17 & 0.00 & - & - & - & - & - & $1.1 \mathrm{E}+01$ & 8.3E-04 & - & - \\
\hline LAWA44-129 & 129 & 318.42 & 0.18 & 0.00 & - & $5.8 \mathrm{E}+03$ & $1.9 \mathrm{E}-03$ & $4.3 \mathrm{E}+04$ & $1.6 \mathrm{E}-02$ & $9.7 \mathrm{E}+00$ & 7.5E-04 & - & - \\
\hline LAWA44-130 & 130 & 321.28 & 0.17 & 0.01 & - & - & - & - & - & $1.5 \mathrm{E}+01$ & $1.2 \mathrm{E}-03$ & - & - \\
\hline LAWA44-131 & 131 & 327.97 & 0.15 & 0.02 & - & - & - & - & - & $1.3 \mathrm{E}+01$ & $1.2 \mathrm{E}-03$ & - & - \\
\hline LAWA44-132 & 132 & 334.43 & 0.16 & 0.01 & - & $1.2 \mathrm{E}+04$ & $4.2 \mathrm{E}-03$ & $4.9 \mathrm{E}+04$ & $2.0 \mathrm{E}-02$ & $1.2 \mathrm{E}+01$ & $9.8 \mathrm{E}-04$ & - & - \\
\hline LAWA44-133 & 133 & 336.84 & 0.18 & 0.01 & - & - & - & - & - & $9.9 \mathrm{E}+00$ & 7.3E-04 & - & - \\
\hline LAWA44-134 & 134 & 339.33 & 0.19 & 0.01 & - & - & - & - & - & $1.0 \mathrm{E}+01$ & $7.4 \mathrm{E}-04$ & - & - \\
\hline LAWA44-135 & 135 & 341.79 & 0.21 & 0.01 & - & $1.4 \mathrm{E}+04$ & $3.8 \mathrm{E}-03$ & $4.3 \mathrm{E}+04$ & $1.4 \mathrm{E}-02$ & $1.0 \mathrm{E}+01$ & $6.7 \mathrm{E}-04$ & - & - \\
\hline LAWA44-136 & 136 & 343.91 & 0.22 & 0.02 & - & - & - & - & - & $9.3 \mathrm{E}+00$ & 5.7E-04 & - & - \\
\hline LAWA44-137 & 137 & 346.87 & 0.13 & 1.28 & - & - & - & - & - & $1.0 \mathrm{E}+01$ & $1.1 \mathrm{E}-03$ & - & - \\
\hline LAWA44-138 & 138 & 349.78 & 0.05 & 0.03 & - & $1.2 \mathrm{E}+04$ & $1.2 \mathrm{E}-02$ & $3.0 \mathrm{E}+04$ & 3.7E-02 & $6.4 \mathrm{E}+00$ & $1.6 \mathrm{E}-03$ & - & - \\
\hline LAWA44-139 & 139 & 351.44 & 0.05 & 0.01 & - & - & - & - & - & $6.0 \mathrm{E}+00$ & $1.8 \mathrm{E}-03$ & - & - \\
\hline LAWA44-140 & 140 & 353.42 & 0.08 & 0.02 & - & - & - & - & - & $7.0 \mathrm{E}+00$ & $1.3 \mathrm{E}-03$ & - & - \\
\hline LAWA44-141 & 141 & 355.80 & 0.08 & 0.01 & - & $8.6 \mathrm{E}+03$ & $5.9 \mathrm{E}-03$ & $4.3 \mathrm{E}+04$ & 3.5E-02 & $8.6 \mathrm{E}+00$ & $1.4 \mathrm{E}-03$ & - & - \\
\hline LAWA44-142 & 142 & 357.95 & 0.09 & 0.01 & - & - & - & - & - & $8.1 \mathrm{E}+00$ & $1.2 \mathrm{E}-03$ & - & - \\
\hline LAWA44-143 & 143 & 360.38 & 0.11 & 0.01 & - & - & - & - & - & $8.3 \mathrm{E}+00$ & $9.9 \mathrm{E}-04$ & - & - \\
\hline LAWA44-144 & 144 & 362.76 & 0.13 & 0.01 & - & $7.2 \mathrm{E}+03$ & 3.3E-03 & $4.0 \mathrm{E}+04$ & $2.2 \mathrm{E}-02$ & $8.0 \mathrm{E}+00$ & 8.7E-04 & - & - \\
\hline LAWA44-145 & 145 & 364.97 & 0.13 & 0.01 & - & - & - & - & - & $7.8 \mathrm{E}+00$ & 8.5E-04 & - & - \\
\hline LAWA44-146 & 146 & 367.40 & 0.13 & 0.01 & - & - & - & - & - & $8.2 \mathrm{E}+00$ & 8.9E-04 & - & - \\
\hline LAWA44-147 & 147 & 369.89 & 0.13 & 0.01 & - & $5.9 \mathrm{E}+03$ & 2.7E-03 & $3.9 \mathrm{E}+04$ & $2.1 \mathrm{E}-02$ & $6.9 \mathrm{E}+00$ & 7.5E-04 & - & - \\
\hline LAWA44-148 & 148 & 372.46 & 0.13 & 0.01 & - & - & - & - & - & $7.5 \mathrm{E}+00$ & 8.1E-04 & - & - \\
\hline
\end{tabular}


Table B1. LAWA44 PUF Test Results

\begin{tabular}{|c|c|c|c|c|c|c|c|c|c|c|c|c|c|}
\hline Sample ID & Vial \# & Time, days & $\theta$ & $\sigma \theta$ & pH & [Al] & Al Rate & [B] & B Rate & [Cr] & Cr Rate & {$[\mathrm{Mg}]$} & Mg Rate \\
\hline LAWA44-149 & 149 & 375.29 & 0.11 & 0.01 & - & - & - & - & - & $7.8 \mathrm{E}+00$ & $9.3 \mathrm{E}-04$ & - & - \\
\hline LAWA44-150 & 150 & 378.26 & 0.13 & 0.00 & - & $5.5 \mathrm{E}+03$ & 4E-03 & $4.0 \mathrm{E}+04$ & $2.1 \mathrm{E}-02$ & $7.1 \mathrm{E}+00$ & 7.4E-04 & - & - \\
\hline LAWA44-151 & 151 & 381.25 & 0.13 & 0.00 & - & - & - & - & - & $7.3 \mathrm{E}+00$ & 7.6E-04 & - & - \\
\hline LAWA44-152 & 152 & 383.85 & 0.13 & 0.01 & - & - & - & - & - & $7.3 \mathrm{E}+00$ & 7.4E-04 & - & - \\
\hline LAWA44-153 & 153 & 386.04 & 0.15 & 0.00 & - & $4.8 \mathrm{E}+03$ & $1.8 \mathrm{E}-03$ & $3.8 \mathrm{E}+04$ & $1.7 \mathrm{E}-02$ & $1.0 \mathrm{E}+01$ & $9.3 \mathrm{E}-04$ & - & - \\
\hline LAWA44-154 & 154 & 388.38 & 0.15 & 0.00 & - & - & - & - & - & $6.9 \mathrm{E}+00$ & $6.2 \mathrm{E}-04$ & - & - \\
\hline LAWA44-155 & 155 & 390.82 & 0.15 & 0.01 & - & - & - & - & - & $7.2 \mathrm{E}+00$ & $6.5 \mathrm{E}-04$ & - & - \\
\hline LAWA44-156 & 156 & 393.51 & 0.15 & 0.01 & - & $5.2 \mathrm{E}+03$ & $2.0 \mathrm{E}-03$ & $3.1 \mathrm{E}+04$ & $1.4 \mathrm{E}-02$ & $5.7 \mathrm{E}+00$ & $5.2 \mathrm{E}-04$ & - & - \\
\hline LAWA44-157 & 157 & 395.88 & 0.13 & 0.01 & - & - & - & - & - & $6.9 \mathrm{E}+00$ & 7.2E-04 & - & - \\
\hline LAWA44-158 & 158 & 397.90 & 0.15 & 0.01 & - & - & - & - & - & $7.8 \mathrm{E}+00$ & 7.0E-04 & - & - \\
\hline LAWA44-159 & 159 & 400.08 & 0.13 & 0.02 & - & $6.8 \mathrm{E}+03$ & 3.0E-03 & $3.2 \mathrm{E}+04$ & $1.6 \mathrm{E}-02$ & $5.5 \mathrm{E}+00$ & 5.7E-04 & - & - \\
\hline LAWA44-160 & 160 & 402.33 & 0.12 & 0.01 & - & - & - & - & - & $6.8 \mathrm{E}+00$ & 7.7E-04 & - & - \\
\hline LAWA44-161 & 161 & 404.71 & 0.15 & 0.02 & - & - & - & - & - & $7.8 \mathrm{E}+00$ & 7.3E-04 & - & - \\
\hline LAWA44-162 & 162 & 406.95 & 0.15 & 0.01 & - & $5.0 \mathrm{E}+03$ & $1.9 \mathrm{E}-03$ & $4.1 \mathrm{E}+04$ & $1.8 \mathrm{E}-02$ & $7.7 \mathrm{E}+00$ & $6.8 \mathrm{E}-04$ & - & - \\
\hline LAWA44-163 & 163 & 409.39 & 0.17 & 0.01 & - & - & - & - & - & $7.1 \mathrm{E}+00$ & 5.6E-04 & - & - \\
\hline LAWA44-164 & 164 & 411.87 & 0.18 & 0.01 & - & $4.3 \mathrm{E}+03$ & $1.4 \mathrm{E}-03$ & $3.7 \mathrm{E}+04$ & $1.4 \mathrm{E}-02$ & $6.8 \mathrm{E}+00$ & 5.2E-04 & - & - \\
\hline LAWA44-165 & 165 & 414.49 & 0.18 & 0.01 & - & $3.4 \mathrm{E}+03$ & $1.1 \mathrm{E}-03$ & $3.6 \mathrm{E}+04$ & $1.3 \mathrm{E}-02$ & $7.0 \mathrm{E}+00$ & 5.3E-04 & - & - \\
\hline LAWA44-166 & 166 & 417.31 & 0.18 & 0.01 & - & $3.8 \mathrm{E}+03$ & $1.2 \mathrm{E}-03$ & $3.7 \mathrm{E}+04$ & $1.4 \mathrm{E}-02$ & $9.1 \mathrm{E}+00$ & $6.8 \mathrm{E}-04$ & - & - \\
\hline LAWA44-167 & 167 & 420.27 & 0.19 & 0.01 & - & $4.3 E+03$ & $1.3 \mathrm{E}-03$ & $3.8 \mathrm{E}+04$ & $1.3 \mathrm{E}-02$ & $7.5 \mathrm{E}+00$ & 5.3E-04 & - & - \\
\hline LAWA44-168 & 168 & 424.29 & 0.19 & 0.01 & - & $3.7 \mathrm{E}+03$ & $1.1 \mathrm{E}-03$ & $3.2 \mathrm{E}+04$ & $1.2 \mathrm{E}-02$ & $3.8 \mathrm{E}+00$ & 2.7E-04 & - & - \\
\hline LAWA44-169 & 169 & 427.89 & 0.20 & 0.01 & - & $3.8 \mathrm{E}+03$ & $1.1 \mathrm{E}-03$ & $3.4 \mathrm{E}+04$ & $1.1 \mathrm{E}-02$ & $4.4 \mathrm{E}+00$ & 3.0E-04 & - & - \\
\hline LAWA44-170 & 170 & 430.36 & 0.18 & 0.01 & - & $3.7 \mathrm{E}+03$ & $1.2 \mathrm{E}-03$ & $3.3 E+04$ & $1.2 \mathrm{E}-02$ & $6.8 \mathrm{E}+00$ & 5.1E-04 & - & - \\
\hline LAWA44-171 & 171 & 432.76 & 0.20 & 0.01 & - & $4.0 \mathrm{E}+03$ & $1.1 \mathrm{E}-03$ & $3.6 \mathrm{E}+04$ & $1.2 \mathrm{E}-02$ & $1.5 \mathrm{E}+00$ & $1.0 \mathrm{E}-04$ & - & - \\
\hline LAWA44-172 & 172 & 434.93 & 0.20 & 0.01 & - & $4.1 \mathrm{E}+03$ & $1.2 \mathrm{E}-03$ & $3.6 \mathrm{E}+04$ & $1.2 \mathrm{E}-02$ & $1.0 \mathrm{E}+01$ & 7.1E-04 & - & - \\
\hline LAWA44-173 & 173 & 437.36 & 0.19 & 0.01 & - & $3.7 \mathrm{E}+03$ & $1.1 \mathrm{E}-03$ & $3.2 \mathrm{E}+04$ & $1.1 \mathrm{E}-02$ & $2.5 \mathrm{E}+00$ & $1.8 \mathrm{E}-04$ & - & - \\
\hline LAWA44-174 & 174 & 439.88 & 0.19 & 0.01 & - & $3.4 \mathrm{E}+03$ & $1.0 \mathrm{E}-03$ & $3.3 E+04$ & $1.2 \mathrm{E}-02$ & $3.0 \mathrm{E}+00$ & 2.2E-04 & - & - \\
\hline LAWA44-175 & 175 & 443.38 & 0.19 & 0.01 & - & $3.9 \mathrm{E}+03$ & $1.2 \mathrm{E}-03$ & $4.8 \mathrm{E}+04$ & $1.7 \mathrm{E}-02$ & $7.7 \mathrm{E}+00$ & 5.5E-04 & - & - \\
\hline LAWA44-176 & 176 & 446.76 & 0.19 & 0.02 & - & $4.8 \mathrm{E}+03$ & $1.5 \mathrm{E}-03$ & $3.6 \mathrm{E}+04$ & $1.3 \mathrm{E}-02$ & $7.0 \mathrm{E}+00$ & 5.1E-04 & - & - \\
\hline LAWA44-177 & 177 & 448.95 & 0.20 & 0.01 & - & $3.8 \mathrm{E}+03$ & $1.1 \mathrm{E}-03$ & $3.1 \mathrm{E}+04$ & $1.0 \mathrm{E}-02$ & $4.2 \mathrm{E}+00$ & $2.8 \mathrm{E}-04$ & - & - \\
\hline LAWA44-178 & 178 & 451.40 & 0.21 & 0.01 & - & $3.6 E+03$ & $9.9 \mathrm{E}-04$ & $3.7 \mathrm{E}+04$ & $1.2 \mathrm{E}-02$ & $5.7 \mathrm{E}+00$ & 3.7E-04 & - & - \\
\hline LAWA44-179 & 179 & 453.86 & 0.22 & 0.01 & - & $3.5 \mathrm{E}+03$ & $9.1 \mathrm{E}-04$ & $3.4 \mathrm{E}+04$ & $1.0 \mathrm{E}-02$ & $4.0 \mathrm{E}+00$ & $2.4 \mathrm{E}-04$ & - & - \\
\hline LAWA44-180 & 180 & 456.06 & 0.23 & 0.01 & - & $3.7 \mathrm{E}+03$ & $9.2 \mathrm{E}-04$ & $3.4 \mathrm{E}+04$ & $1.0 \mathrm{E}-02$ & $5.0 \mathrm{E}+00$ & 3.0E-04 & - & - \\
\hline LAWA44-181 & 181 & 458.41 & 0.23 & 0.01 & - & $3.7 \mathrm{E}+03$ & $9.1 \mathrm{E}-04$ & $3.6 E+04$ & $1.0 \mathrm{E}-02$ & $8.8 \mathrm{E}+00$ & $5.2 \mathrm{E}-04$ & - & - \\
\hline LAWA44-182 & 182 & 460.82 & 0.24 & 0.01 & - & $3.5 \mathrm{E}+03$ & 8.3E-04 & $3.5 \mathrm{E}+04$ & $9.8 \mathrm{E}-03$ & $9.0 \mathrm{E}+00$ & 5.1E-04 & - & - \\
\hline LAWA44-183 & 183 & 463.01 & 0.24 & 0.01 & - & $3.3 \mathrm{E}+03$ & 7.7E-04 & $3.4 \mathrm{E}+04$ & $9.6 \mathrm{E}-03$ & $4.5 \mathrm{E}+00$ & 2.6E-04 & - & - \\
\hline LAWA44-184 & 184 & 465.40 & 0.22 & 0.01 & - & $4.4 \mathrm{E}+03$ & $1.1 \mathrm{E}-03$ & $3.2 \mathrm{E}+04$ & $1.0 \mathrm{E}-02$ & $1.7 \mathrm{E}+00$ & $1.1 \mathrm{E}-04$ & - & - \\
\hline LAWA44-185 & 185 & 468.27 & 0.23 & 0.01 & - & $3.9 \mathrm{E}+03$ & $9.8 \mathrm{E}-04$ & $3.3 E+04$ & $9.8 \mathrm{E}-03$ & $5.0 \mathrm{E}-01$ & 3.0E-05 & - & - \\
\hline
\end{tabular}


Table B1. LAWA44 PUF Test Results

\begin{tabular}{lccccccccccccc}
\hline Sample ID & Vial \# & Time, days & $\theta$ & $\sigma \theta$ & pH & [Al] & Al Rate & [B] & B Rate & [Cr] & Cr Rate & [Mg] & Mg Rate \\
\hline LAWA44-186 & 186 & 475.25 & 0.10 & 0.10 & - & $3.2 \mathrm{E}+03$ & $1.8 \mathrm{E}-03$ & $3.5 \mathrm{E}+04$ & $2.3 \mathrm{E}-02$ & $4.9 \mathrm{E}+00$ & $6.5 \mathrm{E}-04$ & - & - \\
LAWA44-187 & 187 & 481.81 & 0.07 & 0.07 & - & $3.3 \mathrm{E}+03$ & $2.7 \mathrm{E}-03$ & $3.5 \mathrm{E}+04$ & $3.4 \mathrm{E}-02$ & $6.9 \mathrm{E}+00$ & $1.4 \mathrm{E}-03$ & - & - \\
LAWA44-188 & 188 & 484.04 & 0.22 & 0.01 & - & $4.6 \mathrm{E}+03$ & $1.2 \mathrm{E}-03$ & $3.3 \mathrm{E}+04$ & $1.0 \mathrm{E}-02$ & $1.3 \mathrm{E}+01$ & $8.0 \mathrm{E}-04$ & - & - \\
LAWA44-189 & 189 & 486.42 & 0.23 & 0.01 & - & $3.5 \mathrm{E}+03$ & $8.7 \mathrm{E}-04$ & $3.3 \mathrm{E}+04$ & $9.9 \mathrm{E}-03$ & $4.9 \mathrm{E}+00$ & $3.0 \mathrm{E}-04$ & - & - \\
LAWA44-190 & 190 & 488.80 & 0.25 & 0.00 & - & $3.1 \mathrm{E}+03$ & $7.1 \mathrm{E}-04$ & $3.4 \mathrm{E}+04$ & $9.2 \mathrm{E}-03$ & $2.1 \mathrm{E}+00$ & $1.1 \mathrm{E}-04$ & - & - \\
LAWA44-191 & 191 & 491.31 & 0.22 & 0.01 & - & $4.4 \mathrm{E}+03$ & $1.2 \mathrm{E}-03$ & $5.5 \mathrm{E}+04$ & $1.7 \mathrm{E}-02$ & $9.1 \mathrm{E}+00$ & $5.7 \mathrm{E}-04$ & - & - \\
LAWA44-192 & 192 & 494.69 & 0.18 & 0.18 & - & $2.9 \mathrm{E}+03$ & $9.2 \mathrm{E}-04$ & $3.5 \mathrm{E}+04$ & $1.3 \mathrm{E}-02$ & $6.1 \mathrm{E}+00$ & $4.7 \mathrm{E}-04$ & - & - \\
LAWA44-193 & 193 & 497.85 & 0.26 & 0.01 & - & $3.2 \mathrm{E}+03$ & $7.0 \mathrm{E}-04$ & $3.3 \mathrm{E}+04$ & $8.6 \mathrm{E}-03$ & $4.2 \mathrm{E}+00$ & $2.2 \mathrm{E}-04$ & - & - \\
LAWA44-194 & 194 & 500.39 & 0.26 & 0.00 & - & $3.7 \mathrm{E}+03$ & $8.1 \mathrm{E}-04$ & $3.2 \mathrm{E}+04$ & $8.3 \mathrm{E}-03$ & $8.2 \mathrm{E}+00$ & $4.3 \mathrm{E}-04$ & - & - \\
LAWA44-195 & 195 & 497.85 & 0.26 & 0.00 & - & $4.4 \mathrm{E}+03$ & $9.6 \mathrm{E}-04$ & $2.7 \mathrm{E}+04$ & $7.0 \mathrm{E}-03$ & $6.3 \mathrm{E}+00$ & $3.3 \mathrm{E}-04$ & - & - \\
LAWA44-196 & 196 & 500.47 & 0.26 & 0.00 & - & $3.7 \mathrm{E}+03$ & $8.1 \mathrm{E}-04$ & $3.2 \mathrm{E}+04$ & $8.2 \mathrm{E}-03$ & $3.5 \mathrm{E}+00$ & $1.8 \mathrm{E}-04$ & - & - \\
LAWA44-197 & 197 & 508.37 & 0.26 & 0.00 & - & $4.0 \mathrm{E}+03$ & $8.8 \mathrm{E}-04$ & $3.2 \mathrm{E}+04$ & $8.3 \mathrm{E}-03$ & $2.1 \mathrm{E}+01$ & $1.1 \mathrm{E}-03$ & - & - \\
LAWA44-198 & 198 & 514.75 & 0.26 & 0.00 & - & $4.2 \mathrm{E}+03$ & $9.0 \mathrm{E}-04$ & $3.3 \mathrm{E}+04$ & $8.6 \mathrm{E}-03$ & $7.1 \mathrm{E}+00$ & $3.7 \mathrm{E}-04$ & - \\
\hline
\end{tabular}


Table B1. LAWA44 PUF Test Results

\begin{tabular}{|c|c|c|c|c|c|c|c|c|c|c|c|c|c|c|c|}
\hline Sample ID & Vial & Time & $\theta$ & $\sigma \theta$ & pH & [Na] & Na Rate & [Si] & Si Rate & [Ti] & Ti Rate & [Zn] & Zn Rate & {$[\mathrm{Zr}]$} & $\overline{\text { Zr Rate }}$ \\
\hline LWA44-01 & 1 & 0.07 & 0.31 & 0.12 & - & $.9 \mathrm{E}+05$ & $7.7 \mathrm{E}-03$ & $.9 \mathrm{E}+04$ & $2.6 \mathrm{E}-03$ & $.4 \mathrm{E}+01$ & $3.2 \mathrm{E}-05$ & $4.0 \mathrm{E}+02$ & $1.0 \mathrm{E}-04$ & $7.3 \mathrm{E}+01$ & $2.0 \mathrm{E}-05$ \\
\hline NA44-02 & 2 & 0.18 & 0.07 & 0.05 & - & $3.4 \mathrm{E}+05$ & 5.9E-02 & $5 \mathrm{E}+04$ & $1.2 \mathrm{E}-02$ & $.7 E+01$ & $1.5 \mathrm{E}-04$ & $3.4 \mathrm{E}+02$ & $.7 \mathrm{E}-04$ & $4.8 \mathrm{E}+01$ & $6 \mathrm{E}-05$ \\
\hline-03 & 3 & 19 & 0.05 & 01 & - & $E+05$ & E-01 & $E+05$ & 2.6E-02 & $8 \mathrm{E}+01$ & $1.5 \mathrm{E}-04$ & $1.8 \mathrm{E}+02$ & E-04 & $4.6 \mathrm{E}+01$ & E-05 \\
\hline 44-04 & 4 & 3.41 & 0.04 & .01 & - & $8.7 E+05$ & 2.6E-01 & $1 E+05$ & 4.3E-02 & $6.4 \mathrm{E}+00$ & 2.3E-05 & $6.5 \mathrm{E}+01$ & $1.2 \mathrm{E}-04$ & $1.2 \mathrm{E}+01$ & 2.3E-05 \\
\hline LWA44-05 & 5 & 5.74 & 0.03 & 0.01 & - & $6.3 \mathrm{E}+05$ & 2.4E-01 & $1.7 \mathrm{E}+05$ & 4.7E-02 & $.5 \mathrm{E}+01$ & $1.2 \mathrm{E}-04$ & $3.3 E+01$ & 7.8E-05 & $6.3 E+01$ & 1.6E-04 \\
\hline LWA44-06 & 6 & 91 & 0.02 & 0.00 & - & $5.5 \mathrm{E}+05$ & & $1.7 \mathrm{E}+05$ & & $4.5 \mathrm{E}+01$ & 2.9E-04 & $5.8 \mathrm{E}+01$ & & $1.1 \mathrm{E}+02$ & 3.8E-04 \\
\hline LWA44-07 & 7 & 10.37 & 0.03 & 0.01 & - & $5.2 \mathrm{E}+05$ & 2.4E-01 & $1.7 \mathrm{E}+05$ & 5.6E-02 & $7.3 \mathrm{E}+01$ & 4.3E-04 & $6.6 \mathrm{E}+01$ & $1.9 \mathrm{E}-04$ & $1.6 \mathrm{E}+02$ & $5.2 \mathrm{E}-04$ \\
\hline LWA44-08 & 8 & 12.78 & 0.03 & 0.01 & - & $4.9 \mathrm{E}+05$ & 1.8E-01 & $1.6 \mathrm{E}+05$ & 4.2E-02 & $8.0 \mathrm{E}+01$ & 3.6E-04 & $3.3 E+01$ & 7.5E-05 & $1.9 \mathrm{E}+02$ & 4.6E-04 \\
\hline LWA44-09 & 9 & .39 & 0.03 & 0.01 & - & $4.3 E+05$ & 01 & $1.5 \mathrm{E}+05$ & 3.8E-02 & $9.8 \mathrm{E}+01$ & 4.5E-04 & $8.4 \mathrm{E}+01$ & $1.9 \mathrm{E}-04$ & $2.3 \mathrm{E}+02$ & 5.7E-04 \\
\hline $4-10$ & 10 & .90 & 0.03 & 0.00 & - & $4.2 \mathrm{E}+05$ & 1.8 & $1.5 \mathrm{E}+05$ & $4.8 \mathrm{E}-02$ & $1.1 \mathrm{E}+02$ & $6.2 \mathrm{E}-04$ & $5.9 \mathrm{E}+01$ & $1.6 \mathrm{E}-04$ & $2.5 \mathrm{E}+02$ & E-04 \\
\hline LWA44-11 & 11 & 20.05 & 0.03 & 0.01 & - & $4.1 \mathrm{E}+05$ & $1.6 \mathrm{E}-01$ & $1.5 \mathrm{E}+05$ & $4.2 \mathrm{E}-02$ & $1.3 \mathrm{E}+02$ & 6.5E-04 & $6.7 \mathrm{E}+01$ & $1.6 \mathrm{E}-04$ & $3.0 \mathrm{E}+02$ & 7.7E-04 \\
\hline LWA44-12 & 12 & 22.50 & 0.03 & 0.01 & - & $3.7 \mathrm{E}+05$ & 1.3 & $1.4 \mathrm{E}+05$ & 3.7E-02 & $1.4 \mathrm{E}+02$ & $6.2 \mathrm{E}-04$ & $6.3 \mathrm{E}+01$ & -04 & $3.1 \mathrm{E}+02$ & E-04 \\
\hline-13 & 13 & 4.75 & 0.02 & 0.01 & - & $3.6 \mathrm{E}+05$ & 01 & $1.4 \mathrm{E}+05$ & $7.0 \mathrm{E}-02$ & $1.6 \mathrm{E}+02$ & $1.4 \mathrm{E}-03$ & $4.0 \mathrm{E}+01$ & $1.7 \mathrm{E}-04$ & $3.8 \mathrm{E}+02$ & E-03 \\
\hline LWA & 14 & 26.82 & 0.04 & 0.01 & - & $3.7 \mathrm{E}+05$ & $1.1 \mathrm{E}-01$ & $1.4 \mathrm{E}+05$ & $2.8 \mathrm{E}-02$ & $1.4 \mathrm{E}+02$ & 4.8E-04 & $6.1 \mathrm{E}+01$ & $1.1 \mathrm{E}-04$ & $3.1 \mathrm{E}+02$ & 5.9E-04 \\
\hline LW & 15 & .01 & 0.05 & 0.01 & - & $3.8 \mathrm{E}+05$ & 1.0 & $1.4 \mathrm{E}+05$ & 2.7E-02 & $1.6 \mathrm{E}+02$ & 5.5E-04 & $6.4 \mathrm{E}+01$ & -04 & $3.5 \mathrm{E}+02$ & -04 \\
\hline-16 & 16 & 31.40 & 0.04 & 0.01 & - & $3.4 \mathrm{E}+05$ & -01 & $1.3 \mathrm{E}+05$ & $3.0 \mathrm{E}-02$ & $1.7 \mathrm{E}+02$ & $6.6 \mathrm{E}-04$ & $6.5 \mathrm{E}+01$ & 1.3E-04 & $3.7 \mathrm{E}+02$ & 7.6E-04 \\
\hline $\mathrm{LW}$ & 17 & 34.27 & 0.05 & 0.01 & - & $3.2 \mathrm{E}+05$ & 7.9E-02 & $1.2 \mathrm{E}+05$ & 2.2E-02 & $1.8 \mathrm{E}+02$ & 5.5E-04 & 7.5 & $1.2 \mathrm{E}-04$ & $3.9 \mathrm{E}+02$ & E-04 \\
\hline LW & 18 & 36.80 & 0.05 & 0.00 & - & $3.3 \mathrm{E}+05$ & $9.0 \mathrm{E}-02$ & $1.4 \mathrm{E}+05$ & 2.6E-02 & $1.8 \mathrm{E}+02$ & $6.2 \mathrm{E}-04$ & $7.4 \mathrm{E}+01$ & -04 & $4.1 \mathrm{E}+02$ & -04 \\
\hline-19 & 19 & 38.76 & 0.05 & 0.00 & - & $3.5 E+05$ & $9.0 \mathrm{E}-02$ & $1.4 \mathrm{E}+05$ & 2.6E-02 & $1.6 \mathrm{E}+02$ & 5.0E-04 & $7.4 \mathrm{E}+01$ & $1.2 \mathrm{E}-04$ & $3.6 \mathrm{E}+02$ & E-04 \\
\hline LWA & 20 & 40.87 & 0.05 & 0.01 & - & $3.5 \mathrm{E}+05$ & 8.0E-02 & $1.4 \mathrm{E}+05$ & 2.4E-02 & $1.6 \mathrm{E}+02$ & 4.7E-04 & $6.7 \mathrm{E}+01$ & 9.7E-05 & $3.7 \mathrm{E}+02$ & 5.7E-04 \\
\hline LW & 21 & 3.02 & 0.05 & 0.00 & - & $3.3 \mathrm{E}+05$ & 8.5E-02 & $1.4 \mathrm{E}+05$ & 2.6E-02 & $1.7 \mathrm{E}+02$ & 5.5E-04 & $7.6 \mathrm{E}+01$ & -04 & $3.8 \mathrm{E}+02$ & 6.7E-04 \\
\hline $4-22$ & 22 & 5.38 & 0.05 & 0.01 & - & $3.2 E+05$ & 7.3E-02 & $1.4 \mathrm{E}+05$ & 2.3E-02 & $1.8 \mathrm{E}+02$ & 5.1E-04 & $5.4 \mathrm{E}+01$ & 7.9E-05 & $4.0 \mathrm{E}+02$ & E-04 \\
\hline LWA & 23 & 48.28 & 0.05 & 0.01 & - & $3.2 \mathrm{E}+05$ & 7.4E-02 & $1.4 \mathrm{E}+05$ & 2.2E-02 & $1.8 \mathrm{E}+02$ & 5.1E-04 & $7.6 \mathrm{E}+01$ & $1.1 \mathrm{E}-04$ & $3.9 \mathrm{E}+02$ & 6.0E-04 \\
\hline-24 & 24 & 0.83 & 0.05 & 0.01 & - & $2.6 \mathrm{E}+05$ & $6.2 \mathrm{E}-02$ & $1.1 \mathrm{E}+05$ & $1.9 \mathrm{E}-02$ & $2.0 \mathrm{E}+02$ & $6.0 \mathrm{E}-04$ & $6.5 \mathrm{E}+01$ & $9.9 \mathrm{E}-05$ & $4.7 \mathrm{E}+02$ & 7.6E-04 \\
\hline LWA44-25 & 25 & 53.26 & 0.06 & 0.01 & - & $2.9 \mathrm{E}+05$ & $6.0 \mathrm{E}-02$ & $1.3 \mathrm{E}+05$ & $1.9 \mathrm{E}-02$ & $2.2 \mathrm{E}+02$ & 5.6E-04 & $7.0 \mathrm{E}+01$ & $9.1 \mathrm{E}-05$ & $5.0 \mathrm{E}+02$ & 7.0E-04 \\
\hline $\mathrm{LW}$ & 26 & 56.38 & 0.06 & 0.01 & - & $3.1 \mathrm{E}+05$ & 6.4E-02 & $1.4 \mathrm{E}+05$ & $2.0 \mathrm{E}-02$ & $1.8 \mathrm{E}+02$ & 4.7E-04 & $9.0 \mathrm{E}+01$ & $1.2 \mathrm{E}-04$ & $4.4 \mathrm{E}+02$ & $6.1 \mathrm{E}-04$ \\
\hline $\mathrm{LW}$ & 27 & 59.42 & 0.06 & 0.01 & - & $2.9 \mathrm{E}+05$ & $6.4 \mathrm{E}-02$ & $1.3 \mathrm{E}+05$ & $2.0 \mathrm{E}-02$ & $1.8 \mathrm{E}+02$ & 4.9E-04 & $7.3 \mathrm{E}+01$ & $1.0 \mathrm{E}-04$ & $4.1 \mathrm{E}+02$ & $6.0 \mathrm{E}-04$ \\
\hline & 28 & & 0.06 & & - & $2.8 \mathrm{E}+05$ & $6.4 \mathrm{E}-02$ & $1.3 \mathrm{E}+05$ & $2.0 \mathrm{E}-02$ & $1.9 \mathrm{E}+02$ & $5.2 \mathrm{E}-04$ & $6.8 \mathrm{E}+01$ & 9.6E-05 & $4.4 \mathrm{E}+02$ & 6.7E-04 \\
\hline LWA & 29 & 63.91 & 0.06 & 0.01 & - & $2.7 \mathrm{E}+05$ & $5.8 \mathrm{E}-02$ & $1.2 \mathrm{E}+05$ & $1.8 \mathrm{E}-02$ & $1.8 \mathrm{E}+02$ & $4.8 \mathrm{E}-04$ & $6.8 \mathrm{E}+01$ & $9.2 \mathrm{E}-05$ & $4.2 \mathrm{E}+02$ & $6.2 \mathrm{E}-04$ \\
\hline LWA & 30 & 66.40 & 0.06 & 0.01 & - & $2.8 \mathrm{E}+05$ & 5.6E-02 & $1.3 \mathrm{E}+05$ & $1.8 \mathrm{E}-02$ & $1.9 \mathrm{E}+02$ & 4.5E-04 & $7.3 \mathrm{E}+01$ & $9.0 \mathrm{E}-05$ & $4.8 \mathrm{E}+02$ & 6.3E-04 \\
\hline & 31 & 68.76 & 0.07 & 0.01 & - & $2.9 \mathrm{E}+05$ & 5.5E-02 & $1.3 \mathrm{E}+05$ & $1.8 \mathrm{E}-02$ & $2.0 \mathrm{E}+02$ & 4.6E-04 & $6.5 \mathrm{E}+01$ & 7.7E-05 & $4.9 \mathrm{E}+02$ & 6.2E-04 \\
\hline LWA44-32 & 32 & 70.93 & 0.06 & 0.01 & - & $2.5 E+05$ & 4.9E-02 & $1.1 \mathrm{E}+05$ & $1.6 \mathrm{E}-02$ & $1.8 \mathrm{E}+02$ & 4.4E-04 & $6.6 \mathrm{E}+01$ & 8.0E-05 & $4.4 \mathrm{E}+02$ & 5.8E-04 \\
\hline $\mathrm{LW}$ & 33 & 73.41 & 0.06 & 0.01 & - & $2.5 E+05$ & 5.7E-02 & $1.1 \mathrm{E}+05$ & $1.8 \mathrm{E}-02$ & $1.8 \mathrm{E}+02$ & $5.0 \mathrm{E}-04$ & $8.8 \mathrm{E}+01$ & $1.2 \mathrm{E}-04$ & $4.4 \mathrm{E}+02$ & 6.7E-04 \\
\hline LWA & 34 & 75.83 & 0.07 & 0.01 & - & $2.8 \mathrm{E}+05$ & 5.3E-02 & $1.3 \mathrm{E}+05$ & $1.8 \mathrm{E}-02$ & $2.0 \mathrm{E}+02$ & 4.8E-04 & $1.1 \mathrm{E}+02$ & 1.3E-04 & $5.2 \mathrm{E}+02$ & 6.6E-04 \\
\hline LWA44-35 & 35 & 77.99 & 0.05 & 0.01 & - & $2.6 \mathrm{E}+05$ & 6.3E-02 & $1.2 \mathrm{E}+05$ & $2.0 \mathrm{E}-02$ & $1.9 \mathrm{E}+02$ & 5.6E-04 & $5.0 \mathrm{E}+01$ & 7.5E-05 & $5.2 \mathrm{E}+02$ & 8.3E-04 \\
\hline LWA & 36 & 80.40 & 0.05 & 0.01 & - & $2.5 E+05$ & 6.3E-02 & $1.1 \mathrm{E}+05$ & $1.9 \mathrm{E}-02$ & $1.7 \mathrm{E}+02$ & 5.3E-04 & $3.6 \mathrm{E}+01$ & 5.7E-05 & $4.8 \mathrm{E}+02$ & 8.1E-04 \\
\hline LWA44-37 & 37 & 82.77 & 0.05 & 0.01 & - & $2.6 \mathrm{E}+05$ & 6.1E-02 & $1.1 \mathrm{E}+05$ & $1.9 \mathrm{E}-02$ & $1.8 \mathrm{E}+02$ & $5.2 \mathrm{E}-04$ & $3.0 \mathrm{E}+01$ & 4.4E-05 & $5.1 \mathrm{E}+02$ & 7.9E-04 \\
\hline LWA44-38 & 38 & 84.78 & 0.06 & 0.01 & - & $2.8 \mathrm{E}+05$ & $6.4 \mathrm{E}-02$ & $1.3 \mathrm{E}+05$ & $2.1 \mathrm{E}-02$ & $2.0 \mathrm{E}+02$ & 5.7E-04 & $3.5 \mathrm{E}+01$ & $5.0 \mathrm{E}-05$ & $5.6 \mathrm{E}+02$ & 8.5E-04 \\
\hline LWA44-39 & 39 & 87.92 & 0.06 & 0.01 & - & $2.5 \mathrm{E}+05$ & 5.5E-02 & $1.1 \mathrm{E}+05$ & $1.7 \mathrm{E}-02$ & $1.9 \mathrm{E}+02$ & 5.3E-04 & $4.4 \mathrm{E}+01$ & $6.1 \mathrm{E}-05$ & $5.5 \mathrm{E}+02$ & 8.1E-04 \\
\hline
\end{tabular}


Table B1. LAWA44 PUF Test Results

\begin{tabular}{|c|c|c|c|c|c|c|c|c|c|c|c|c|c|c|c|}
\hline Sample ID & Vial & ime & $\theta$ & $\sigma \theta$ & pH & [Na] & a Rate & [Si] & Si Rate & [Ti] & Ti Rate & [Zn] & Zn Rate & [Zr] & $21 \mathrm{Ne}$ \\
\hline LWA44-40 & 40 & 91.56 & 0.07 & 0.01 & - & $2.7 E+05$ & 5.1E-02 & $1.2 \mathrm{E}+05$ & $1.6 \mathrm{E}-02$ & $1.9 \mathrm{E}+02$ & $4.5 \mathrm{E}-04$ & $3.6 \mathrm{E}+01$ & $4.3 \mathrm{E}-05$ & $5.4 \mathrm{E}+02$ & $6.8 \mathrm{E}-04$ \\
\hline LWA44-41 & 41 & 94.49 & 0.05 & 0.01 & - & $2.3 \mathrm{E}+05$ & $5.8 \mathrm{E}-02$ & $E+05$ & $1.8 \mathrm{E}-02$ & $1.8 \mathrm{E}+02$ & 5.6E-04 & +01 & 2E-05 & +02 & 7E-04 \\
\hline $44-42$ & 42 & 96.99 & 05 & 01 & - & +05 & -02 & $E+05$ & $2.0 \mathrm{E}-02$ & $E+02$ & 2E-04 & +01 & 7E-05 & $8 \mathrm{E}+02$ & E-04 \\
\hline LWA44-43 & 43 & 98.95 & 0.07 & 0.00 & - & $3.1 \mathrm{E}+05$ & 5.8E-02 & $1.4 \mathrm{E}+05$ & $1.8 \mathrm{E}-02$ & $2.0 \mathrm{E}+02$ & 4.7E-04 & $4.7 E+01$ & $5.4 \mathrm{E}-05$ & $5.8 \mathrm{E}+02$ & 7.2E-04 \\
\hline LWA44-44 & 44 & 102.33 & 0.07 & 0.01 & - & $2.7 \mathrm{E}+05$ & 5.3E-02 & $1.3 \mathrm{E}+05$ & $1.7 \mathrm{E}-02$ & $2.1 \mathrm{E}+02$ & -04 & +01 & E-05 & +02 & E-04 \\
\hline LWA44-45 & 45 & 105.95 & 0.07 & 0.00 & - & $2.4 \mathrm{E}+05$ & 4.4E-02 & $1.1 \mathrm{E}+05$ & $1.4 \mathrm{E}-02$ & $2.0 \mathrm{E}+02$ & 4.7E-04 & $4.6 \mathrm{E}+01$ & 5.3E-05 & $5.9 \mathrm{E}+02$ & $.3 E-04$ \\
\hline LWA44-46 & 46 & 108.41 & 0.07 & 0.01 & - & $2.7 E+05$ & 5.1E-02 & $1.2 \mathrm{E}+05$ & $1.7 \mathrm{E}-02$ & $1.9 \mathrm{E}+02$ & 4.5E-04 & $5.3 \mathrm{E}+01$ & 6.3E-05 & $5.6 \mathrm{E}+02$ & 7.1E-04 \\
\hline $44-47$ & 47 & 110.82 & 0.07 & 0.01 & - & $2.6 \mathrm{E}+05$ & $4.8 \mathrm{E}-02$ & $1.2 \mathrm{E}+05$ & $1.6 \mathrm{E}-02$ & $2.1 \mathrm{E}+02$ & -04 & +01 & 4E-05 & $6.2 \mathrm{E}+02$ & 7.9E-04 \\
\hline LWA44-48 & 48 & 112.98 & 0.07 & 0.01 & - & $2.7 \mathrm{E}+05$ & 4.8E-02 & $1.2 \mathrm{E}+05$ & $1.6 \mathrm{E}-02$ & $2.2 \mathrm{E}+02$ & $4.9 \mathrm{E}-04$ & $4.9 \mathrm{E}+01$ & 5.6E-05 & $6.4 \mathrm{E}+02$ & 7.9E-04 \\
\hline LWA44-49 & 49 & 115.44 & 0.06 & 0.01 & - & $2.1 \mathrm{E}+05$ & 4.1E-02 & $9.5 \mathrm{E}+04$ & $1.3 \mathrm{E}-02$ & $1.8 \mathrm{E}+02$ & $4.4 \mathrm{E}-04$ & $3.5 \mathrm{E}+01$ & $3 \mathrm{E}-05$ & $4 \mathrm{E}+02$ & 7.1E-04 \\
\hline LWA44-50 & 50 & 117.82 & 0.07 & 0.01 & - & $2.8 \mathrm{E}$ & $4.8 \mathrm{E}-02$ & $1.3 \mathrm{E}+05$ & $1.6 \mathrm{E}-02$ & $1.9 \mathrm{E}+02$ & $4.1 \mathrm{E}-04$ & $4.3 \mathrm{E}+01$ & 4.7E-05 & $5.6 \mathrm{E}+02$ & 6.6E-04 \\
\hline LWA44-51 & 51 & 119.93 & 0.07 & 0.01 & - & $2.6 \mathrm{E}+05$ & 4.6E-02 & $1.3 \mathrm{E}+05$ & $1.6 \mathrm{E}-02$ & $2.0 \mathrm{E}+02$ & 4.4E-04 & $4.1 \mathrm{E}+01$ & 4.5E-05 & $5.9 \mathrm{E}+02$ & 7.1E-04 \\
\hline $4-52$ & 52 & 122.35 & 0.07 & 0.01 & - & $2.1 \mathrm{E}+05$ & 3.6E-02 & $9.8 \mathrm{E}+04$ & $1.2 \mathrm{E}-02$ & $2.0 \mathrm{E}+02$ & 4.3E-04 & $4.6 \mathrm{E}+01$ & 9E-05 & $6.0 \mathrm{E}+02$ & E-04 \\
\hline LWA44-53 & 53 & 124.75 & 0.10 & 0.01 & - & $2.4 \mathrm{E}+05$ & 3.0E-02 & $1.1 \mathrm{E}+05$ & $1.0 \mathrm{E}-02$ & $1.9 \mathrm{E}+02$ & 3.0E-04 & $4.9 \mathrm{E}+01$ & 3.8E-05 & $5.7 \mathrm{E}+02$ & $4.8 \mathrm{E}-04$ \\
\hline LWA & 54 & 126.90 & 0.09 & 0.01 & - & +05 & 3.5E-02 & $1.1 \mathrm{E}+05$ & $1.2 \mathrm{E}-02$ & $2.0 \mathrm{E}+02$ & 3.6E-04 & +01 & -05 & +02 & 5.8E-04 \\
\hline $\mathrm{LW}$ & 55 & 129.36 & 0.08 & 0.00 & - & $2.0 \mathrm{E}+05$ & 3.0E-02 & $9.1 \mathrm{E}+04$ & $1.0 \mathrm{E}-02$ & $2.0 \mathrm{E}+02$ & 3.8E-04 & +01 & $1 \mathrm{E}-05$ & $.8 \mathrm{E}+02$ & E-04 \\
\hline LWA44-56 & 56 & 131.75 & 0.09 & 0.01 & - & 2.2 & 3.0E-02 & $1.0 \mathrm{E}+05$ & $9.9 \mathrm{E}-03$ & $1.9 \mathrm{E}+02$ & 3.2E-04 & 4.3 & 3.7E-05 & $5.6 \mathrm{E}+02$ & $5.2 \mathrm{E}-04$ \\
\hline $4-57$ & 57 & 133.86 & 0.08 & 0.01 & - & $2.6 \mathrm{E}+05$ & 3.8E-02 & $1.2 \mathrm{E}+05$ & $1.3 \mathrm{E}-02$ & $1.7 \mathrm{E}+02$ & $3.2 \mathrm{E}-04$ & +01 & -05 & +02 & 5.0E-04 \\
\hline $4-58$ & 58 & 136.34 & 0.08 & 0.00 & - & $2.9 \mathrm{E}+05$ & 4.6E-02 & $1.0 \mathrm{E}+05$ & $1.1 \mathrm{E}-02$ & $1.7 \mathrm{E}+02$ & $3.4 \mathrm{E}-04$ & +01 & E-05 & $5.0 \mathrm{E}+02$ & E-04 \\
\hline LWA & 59 & 139.20 & 0.08 & 0.00 & - & $3.6 \mathrm{E}+05$ & 5.5E-02 & $1.1 \mathrm{E}+05$ & $1.2 \mathrm{E}-02$ & 1.4 & 2.7E-04 & 6.9 & 6.7E-05 & 4.2 & 4.4E-04 \\
\hline $4-60$ & 60 & 141.26 & 0.08 & 0.00 & - & $E+05$ & 5.2E-02 & $9.7 \mathrm{E}+04$ & $1.1 \mathrm{E}-02$ & $1.4 \mathrm{E}+02$ & 2.7E-04 & +01 & E-05 & +02 & 4.3E-04 \\
\hline LWA44-61 & 61 & 143.82 & 0.08 & 0.00 & - & $3.4 \mathrm{E}+05$ & 5.4E-02 & $9.2 \mathrm{E}+04$ & $1.0 \mathrm{E}-02$ & $1.4 \mathrm{E}+02$ & 2.7E-04 & $6.1 \mathrm{E}+01$ & $.0 \mathrm{E}-05$ & $4.2 \mathrm{E}+02$ & 4.4E-04 \\
\hline $\mathrm{LW}$ & 62 & 147.44 & 0.08 & 0.01 & - & $3.7 E+05$ & 5.5E-02 & $8.8 \mathrm{E}+04$ & $9.5 \mathrm{E}-03$ & $1.4 \mathrm{E}+02$ & 2.7E-04 & 3.5 & E-05 & $4.0 \mathrm{E}+02$ & 4.0E-04 \\
\hline $4-63$ & 63 & 150.33 & 0.07 & 0.00 & - & $3.2 E+05$ & 5.5E-02 & $7.7 \mathrm{E}+04$ & $9.4 \mathrm{E}-03$ & $1.3 \mathrm{E}+02$ & 2.8E-04 & $3.2 \mathrm{E}+01$ & 3.4E-05 & $3.8 \mathrm{E}+02$ & 4.4E-04 \\
\hline LWA44-64 & 64 & 152.73 & 0.08 & 0.00 & - & $3.2 E+05$ & 5.1E-02 & $7.3 \mathrm{E}+04$ & $8.4 \mathrm{E}-03$ & $1.2 \mathrm{E}+02$ & $2.4 \mathrm{E}-04$ & $2.9 \mathrm{E}+01$ & 3.0E-05 & $3.3 \mathrm{E}+02$ & 3.6E-04 \\
\hline LWA44-65 & 65 & 154.98 & 0.08 & 0.01 & - & $3.0 \mathrm{E}+05$ & 4.6E-02 & $7.1 \mathrm{E}+04$ & 7.8E-03 & $1.2 \mathrm{E}+02$ & 2.3E-04 & $2.7 \mathrm{E}+01$ & 2.6E-05 & $3.5 \mathrm{E}+02$ & 3.6E-04 \\
\hline-66 & 6 & 157.41 & 0.07 & 0.00 & - & $\Xi+05$ & 3.8E-02 & $7.5 \mathrm{E}+04$ & $9.3 \mathrm{E}-03$ & $1.4 \mathrm{E}+02$ & $3.1 \mathrm{E}-04$ & $2.7 \mathrm{E}+01$ & 2.9E-05 & $4.2 \mathrm{E}+02$ & 4.8E-04 \\
\hline LWA & 67 & 159.82 & 0.08 & 0.01 & - & $2.1 \mathrm{E}+05$ & 02 & $7.8 \mathrm{E}+04$ & $9.2 \mathrm{E}-03$ & $1.7 \mathrm{E}+02$ & 3.5E-04 & $3.1 \mathrm{E}+01$ & 3.2E-05 & $5.1 \mathrm{E}+02$ & 5.7E-04 \\
\hline LWA44-68 & 68 & 161.96 & 0.08 & 0.01 & - & $1.8 \mathrm{E}+05$ & 3.1E-02 & $6.9 \mathrm{E}+04$ & $8.2 \mathrm{E}-03$ & $1.5 \mathrm{E}+02$ & 3.1E-04 & $2.7 \mathrm{E}+01$ & 2.8E-05 & $4.6 \mathrm{E}+02$ & 5.1E-04 \\
\hline $4-69$ & 69 & 164.35 & 0.07 & 0.01 & - & $1.8 \mathrm{E}+05$ & 3.2E-02 & $7.2 \mathrm{E}+04$ & $9.1 \mathrm{E}-03$ & $1.6 \mathrm{E}+02$ & 3.5E-04 & $2.8 \mathrm{E}+01$ & 3.1E-05 & $4.8 \mathrm{E}+02$ & 5.7E-04 \\
\hline LWA44-70 & 70 & 166.86 & 0.07 & 0.01 & - & $1.6 \mathrm{E}+05$ & 2.8E-02 & $6.6 \mathrm{E}+04$ & $8.2 \mathrm{E}-03$ & $1.5 \mathrm{E}+02$ & $3.2 \mathrm{E}-04$ & $2.5 \mathrm{E}+01$ & 2.7E-05 & $4.5 \mathrm{E}+02$ & 5.3E-04 \\
\hline LWA44-71 & 71 & 169.03 & 0.08 & 0.01 & - & $2.0 \mathrm{E}+05$ & 3.0E-02 & $8.3 E+04$ & 8.9E-03 & $1.5 \mathrm{E}+02$ & 2.8E-04 & $2.9 \mathrm{E}+01$ & 2.7E-05 & $4.5 \mathrm{E}+02$ & 4.6E-04 \\
\hline LWA44-72 & 72 & 171.35 & 0.09 & 0.00 & - & $1.8 \mathrm{E}+05$ & 2.6E-02 & $7.6 \mathrm{E}+04$ & 7.9E-03 & $1.3 \mathrm{E}+02$ & 2.3E-04 & $2.5 \mathrm{E}+01$ & 2.2E-05 & $3.9 \mathrm{E}+02$ & 3.8E-04 \\
\hline LWA44-73 & 73 & 173.85 & 0.08 & 0.01 & - & $2.0 \mathrm{E}+05$ & 3.0E-02 & $8.9 \mathrm{E}+04$ & $9.4 \mathrm{E}-03$ & $1.2 \mathrm{E}+02$ & 2.3E-04 & $2.5 \mathrm{E}+01$ & 2.3E-05 & $3.8 \mathrm{E}+02$ & 3.8E-04 \\
\hline LWA44-74 & 74 & 176.00 & 0.06 & 0.01 & - & $1.8 \mathrm{E}+05$ & 3.6E-02 & $7.9 \mathrm{E}+04$ & $1.1 \mathrm{E}-02$ & $1.2 \mathrm{E}+02$ & 3.0E-04 & $2.8 \mathrm{E}+01$ & 3.5E-05 & $3.6 \mathrm{E}+02$ & 5.0E-04 \\
\hline-75 & 75 & 178.33 & 0.06 & 0.01 & - & $2.0 \mathrm{E}+05$ & 4.5E-02 & $8.9 \mathrm{E}+04$ & $1.4 \mathrm{E}-02$ & $1.6 \mathrm{E}+02$ & 4.3E-04 & $7.1 \mathrm{E}+01$ & 9.7E-05 & $4.9 \mathrm{E}+02$ & 7.2E-04 \\
\hline LWA44-76 & 76 & 180.80 & 0.06 & 0.02 & - & $2.0 \mathrm{E}+05$ & 4.1E-02 & $9.0 \mathrm{E}+04$ & $1.3 \mathrm{E}-02$ & $1.4 \mathrm{E}+02$ & 3.5E-04 & $3.4 \mathrm{E}+01$ & 4.4E-05 & $4.4 \mathrm{E}+02$ & $6.2 \mathrm{E}-04$ \\
\hline LWA44-77 & 77 & 183.45 & 0.08 & 0.01 & - & $2.1 \mathrm{E}+05$ & 3.5E-02 & $9.7 \mathrm{E}+04$ & $1.1 \mathrm{E}-02$ & $1.3 \mathrm{E}+02$ & 2.7E-04 & $3.9 \mathrm{E}+01$ & 4.0E-05 & $4.1 \mathrm{E}+02$ & 4.6E-04 \\
\hline LWA44-78 & 78 & 186.47 & 0.05 & 0.02 & - & $2.1 \mathrm{E}+05$ & $5.9 \mathrm{E}-02$ & $1.0 \mathrm{E}+05$ & $2.1 \mathrm{E}-02$ & $1.4 \mathrm{E}+02$ & 4.9E-04 & $4.4 \mathrm{E}+01$ & 7.5E-05 & $4.2 \mathrm{E}+02$ & 7.7E-04 \\
\hline LWA44-79 & 79 & 189.53 & 0.04 & 0.01 & - & $2.4 \mathrm{E}+05$ & 7.1E-02 & $1.3 \mathrm{E}+05$ & $2.8 \mathrm{E}-02$ & $1.3 \mathrm{E}+02$ & $4.9 \mathrm{E}-04$ & $4.5 \mathrm{E}+01$ & 8.2E-05 & $3.9 \mathrm{E}+02$ & 7.7E-04 \\
\hline
\end{tabular}


Table B1. LAWA44 PUF Test Results

\begin{tabular}{|c|c|c|c|c|c|c|c|c|c|c|c|c|c|c|c|}
\hline Sample ID & Vial & Time & $\theta$ & $\sigma \theta$ & pH & [Na] & Na Rate & [Si] & Si Rate & [Ti] & Ti Rate & [Zn] & Zn Rate & [Zr] & Zr Rate \\
\hline LWA44-80 & 80 & 192.41 & 0.05 & 0.01 & - & $2.2 \mathrm{E}+05$ & 5.6E-02 & $1.2 \mathrm{E}+05$ & $2.2 \mathrm{E}-02$ & $1.4 \mathrm{E}+02$ & 4.2E-04 & $4.5 \mathrm{E}+01$ & 7.0E-05 & $4.0 \mathrm{E}+02$ & $6.7 \mathrm{E}-04$ \\
\hline LWA44-81 & 81 & 194.83 & 0.04 & 0.02 & - & $2.6 \mathrm{E}+05$ & 8.0E-02 & $1.6 \mathrm{E}+05$ & 3.5E-02 & $5.2 \mathrm{E}+02$ & 2.0E-03 & $1.2 \mathrm{E}+02$ & 2.3E-04 & $1.3 \mathrm{E}+03$ & $2.8 \mathrm{E}-03$ \\
\hline LWA44-82 & 82 & 197.50 & 0.03 & 0.00 & - & $1.5 \mathrm{E}+05$ & 6.1E-02 & $6.8 \mathrm{E}+04$ & $2.0 \mathrm{E}-02$ & $1.8 \mathrm{E}+02$ & $9.4 \mathrm{E}-04$ & $3.7 \mathrm{E}+01$ & 9.6E-05 & $5.6 \mathrm{E}+02$ & 1.6E-03 \\
\hline LWA44-83 & 83 & 199.86 & 0.02 & 0.00 & - & $1.9 \mathrm{E}+05$ & 9.9E-02 & $8.6 \mathrm{E}+04$ & 3.3E-02 & $1.8 \mathrm{E}+02$ & $1.2 \mathrm{E}-03$ & $3.5 \mathrm{E}+01$ & $1.1 \mathrm{E}-04$ & $5.7 \mathrm{E}+02$ & 2.0E-03 \\
\hline LWA44-84 & 84 & 201.73 & 0.04 & 0.01 & - & $2.1 \mathrm{E}+05$ & 7.1E-02 & $9.7 \mathrm{E}+04$ & 2.3E-02 & $1.8 \mathrm{E}+02$ & 7.7E-04 & $3.6 \mathrm{E}+01$ & 7.4E-05 & $7.4 \mathrm{E}+02$ & $1.6 \mathrm{E}-03$ \\
\hline LWA44-85 & 85 & 203.92 & 0.03 & 0.00 & - & $2.0 \mathrm{E}+05$ & 8.4E-02 & $9.8 \mathrm{E}+04$ & 2.9E-02 & $1.8 \mathrm{E}+02$ & 9.3E-04 & $4.3 \mathrm{E}+01$ & $1.1 \mathrm{E}-04$ & $5.6 \mathrm{E}+02$ & 1.6E-03 \\
\hline LWA44-86 & 86 & 206.37 & 0.02 & 0.00 & - & $2.0 \mathrm{E}+05$ & $1.1 \mathrm{E}-01$ & $9.5 \mathrm{E}+04$ & $3.8 \mathrm{E}-02$ & $1.7 \mathrm{E}+02$ & $1.2 \mathrm{E}-03$ & $4.1 \mathrm{E}+01$ & $1.4 \mathrm{E}-04$ & $5.4 \mathrm{E}+02$ & 2.0E-03 \\
\hline LWA44-87 & 87 & 208.77 & 0.02 & 0.00 & - & $2.0 \mathrm{E}+05$ & $1.1 \mathrm{E}-01$ & $9.7 \mathrm{E}+04$ & $3.8 \mathrm{E}-02$ & $1.8 \mathrm{E}+02$ & $1.2 \mathrm{E}-03$ & $4.4 \mathrm{E}+01$ & 1.5E-04 & $5.6 \mathrm{E}+02$ & $2.0 \mathrm{E}-03$ \\
\hline LWA44-88 & 88 & 210.97 & 0.03 & 0.01 & - & $2.2 \mathrm{E}+05$ & $9.8 \mathrm{E}-02$ & $1.0 \mathrm{E}+05$ & 3.3E-02 & $1.9 \mathrm{E}+02$ & $1.1 \mathrm{E}-03$ & $4.3 \mathrm{E}+01$ & $1.2 \mathrm{E}-04$ & $5.8 \mathrm{E}+02$ & 1.7E-03 \\
\hline LWA44-89 & 89 & 213.40 & 0.02 & 0.01 & - & $2.2 \mathrm{E}+05$ & 1.2E-01 & $1.1 \mathrm{E}+05$ & $4.0 \mathrm{E}-02$ & $1.9 \mathrm{E}+02$ & 1.2E-03 & $4.2 \mathrm{E}+01$ & $1.4 \mathrm{E}-04$ & $5.9 \mathrm{E}+02$ & $2.0 \mathrm{E}-03$ \\
\hline LWA44-90 & 90 & 215.80 & 0.02 & 0.01 & - & $2.2 \mathrm{E}+05$ & $1.2 \mathrm{E}-01$ & $1.1 \mathrm{E}+05$ & $4.2 \mathrm{E}-02$ & $1.9 \mathrm{E}+02$ & 1.3E-03 & $3.6 \mathrm{E}+01$ & $1.2 \mathrm{E}-04$ & $5.9 \mathrm{E}+02$ & 2.1E-03 \\
\hline LWA44-91 & 91 & 217.93 & 0.02 & 0.01 & - & $2.1 \mathrm{E}+05$ & $1.5 \mathrm{E}-01$ & $1.0 \mathrm{E}+05$ & $5.1 \mathrm{E}-02$ & $1.9 \mathrm{E}+02$ & 1.7E-03 & $4.6 \mathrm{E}+01$ & $2.0 \mathrm{E}-04$ & $5.7 \mathrm{E}+02$ & 2.7E-03 \\
\hline LWA44-92 & 92 & 220.36 & 0.02 & 0.00 & - & $2.0 \mathrm{E}+05$ & 1.1E-01 & $9.8 \mathrm{E}+04$ & 3.7E-02 & $1.9 \mathrm{E}+02$ & $1.2 \mathrm{E}-03$ & $5.0 \mathrm{E}+01$ & 1.7E-04 & $5.8 \mathrm{E}+02$ & $2.1 \mathrm{E}-03$ \\
\hline LWA44-93 & 93 & 222.84 & 0.03 & 0.00 & - & $2.2 \mathrm{E}+05$ & 9.6E-02 & $1.1 \mathrm{E}+05$ & $3.4 \mathrm{E}-02$ & $2.0 \mathrm{E}+02$ & $1.1 \mathrm{E}-03$ & $4.3 \mathrm{E}+01$ & $1.2 \mathrm{E}-04$ & $6.0 \mathrm{E}+02$ & $1.8 \mathrm{E}-03$ \\
\hline LWA44-94 & 94 & 225.00 & 0.04 & 0.02 & - & $2.1 \mathrm{E}+05$ & 5.9E-02 & $1.0 \mathrm{E}+05$ & 2.1E-02 & $1.9 \mathrm{E}+02$ & 6.6E-04 & $4.8 \mathrm{E}+01$ & 8.5E-05 & $5.8 \mathrm{E}+02$ & $1.1 \mathrm{E}-03$ \\
\hline LWA44-95 & 95 & 227.50 & 0.07 & 0.00 & - & $2.9 \mathrm{E}+05$ & 4.9E-02 & $1.5 \mathrm{E}+05$ & $1.9 \mathrm{E}-02$ & $2.2 \mathrm{E}+02$ & 4.8E-04 & $5.3 \mathrm{E}+01$ & 5.7E-05 & $6.3 \mathrm{E}+02$ & 7.2E-04 \\
\hline LWA44-96 & 96 & 230.01 & 0.04 & 0.00 & - & $2.1 \mathrm{E}+05$ & $6.2 \mathrm{E}-02$ & $1.2 \mathrm{E}+05$ & $2.5 \mathrm{E}-02$ & $2.9 \mathrm{E}+02$ & $1.1 \mathrm{E}-03$ & $5.2 \mathrm{E}+01$ & $9.6 \mathrm{E}-05$ & $8.6 \mathrm{E}+02$ & 1.7E-03 \\
\hline LWA44-97 & 97 & 232.10 & 0.04 & 0.01 & - & $1.8 \mathrm{E}+05$ & 5.9E-02 & $9.0 \mathrm{E}+04$ & $2.1 \mathrm{E}-02$ & $2.6 \mathrm{E}+02$ & $1.1 \mathrm{E}-03$ & $4.9 \mathrm{E}+01$ & $9.9 \mathrm{E}-05$ & $7.9 \mathrm{E}+02$ & $1.7 \mathrm{E}-03$ \\
\hline LWA44-98 & 98 & 234.46 & 0.03 & 0.02 & - & $1.5 \mathrm{E}+05$ & 5.3E-02 & $7.1 \mathrm{E}+04$ & $1.8 \mathrm{E}-02$ & $2.0 \mathrm{E}+02$ & 9.2E-04 & $5.0 \mathrm{E}+01$ & 1.1E-04 & $5.9 \mathrm{E}+02$ & $1.4 \mathrm{E}-03$ \\
\hline LWA44-99 & 99 & 236.86 & 0.09 & 0.00 & - & $2.1 \mathrm{E}+05$ & 3.0E-02 & $9.9 \mathrm{E}+04$ & $1.0 \mathrm{E}-02$ & $2.1 \mathrm{E}+02$ & 3.8E-04 & $7.3 \mathrm{E}+01$ & $6.6 \mathrm{E}-05$ & $6.4 \mathrm{E}+02$ & $6.2 \mathrm{E}-04$ \\
\hline LWA44-100 & 100 & 238.96 & 0.10 & 0.00 & - & $2.4 \mathrm{E}+05$ & 3.1E-02 & $1.2 \mathrm{E}+05$ & $1.1 \mathrm{E}-02$ & $2.0 \mathrm{E}+02$ & 3.3E-04 & $4.5 \mathrm{E}+01$ & 3.6E-05 & $6.0 \mathrm{E}+02$ & 5.2E-04 \\
\hline LWA44-101 & 101 & 241.37 & 0.10 & 0.00 & - & $2.4 \mathrm{E}+05$ & 2.9E-02 & $1.2 \mathrm{E}+05$ & $1.1 \mathrm{E}-02$ & $2.0 \mathrm{E}+02$ & $3.0 \mathrm{E}-04$ & $5.1 \mathrm{E}+01$ & 3.8E-05 & $6.1 \mathrm{E}+02$ & $5.0 \mathrm{E}-04$ \\
\hline LWA44-102 & 102 & 243.81 & 0.06 & 0.02 & - & $2.1 \mathrm{E}+05$ & 4.1E-02 & $1.1 \mathrm{E}+05$ & $1.5 \mathrm{E}-02$ & $1.9 \mathrm{E}+02$ & 4.6E-04 & $4.9 \mathrm{E}+01$ & $6.0 \mathrm{E}-05$ & $5.8 \mathrm{E}+02$ & 7.6E-04 \\
\hline LWA44-103 & 103 & 245.97 & 0.06 & 0.00 & - & $1.6 \mathrm{E}+05$ & $3.2 \mathrm{E}-02$ & $8.1 \mathrm{E}+04$ & $1.1 \mathrm{E}-02$ & $1.7 \mathrm{E}+02$ & $4.2 \mathrm{E}-04$ & $4.4 \mathrm{E}+01$ & $5.4 \mathrm{E}-05$ & $5.4 \mathrm{E}+02$ & 7.1E-04 \\
\hline LWA44-104 & 104 & 248.43 & 0.07 & 0.00 & - & $2.4 \mathrm{E}+05$ & 4.1E-02 & $1.2 \mathrm{E}+05$ & $1.5 \mathrm{E}-02$ & $2.2 \mathrm{E}+02$ & $4.8 \mathrm{E}-04$ & $4.6 \mathrm{E}+01$ & $5.0 \mathrm{E}-05$ & $6.7 \mathrm{E}+02$ & 7.8E-04 \\
\hline LWA44-105 & 105 & 250.91 & 0.07 & 0.00 & - & $2.0 \mathrm{E}+05$ & 3.4E-02 & $1.2 \mathrm{E}+05$ & $1.5 \mathrm{E}-02$ & $2.0 \mathrm{E}+02$ & $4.2 \mathrm{E}-04$ & $3.0 \mathrm{E}+01$ & 3.3E-05 & $5.9 \mathrm{E}+02$ & 6.8E-04 \\
\hline LWA44-106 & 106 & 253.43 & 0.07 & 0.01 & - & - & - & - & - & - & - & - & - & - & - \\
\hline LWA44-107 & 107 & 255.80 & 0.07 & 0.00 & - & - & - & - & - & - & - & - & - & - & - \\
\hline LWA44-108 & 108 & 257.88 & 0.06 & 0.03 & - & $2.7 \mathrm{E}+05$ & 5.7E-02 & $1.6 \mathrm{E}+05$ & 2.3E-02 & $2.8 \mathrm{E}+02$ & 7.2E-04 & $4.6 \mathrm{E}+01$ & $6.1 \mathrm{E}-05$ & $8.1 \mathrm{E}+02$ & $1.1 \mathrm{E}-03$ \\
\hline LWA44-109 & 109 & 260.34 & 0.05 & 0.01 & - & - & - & - & - & - & - & - & - & - & - \\
\hline LWA44-110 & 110 & 262.74 & 0.05 & 0.01 & - & - & - & - & - & - & - & - & - & - & - \\
\hline LWA44-111 & 111 & 264.82 & 0.05 & 0.01 & - & $2.1 \mathrm{E}+05$ & 5.1E-02 & $1.3 \mathrm{E}+05$ & $2.2 \mathrm{E}-02$ & $2.2 \mathrm{E}+02$ & 6.7E-04 & $3.6 \mathrm{E}+01$ & 5.6E-05 & $6.7 \mathrm{E}+02$ & $1.1 \mathrm{E}-03$ \\
\hline LWA44-112 & 112 & 266.94 & 0.05 & 0.01 & - & - & - & - & - & - & - & - & - & - & - \\
\hline LWA44-113 & 113 & 273.90 & 0.04 & 0.01 & - & - & - & - & - & - & - & - & - & - & - \\
\hline LWA44-114 & 114 & 280.95 & 0.04 & 0.01 & - & $2.2 E+05$ & 6.9E-02 & $1.3 \mathrm{E}+05$ & $2.9 \mathrm{E}-02$ & $2.3 \mathrm{E}+02$ & $9.0 \mathrm{E}-04$ & $2.3 \mathrm{E}+01$ & 4.6E-05 & $7.0 \mathrm{E}+02$ & $1.5 \mathrm{E}-03$ \\
\hline LWA44-115 & 115 & 283.39 & 0.03 & 0.00 & - & - & - & - & - & - & - & - & - & - & - \\
\hline LWA44-116 & 116 & 285.88 & 0.05 & 0.01 & - & - & - & - & - & - & - & - & - & - & - \\
\hline LWA44-117 & 117 & 288.04 & 0.04 & 0.01 & - & $1.9 \mathrm{E}+05$ & $6.1 \mathrm{E}-02$ & $1.1 \mathrm{E}+05$ & $2.5 \mathrm{E}-02$ & $2.1 \mathrm{E}+02$ & 7.9E-04 & $2.6 \mathrm{E}+01$ & 5.1E-05 & $6.1 \mathrm{E}+02$ & $1.3 \mathrm{E}-03$ \\
\hline LWA44-118 & 118 & 290.44 & 0.05 & 0.01 & - & - & - & - & - & - & - & - & - & - & - \\
\hline LWA44-119 & 119 & 292.95 & 0.05 & 0.01 & - & - & - & - & - & - & - & - & - & - & - \\
\hline
\end{tabular}


Table B1. LAWA44 PUF Test Results

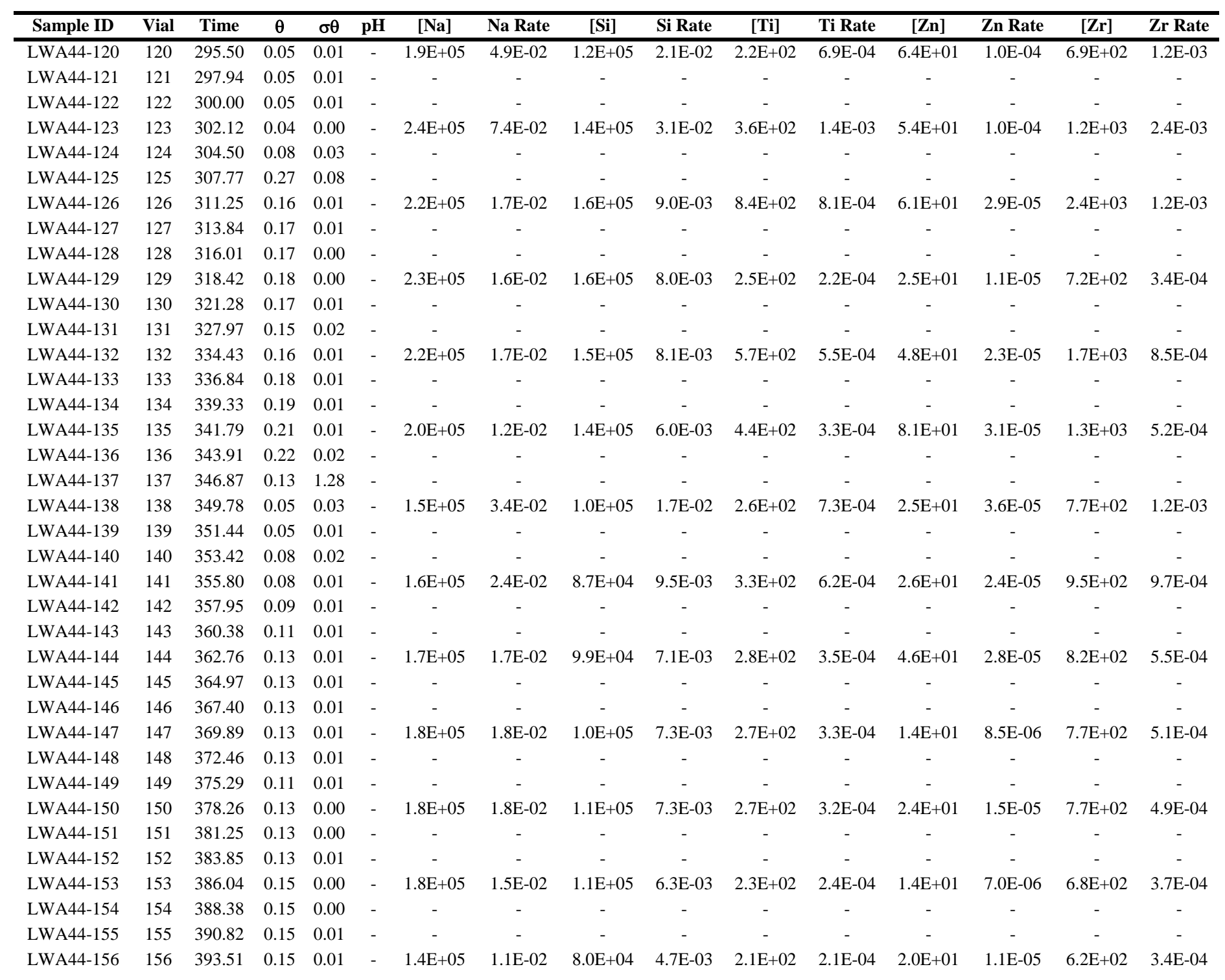


Table B1. LAWA44 PUF Test Results

\begin{tabular}{|c|c|c|c|c|c|c|c|c|c|c|c|c|c|c|c|}
\hline Sample ID & Vial & Time & $\theta$ & $\overline{\sigma \theta}$ & pH & {$[\mathrm{Na}]$} & Na Rate & [Si] & Si Rate & [Ti] & Ti Rate & [Zn] & Zn Rate & {$[\mathrm{Zr}]$} & $\overline{\text { Zr Rate }}$ \\
\hline LWA44-157 & 157 & 395.88 & 0.13 & 0.01 & - & - & - & - & - & - & - & - & - & - & - \\
\hline LWA44-158 & 158 & 397.90 & 0.15 & 0.01 & - & - & - & - & - & - & - & - & - & - & - \\
\hline LWA44-159 & 159 & 400.08 & 0.13 & 0.02 & - & $7 \mathrm{E}+05$ & $1.6 \mathrm{E}-02$ & $0 \mathrm{E}+05$ & 7.1E-03 & $2.5 \mathrm{E}+02$ & $3.0 \mathrm{E}-04$ & $4.6 \mathrm{E}+01$ & 2.8E-05 & $7.5 \mathrm{E}+02$ & 4.9E-04 \\
\hline LWA44-161 & 161 & 404.71 & 0.15 & 0.02 & - & - & - & - & - & - & - & - & - & - & - \\
\hline LWA44-162 & 162 & 406.95 & 0.15 & 0.01 & - & $1.8 \mathrm{E}+05$ & $1.5 \mathrm{E}-02$ & $1.1 \mathrm{E}+05$ & $6.4 \mathrm{E}-03$ & $2.6 \mathrm{E}+02$ & 2.7E-04 & $7.4 \mathrm{E}+01$ & 3.8E-05 & $7.8 \mathrm{E}+02$ & 4.3E-04 \\
\hline LWA44-163 & 163 & 409.39 & 0.17 & 0.01 & - & - & - & - & - & - & - & - & - & - & - \\
\hline LWA44-166 & 166 & 417.31 & 0.18 & 0.01 & - & $1.9 \mathrm{E}+05$ & 1.3E-02 & $1.0 \mathrm{E}+05$ & $5.0 \mathrm{E}-03$ & $2.0 \mathrm{E}+02$ & $1.7 \mathrm{E}-04$ & - & $0.0 \mathrm{E}+00$ & $5.4 \mathrm{E}+02$ & 2.5E-04 \\
\hline LWA44-167 & 167 & 420.27 & 0.19 & 0.01 & - & $2.0 \mathrm{E}+05$ & 1.3E-02 & $1.1 \mathrm{E}+05$ & $5.0 \mathrm{E}-03$ & $2.6 \mathrm{E}+02$ & $2.1 \mathrm{E}-04$ & - & $0.0 \mathrm{E}+00$ & $5.5 \mathrm{E}+02$ & 2.4E-04 \\
\hline LWA44-168 & 168 & 424.29 & 0.19 & 0.01 & - & $1.7 \mathrm{E}+05$ & 1.1E-02 & $8.6 \mathrm{E}+04$ & $4.1 \mathrm{E}-03$ & $1.6 \mathrm{E}+02$ & $1.4 \mathrm{E}-04$ & - & $0.0 \mathrm{E}+00$ & $4.6 \mathrm{E}+02$ & 2.1E-04 \\
\hline LWA44-169 & 169 & 427.89 & 0.20 & 0.01 & - & $1.8 \mathrm{E}+05$ & 1.1E-02 & $8.9 \mathrm{E}+04$ & $4.0 \mathrm{E}-03$ & $1.7 \mathrm{E}+02$ & 1.3E-04 & - & $0.0 \mathrm{E}+00$ & $4.9 \mathrm{E}+02$ & 2.1E-04 \\
\hline LWA44-170 & 170 & 430.36 & 0.18 & 0.01 & - & $1.7 \mathrm{E}+05$ & 1.1E-02 & $8.8 \mathrm{E}+04$ & 4.3E-03 & $2.0 \mathrm{E}+02$ & 1.7E-04 & - & $0.0 \mathrm{E}+00$ & $4.6 \mathrm{E}+02$ & 2.1E-04 \\
\hline LWA44-172 & 172 & 434.93 & 0.20 & 0.01 & - & $2.0 \mathrm{E}+05$ & 1.2E-02 & $9.6 \mathrm{E}+04$ & 4.3E-03 & $1.8 \mathrm{E}+02$ & $1.4 \mathrm{E}-04$ & $7.6 \mathrm{E}+00$ & 3.0E-06 & $5.3 E+02$ & 2.2E-04 \\
\hline LWA44-173 & 173 & 437.36 & 0.19 & 0.01 & - & $1.7 \mathrm{E}+05$ & 1.1E-02 & $8.5 E+04$ & $4.1 \mathrm{E}-03$ & $1.7 \mathrm{E}+02$ & $1.4 \mathrm{E}-04$ & - & $0.0 \mathrm{E}+00$ & $4.3 \mathrm{E}+02$ & $1.9 \mathrm{E}-04$ \\
\hline LWA44-174 & 174 & 439.88 & 0.19 & 0.01 & - & $1.7 \mathrm{E}+05$ & 1.1E-02 & $8.7 \mathrm{E}+04$ & $4.1 \mathrm{E}-03$ & $1.6 \mathrm{E}+02$ & 1.3E-04 & - & $0.0 \mathrm{E}+00$ & $4.2 \mathrm{E}+02$ & $1.9 \mathrm{E}-04$ \\
\hline LWA44-175 & 175 & 443.38 & 0.19 & 0.01 & - & $2.7 E+05$ & 1.8E-02 & $1.2 \mathrm{E}+05$ & $5.4 \mathrm{E}-03$ & $1.9 \mathrm{E}+02$ & $1.6 \mathrm{E}-04$ & - & $0.0 \mathrm{E}+00$ & $5.4 \mathrm{E}+02$ & 2.4E-04 \\
\hline LWA44-176 & 176 & 446.76 & 0.19 & 0.02 & - & $2.1 \mathrm{E}+05$ & $1.4 \mathrm{E}-02$ & $1.1 \mathrm{E}+05$ & 5.3E-03 & $1.8 \mathrm{E}+02$ & $1.5 \mathrm{E}-04$ & - & $0.0 \mathrm{E}+00$ & $5.1 \mathrm{E}+02$ & 2.3E-04 \\
\hline LWA44-177 & 177 & 448.95 & 0.20 & 0.01 & - & $1.7 \mathrm{E}+05$ & $1.0 \mathrm{E}-02$ & $8.4 \mathrm{E}+04$ & $3.7 \mathrm{E}-03$ & $1.5 \mathrm{E}+02$ & $1.1 \mathrm{E}-04$ & - & $0.0 \mathrm{E}+00$ & $4.1 \mathrm{E}+02$ & 1.7E-04 \\
\hline LWA44-178 & 178 & 451.40 & 0.21 & 0.01 & - & $1.9 \mathrm{E}+05$ & $1.2 \mathrm{E}-02$ & $9.8 \mathrm{E}+04$ & 4.2E-03 & $1.6 \mathrm{E}+02$ & $1.2 \mathrm{E}-04$ & - & $0.0 \mathrm{E}+00$ & $4.6 \mathrm{E}+02$ & 1.9E-04 \\
\hline LWA44-179 & 179 & 453.86 & 0.22 & 0.01 & - & $1.8 \mathrm{E}+05$ & $1.0 \mathrm{E}-02$ & $9.6 \mathrm{E}+04$ & 3.9E-03 & $1.4 \mathrm{E}+02$ & $1.0 \mathrm{E}-04$ & - & $0.0 \mathrm{E}+00$ & $4.1 \mathrm{E}+02$ & 1.6E-04 \\
\hline LWA44-180 & 180 & 456.06 & 0.23 & 0.01 & - & $1.9 \mathrm{E}+05$ & $1.0 \mathrm{E}-02$ & $9.9 \mathrm{E}+04$ & 3.9E-03 & $1.6 \mathrm{E}+02$ & $1.1 \mathrm{E}-04$ & - & $0.0 \mathrm{E}+00$ & $4.6 \mathrm{E}+02$ & 1.7E-04 \\
\hline LWA44-181 & 181 & 458.41 & 0.23 & 0.01 & - & $1.9 \mathrm{E}+05$ & $1.0 \mathrm{E}-02$ & $9.9 \mathrm{E}+04$ & 3.9E-03 & $1.6 \mathrm{E}+02$ & $1.1 \mathrm{E}-04$ & - & $0.0 \mathrm{E}+00$ & $4.5 \mathrm{E}+02$ & 1.6E-04 \\
\hline LWA44-182 & 182 & 460.82 & 0.24 & 0.01 & - & $1.9 \mathrm{E}+05$ & $1.0 \mathrm{E}-02$ & $9.9 \mathrm{E}+04$ & 3.7E-03 & $1.6 \mathrm{E}+02$ & $1.0 \mathrm{E}-04$ & - & $0.0 \mathrm{E}+00$ & $4.1 \mathrm{E}+02$ & $1.4 \mathrm{E}-04$ \\
\hline LWA44-183 & 183 & 463.01 & 0.24 & 0.01 & - & $1.8 \mathrm{E}+05$ & 9.2E-03 & $9.7 \mathrm{E}+04$ & 3.6E-03 & $1.5 \mathrm{E}+02$ & 9.5E-05 & - & $0.0 \mathrm{E}+00$ & $3.7 \mathrm{E}+02$ & 1.3E-04 \\
\hline LWA44-184 & 184 & 465.40 & 0.22 & 0.01 & - & $1.8 \mathrm{E}+05$ & 1.1E-02 & $1.0 \mathrm{E}+05$ & 4.1E-03 & $1.7 \mathrm{E}+02$ & $1.2 \mathrm{E}-04$ & - & $0.0 \mathrm{E}+00$ & $4.6 \mathrm{E}+02$ & $1.8 \mathrm{E}-04$ \\
\hline LWA44-185 & 185 & 468.27 & 0.23 & 0.01 & - & $1.7 \mathrm{E}+05$ & 9.7E-03 & $8.8 \mathrm{E}+04$ & $3.5 \mathrm{E}-03$ & $1.4 \mathrm{E}+02$ & $1.0 \mathrm{E}-04$ & - & $0.0 \mathrm{E}+00$ & $4.3 \mathrm{E}+02$ & 1.6E-04 \\
\hline LWA44-186 & 186 & 475.25 & 0.10 & 0.10 & - & $1.8 \mathrm{E}+05$ & 2.2E-02 & $9.8 \mathrm{E}+04$ & $8.5 \mathrm{E}-03$ & $1.5 \mathrm{E}+02$ & 2.3E-04 & - & $0.0 \mathrm{E}+00$ & $4.2 \mathrm{E}+02$ & 3.5E-04 \\
\hline LWA44-187 & 187 & 481.81 & 0.07 & 0.07 & - & $1.8 \mathrm{E}+05$ & 3.3E-02 & $1.0 \mathrm{E}+05$ & $1.3 \mathrm{E}-02$ & $1.6 \mathrm{E}+02$ & 3.6E-04 & - & $0.0 \mathrm{E}+00$ & $4.6 \mathrm{E}+02$ & 5.6E-04 \\
\hline LWA44-188 & 188 & 484.04 & 0.22 & 0.01 & - & $1.8 \mathrm{E}+05$ & 1.1E-02 & $1.1 \mathrm{E}+05$ & 4.4E-03 & $2.2 \mathrm{E}+02$ & $1.6 \mathrm{E}-04$ & - & $0.0 \mathrm{E}+00$ & $6.2 \mathrm{E}+02$ & 2.4E-04 \\
\hline LWA44-189 & 189 & 486.42 & 0.23 & 0.01 & - & $1.8 \mathrm{E}+05$ & 9.9E-03 & $9.3 \mathrm{E}+04$ & $3.7 \mathrm{E}-03$ & $1.4 \mathrm{E}+02$ & $9.8 \mathrm{E}-05$ & - & $0.0 \mathrm{E}+00$ & $4.2 \mathrm{E}+02$ & 1.6E-04 \\
\hline LWA44-190 & 190 & 488.80 & 0.25 & 0.00 & - & $1.8 \mathrm{E}+05$ & $9.0 \mathrm{E}-03$ & $9.5 \mathrm{E}+04$ & $3.5 \mathrm{E}-03$ & $1.5 \mathrm{E}+02$ & $9.2 \mathrm{E}-05$ & - & $0.0 \mathrm{E}+00$ & $4.2 \mathrm{E}+02$ & $1.4 \mathrm{E}-04$ \\
\hline LWA44-191 & 191 & 491.31 & 0.22 & 0.01 & - & $3.1 \mathrm{E}+05$ & 1.8E-02 & $1.1 \mathrm{E}+05$ & 4.4E-03 & $2.2 \mathrm{E}+02$ & $1.6 \mathrm{E}-04$ & - & $0.0 \mathrm{E}+00$ & $6.3 \mathrm{E}+02$ & 2.4E-04 \\
\hline LWA44-192 & 192 & 494.69 & 0.18 & 0.18 & - & $1.7 \mathrm{E}+05$ & $1.2 \mathrm{E}-02$ & $9.1 \mathrm{E}+04$ & 4.6E-03 & $1.5 \mathrm{E}+02$ & 1.3E-04 & - & $0.0 \mathrm{E}+00$ & $4.1 \mathrm{E}+02$ & 1.9E-04 \\
\hline LWA44-193 & 193 & 497.85 & 0.26 & 0.01 & - & $1.8 \mathrm{E}+05$ & 8.6E-03 & $1.0 \mathrm{E}+05$ & 3.5E-03 & $2.3 \mathrm{E}+02$ & 1.4E-04 & - & $0.0 \mathrm{E}+00$ & $5.5 \mathrm{E}+02$ & $1.8 \mathrm{E}-04$ \\
\hline
\end{tabular}


Table B1. LAWA44 PUF Test Results

\begin{tabular}{|c|c|c|c|c|c|c|c|c|c|c|c|c|c|c|c|}
\hline Sample ID & Vial & Time & $\bar{\theta}$ & $\overline{\sigma \theta}$ & pH & [Na] & Na Rate & [Si] & Si Rate & [Ti] & Ti Rate & [Zn] & Zn Rate & {$[\mathrm{Zr}]$} & Zr Rate \\
\hline LWA44-194 & 194 & 500.39 & 0.26 & 0.00 & - & $1.9 \mathrm{E}+05$ & $8.9 \mathrm{E}-03$ & $1.1 \mathrm{E}+05$ & $3.7 \mathrm{E}-03$ & $3.0 \mathrm{E}+02$ & $1.8 \mathrm{E}-04$ & $6.1 \mathrm{E}+00$ & $1.8 \mathrm{E}-06$ & $7.9 \mathrm{E}+02$ & $2.6 \mathrm{E}-04$ \\
\hline LWA44-195 & 195 & 497.85 & 0.26 & 0.00 & - & $1.7 \mathrm{E}+05$ & 8.2E-03 & $9.9 \mathrm{E}+04$ & $3.4 \mathrm{E}-03$ & $2.7 \mathrm{E}+02$ & $1.6 \mathrm{E}-04$ & $2.4 \mathrm{E}+00$ & 7.1E-07 & $7.2 \mathrm{E}+02$ & 2.3E-04 \\
\hline LWA44-196 & 196 & 500.47 & 0.26 & 0.00 & - & $1.7 \mathrm{E}+05$ & 8.1E-03 & $9.4 \mathrm{E}+04$ & $3.2 \mathrm{E}-03$ & $2.1 \mathrm{E}+02$ & $1.2 \mathrm{E}-04$ & - & $0.0 \mathrm{E}+00$ & $5.8 \mathrm{E}+02$ & $1.9 \mathrm{E}-04$ \\
\hline LWA44-197 & 197 & 508.37 & 0.26 & 0.00 & - & $1.7 \mathrm{E}+05$ & 8.0E-03 & $9.7 \mathrm{E}+04$ & 3.3E-03 & $2.3 \mathrm{E}+02$ & $1.4 \mathrm{E}-04$ & - & $0.0 \mathrm{E}+00$ & $6.3 \mathrm{E}+02$ & $2.0 \mathrm{E}-04$ \\
\hline LWA44-198 & 198 & 514.75 & 0.26 & 0.00 & - & $1.8 \mathrm{E}+05$ & 8.5E-03 & $9.9 \mathrm{E}+04$ & $3.4 \mathrm{E}-03$ & $2.5 \mathrm{E}+02$ & $1.5 \mathrm{E}-04$ & $3.6 \mathrm{E}+00$ & $1.1 \mathrm{E}-06$ & $7.1 \mathrm{E}+02$ & 2.3E-04 \\
\hline
\end{tabular}




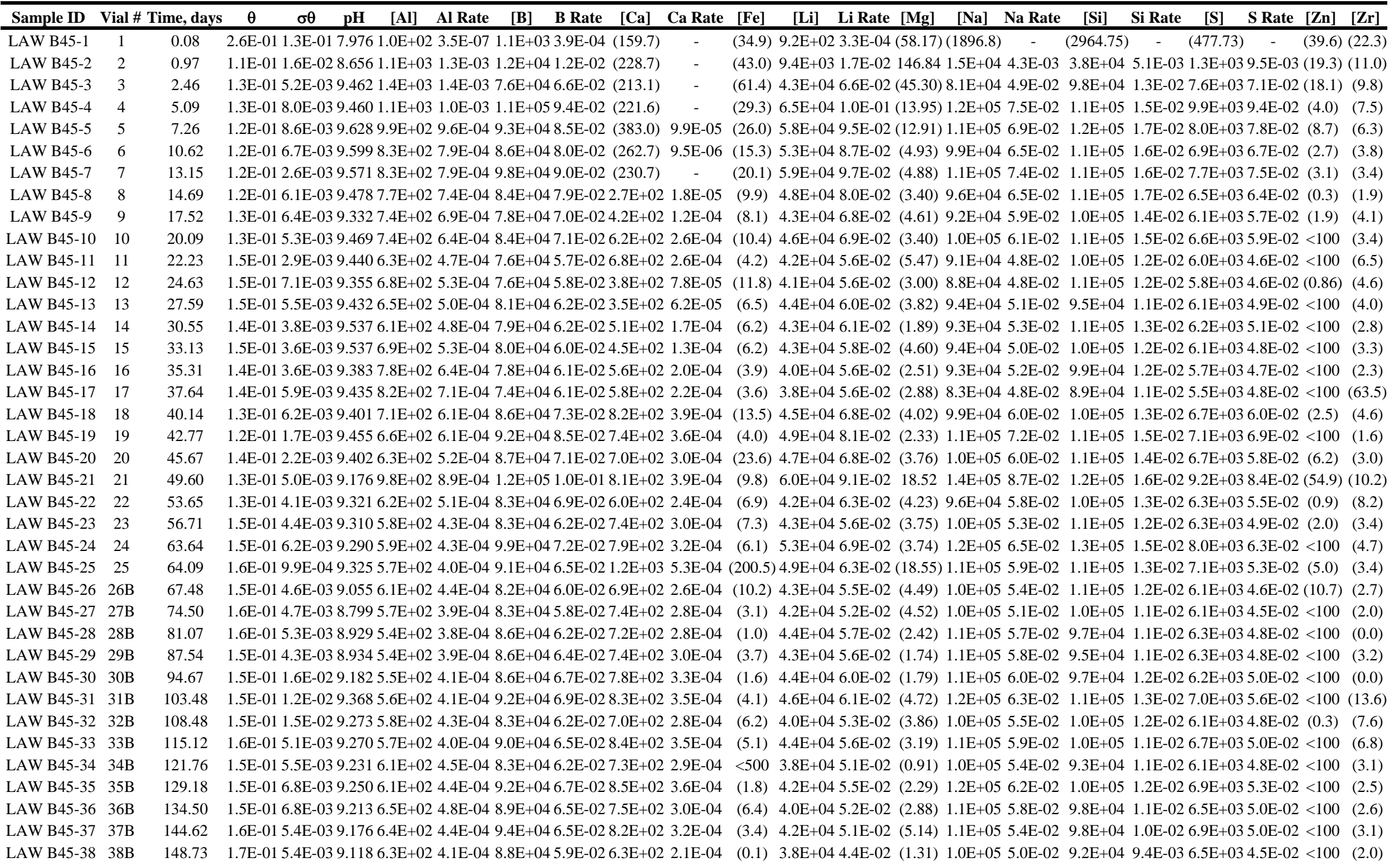




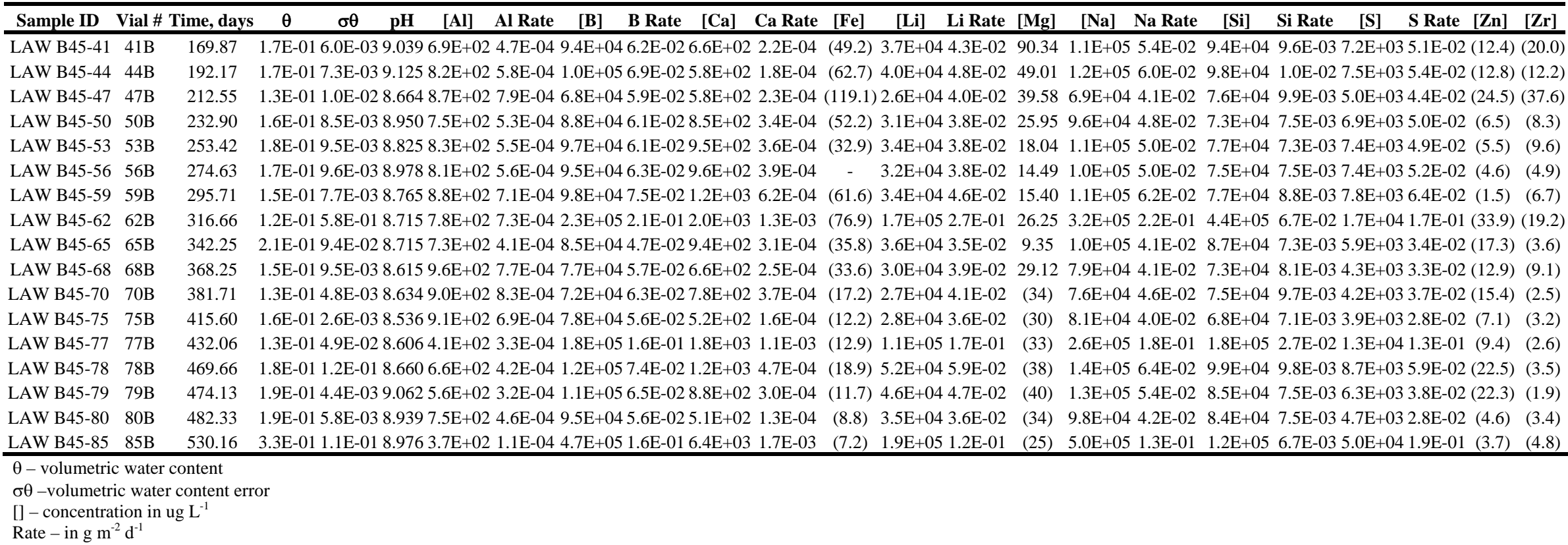




\begin{tabular}{|c|c|c|c|c|c|c|c|c|c|c|c|c|c|c|c|c|c|c|c|c|c|c|c|}
\hline San & $\pi$ & & $\theta$ & $\sigma \theta$ & $\mathrm{pH}$ & [Al] & Al Rate & [B] & Rate & [Ca] & Rate & {$[\mathrm{Fe}]$} & [Li] & Rate & [Mg] & [Na] & Rate & [Si] & $\mathbf{R a}$ & [S] & Rate & Zn] & [Zr] \\
\hline $22-1$ & $\overline{1}$ & 07 & & & 85 & 88.7) & & & & 56.6) & & $(4.4)$ & $320.2)$ & & & 6089.5) & & $\overline{-50}+4$ & & 65.27) & & $5.0)$ & 125 \\
\hline $2-2$ & 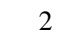 & & & & 10 & & & & & & - & 6) & 3 & & & & & & BE-03 & & E-02 & & \\
\hline $2-3$ & 3 & & & & & & & & & & - & & & & & & & & -02 & & -01 & & 15.6) \\
\hline & 4 & & & & & & & & & & - & & & & & & & & & & & & \\
\hline & 5 & & & & & & & & & & 4E- -( & & & & & & & & & & & & $5.5)$ \\
\hline & 6 & & & & & & & & & $(72.4)$ & 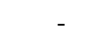 & & & & & & & & 02 & & & & 4.9) \\
\hline V C22-7 & 7 & & & & 8.935 & & $3.0 E^{-0}=$ & & & (94.4) & - & & & 3E-01 & & & $1.2 \mathrm{E}+00$ & & 3E-01 & & $E+00$ & & 5.7) \\
\hline & 8 & & & & 8.294 & & 3.5E-C & & & $5.7 \mathrm{E}$ & 2E-02 & & & $31.1 \mathrm{E}+00$ & & & & & 01 & & $E+00$ & & (3.0) \\
\hline & 0 & & & & & & & & & & & & & & & & & & & & & & 7.6) \\
\hline $2-10$ & 10 & & & & & & & & & & - & & & & & & & & 02 & & & & 2.4) \\
\hline-11 & 11 & & & & & & & & & & - & & & & & & & & & & -01 & & 4.3) \\
\hline-12 & 12 & & & & 9.245 & & & & & & - & & & OE-0? & & & & & 2.2E-02 & & E-01 & & (11.3) \\
\hline-13 & 13 & & & & & & & & & & - & & & & & & & & & & & & 7.6) \\
\hline-14 & 14 & & & & & & & & & & - & & & & & & & & 02 & & -01 & & $8.2)$ \\
\hline & 15 & & & & & & & & & & & & & & & & & & & & & & 5.4) \\
\hline-16 & 16 & & & & & & & & & & - & & & & & & & & & & -01 & & $3.2)$ \\
\hline & 1 & & & & 9.863 & & & & & & - & & & & & & & & & & -01 & & 4.2) \\
\hline & 1 & & & & & & & & & & - & & & & & & & & & & & & 3.5) \\
\hline & 19 & & & & 9. & & & & & & & & & & & & & & 2 & & -01 & & $8)$ \\
\hline-20 & 20 & & & & & & & & & & & & & & & & & & & & & & $3.5)$ \\
\hline-21 & 21 & & & & 9 & & & & & & - & & & & & & & & & & -01 & & 3.3) \\
\hline & 22 & & & & 9.606 & & & & & & - & (5.2) & & & & & & & & & -01 & 00 & 2.9) \\
\hline $2-23$ & 2 & & & & 9.4 & & & & & & - & & & & & & & & & & 01 & & (17.6) \\
\hline & 2 & & & & & & & & & & - & & & & & & & & & & -01 & & 1) \\
\hline & 25 & & & & & & & & & & & & & & & & & & & & & & $6.4)$ \\
\hline-26 & $6 B$ & & & & 9.452 & & & & & & - & 6) & 2. & 02 & & & & & 02 & & -01 & 5.1) & $6.1)$ \\
\hline $2-27$ & 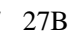 & & & & 9.267 & & & & & & - & (8.7) & & 4 7.7E-02 & (9.7) & & & & & & -02 & 9.3) & (8.2) \\
\hline $2-28$ & 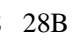 & & & & 9.543 & & & & & & 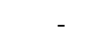 & & & & & & & & & & & 4.7) & (100.1) \\
\hline & & & & & & & & & & & & & & & & & & & & & & & $2.0)$ \\
\hline & 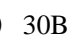 & & & & & & & & & & - & & & & & & & & & & -02 & & 7.2) \\
\hline $2-31$ & $1 \mathrm{~B}$ & & & & 9.151 & & & & & & - & & & & 4) & +05 & & & & & -02 & $2.6)$ & $6.5)$ \\
\hline $2-32$ & $32 \mathrm{~B}$ & 3.49 & $\mathrm{OF}$ - & 1.3 & 8.528 & $1.4 \mathrm{E}+$ & $3.5 \mathrm{E}$ & 4.5 & 5.4E-02 & (13. & - & (66.9) & $1.6 \mathrm{E}$ & 4 4.9E-02 & (3.6) & $1.6 \mathrm{E}+05$ & $5.1 \mathrm{E}-02$ & $1.3 \mathrm{E}+05$ & $2.0 \mathrm{E}-02$ & 2. & 5.6E-02 & 8.3) & (14.4) \\
\hline-33 & 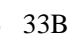 & & & & 9.307 & & & & & & - & & & & & & & & & & -02 & 0 & (21.7) \\
\hline & & & & & .00 & & & & & & - & & & & & & & & & & & & $(11.7)$ \\
\hline $2-35$ & טل & & & & 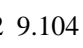 & & & & & & & 4) & & & & & & & 02 & & E-02 & 5.8) & (10.5) \\
\hline $2-36$ & $6 \mathrm{~B}$ & & 2 & 7. & 8.917 & $1.7 \mathrm{E}+03$ & 33. & $5.4 \mathrm{E}+04$ & $1.1 \mathrm{E}-01$ & $(28.0)$ & - & (6.2) & $1.4 \mathrm{E}+04$ & 4 7.2E-02 & (3.7) & $1.6 \mathrm{E}+05$ & $8.8 \mathrm{E}-02$ & $9.2 \mathrm{E}+04$ & $2.4 \mathrm{E}-02$ & $2.7 \mathrm{E}+03$ & $9.9 \mathrm{E}-02$ & $3.3)$ & $6.1)$ \\
\hline & 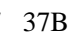 & & & & & & & & & & - & & & 4 7.3E & & & $8.0 \mathrm{~F}$ & & 2.7E-02 & & 8.3E-02 & & 6.3) \\
\hline LAW C22-38 & $38 \mathrm{~B}$ & 148.75 & $1.75=02$ & $1.5 \mathrm{E}-02$ & 8.835 & $1.5 \mathrm{E}+03$ & 2.3E-03 & $4.0 \mathrm{E}+04$ & $6.6 \mathrm{E}-02$ & (76.7) & & (18.0) & $8.9 \mathrm{E}+03$ & 3.7E-02 & (3.8) & $1 \mathrm{E}+05$ & 4.7E-02 & $6.1 \mathrm{E}+04$ & $1.2 \mathrm{E}-02$ & $2.0 \mathrm{E}+03$ & $5.8 \mathrm{E}-02$ & (45.6) & (3.8) \\
\hline
\end{tabular}


Table B3. LAWC22 PUF Test Results

\begin{tabular}{|c|c|c|c|c|c|c|c|c|c|c|c|c|c|c|c|c|c|c|c|c|c|}
\hline ID & Vial & ys & $\sigma \theta$ & pH & [Al] & Al Rate & [B] & B Rate & [Ca] & Ca Rate & {$[\mathrm{Fe}]$} & [Li] & Li Rate [Mg] & [Na] & Na Rate & [Si] & Si Rate & [S] & S Rate & [Zn] & [Zr] \\
\hline LAW C22-41 & $41 \mathrm{~B}$ & 169.88 & 6.4E-02 6.5E-03 & 8.906 & $2.0 \mathrm{E}+03$ & $3.6 \mathrm{E}-03$ & $5.1 \mathrm{E}+04$ & 4 9.7E-02 & (35.5) & - & (26.9) & $1.3 \mathrm{E}+04$ & 4 6.3E-02 (16 & $1.5 \mathrm{E}+05$ & 7.7E-02 & $8.4 \mathrm{E}+04$ & $2.0 \mathrm{E}-02$ & $2.4 \mathrm{E}+03$ & 8.2E-02 & (5.5) & (11.5) \\
\hline LAW C22-44 & $44 \mathrm{~B}$ & 192.18 & 1.1 & 9.094 & $2.2 \mathrm{E}+03$ & & & 4 6.4E-02 & (68.0) & $\begin{array}{ll}- & - \\
\end{array}$ & (1.0) & & 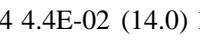 & & 5.3E-02 & $9.9 \mathrm{E}+04$ & 1.4E-02 & $2.6 \mathrm{E}+03$ & $5.4 \mathrm{E}-02$ & (2.3) & (9.3) \\
\hline LAW C22-47 & $47 \mathrm{~B}$ & 215.08 & & 38 & & 2.2 & & 48.0 & 850.09 & $7 \mathrm{E}-$ & ( & & 5) & $1.5 \mathrm{E}+05$ & -02 & $1.3 \mathrm{E}+05$ & 5.5E-03 & $1.7 \mathrm{E}+03$ & $9.1 \mathrm{E}-03$ & (68.3) & (18.8) \\
\hline LAW C22-50 & $50 \mathrm{~B}$ & 233.12 & $1.1 \mathrm{E}$ & 9.264 & $2.2 \mathrm{E}+03$ & $2.2 \mathrm{E}$ & & 4 5.1E-02 & (135.0) & - & $(8.0)$ & 1 & $(12.9)$ & $1.3 \mathrm{E}+05$ & $3.8 \mathrm{E}-02$ & $8.3 \mathrm{E}+04$ & $1.2 \mathrm{E}-02$ & $1.8 \mathrm{E}+03$ & $3.2 \mathrm{E}-02$ & $<100$ & (9.1) \\
\hline LAW C22-53 & $53 \mathrm{~B}$ & 253.43 & $1.5 \mathrm{E}-011.1 \mathrm{E}-02$ & 9.273 & $2.1 \mathrm{E}+03$ & 1.6E-03 & $4.6 \mathrm{E}+04$ & 4 3.8E-02 & (99.0) & - & (29.4) & $1.4 \mathrm{E}$ & 4 2.9E-02 (8.9) & $1.4 \mathrm{E}+05$ & $3.2 \mathrm{E}-02$ & $9.9 \mathrm{E}+04$ & $1.1 \mathrm{E}-02$ & $2.5 \mathrm{E}+03$ & 3.9E-02 & (3.5) & (8.6) \\
\hline LAW C22-56 & $56 \mathrm{~B}$ & 274.64 & $1.5 \mathrm{~B}$ & 9. & $2.0 \mathrm{I}$ & 31. & $5.0 \mathrm{E}$ & 44.1 & (111.5) & - & $(40.1)$ & & $02(9.2)$ & 05 & $3.3 \mathrm{E}-02$ & $9.6 \mathrm{E}+04$ & $1.0 \mathrm{E}-02$ & $2.4 \mathrm{E}+03$ & 3.7E-02 & (1.8) & $(10.2)$ \\
\hline LAW C22-59 & $59 \mathrm{~B}$ & 295.73 & 1.1 & 9. & 1.9 & & & 46.4 & $(15$ & - & (38 & & 5) & & 02 & $1.0 \mathrm{E}+05$ & $1.5 \mathrm{E}-02$ & $2.6 \mathrm{E}+03$ & $5.5 \mathrm{E}-02$ & (10.4) & (10.3) \\
\hline LAW C22-62 & $62 \mathrm{~B}$ & 316.67 & $6.8 \mathrm{E}-027.7 \mathrm{I}$ & 9. & $2.1 \mathrm{E}$ & & & 41.1 & (126.1) & 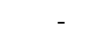 & $(26.2)$ & 1.6 & $02(7.8)$ & $1.7 \mathrm{E}+05$ & 8.6 & $9.8 \mathrm{E}+04$ & 2.3E-02 & $3.0 \mathrm{E}+03$ & $1.0 \mathrm{E}-01$ & (1.4) & (9.6) \\
\hline LAW C22-65 & $65 B$ & 339.29 & $1.2 \mathrm{E}-011.1 \mathrm{E}-02$ & 9.729 & $2.1 \mathrm{E}+03$ & 31.9 & $9.6 \mathrm{E}$ & 4 9.8E-02 & (197.2) & - & (74.8) & $2.2 \mathrm{E}$ & $02(19.7)$ & $2.6 \mathrm{E}+05$ & $7.4 \mathrm{E}-02$ & $1.1 \mathrm{E}+05$ & $1.5 \mathrm{E}-02$ & $4.4 \mathrm{E}+03$ & $9.0 \mathrm{E}-02$ & $<100$ & (7.1) \\
\hline LAW C22-68 & $68 \mathrm{~B}$ & 368.26 & $1.1 \mathrm{E}-011.1 \mathrm{E}-02$ & 9.629 & $1.8 \mathrm{E}+03$ & $31.8 \mathrm{I}$ & $8.7 \mathrm{E}^{+}$ & 4 9.4E-02 & (215.0) & - & (58.9) & $2.0 \mathrm{E}$ & 45.5 & $2.4 \mathrm{E}+05$ & 7.1E-02 & $1.0 \mathrm{E}+05$ & $1.4 \mathrm{E}-02$ & $3.9 \mathrm{E}+03$ & $8.4 \mathrm{E}-02$ & (4.6) & (13.6) \\
\hline LAW C22-70 & $70 \mathrm{~B}$ & 381.72 & $1.1 \mathrm{E}-016.0 \mathrm{E}-03$ & 9.788 & $1.8 \mathrm{E}+03$ & 31.7 & $1.4 \mathrm{E}$ & 5 1.5E-01 & 333.64 & 7.7E-05 & (8.5) & $2.7 \mathrm{E}-$ & 4 7.8E-02 (29 & $3.5 \mathrm{E}+05$ & $1.1 \mathrm{E}-01$ & $1.0 \mathrm{E}+05$ & $1.5 \mathrm{E}-02$ & $6.6 \mathrm{E}+03$ & $1.5 \mathrm{E}-01$ & (20.3) & (1.3) \\
\hline AW & 75B & 415.61 & 1.2 & 10. & $1.6 \mathrm{E}$ & 31. & $1.8 \mathrm{~F}$ & 51.9 & 353.40 & $9.2 \mathrm{E}-05$ & (9.7) & $3.6 \mathrm{E}+04$ & 49. & $4.7 \mathrm{E}+05$ & $1.4 \mathrm{E}-01$ & $1.2 \mathrm{E}+05$ & 1.6E-02 & $7.9 \mathrm{E}+03$ & $1.8 \mathrm{E}-01$ & (8.2) & $(0.6)$ \\
\hline-77 & $77 \mathrm{~B}$ & 429.63 & $1.1 \mathrm{E}$ & 0.1 & 1.4 & 31.4 & $2.0 \mathrm{E}$ & 52.2 & 309.22 & $5.5 \mathrm{E}-0$ & 75. & $4.0 \mathrm{t}$ & (3 & 05 & $1.7 \mathrm{E}-01$ & $1.4 \mathrm{E}+05$ & $2.1 \mathrm{E}-02$ & $8.7 \mathrm{E}+03$ & 2.1E-01 & (51.3) & (36.9) \\
\hline LAW C22-78 & 78B & 465.14 & 2.5E-01 4.3E-01 & 9.902 & $8.4 \mathrm{E}+02$ & 3.5E-04 & $1.9 \mathrm{E}+05$ & 5 9.0E-02 & 278.15 & $1.2 \mathrm{E}-05$ & (15.9) & $4.6 \mathrm{E}+04$ & 4 5.9E-02 (27.3) & $5.4 \mathrm{E}+05$ & 7.6E-02 & $1.6 \mathrm{E}+05$ & 1.0E-02 & $2.5 \mathrm{E}+04$ & 2.7E-01 & $(28.0)$ & (8.9) \\
\hline LAW C22-79 & $79 \mathrm{~B}$ & 476.14 & 3.2E-01 1.4E-01 & 9.518 & $6.0 \mathrm{E}+02$ & 1.8E-04 & $1.6 \mathrm{E}+05$ & 5 6.0E-02 & $(99.0)$ & - & (12.9) & $5.0 \mathrm{E}+04$ & 4 5.0E-02 (16.6) & $5.5 \mathrm{E}+05$ & $6.0 \mathrm{E}-02$ & $2.5 E+05$ & $1.3 \mathrm{E}-02$ & $3.1 \mathrm{E}+04$ & 2.7E-01 & (8.4) & $(21.2)$ \\
\hline LAW C22-80 & $80 \mathrm{~B}$ & 484.79 & 4.0E-01 2.0E-02 & 9.446 & $2.0 \mathrm{E}+02$ & $2.9 \mathrm{E}-05$ & $2.3 \mathrm{E}+05$ & 5 6.9E-02 & $(76.4)$ & - & $(6.5)$ & $6.1 \mathrm{E}+04$ & 4 4.9E-02 (19.2) & $6.0 \mathrm{E}+05$ & $5.2 \mathrm{E}-02$ & $1.6 \mathrm{E}+05$ & $6.4 \mathrm{E}-03$ & $3.5 \mathrm{E}+04$ & $2.4 \mathrm{E}-01$ & $(11.2)$ & $(15.2)$ \\
\hline
\end{tabular}

$\theta$ - volumetric water content

$\sigma \theta$-volumetric water content error

[] - concentration in ug $\mathrm{L}^{-1}$

Rate - in $\mathrm{g} \mathrm{m}^{-2} \mathrm{~d}^{-1}$ 


\begin{tabular}{|c|c|c|c|c|c|c|c|c|c|c|c|c|c|c|c|c|}
\hline Sample ID & Vial \# & ime, days & $\theta$ & $\sigma \theta$ & pH & [Al] & Al Rate & B Rate & [Ca] & Ca Rate & {$[\mathrm{K}]$} & K Rate & {$[\mathrm{Li}]$} & Li Rate & [Na] & Na Rate \\
\hline LAW AN102-1 & 1 & 0.18 & $1.4 \mathrm{E}-01$ & $9.6 \mathrm{E}-02$ & 12.2857 & $1.8 \mathrm{E}+03$ & 3 1.4E-03 & $2.2 \mathrm{E}+03 \quad 1.7 \mathrm{E}-03$ & (84.2) & - & - & - & $1.8 \mathrm{E}+03$ & $32.8 \mathrm{E}-03$ & $1.2 \mathrm{E}+04$ & $48.1 \mathrm{E}-04$ \\
\hline LAW AN102-2 & 2 & 91 & & & & & 3 1.7E-03 & $1.1 \mathrm{E}+046$ & $(142.5)$ & - & - & - & $.7 E+03$ & 3 1.1E-02 & $4.6 \mathrm{E}+04$ & $47.6 \mathrm{E}-03$ \\
\hline LAW AN102-3 & 3 & 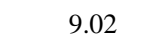 & & & & & 3 9.4E-04 & $1.9 \mathrm{E}+042.1 \mathrm{E}-02$ & (101.9) & - & 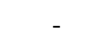 & 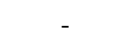 & & & $5.6 \mathrm{E}+04$ & 4 1.9E-02 \\
\hline LAW AN102-4 & 4 & .83 & 3E-01 & 3.2E-02 & 9.7519 & $6.1 \mathrm{E}+02$ & 2 4.4E-04 & $6.1 \mathrm{E}+04$ 5.6E-02 & $1.3 \mathrm{E}+03$ & 6.5E-04 & - & - & $4 \mathrm{E}+04$ & 4 5.2E-02 & $1.5 \mathrm{E}+05$ & 4.8E-02 \\
\hline LAW AN102-5 & 5 & 15.87 & $1.0 \mathrm{E}-01$ & $1.3 \mathrm{E}-02$ & 9.6756 & $9.9 \mathrm{E}+02$ & 2 9.8E-04 & 8.7E+04 9.9E-02 & $9.2 \mathrm{E}+02$ & 5.4E-04 & - & - & $3.9 \mathrm{E}+04$ & 4 1.1E-01 & $2.3 \mathrm{E}+05$ & 5 9.3E-02 \\
\hline LAW AN102-6 & 6 & 7.34 & $1 \mathrm{E}-01$ & $2.4 \mathrm{E}$ & 9.3195 & $1.2 \mathrm{E}+03$ & 3 1.2E-03 & $5.2 \mathrm{E}+04$ 5.6E-02 & $4.1 \mathrm{E}+02$ & $1.2 \mathrm{E}-04$ & - & - & $2.2 \mathrm{E}+04$ & & $1.4 \mathrm{E}+05$ & 5.3E-02 \\
\hline LAW AN102-7 & 7 & .96 & & & 9.02 & $1.6 \mathrm{E}+03$ & 3 7.6E-04 & $6.7 \mathrm{E}+043.6$ & $1.8 \mathrm{E}+03$ & 5.7E-04 & - & - & & & $2.0 \mathrm{E}+05$ & 3.9E-02 \\
\hline LAW AN102-8 & 8 & .96 & $.0 \mathrm{E}-$ & & 9.4324 & $1.9 \mathrm{E}+03$ & 3 2.6E-03 & $4.0 \mathrm{E}+045.9$ & $8.7 \mathrm{E}+02$ & $6.5 \mathrm{E}-04$ & - & - & $2.1 \mathrm{E}+04$ & 47.7 & $1.3 \mathrm{E}+05$ & 6.6E-02 \\
\hline LAW AN102-9 & 9 & & $6 \mathrm{E}-$ & & 9.3851 & $1.7 \mathrm{E}+03$ & 3 2.1E-03 & $4.4 \mathrm{E}+046.1 \mathrm{l}$ & $6.2 \mathrm{E}+02$ & $3.6 \mathrm{E}-04$ & - & - & $2.0 \mathrm{E}+04$ & & $1.2 \mathrm{E}+05$ & 5.7E-02 \\
\hline LAW AN102-10 & 10 & 27.89 & $9.0 \mathrm{E}-02$ & $2.2 \mathrm{E}-03$ & 9.3035 & $1.7 \mathrm{E}+03$ & $32.0 \mathrm{E}-03$ & $4.2 \mathrm{E}+045.5 \mathrm{E}-02$ & $4.7 \mathrm{E}+02$ & 2.0E-04 & - & - & $1.9 \mathrm{E}+04$ & 4 6.0E-02 & $1.1 \mathrm{E}+05$ & $5.0 \mathrm{E}-02$ \\
\hline LAW AN102-11 & 11 & .80 & $8.8 \mathrm{E}-02$ & & 9.8567 & $1.7 \mathrm{E}+03$ & 3 2.1E-03 & $4.0 \mathrm{E}$ & & 9.3E-05 & - & - & & & $1.1 \mathrm{E}+05$ & 4.9E-02 \\
\hline LAW AN102-12 & 12 & 3 & $9.0 \mathrm{~F}$ & & 9.7 & $1.5 \mathrm{E}$ & 3 1.8E-03 & 3.8 & 02 & $1.5 \mathrm{E}-04$ & - & - & $1.6 \mathrm{E}+04$ & 45. & $9.7 \mathrm{E}+04$ & $4 \quad 4.4 \mathrm{E}-02$ \\
\hline LAW A & 13 & & $9.3 \mathrm{~F}$ & & 10. & $1.6 \mathrm{I}$ & 3 1.8E-03 & 4.21 & & $1.2 \mathrm{E}-04$ & & - & & & +05 & 4.5E-02 \\
\hline $102-14$ & 14 & .03 & $9.0 \mathrm{E}$ & $1.9 \mathrm{E}$ & 9.5 & $1.6 \mathrm{E}+03$ & 3 1.9E-03 & $3.9 \mathrm{E}+04$ 5.2E-02 & $3.8 \mathrm{E}+02$ & $1.2 \mathrm{E}-04$ & - & - & $1.6 \mathrm{E}+04$ & & $9.9 \mathrm{E}+04$ & $4 \quad 4.4 \mathrm{E}-02$ \\
\hline $102-15$ & 15 & -0 & $90 \mathrm{~F}$ & & 9.3221 & $1.5 \mathrm{E}+03$ & 3 1.8E-03 & $3.6 \mathrm{E}$ & & 5.1E-05 & - & - & & & +04 & $4 \quad 3.8 \mathrm{E}-02$ \\
\hline $2-16$ & 16 & .97 & 9.1 & & 9.2 & $1.4 \mathrm{H}$ & 3 1.7E-03 & 4.0 & & 3.51 & - & - & & & & 4 4.3E-02 \\
\hline LAW A & 17 & & $9.1 \mathrm{~F}$ & & 9.3 & $1.6 \mathrm{H}$ & 3 1.9E-03 & 045. & 2 & $1.2 \mathrm{E}$ & - & 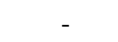 & +04 & 44. & +04 & $4 \quad 4.0 \mathrm{E}-02$ \\
\hline LAW A & 18 & & $8.6 \mathrm{H}$ & & & $1.5 \mathrm{E}+03$ & 31.9 & -045. & 02 & $1.0 \mathrm{E}$ & - & - & 504 & & +04 & 4 3.9E-02 \\
\hline $02-19$ & 19 & .92 & 75 & & & $1.5 \mathrm{E}+03$ & $32.1 \mathrm{E}-03$ & $3.4 \mathrm{~F}$ & 02 & $1.4 \mathrm{E}-04$ & - & - & & & $8.1 \mathrm{E}+04$ & 4 4.3E-02 \\
\hline $102-20$ & 20 & 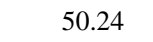 & 7.81 & 2.1 & 9.3853 & $1.5 \mathrm{E}+03$ & 3 2.1E-03 & $3.7 \mathrm{E}$ & $3.6 \mathrm{E}+02$ & $1.2 \mathrm{E}-04$ & - & - & & 2 & $8.8 \mathrm{E}+04$ & 4 4.5E-02 \\
\hline LAW AN102-21 & 21 & - & $7.9 \mathrm{~F}$ & $1.4 \mathrm{E}$ & 9.3077 & $1.5 \mathrm{E}+03$ & 3 2.1E-03 & 3.61 & (194.4) & - & - & - & & 4 & $8.2 \mathrm{E}+04$ & $4 \quad 4.1 \mathrm{E}-02$ \\
\hline LAW AN102-22 & 22 & & $8.2 \mathrm{E}$ & & 9.2793 & $1.5 \mathrm{E}+03$ & 3 2.0E-03 & $3.4 \mathrm{E}+044$ & 02 & $1.1 \mathrm{E}$ & - & - & +04 & 44 & +04 & 4 3.7E-02 \\
\hline LAW A & 23 & & 8.31 & & 9.1 & 1.6 & 32.1 & 3.4 & 02 & $8.0 \mathrm{E}$ & - & - & 504 & 44 & +04 & 4 3.8E-02 \\
\hline LAW A & 24 & & 8. & & 9.1 & $1.6 \mathrm{E}+03$ & $32.1 \mathrm{E}-03$ & $3.4 \mathrm{E}$ & $3.2 \mathrm{E}+02$ & $6.8 \mathrm{E}-05$ & - & - & +04 & 2 & $7.7 \mathrm{E}+04$ & $43.6 \mathrm{E}-02$ \\
\hline LAW A & 25 & & $8.6 \mathrm{H}$ & & 8.9 & $1.6 \mathrm{E}+03$ & 3 2.0E-03 & 3.2 & $4.0 \mathrm{E}+02$ & $1.4 \mathrm{E}-04$ & - & - & +04 & 43. & $7.3 \mathrm{E}+04$ & 4 3.3E-02 \\
\hline LAW AN102-26 & 26 & 0 & $9.0 \mathrm{E}-$ & 3.3 & 8.9757 & $1.6 \mathrm{E}+03$ & 3 2.0E-03 & $3.2 \mathrm{E}+04$ 4.2E-02 & $3.5 \mathrm{E}+02$ & $9.3 \mathrm{E}-05$ & - & - & +04 & 4 3.2E-02 & $7.2 \mathrm{E}+04$ & $4 \quad 3.1 \mathrm{E}-02$ \\
\hline $2-27$ & 27 & & & & & & & 3.2 & & $7.0 \mathrm{E}-05$ & - & - & +04 & 43.2 & +04 & 4 3.1E-02 \\
\hline-30 & 30 & 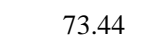 & 8.8 & 2 & 8.8 & $5.0 \mathrm{E}+03$ & 3 5.9E-03 & $3.4 \mathrm{E}$ & 9) & - & $3.6 \mathrm{E}+04$ & $9 \mathrm{E}-01$ & +03 & 02 & +04 & 4 3.3E-02 \\
\hline LAW A & 33B & 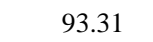 & $9.0 \mathrm{E}-02$ & 02 & 8.7587 & $1.4 \mathrm{E}+03$ & 3 1.2E-03 & $3.4 \mathrm{E}+04$ 4.2E-02 & (786.8) & - & $2.8 \mathrm{E}+0$ & E-02 & -04 & & +04 & 4 3.7E-02 \\
\hline LAW A & $36 \mathrm{~B}$ & 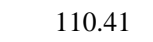 & $9.4 \mathrm{E}-02$ & $3.4 \mathrm{E}-03$ & 8.4247 & $5.6 \mathrm{E}+03$ & 3 6.2E-03 & 3.3E+04 3.9E-02 & (748.1) & - & $4.5 \mathrm{E}+04$ & 4 5.1E-01 & +03 & & $6.1 \mathrm{E}+04$ & 4 2.9E-02 \\
\hline $2-39$ & 391 & & $9.6 \mathrm{E}-02$ & & 8.5 & $2.1 \mathrm{E}+03$ & $32.0 \mathrm{E}-03$ & $3.3 \mathrm{E}+04$ 3.9E- & & - & $4.3 \mathrm{E}+04$ & $4.4 \mathrm{E}$ & 03 & & $6.3 \mathrm{E}+04$ & 4 2.9E-02 \\
\hline LAW A & $42 \mathrm{~B}$ & & $1.2 \mathrm{E}-01$ & 7. & 8.1638 & $2.1 \mathrm{E}+03$ & 3 1.5E-03 & $3.5 \mathrm{E}+043.2$ & (589.8) & - & $4.5 \mathrm{E}+04$ & 4 3.8E-01 & +03 & 31.6 & +04 & $42.5 \mathrm{E}-02$ \\
\hline $102-45$ & $45 B$ & 170.31 & $1.3 \mathrm{E}-01$ & 7.3E-03 & 8.3527 & $2.1 \mathrm{E}+03$ & 3 1.4E-03 & $3.6 \mathrm{E}+04$ 3.1E-02 & (587.3) & - & $4.9 \mathrm{E}+04$ & 4 4.2E-01 & +03 & 3 1.6E-02 & $7.5 \mathrm{E}+04$ & 4 2.5E-02 \\
\hline LAW AN102-48 & $48 \mathrm{~B}$ & 1.38 & $1.5 \mathrm{E}-01$ & $1.0 \mathrm{E}-02$ & 8.2165 & $2.7 \mathrm{E}+03$ & 3 1.6E-03 & $3.8 \mathrm{E}+04$ 2.8E-02 & $1.2 \mathrm{E}+03$ & $1.4 \mathrm{E}-04$ & $5.2 \mathrm{E}+04$ & 4 4.2E-01 & $8.2 \mathrm{E}+03$ & 3 1.4E-02 & $7.9 \mathrm{E}+04$ & 4 2.3E-02 \\
\hline $02-51$ & $51 B$ & & $1.7 \mathrm{E}-01$ & 7.5E-03 & 8.8967 & $1.7 \mathrm{E}+03$ & 3 8.4E-04 & $5.2 \mathrm{E}+04$ 3.5E-02 & (864.6) & - & $6.9 \mathrm{E}+04$ & 4 6.1E- & $1.6 \mathrm{E}+04$ & $42.5 \mathrm{E}-$ & $1.3 \mathrm{E}+05$ & 3.6E-02 \\
\hline $2-54$ & $54 \mathrm{~B}$ & & 1.61 & & 9.21 & $2.2 \mathrm{E}+03$ & $31.1 \mathrm{E}-03$ & $3.5 \mathrm{E}+042.4 \mathrm{E}-02$ & & - & & & +03 & & $8.2 \mathrm{E}+04$ & 4 2.2E-02 \\
\hline $02-56$ & $56 \mathrm{~B}$ & & $1.5 \mathrm{E}-01$ & -03 & 8.0316 & $2.1 \mathrm{E}+03$ & 3 1.2E-03 & 3.3E+04 2.5E-02 & & - & $5.9 \mathrm{E}+04$ & 4 5.3E-01 & +03 & 31.4 & $6.9 \mathrm{E}+04$ & $42.0 \mathrm{E}-02$ \\
\hline LAW AN102-60 & $60 \mathrm{~B}$ & 285.04 & $1.9 \mathrm{E}-01$ & $8.1 \mathrm{E}-03$ & 8.8593 & $1.9 \mathrm{E}+03$ & 3 8.3E-04 & $3.6 \mathrm{E}+04$ 2.1E-02 & (578.6) & - & $5.0 \mathrm{E}+04$ & 4 3.1E-01 & $8.8 \mathrm{E}+03$ & 3 1.2E-02 & $8.3 \mathrm{E}+04$ & 4 1.9E-02 \\
\hline LAW AN102-65 & $65 B$ & 318.55 & 2.3E-01 & $3.1 \mathrm{E}-03$ & 8.6663 & $1.7 \mathrm{E}+03$ & 3 5.8E-04 & 4.6E+04 2.3E-02 & (542.4) & - & $3.7 \mathrm{E}+04$ & 4 1.2E-01 & $9.5 \mathrm{E}+03$ & 3 1.1E-02 & $9.7 \mathrm{E}+04$ & $41.9 \mathrm{E}-02$ \\
\hline $2-70$ & $70 \mathrm{~B}$ & & $2.4 \mathrm{E}-01$ & $1.3 \mathrm{E}-02$ & 8.8846 & $2.3 \mathrm{E}+03$ & 3 8.4E-04 & $5.7 \mathrm{E}+04$ 2.7E-02 & (865.5) & - & $4.8 \mathrm{E}+04$ & 4 2.3E-C & $1.4 \mathrm{E}+04$ & 4 1.6E- & $1.3 \mathrm{E}+05$ & 2.4E-02 \\
\hline LAW AN102-73 & $73 B$ & 396.57 & $2.8 \mathrm{E}-01$ & $6.6 \mathrm{E}-03$ & 9.0630 & $2.1 \mathrm{E}+03$ & $36.5 \mathrm{E}-04$ & $3.6 \mathrm{E}+041.4 \mathrm{E}-02$ & (291.8) & - & $1.9 \mathrm{E}+04$ & $4-5.2 \mathrm{E}-02$ & $1.3 \mathrm{E}+04$ & 4 1.2E-02 & $9.6 \mathrm{E}+04$ & $41.5 \mathrm{E}-02$ \\
\hline
\end{tabular}


Table B4. LAWAN102 PUF Test Results

\begin{tabular}{|c|c|c|c|c|c|c|c|c|c|c|c|c|c|c|c|c|c|}
\hline Sample ID & Vial \# & ays & $\theta$ & $\sigma \theta$ & pH & [AI] & Al Rate & [B] & B Rate & [Ca] & Ca Rate & [K] & K Rate & [Li] & Li Rate & [Na] & Na Rate \\
\hline & $75 B$ & & $9 \mathrm{~F}$ & & 876 & 3 & -04 & 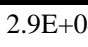 & -02 & (356.8) & - & $-5 \pi$ & & 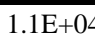 & -0 & 4 & 44 \\
\hline LA & $80 \mathrm{~B}$ & & 2.8 & 2 & 8.9797 & 03 & 04 & $3.2 \mathrm{~F}$ & 02 & (367.3) & ) & 4. & & $2 \mathrm{E}+02$ & -02 & $8.4 \mathrm{E}+04$ & .3E-02 \\
\hline LAW AN102-84 & $84 \mathrm{~B}$ & 473.52 & 2.7E-01 & $2.9 \mathrm{E}-03$ & 8.6410 & $2.1 \mathrm{E}+03$ & $36.6 \mathrm{E}-04$ & $2.5 \mathrm{E}+0$ & 4 1.0E-02 & (272.5) & - & $3.5 \mathrm{E}+0$ & $48.8 \mathrm{E}-02$ & $7.3 \mathrm{E}+03$ & 3 6.7E-03 & $5.4 \mathrm{E}+04$ & $48.7 \mathrm{E}-03$ \\
\hline
\end{tabular}

LAW AN102-84 84B

$\theta$-volumetric water content

$\sigma \theta$-volumetric water content error

[] - concentration in ug $\mathrm{L}^{-1}$

Rate - in $\mathrm{g} \mathrm{m}^{-2} \mathrm{~d}^{-1}$ 
Table B4. LAWAN102 PUF Test Results

\begin{tabular}{|c|c|c|c|c|c|c|c|c|c|c|c|c|}
\hline Sample ID & Vial \# " & Time, days & $\sigma \theta$ & pH & [Si] & Si Rate & [S] & S Rate & {$\left[{ }^{99} \mathrm{Tc}\right]^{9}$} & ${ }^{99}$ Tc Rate & [U] & U Rate \\
\hline LAW AN102-1 & 1 & 0.18 & 1.4E-01 9.6E-0 & 2857 & $1.5 \mathrm{E}+04$ & 4 5.8E-04 & $(446.5)$ & - & $(0.015)$ & - & $1.5 \mathrm{E}-02$ & - \\
\hline LAW AN102-2 & 2 & 0.91 & 2.1E-01 3.1E- & 10.0623 & $4.8 \mathrm{E}+04$ & $43.0 \mathrm{E}-$ & $2.5 \mathrm{E}+03$ & 2.9E-02 & 2 1.2E-01 & 2.5E-03 & 3.5E-02 & - \\
\hline LAW AN102-3 & 3 & 9.02 & 1 & 10 & & & & $31.5 \mathrm{E}-01$ & 1E-01 & 1.0E-02 & 4.5E-02 & 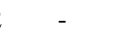 \\
\hline LAW AN102-4 & 4 & 14.83 & 1.3 & & & & & 44 & E-01 & 4.2E-02 & 1.6 & $6 \mathrm{E}-$ \\
\hline LAW AN102-5 & 5 & 15.87 & $1.0 \mathrm{E}-$ & 9.6756 & $1.4 \mathrm{E}+05$ & & & $46.9 \mathrm{E}$ & E-01 & 6.5E-02 & & \\
\hline LAW AN102-6 & 6 & 17.34 & $1.1 \mathrm{E}-012.4 \mathrm{E}$ & 195 & $1.1 \mathrm{E}+05$ & & & $7 \mathrm{E}$ & E-01 & 3.5E-02 & 2.4 & \\
\hline LAW AN102-7 & 7 & 20.96 & 2.2E-01 7.7E- & 9.0207 & $1.5 \mathrm{E}+05$ & & $1.8 \mathrm{E}-$ & 42.4E-01 & $4 \mathrm{E}-01$ & 2.3E-02 & 5.4 & 85E-04 \\
\hline LAW AN102-8 & 8 & 22.96 & $8.0 \mathrm{E}$ & 9. & & & & 3.0E-01 & 14.7E-01 & 3.9E-02 & & $1.14 \mathrm{E}-03$ \\
\hline LAW AN102-9 & 9 & 24.37 & $8.6 \mathrm{E}-$ & 51 & $1.1 \mathrm{I}$ & & & $3.9 \mathrm{E}$ & -01 & 4.1E-02 & & 17E-03 \\
\hline LAW AN102-10 & 10 & 7.89 & 9.0 & 35 & & & & JE & -01 & 3.7E-02 & & $13 \mathrm{E}-03$ \\
\hline LAW AN102-11 & 11 & 29.80 & $8.8 \mathrm{E}$ & 567 & & & & $7 \mathrm{E}-02$ & E-01 & 3.6E-02 & & 17E-03 \\
\hline LAW AN102-12 & 12 & 31.33 & $9.0 \mathrm{E}-$ & 9.7612 & 9.31 & & & 38.5E-02 & E-01 & 3.2E-02 & & $8.42 \mathrm{E}-04$ \\
\hline LAW AN102-13 & 313 & 34.54 & 9.3 & & & & & 8.1E-02 & E-01 & 3.5E-02 & 3.2 & 8.99E-04 \\
\hline LAW AN102-14 & 14 & 36.03 & 9.0 & & & & & 85 & -01 & 3.6E-02 & & 02E-03 \\
\hline $2-15$ & 15 & 50 & & & & & & 30.65 & 01 & 3.3E-02 & & \\
\hline LAW AN102-16 & 16 & 40.97 & $9.1 \mathrm{E}$ & 9. & 8.9 & & & 6.6E-02 & -01 & 3.6E-02 & & -04 \\
\hline LAW AN102-17 & 77 & 44.15 & $9.1 \mathrm{E}-$ & 9.38 & 8.8 & & 2.2 & $3.5 \mathrm{E}$ & -01 & 2.9E-02 & & -04 \\
\hline LAW AN102-18 & 318 & 45.51 & $8.6 \mathrm{E}$ & 9.2 & 8.2 & & 2.2 & $36.1 \mathrm{E}$ & E-01 & 3.4E-02 & 3.0 & $8.75 \mathrm{E}-04$ \\
\hline LAW AN102-19 & 19 & 47.92 & 7.5 & 50 & 7.9 & & & $4 \mathrm{E}$ & -01 & 3.6E-02 & & 04 \\
\hline LAW AN1 & 20 & 50.24 & & & & & & 37 & -01 & 3.7 & & -04 \\
\hline LAW AN102-21 & 21 & 52.56 & 7.5 & & 8.1 & & & $6.2 \mathrm{E}$ & -01 & 3.6E-02 & & 71E-04 \\
\hline LAW AN102-22 & 22 & 54.94 & $8.2 \mathrm{E}$ & 9.2793 & $7.4 \mathrm{I}$ & 41.3 & 2.0 & $3.6 \mathrm{E}$ & 2 4.2E-01 & 3.3E-02 & & $9.41 \mathrm{E}-04$ \\
\hline LAW AN102-23 & 323 & 57.07 & $8.3 \mathrm{E}-021.2 \mathrm{E}-$ & 9.1932 & 7.4 & 41.3 & & $36.0 \mathrm{E}$ & $24.2 \mathrm{E}-01$ & 3.3E-02 & 2.8 & $8.40 \mathrm{E}-04$ \\
\hline LAW AN102-24 & 424 & 59.36 & 8.3 & 9. & 7.3 & & & $5.5 \mathrm{E}$ & $\mathrm{E}-01$ & 3.2E-02 & 2.8 & -04 \\
\hline LAW AN102-25 & 5 & 61.98 & 8.6 & 8. & 7.0 & & & 35 & -01 & 3.0E-02 & 2.5 & -04 \\
\hline LAW AN102-26 & 26 & 64.20 & 9.0 & 8. & $6.7 \mathrm{I}$ & & & 34 & -01 & 2.9E-02 & & $7 \mathrm{E}-04$ \\
\hline LAW AN102-27 & 77 & 66.41 & 8.7E-02 2.01 & 8.9849 & $6.6 \mathrm{E}+04$ & 41.1 & $1.9 \mathrm{E}$ & 4.8E-02 & $24.0 \mathrm{E}-01$ & 3.0E-02 & 2.7 & $7.81 \mathrm{E}-04$ \\
\hline LAW AN102-30 & 30 & 73.44 & 8.8E-02 2.8 & 8.8954 & $6.2 \mathrm{~F}$ & 41.0 & $(1,7$ & - & 4.3E-01 & 3.4E-02 & 2.9 & $1.38 \mathrm{E}-04$ \\
\hline $2-33$ & $33 \mathrm{~B}$ & 31 & $9.0 \mathrm{E}$ & & 7.3 & 41. & & - & 4.1E-01 & 3.1E-02 & 2.8 & -04 \\
\hline LAW AN102-36 & $36 \mathrm{~B}$ & 110.41 & $9.4 \mathrm{E}$ & 8.4247 & 5.81 & 48. & $(1,945)$ & - & 4.3E-01 & 3.2E-02 & 2.8 & E-05 \\
\hline LAW AN102-39 & 39B & 129.41 & 9.6E-02 2.9E-03 & 8.5182 & $5.6 \mathrm{E}+04$ & 48.2 & $(1,958)$ & - & 4.3E-01 & 3.2E-02 & 3.91 & $4.61 \mathrm{E}-04$ \\
\hline LAW AN102-42 & $42 \mathrm{~B}$ & 150.29 & $1.2 \mathrm{E}-017.0 \mathrm{E}-0$ & 8.1638 & $6.0 \mathrm{E}+04$ & 46.5 & & - & 4.4E-01 & 2.5E-02 & 3.3 & -04 \\
\hline LAW A & $45 B$ & 170.31 & $1.3 \mathrm{E}-017.3$ & 8.3 & 6.2 & 46. & & - & 4.7E-01 & 2.5E-02 & 4.1 & -04 \\
\hline LAW AN102-48 & $48 \mathrm{~B}$ & 191.38 & $1.5 \mathrm{E}-011.0$ & 8.2165 & $6.3 \mathrm{E}+04$ & 45. & $(2, \mathrm{C}$ & - & $4.9 \mathrm{E}-01$ & 2.2E-02 & $4.4 \mathrm{I}$ & E-04 \\
\hline LAW AN102-51 & $51 \mathrm{~B}$ & 219.48 & 1.7E-01 7.5E-03 & 8.8967 & $9.4 \mathrm{E}+04$ & 4 8.5E-03 & $(2,793)$ & - & $5.0 \mathrm{E}-01$ & 2.1E-02 & 4.4E-01 & $3.43 \mathrm{E}-04$ \\
\hline LAW AN102-54 & - $54 \mathrm{~B}$ & 241.42 & $1.6 \mathrm{E}-018.1 \mathrm{E}-03$ & 9.2160 & $6.5 \mathrm{E}+04$ & 4 5.6E-03 & $(1,782)$ & - & 4.4E-01 & $1.8 \mathrm{E}-02$ & 4.7E-01 & $4.17 \mathrm{E}-04$ \\
\hline $2-56$ & $56 \mathrm{~B}$ & 256.53 & $1.5 \mathrm{E}-017$. & & 5.9 & & & - & 3.8E-01 & 1.7E-02 & & \\
\hline LAW AN102-60 & $60 \mathrm{~B}$ & 285.04 & $1.9 \mathrm{E}-018.1 \mathrm{E}-\mathrm{C}$ & 8.8593 & $6.4 \mathrm{E}+04$ & 4 4.7E-03 & $(1,937)$ & - & 4.3E-01 & 1.5E-02 & 6.31 & $.07 \mathrm{E}-04$ \\
\hline LAW AN102-65 & $65 \mathrm{~B}$ & 318.55 & 2.3E-01 3.1E-03 & 8.6663 & $6.8 \mathrm{E}+04$ & 4 4.2E-03 & 2,501 & - & $6.0 \mathrm{E}-01$ & 1.8E-02 & $6.8 \mathrm{E}-01$ & 5.75E-04 \\
\hline LAW AN102-70 & $70 \mathrm{~B}$ & 362.44 & 2.4E-01 1.3E-02 & 8.8846 & $7.2 \mathrm{E}+04$ & 4 4.4E-03 & 2,513 & - & 5.5E-01 & 1.6E-02 & $9.3 \mathrm{E}-01$ & 8.79E-04 \\
\hline LAW AN102-73 & 73B & 396.57 & 2.8E-01 6.6E-03 & 9.0630 & $7.7 \mathrm{E}+04$ & 4 4.0E-03 & $(1,510)$ & - & 3.8E-01 & $9.2 \mathrm{E}-03$ & $1.0 \mathrm{E}+00$ & $8.52 \mathrm{E}-04$ \\
\hline
\end{tabular}


Table B4. LAWAN102 PUF Test Results

\begin{tabular}{|c|c|c|c|c|c|c|c|c|c|c|c|c|c|}
\hline Sample ID & Vial \# & Time, days & $\theta$ & $\sigma \theta$ & pH & [Si] & Si Rate & [S] & S Rate & {$\left[{ }^{99} \mathrm{Tc}\right]$} & ${ }^{99}$ Tc Rate & [U] & U Rate \\
\hline LAW AN102-75 & $75 B$ & 408.46 & $2.9 \mathrm{E}-01$ & $2.9 \mathrm{E}-03$ & 8.8762 & $6.8 \mathrm{E}+04$ & $3.4 \mathrm{E}-03$ & $(1,175)$ & - & $3.2 \mathrm{E}-01$ & $7.5 \mathrm{E}-03$ & $9.6 \mathrm{E}-01$ & 7.69E-04 \\
\hline LAW AN102-80 & 80B & 444.42 & $2.8 \mathrm{E}-01$ & 2.7E-03 & 8.9797 & $7.5 E+04$ & $3.9 \mathrm{E}-03$ & $(1,544)$ & - & 3.7E-01 & 8.9E-03 & $9.5 \mathrm{E}-01$ & 7.56E-04 \\
\hline LAW AN102-84 & $84 \mathrm{~B}$ & 473.52 & $2.7 \mathrm{E}-01$ & $2.9 \mathrm{E}-03$ & 8.6410 & $5.7 \mathrm{E}+04$ & $2.9 \mathrm{E}-03$ & (955) & - & $2.9 \mathrm{E}-01$ & $7.1 \mathrm{E}-03$ & $9.1 \mathrm{E}-01$ & 7.49E-04 \\
\hline
\end{tabular}


Table B5. LAWAP101 PUF Test Results

\begin{tabular}{|c|c|c|c|c|c|c|c|c|c|c|c|c|c|c|c|c|c|c|c|c|c|c|c|}
\hline Sam & ial & \# Time, days & $\theta$ & $\sigma \theta$ & pH & [Al] & I Rate & [B] & B Rate & [Ca] & {$[\mathrm{Fe}]$} & [K] & K Rate & [Na] & Na Rate & [Si] & Si Rate & [S] & S Rate & [Ti] & i Rate & [Zr] & Zr Rate \\
\hline LAW AP101-1 & 1 & 0.00 & 0.168 & 30.030 & 8.852 & (347) & - & $2.5 \mathrm{E}+03$ & 3 3.4E-04 & $(210.7)$ & (31.6) & $1.3 \mathrm{E}+0$ & 5 7.3E-02 ( & (11514.6) & - & $(4,552)$ & 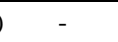 & $(682)$ & - & (9.4) & - & (9.9) & - \\
\hline & 2 & & & & 8.798 & (294) & & & & & & & & & & & & & & & & $9.0)$ & \\
\hline & 3 & & & & & 3.E+ & 4 & +3. & & & & & & $1.3 \mathrm{E}+06$ & 2.0E-01 & $1.9 \mathrm{E}+05$ & 2 & $1.7 \mathrm{E}+$ & -01 & $(25.2)$ & & & \\
\hline LAW & 4 & 52 & & & & 4 2.E+ & 3E-03 & $3.4 \mathrm{E}$ & & $(30.2)$ & & & & $1.3 \mathrm{E}+06$ & 5E-01 & & 5 3.6E-02 & & $3 \mathrm{E}-01$ & $(15.8)$ & 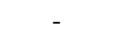 & (7.7) & 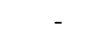 \\
\hline LA & 5 & 65 & & 0.0 & 11. & 3.E & 3 2.9E-03 & $2.4 \mathrm{E}$ & & $\mathrm{N}$ & & & & & $1.5 \mathrm{E}-01$ & $2.6 \mathrm{E}$ & 5 2.7E-02 & $1.0 \mathrm{E}$ & $41.1 \mathrm{E}-018$ & $8.3 \mathrm{E}+01$ & 6.1E-05 & (63.2) & 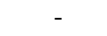 \\
\hline LAW & 6 & 61 & 0.1 & & 311 & $23 . \mathrm{E}$ & $2.4 \mathrm{~L}$ & 2.6 & 52.3 & $(19$ & & & & 05 & 1 & & S.1E & & $41.3 \mathrm{E}-01$ & (49.3) & 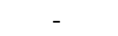 & (47.7) & 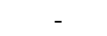 \\
\hline LA & 7 & 5 & & & & & & & & & & & & & & & & & 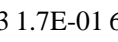 & & $.5 \mathrm{E}-05$ & $(5$ & \\
\hline & 8 & & & & & & & & & & & & & & & & & & & & -04 & & \\
\hline $\mathrm{L}$ & $\mathrm{s}$ & & & & & & & & & & & & & & & & & & $8 \mathrm{E}-025$ & & & & - \\
\hline & & & & & & & & & & & & & & & & & & & - & & & & 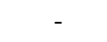 \\
\hline LAV & 12 & .05 & 0.125 & & 11 & $5 . \mathrm{E}$ & 34. & 1. & 59.8 & $(37$ & $(15$ & & & & 9. & & & & - & 1.6 & $2.7 \mathrm{E}-$ & & E-04 \\
\hline & & & & & & & & & & & & & & & & & & & & & & & 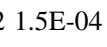 \\
\hline & 16 & 52 & & & & & & & & & & & & & & & & & - & 2.5 & $F_{-}-$ & & -04 \\
\hline & & & 8 & & & $56 . \mathrm{E}$ & & & & & & & & & & & & & - & 2.0 & 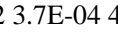 & & 04 \\
\hline LA & & & 0 & & 11 & 7.E- & 3 5.6E-03 & 7.0 & 46. & $(44$ & $(21$ & & & 05 & 5.9 & & & & - & $2.6 \mathrm{I}$ & 4.7E-04 6 & & E-04 \\
\hline & & & & & & & & & & & & & & & & & & & - & & & & 04 \\
\hline & 2 & & & & 510 & 71.E & & & & & & & & & & & & & - & 3.0 & 47 & & $.2 \mathrm{E}-04$ \\
\hline & 29 & & 0 & & & & & & & & & & & & & & & & - & 3.0 & 47 & & $1 \mathrm{E}-04$ \\
\hline $1-32$ & 32 & .43 & 0.076 & & 9.868 & $6 . E+03$ & 3 9.4E-03 & 4.6 & & (32 & )$(29$ & & 551. & $2.0 \mathrm{E}+05$ & $6.2 \mathrm{E}-02$ & & $41.7 \mathrm{E}$ & & - & $3.3 \mathrm{E}+02$ & 1.1E-03 7 & 7.71 & 2.1.1E-03 \\
\hline LAW AP101-35 & 35 & 107.51 & 0.068 & 0.028 & 9.710 & 7.E+03 & 3 1.1E-02 & $4.1 \mathrm{E}+04$ & $46.6 \mathrm{E}-02$ & (129.4) & ) & $1.1 \mathrm{E}+0$ & 5 1.3E-01 & $1.8 \mathrm{E}+05$ & 6.1E-02 & 8.2 & 4 1.8E-02 & $(1,139)$ & - & $3.4 \mathrm{E}+02$ & $1.2 \mathrm{E}-037$ & $7.9 \mathrm{E}$ & $1.3 \mathrm{E}-03$ \\
\hline
\end{tabular}

$\theta$ - volumetric water content

$\sigma \theta$-volumetric water content error

[] - concentration in ug $\mathrm{L}^{-1}$

Rate - in $\mathrm{g} \mathrm{m}^{-2} \mathrm{~d}^{-1}$ 
Appendix C

Product Consistency Test Results 
Table C1. LAWA44 PCT Test Results

\begin{tabular}{|c|c|c|c|c|c|c|c|c|c|c|c|c|c|c|c|c|}
\hline Sample ID & S/V Ratio, $\mathrm{m}^{-1}$ & Time & $\begin{array}{l}\text { Reaction Progress } \\
\left(\mathrm{mol} \mathrm{kg}^{-1}\right)\end{array}$ & $\begin{array}{l}\text { Norm. Al } \\
\left(\mathrm{mg} \mathrm{L}^{-1}\right)\end{array}$ & $\begin{array}{l}\text { Norm. B } \\
\left(\mathrm{mg} \mathrm{L}^{-1}\right)\end{array}$ & $\begin{array}{c}\text { Norm. Ca } \\
\left(\mathrm{mg} \mathrm{L}^{-1}\right) \\
\end{array}$ & $\begin{array}{l}\text { Norm. Fe } \\
\left(\mathrm{mg} \mathrm{L}^{-1}\right)\end{array}$ & $\begin{array}{l}\text { Norm. K } \\
\left(\mathrm{mg} \mathrm{L}^{-1}\right)\end{array}$ & $\begin{array}{c}\text { Norm. Mg } \\
\left(\mathrm{mg} \mathrm{L}^{-1}\right)\end{array}$ & $\begin{array}{c}\text { Norm. Na } \\
\left(\mathrm{mg} \mathrm{L}^{-1}\right)\end{array}$ & $\begin{array}{l}\text { Norm. P } \\
\left(\mathrm{mg} \mathrm{L}^{-1}\right)\end{array}$ & $\begin{array}{c}\text { Norm. Si } \\
\left(\mathrm{mg} \mathrm{L}^{-1}\right)\end{array}$ & $\begin{array}{l}\text { Norm. S } \\
\left(\mathrm{mg} \mathrm{L}^{-1}\right)\end{array}$ & $\begin{array}{c}\text { Norm. Ti } \\
\left(\mathrm{mg} \mathrm{L}^{-1}\right)\end{array}$ & $\begin{array}{c}\text { Norm. Zr } \\
\left(\mathrm{mg} \mathrm{L}^{-1}\right)\end{array}$ & $\begin{array}{c}\text { Norm. Zn } \\
\left(\mathrm{mg} \mathrm{L}^{-1}\right)\end{array}$ \\
\hline PCT-2003-1 & 20000 & 7 & $1.0 \mathrm{E}-01$ & $2.6 \mathrm{E}+02$ & $6.7 \mathrm{E}+03$ & - & - & - & - & $6.2 \mathrm{E}+03$ & - & $1.3 \mathrm{E}+03$ & - & - & - & - \\
\hline РCT-2003-2 & 20000 & 14 & $1.2 \mathrm{E}-01$ & $3.4 \mathrm{E}+02$ & $8.0 \mathrm{E}+03$ & - & - & - & - & $7.9 \mathrm{E}+03$ & - & $1.5 \mathrm{E}+03$ & - & - & - & - \\
\hline PCT-2003-3 & 20000 & 21 & $1.9 \mathrm{E}-01$ & $2.4 \mathrm{E}+02$ & $1.3 \mathrm{E}+04$ & - & - & - & - & $1.2 \mathrm{E}+04$ & - & $2.2 \mathrm{E}+03$ & - & - & - & - \\
\hline РCT-2003-4 & 20000 & 28 & $2.0 \mathrm{E}-01$ & $2.2 \mathrm{E}+02$ & $1.4 \mathrm{E}+04$ & - & - & - & - & $1.2 \mathrm{E}+04$ & - & $2.3 E+03$ & - & - & - & - \\
\hline PCT-2003-5 & 20000 & 35 & $2.0 \mathrm{E}-01$ & $2.5 \mathrm{E}+02$ & $1.3 \mathrm{E}+04$ & $2.1 \mathrm{E}+02$ & $4.1 \mathrm{E}+00$ & $4.3 \mathrm{E}+03$ & $7.2 \mathrm{E}+01$ & $1.1 \mathrm{E}+04$ & $3.0 \mathrm{E}+04$ & $2.4 \mathrm{E}+03$ & $1.9 \mathrm{E}+04$ & 5.3E-01 & $3.5 \mathrm{E}+00$ & $2.7 \mathrm{E}+01$ \\
\hline PCT-2003-6 & 20000 & 42 & $1.8 \mathrm{E}-01$ & $2.0 \mathrm{E}+02$ & $1.2 \mathrm{E}+04$ & $2.4 \mathrm{E}+02$ & $8.6 \mathrm{E}+00$ & $3.8 \mathrm{E}+03$ & $4.4 \mathrm{E}+01$ & $1.0 \mathrm{E}+04$ & $9.0 \mathrm{E}+03$ & $2.2 \mathrm{E}+03$ & $2.4 \mathrm{E}+04$ & - & $1.3 \mathrm{E}+00$ & $2.4 \mathrm{E}+01$ \\
\hline РCT-2003-7 & 20000 & 49 & $2.4 \mathrm{E}-01$ & $1.3 \mathrm{E}+02$ & $1.6 \mathrm{E}+04$ & $1.8 \mathrm{E}+02$ & $7.5 \mathrm{E}+00$ & $4.5 E+03$ & $1.1 \mathrm{E}+02$ & $1.2 \mathrm{E}+04$ & $2.9 \mathrm{E}+04$ & $2.7 \mathrm{E}+03$ & $1.2 \mathrm{E}+04$ & $2.7 \mathrm{E}+00$ & - & $3.2 \mathrm{E}+01$ \\
\hline PCT-2003-8 & 20000 & 56 & $2.7 \mathrm{E}-01$ & $8.3 E+01$ & $1.8 \mathrm{E}+04$ & $1.7 \mathrm{E}+02$ & $7.8 \mathrm{E}+00$ & $5.0 \mathrm{E}+03$ & $9.6 \mathrm{E}+01$ & $1.3 \mathrm{E}+04$ & - & $2.7 \mathrm{E}+03$ & $2.4 \mathrm{E}+04$ & $1.5 \mathrm{E}-01$ & $4.8 \mathrm{E}-01$ & $9.4 \mathrm{E}+01$ \\
\hline
\end{tabular}


Table C2. LAWB45 PCT Test Results

\begin{tabular}{|c|c|c|c|c|c|c|c|c|c|}
\hline Sample ID & S/V Ratio, $\mathrm{m}^{-1}$ & Time, days & $\begin{array}{l}\text { Reaction Progress } \\
\left(\mathrm{mol} \mathrm{kg}^{-1}\right)\end{array}$ & $\begin{array}{c}\text { Norm. Al } \\
\left(\mathrm{mg} \mathrm{L}^{-1}\right)\end{array}$ & $\begin{array}{l}\text { Norm. B } \\
\left(\mathrm{mg} \mathrm{L}^{-1}\right)\end{array}$ & $\begin{array}{c}\text { Norm. Ca } \\
\left(\mathrm{mg} \mathrm{L}^{-1}\right)\end{array}$ & $\begin{array}{c}\text { Norm. Li } \\
\left(\mathrm{mg} \mathrm{L}^{-1}\right)\end{array}$ & $\begin{array}{c}\text { Norm. Na } \\
\left(\mathrm{mg} \mathrm{L}^{-1}\right)\end{array}$ & $\begin{array}{r}\text { Norm. Si } \\
\left(\mathrm{mg} \mathrm{L}^{-1}\right)\end{array}$ \\
\hline LAW B45-10A-5.1F & 2000 & 7 & 3.5E-02 & $4.3 \mathrm{E}+01$ & $2.2 \mathrm{E}+03$ & $4.7 \mathrm{E}+01$ & $8.6 \mathrm{E}+02$ & $1.9 \mathrm{E}+03$ & $6.4 \mathrm{E}+02$ \\
\hline LAW B45-10A-5.2F & 2000 & 14 & 5.3E-02 & $4.3 \mathrm{E}+01$ & $3.3 \mathrm{E}+03$ & $6.4 \mathrm{E}+01$ & $1.4 \mathrm{E}+03$ & $2.9 \mathrm{E}+03$ & $6.7 \mathrm{E}+02$ \\
\hline LAW B45-10A-5.3F & 2000 & 21 & 8.6E-02 & $3.5 \mathrm{E}+01$ & $5.4 \mathrm{E}+03$ & $4.4 \mathrm{E}+01$ & $2.3 E+03$ & $4.6 \mathrm{E}+03$ & $8.1 \mathrm{E}+02$ \\
\hline LAW B45-1A-5.1F & 20000 & 7 & $1.1 \mathrm{E}-01$ & $4.4 \mathrm{E}+01$ & $6.9 \mathrm{E}+03$ & $3.8 \mathrm{E}+01$ & $3.3 \mathrm{E}+03$ & $5.5 \mathrm{E}+03$ & $1.0 \mathrm{E}+03$ \\
\hline LAW B45-1A-5.2F & 20000 & 14 & $1.4 \mathrm{E}-01$ & $3.5 \mathrm{E}+01$ & $9.0 \mathrm{E}+03$ & $8.0 \mathrm{E}+01$ & $4.1 \mathrm{E}+03$ & $6.9 \mathrm{E}+03$ & $9.5 \mathrm{E}+02$ \\
\hline LAW B45-1A-5.3F & 20000 & 21 & $2.2 \mathrm{E}-01$ & $4.3 \mathrm{E}+01$ & $1.4 \mathrm{E}+04$ & $9.8 \mathrm{E}+01$ & $6.2 \mathrm{E}+03$ & $1.1 \mathrm{E}+04$ & $1.1 \mathrm{E}+03$ \\
\hline
\end{tabular}


Table C3. LAWC22 PCT Test Results

\begin{tabular}{|c|c|c|c|c|c|c|c|c|c|}
\hline Sample ID & S/V Ratio, $\mathrm{m}^{-1}$ & Time, days & $\begin{array}{l}\text { Reaction Progress } \\
\left(\mathrm{mol} \mathrm{kg}^{-1}\right)\end{array}$ & $\begin{array}{c}\text { Norm. Al } \\
\left(\mathrm{mg} \mathrm{L}^{-1}\right)\end{array}$ & $\begin{array}{l}\text { Norm. B } \\
\left(\mathrm{mg} \mathrm{L}^{-1}\right)\end{array}$ & $\begin{array}{c}\text { Norm. Li } \\
\left(\mathrm{mg} \mathrm{L}^{-1}\right)\end{array}$ & $\begin{array}{c}\text { Norm. Mg } \\
\left(\mathrm{mg} \mathrm{L}^{-1}\right)\end{array}$ & $\begin{array}{c}\text { Norm. Na } \\
\left(\mathrm{mg} \mathrm{L}^{-1}\right)\end{array}$ & $\begin{array}{r}\text { Norm. Si } \\
\left(\mathrm{mg} \mathrm{L}^{-1}\right)\end{array}$ \\
\hline LAW C22-10A-5.1F & 2000 & 7 & $9.1 \mathrm{E}-03$ & $3.6 \mathrm{E}+01$ & $5.9 \mathrm{E}+02$ & - & $2.6 \mathrm{E}+01$ & $5.0 \mathrm{E}+02$ & $4.7 \mathrm{E}+02$ \\
\hline LAW C22-10A-5.2F & 2000 & 14 & $1.1 \mathrm{E}-02$ & $5.0 \mathrm{E}+01$ & $7.0 \mathrm{E}+02$ & $6.6 \mathrm{E}+01$ & $1.1 \mathrm{E}+01$ & $6.2 \mathrm{E}+02$ & $4.2 \mathrm{E}+02$ \\
\hline LAW C22-10A-5.3F & 2000 & 21 & $1.2 \mathrm{E}-02$ & $6.4 \mathrm{E}+01$ & $7.5 \mathrm{E}+02$ & $8.7 \mathrm{E}+01$ & $1.7 \mathrm{E}+01$ & $6.8 \mathrm{E}+02$ & $4.0 \mathrm{E}+02$ \\
\hline LAW C22-1A-5.1F & 20000 & 7 & $4.1 \mathrm{E}-02$ & $8.4 \mathrm{E}+01$ & $2.7 \mathrm{E}+03$ & $1.6 \mathrm{E}+03$ & $3.5 \mathrm{E}+01$ & $2.4 \mathrm{E}+03$ & $8.9 \mathrm{E}+02$ \\
\hline LAW C22-1A-5.2F & 20000 & 14 & $5.0 \mathrm{E}-02$ & $8.9 \mathrm{E}+01$ & $3.2 \mathrm{E}+03$ & $2.1 \mathrm{E}+03$ & $2.0 \mathrm{E}+01$ & $3.0 \mathrm{E}+03$ & $9.1 \mathrm{E}+02$ \\
\hline LAW C22-1A-5.3F & 20000 & 21 & $6.6 \mathrm{E}-02$ & $1.1 \mathrm{E}+02$ & $4.2 \mathrm{E}+03$ & $2.9 \mathrm{E}+03$ & - & $3.8 \mathrm{E}+03$ & $1.0 \mathrm{E}+03$ \\
\hline
\end{tabular}


Appendix D

Microbial Experiment Test Results 
Table D1. Microbial Experiment Test Conditions

\begin{tabular}{|c|c|c|c|c|c|c|c|c|}
\hline Expt. ID\# & Description & $\begin{array}{c}\text { Glass } \\
\text { added (g) }\end{array}$ & DIW (mL) & PBS (mL) & SPS (mL) & $\begin{array}{c}\text { addtl C } \\
\text { (mL) }\end{array}$ & culture & Temp $\left({ }^{\circ} \mathrm{C}\right)$ \\
\hline MBD44-1 & Expt & 0.5 & 50 & 0 & 0 & 0 & ТРМ & 19 \\
\hline MBD44-2 & Expt & 0.5 & 10 & 40 & 0 & 0 & TPM & 19 \\
\hline MBD44-3 & Expt & 0.5 & 10 & 40 & 0 & 0 & TPM & 19 \\
\hline MBD44-4 & Expt & 0.5 & 9 & 40 & 0 & 1 & ТРМ & 19 \\
\hline MBD44-5 & Expt & 0.5 & 9 & 40 & 0 & 1 & TPM & 19 \\
\hline MBD44-6 & Expt & 0.5 & 50 & 0 & 0 & 0 & TPM & 40 \\
\hline MBD44-7 & Expt & 0.5 & 10 & 40 & 0 & 0 & ТРМ & 40 \\
\hline MBD44-8 & Expt & 0.5 & 10 & 40 & 0 & 0 & TPM & 40 \\
\hline MBD44-9 & Expt & 0.5 & 9 & 40 & 0 & 1 & ТРM & 40 \\
\hline MBD44-10 & Expt & 0.5 & 9 & 40 & 0 & 1 & ТРM & 40 \\
\hline MBD44-11 & Expt & 0.5 & 50 & 0 & 0 & 0 & HSE & 19 \\
\hline MBD44-12 & Expt & 0.5 & 10 & 0 & 40 & 0 & HSE & 19 \\
\hline MBD44-13 & Expt & 0.5 & 10 & 0 & 40 & 0 & HSE & 19 \\
\hline MBD44-14 & Expt & 0.5 & 9 & 0 & 40 & 1 & HSE & 19 \\
\hline MBD44-15 & Expt & 0.5 & 9 & 0 & 40 & 1 & HSE & 19 \\
\hline MBD44-16 & Expt & 0.5 & 50 & 0 & 0 & 0 & HSE & 40 \\
\hline MBD44-17 & Expt & 0.5 & 10 & 0 & 40 & 0 & HSE & 40 \\
\hline MBD44-18 & Expt & 0.5 & 10 & 0 & 40 & 0 & HSE & 40 \\
\hline MBD44-19 & Expt & 0.5 & 9 & 0 & 40 & 1 & HSE & 40 \\
\hline MBD44-20 & Expt & 0.5 & 9 & 0 & 40 & 1 & HSE & 40 \\
\hline MBD44-21 & Blank & 0.5 & 50 & 0 & 0 & 0 & none & 19 \\
\hline MBD44-22 & Blank & 0.5 & 10 & 0 & 40 & 0 & none & 19 \\
\hline MBD44-23 & Blank & 0.5 & 10 & 40 & 0 & 0 & none & 19 \\
\hline MBD44-24 & Blank & 0.5 & 9 & 0 & 40 & 1 & none & 19 \\
\hline MBD44-25 & Blank & 0.5 & 9 & 40 & 0 & 1 & none & 19 \\
\hline MBD44-26 & Blank & 0.5 & 50 & 0 & 0 & 0 & none & 40 \\
\hline MBD44-27 & Blank & 0.5 & 10 & 0 & 40 & 0 & none & 40 \\
\hline MBD44-28 & Blank & 0.5 & 10 & 40 & 0 & 0 & none & 40 \\
\hline MBD44-29 & Blank & 0.5 & 9 & 0 & 40 & 1 & none & 40 \\
\hline
\end{tabular}


Table D1. Microbial Experiment Test Conditions

\begin{tabular}{ccccccccc}
\hline & \multicolumn{1}{c}{ Glass } & & & & addtl C & & \\
Expt. ID\# & Description & added (g) & DIW (mL) & PBS (mL) & SPS (mL) & culture & Temp $\left({ }^{\circ} \mathrm{C}\right)$ \\
\hline MBD44-30 & Blank & 0.5 & 9 & 40 & 0 & 1 & none & 40 \\
MBD44-31 & Control & 0 & 50 & 0 & 0 & 0 & none & 19 \\
MBD44-32 & Control & 0 & 10 & 0 & 40 & 0 & none & 19 \\
MBD44-33 & Control & 0 & 10 & 40 & 0 & 0 & none & 19 \\
MBD44-34 & Control & 0 & 9 & 0 & 40 & 1 & none & 19 \\
MBD44-35 & Control & 0 & 9 & 40 & 0 & 1 & none & 19 \\
MBD44-36 & Control & 0 & 50 & 0 & 0 & 0 & none & 40 \\
MBD44-37 & Control & 0 & 10 & 0 & 40 & 0 & none & 40 \\
MBD44-38 & Control & 0 & 10 & 40 & 0 & 0 & none & 40 \\
MBD44-39 & Control & 0 & 9 & 0 & 40 & 1 & none & 40 \\
MBD44-40 & Control & 0 & 9 & 40 & 0 & 1 & none & 40
\end{tabular}


Table D2. Microbial Experiment Test Results

\begin{tabular}{|c|c|c|c|c|c|c|c|c|c|c|c|c|c|}
\hline \multirow[t]{2}{*}{ Type } & \multirow[t]{2}{*}{ Test ID } & \multicolumn{4}{|c|}{$[\mathrm{Al}]$} & \multicolumn{4}{|c|}{$[\mathrm{B}]$} & \multicolumn{4}{|c|}{$[\mathrm{Si}]$} \\
\hline & & 1 & 3 & 4 & 5 & 1 & 3 & 4 & 5 & 1 & 3 & 4 & 5 \\
\hline $\mathrm{TPM}^{1}$ & MBD44-1.1 & 71 & (32) & 20 & $*$ & 421 & 628 & 850 & $*$ & 3300 & (3695) & 4,227 & * \\
\hline $\mathrm{HSE}^{2}$ & MBD44-11.1 & 3070 & 3854 & 1,966 & $*$ & 981 & 1606 & 2,572 & $*$ & 13921 & 16173 & 12,755 & * \\
\hline none & MBD44-21.1 & 113 & 337 & 309 & $*$ & 580 & 635 & 871 & $*$ & 4407 & (3934) & 4,652 & * \\
\hline ТРM & MBD44-2.1 & 29 & 419 & 15 & $*$ & 321 & 513 & 780 & $*$ & 1255 & (1912) & 2,732 & $*$ \\
\hline none & MBD44-23.1 & 28 & (41) & 38 & $*$ & 419 & 553 & 843 & $*$ & 1971 & (2609) & 4,032 & $*$ \\
\hline HSE & MBD44-12.1 & 13256 & 9064 & 10,600 & $*$ & 1134 & 1524 & 2,021 & $*$ & 42423 & 27644 & 30,147 & $*$ \\
\hline none & MBD44-22.1 & 970 & 1980 & 3,101 & $*$ & 929 & 1765 & 2,698 & $*$ & 6527 & 13225 & 18,684 & $*$ \\
\hline TPM & MBD44-3.1 & (19) & 127 & 15 & $*$ & 299 & 504 & 766 & $*$ & 1486 & (1834) & 2,746 & * \\
\hline none & MBD44-23.1 & 28 & (41) & 38 & $*$ & 419 & 553 & 843 & $*$ & 1971 & (2609) & 4,032 & $*$ \\
\hline HSE & MBD44-13.1 & 12572 & 10916 & 9,101 & $*$ & 1143 & 1509 & 1,907 & $*$ & 42200 & 32175 & 27,386 & $*$ \\
\hline none & MBD44-22.1 & 970 & 1980 & 3,101 & $*$ & 929 & 1765 & 2,698 & $*$ & 6527 & 13225 & 18,684 & $*$ \\
\hline ТРM & MBD44-4.1 & 34 & (32) & 46 & $*$ & 283 & 506 & 745 & $*$ & 1178 & (1279) & 1,639 & $*$ \\
\hline none & MBD44-25.1 & 47 & (64) & 25 & $*$ & 242 & 281 & $(421)$ & $*$ & 1411 & (1153) & 1,432 & * \\
\hline HSE & MBD44-14.1 & 3331 & 177 & 216 & $*$ & 836 & 918 & 1,055 & $*$ & 20193 & 18200 & 15,683 & * \\
\hline none & MBD44-24.1 & 573 & 1509 & 89 & $*$ & 737 & 1272 & 1,899 & $*$ & 6196 & 9902 & 11,037 & $*$ \\
\hline ТРM & MBD44-5.1 & 28 & (19) & 39 & $*$ & 282 & 454 & 684 & $*$ & $(704)$ & $(701)$ & 982 & $*$ \\
\hline none & MBD44-25.1 & 47 & (64) & 25 & $*$ & 242 & 281 & $(421)$ & $*$ & 1411 & (1153) & 1,432 & $*$ \\
\hline HSE & MBD44-15.1 & $(22)$ & (20) & 599 & $*$ & 805 & 952 & 1,277 & $*$ & 19553 & 18313 & 19,932 & $*$ \\
\hline none & MBD44-24.1 & 573 & 1509 & 89 & $*$ & 737 & 1272 & 1,899 & $*$ & 6196 & 9902 & 11,037 & $*$ \\
\hline
\end{tabular}

TPM - denotes Thiobacillus perometabolis culture

HSE - denotes Hanford Soil Extract

none - denotes blank samples

[] - denotes concentration in $\mu \mathrm{g} \mathrm{L}^{-1}$

() - denotes value is below estimated limit of quantification 
Table D2. Microbial Experiment Test Results

\begin{tabular}{|c|c|c|c|c|c|c|c|c|c|c|c|c|c|}
\hline \multirow[t]{2}{*}{ Type } & \multirow[t]{2}{*}{ Test ID } & \multicolumn{4}{|c|}{$[\mathrm{Al}]$} & \multicolumn{4}{|c|}{ [B] } & \multicolumn{4}{|c|}{$[\mathrm{Si}]$} \\
\hline & & 1 & 3 & 4 & 5 & 1 & 3 & 4 & 5 & 1 & 3 & 4 & 5 \\
\hline $\mathrm{TPM}^{1}$ & MBD44-6.1 & 643 & 3497 & 1,230 & 1,121 & 1513 & 1573 & 2,086 & 2,360 & 10331 & 10822 & 11,182 & 11,882 \\
\hline $\mathrm{HSE}^{2}$ & MBD44-16.1 & 3427 & 1128 & 5,181 & 5,731 & 3083 & 5264 & 10,418 & 12,617 & 23997 & 18163 & 35,668 & 41,875 \\
\hline none & MBD44-26.1 & 1052 & 789 & 1,278 & 1,338 & 1470 & 1566 & 2,108 & 2,294 & 10101 & 9092 & 11,584 & 12,416 \\
\hline TPM & MBD44-7.1 & 297 & 789 & 621 & 571 & 777 & 1073 & 1,701 & 2,060 & 4497 & 5390 & 6,055 & 6,494 \\
\hline none & MBD44-28.1 & 66 & (70) & 186 & 134 & 1392 & 2126 & 3,415 & 3,979 & 5574 & 7382 & 8,893 & 10,095 \\
\hline HSE & MBD44-17.1 & 25181 & 11881 & 12,443 & 14,693 & 2227 & 2672 & 3,996 & 5,108 & 76565 & 35276 & 34,250 & 43,889 \\
\hline none & MBD44-27.1 & 3693 & 3556 & 4,031 & 4,053 & 3272 & 3803 & 5,213 & 6,275 & 24241 & 23657 & 24,311 & 25,938 \\
\hline TPM & MBD44-8.1 & 459 & 894 & 544 & 1,769 & 853 & 1098 & 1,683 & 2,109 & 4931 & 5340 & 5,950 & 7,029 \\
\hline none & MBD44-28.1 & 66 & $(70)$ & 186 & 134 & 1392 & 2126 & 3,415 & 3,979 & 5574 & 7382 & 8,893 & 10,095 \\
\hline HSE & MBD44-18.1 & 21667 & 12841 & 10,637 & 13,617 & 2036 & 2514 & 3,897 & 4,772 & 68562 & 37275 & 31,368 & 40,814 \\
\hline none & MBD44-28.1 & 66 & (70) & 186 & 134 & 1392 & 2126 & 3,415 & 3,979 & 5574 & 7382 & 8,893 & 10,095 \\
\hline TPM & MBD44-9.1 & 35 & 2900 & 36 & (13) & 457 & 920 & 1,624 & 2,436 & 1302 & (2425) & 2,957 & 4,796 \\
\hline none & MBD44-30.1 & 54 & (24) & 39 & 896 & 677 & 1172 & 2,568 & 3,436 & 2197 & 3741 & 7,734 & 10,805 \\
\hline HSE & MBD44-19.1 & 77 & (21) & 158 & 144 & 2559 & 3424 & 4,817 & 5,209 & 30676 & 30248 & 29,220 & 28,228 \\
\hline none & MBD44-29.1 & 2120 & 3670 & 5,339 & 5,054 & 1961 & 3198 & 5,014 & 6,446 & 15884 & 24951 & 28,838 & 32,810 \\
\hline TPM & MBD44-10.1 & 35 & (83) & 23 & 45 & 473 & 780 & 1,542 & 2,487 & 1283 & (1460) & 2,659 & 4,395 \\
\hline none & MBD44-30.1 & 54 & (24) & 39 & 896 & 677 & 1172 & 2,568 & 3,436 & 2197 & 3741 & 7,734 & 10,805 \\
\hline HSE & MBD44-20.1 & 41 & (97) & 88 & 97 & 2116 & 2849 & 4,151 & 4,795 & 26766 & 27841 & 27,853 & 28,315 \\
\hline none & MBD44-29.1 & 2120 & 3670 & 5,339 & 5,054 & 1961 & 3198 & 5,014 & 6,446 & 15884 & 24951 & 28,838 & 32,810 \\
\hline
\end{tabular}

TPM - denotes Thiobacillus perometabolis culture

HSE - denotes Hanford Soil Extract

none - denotes blank samples

[] - denotes concentration in $\mu \mathrm{g} \mathrm{L}^{-1}$

() - denotes value is below estimated limit of quantification 
No. of

$\underline{\text { Copies }}$

OFFSITE

1 Catholic University of America

Vitreous State Laboratory

Washington D.C. 20064

Attn: Ian L. Pegg

2 Westinghouse Savannah River Company

P.O. Box 616

Aiken, SC 29802

Attn: G. G. Wicks

D. K. Peeler

1 Sandia National Laboratories

1515 Eubank SE - MSIN 0748

Albuquerque, NM 87123-0748

Attn: R. D. Waters

1 SCK-CEN

(Nuclear Research Centre)

Waste \& Disposal Department

Boeretang 200, B-2400

Mol, Belgium

Attn: Pierre Van Iseghem
No. of

Copies

\section{ONSITE}

11 U.S. Department of Energy Office of River Protection

C. A. Babel, H6-60

B. L. Foley, A6-38

J. P. Hanson, A5-13

R. D. Hildebrand, A6-38

K. A. Kapsi, A5-13

P. E. Lamont, H6-60

B. M. Mauss, H6-60

J. G. Morse, A6-38

K. M. Thompson, A6-38

DOE Public Reading Room, H2-53 (2)

20 CH2M HILL Hanford, Inc.

K. D. Boomer, H6-19

K. A. Gasper, H6-03

D. W. Hamilton, H6-03

T. E. Jones, E6-35

M. E. Johnson, H6-19

W. A. Kitchen, H6-03

S. Lambert, E6-35

F. M. Mann, E6-35 (5)

W. J. McMahon, E6-35

D. A. Myers, E6-35

G. Parsons, H6-19

R. W. Powell, H6-03

R. E. Raymond, H6-22

G. W. Reddick, Jr., R1-44

C. N. Wilson, H4-02

2 Flour Federal Services, Inc.

R. Khaleel, E6-17

R. J. Puigh, E6-17 
No. of

$\underline{\text { Copies }}$

\section{ONSITE}

35 Pacific Northwest National Laboratory

D. H. Bacon, K9-33

L. M. Bagaasen, K6-28

M. J. Fayer, K9-33

J. P. Icenhower, K6-81

K. M. Krupka, K6-81

P. F. Martin, K6-81

B. P. McGrail, K6-81 (10)

E. M. Pierce, K6-81 (10)

L. R. Reed, K6-81

E. A. Rodriguez, K6-81

H. T. Schaef, K6-81

R. J. Serne, P7-22

W. J. Shaw, K2-57

J. S. Tixier, K6-24

J. D. Vienna, K6-24

D. M. Wellman, K6-81

Information Release, K1-06 (2) 